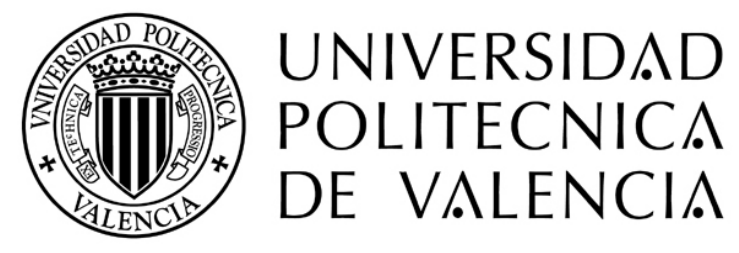

Departamento de Ciencia Animal

\title{
TERMOESTABILIDAD DE SUSTANCIAS ANTIMICROBIANAS EN LA LECHE
}

\section{TESIS DOCTORAL}

Marta Isabel Roca Marugán

Directores:

$M^{a}$ Pilar Molina Pons

Rafael Lisandro Althaus

Valencia, 2008

Trabajo cofinanciado por la Comisión Interministerial de Ciencia y Tecnología del Ministerio de Educación y Ciencia y por Fondos Feder

(Proyecto AGL2003-03663) 

$M^{a}$ PILAR MOLINA PONS CATEDRATICA DE UNIVERSIDAD DEL DEPARTAMENTO DE CIENCIA ANIMAL DE LA UNIVERSIDAD POLITECNICA DE VALENCIA

\begin{abstract}
$\mathbf{Y}$
RAFAEL LISANDRO ALTHAUS PROFESOR TITULAR DEL DEPARTAMENTO DE CIENCIAS BASICAS DE LA FACULTAD DE CIENCIAS VETERINARIAS DE LA UNIVERSIDAD NACIONAL DEL LITORAL (REPUBLICA ARGENTINA)
\end{abstract}

\title{
INFORMAN:
}

Que la Tesis Doctoral titulada "TERMOESTABILIDAD DE SUSTANCIAS ANTIMICROBIANAS EN LA LECHE" ha sido realizada por la Ingeniera Agrónoma Dña. Marta Roca Marugán en el Departamento de Ciencia Animal bajo su dirección y que, una vez revisado y comprobado el trabajo, consideran que reúne los requisitos necesarios para la obtención del grado de Doctor por lo que autorizan su presentación.

Y para que así conste firman el presente informe en Valencia a treinta de mayo de dos mil ocho. 



\section{AGRADECIMIENTOS}

En primer lugar quisiera agradecer a mi directora de tesis, Pilar Molina, por todos estos años de apoyo, trabajo, dedicación, bajones e ilusiones. Por enseñarme tantas cosas y creer en mí a pesar de los malos momentos. Por transmitirme la ilusión por la investigación y la satisfacción del trabajo bien hecho. Por abrirme puertas y darme oportunidades. Por tu amistad.

A mi codirector de Tesis Rafael Althaus, por estar cerca aunque a miles de kilómetros. Por tu paciencia, tus buenos consejos, tu optimismo a pesar de los obstáculos y por estar siempre dispuesto a echarme una mano.

A todo el personal del Laboratorio de Salud Pública de Albal, por acogerme y darme su apoyo, especialmente un millón de gracias a Manolo y Merche por dejarme trastear en sus cromatógrafos y enseñarme todo un mundo nuevo.

A toda la gente del Laboratorio Lactológico de Lekunberri, especialmente a Marisa, Luisa y Edurne del departamento de i+d por su colaboración en la realización experimental de esta tesis. Gracias por acogerme y compartir vuestros conocimientos conmigo, por vuestra dedicación, ayuda inestimable y demostrado cariño.

A Mari Carmen Beltrán, por estar desde el principio. Por enseñarme a trabajar en el laboratorio y ayudarme en todo momento. ¡Me ha encantado vivir esta experiencia contigo!

A mis compañeros de aventuras y desventuras del departamento que siempre habéis estado a mi lado, aunque algunos ya estéis lejos: Fernando, Arantxa, Salva, $\mathrm{Pau}$, Yolanda, Irene, Óscar, Andrés, Mila, Marta y Elena. Gracias por tantos buenos momentos, risas y charlas. Por compartir tanto tiempo juntos y hacer que todo sea siempre tan agradable. Y a Antonio, por hacerme creer en algún momento que formaba parte de "el otro equipo" gracias por contar siempre conmigo.

Sobre todo a María y Vero, por vuestra sincera amistad y cariño dentro y fuera. Siempre hacéis que todo sea especial...Tenéis mucha culpa de que esto se haya echo realidad.

No quiero olvidarme de toda la gente del departamento que me ha mostrado siempre su confianza y cariño, y han hecho más agradable mi estancia durante todos estos años.

Y por supuesto a mis amigos de ahora y siempre, Carmen, Estivi, Marteta, Carol, Miguel, Pablo, Cleto, Ici, Mar, Vic, Geppe, Carlos, Bea, Gon, Lucía, Laia, Julián, Mariano... no se que haría sin vosotros, sois los mejores!

A mi familia, por todo. 



\section{RESUMEN}

La presencia de residuos de sustancias antimicrobianas en la leche supone un riesgo para la salud pública, ya que pueden ocasionar alergias, antibioresistencias y alteraciones intestinales, entre otros problemas. Además es una de las principales preocupaciones de la industria lechera, por su influencia negativa en los procesos de elaboración de determinados productos lácteos como el yogur y el queso.

La información disponible sobre la termoestabilidad de los residuos de medicamentos en la leche, en concreto, en lo referente a las temperaturas de refrigeración y congelación empleadas a lo largo de las etapas de producción, transporte y análisis, así como de los tratamientos térmicos de calor utilizados en los laboratorios de control y en las industrias lácteas es, hasta el momento, muy limitada.

Por ello se planteó la realización de este trabajo donde se ha evaluado por una parte la influencia de las condiciones de almacenamiento de la leche, en refrigeración y congelación, sobre algunos antimicrobianos pertenecientes a los antibióticos betalactámicos, tetraciclinas y sulfonamidas y por otra, se ha analizado el efecto del calentamiento de la leche a distintas temperaturas sobre la estabilidad de estas sustancias.

El estudio de la influencia de la refrigeración $\left(4 \pm 2{ }^{\circ} \mathrm{C}\right)$ y congelación $(-20 \pm 2$ $\left.{ }^{\circ} \mathrm{C}\right)$ sobre los antimicrobianos en la leche se realizó mediante el análisis de muestras enriquecidas con 20 sustancias pertenecientes a los grupos de los antibióticos betalactámicos (penicilinas y cefalosporinas), tetraciclinas y sulfonamidas, a las concentraciones equivalentes a los Límites Máximos de Residuos (LMR), así como en sus correspondientes extractos obtenidos previo al análisis cromatográfico. Las determinaciones se realizaron mediante un equipo HPLC-MS/MS los días $0,1,2,3,7$, 10, 15 y 30 de almacenamiento. La influencia del tiempo de conservación y el tipo de matriz (leche y extracto) sobre las pérdidas de concentración de los antimicrobianos se determinó mediante la aplicación del modelo cinético de primer orden a partir del cual se estimaron los porcentajes de degradación de cada sustancia estudiada.

Los resultados obtenidos indican que la refrigeración y la congelación de la leche afectan a los antibióticos betalactámicos y tetraciclinas, tanto en los extractos como en las propias muestras, y no presentan ningún efecto sobre la estabilidad de las sulfonamidas. También señalan que la estabilidad de cada antimicrobiano depende de la temperatura empleada y del tiempo de almacenamiento, así como su interacción con el tipo de matriz (leche y extracto). Las pérdidas estimadas en la leche refrigerada durante 7 días oscilan entre el 14 y $90 \%$ siendo los antibióticos betalactámicos a excepción de la cefalexina las moléculas más inestables. En los extractos las pérdidas son, en casi todos los casos, menores. En la congelación los antimicrobianos mostraron por lo general mayor estabilidad en las muestras que en los extractos con porcentajes de degradación a los 7 días de congelación comprendidos entre 6,7 y $68,4 \%$ correspondiendo de nuevo las mayores degradaciones a los antibióticos betalactámicos, a excepción de la cefalexina y la cefquinoma.

Por otra parte, los experimentos para analizar el efecto del calentamiento sobre la estabilidad de los antimicrobianos en la leche se llevaron a cabo mediante el estudio de cinco tratamientos consistentes en el calentamiento a $60,70,80,90$ y $100{ }^{\circ} \mathrm{C}$ a diferentes tiempos sobre muestras adicionadas con un total de 22 sustancias antimicrobianas. En este estudio, los antimicrobianos pertenecientes al grupo de antibióticos betalactámicos y tetraciclinas se analizaron preparando soluciones fortificadas de leche a una concentración de $5000 \mu \mathrm{g} / \mathrm{kg}$ y analizando las muestras 
tratadas a los diferentes tiempos de cada una de las temperaturas mediante un equipo HPLC-UV (penicilinas) y HPLC-PDA (cefalosporinas y tetraciclinas). En el caso de las sulfonamidas las muestras de leche se fortificaron a una concentración equivalente a $200 \mu \mathrm{g} / \mathrm{kg}$ y se analizaron mediante HPLC-MS/MS. Los resultados de las pérdidas de concentración, a las diferentes temperaturas y tiempos de tratamiento, se interpretaron mediante la aplicación del modelo cinético de primer orden y la ecuación de Arrhenius, a partir de los cuales se estimaron los porcentajes de degradación de cada antimicrobiano para los tratamientos térmicos de calor, realizados frecuentemente, en los laboratorios de control así como en las industrias lácteas.

De los resultados obtenidos en este estudio se concluye que la aplicación del modelo cinético de primer orden es adecuada para el estudio de la degradación térmica de los antimicrobianos en la leche. También, a partir del cálculo de la energía de activación y los tiempos de vida media, se deduce que las cefalosporinas son las moléculas más inestables, mientras que las tetraciclinas y sulfonamidas resultan mucho más termoresistentes. Respecto a la estimación de los porcentajes de degradación, según diferentes tratamientos, se observa que aquellos del laboratorio $\left(40{ }^{\circ} \mathrm{C}-10 \mathrm{~min}\right.$ y $83^{\circ} \mathrm{C}-10 \mathrm{~min}$ ) no producen apenas efectos, excepto el tratamiento de $83^{\circ} \mathrm{C}$ durante 10 minutos sobre algunas cefalosporinas. En cuanto a los tratamientos industriales $\left(63^{\circ} \mathrm{C}-30 \mathrm{~min}, 72{ }^{\circ} \mathrm{C}-15 \mathrm{~s}, 120^{\circ} \mathrm{C}-20 \mathrm{~min}\right.$ y $\left.140{ }^{\circ} \mathrm{C}-4 \mathrm{~s}\right)$, la mayoría de ellos no parecen influir en la degradación de los antimicrobianos, excepto el tratamiento de $63{ }^{\circ} \mathrm{C}$ durante 30 minutos en las cefalosporinas con porcentajes de degradación comprendidos entre el 14,0\% (cefuroxime) y el 36,2\% (cefapirina), y la esterilización de la leche en su envase $\left(120{ }^{\circ} \mathrm{C}-20\right.$ minutos) que provoca pérdidas importantes $(37,4-100 \%)$ en todos los antibióticos betalactámicos, tetraciclinas y sulfonamidas, excepto para la sulfadimetoxina $(6,5 \%)$ y sulfatiazol $(9,9 \%)$.

De todo ello, se puede resumir que las condiciones de almacenamiento, en refrigeración y congelación, de la leche pueden afectar a la estabilidad de los antibióticos betalactámicos y tetraciclinas por lo que se recomienda conservar las muestras de leche el mínimo tiempo posible antes de su análisis, tanto a $4{ }^{\circ} \mathrm{C}$ como a $20^{\circ} \mathrm{C}$, así como plantear la posibilidad de almacenar extractos en aquellas moléculas que presentan mayor estabilidad respecto a las muestras de leche. De esta forma se pretende reducir la posible variabilidad entre los resultados analíticos realizados en una misma muestra de leche a lo largo del tiempo y que puede ser la causa de resultados contradictorios entre los obtenidos en las diferentes etapas de control.

En cuanto a los tratamientos térmicos de calor aquellos realizados en los laboratorios no producen apenas efectos de degradación sobre los antimicrobianos, al igual que los realizados en la industria láctea, salvo la esterilización de la leche en su envase, lo que significa que la mayor parte de tratamientos térmicos no actúan como barrera para impedir la llegada de sustancias antimicrobianas al consumidor, y por ello resulta necesario aplicar correctamente las medidas preventivas y de control a lo largo de toda la cadena de producción de la leche para evitar el riesgo potencial de la presencia de estas sustancias.

Los resultados de este trabajo establecen un punto de partida hacia futuros estudios, así sería interesante analizar la estabilidad de otros grupos de antimicrobianos de uso emergente en la leche. También se considera de gran interés estudiar los cambios moleculares que se pueden producir en los antimicrobianos debido a los tratamientos térmicos y los posibles efectos toxicológicos y/o tecnológicos de sus metabolitos. Todo ello para colaborar con uno de los principios básicos de la seguridad alimentaria que es la protección del consumidor. 


\section{RESUM}

La presència de residus de substàncies antimicrobianes a la llet suposa un risc per a la salut pública, ja que poden ocasionar al-lèrgies, antibioresistències $\mathrm{i}$ alteracions intestinals, entre altres problemes. A més a més, és una de les principals preocupacions de la indústria lletera, per la seua influència negativa en els processos d'elaboració de determinats productes lactis com el iogurt i el formatge.

La informació disponible sobre la termoestabilitat dels residus de medicaments en la llet, en concret, pel que fa a les temperatures de refrigeració i congelació emprades al llarg de les etapes de producció, transport i anàlisi, així com dels tractaments tèrmics de calor utilitzats en els laboratoris de control i en les indústries làcties és, fins al moment, molt limitada.

Per això, es va plantejar la realització d'aquest treball on s'ha avaluat d'una banda la influència de les condicions d'emmagatzemament de la llet, en refrigeració i congelació, sobre algunes substàncies antimicrobianes pertanyents als grups d'antibiòtics betalactàmics, tetraciclines i sulfonamides i d'una altra, s'ha analitzat l'efecte del calfament de la llet a distintes temperatures sobre l'estabilitat d'aquestes substàncies.

L'estudi de la influència de la refrigeració $\left(4 \pm 2{ }^{\circ} \mathrm{C}\right)$ i congelació $\left(-20 \pm 2{ }^{\circ} \mathrm{C}\right)$ sobre els antimicrobians en la llet es va realitzar per mitjà de l'anàlisi de mostres fortificades, a les concentracions equivalents als Límits Màxims de Residus (LMR) de 20 substàncies pertanyents als grups dels antibiòtics betalactàmics (penicillines $\mathrm{i}$ cefalosporines), tetraciclines i sulfonamides, així com en els seus corresponents extractes obtinguts previu al anàlisis cromatogràfic. Les determinacions es van realitzar mitjançant un equip HPLC-MS/MS els dies $0,1,2,3,7,10,15$ i 30 d'emmagatzemament. La influència del temps de conservació i el tipus de matriu (llet i extracte) sobre les pèrdues de concentració dels antimicrobians es va determinar per mitjà de l'aplicació del model cinètic de primer ordre, a partir del qual es van estimar els percentatges de degradació de cada substància estudiada.

Els resultats obtinguts indiquen que la refrigeració i la congelació de la llet afecten els antibiòtics betalactàmics i tetraciclines, tant en els extractes com en les mateixes mostres, i no presenten cap efecte sobre l'estabilitat de les sulfonamides. També assenyalen que l'estabilitat de cada antimicrobià depèn de la temperatura emprada i del temps d'emmagatzemament, així com la seua interacció amb el tipus de matriu (llet i extracte). Les pèrdues estimades en la llet refrigerada durant 7 dies oscillen entre el 14 i $90 \%$ i són els antibiòtics betalactàmics a excepció de la cefalexina les molècules més inestables. En els extractes les pèrdues són, en quasi tots els casos, menors. En la congelació els antimicrobians van mostrar generalment major estabilitat en les mostres que en els extractes amb percentatges de degradació als 7 dies de congelació compresos entre 6,7 i 68,4\% corresponent de nou les majors degradacions als antibiòtics betalactàmics, a excepció de la cefalexina i la cefquinoma.

D'altra banda, els experiments per analitzar l'efecte del calfament sobre l'estabilitat dels antimicrobians en la llet es van dur a terme mitjançant l'estudi de cinc tractaments tèrmics consistents en el calfament a $60,70,80,90$ i $100{ }^{\circ} \mathrm{C}$ a diferents temps sobre mostres fortificades amb un total de 22 substàncies antimicrobianes. En aquest estudi, els antimicrobians pertanyents al grup d'antibiòtics betalactàmics i tetraciclines es van analitzar preparant solucions fortificades de llet a una concentració de $5000 \mu \mathrm{g} / \mathrm{Kg}$ i analitzant les mostres tractades als diferents temps de cada una de les temperatures per mitjà d'un equip HPLC-UV (penicil-lines) i HPLC-PDA 
(cefalosporines i tetraciclines). En el cas de les sulfonamides les mostres de llet es van fortificar a una concentració equivalent a $200 \mu \mathrm{g} / \mathrm{Kg}$ i es van analitzar per mitjà de HPLC-MS/MS. Els resultats de les pèrdues de concentració, a les diferents temperatures i temps de tractament, es van interpretar per mitjà de l'aplicació del model cinètic de primer orde i l'equació d' Arrhenius, a partir dels quals es van estimar els percentatges de degradació de cada antimicrobià per als tractaments tèrmics de calor, realitzats freqüentment, en els laboratoris de control, així com en les indústries làcties.

Dels resultats obtinguts en aquest estudi es conclou que l'aplicació del model cinètic de primer orde és adequada per a l'estudi de la degradació tèrmica dels antimicrobians en la llet. També, a partir del càlcul de l'energia d'activació i els temps de vida mitjana, es dedueix que les cefalosporines són les molècules més inestables, mentres que les tetraciclines i sulfonamides resulten molt més termoresistents. Respecte a l'estimació dels percentatges de degradació, segons diferents tractaments, s'observa que aquells del laboratori $\left(40^{\circ} \mathrm{C}-10 \mathrm{~min}\right.$ i $\left.83^{\circ} \mathrm{C}-10 \mathrm{~min}\right)$ no produeixen a penes efectes, excepte el tractament de $83^{\circ} \mathrm{C}$ durant 10 minuts sobre algunes cefalosporines. Quant als tractaments industrials $\left(63^{\circ} \mathrm{C}-30 \mathrm{~min}, 72{ }^{\circ} \mathrm{C}-15 \mathrm{~s}, 120^{\circ} \mathrm{C}-20\right.$ min i $140{ }^{\circ} \mathrm{C}-4 \mathrm{~s}$ ), la majoria d'ells no semblen influir en la degradació dels antimicrobians, excepte el tractament de $63^{\circ} \mathrm{C}$ durant 30 minuts en les cefalosporines amb percentatges de degradació compresos entre el 14,0\% (cefuroxime) i el $36,2 \%$ (cefapirina), i l'esterilització de la llet en el seu envàs $\left(120^{\circ} \mathrm{C}-20\right.$ minuts) que provoca pèrdues importants $(37,4-100 \%)$ en tots els antibiòtics betalactàmics, tetraciclines $\mathrm{i}$ sulfonamides, excepte per a la sulfadimetoxina $(6,5 \%)$ i sulfatiazol $(9,9 \%)$.

De tot això, es pot resumir que les condicions d'emmagatzemament, en refrigeració i congelació, de la llet poden afectar l'estabilitat dels antibiòtics betalactàmics $i$ tetraciclines per la qual cosa es recomana conservar les mostres de llet el mínim temps possible abans del seu anàlisi, tant a $4^{\circ} \mathrm{C}$ com a $-20^{\circ} \mathrm{C}$, així com plantejar la possibilitat d'emmagatzemar extractes en aquelles molècules que presenten major estabilitat respecte a les mostres de llet. D'aquesta manera es pretén reduir la possible variabilitat entre els resultats analítics realitzats en una mateixa mostra de llet al llarg del temps i que pot ser la causa de resultats contradictoris entre les diferents etapes de control.

Quant als tractaments tèrmics de calor, aquells realitzats en els laboratoris no produeixen a penes efectes de degradació sobre els antimicrobians, així com els realitzats en la indústria làctia, excepte l'esterilització de la llet en el seu envàs, la qual cosa significa que la major part de tractaments tèrmics no actuen com a barrera per a impedir l'arribada de substàncies antimicrobianes al consumidor, i per això resulta necessari aplicar correctament les mesures preventives i de control al llarg de tota la cadena de producció de la llet per a evitar el risc potencial de la presència d'aquestes substàncies.

Els resultats d'aquest treball estableixen un punt de partida cap a futurs estudis. Així, seria interessant analitzar l'estabilitat d'altres grups d'antimicrobians d'ús emergent en la llet. També es considera de gran interès estudiar els canvis moleculars que es poden produir en els antimicrobians a causa dels tractaments tèrmics i els possibles efectes toxicològics i/o tecnològics dels seus metabòlits. Tot això per a colllaborar amb un dels principis bàsics de la seguretat alimentària que és la protecció del consumidor. 


\section{SUMMARY}

The presence of antimicrobial residues in milk constitutes a public health risk as they may provoke allergies, resistance to antibiotics and intestinal alterations, among other things. It is, moreover, one of the dairy industry's main concerns, as they may have a negative effect on the manufacturing process of some dairy products, such as yoghurt and cheese. The amount of information available on the heat stability of the residues in milk is very limited, particularly so when referring to the refrigeration and freezing temperatures used throughout the production stages, transport and analysis, as well as the heat treatments used in the control laboratories and dairy industries.

Therefore, the aim of this study is to carry out a two-fold analysis. On the one hand, to evaluate the influence of refrigerated and frozen storage conditions on the presence of antimicrobial substances belonging to groups of betalactams, tetracyclines and sulphonamides and, on the other, to analyse the effect that heating milk to different temperatures has on the stability of these substances.

The influence that refrigeration $\left(4 \pm 2{ }^{\circ} \mathrm{C}\right)$ and freezing $\left(-20 \pm 2{ }^{\circ} \mathrm{C}\right)$ has on antimicrobial presence in milk has been studied by means of analysing samples of 20 substances that have been spiked at Maximum Residue Limits (MRL) equivalent concentrations. These substances belong to the betalactam (penicillins and cephalosporins), tetracycline and sulphonamide antimicrobial groups and their corresponding extracts. HPLC-MS/MS equipment was used to carry out the chromatographic analysis of the milk samples and extracts after 0, 1, 2, 3, 7, 10, 15 and 30 days of storage. How much refrigeration and freezing time and the type of matrix (milk and extracts) influenced the loss in concentration of the antimicrobial substances was determined by applying the multiple linear regression model and estimating the degradation percentages of each substance.

From the obtained results, it can be concluded that refrigeration and freezing do affect the betalactam and tetracycline antibiotics present in both the extracts and the milk samples, but have no effect on the stability of sulphonamides. It may also be seen that the stability of each substance depends on temperature, storage time and the interaction with the type of matrix (milk and extracts). Although the estimated losses in the milk samples refrigerated for 7 days ranged between 14 and $90 \%$ for every substance, the most unstable molecules were the betalactam antibiotics (with the exception of cephalexin). Nearly all the extracts experienced smaller losses. When frozen, most of the antimicrobial samples were more stable than the extracts. After 7 days of frozen storage, the degradation percentages ranged between 6.7 and $68.4 \%$, and once again, the betalactams were the antibiotics that degraded the most, except for cephalexin and cefquinome.

To analyse the effect of heating on antimicrobial stability in milk, an experiment was performed consisting of 5 heat treatments at $60,70,80,90$ and $100^{\circ} \mathrm{C}$ for different periods of time on samples spiked with 22 antimicrobial substances. In this study, the antimicrobial substances belonging to the betalactam and tetracycline antibiotic groups were analysed by preparing milk solutions that have been spiked at a concentration of $5000 \mu \mathrm{g} / \mathrm{Kg}$ and by analysing the samples treated for different periods of time at each of the temperatures, using two pieces of equipment: HPLC-UV for penicillins and 
HPLC-PDA for cephalosporins and tetracyclines. In the case of the sulphonamides, the milk samples were spiked at a concentration equivalent to $200 \mu \mathrm{gKg}$ and were analysed using HPLC-MS/MS. At the different temperatures and after different treatment times, each substance loses concentration and these losses were analysed by applying the first order kinetic model and the Arrhenius equation. From these analyses, the degradation percentages of each antimicrobial substance were estimated for the heat treatments that are widely used both in the control laboratories and the dairy industry.

From the results obtained in this study, it can be concluded that it is suitable to apply the first order kinetic model to study heat degradation of antimicrobial substances in milk. It may also be deduced, from the calculation of the activation energy and the half-lives, that cephalosporins are the most unstable molecules, whereas tetracyclines and sulphonamides are much more heat resistant. As regards the estimation of degradation percentage as influenced by different treatments, it may be seen that those used in laboratories $\left(40{ }^{\circ} \mathrm{C}-10 \mathrm{~min}\right.$ and $\left.83{ }^{\circ} \mathrm{C}-10 \mathrm{~min}\right)$ produce hardly any effects, except for the treatment at $83^{\circ} \mathrm{C}$ for $10 \mathrm{~min}$ on some cephalosporins. Concerning the industrial treatments $\left(63^{\circ} \mathrm{C}-30 \mathrm{~min}, 72^{\circ} \mathrm{C}-15 \mathrm{sec}, 120^{\circ} \mathrm{C}-20 \mathrm{~min}\right.$ y 140 ${ }^{\circ} \mathrm{C}-10 \mathrm{sec}$ ), it seems that most of them have no effect upon antimicrobial degradation, with two exceptions; the treatment at $63^{\circ} \mathrm{C}$ for 30 minutes has a degrading effect on cephalosporins, reaching percentages ranging between $14 \%$ (cefuroxime) and $36.2 \%$ (cefapirin) and the milk sterilization $\left(120^{\circ} \mathrm{C}-20 \mathrm{~min}\right.$ ) which leads to significant losses (37.4-100\%) in all the betalactam, tetracycline and sulphonamide antibiotics, except for sulfadimethoxine $(6.5 \%)$ and sulfathiazole $(9.9 \%)$.

It can be concluded from this that milk sample storage conditions, both refrigeration and freezing, can affect the stability of betalactam and tetracycline antibiotics. This is why it is advisable to keep the milk samples for the shortest possible time prior to analysis (both at $4{ }^{\circ} \mathrm{C}$ and $-20^{\circ} \mathrm{C}$ ) and also to study the possibility of storing extracts of those molecules that are mores stable then the milk samples. In this way, the aim is to reduce the possible variability in the results of the analysis carried out on the same milk sample over a period of time and which may be behind the contradictory results obtained during the different control stages.

Regarding the heat treatments, neither those performed in the laboratories nor the ones used in the dairy industry, produce hardly any degradation effects on antimicrobial substances, except for milk sterilization $\left(120^{\circ} \mathrm{C}-20 \mathrm{~min}\right)$. This means that, as most of the heat treatments do not act as a barrier preventing antimicrobial substances from reaching the consumer, it is necessary to apply the preventative and control methods correctly throughout the whole milk production chain to avoid any potential risk caused by the presence of these substances.

The results of this work establish a starting point for future studies and it would be of interest to analyse the stability of other antimicrobial groups that are being used more and more in milk. It is also relevant to study the molecular changes that can be brought about in the antibiotics by the heat treatments and the possible toxicological and/or technological effects of their metabolites. All of this contributes towards improving one of the basic principles of food safety: consumer protection. 
ÍNDICES 



\section{ÍNDICE GENERAL}

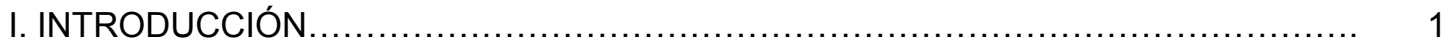

1. SUSTANCIAS ANTIMICROBIANAS EN MEDICINA VETERINARIA ................... 1

1.1. CONSIDERACIONES PREVIAS..................................................

1.2. PROPIEDADES GENERALES DE LOS ANTIMICROBIANOS ..................... 4

1.2.1. Conceptos generales y clasificación............................................. 4

1.2.2. Principales grupos de antimicrobianos en medicina veterinaria.................... 5

1.2.2.1. Antibióticos betalactámicos............................................. 5

1.2.2.2. Tetraciclinas........................................................... 10

1.2.2.3. Sulfonamidas ................................................ 12

1.2.2.4. Otros grupos de antimicrobianos.................................... 13

1.3. ANTIMICROBIANOS EMPLEADOS EN VACUNO LECHERO........................ 15

2. PRESENCIA Y CONTROL DE RESIDUOS DE ANTIMICROBIANOS EN LA LECHE 19 2.1. CAUSAS Y CONSECUENCIAS DE LA PRESENCIA DE RESIDUOS DE ANTIMICROBIANOS EN LA LECHE.

2.1.1. Origen de la presencia de residuos de antimicrobianos en la leche............. 19

2.1.2. Efectos de la presencia de residuos de antimicrobianos en la leche............. 21

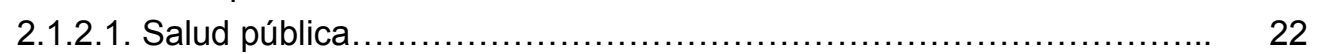

2.1.2.2. Industria láctea......................................................... 23

2.1.2.3. Productor de leche ...................................................... 24

2.2. CONTROL DE LA PRESENCIA DE ANTIMICROBIANOS EN LA LECHE.......... 25

2.2.1. Medidas de control............................................................ 25

2.2.1.1. Límites Máximos de Residuos................................... 25

2.2.1.2. Planes de control.............................................. 26

2.2.2. Sistema de detección de residuos de antimicrobianos en la leche.................. 29

2.2.2.1. Generalidades...................................................... 29

2.2.2.2. Métodos de detección de residuos de antimicrobianos en la leche..... 31

3. DETECCIÓN DE ANTIMICROBIANOS EN LA LECHE POR HPLC.................. 32

3.1. GENERALIDADES .................................................................... 32

3.2. MÉTODOS DE DETECCIÓN...................................................... 34

3.2.1. Consideraciones previas................................................ 34

3.2.2. Detectores convencionales................................................ 36

3.2.3. Espectrometría de masas .......................................... 38

3.2.3.1. Generalidades................................................ 38

3.2.3.2. LC-ESI-MS/MS (triple cuadrupolo) ................................ 39

3.3. TÉCNICAS DE CROMATOGRAFÍA LÍQUIDA PARA LA DETECCIÓN DE

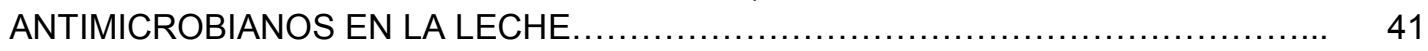

3.3.1. Antibióticos betaláctamicos.................................................... 41

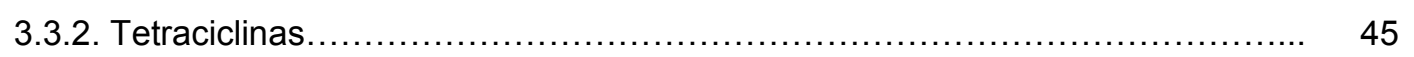

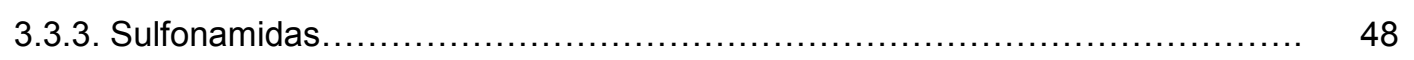

4. TERMOESTABILIDAD DE LAS SUSTANCIAS ANTIMICROBIANAS ................... 50

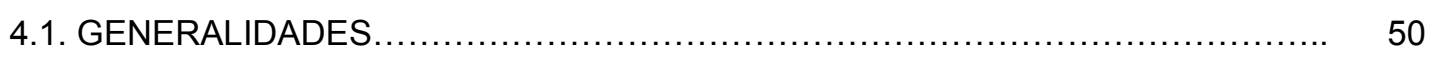

4.1.1. Estabilidad de los medicamentos en disolución................................... 50

4.1.2. Factores que afectan a la estabilidad de los medicamentos en disolución....... 51

4.2. EFECTO DE LA TEMPERATURA SOBRE LA ESTABILIDAD DE LAS SUSTANCIAS ANTIMICROBIANAS EN LA LECHE. 
4.2.1. Consideraciones previas.

4.2.2. Estabilidad de los antimicrobianos durante el almacenamiento.................. 55

4.2.2.1. Antibióticos betalactámicos........................................... 55

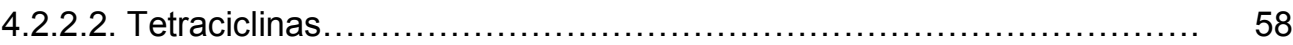

4.2.2.3. Sulfonamidas.................................................... 60

4.2.3. Efecto del calentamiento sobre la estabilidad de los antimicrobianos........... 62

4.2.3.1. Antibióticos betalactámicos.............................................. 62

4.2.3.2. Tetraciclinas. ........................................................... 67

4.2.3.3. Sulfonamidas......................................................... 70

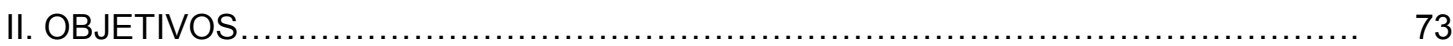

III. MATERIAL Y MÉTODOS ......................................................... 75

1. PRIMER ESTUDIO: Influencia de las condiciones de almacenamiento sobre la

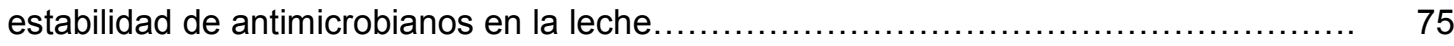

1.1. DISEÑO EXPERIMENTAL......................................................... 75

1.2. PATRONES Y MUESTRAS FORTIFICADAS ..................................... 76

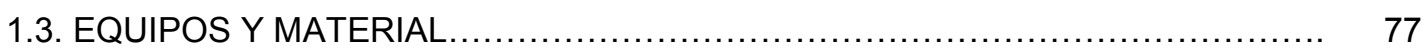

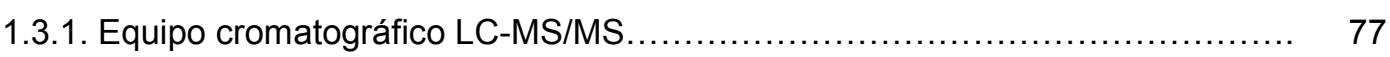

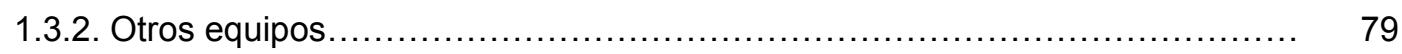

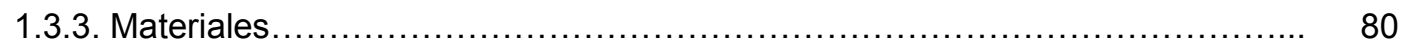

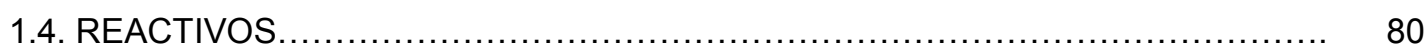

1.4.1. Fase móvil del sistema de análisis cromatográfico.............................. 80

1.4.2. Otros reactivos................................................................ 81

1.5. DETERMINACIÓN CROMATOGRÁFICA DE LOS ANTIMICROBIANOS........... 81

1.5.1. Análisis cromatográfico de los antibióticos betalactámicos...................... 81

1.5.1.1. Extracción y purificación de las muestras................................... 81

1.5.1.2. Separación y detección cromatográfica............................... 82

1.5.1.3. Interpretación de los cromatogramas................................ 83

1.5.2. Análisis cromatográfico de las tetraciclinas..................................... 85

1.5.2.1. Extracción y purificación de las muestras................................ 86

1.5.2.2. Separación y detección cromatográfica................................. 86

1.5.2.3. Interpretación de los cromatogramas..................................... 87

1.5.3. Análisis cromatográfico de las sulfonamidas............................... 89

1.5.3.1. Extracción y purificación de las muestras................................ 89

1.5.3.2. Separación y detección cromatográfica.................................. 89

1.5.3.3. Interpretación de los cromatogramas...................................... 91

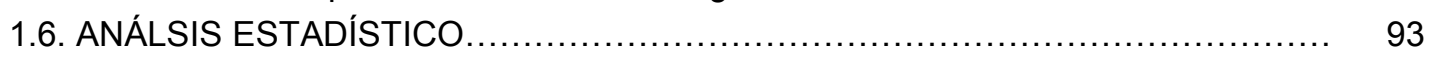

1.6.1. Estudio de la degradación de antimicrobianos mediante modelos de primer orden......

1.6.2. Estimación de los porcentajes de degradación de los antimicrobianos.......... 94

2. SEGUNDO ESTUDIO. Efecto de diferentes tratamientos térmicos de calor sobre la estabilidad de los antimicrobianos en la leche............................................... 95

2.1. DISEÑO EXPERIMENTAL...................................................... 95

2.2. PATRONES Y MUESTRAS FORTIFICADAS..................................... 95

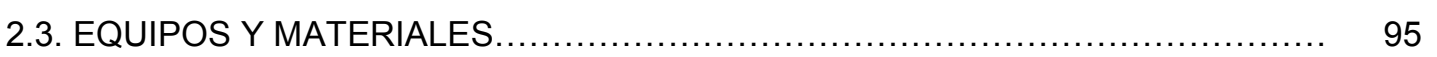

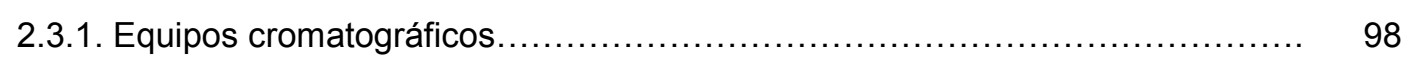

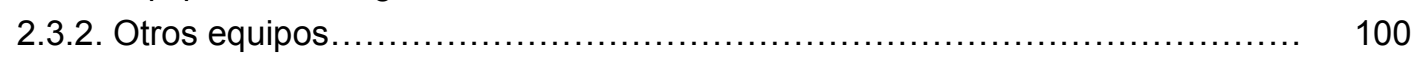

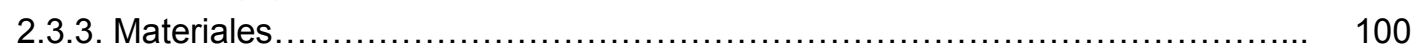


2.4.1. Fase móvil del sistema cromatográfico "cleanup"............................... 101

2.4.2. Fase móvil del sistema cromatográfico de análisis con detector UV ............ 101

2.4.3. Fase móvil del sistema cromatográfico de análisis con detector MS/MS....... 102

2.4.4. Otros reactivos..................................................................... 102

2.5. ANÁLISIS CROMATOGRÁFICO DE LOS ANTIMICROBIANOS ................... 103

2.5.1. Determinación cromatográfica de los antibióticos betalactámicos................ 103

2.5.1.1. Preparación y extracción de la muestra.................................. 104

2.5.1.2. Separación de fracciones por "cleanup"................................ 104

2.5.1.3. Análisis cromatográfico .............................................. 106

2.5.1.4. Interpretación de los cromatogramas................................. 107

2.5.2. Determinación cromatográfica de las tetraciclinas............................. 110

2.5.2.1. Preparación y extracción de la muestra................................. 110

2.5.2.2. Análisis cromatográfico......................................... 111

2.5.2.3. Interpretación de los cromatogramas.................................. 111

2.5.3. Determinación cromatográfica de las sulfonamidas............................ 112

2.5.3.1. Preparación y extracción de la muestra................................... 113

2.5.3.2. Separación y detección cromatográfica................................. 113

2.5.3.3. Interpretación de los cromatogramas................................. 113

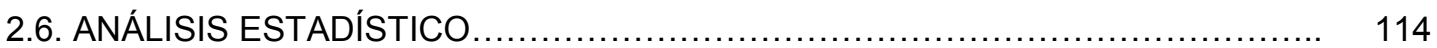

2.6.1. Estudio de la degradación térmica de antimicrobianos mediante modelos de primer orden.

114

2.6.2. Cálculo de la energía de activación............................................. 116

2.6.3. Estimación de los porcentajes de degradación de los antimicrobianos para diferentes tratamientos térmicos......................................................

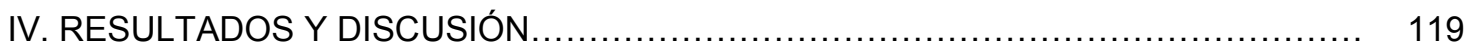

1. PRIMER ESTUDIO. Influencia de las condiciones de almacenamiento sobre la estabilidad de antimicrobianos en la leche................................................ 119

1.1. ANTIBIÓTICOS BETALACTÁMICOS: PENICILINAS............................... 119

1.1.1. Influencia de la refrigeración de las muestras y extractos de leche.............. 119

1.1.2. Influencia de la congelación de las muestras y extractos de leche............... 125

1.2. ANTIBIÓTICOS BETALACTÁMICOS: CEFALOSPORINAS........................ 132

1.2.1. Influencia de la refrigeración de las muestras y extractos de leche.............. 132

1.2.2. Influencia de la congelación de las muestras y extractos de leche............... 138

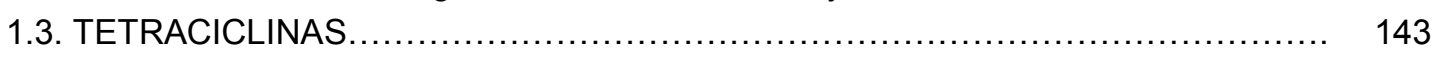

1.3.1. Influencia de la refrigeración de las muestras y extractos de leche ............... 143

1.3.2. Influencia de la congelación de las muestras y extractos de leche.............. 149

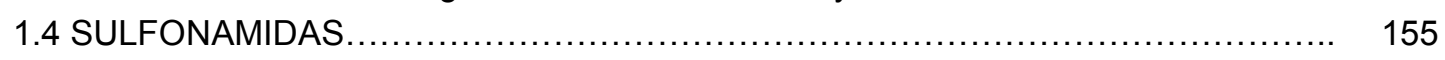

1.4.1 Influencia de la refrigeración de las muestras y extractos de leche............... 155

1.4.2 Influencia de la congelación de las muestras y extractos de leche................ 158

2. SEGUNDO ESTUDIO. Efecto de diferentes tratamientos térmicos de calor sobre la estabilidad de los antimicrobianos en la leche.

2.1. ANTIBIÓTICOS BETALACTÁMICOS: PENICILINAS ................................ 161

2.1.1.Estudio de la degradación térmica de las penicilinas mediante modelos de primer orden.

2.1.2. Cálculo de la energía de activación............................................

2.1.3. Estimación de la degradación de penicilinas para diferentes tratamientos térmicos. 
2.2. ANTIBIÓTICOS BETALACTÁMICOS: CEFALOSPORINAS

2.2.1.Estudio de la degradación térmica de las cefalosporinas mediante modelos de primer orden.

2.2.2. Cálculo de la energía de activación.

2.2.3. Estimación de la degradación de cefalosporinas para diferentes tratamientos térmicos.

2.3. TETRACICLINAS.

2.3.1.Estudio de la degradación térmica de las tetraciclinas mediante modelos de primer orden.

2.3.2. Cálculo de la energía de activación.

2.3.3. Estimación de la degradación de tetraciclinas para diferentes tratamientos térmicos

2.4. SULFONAMIDAS

2.4.1. Estudio de la degradación térmica de las sulfonamidas mediante modelos de primer orden.

2.4.2. Cálculo de la energía de activación

2.4.3. Estimación de la degradación de sulfonamidas para diferentes tratamientos térmicos.....

V. CONCLUSIONES 


\section{ÍNDICE DE CUADROS}

Cuadro 1. Gasto mundial y europeo de medicamentos en sanidad animal.

Cuadro 2. Distribución mundial del gasto en medicamentos en sanidad animal por especies.

Cuadro 3. Consumo de antimicrobianos en medicina veterinaria en Europa.....

Cuadro 4. Clasificación de los diferentes agentes antimicrobianos

Cuadro 5. Frecuencia de utilización de antimicrobianos en los tratamientos antimamíticos.

Cuadro 6. Límites Máximos de Residuos en leche de vaca.

Cuadro 7. Métodos de confirmación para residuos orgánicos o contaminantes.

Cuadro 8. Técnicas de cromatografía líquida con detectores convencionales para el análisis de antibióticos betalactámicos en la leche.

Cuadro 9. Técnicas de cromatografía líquida con espectroscopia de masas para el análisis de antibióticos betalactámicos en la leche.

Cuadro 10. Técnicas de cromatografía líquida con detectores convencionales para el análisis de tetraciclinas en la leche

Cuadro 11. Técnicas de cromatografía líquida con espectroscopia de masas para el análisis de tetraciclinas en la leche.

Cuadro 12. Técnicas de cromatografía líquida con detectores convencionales y de masas para el análisis de sulfonamidas en la leche.

Cuadro 13. Parámetros relativos a los órdenes de reacción

Cuadro 14. Efecto de los tratamientos térmicos sobre los antibióticos betalactámicos en leche y otras matrices líquidas.

Cuadro 15. Efecto del tratamiento térmico sobre las tetraciclinas en la leche y otras matrices líquidas.

Cuadro 16. Efecto del tratamiento térmico sobre las sulfonamidas en la leche y otras matrices líquidas.

Cuadro 17. Antimicrobianos, concentraciones y disolventes utilizados

Cuadro 18. Condiciones del espectrómetro de masas para la identificación y cuantificación de antibióticos betalactámicos.

Cuadro 19. Ecuaciones de las rectas de calibrado de los antibióticos

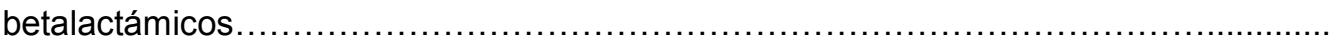

Cuadro 20. Condiciones del espectrómetro de masas para la identificación y cuantificación de las tetraciclinas.

Cuadro 21. Ecuaciones de las rectas de calibrado de las tetraciclinas.

Cuadro 22. Condiciones del espectrómetro de masas para la identificación y cuantificación de sulfonamidas....

Cuadro 23. Ecuaciones de las rectas de calibrado de las sulfonamidas.....

Cuadro 24. Temperaturas y tiempos empleados en el estudio de diferentes tratamientos térmicos sobre la estabilidad de los antimicrobianos en la leche.

Cuadro 25. Antimicrobianos y disolventes utilizados.................................. 97

Cuadro 26. Fracciones relativas a las penicilinas....................................... 106

Cuadro 27. Ecuaciones correspondientes a las rectas de calibrado de los antibióticos betalactámicos. 
Cuadro 28. Ecuaciones correspondientes a las recta de calibrado de las tetraciclinas.

Cuadro 29. Efecto del tiempo de refrigeración y de la matriz sobre la concentración de penicilinas en muestras de leche.

Cuadro 30. Ecuaciones de regresión lineal múltiple de los efectos del tiempo de refrigeración y de la matriz sobre la concentración de penicilinas

Cuadro 31. Porcentajes de degradación de penicilinas en muestras de leche refrigeradas

Cuadro 32. Porcentajes de degradación de penicilinas en extractos de leche refrigerados

Cuadro 33.Tiempos de vida media $\left(t_{1 / 2}\right)$ de las penicilinas en muestras de leche y extractos refrigerados.

Cuadro 34. Efecto del tiempo de congelación y de la matriz sobre la concentración de penicilinas

Cuadro 35. Ecuaciones de regresión lineal múltiple de los efectos del tiempo de congelación y de la matriz sobre la concentración de penicilinas.

Cuadro 36. Porcentajes de degradación de penicilinas en muestras de leche congeladas

Cuadro 37. Porcentajes de degradación de penicilinas en extractos de leche congelados

Cuadro 38. Tiempos de vida media $\left(t_{1 / 2}\right)$ de las penicilinas en muestras de leche y extractos congelados.

Cuadro 39. Efecto del tiempo de refrigeración y de la matriz sobre la concentración de cefalosporinas.

Cuadro 40. Ecuaciones de regresión lineal múltiple de los efectos del tiempo de refrigeración y de la matriz sobre la concentración de cefalosporinas.

Cuadro 41. Porcentajes de degradación de cefalosporinas en muestras de leche refrigeradas.

Cuadro 42. Porcentajes de degradación de cefalosporinas en extractos de leche refrigerados.

Cuadro 43. Tiempos de vida media $\left(t_{1 / 2}\right)$ de las cefalosporinas en muestras de leche y extractos refrigerados.

Cuadro 44. Efecto del tiempo de congelación y de la matriz sobre la concentración de cefalosporinas.

Cuadro 45. Ecuaciones de regresión lineal múltiple de los efectos del tiempo de congelación y de la matriz sobre la concentración de cefalosporinas.

Cuadro 46. Porcentajes de degradación de cefalosporinas en muestras de leche congeladas.

Cuadro 47. Porcentajes de degradación de cefalosporinas en extractos de leche congeladas.

Cuadro 48. Tiempos de vida media $\left(t_{1 / 2}\right)$ de las cefalosporinas en muestras de leche y extractos congelados.

Cuadro 49. Efecto del tiempo de refrigeración y de la matriz sobre la concentración de tetraciclinas.

Cuadro 50. Ecuaciones de regresión lineal múltiple de los efectos del tiempo de refrigeración y de la matriz sobre la concentración de tetraciclinas. 
Cuadro 51. Porcentajes de degradación de tetraciclinas en muestras de leche refrigeradas

Cuadro 52. Porcentajes de degradación de tetraciclinas en extractos de leche refrigeradas.

Cuadro 53. Tiempos de vida media $\left(t_{1 / 2}\right)$ de las tetraciclinas en muestras de leche y extractos refrigerados

Cuadro 54. Efecto del tiempo de congelación y de la matriz sobre la concentración de tetraciclinas.

Cuadro 55. Ecuaciones de regresión lineal múltiple de los efectos del tiempo de congelación y de la matriz sobre la concentración de tetraciclinas.

Cuadro 56. Porcentajes de degradación de tetraciclinas en muestras de leche congeladas

Cuadro 57. Porcentajes de degradación de tetraciclinas en extractos de leche congelados

Cuadro 58. Tiempos de vida media $\left(t_{1 / 2}\right)$ de las tetraciclinas en muestras de leche y extractos congelados.

Cuadro 59. Efecto del tiempo de refrigeración y de la matriz sobre la concentración de sulfonamidas.

Cuadro 60. Efecto del tiempo de congelación y de la matriz sobre la concentración de sulfonamidas.

Cuadro 61. Parámetros resultantes de la aplicación del modelo cinético de primer orden a la degradación de la amoxicilina en la leche a diferentes temperaturas.

Cuadro 62. Parámetros resultantes de la aplicación del modelo cinético de primer orden a la degradación de la ampicilina en la leche a diferentes temperaturas.

Cuadro 63. Parámetros resultantes de la aplicación del modelo cinético de primer orden a la degradación de la cloxacilina en la leche a diferentes temperaturas.

Cuadro 64. Parámetros resultantes de la aplicación del modelo cinético de primer orden a la degradación de la penicilina $\mathrm{G}$ en la leche a diferentes temperaturas

Cuadro 65. Tiempos de vida media $\left(\mathrm{t}_{1 / 2}\right)$ estimados para las penicilinas en la leche a diferentes temperaturas de calentamiento.

Cuadro 66. Ecuación de Arrhenius aplicada a la degradación térmica de las penicilinas en la leche.

Cuadro 67. Porcentajes de degradación de las penicilinas en la leche para diferentes tratamientos térmicos.

Cuadro 68. Parámetros resultantes de la aplicación del modelo cinético de primer orden a la degradación de la cefalexina en la leche a diferentes temperaturas.

Cuadro 69. Parámetros resultantes de la aplicación del modelo cinético de primer orden a la degradación del cefalonio en la leche a diferentes temperaturas.

Cuadro 70. Parámetros resultantes de la aplicación del modelo cinético de primer orden a la degradación de la cefapirina en la leche a diferentes temperaturas.

Cuadro 71. Parámetros resultantes de la aplicación del modelo cinético de primer orden a la degradación de la cefoperazona en la leche a diferentes temperaturas.......

Cuadro 72 Parámetros resultantes de la aplicación del modelo cinético de primer orden a la degradación de la cefquinoma en la leche a diferentes temperaturas..........

Cuadro 73. Parámetros resultantes de la aplicación del modelo cinético de primer orden a la degradación de la cefuroxima en la leche a diferentes temperaturas. 
Cuadro 74. Tiempos de vida media ( $\left.t_{1 / 2}\right)$ estimados para las penicilinas en la leche a diferentes temperaturas de calentamiento.

Cuadro 75. Ecuación de Arrhenius aplicada a la degradación térmica de las cefalosporinas en la leche.

Cuadro 76. Porcentaje de degradación de las cefalosporinas en leche para diferentes tratamientos térmicos.

Cuadro 77. Parámetros resultantes de la aplicación del modelo cinético de primer orden a la degradación de la clortetraciclina en la leche a diferentes temperaturas......

Cuadro 78. Parámetros resultantes de la aplicación del modelo cinético de primer orden a la degradación de la doxicilina en la leche a diferentes temperaturas.

Cuadro 79. Parámetros resultantes de la aplicación del modelo cinético de primer orden a la degradación de la oxitetraciclina en la leche a diferentes temperaturas.

Cuadro 80. Parámetros resultantes de la aplicación del modelo cinético de primer orden a la degradación de la tetraciclina en la leche a diferentes temperaturas.

Cuadro 81. Tiempos de vida media $\left(t_{1 / 2}\right)$ estimados para las tetraciclinas en la leche a diferentes temperaturas de calentamiento.

Cuadro 82. Ecuación de Arrhenius aplicada a la degradación térmica de las tetraciclinas en la leche

Cuadro 83. porcentajes de degradación de tetraciclinas en la leche para diferentes tratamientos térmicos.

Cuadro 84. Ecuaciones resultantes de la aplicación del modelo cinético de primer orden a la degradación térmica de la sulfacloropiridazina con el tiempo.....

Cuadro 85 Ecuaciones resultantes de la aplicación del modelo cinético de primer orden a la degradación térmica de la sulfadiazina con el tiempo.

Cuadro 86. Ecuaciones resultantes de la aplicación del modelo cinético de primer orden a la degradación térmica de la sulfadimetoxina con el tiempo.

Cuadro 87. Ecuaciones resultantes de la aplicación del modelo cinético de primer orden a la degradación térmica de la sulfamerazina con el tiempo.

Cuadro 88. Ecuaciones resultantes de la aplicación del modelo cinético de primer orden a la degradación térmica de la sulfametazina con el tiempo.

Cuadro 89. Ecuaciones resultantes de la aplicación del modelo cinético de primer orden a la degradación térmica de la sulfapiridina con el tiempo. ....

Cuadro 90. Ecuaciones resultantes de la aplicación del modelo cinético de primer orden a la degradación térmica de la sulfaquinoxalina con el tiempo.

Cuadro 91. Ecuaciones resultantes de la aplicación del modelo cinético de primer orden a la degradación térmica del sulfatiazol con el tiempo.

Cuadro 92. Tiempos de vida media $\left(t_{1 / 2}\right)$ estimados para las sulfonamidas en la leche a diferentes temperaturas de calentamiento

Cuadro 93. Ecuación de Arrhenius aplicada a la degradación térmica de las sulfonamidas en la leche.

Cuadro 94. Porcentajes de degradación de las sulfonamidas en la leche para diferentes tratamientos térmicos. 


\section{ÍNDICE DE FIGURAS}

Figura 1. Frecuencias de uso de antimicrobianos por vía intramamaria empleados en ganado vacuno en lactación.

Figura 2. Frecuencias de uso de antimicrobianos por vía intramamaria empleados en ganado vacuno en el secado.

Figura 3. Causas de la presencia de residuos en la leche debido a tratamientos antimamíticos.

Figura 4. Esquema de las diferentes etapas implicadas en el sistema de trazabilidad.....

Figura 5. Controles mínimos exigidos en el Módulo de Calidad Letra

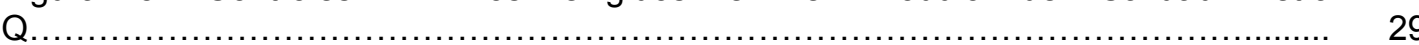

Figura 6. Sistema integrado de control de inhibidores en la leche........................ $\quad 30$

Figura 7. Separación de compuestos en la columna cromatográfica..................... 33

Figura 8. Cromatografía de fase inversa.................................................... 33

Figura 9. Esquema general de un sistema de cromatografía líquida....................... 34

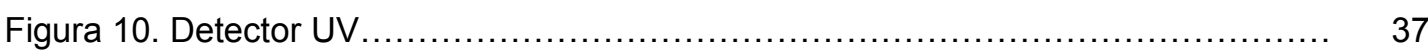

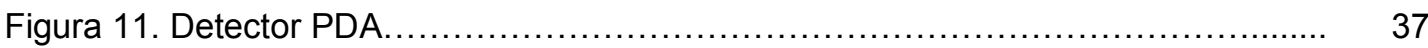

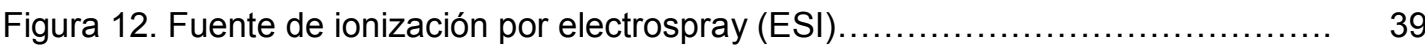

Figura 13. Espectrómetro de masas tipo triple cuadrupolo................................ 40

Figura 14. Variación de la concentración de penicilina $G$ en muestras y extractos de leche refrigerados

Figura 15. Porcentaje de inactivación de las penicilinas en la leche con diferentes tratamientos térmicos.

Figura 16. Porcentaje de inactivación de las cefalosporinas en la leche con diferentes tratamientos térmicos

Figura 17. Porcentaje de inactivación de las tetraciclinas en la leche con diferentes tratamientos térmicos.

Figura 18. Porcentaje de inactivación de las sulfonamidas en la leche con diferentes tratamientos térmicos.

Figura 19. Diseño experimental empleado en el estudio de la influencia de las condiciones de almacenamiento sobre la estabilidad de antimicrobianos en la leche.......

Figura 20. Equipo cromatográfico y detector de espectometría de masas.

Figura 21. Espectro correspondiente al ión precursor de la cloxacilina en leche el primer día de refrigeración.

Figura 22. Cromatogramas correspondientes a los iones primario y secundario de la cloxacilina en leche el primer día de refrigeración.

Figura 23. Espectro correspondiente al ión precursor de la oxitetraciclina en leche el primer día de refrigración.

Figura 24. Cromatogramas correspondientes a los iones primarios y secundarios de la oxitetraciclina en la leche el primer día de refrigeración.

Figura 25. Espectro correspondiente al ión precursor del sulfatiazol en leche el primer día de refrigeración.

Figura 26. Cromatogramas correspondientes a los iones primario y secundario del sulfatiazol en leche el primer día de refrigeración. 
Figura 27. Colector automático de fracciones........................................ 99

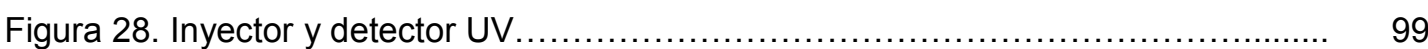

Figura 29. Sistema integrado de análisis.............................................. 99

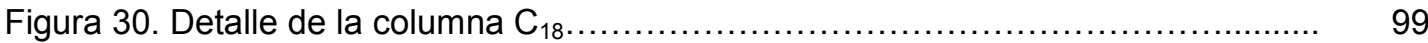

Figura 31. Cromatograma y tabla de resultados de las cefalosporinas recogidas en la fracción 5 (F5) del sistema cromatográfico de "cleanup".

Figura 32. Cromatograma y tabla de resultados obtenidos en el análisis cromatográfico de las tetraciclinas.

Figura 33. Espectro de masas del ión precursor relativo a la sulfadiazina a los 30 minutos de tratamiento a $70^{\circ} \mathrm{C}$.

Figura 34. Cromatogramas de los iones primario y secundario de la sulfadiazina a los 30 minutos de tratamiento a $70^{\circ} \mathrm{C}$.....

Figura 35. Porcentajes de variación de la concentración de penicilinas en los extractos y muestras de leche con el tiempo de refrigeración.

Figura 36. Efecto del tiempo de refrigeración sobre la concentración de penicilinas en muestras de leche.

Figura 37. Efecto del tiempo de refrigeración sobre la concentración de penicilinas en extractos de leche.

Figura 38. Porcentajes de variación de la concentración de penicilinas en los extractos y muestras de leche con el tiempo de congelación.

Figura 39. Efecto del tiempo de congelación sobre la concentración de penicilinas en muestras de leche.

Figura 40. Efecto del tiempo de congelación sobre la concentración de penicilinas en extractos de leche.

Figura 41. Porcentajes de variación de la concentración de cefalosporinas en los extractos y muestras de leche con el tiempo de refrigeración.

Figura 42. Efecto del tiempo de refrigeración sobre la concentración de cefalosporinas en muestras de leche.

Figura 43. Efecto del tiempo de refrigeración sobre la concentración de cefalosporinas en extractos de leche.

Figura 44. Porcentajes de variación de la concentración de cefalosporinas en los extractos y muestras de leche congelados.

Figura 45. Efecto del tiempo de congelación sobre la concentración de

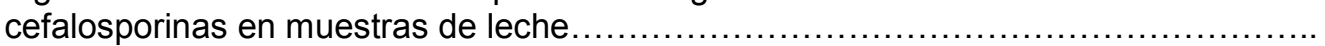

Figura 46. Efecto del tiempo de congelación sobre la concentración de cefalosporinas en extractos de leche......

Figura 47. Porcentajes de variación de la concentración de tetraciclinas en los extractos y muestras de leche durante el tiempo de refrigeración.

Figura 48. Efecto del tiempo de refrigeración sobre la concentración de tetraciclinas en muestras de leche.

Figura 49. Efecto del tiempo de refrigeración sobre la concentración de tetraciclinas en extractos de leche.

Figura 50. Porcentajes de variación de la concentración de tetraciclinas en los extractos y muestras de leche con el tiempo de congelación...

Figura 51. Efecto del tiempo de congelación sobre la concentración de tetraciclinas en muestras de leche. 
Figura 52. Efecto del tiempo de congelación sobre la concentración de tetraciclinas en extractos de leche.

Figura 53. Porcentajes de variación de la concentración de sulfonamidas en los extractos y muestras de leche con el tiempo de refrigeración.

Figura 54. Porcentajes de variación de la concentración de sulfonamidas en los extractos y muestras de leche con el tiempo de congelación

Figura 55. Relación entre la concentración de amoxicilina en la leche y el tiempo de calentamiento a diferentes temperaturas

Figura 56. Relación entre la concentración de ampicilina en la leche y el tiempo de calentamiento a diferentes temperaturas.

Figura 57. Relación entre la concentración de cloxacilina en la leche y el tiempo de calentamiento a diferentes temperaturas.

Figura 58. Relación entre la concentración de penicilina $\mathrm{G}$ en la leche y el tiempo de calentamiento a diferentes temperaturas.

Figura 59. Representación gráfica de la ecuación de Arrhenius para las penicilinas.....

Figura 60. Relación entre la concentración de cefalexina en la leche y el tiempo de calentamiento a diferentes temperaturas.

Figura 61. Relación entre la concentración de cefalonio en la leche y el tiempo de calentamiento a diferentes temperaturas.

Figura 62. Relación entre la concentración de cefapirina en la leche y el tiempo de calentamiento a diferentes temperaturas

Figura 63. Relación entre la concentración de cefoperazona en la leche y el tiempo de calentamiento a diferentes temperaturas.

Figura 64. Relación entre la concentración de cefoperazona en la leche y el tiempo de calentamiento a diferentes temperaturas.

Figura 65. Relación entre la concentración de cefoperazona en la leche y el tiempo de calentamiento a diferentes temperaturas.

Figura 66 Representación gráfica de la ecuación de Arrhenius para las cefalosporinas.

Figura 67. Relación entre la concentración de clortetraciclina en la leche y el tiempo de calentamiento a diferentes temperaturas.

Figura 68. Relación entre la concentración de doxicilina en la leche y el tiempo de calentamiento a diferentes temperaturas.

Figura 69. Relación entre la concentración de oxitetraciclina en la leche y el tiempo de calentamiento a diferentes temperaturas.

Figura 70. Relación entre la concentración de tetraciclina en la leche y el tiempo de calentamiento a diferentes temperaturas.

Figura 71. Representación gráfica de la ecuación de Arrhenius para las tetraciclinas......

Figura 72. Relación entre la concentración de sulfacloropiradizina en la leche y el tiempo de calentamiento a distintas temperaturas.

Figura 73. Relación entre la concentración de sulfadiazina en la leche y el tiempo de calentamiento a diferentes temperaturas.

Figura 74. Relación entre la concentración de sulfadimetoxina en la leche y el tiempo de calentamiento a diferentes temperaturas.

Figura 75. Relación entre la concentración de sulfamerazina en la leche y el tiempo de calentamiento a diferentes temperaturas..... 
Figura 76. Relación entre la concentración de sulfametazina en la leche y el tiempo de calentamiento a diferentes temperaturas

Figura 77. Relación entre la concentración de sulfapiridina en la leche y el tiempo de calentamiento a diferentes temperaturas

Figura 78. Relación entre la concentración de sulfaquinoxalina en la leche y el tiempo de calentamiento a diferentes temperaturas....

Figura 79. Relación entre la concentración de sulfatiazol en la leche y el tiempo de calentamiento a diferentes temperaturas.

Figura 80. Representación gráfica de la ecuación de Arrhenius para la sulfacloropiradizina, sulfadiazina, sulfadimetoxina y sulfamerazina.

Figura 81. Representación gráfica de la ecuación de Arrhenius para la sulfametazina, sulfapiridina, sulfaquinoxalina y sulfatiazol. 
INTRODUCCIÓN 



\section{INTRODUCCIÓN}

\section{SUSTANCIAS ANTIMICROBIANAS EN MEDICINA VETERINARIA}

\subsection{CONSIDERACIONES PREVIAS}

El uso de medicamentos veterinarios, y concretamente aquellos de tipo antiinfeccioso, representa una práctica muy frecuente en la cría y explotación del ganado, que resulta necesaria para el mantenimiento de un nivel productivo económicamente rentable (IFAH, 2006).

Actualmente, existe una gran variedad de sustancias que se emplean en el tratamiento de las enfermedades que afectan tanto a los animales de compañía como a los destinados a la producción de alimentos para consumo humano.

Entre estas sustancias hay que destacar a los agentes antimicrobianos, que se definen, de forma general, como productos que son capaces de destruir o inhibir el crecimiento de otros microorganismos $y$, además, son efectivos a bajas concentraciones (Mateos, 2002).

A diferencia de la medicina humana, el empleo de antimicrobianos en animales productores de alimentos ha tenido dos finalidades principales, por un lado la prevención y el control de infecciones microbianas, y por otro lado el uso como promotores del crecimiento.

Las recomendaciones de la Unión Europea sobre el uso prudente de agentes antimicrobianos en medicina humana (Recomendación 2002/77/CEE), debido principalmente a la enorme preocupación generada por la aparición de microorganismos resistentes a estas sustancias, ha tenido consecuencias directas sobre el empleo de antimicrobianos en sanidad animal.

Así, la prohibición paulatina por parte de la UE del uso de antibióticos como promotores del crecimiento ha supuesto un descenso en el uso de los mismos. Según las cifras de la "International Federation of Animal Health" (IFAH, 1997), de las más de 10.000 toneladas de antibióticos empleadas en la UE en 1996, aproximadamente un $50 \%$ se distribuyó en medicina veterinaria, y de esta cantidad el 33\% como agentes terapéuticos y/o profilácticos y el 15\% como promotores del crecimiento.

En 1999, las cifras señaladas (IFAH, 2001) indicaban que tan sólo un $29 \%$ de antibióticos se emplearon en medicina veterinaria y solamente un $6 \%$ como promotores del crecimiento. 
Sin embargo, a pesar de estas restricciones en el año 2005 (últimos datos disponibles), más del $15 \%$ del gasto mundial y más de $21 \%$ del gasto europeo en medicamentos veterinarios correspondió a sustancias antimicrobianas (IFAH, 2006), tal y como se aprecia en el Cuadro 1.

Cuadro 1. Gasto mundial y europeo de medicamentos en sanidad animal

\begin{tabular}{|lcc|}
\hline \multirow{2}{*}{ Medicamentos veterinarios } & \multicolumn{2}{c|}{ Gasto (\%) } \\
\cline { 2 - 3 } & Mundial & Europeo \\
\hline Antimicrobianos & $\mathbf{1 5 , 8}$ & $\mathbf{2 1 , 6}$ \\
Antiparasitarios & 28,4 & 27,1 \\
Vacunas & 22,6 & 23,4 \\
Productos de uso tópico & 13 & 7,2 \\
Otros & 20,2 & 20,7 \\
\hline Total & $\mathbf{1 4 , 9}$ billones \$ & $\mathbf{2 , 8}$ millones \$ \\
\hline
\end{tabular}

Fuente: IFAH (2006)

Por otra parte, la distribución del gasto de los medicamentos veterinarios en función de las distintas especies de destino se presenta en el Cuadro 2, donde se observa que de las especies ganaderas es el bovino el principal destinatario de medicamentos a nivel mundial.

Cuadro 2. Distribución mundial del gasto en medicamentos empleados en sanidad animal por especies

\begin{tabular}{|lc|}
\hline \multicolumn{1}{|c|}{ Especie } & Distribución (\%) \\
\hline Bovino & $\mathbf{2 7}$ \\
Ovino & 5 \\
Porcino & 16 \\
Avícola & 11 \\
Animales de compañía/otros & 40 \\
\hline Total: 14,9 billones \$ & \\
\hline
\end{tabular}

Fuente: IFAH (2006)

Es importante resaltar que el análisis del consumo de fármacos 0 medicamentos, tanto en sanidad animal como en humana, es una cuestión complicada. Este análisis requiere de una unidad de medida internacional estandarizada que se pueda aplicar a las diferentes metodologías de recogida de datos y permita a su vez una descripción lo más completa posible sobre el consumo real existente de estas sustancias, así como permitir comparaciones geográficas, temporales, etc. (Chauvin et al., 2001). 
A lo largo de los años se han utilizado distintos sistemas unitarios para medir el consumo de fármacos, basados en diferentes criterios: económicos o financieros (datos de ventas de empresas farmacéuticas y costes terapéuticos), ponderados (peso total o dosis de principio activo), ligados al tratamiento (dosis definida diaria o prescrita) o incluso prácticos (número de cánulas o preparados vendidos).

Por otro lado, en cuanto a la distribución del consumo de los distintos grupos de antimicrobianos para uso terapéutico animal en Europa, Bywater (2004), asegura que la recopilación de datos es un trabajo difícil de realizar, debido en parte a la existencia de un mercado de fármacos genéricos desconocido entre fronteras y al hecho de que no todas las compañías farmacéuticas están asociadas a grandes organizaciones industriales.

Los únicos datos disponibles y fiables actualmente son los que ofrecen los distintos gobiernos a través del contacto directo con las compañías farmacéuticas, como es el caso del Reino Unido, o mediante la obligación oficial de informar acerca de todas las ventas llevadas a cabo en el país, como es el caso de Dinamarca, Finlandia y Suecia (Sarmah et al., 2006).

Por todos estos motivos, la recopilación y procesamiento de datos sobre consumo o distribución de antimicrobianos en sanidad animal en Europa es una tarea difícil y los datos oficiales más actuales de que se disponen fueron elaborados por IFAH en 1999. Estos datos se seleccionaron en base a un estudio ponderado de los distintos principios activos empleados en sanidad animal en el periodo comprendido entre 1997 y 1999, y son los que se presentan en el Cuadro 3.

Cuadro 3. Consumo de antimicrobianos en medicina veterinaria en Europa

\begin{tabular}{|lc|}
\hline \multicolumn{1}{|c}{ Antimicrobianos } & Distribución (\%) \\
\hline Betalactámicos & 9 \\
Tetraciclinas & 66 \\
Macrólidos & 12 \\
Aminoglucósidos & 4 \\
Fluoroquinolonas & 1 \\
Sulfonamidas/trimetoprim & 2 \\
Otros & 6 \\
\hline
\end{tabular}

Fuente: IFAH (1999)

Como se aprecia en dicho Cuadro, los antibióticos betalactámicos (9\%) junto a las tetraciclinas $(66 \%)$, suponen juntos tres cuartas partes del uso terapéutico total de 
antimicrobianos en el sector veterinario, seguidos de los macrólidos con un $12 \%$ y en menor medida por los otros grupos.

También es importante resaltar que actualmente la Organización Mundial para la Sanidad Animal (OIE, 2007), establece en el "Código Sanitario para los Animales Terrestres" un capítulo donde se establecen las directrices para el seguimiento de las cantidades de antimicrobianos utilizados en producción animal a lo largo del tiempo y analizar el posible riesgo derivado de su utilización.

\subsection{PROPIEDADES GENERALES DE LOS ANTIMICROBIANOS}

\subsubsection{Conceptos generales y clasificación}

Los antimicrobianos son sustancias derivadas de diferentes microorganismos o sintetizadas químicamente que, como se ha citado anteriormente, poseen la capacidad de inhibir o destruir los procesos vitales de las bacterias.

Estas sustancias se utilizan en el tratamiento de infecciones a bajas concentraciones que no tienen efecto tóxico sobre el hospedador infectado, pero si que son tóxicas para las bacterias, diciéndose entonces que estos agentes tienen un efecto terapéutico (Domínguez y Moreno, 2001).

Las propiedades que se buscan en un agente antmicrobiano para ser utilizado en el tratamiento de enfermedades infecciosas, se pueden resumir en (Rang et al., 2000):

- Elevada actividad antimicrobiana, eficaz y selectiva; y que no se vea reducida por la biotransformación que sufra en el cuerpo.

- Las características farmacocinéticas deben proporcionar valores en los lugares de acción altos, y ser mantenidos durante tiempos largos.

- Baja toxicidad para el huésped.

- No debe generar resistencias bacterianas.

- Que sea eficaz por vía tópica, oral o parenteral.

- De alta penetrabilidad.

- Que sea estable, no lábil.

- Fácil de producir en grandes cantidades y a bajo coste.

Es prácticamente imposible encontrar todas las características mencionadas anteriormente en una misma sustancia, por lo que generalmente se recurre a 
combinaciones de antimicrobianos para mejorar la efectividad de los tratamientos. Sin embargo, no todas las combinaciones de estas sustancias son viables debido a la incompatibilidad química de sus estructuras (Löscher, 1994).

Aunque los antimicrobianos están constituidos por muchas clases de compuestos, a menudo se clasifican en diferentes grupos. Las múltiples clasificaciones existentes presentan diferentes características y han sido realizadas basándose en distintos criterios, por tal motivo es difícil determinar cuál es la clasificación más adecuada. Actualmente el sistema más utilizado por la comunidad científica es el que agrupa a estos compuestos por similitud química, según los núcleos base de sus estructuras, que les confieren cierta semejanza en sus propiedades físico-químicas y farmacológicas.

En el Cuadro 4 se muestra una clasificación de los agentes antimicrobianos realizada a partir de diferentes autores (Sumano y Ocampo, 1997; Merck \& CO, 2003), agrupándolos según su estructura química. En dicho Cuadro se presentan los grupos de antibióticos betalactámicos, aminoglucósidos, macrólidos, quinolonas y tetraciclinas, así como el grupo quimioterapéutico de las sulfonamidas y otros agentes antimicrobianos, dividiéndolos en las diferentes familias y moléculas que los componen.

Las propiedades y características de los grupos de antimicrobianos más importantes utilizados en medicina veterinaria se resumen en los apartados siguientes.

\subsubsection{Principales grupos de antimicrobianos en medicina veterinaria}

\subsubsection{Antibióticos betalactámicos}

El grupo de los antibióticos betalactámicos, formado por las penicilinas y las cefalosporinas, se trata de un grupo de antibióticos, al igual que sus derivados, ampliamente distribuido en la terapia contra la mamitis en el ganado lechero (Honkanen-Buzalski y Reybroeck, 1995).

Las penicilinas y las cefalosporinas son sustancias similares estructuralmente y en sus mecanismos de acción, aunque difieren en cuanto a su espectro antibacteriano y su farmacocinética.

Los antibióticos betalactámicos previenen la transpeptidación entre cadenas de peptidoglicanos, inhibiendo la síntesis de la pared celular bacteriana. 
Cuadro 4. Clasificación de los diferentes agentes antimicrobianos

\begin{tabular}{|c|c|c|}
\hline Grupos & Familias & Antimicrobianos \\
\hline \multicolumn{3}{|c|}{ Betalactámicos: Poseen en su estructura el anillo betalactámico } \\
\hline Penicilinas & $\begin{array}{l}\text { Naturales } \\
\text { Aminopenicilinas } \\
\text { Resistentes a } \beta \text {-lactamasas } \\
\text { Amplio espectro }\end{array}$ & $\begin{array}{l}\text { Penicilina G, penicilina V } \\
\text { Amoxicilina, ampicilina } \\
\text { Oxacilina, cloxacilina, dicloxaciclina, nafacilina } \\
\text { Ticarcilina, carbencilina }\end{array}$ \\
\hline Cefalosporinas & $\begin{array}{l}\text { Primera generación } \\
\text { Segunda generación } \\
\text { Tercera generación } \\
\text { Cuarta generación }\end{array}$ & $\begin{array}{l}\text { Cefalotina cefapirina, cefalexina, cefadroxil, } \\
\text { Cefuroxima, ceforanida, cefamandol, cefoxitina } \\
\text { Ceftiofur, ceftriaxona, cefotaxima, cefoperazona } \\
\text { Cefepima, cefquinoma }\end{array}$ \\
\hline Otros & $\begin{array}{l}\text { Carbapenems } \\
\text { Monobactamas } \\
\text { Acido Clavulánico }\end{array}$ & $\begin{array}{l}\text { Imipenem } \\
\text { Aztreonam }\end{array}$ \\
\hline \multicolumn{3}{|c|}{ Aminoglucósidos: Consisten en azúcares aminados y un anillo llamado aminociclitol } \\
\hline & $\begin{array}{l}\text { Espectro reducido } \\
\text { Amplio espectro } \\
\text { Diversos }\end{array}$ & $\begin{array}{l}\text { Estreptomicina, dihidroestreptomicina } \\
\text { Neomicina, canamicina, gentamicina, } \\
\text { tobramicina } \\
\text { Apramicina }\end{array}$ \\
\hline \multicolumn{3}{|c|}{ Macrólidos: Poseen en su estructura un anillo latónico con azúcares aminados. } \\
\hline & $\begin{array}{l}\text { Anillo de } 12 \text { constituyentes } \\
\text { Anillo de } 14 \text { constituyentes } \\
\text { Anillo de } 16 \text { constituyentes }\end{array}$ & $\begin{array}{l}\text { Sin uso en práctica clínica } \\
\text { Eritromicina, oleandomicina, troleandomicina } \\
\text { Tilosina, espiramicina, josamicina }\end{array}$ \\
\hline \multicolumn{3}{|c|}{ Quinolonas: Derivados del ácido carboxílico } \\
\hline & $\begin{array}{l}\text { Primera generación } \\
\text { Segunda generación } \\
\text { Tercera generación }\end{array}$ & $\begin{array}{l}\text { Ácido nalidíxico, Á. pipemídico, Á. oxocínico } \\
\text { Flumequina, ciprofloxacina, norfloxacina } \\
\text { Enrofloxacina, danofloxacina, sarafloxacina }\end{array}$ \\
\hline \multicolumn{3}{|c|}{ Tetraciclinas: Tienen en común en su estructura el anillo naftaleno (4 anillos) } \\
\hline & $\begin{array}{l}\text { Acción corta } \\
\text { Acción intermedia } \\
\text { Acción prolongada }\end{array}$ & $\begin{array}{l}\text { Tetraciclina, oxitetraciclina, clortetraciclina } \\
\text { Demetilclortetraciclina, metaciclina } \\
\text { Doxiciclina, minociclina }\end{array}$ \\
\hline \multicolumn{3}{|c|}{ Sulfonamidas: El núcleo básico es p-amino-bencenosulfonamida } \\
\hline & $\begin{array}{l}\text { Uso habitual } \\
\text { Muy solubles (urinarias) } \\
\text { Poco solubles (entéricas) } \\
\text { Potenciadas } \\
\text { Uso tópico }\end{array}$ & $\begin{array}{l}\text { Sulfatiazol, sulfametazina, sulfadiacina } \\
\text { Sulfisoxazol, sulfasomidina } \\
\text { Sulfaguanidina, succinilsulfatiazol } \\
\text { Sulfonamidas + diaminopirimidinas } \\
\text { Sulfacetamida, sulfadiacina de plata }\end{array}$ \\
\hline
\end{tabular}


Aunque hoy en día las penicilinas y las cefalosporinas son los antibióticos betalactámicos más comúnmente utilizados, en los últimos años se ha avanzado mucho en el desarrollo de nuevas sustancias como los inhibidores de la betalactamasa, las carbapemas y los monobactámicos (Adams, 2003).

Hay que señalar que el consumo de antibióticos betalactámicos, solos o combinados, casi se ha triplicado como consecuencia de la comercialización de algunas moléculas concretas: amoxicilina-clavulánico, cefalexina, ceftiofur y cefquinoma, que han desplazado a la asociación clásica 'penicilina-estreptomicina' de gran éxito terapéutico (Marco et al., 2001).

\section{$\underline{\text { Penicilinas }}$}

En el año 1928, el doctor Alexander Fleming, durante una investigación bacteriológica de un cultivo de estafilococos descubre que, al ser contaminado el cultivo por un hongo, en torno a este, los estafilococos no desarrollan colonias. Debido a que el hongo pertenecía al género Penicillium, Fleming denominó a esta nueva sustancia "penicilina".

A pesar de que esta observación fue confirmada por otros investigadores, no fue hasta 1941 cuando comenzó a extenderse la utilización terapéutica de la penicilina.

Las primeras penicilinas, llamadas "naturales" fueron obtenidas adicionando diferentes precursores al medio de cultivo de Penicillium notatum y Penicillium chrysogenum. Las penicilinas semisintéticas se preparan en el laboratorio utilizando como materia prima el ácido 6-aminopenicilánico producido con el cultivo de Penicillium.

Estas sustancias constan de dos porciones, un ácido 6-aminopenicilánico, que resulta de la unión de un anillo de tiazolidina con un anillo betalactámico y una cadena lateral, unida al carbono 6 del anillo betalactámico. Esta cadena lateral es la que determina muchas de las características antibacterianas y farmacológicas de cada penicilina, como son la resistencia a la penicilinasa, enzima producida por muchas bacterias, o la resistencia al medio ácido.

Las penicilinas son bactericidas debido a su capacidad de inhibir la síntesis de la pared celular bacteriana y de activar enzimas que destruyen dicha pared. La ruptura del anillo betalactámico, que se produce por la acción de la penicilinasa o la pérdida de la cadena lateral, por acción de una amidasa, llevan a la pérdida de la actividad antibacteriana. 
Estos compuestos se clasifican principalmente en función de su espectro antibacteriano en:

- Penicilinas naturales (penicilina G y sus sales): Actúan contra microorganismos "gram positivos" y algunos "gram negativos"

- Aminopenicilinas (ampicilina, amoxicilina, tircarcilina y carbencilina): Menos activas contra microorganismos "gram positivos" y mejor acción contra "gram negativos"

- Penicilinas resistentes a betalactamasas o penicilinasas (cloxacilina, dicloxacilina, oxacilina y nafacilina)

- Penicilinas potenciadas o de amplio espectro (amoxicilina-clavulanatopotásico)

La mayoría de penicilinas en disolución acuosa se absorben rápidamente a partir de los lugares de inyección parenteral. Cuando se administran por vía oral, el grado de absorción es variable, dependiendo de su estabilidad en medio ácido y de su adsorción con la comida. Se distribuyen ampliamente por los líquidos y tejidos corporales al ser insolubles en lípidos, pero no penetran en las células de los mamíferos (Rang et al., 2000).

La mayor parte de una penicilina administrada por vía parenteral se elimina por la orina. Otras vías de eliminación son la biliar y la mamaria, aunque en cantidades mucho más pequeñas (Merck \& COL, 2003).

En cuanto a su utilización, la penicilina $G$ se emplea en la terapia de enfermedades infecciosas de todas las especies animales pero su mayor uso es en el control de la mamitis bovina, en forma de preparados intramamarios principalmente, y para el tratamiento de infecciones de los sistemas gastrointestinal urinario y respiratorio del ganado vacuno lechero (Botsoglou y Fletouris, 2001).

Los efectos adversos más importantes que pueden provocar las penicilinas son las reacciones de hipersensibilidad, que pueden causar desde simples reacciones alérgicas hasta choques anafilácticos que pueden llegar a la muerte en casos extremos (Adams, 2003).

Hay que señalar que las penicilinas se excretan generalmente en forma inalterada, aunque parte de la dosis administrada $(<20 \%)$ puede sufrir transformaciones metabólicas, y los derivados del ácido peniciloico que se forman tienden a ser alergénicos (Sumano y Ocampo, 1997). 


\section{Cefalosporinas}

El Cephalosporium acremonium, hongo de abundante crecimiento en las aguas de la costa de Cerdeña (Italia), fue la primera fuente productora de cefalosporinas descubiertas por Giuseppe Brotzu entre los años 1945 y 1948.

Actualmente, las cefalosporinas naturales se producen principalmente a partir de los hongos Cephalosporium acremonium y Cephalosporium salmosynematum, y a partir de estas derivan las cefalosporinas semisintéticas que se utilizan en medicina terapéutica.

Estos compuestos tienen indicaciones análogas a las penicilinas en medicina veterinaria, aunque difieren de estas en las siguientes características:

- Poseen un mayor espectro de actividad que las penicilinas del grupo G. Son activas también contra microorganismos "gram negativos".

- Son antibióticos que, en general, son más resistentes a las betalactamasas.

- Las cefalosporinas poseen mayores efectos adversos y tóxicos que las penicilinas.

- Son agentes de un costo significativamente mayor que las penicilinas.

El núcleo activo de las cefalosporinas es el ácido 7-aminocefalosporánico, cuya estructura química es similar al ácido 6-aminopenicilánico. Poseen un anillo betalactámico, y en vez del anillo pentagonal de tiazolidona de las penicilinas, tienen un anillo hexagonal de dihidrotiazina. Los derivados semisintéticos se obtienen a partir de sustituciones que se realizan a partir de la cadena lateral del anillo betalactámico.

Son antibióticos bactericidas cuyo mecanismo de acción es similar al de las penicilinas, interfiriendo en la etapa de síntesis y unión de peptidoglicanos de la pared celular, y produciendo la lísis de la bacteria.

La clasificación de las cefalosporinas se ha orientado tradicionalmente en generaciones, basada en la aparición cronológica de las mismas. Este es un criterio relativamente arbitrario, aunque existen diferencias en lo referente a espectros de acción y capacidad de resistencia a las betalactamasas por parte de las cefalosporinas de distintas generaciones:

- Primera generación (cefadroxil, cefalexina, cefazolina, cefapirina y cefalotina): gran actividad contra bacterias "gram positivas", "gram negativas" y bacterias anaerobias. 
- Segunda generación (cefamandol, ceforanida, ceforanida, cefuroxima): Igual o menor eficacia que las de primera generación contra microorganismos "gram positivos" y más eficacia contra "gram negativos". Uso reservado en infecciones resistentes a cefalosporinas de primera generación.

- Tercera generación (ceftiofur, cefoperazona, cefotaxima, ceftriaxona): más eficaces contra bacterias "gram negativas" resistentes y contra Pseudomonas aeuroginosa, menos eficaces contra "gram positivos".

- Cuarta generación (cefepima, cefquinoma): acción contra "gram positivos" y "gram negativos".

En vacas lecheras, las cefalosporinas se utilizan principalmente en preparaciones intramamarias para el tratamiento de las mamitis durante el secado y la lactación. Otros usos terapeúticos de estas sustancias son el tratamiento intrauterino de la metritis y el tratamiento parenteral de infecciones en ganado vacuno, ovino, caprino y porcino (Botsoglou y Fletouris, 2001).

La mayoría de las cefalosporinas se excretan por secreción renal, aunque la eliminación biliar de los compuestos más recientes como la cefoperazona puede ser importante (Merck \& COL, 2003).

Hay que resaltar que las cefalosporinas son agentes que pueden producir efectos adversos importantes tales como reacciones alérgicas de hipersensibilidad similares a las producidas por las penicilinas, nefrotoxicidad y otros efectos como diarreas y reacciones hematológicas (Adams, 2003).

\subsubsection{Tetraciclinas}

El descubrimiento de la primera tetraciclina tuvo lugar en 1945. Fue aislada del caldo de cultivo de una cepa de Streptomyces aureofaciens, y recibió por ello el nombre de aureomicina, principio activo al que actualmente se denomina clortetraciclina.

El segundo componente del grupo fue aislado a partir de una cepa mutante de Streptomyces y se denominó demeclociclina. Estos dos compuestos, junto con la oxitetraciclina y la tetraciclina, constituyen las tetraciclinas de primera generación o naturales, las restantes son derivados semisintéticos y forman las tetraciclinas de segunda generación, entre las que se incluyen la metaciclina, doxiciclina y minociclina. 
Todos los derivados de la tetraciclina son sustancias cristalinas, amarillentas y anfóteras que forman sales con ácidos y bases en solución acuosa. Se caracterizan además por presentar fluorescencia cuando se exponen a la luz ultravioleta y por su inestabilidad a la luz directa y $\mathrm{pH}$ elevados.

Las tetraciclinas poseen todas un núcleo de estructura tetracíclica lineal compuesta de cuatro anillos fusionados. La suma de diferentes grupos funcionales ha dado lugar a numerosos compuestos que pueden agruparse en tres generaciones según el orden de su descubrimiento.

Por otra parte las tetraciclinas se clasifican tradicionalmente atendiendo a la duración de su actividad farmacológica, ya que las principales diferencias entre ellas radican en su comportamiento farmacocinético. Se dividen por lo tanto en:

- Compuestos de acción corta: tetraciclina, oxitetraciclina, clortetraciclina.

- Compuestos de acción intermedia: dimetil-elortetraciclina y metaciclina.

- Compuestos de acción prolongada: doxiciclina y minociclina.

Estos compuestos poseen actividad antimicrobiana por su unión a la unidad 30S de los ribosomas de microorganismos sensibles, interfiriendo en la síntesis proteica y por lo tanto en el crecimiento y multiplicación de los microorganismos (Merck \& CO, 2003).

Las tetraciclinas son los antibióticos más utilizados mundialmente en producción animal debido a su amplio espectro de actuación que inhibe el crecimiento de una extensa variedad de bacilos y cocos "gram positivos" y bacilos "gram negativos" (Brucella, Legionella pneumophyla, Helicobacter pilory, Borrelia recurrentis), así como sobre Rickettsia, Mycoplasma, Chlamydia y Espiroquetas (Cinquina et al., 2003; Zhao et al., 2004)

Se usan principalmente para tratar infecciones sistémicas en ganado vacuno como enteritis bacterianas, metritis, mamitis, etc. y locales como la queratoconjuntivitis infecciosa y clamidiasis entre otras enfermedades específicas.

Actualmente su utilización para el tratamiento de mamitis en ganado vacuno lechero está siendo limitada a favor de los antibióticos llamados de "nueva generación" como las cefalosporinas de $3^{\mathrm{a}}$ y $4^{\mathrm{a}}$ generación, nuevos aminoglucósidos, y las fluoroquinolonas (Busani et al., 2003, 2004).

En general, entre el 50 y el $80 \%$ de las tetraciclinas se excretan principalmente por vía renal y entre el 10 y el $20 \%$ por eliminación biliar. También se eliminan en la leche, alcanzando concentraciones máximas a las 6 horas de administración parenteral y 
detectándose pequeñas cantidades hasta 48 horas después del tratamiento (Merck \& CO, 2003).

Las tetraciclinas son potencialmente nefrotóxicas y están contraindicadas, excepto la doxicilina, en presencia de insuficiencia renal. A dosis elevadas pueden causar al igual que los antibióticos betalactámicos reacciones de hipersensibilidad y por lo tanto provocar alergias. También pueden causar trastornos gastrointestinales y reacciones hepáticas en algunos casos.

\subsubsection{Sulfonamidas}

Las sulfonamidas fueron los primeros agentes quimioterapéuticos eficaces que se emplearon sistemáticamente en la prevención y cura de las infecciones bacterianas (Sumano y Ocampo, 1997; Pérez-Trallero e Iglesias, 2003).

Son compuestos antimicrobianos sintéticos de amplio espectro con actividad frente a una gran variedad de microorganismos "gram positivos" y "gram negativos" cuyo uso frecuente ha desarrollado actualmente amplias resistencias en muchos microorganismos.

La mayor parte de las sulfonamidas útiles en quimioterapia son derivados de la sulfanilamida. Todas tienen el mismo núcleo, al que se van añadiendo o sustituyendo varios grupos funcionales al grupo amido. Estos cambios originan compuestos con distintas propiedades físicas, químicas, farmacológicas y antibacterianas.

Las distintas sulfonamidas y derivados pueden clasificarse en varios grupos, basados principalmente en sus indicaciones y en la duración de su acción en el organismo:

- Compuestos de uso habitual: sulfatiazol, sulfametazina, sulfapiridina, sulfadimetoxina, etc.

- Compuestos muy solubles, empleados en infecciones urinarias: sulfisoxazol, sulfasomidina, etc.

- Compuestos poco solubles, empleados en infecciones entéricas: talilsulfatiazol, succinilsulfatiazol, salicilazosulfapiridina, etc.

- Compuestos potenciados: trimetoprim-sulfadiacina, trimetoprimsulfametoxazol, trimetoprim-sulfadoxina, etc.

- Compuestos de uso tópico: sulfacetamina para uso oftalmológico, mafenida y sulfadiacina para quemaduras, sufatiazol para heridas, etc. 
El mecanismo de acción de las sulfonamidas es complejo y actúa bloqueando distintas enzimas entre las que se encuentran las implicadas en la síntesis de las bases púricas y otros procesos celulares, dando lugar a la supresión de la síntesis proteica, alteración de los procesos metabólicos e inhibición del crecimiento y multiplicación de los microorganismos.

Estos quiomioterapeúticos inhiben las bacterias "gram negativas" y "gram positivas", algunas Clamidias, Nocardia, Actinomyces spp, y algunos protozoos. Las más activas pueden actuar frente varias especies de Streptococcus, Staphylococcus, Salmonella, Pasteurella e incluso Escherichia coli.

Las sulfonamidas se usan normalmente para tratar o evitar enfermedades sistémicas o locales. Entre las infecciones que se tratan están, la coccidiosis, mamitis, metritis, colibacilosis, poliartritis, infecciones respiratorias y toxoplasmosis.

La mayoría de las sulfonamidas se excretan principalmente en la orina, mientras que la bilis, las heces, la leche y el sudor constituyen vías de eliminación de menor importancia (Merck \& COL, 2003).

Una de las principales desventajas de estas sustancias en comparación con otros antimicrobianos más recientemente comercializados es la elevada frecuencia de efectos secundarios, como reacciones de hipersensibilidad, trastornos gastrointestinales y reacciones hematológicas, entre las más importantes (Adams, 2003).

\subsubsection{Otros grupos de antimicrobianos}

Entre los otros grupos de antimicrobianos empleados en medicina veterinaria, destacan los antibióticos aminoglucósidos que en general, son usados en el tratamiento de una gran variedad de infecciones entéricas, respiratorias y otras infecciones causadas por gérmenes "gram negativos", como la colibacilosis y salmonelosis de terneros y cerdos (Adams, 2003).

Todos los antibióticos de este grupo (estreptomicina, gentamicina, kanamicina, neomicina, espectinomicina, etc.) tienen propiedades farmacocinéticas parecidas y efecto bactericida al interaccionar con el ribosoma bacteriano asociado a la membrana celular.

En ganado vacuno lechero los aminoglucósidos, solos o en combinación con otros antimicrobianos como los betalactámicos, tetraciclinas y macrólidos, se utilizan por vía intramamaria para el tratamiento de la mamitis, por vía intrauterina en el caso de metritis y por vía parenteral para el tratamiento de procesos respiratorios (Botsoglou y Fletouris, 2001). 
Por otro lado, el grupo de los macrólidos lo constituyen un conjunto de compuestos estructuralmente emparentados, que se caracterizan por poseer un anillo lactónico macrocíclico de 12 a 20 átomos de carbono, al cual están unidos desoxiazúcares mediante enlaces glucosídicos. Los miembros del grupo incluyen principalmente a la eritromicina, tirosina, carbomicina, espiramicina, y lincomicina entre otros.

Los macrólidos son activos frente a la mayoría de las bacterias aerobias y anaerobias "gram positivas" (con limitada o nula actividad frente a la mayoría de bacterias "gram negativas"), aunque hay variaciones considerables con respecto a su potencia y actividad.

Las indicaciones generales incluyen infecciones de las vías respiratorias superiores, bronconeumonía, enteritis bacteriana, metritis, piodermatitis, infecciones urinarias, artritis y otras.

Otro grupo importante en la actualidad, son las quinolonas y fluoroquinolonas. Se trata del grupo farmacológico de mayor desarrollo en estos momentos y su uso en medicina veterinaria se ha incrementado enormemente en los últimos diez años.

Estos productos son fármacos antibacterianos sintéticos que presentan una estructura quinolónica común. Los distintos radicales químicos y cadenas laterales son los responsables de las diferentes características físicas de cada fármaco.

Se distinguen tres generaciones de quinolonas con potencia antibacteriana y características farmacológicas progresivamente mejores: quinolonas de $1^{\text {a }}$ generación (ac. nalidíxico, ac oxocínico), de $2^{a}$ generación (flumequina, norfloxacina) y de $3^{a}$ generación (enrofloxacina, danofloxacina, sarafloxacina) (Sumano y Ocampo, 1997; Merck \& COL, 2003).

Estos compuestos se emplean cada vez más en clínica veterinaria bovina para el tratamiento de las enteritis neonatales y enfermedades respiratorias, y en algunos casos, para el tratamiento sistémico de la mamitis colibacilar (Busani et al., 2004).

Además de estos grupos de antimicrobianos existen otros compuestos que no se engloban en ninguno de los grupos mencionados anteriormente pero son importantes a nivel ganadero. Entre ellos cabe destacar los antibióticos glucopeptídicos, sobretodo la vancomicina con acción bactericida eficaz frente a bacterias "gram positivas", los antibióticos polimixinas donde la polimixina B y la colistina son las dos sustancias de principal uso con efecto bactericida rápido y selectivo en bacilos "gram negativos" y la bacitrina, antibiótico polipeptídico con un gran espectro de actividad, muy activo frente a microorganismos "gram positivos" y de efectos tóxicos graves en el riñon. 


\subsection{ANTIMICROBIANOS EMPLEADOS EN GANADO VACUNO LECHERO}

Actualmente las enfermedades infecciosas más importantes del ganado vacuno son las mamitis, metritis, neumonías, enteritis y cojeras (Zwald et al., 2004; Sawant et al., 2005), y para el tratamiento de estas patologías es frecuente el uso de medicamentos veterinarios antimicrobianos.

En el caso del vacuno lechero, la mamitis es una de las patologías más frecuentes y la que más pérdidas económicas y gasto veterinario conlleva (Gruet et al., 2001; Sawant et al., 2005). No es extraño por lo tanto, que la mayor parte de los residuos de sustancias antibacterianas detectadas en la leche, procedan de terapias relacionadas con la glándula mamaria (hasta en un $90 \%$ de los casos), bien por tratamientos ligados a mamitis clínicas, o por las terapias preventivas de secado (Fabre et al., 1995; Erskine et al., 2003), .

El impacto de las mamitis ha dado lugar al desarrollo de diversas estrategias terapéuticas para controlar la infección. Así, se han utilizado numerosos medicamentos (antimicrobianos, antiinflamatorios, vacunas, vitaminas, citoquinas, homeopatía) y se han ensayado distintas rutas de administración (sistémica, intramamaria o aplicación local). Sin embargo, como ya se ha señalado anteriormente el tratamiento de las mamitis concierne fundamentalmente a los medicamentos antimicrobianos (Gruet et al., 2001).

Para seleccionar una determinada molécula antimicrobiana, es necesario realizar unas consideraciones económicas, ya que hay que intentar buscar un equilibrio entre el mejor tratamiento posible y los periodos de supresión más adecuados para permitir una pronta comercialización de la leche procedente de animales en tratamiento.

Además, para que un medicamento destinado al tratamiento de animales productores de alimentos pueda ser utilizado, los principios activos que contiene deben estar incluidos en los anexos I, II o III del Reglamento 2377/90/CEE en el que se establece un procedimiento comunitario de fijación de los Límites Máximos de Residuos (LMR) de medicamentos veterinarios en los alimentos de origen animal, y presentar un LMR en leche de vaca.

En general, los antimicrobianos se pueden utilizar en las mamitis en dos fases del ciclo productivo: para tratar vacas en lactación en el momento en que aparece el brote o para reducir las infecciones subclínicas durante el periodo seco y así aumentar la vida productiva del animal (Gruet et al., 2001; Erskine et al., 2003). En cualquier caso, la terapia más adecuada debe basarse en el conocimiento previo de la etiología de la infección (Méndez et al., 1999). 
Según Gruet et al. (2001) el número de sustancias disponibles en Europa para el tratamiento de mamitis no es muy elevado, ya que la mayor parte de los principios activos comerciales se encuentran incluidos en el grupo de los betalactámicos o son combinaciones de éstos con algún macrólido, quinolona o aminoglucósido.

Con respecto a las sustancias empleadas en España para el tratamiento de la mamitis, Zorraquino et al. (2007) elaboraron recientemente un estudio para el Ministerio de Agricultura, Pesca y Alimentación donde se calcularon las frecuencias de utilización de moléculas de antimicrobianos en los tratamientos antimamíticos en nuestro país, durante el año 2006, basándose en los preparados vendidos durante ese año por los laboratorios asociados a Veterindustria.

Los datos recogidos en dicho estudio para preparados intramamarios en lactación y secado se presentan en las Figuras 1 y 2 respectivamente.

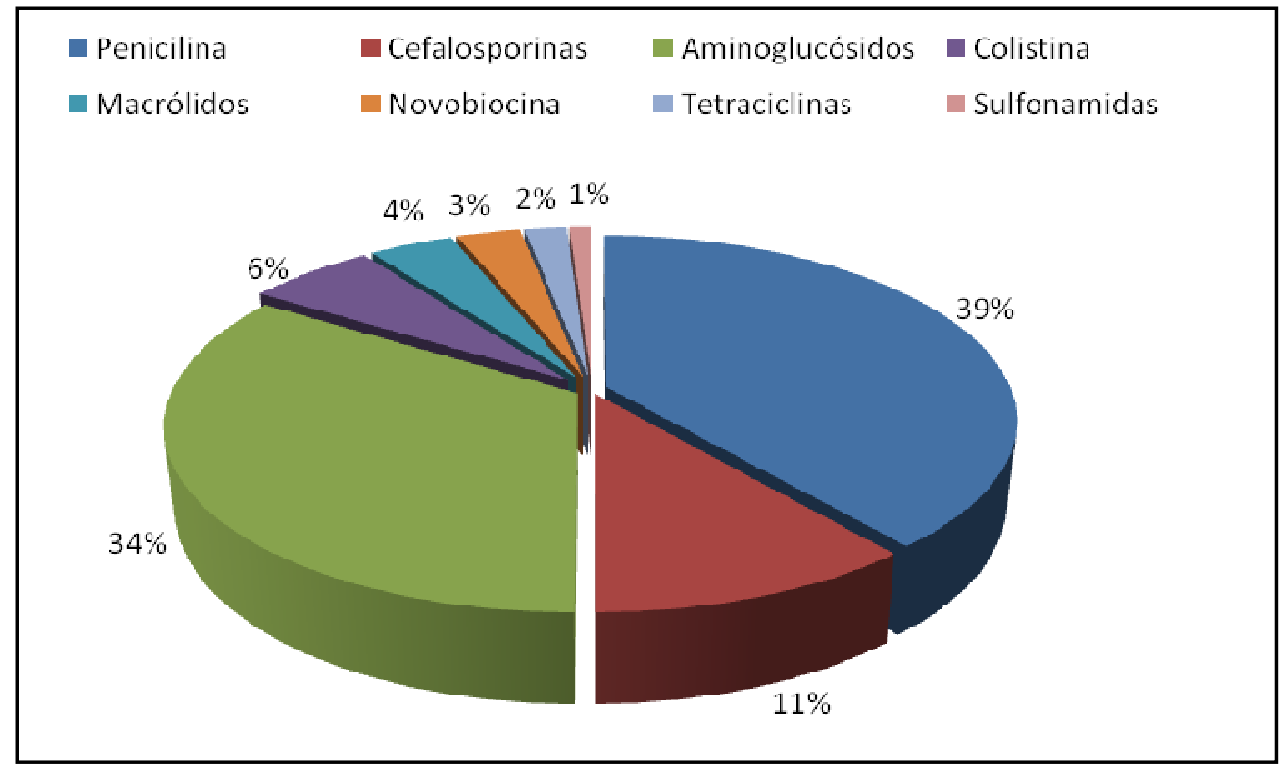

Figura 1. Frecuencias de uso de antimicrobianos por vía intramamaria empleados en ganado vacuno en lactación

Fuente: Zorraquino et al. (2007)

Como se aprecia en la Figura 1, los antibióticos betalactámicos, siguen siendo los agentes antimicrobianos más empleados actualmente en los tratamientos intramamarios contra la mamitis en vacas en lactación, representando el $50 \%$ del total de ventas y destacando sobretodo las penicilinas con un $39 \%$ de preparados suministrados por los laboratorios. 


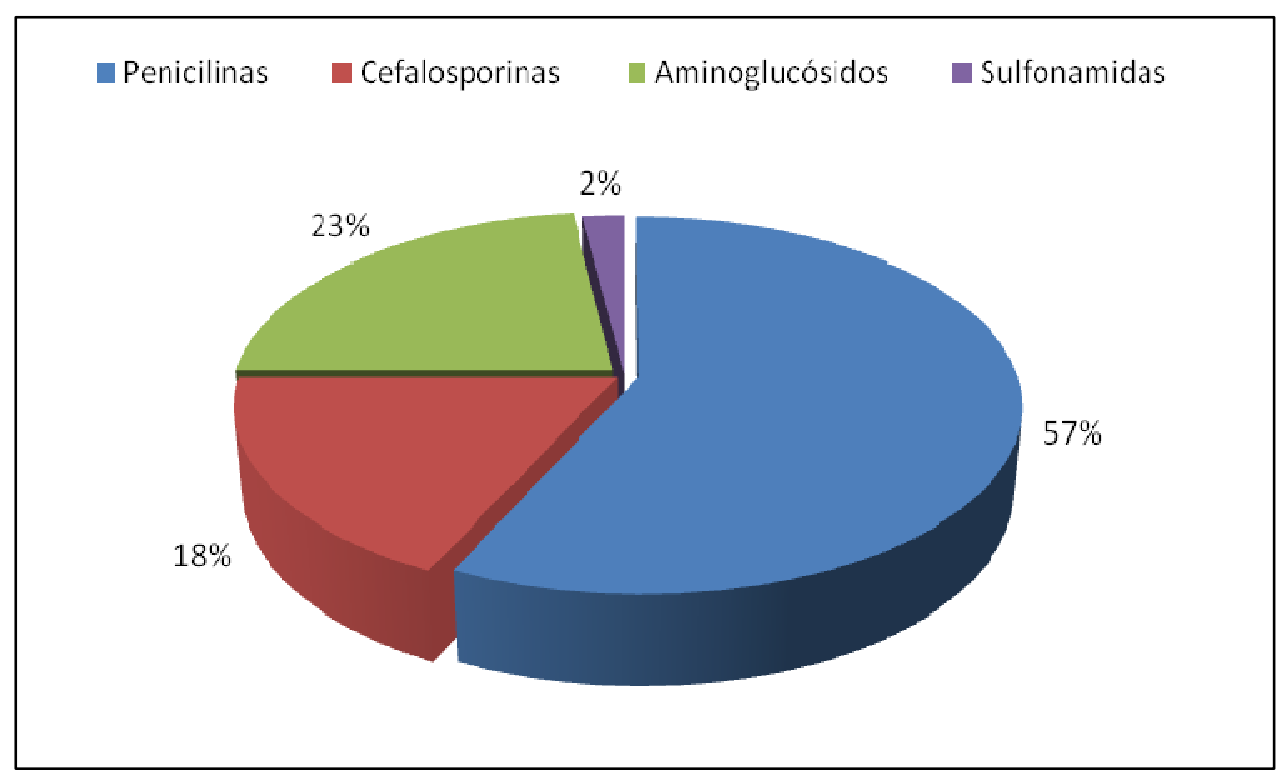

Figura 2. Frecuencias de uso de antimicrobianos por vía intramamaria empleados en ganado vacuno en el secado

Fuente: Zorraquino et al. (2007)

Los aminoglucósidos también presentan un porcentaje de utilización elevado (34\%), ya que estos compuestos suelen aplicarse conjuntamente con otra molécula perteneciente al grupo de los antibióticos betalactámicos.

En cuanto al resto de agentes antimicrobianos suministrados, éstos presentan bajos porcentajes de utilización con valores que varían entre un $6 \%$ en el caso de la colistina y un $1 \%$ para las sulfonamidas.

Respecto a las frecuencias de utilización de antimicrobianos en el secado (Figura 2), los antibióticos betalactámicos presentan de nuevo el mayor porcentaje (75\%), destacando las penicilinas con un porcentaje de utilización del $57 \%$, seguido por los aminoglucósidos con $23 \%$, cefalosporinas con un $18 \%$ y las sulfonamidas con un $2 \%$.

En el caso de las preparaciones para inyectables, resultó imposible realizar un cálculo de las dosis y la frecuencia de uso de las sustancias antimamíticas, ya que en la información aportada por Veterindustria se incluyen también una gran variedad de productos que no están indicados específicamente para el tratamiento de la mamitis.

Por otra parte, en el estudio realizado por Zorraquino et al. (2007), también se efectuó una encuesta a veterinarios o equipos de veterinarios que trabajan en programas de mejora de la calidad de leche y/o control de mamitis a lo largo de toda la geografía española, para evaluar la frecuencia de uso y riesgo de exposición a la presencia de residuos de medicamentos antimicrobianos en la leche cruda de vaca en España. 
Los datos obtenidos en dichas encuestas aportan información de aproximadamente el $25 \%$ de las explotaciones de ganado vacuno lechero (6.618 explotaciones) que engloban un censo de aproximadamente de 333.423 vacas lecheras que equivalen al $35 \%$ de la cabaña nacional. En el Cuadro 5 se muestran los resultados recogidos en las encuestas tanto para los tratamientos intramamarios (lactación y secado) como para los inyectables.

Cuadro 5. Frecuencia (\%) de utilización de antimicrobianos en los tratamientos antimamíticos

\begin{tabular}{|lccc|}
\hline \multirow{2}{*}{$\begin{array}{c}\text { Grupos } \\
\text { antimicrobianos }\end{array}$} & \multicolumn{2}{c}{$\begin{array}{c}\text { Tratamientos } \\
\text { intramamarios }\end{array}$} & \multirow{2}{*}{$\begin{array}{c}\text { Tratamientos } \\
\text { inyectables }\end{array}$} \\
\cline { 2 - 3 } & Lactación & Secado & \\
\hline Penicilinas & 33 & 57 & 55 \\
Cefalosporinas & 14 & 15 & 7 \\
Aminoglucósidos & 38 & 28 & 9 \\
Macrólidos & 5 & $<1$ & 5 \\
Colistina & 4 & $<1$ & 2 \\
Sulfonamidas & 2 & $<1$ & 2 \\
Tetraciclinas & 2 & $<1$ & - \\
Novobiocina & 2 & $<1$ & - \\
Trimetroprim & - & $<1$ & 2 \\
Quinolonas & - & - & 18 \\
\hline
\end{tabular}

Fuente: Zorraquino et al. (2007)

Como se aprecia en dicho Cuadro, los datos obtenidos de estas encuestas muestran una gran correspondencia con las frecuencias de uso calculadas a partir de los datos de Veterindustria (Figuras 1 y 2 ). Así, los antibióticos betalactámicos y los aminoglucósidos son los grupos de antimicrobianos para el tratamiento de las mamitis que más se utilizan, tanto en lactación como en secado, e incluso en los tratamientos inyectables.

Sin embargo, hay que indicar que el uso de antimicrobianos también se encuentra ligado al tratamiento de otras enfermedades infecciosas del ganado vacuno, y que la leche de animales tratados para estas enfermedades también podría estar contaminada con residuos, si la gestión del tratamiento no se realiza correctamente. 
Los procesos patológicos de mayor importancia tras las mamitis son las metritis y las afecciones podales (Zwald et al., 2004; Sawant et al., 2005), aunque tampoco hay que olvidar las neumonías, diarreas, eczemas, furunculosis, etc.

Para el tratamiento de las cojeras y las metritis de naturaleza infecciosa se indican asociaciones de penicilinas y estreptomicina, cefalosporinas de $1^{\mathrm{a}}, 2^{\mathrm{a}}$ y $3^{\mathrm{a}}$ generación, oxitetraciclina, macrólidos y sulfonamidas (Veterindustria, 2006).

\section{PRESENCIA Y CONTROL DE RESIDUOS DE ANTIMICROBIANOS EN LA LECHE}

\subsection{CAUSAS $Y$ CONSECUENCIAS DE LA PRESENCIA DE RESIDUOS DE ANTIMICROBIANOS EN LA LECHE}

\subsubsection{Origen de la presencia de residuos de antimicrobianos en la leche}

Las sustancias antimicrobianas se pueden administrar de diferentes formas, fundamentalmente por vía parenteral (subcutánea, intramuscular, endovenosa, etc.), intramamaria y oral en forma de aditivos alimenticios o disueltos en el agua, para solucionar las infecciones que sufren o que podrían padecer los animales.

La mayor parte de los fármacos se distribuyen casi inmediatamente en todo el organismo, especialmente si son administrados por vía intravenosa. En otros casos, el desplazamiento del medicamento en el organismo es más lento y obedece a leyes físicoquímicas y bioquímicas específicas.

A través del metabolismo de un fármaco, se producen una serie de cambios químicos en el mismo, generalmente inducidos por enzimas, antes de su eliminación final en el organismo, de manera que este proceso se considera uno de los mecanismos de eliminación fisiológica o de disminución de la actividad del medicamento suministrado. En ocasiones, este metabolismo puede tener un efecto contrario, y generar un compuesto intermediario con actividad o toxicidad mayor (Sumano y Ocampo, 1997).

A su vez, la eliminación en el organismo de la forma activa del medicamento depende esencialmente de los procesos de biotransformación y excreción, aunque también de otros factores, entre los que destacan el $\mathrm{pH}$, solubilidad del fármaco en lípidos y unión de éste a proteínas plasmáticas (Rang et al., 2000). Estos factores pueden verse, a su vez, alterados por la propia enfermedad y provocar cambios sistémicos o locales en la distribución de dicha sustancia en el organismo.

La forma más utilizada para expresar la velocidad a la que se eliminan los medicamentos es mediante el concepto de "vida media $\left(t_{1 / 2}\right)$ ", que se define como "el 
tiempo necesario para que se reduzca en un $50 \%$ una concentración plasmática determinada" (Haagsma, 1993).

Por otra parte, en orden de importancia, las vías de excreción de los medicamentos son renal, biliar, pulmonar, mamaria, salival, secreciones gastrointestinales, a través de la piel y la vía genital.

Existen una serie de factores inherentes a la aplicación de las sustancias antimicrobianas (Debackere, 1995), que pueden influir en la calidad y en la duración de los tiempos de excreción y por lo tanto en su presencia en la leche, tales como la naturaleza del antibiótico, la dosis administrada, la influencia del excipiente, la vía de administración y el estado sanitario de la ubre.

Además de todos los factores mencionados anteriormente, uno de los aspectos más importantes que condiciona la cantidad de residuos presente en un producto es el tiempo transcurrido entre el cese de la administración de las sustancias antibacterianas al animal y la obtención de éste. La cantidad de residuos será mayor en aquellos casos en los que dicho periodo no sea lo suficientemente largo como para permitir la completa eliminación de los residuos del organismo del animal (Botsoglou y Fletouris, 1996).

Se define como "tiempo de espera" o de seguridad de un antimicrobiano al tiempo necesario que debe transcurrir tras la última aplicación del medicamento y el aprovechamiento de los alimentos obtenidos del animal tratado. Este tiempo de espera, constituye una característica esencial y específica del medicamento para cada tipo de producto (carne, leche, huevos, etc.) y su respeto es necesario para evitar la presencia de residuos en los alimentos por encima de los Límites Máximos de Residuos establecidos por la legislación para cada fármaco y matriz alimentaria.

Por otra parte, se debe señalar que de acuerdo a la Ley 29/2006 del Estado Español de 26 de Julio, sobre garantías y uso racional de medicamentos y productos sanitarios, se deben utilizar únicamente los medicamentos que han sido evaluados y aprobados por la Agencia Española del Medicamento y Productos Sanitarios (AEMPS), o por la Agencia Europea del Medicamento (EMEA), y que tienen que estar correctamente registrados y autorizados para su comercialización y utilización. Además, es necesario respetar las condiciones de utilización de acuerdo con las dosis y vías recomendadas por el fabricante, y los tiempos de espera que se especifican en el medicamento, para dichas dosis.

Respecto a la presencia de residuos en la leche de vaca, el servicio técnico de la cooperativa lechera COVAP (Córdoba), realizó una encuesta sobre 175 casos positivos encontrados a partir del análisis de 95.000 muestras de leche. En todos los casos se 
determinó la implicación del tratamiento de la mamitis, y las causas de la presencia de residuos se clasificaron en los diferentes conceptos que se presentan en la Figura 3.

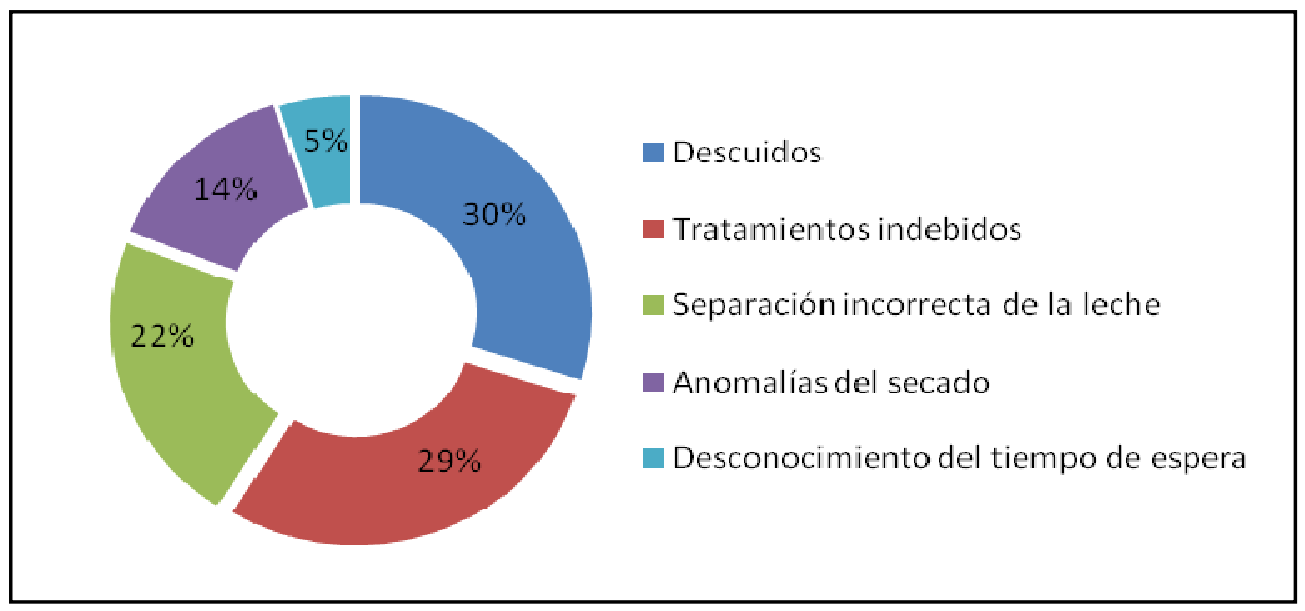

Figura 3. Causas de la presencia de residuos en la leche debido a tratamientos antimamíticos

Fuente: A partir de Sánchez et al. (2001)

Por todo ello, resulta fundamental establecer "Códigos de Buenas Prácticas Ganaderas" en las explotaciones lecheras, en especial en lo que se refiere al uso de medicamentos, para evitar el uso indebido de los mismos e intentar reducir de esta forma la presencia de residuos en la leche cruda y su posible ingreso en la cadena alimentaria.

\subsubsection{Efectos de la presencia de residuos de antimicrobianos en la leche}

Los efectos positivos de la terapia con agentes antimicrobianos en el ganado lechero se contrarrestan con el hecho de que se pueden encontrar residuos de estas sustancias en la leche de los animales en lactación, incluso varios días después de finalizar el tratamiento.

Si por alguna razón la leche que contiene antibióticos se introduce en el circuito lechero, puede contaminar la leche almacenada en el tanque de la granja, en la cisterna de recogida o incluso en los grandes silos de almacenamiento de las industrias, provocando lo que se denomina una "contaminación en cadena” (Zorraquino, 1996).

Por este motivo, dentro de los programas de control de calidad de la leche utilizada como materia prima para obtener productos alimentarios, existe un apartado dedicado a controlar la presencia de residuos de sustancias antimicrobianas, que influyen directamente en la calidad de la misma, tanto por su repercusión sanitaria como tecnológica. Además, hay que añadir la gran importancia que puede llegar a tener la detección de residuos para los propios productores de leche al verse afectados 
económicamente si se detecta leche con residuos y se declara no apta para el consumo humano.

\subsubsection{Salud pública}

La presencia de residuos de antimicrobianos en la leche puede producir efectos negativos sobre la salud humana (Moretain, 1996; Anthony et al., 2001; Demoly y Romano, 2005). Los principales problemas que se pueden encontrar se resumen en:

- Sensibilización a los antibióticos producida por una ingestión repetida de pequeñas dosis.

- Procesos alérgicos que pueden, en casos extremos, llevar a la anafilaxia.

- Perturbaciones pasajeras en la flora intestinal del consumidor.

- Reacciones de intoxicación frente a determinados antibióticos de gran toxicidad.

- Desarrollo de resistencias a agentes antibacterianos como resultado de la exposición repetida de las bacterias a dichas sustancias.

Todos estos efectos son de vital importancia para la salud del consumidor, pero sin duda alguna es el desarrollo de resistencias a los antimicrobianos, la principal preocupación en la actualidad (Tollefson y Karp, 2004).

Durante la última década, la Organización Mundial de la Salud (OMS) y la Organización Mundial de la Sanidad Animal (OIE) junto a la Organización de las Naciones Unidas para la Agricultura y la Alimentación (FAO) y la Comisión del Codex Alimentarius, han abordado el riesgo potencial, derivado del uso de antimicrobianos en el tratamiento y la prevención de enfermedades en animales destinados a la producción de alimentos, de que aparezcan y se extiendan organismos resistentes a los agentes antimicrobianos.

Concretamente, el hecho de que se empleen en gran medida las mismas clases de antimicrobianos en humanos y animales y de que se hayan elaborado muy pocos antibióticos nuevos para sustituir a los que se han vuelto relativamente ineficaces a causa de las resistencias, ha dado lugar a un acuerdo sobre la necesidad de crear ciertas medidas, como el uso responsable y prudente de los antimicrobianos o la vigilancia de la aparición de resistencias a estos agentes en medicina humana y veterinaria.

Por todos estos motivos, las distintas organizaciones han ido desarrollando una serie de actividades y procesos de armonización y globalización internacional enfocados a la contención de la aparición de resistencias a los antimicrobianos transmitida por los alimentos (Codex Alimentarius, 2007) 
Estas actividades han abordado con especial énfasis el uso racional de antimicrobianos en producción animal, incluyendo en ellos programas de farmacovigilancia de resistencias bacterianas con el fin de disminuir el riesgo de transmisión a la población humana, asegurar la eficacia terapéutica de estos agentes en las especies de destino y asegurar que los productos originados de animales tratados con antimicrobianos lleguen sin residuos a la población humana.

\subsubsection{Industria láctea}

Por otro lado, desde un punto de vista tecnológico, la presencia de sustancias farmacológicas en la leche afecta a los procesos bacterianos en la elaboración de productos fermentados tales como el queso y el yogur. La presencia de estos residuos afecta a la flora láctica dando lugar a procesos de mala calidad (Packham et al., 2001), como el retraso en la acidificación o la dificultad en el cuajado y la maduración (Mourot y Loussouarn, 1981; Brady y Katz, 1987, Suhren, 1995), llegando incluso a inhibir completamente la fermentación en algunos casos.

Los daños tecnológicos que produce la presencia de estos residuos dependen de la naturaleza de los antibióticos, su concentración en la leche y el tipo de producto a fabricar (Mäyra-Mäkinen, 1995).

Así, Goursand (1991) señala que la presencia de bajos niveles de antibióticos en la leche utilizada para la elaboración de queso, puede ser la causa de defectos en su sabor, textura desigual, mal desarrollo y la tendencia a la fermentación del ácido butírico.

En un trabajo más reciente, Berruga et al. (2007a), analizaron la influencia de la presencia de antibióticos betalactámicos (penicilina G, ampicilina, amoxicilina, ceftiofur y cefalexina) en la leche de oveja empleada en la fabricación de queso Manchego. Los resultados de este estudio muestran que la presencia de estas sustancias a concentraciones equivalentes a sus LMRs provocan un retraso en la acidificación de la leche entre 5 y 295 minutos, sobretodo en el caso del ceftiofur.

Por otra parte, en cuanto a la elaboración del yogur, Grunwald y Petz (2003), observaron que la coagulación se ve afectada de un modo negativo conforme aumenta la concentración de residuos de penicilinas en las muestras de leche, en especial, cuando los tiempos empleados en los procesos son largos. Estos autores, determinan que concentraciones equivalentes a $8 \mu \mathrm{g} / \mathrm{kg}$ de penicilina y equivalentes o superiores a 60 $\mu \mathrm{g} / \mathrm{kg}$ de cloxacilina, oxacilina y dicloxacilina en la leche inhiben fuertemente el proceso de fermentación del yogur. 
Berruga et al. (2007b) también estudiaron el efecto de la presencia de penicilinas durante la fermentación del yogur elaborado con leche de oveja. Estos autores indican, que por lo general, un incremento en la concentración de penicilinas presentes en la leche lleva a la necesidad de aumentar el tiempo de incubación para completar correctamente el proceso de fermentación del yogur. Para que esto ocurra, la penicilina $\mathrm{G}$ tiene que estar presente en concentraciones superiores a $6 \mu \mathrm{g} / \mathrm{kg}$ (>LMR) mientras que $2 \mu \mathrm{g} / \mathrm{kg}$ de amoxicilina en la leche (< LMR) ya produce un retraso de 41 minutos en la fermentación.

También, la presencia de residuos de antibióticos puede influir en el resultado del recuento de gérmenes, produciendo interferencias en la prueba de la reductasa y dando resultados erróneos en el recuento de patógenos, falseando de esta forma la calidad higiénica de la leche (Moretain, 1996).

Por otro lado, es importante señalar que algunas de las sustancias farmacológicas presentes en la leche resisten las altas temperaturas, por lo que pueden llegar al consumidor aún después de haber sido sometidas a tratamientos térmicos en la industria (Oda y Hiwaki, 1996; Zorraquino, 2005; Zorraquino et al., 2008 a,b), lo que agrava todavía más el problema que supone la presencia de estos residuos para la salud.

\subsubsection{Productor de leche}

Tampoco hay que olvidar la importancia que tiene la presencia de residuos en la leche para el propio ganadero o productor de leche, ya que puede llevar a la prohibición por parte de las autoridades sanitarias de la comercialización de la leche cruda, al ser calificada esta como "no apta para consumo humano" por contener residuos de determinadas sustancias entre las que se encuentran los medicamentos, según el Reglamento CE 853/2004 donde se establecen las normas especificas de higiene de los alimentos de origen animal.

Además, recientemente ante las inspecciones realizadas por la Oficina de Inspección Veterinaria (OAV) de la Unión Europea en Septiembre de 2006 y Abril de 2007, para verificar la eficacia de los controles oficiales realizados en los productos de origen animal, carne y leche, se detectaron graves deficiencias en el control de ésta última y sus productos derivados. Este hecho ocasionó la puesta en marcha por parte del Ministerio de Agricultura, Pesca y Alimentación, en Julio de 2007, de un "Plan reforzado de España de Control de las Condiciones Higiénico-Sanitarias de leche de vacuno".

En el citado Plan se han intensificado los controles oficiales y se ha establecido un protocolo estricto de actuación para el seguimiento de las deficiencias, a la vez que se 
ha establecido la necesidad del completo funcionamiento de los módulos de trazabilidad y calidad de la leche integrantes del sistema de información "Letra Q".

Por ello, ha sido publicado el Real Decreto 1728/2007 de 21 de Diciembre, en el que se establece la normativa básica de control que deben cumplir los operadores del sector lácteo y que modifica, en parte, al Real Decreto 217/2004 que establecía las bases del sistema de trazabilidad para la leche en nuestro país.

La posible restricción de la comercialización de la leche, así como los gastos de almacenamiento y/o los costes derivados de su destrucción por incumplimiento de los requisitos del Plan de control, son responsabilidad del ganadero y representan, por lo tanto, pérdidas económicas importantes.

\subsection{CONTROL DE LA PRESENCIA DE ANTIMICROBIANOS EN LA LECHE}

\subsubsection{Medidas de control}

\subsubsection{Límites Máximos de Residuos}

La Unión Europea (UE) divide a los productos de uso veterinario en dos grupos. En el primero, se incluyen los medicamentos convencionales (empleados en tratamientos profilácticos, terapéuticos, vacunas y otros productos inmunológicos) y está regulado por la Directiva 2001/82/CEE. El segundo grupo de sustancias estaba regulado hasta el año 2003 por la Directiva 70/524/CEE, que fue derogada mediante el Reglamento 1831/2003 CEE, sobre el uso de aditivos en la alimentación animal. Este Reglamento, en lo que respecta a antibióticos, prohíbe su utilización como aditivos para alimentación animal, admitiendo sólo los coccidiostáticos y los histomonostáticos.

Para controlar la presencia de residuos de medicamentos en los alimentos, la UE ha establecido los Límites Máximos de Residuos (LMR), competencia del Grupo de trabajo de Seguridad de Residuos del Comité de Medicamentos Veterinarios (CVMP, del inglés Committee for Veterinary Medicinal Products). El mecanismo por el cual se regula la determinación de los LMRs está legislado en el Reglamento 2377/90/CEE.

Según este Reglamento el LMR se define como "el contenido máximo de concentración de residuos resultante de la utilización de un medicamento veterinario (expresado en $\mu \mathrm{g} / \mathrm{kg} \circ \mathrm{g} / \mathrm{kg}$ sobre la base del peso en fresco) autorizada en la Comunidad o reconocida como admisible en un producto alimenticio".

La Unión Europea ha registrado todas las sustancias farmacológicamente activas que se utilizan en animales productores de alimentos, incluyéndolas en uno de los 4 anexos del Reglamento 2377/90/CEE. 
Así, en el Anexo I se incluyen aquellas sustancias en las que se ha establecido el LMR definitivo para uno o más productos animales y en el Anexo II se encuentran aquellas que no es necesario establecer su LMR porque se consideran seguras, en el Anexo III se incluyen las sustancias que tienen un LMR provisional (MRLP, pendiente de más estudios) y en el Anexo IV se presentan los agentes que no poseen LMR porque se consideran que son inseguros para el consumidor y su presencia constituye un riesgo para la salud del mismo (cloranfenicol, nitrofuranos, etc.). Estas sustancias están terminantemente prohibidas para uso en animales de producción.

En el Cuadro 6 se indican los diferentes LMRs recogidos en la Legislación Europea, para sustancias quimioterapeúticas y muchos de los antibióticos utilizados en ganado lechero de acuerdo con el Reglamento 2377/90/CEE y sucesivas modificaciones.

\subsubsection{Planes de control}

El control de la presencia de residuos de antibióticos en la leche está regulado por la Directiva 96/23/CEE, en la cual se establece que los Estados Miembros de la UE deberán vigilar la presencia de residuos de antibióticos y de otros medicamentos veterinarios en la leche dentro de un Plan Nacional de Investigación de residuos de carácter anual (PNIR).

Por otro lado, el Reglamento 178/2002/CEE del Parlamento Europeo y del Consejo, establece la necesidad para las empresas alimentarias de poner en práctica a partir del 1 de enero de 2005, sistemas que permitan, en todas las etapas de producción, transformación y distribución, asegurar la trazabilidad de los alimentos.

Con este fin el Ministerio de Agricultura, Pesca y Alimentación (MAPYA) publicó el Real Decreto 217/2004, donde se regulaban la identificación y registro de los agentes, establecimientos y contenedores que intervienen en el sector lácteo, y el registro de los movimientos de la leche cruda de vaca. Este Real Decreto creó la herramienta que permite establecer la trazabilidad en la leche cruda de vaca en España, mediante el Módulo de trazabilidad de la "base de datos Letra Q" (LEche TRAzabilidad Qualidad), una aplicación informática integrada en el sistema de información Letra $Q$, donde están registrados todos los agentes y contenedores del sector lácteo.

En la "base de datos Letra Q" los responsables de los centros lácteos registran todos los movimientos que se producen entre contenedores, desde que la leche cruda de vaca sale de la explotación productora hasta que llega a un centro lácteo de transformación. 
Cuadro 6. Límites Máximos de Residuos en leche de vaca

\begin{tabular}{|lc|lc|}
\hline Antimicrobianos & LMR* $^{*}$ & \multicolumn{1}{|l|}{ Antimicrobianos } & LMR \\
\hline Betalactámicos & & (cont.) & \\
Bencilpenicilina & 4 & Sulfadimetoxipiridazina & 100 \\
Ampicilina & 4 & Macrólidos/lincosamidas & \\
Amoxicilina & 4 & Eritromicina & 40 \\
Penetamato & 4 & Espiramicina & 200 \\
Nafcilina & 30 & Tilmicosina & 50 \\
Cloxacilina & 30 & Tilosina & 50 \\
Dicloxacilina & 30 & Lincomicina & 150 \\
Oxacilina & 30 & Pirlimicina & 100 \\
Cefacetrilo & 125 & Aminoglucósidos & \\
Cefalexina & 100 & Gentamicina & 100 \\
Cefalonio & 20 & Kanamicina & 150 \\
Cefoperazona & 50 & Neomicina & 1500 \\
Ceftiofur & 100 & Espectinomicina & 200 \\
Cefquinoma & 20 & DH/Estreptomicina & 200 \\
Cefapirina & 60 & Quinolonas & \\
Cefazolina & 50 & Danofloxacina & 30 \\
Tetraciclinas & & Enrofloxacina & 100 \\
Clortetraciclina & 100 & Flumequina & 50 \\
Oxitetraciclina & 100 & Marbofloxacina & 75 \\
Tetraciclina & 100 & Otros & 50 \\
Sulfonamidas & & Acido clavulánico & 200 \\
Sulfadiacina & 100 & Bacitracina & 50 \\
Sulfadimetoxina & 100 & Baquiloprim & 50 \\
Sulfadimidina & 100 & Colistina & 50 \\
Sulfadoxina & 100 & Novobiocina & 50 \\
Sulfanilamida & 100 & Rifaximina & \\
Sulfametazina & 100 & Tianfenicol & \\
Sulfatiazol & 100 & Trimetoprima & \\
\hline
\end{tabular}

*LMR: $\mu \mathrm{g} / \mathrm{kg}$

Fuente: http://sinaem.agemed.es/lmrs (Febrero, 2008)

En la Figura 4 se representa un esquema del sistema para asegurar la trazabilidad de la leche, expuesto en el Real Decreto 217/2004. Con el establecimiento de estos programas de trazabilidad se ha pretendido mejorar la transparencia en los circuitos de comercialización avanzando en la mejora y control de la calidad de la leche y facilitando al sector el acceso a la información. 


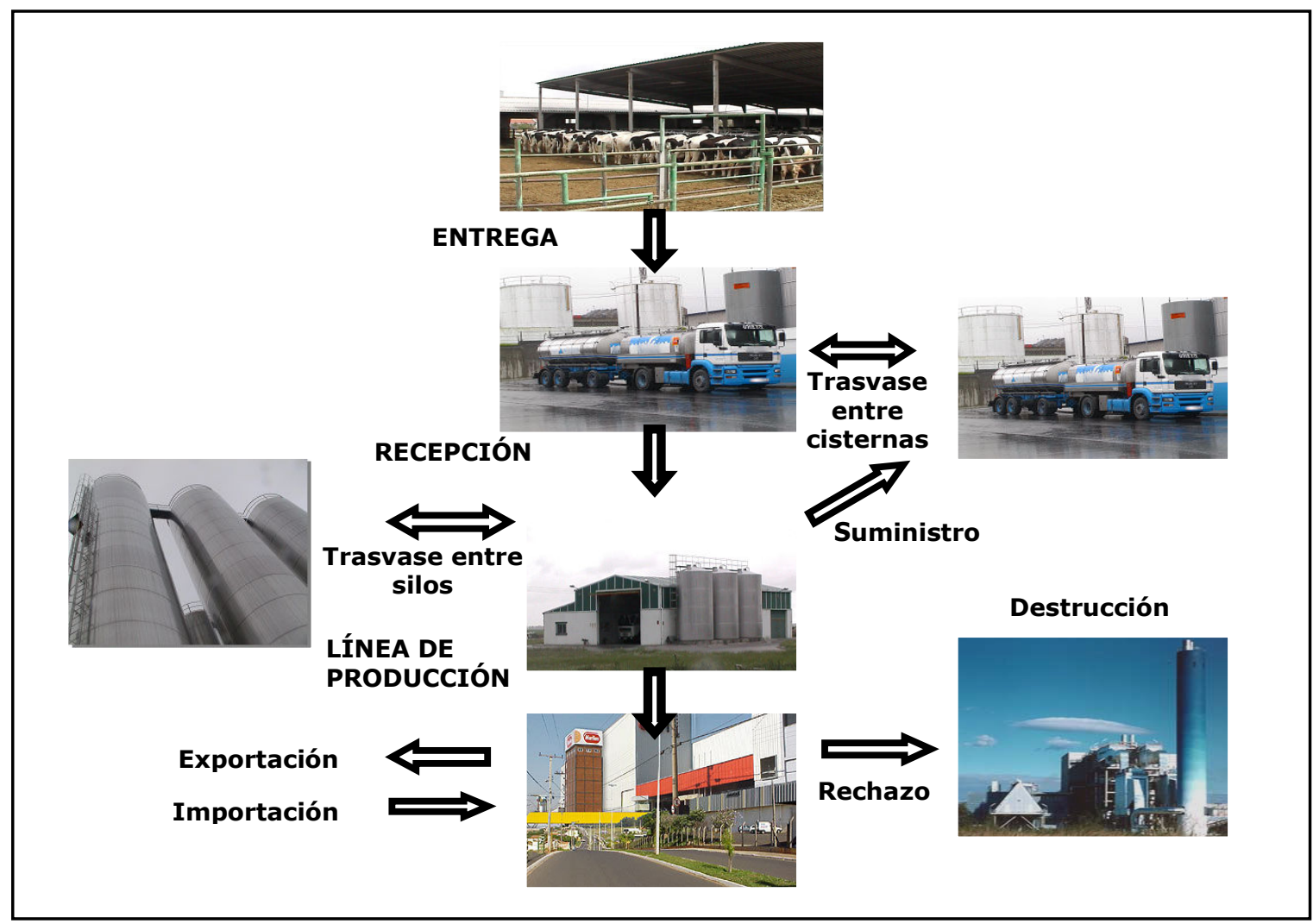

Figura 4. Esquema de las diferentes etapas implicadas en el sistema de trazabilidad Fuente: MAPYA (2006)

Por otro lado, con el fin de garantizar el cumplimiento de los requisitos de calidad indicados en los Reglamentos 852 y 853/2004/CEE donde se establecen respectivamente las normas generales relativas a la higiene de los productos alimenticios y las específicas para aquellos de origen animal, y también para asegurar el cumplimento de los controles oficiales a llevar a cabo en el control de residuos de productos animales destinados a consumo humano (Reglamentos 854 y 882/2004/CEE), el MAPYA ha publicado el nuevo Real Decreto 1728/2007.

En el Real Decreto 1728/2007 se estable la normativa básica de control del sector lácteo indicando por un lado los controles mínimos obligatorios sobre la calidad de la leche cruda de vaca a realizar por los operadores del sector lácteo y los transportistas, así como las bases para la realización de los controles oficiales en el ámbito de las exigencias de calidad de la producción de la leche modificando el Real Decreto $217 / 2004$.

En la Figura 5 se exponen el tipo de controles (mínimos obligatorios y oficiales) y las etapas de muestreo que se deben llevar a cabo tanto en las explotaciones y cisternas de transporte como en los centros lácteos de transformación. 


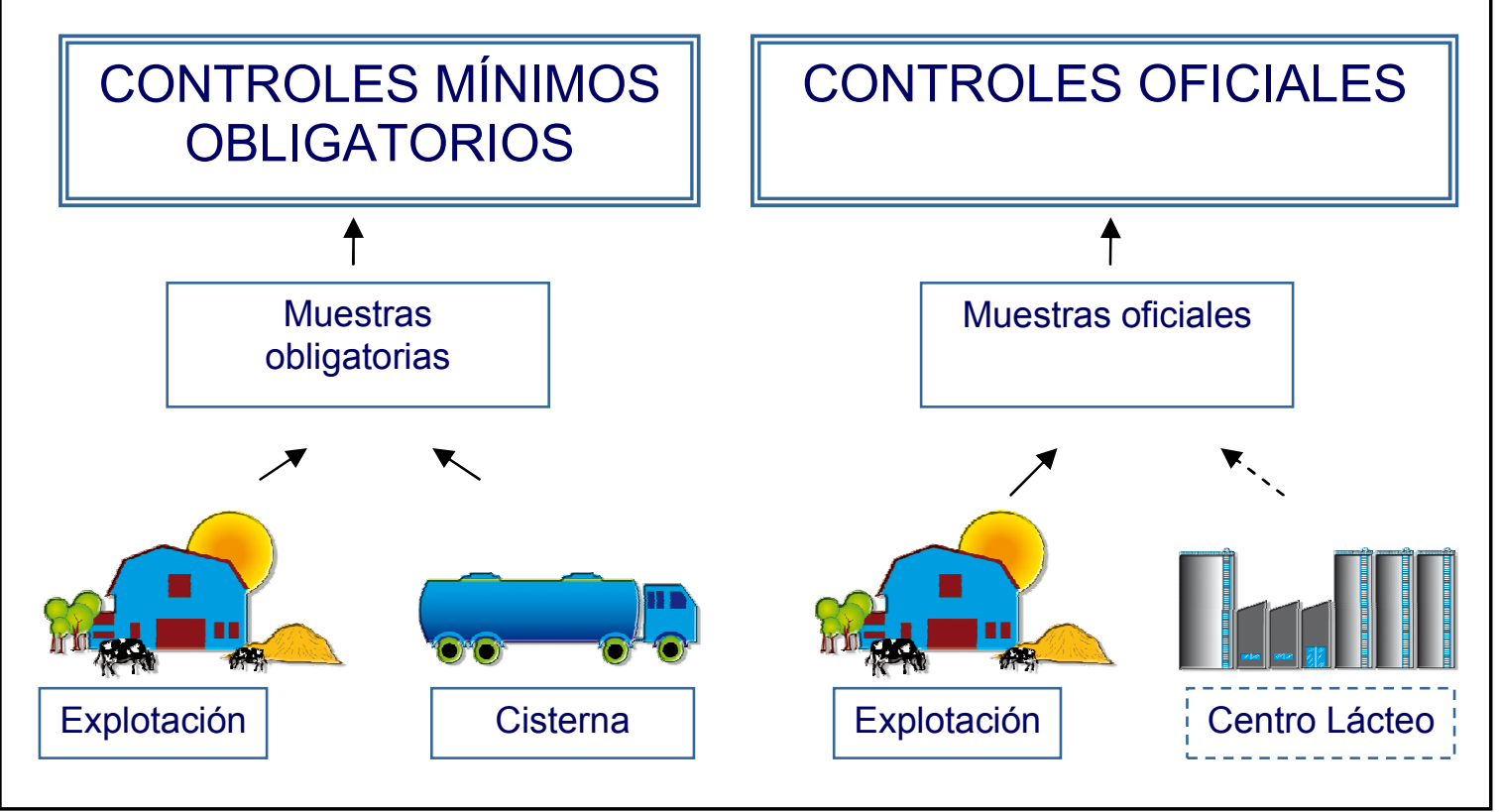

Figura 5. Controles mínimos exigidos en el Módulo de Calidad Letra Q Fuente: MAPYA (2006)

El Real Decreto 1728/2007 completa por lo tanto el sistema de información Letra Q con el "Módulo de Calidad", aplicación informática donde confluyen administración, operadores, productores y laboratorios registrados y oficiales.

Todos los laboratorios de análisis obligatorios comunicarán a la base de datos Letra $Q$, los resultados de los análisis de las muestras de autocontrol tomadas en las explotaciones antes de la carga de la leche y en las cisternas y en los centros lácteos previo a la descarga de ésta en los silos de las industrias.

Desde la "base de datos Letra Q" se generaran alarmas o avisos a las autoridades competentes de las comunidades autónomas para comunicar mensualmente los incumplimientos en células somáticas y bacteriología y diariamente los resultados positivos a la prueba de inhibidores. En el caso de incumplimiento, en especial en la prueba de inhibidores se procederá a la inmovilización de la leche y a su posterior destrucción.

\subsubsection{Sistema de detección de residuos de antimicrobianos en la leche}

\subsubsection{Generalidades}

Los diversos métodos para la detección de residuos en la leche se empezaron a utilizar alrededor de los años 50 (Bishop y White, 1984) y se basaban principalmente en pruebas de inhibición microbiana como la de difusión en agar, en la inhibición de la 
producción de ácido o en la inhibición de la coagulación de cultivos iniciadores (Mitchell et al., 1998).

Desde esa época se han mejorado ostensiblemente muchas de las características de estos métodos como la rapidez de respuesta, exactitud, sencillez y sensibilidad, al tiempo que se han desarrollado numerosos métodos basados en técnicas inmunológicas o receptores proteicos/microbianos que han reducido los tiempos de ensayo a escasos minutos. Las últimas tecnologías han integrado además las técnicas inmunoenzimáticas con aplicaciones electrónicas dando como resultado métodos basados en biosensores de alta especificidad y sensibilidad, que ofrecen un futuro prometedor dentro del campo de la detección de residuos en alimentos.

Sin embargo, el problema de analizar residuos en la leche es complejo, ya que no se sabe cuándo existe un residuo, y si existe se desconoce el tipo y la cantidad del mismo. La estrategia analítica para detectar el mayor número de sustancias antimicrobianas en la leche se debe basar en combinar las metodologías existentes según el objetivo planteado.

En la Figura 6 se expone un sistema integrado de control de detección y control de residuos de antibióticos y sulfonamidas basado en el propuesto por Heeschen y Shuren (1995) en el Simposio de la Federación Internacional de Lechería (FIL) celebrado en Kiel (Alemania) sobre "Residuos de medicamentos antimicrobianos y otros inhibidores en leche".

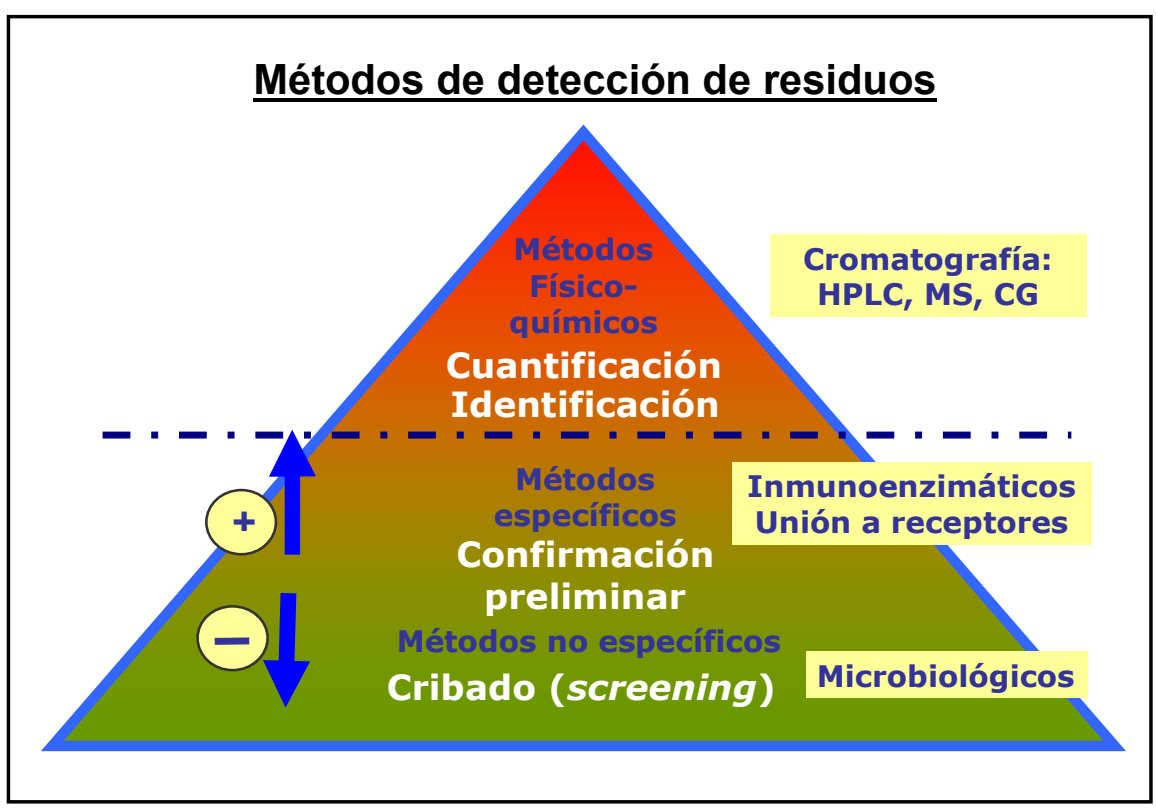

Figura 6. Sistema integrado de control de inhibidores en la leche Fuente: elaborado a partir de Heeschen y Shuren (1995) 
En este sistema se propone una primera etapa en la que se realiza un control "primario" o de cribado más general mediante un método cualitativo seguido de una confirmación preliminar con los métodos específicos y una segunda etapa donde se procede a la confirmación cuantitativa de los residuos por métodos analíticos físicoquímicos.

Actualmente la Unión Europea a partir de la Decisión 2002/657/CEE clasifica los métodos analíticos de detección de sustancias inhibidoras en la leche como métodos cualitativos o cuantitativos en función de las características de funcionamiento de cada uno de ellos.

\subsubsection{Métodos de detección de residuos de antimicrobianos en la leche}

Los métodos cualitativos, empleados en la primera fase de cribado del sistema de control, se clasifican a su vez en métodos microbiológicos, capaces de detectar la presencia o ausencia de un residuo en una muestra, y en métodos de confirmación cualitativa, específicos para la detección de un determinado grupo de antibióticos.

Los métodos microbiológicos de cribado están basados fundamentalmente en pruebas de inhibición del crecimiento de un microorganismo específico, empleando para la detección de esta inhibición, diversos sistemas como indicadores de $\mathrm{pH}$, redox, bioluminiscencia, etc. Estos métodos aprovechan fundamentalmente la capacidad de las bacterias de producir ácido, reducir colorantes o producir halos de inhibición en un medio de cultivo, de manera que el resultado se puede interpretar visualmente.

El BRT ${ }^{\circledR}$, BR-Test $^{\circledR}$, Copan $^{\circledR}$, Delvotest ${ }^{\circledR}$ o Eclipse ${ }^{\circledR}$ son algunos de los métodos más utilizados hoy en día y todos ellos emplean el Geobacillus steraothermophilus var. calidolactis, antes denominado Bacillus stearothermophilus (Nazina et al., 2001), como microorganismo de prueba.

Por otro lado, entre los métodos de confirmación cualitativos utilizados en la fase de cribado, existen actualmente en el mercado distintos tipos de métodos enzimáticos, inmunoenzimáticos, de unión a receptores, etc., que permiten detectar de una forma más específica y por lo general más rápida, la presencia de residuos de antibióticos y sulfonamidas en la leche (Bishop y White, 1984; Mitchell et al., 1998; Botsoglou y Fletouris, 2001; Zorraquino et al., 2003).

Entre los métodos más importantes hay que destacar el método enzimático Penzym ${ }^{\circledR}$ y otro grupo de métodos basados en técnicas inmunoenzimáticas, ELISA o RIA (Macho, 2003), así como los métodos de unión a receptores proteicos, de gran desarrollo 
en la actualidad, donde destacan el método SNAP ${ }^{\circledR}$, Delvo-X-Press $^{\circledR} \beta L$, Twinsensor, Beta $\operatorname{Star}^{\circledR}$ y ROSA ${ }^{\circledR}$ Charm, entre otros.

En cuanto a los métodos utilizados en la fase de confirmación y cuantificación, se emplean métodos físico-químicos que se utilizan para identificar y cuantificar de una forma inequívoca la presencia de residuos de antimicrobianos en las muestras de leche.

Se han desarrollado numerosas metodologías que se encuentran disponibles para la detección cuantitativa de diversos grupos de antimicrobianos. Sin embargo, estos métodos son caros y muy laboriosos, y también requieren haber analizado mediante instrumentación muy precisa un amplio rango de controles positivos a diversas concentraciones conocidas para poder extrapolar mediante curvas patrón la concentración de la muestra problema.

Las técnicas cromatográficas son las que se emplean con mayor frecuencia. Existen varios tipos de métodos, como la cromatografía de gases (GC), la cromatografía de capa fina (TLC), la cromatografía de capa fina/bioautografía (TLC/BA) o la cromatografía líquida (HPLC).

En la actualidad, las técnicas cromatográficas son las que se emplean con mayor frecuencia para la identificación y cuantificación de residuos de antimicrobianos en la leche, especialmente la cromatografía líquida de alta resolución (HPLC) del inglés High Performance Liquid Chromatography, denominada actualmente de una forma más simple como cromatografía líquida (LC) también del inglés Liquid Chromatography.

\section{DETECCIÓN DE ANTIMICROBIANOS EN LA LECHE POR HPLC}

\subsection{GENERALIDADES}

La cromatografía líquida de alta resolución (HPLC o LC) es una técnica que se utiliza para separar compuestos de una mezcla o muestra en las diferentes sustancias individuales que la componen. Esta separación de compuestos ocurre cuando la muestra se introduce en una fase móvil líquida que atraviesa, con una presión elevada, una fase estacionaria, sólida y fija, denominada columna cromatográfica.

La fase móvil y la columna de un sistema cromatográfico se eligen de forma que los distintos componentes de la muestra presenten diferentes solubilidades 0 interacciones para cada una de ellas.

La columna contiene un determinado material cromatográfico empacado que sirve para realizar la separación de los compuestos presentes en la mezcla inicial a su paso por esta. De esta forma, un compuesto totalmente soluble en la columna tardará más 
tiempo en atravesarla que un compuesto poco soluble en esta fase pero muy soluble en la fase móvil.

En la Figura 7 se presenta un esquema de la separación de compuestos realizada en el interior de una columna cromatográfica.

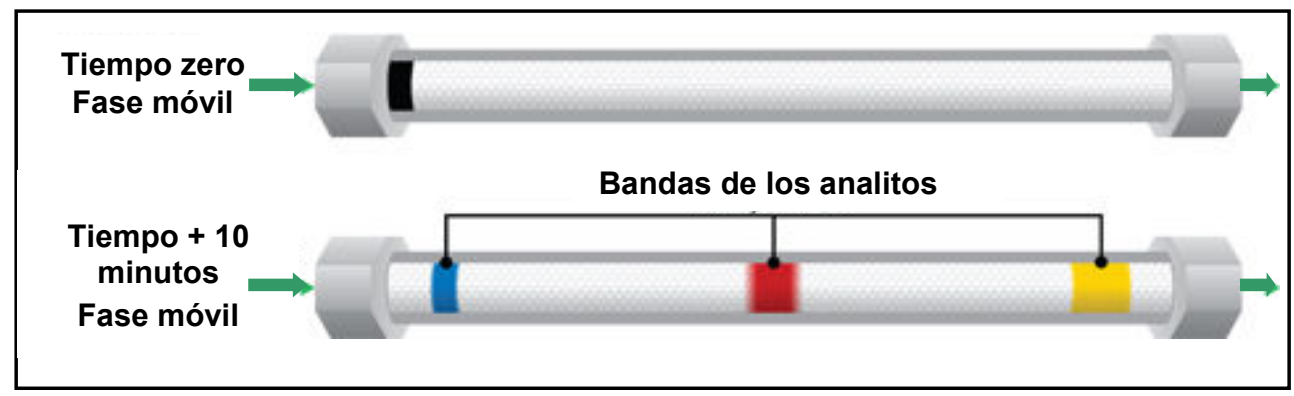

Figura 7. Separación de compuestos en la columna cromatográfica

Fuente: elaborado a partir de http://www.library4science.com

Dependiendo de la naturaleza de los compuestos a analizar, de la fase móvil y de la columna utilizada, se describen diferentes tipos de cromatografía líquida, como la cromatografía en fase normal, fase inversa, exclusión molecular o intercambio iónico, entre otras.

Actualmente casi todos los procedimientos empleados para la determinación de compuestos antimicrobianos, utilizan la técnica LC en fase inversa. Este tipo de cromatografía es tan ampliamente empleada que a menudo se le denomina HPLC o LC sin ningún tipo de especificación adicional, y es en este modo como se va a denominar en este documento.

La técnica se basa en el principio de las interacciones hidrofóbicas que resultan de las fuerzas de repulsión entre una fase móvil de polaridad moderada, un compuesto relativamente apolar y una fase estacionaria apolar (normalmente columna de silica tratada $\mathrm{C}_{18}$ ). En la Figura 8 se esquematiza el fundamento de esta técnica.

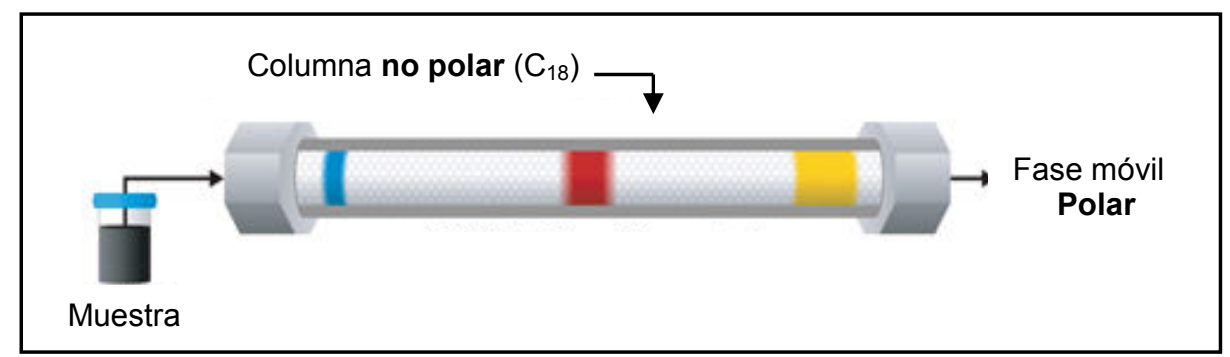

Figura 8. Cromatografía de fase inversa

Fuente: elaborado a partir de http://www.library4science.com 
Todos los sistemas cromatográficos cuentan además con un sistema de detección acoplado al sistema de separación, que identifica los compuestos eluidos de la columna y traduce la señal recibida en forma de cromatograma.

A partir del cromatograma (representación gráfica), se identifica y cuantifica el residuo o analito analizado, utilizando el tiempo de retención obtenido, el área del pico del cromatograma y en caso de existir, la comparación del espectro del compuesto con librerías existentes en el sistema o "software" empleado.

En la Figura 9 se presenta un esquema de los componentes y funcionamiento general de un sistema básico de cromatografía liquida.

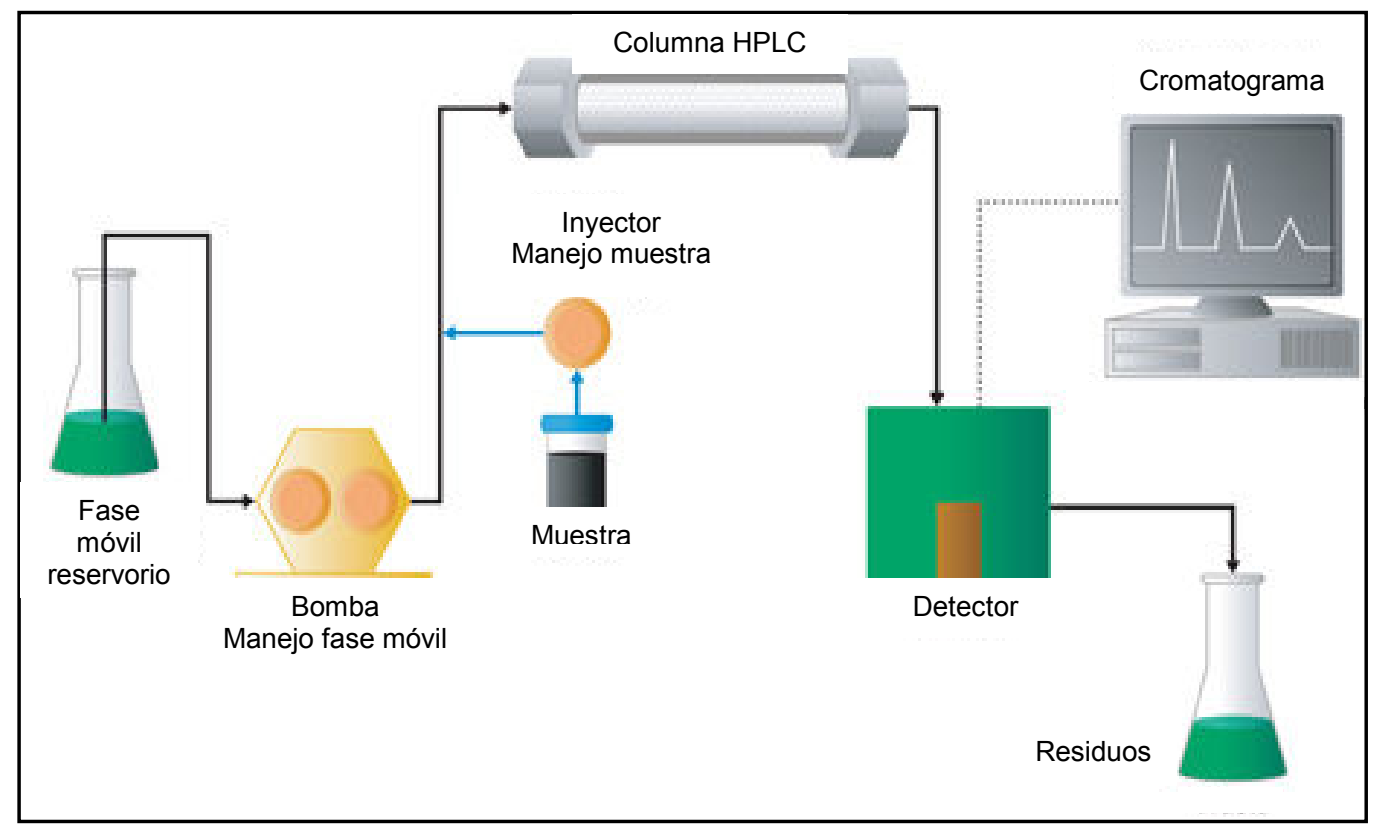

Figura 9. Esquema general de un sistema de cromatografía líquida Fuente: elaborado a partir de http://www.library4science.com

\subsection{MÉTODOS DE DETECCIÓN}

\subsubsection{Consideraciones previas}

Se han realizado diversos estudios sobre la determinación de residuos de productos veterinarios en la leche que ponen de manifiesto la importancia de la técnica LC acoplada a diferentes detectores (ultravioleta-visible, fotodiodos, fluorométricos, refractométricos, electroquímicos, radiométricos, viscosimétricos, evaporativos de "lightscattering", masas, etc.) para la cuantificación de residuos, especialmente en antibióticos betalactámicos (Sorensen et al., 1997; Becker et al., 2004; Holstege et al., 2007) y en menor grado para el resto de grupos de antimicrobianos (Moats y Harik-Khan, 1995; Zhang et al., 2005; Koesukwiwat et al., 2007; Spisso et al., 2007). 
Algunos de los detectores tradicionales ofrecen datos en dos dimensiones, representando la intensidad de la señal obtenida en función del tiempo (detector ultravioleta de longitud de onda fija). Otros sin embargo (fotodiodos, masas, etc.), son capaces de ofrecer estos datos en tres dimensiones, mostrando también los datos espectrales de cada punto y ofreciendo una herramienta muy útil para identificar la naturaleza del analito.

Las técnicas LC acopladas a detectores convencionales, sobretodo los detectores UV-visible (HPLC-UV o LC-UV), han sido generalmente las más utilizadas para la confirmación de residuos de antimicrobianos en productos alimenticios. Sin embargo estas técnicas tienen algunas limitaciones como la baja sensibilidad y selectividad que pueden presentar en ocasiones, además de requerir de una costosa fase previa de purificación de la muestra para eliminar las interferencias de la matriz (Sorensen et al., 1997; Taguchi et al., 1999; Ghidini et al., 2003).

Por ello, se están introduciendo cada vez más en los laboratorios de control las técnicas de cromatografía líquida combinada con espectroscopia de masas (LC-MS), ya que esta técnica es capaz de proporcionar la información estructural necesaria (espectro de masas) para la confirmación de resultados positivos que los sistemas LC con detectores convencionales no son capaces de obtener.

Además, la Decisión 2002/657/CEE por la que se aplica la Directica 96/23/CEE en cuanto al funcionamiento de los métodos analíticos y la interpretación de los resultados, cita explícitamente que "los métodos de confirmación para residuos orgánicos o contaminantes basados exclusivamente en los análisis cromatográficos que prescinden de la detección espectrométrica no convienen por sí solos como métodos de confirmación. No obstante, si una técnica por sí sola carece de la especificidad necesaria, dicha especificidad se obtendrá por medio de procedimientos analíticos consistentes en combinaciones adecuadas de limpieza, separación cromatográfica y detección espectrométrica".

Los métodos o combinaciones de métodos que se consideran adecuados para la identificación de los residuos a controlar en los animales vivos y sus productos se resumen en el Cuadro 7 en donde se señalan las diferentes técnicas de medición recomendadas para el análisis de las sustancias recogidas en el Anexo I de la Directiva 96/23/CEE (Grupo A: sustancias con efecto anabolizante y sustancias no autorizadas; Grupo B: medicamentos veterinarios y contaminantes). 
Cuadro 7. Métodos de confirmación para residuos orgánicos o contaminantes

\begin{tabular}{|c|c|c|}
\hline Técnica de medición & $\begin{array}{l}\text { Sustancias Anexo I } \\
\text { de la Directiva } \\
\text { 96/23/CE }\end{array}$ & Limitaciones \\
\hline & & $\begin{array}{l}\text { Sólo si sucede a una separación por } \\
\text { cromatografía en línea y fuera de línea }\end{array}$ \\
\hline $\begin{array}{l}\text { LC o GC con detección } \\
\text { por espectrometría de masas }\end{array}$ & Grupos A y B & $\begin{array}{l}\text { Sólo si se utilizan técnicas de barrido } \\
\text { completo o técnicas que no registran los } \\
\text { espectros de masa completos pero } \\
\text { incluyen al menos } 3 \text { (grupo B) o } 4 \text { (grupo } \\
\text { A) puntos de identificación }\end{array}$ \\
\hline $\begin{array}{l}\text { LC o GC con detección espectrométrica } \\
\text { de IR }\end{array}$ & Grupos A y B & $\begin{array}{l}\text { Deben cumplirse requisitos específicos de } \\
\text { absorción en la espectrometría de IR }\end{array}$ \\
\hline LC-PDA barrido completo & Grupo B & $\begin{array}{l}\text { Deben cumplirse requisitos específicos de } \\
\text { absorción en la espectrometría de UV }\end{array}$ \\
\hline LC-fluorescencia & Grupo B & $\begin{array}{l}\text { Sólo se aplica a las moléculas que } \\
\text { presentan fluorescencia natural y a las que } \\
\text { la presentan después de transformación }\end{array}$ \\
\hline $\begin{array}{l}\text { 2-D TLC-UV/VIS por } \\
\text { barrido completo }\end{array}$ & Grupo B & Se requieren la TLC y la cocromatografía \\
\hline $\begin{array}{l}\text { GC-Detección de la captación } \\
\text { electrónica }\end{array}$ & Grupo B & $\begin{array}{l}\text { Sólo si se utilizan dos columnas de } \\
\text { polaridad diferente }\end{array}$ \\
\hline LC-inmunograma & Grupo B & $\begin{array}{l}\text { Sólo si se utilizan al menos dos sistemas } \\
\text { cromatográficos o un segundo método de } \\
\text { detección independiente }\end{array}$ \\
\hline LC-UV/VIS (longitud de onda única) & Grupo B & $\begin{array}{l}\text { Sólo si se utilizan al menos dos sistemas } \\
\text { cromatográficos o un segundo método de } \\
\text { detección independiente }\end{array}$ \\
\hline \multicolumn{3}{|c|}{$\begin{array}{l}\text { Grupo A: sustancias con efecto anabolizante y sustancias no autorizadas; Grupo B: medicamentos veterinarios y } \\
\text { contaminantes; LC: cromatografía líquida; GC: cromatografía de gases; IR: infrarrojos; PDA: Fotodiodos; TLC } \\
\text { cromatografía de capa fina; UVIVIS: Iuz ultravioleta visible. }\end{array}$} \\
\hline
\end{tabular}

Fuente: Decisión 2002/657/CEE

\subsubsection{Detectores convencionales}

Como se ha comentado en el apartado anterior, los detectores de absorción UV son algunos de los métodos de detección acoplados a la cromatografía líquida más utilizados tradicionalmente para la separación e identificación de compuestos en matrices alimentarias.

Los detectores UV se utilizan para la detección de sustancias con un rango de absorbancias entre 180 y $350 \mathrm{~nm}$. El sensor en este tipo de detector consiste en una 
celda de flujo por donde pasa el eluyente con un camino óptico por donde atraviesa la luz procedente de una fuente UV e incide en una célula fotoeléctrica (array).

La señal fotoeléctrica creada se procesa electrónicamente y se transmite al ordenador en forma de cromatograma. Los detectores UV más simples son los que trabajan realizando las mediciones a una única longitud de onda fija.

Existen detectores UV más complejos, donde se engloban los detectores PDA (photodiode array detection), capaces de medir longitudes de onda variables y registrar el espectro UV del eluyente que atraviesa la columna durante todo el análsis. Estos sistemas son capaces de ofrecer no solo el cromatograma (representación de la fuerza de la señal obtenida), sino el espectro UV del analito analizado.

Los detectores de fluorescencia, son otro tipo de sistemas de detección muy utilizados en la cromatografía líquida, que presentan sensibilidades muy elevadas pero que solo son capaces de ofrecer una respuesta lineal en un determinado rango de concentraciones.

Estos detectores utilizan una célula de flujo como sensor a través del cual, la luz pasa axialmente. Junto a esta célula se encuentra una fotocélula que capta la luz emitida. Cuando el soluto es excitado, la fluorescencia emitida llega a la fotocélula donde se procesa electrónicamente y se transmite al ordenador.

Estos sistemas tienen el inconveniente de que muchas sustancias no poseen fluorescencia natural por lo que en muchas ocasiones es necesario derivatizar la muestra antes o después de la inserción en la columna cromatográfica.

En las Figuras 10 y 11 se presentan los esquemas generales de los componentes y funcionamiento de los detectores UV y PDA, descritos anteriormente y que son los que se han empleado en diferentes experimentos del presente estudio.

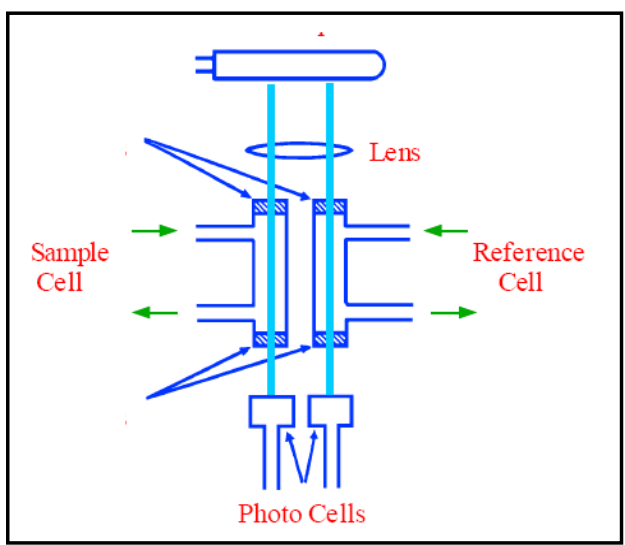

Figura 10. Detector UV

Fuente: http://www.library4science.com

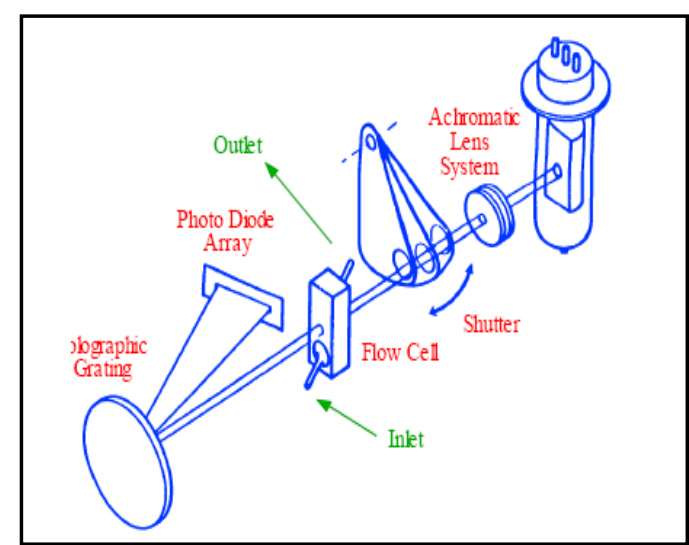

Figura 11. Detector PDA

Fuente: http://www.library4science.com 


\subsubsection{Espectrometría de masas}

\subsubsection{Generalidades}

Los espectrómetros o detectores de masas (MS) trabajan pulverizando en primer lugar la muestra líquida en vapor e ionizando a continuación las moléculas de la muestra a su paso por una fuente de ionización, cargándolas positiva o negativamente. Dependiendo de las características de funcionamiento del espectrómetro (tipo analizador, voltajes de cono, campos electromagnéticos, etc.), los iones recién formados (precursores) se seleccionan directamente para identificar al analito o se fraccionan de una única forma en iones hijos, que son los que a continuación se seleccionan e identifican de acuerdo a la relación entre su masa y carga $(\mathrm{m} / \mathrm{z})$, y a partir de los cuales se cuantifica la cantidad de analito presente en la muestra.

Algunos de los componentes más importantes de un espectrómetro de masas son por lo tanto la fuente de ionización que genera los iones y por otro lado, el tipo de analizador que los selecciona, fracciona e identifica.

Existen diferentes tipos de fuentes de ionización (electroespray, ionización química a presión atmosférica, fotoionización a presión atmosférica, etc.) y distintos tipos de analizadores (cuadrupolo, trampa iónica, tiempo de vuelo, etc.) que se utilizan y combinan entre ellos dependiendo del compuesto que se pretende identificar y cuantificar.

Actualmente las técnicas más novedosas y potentes empleadas para la confirmación de la presencia de antimicrobianos en la leche y otras matrices alimentarias trabajan en "fase múltiple" más conocida como "tandem MS", "MS/MS" o "MS".

Estas técnicas funcionan combinando varios analizadores dentro del espectrómetro y son capaces de seleccionar únicamente los iones precursores e hijos que se quieren analizar e identificarlos y cuantificarlos con elevada selectividad, sensibilidad y precisión.

Una de las técnicas más importantes utilizada hoy en día en la determinación y cuantificación de residuos de antimicrobianos en matrices alimentarias es el sistema LC con fuente de ionización por electrospray acoplada a espectrómetro de masas de tipo triple cuadrupolo (Daeseleire et al., 2000; Van Rhijn et al., 2002; Becker et al., 2004; Makeswara et al., 2005; Andersen et al., 2005; De Ruyck y de Rieder, 2007). El fundamento y funcionamiento general de esta técnica (LC-ESI-MS/MS) se describe en el apartado siguiente. 


\subsubsection{LC-ESI-MS/MS (triple cuadrupolo)}

En este sistema cromatográfico el eluyente procedente de la columna del módulo de separación cromatográfica se inyecta directamente en el capilar de la cámara de la fuente de ionización por electrospray del espectrómetro de masas. En este capilar, la muestra se somete a un fuerte campo eléctrico que provoca su ionización, y al salir, la aplicación de nitrógeno a presión atmosférica hace que la muestra se nebulice en un spray de pequeñas gotas cargadas que contienen los compuestos ionizados.

A continuación se aplica un gas de desolvatación caliente, normalmente argon, para evaporar el solvente contenido en las gotas. Este proceso hace que las partículas reduzcan su tamaño y por lo tanto la densidad de cargas en su superficie aumenta, creando fuertes fuerzas de repulsión entre ellas (mayores que las de cohesión dentro de la propia gota) que producen la liberación en la fase gaseosa, de multitud de iones con una determinada relación masa/carga $(\mathrm{m} / \mathrm{z})$.

Los iones formados se dirigen hacia el cono de entrada del analizador del espectrómetro con la ayuda de la corriente de nitrógeno para ser analizados por el detector de masas. Una vez los iones entran en el sistema de detección, llegan al primer cuadrupolo donde se someten a un voltaje que crea un campo electromagnético que deja pasar únicamente aquellos iones con una relación $\mathrm{m} / \mathrm{z}$ específica. Estos iones son los iones precursores también denominados iones padres o moleculares del analito que queremos identificar.

En la Figura 12 se presenta un esquema del funcionamiento de la fuente de ionización por electrospray.

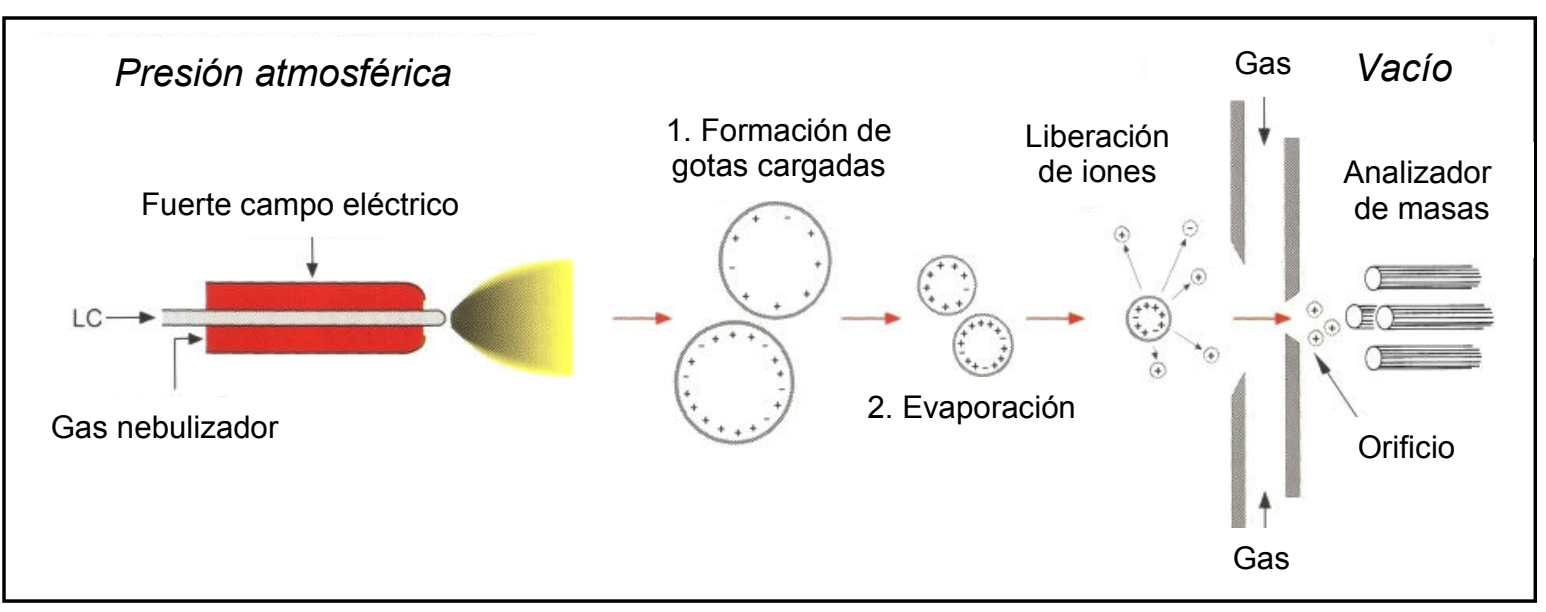

Figura 12. Fuente de ionización por electrospary (ESI)

Fuente: elaborado a partir de http://imaisd.usc.es 
Los iones precursores que han atravesado la primera fase llegan al segundo cuadrupolo denominado celda de colisión. En esta celda se realiza la fragmentación de los iones precursores por colisión inducida al aplicar un gas y una energía de colisión que hacen que estos iones colisionen entre ellos y con partículas neutras y se fragmenten en iones hijos o producto.

Los iones hijos mayoritarios formados (hijos primarios) asociados a un determinado voltaje de colisión, son los que nos van a servir para cuantificar de forma inequívoca el analito analizado. Los iones hijos secundarios (hijos secundarios) son los que nos van a servir para confirmar la identidad del analito analizado.

El tercer cuadrupolo tiene la función de seleccionar los iones precursores, primarios y secundarios elegidos para el análisis y llevarlos hasta el detector para ofrecer el espectro de las masas (m/z) de los iones detectados. En la Figura 13 se muestra un esquema del funcionamiento general del espectómetro de masas triple cuadrupolo.

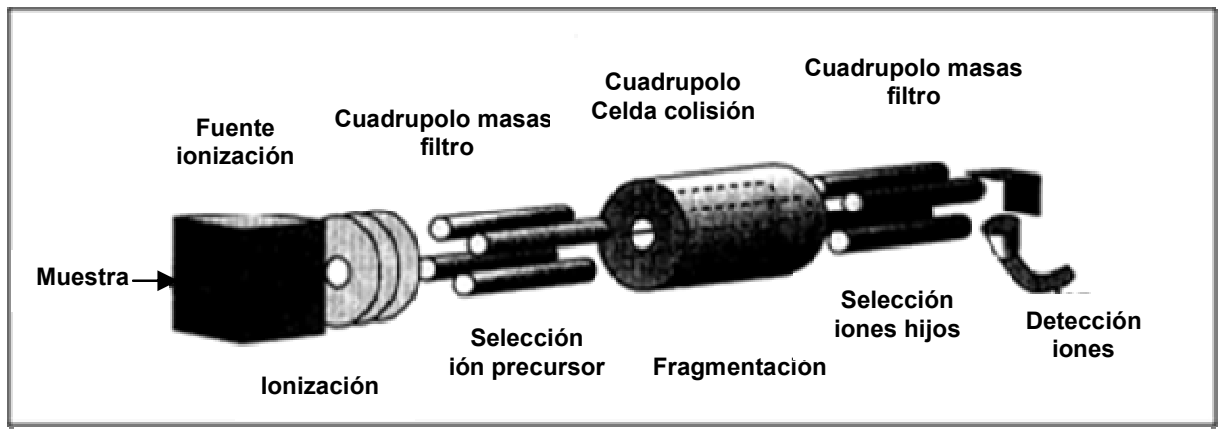

Figura 13. Espectrómetro de masas tipo triple cuadrupolo

Fuente: elaborado a partir de http://www.library4science.com

El espectro de masas contiene las señales másicas correspondientes no solo al ión precursor sino también las relativas a los iones procedentes de la fragmentación o iones hijos (primarios y secundarios). La identificación del analito se realiza por un lado mediante el tiempo de retención (RT) que viene determinado por la separación cromatográfica y equivale al establecido en el calibrado del equipo (curva patrón), y por otro lado por la identificación en el detector basada en 4 características intrínsecas de cada molécula o analito empleado: peso molecular del ión precursor, voltaje de cono, energía de colisión y pesos moleculares de los iones hijo.

También se puede verificar la relación "ión ratio" existente entre los iones hijos formados en la fragmentación del ión precursor. Esta relación tiene unos valores diferentes en función de cada analito, que se obtienen en la fase de puesta a punto de la técnica. 


\subsection{TÉCNICAS DE CROMATOGRAFÍA LÍQUIDA PARA LA DETECCIÓN DE ANTIMICROBIANOS EN LA LECHE}

A continuación en los siguientes apartados se presenta una revisión de las técnicas de cromatografía líquida (LC) acopladas a diferentes detectores más empleadas, desde el año 1995 hasta nuestros días, en la detección de antibióticos betalactámicos, tetraciclinas y sulfonamidas en la leche

\subsubsection{Antibióticos betalactámicos}

Las técnicas más utilizadas en el análisis de antibióticos betalactámicos en la leche han sido de cromatografía líquida con fraccionamiento por "cleanup", y con detectores convencionales tales como el de fluorescencia, fotodiodos y UV-visible (Holstege et al., 2002).

Algunos de los principales estudios sobre detección de betalactámicos en la leche, donde se han empleado estas técnicas, se sintetizan cronológicamente en el Cuadro 8 atendiendo a la naturaleza del analito, preparación de la muestra, sistema de detección empleado y características de funcionamiento del método empleado.

Como se aprecia en dicho Cuadro, la mayoría de las técnicas LC acopladas a detectores convencionales necesitan un complicado procesamiento de la muestra, previo al análisis, en varias fases sucesivas.

Así algunas de ellas, requieren de un primer paso de centrifugación (Tarbin et al., 1995; Sorensen et al., 1997 y Sorensen y Snor, 2000) para proceder al desnatado o eliminación de la grasa de la leche, de forma que ésta no interaccione en el análisis y permita la correcta extracción del analito de la muestra.

El sistema "cleanup" SPE, sistema de purificación o separación por extracción en fase sólida, es el sistema de extracción más empleado por casi todos los autores, lo que demuestra que esta técnica representa una herramienta muy útil en la extracción de residuos de antibióticos betalactámicos en la leche. Los porcentajes de recuperación obtenidos con el empleo de esta técnica muestran valores comprendidos entre $61,1 \%$ y $102 \%$.

Por otra parte, hay técnicas que también precisan de una etapa de derivatización de la muestra mediante la adición de reactivos, para amplificar la señal del analito (Tarbin et al., 1995; Sorensen et al., 1997; Verdon y Couedor, 1998; Marchetti et al., 2001) o para poder detectarlas en el detector de fluorescencia como es el caso del método descrito por Luo et al. (1997). 


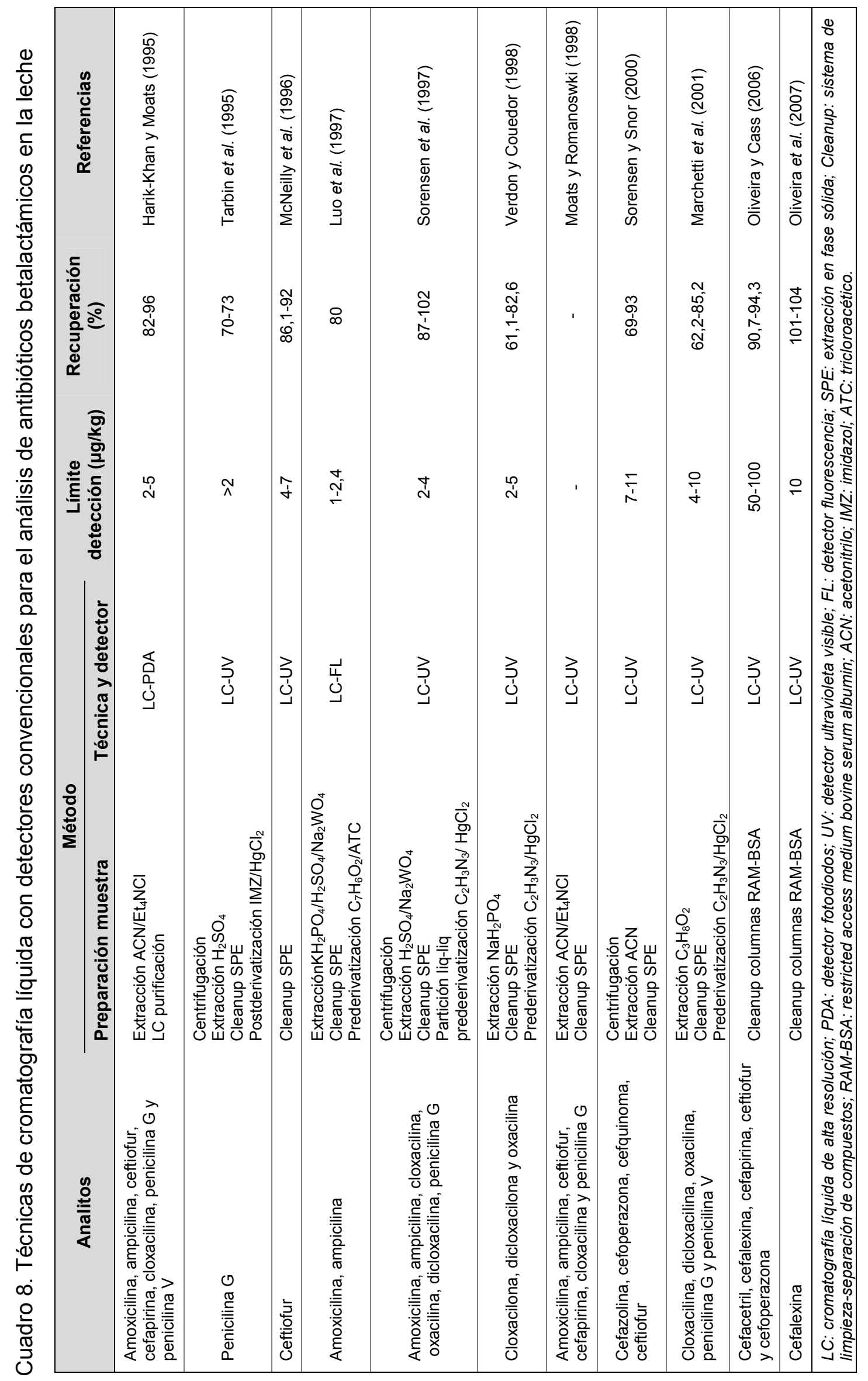


Recientemente se han introducido las nuevas columnas RAM-BSA (Restricted Access Medium Bovine Serum Albumin) acopladas a la cromatografía líquida para la detección de residuos de antibióticos betalactámicos en la leche (Oliveira y Cass, 2006; Oliveira et al., 2007). Estas columnas se acoplan "en línea" al sistema cromatográfico y retienen en su interior la fase proteica y otras macromoléculas presentes en la matriz.

Estos métodos han sido empleados para la determinación de cefalosporinas mostrando buenos límites de detección por debajo de los LMR de los analitos y porcentajes de recuperación muy elevados (90,7-104\%).

Todas las técnicas representadas en el Cuadro 8 son adecuadas para la detección de algunas sustancias betalactámicas, en especial para las penicilinas. Sin embargo, estos métodos no son una herramienta fiable para la confirmación inequívoca de compuestos, por lo que en los últimos años se han desarrollado numerosos métodos LC acoplados a espectrómetros de masas.

Estos detectores mejoran en algunos casos la sensibilidad y selectividad de la detección y permiten la identificación de un mayor número de compuestos o antibióticos betalactámicos en la leche. El Cuadro 9 resume los principales trabajos realizados por diferentes autores donde se emplean este tipo de detectores.

A partir de los datos presentados en el Cuadro 9 se puede deducir que las técnicas cromatográficas acopladas a detectores de masas representan una herramienta sensible y muy selectiva para la identificación y cuantificación de residuos de antibióticos betalactámicos en la leche, sin necesidad de realizar numerosos pasos previos de purificación de la muestra.

La mayoría de las técnicas descritas emplean una extracción simple del analito mediante la adición de reactivos y una segunda etapa de extracción en fase sólida (SPE) para realizar la desproteinización de la muestra y eliminar las interferencias de la matriz, excepto el trabajo realizado por Makeswara et al. (2005), sobre la detección del ceftiofur, que incluye en el procesamiento de la muestra, varias etapas sucesivas, incluyendo centrifugación, SPE, derivatización y SPE de intercambio catiónico.

Por otra parte, los límites de detección obtenidos por los distintos autores permiten cuantificar los residuos de antibióticos betalactámicos a concentraciones bajas siempre por debajo de los LMRs establecidos por la legislación. Los porcentajes de recuperación también son adecuados con valores dentro del intervalo (70-110\%) recomendado por la Decisión 2002/657/CEE, excepto en dos de los estudios (Daeseleire et al., 2000; Ghidini et al., 2003), que presentan recuperaciones más bajas entre el 57$88 \%$ y $28-82 \%$ respectivamente. 


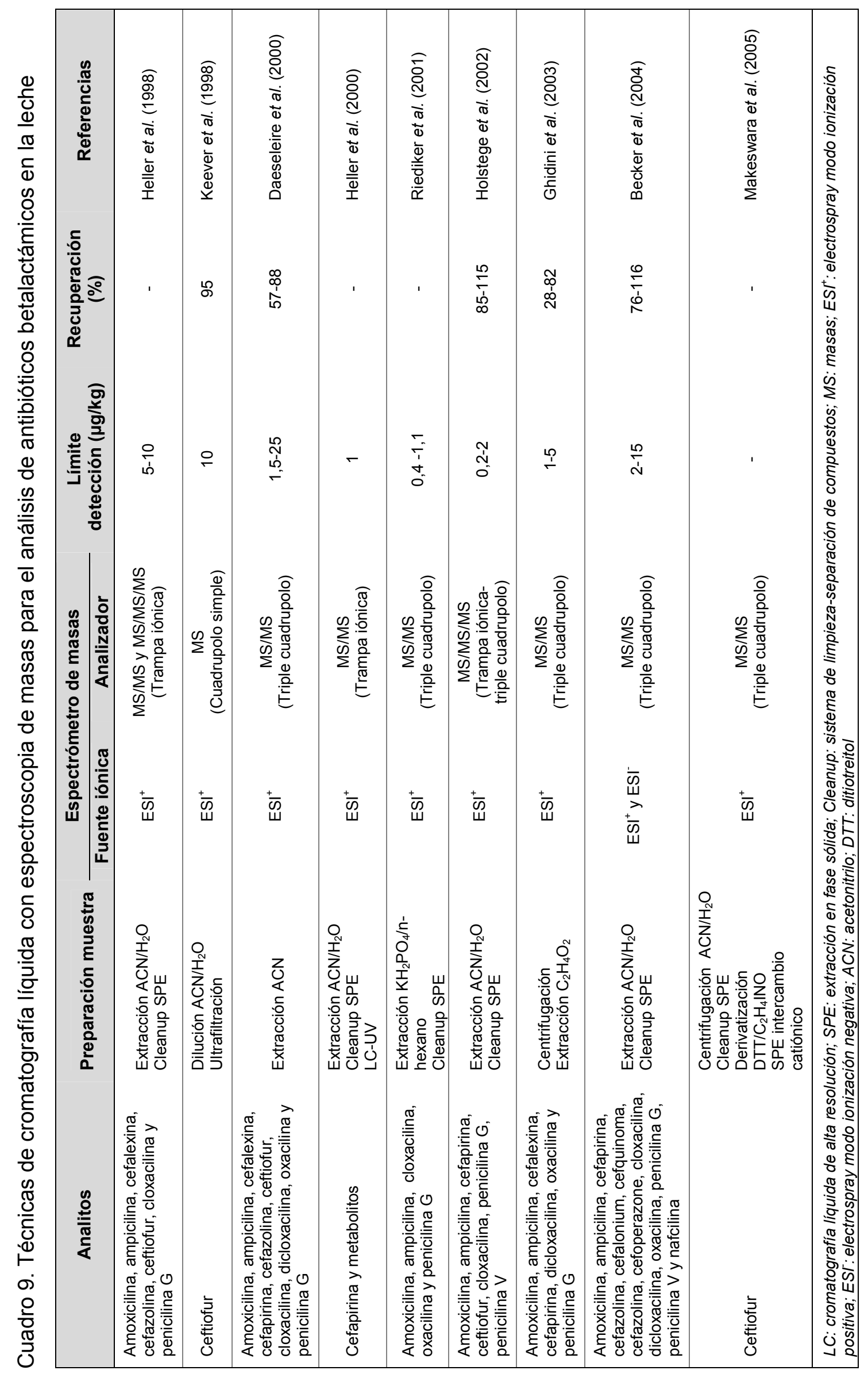




\subsubsection{Tetraciclinas}

En el caso de las tetraciclinas, las técnicas de identificación y cuantificación más utilizadas tradicionalmente son las que combinan la cromatografía líquida con detectores de fluorescencia, ultravioleta y fotodiodos (Carson y Breslyn, 1996; Kaale et al., 2007). Los principales trabajos realizados por diferentes autores sobre el uso de técnicas cromatográficas con este tipo de detectores para el análisis de tetraciclinas en la leche, se resumen en el Cuadro 10.

Como se observa en dicho Cuadro, muchos de los métodos empleados utilizan como "cleanup" una extracción en fase sólida antes del análisis cromatogáfico (Brandsteterová et al., 1997; Furusawa, 2003; Cinquina et al., 2003; Fritz et al., 2007; Samanidou et al., 2007). Sin embargo, otros autores han investigado sobre técnicas "cleanup" como la utilización de agentes quelantes y columnas MCAC (Metal Chelate Affinity) (Carson y Breslyn, 1996; Ruela et al., 2005), o el sistema MSPD de dispersión en fase sólida (Brandsteterová et al., 1997). En ambas técnicas se obtienen buenos límites de detección para las distintas tetraciclinas con valores entre 10 y $40 \mu \mathrm{g} / \mathrm{kg}$ y porcentajes de recuperación entre el $60-110 \%$.

En la mayoría de los trabajos presentados, los detectores de luz ultravioleta (UVvisible y PDA) son los más empleados, ya que estas técnicas son simples, no requieren de equipamientos complejos y disponen de la sensibilidad suficiente para determinar residuos de tetraciclinas en la leche por debajo de sus LMRs. Además resultan métodos suficientemente rápidos como para procesar un gran número de muestras en un solo día (Moats y Harik-Khan, 1996).

Por otro lado, Spisso et al. (2007), utilizaron un detector de fluorescencia para la determinación de tetraciclinas, mediante derivatización post-columna de la muestra, obteniendo un límite de detección entre un 5 y $35 \mu \mathrm{g} / \mathrm{kg}$ y unos porcentajes de recuperación entre el 61 y $115 \%$.

Actualmente se están introduciendo junto a estas técnicas, algunos métodos de confirmación por espectrocopía de masas. Los trabajos más destacados de la revisión bibliográfica que se han encontrado se presentan en el Cuadro 11.

La mayoría de estos métodos utilizan una fuente iónica $\mathrm{ESI}^{+}$y un espectrómetro de masas con analizador simple cuadrupolo (Koesukwiwat et al., 2007; Martins-Júniors et al., 2007) o analizador MS/MS de triple cuadrupolo (Andersen et al., 2005; Zhang et al., 2005; De Ruyck y de Rieder, 2007), excepto Carson et al. (1998) que emplean una fuente conocida como "haz de partículas" (particle beam). 


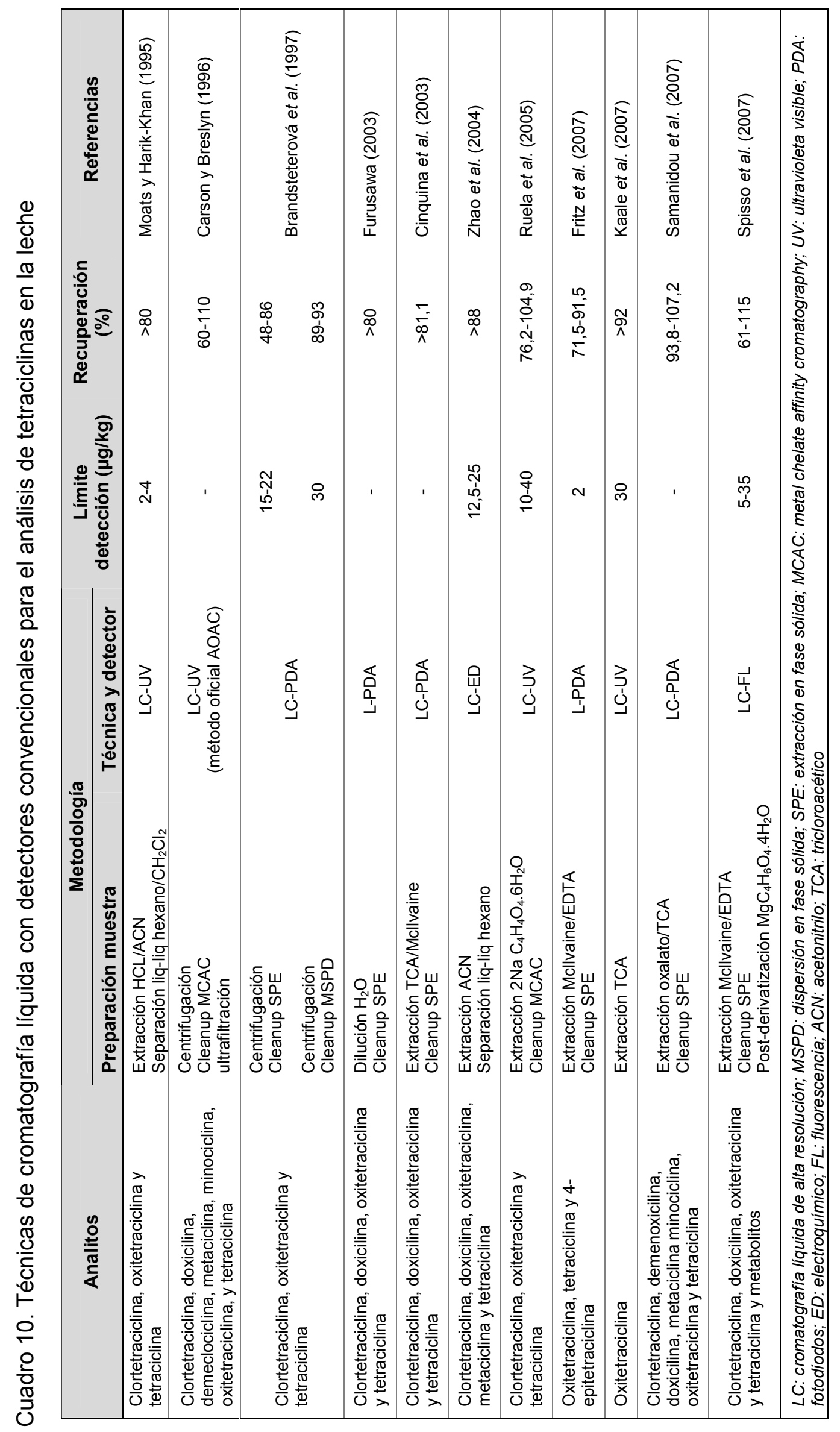




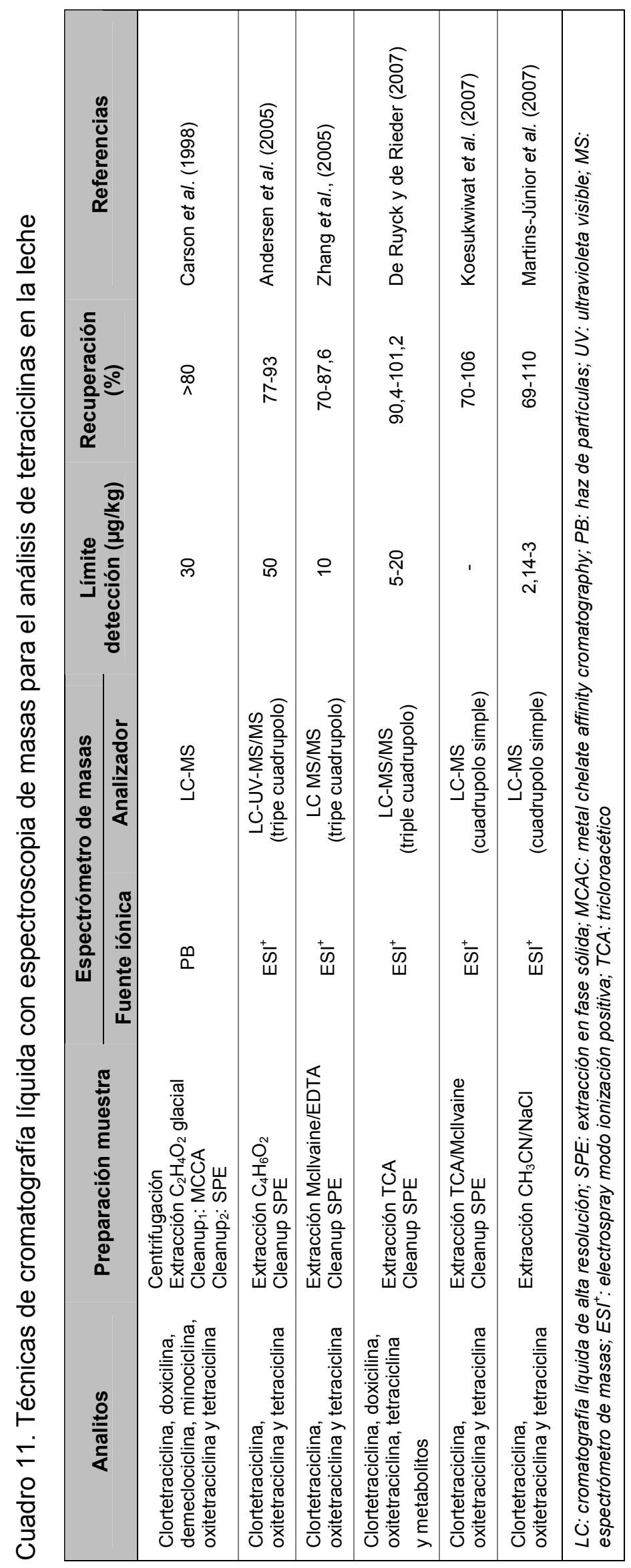


La metodología empleada en las técnicas LC-MS para la purificación del analito de la muestra de leche se realiza de una forma sencilla, en una o dos etapas consistentes en una extracción mediante la adición de reactivos y un "cleanup" SPE. Sin embargo en el estudio realizado por Carson et al. (1998), la extracción del analito fue más complicada ya que requirió de varias etapas "Cleanup", una MCAC (columnas de afinidad metálica) y otra SPE antes del análsis cromatográfico.

Los límites de detección obtenidos por los diferentes autores fueron adecuados en todos los casos, siempre con valores inferiores al LMR establecido por la UE para las tetraciclinas $(100 \mu \mathrm{g} / \mathrm{kg})$. También, los porcentajes de recuperación indicados presentaron valores acordes con el intervalo (70-110\%) recomendado por la legislación.

\subsubsection{Sulfonamidas}

En cuanto a los sistemas cromatográficos empleados para la determinación de sulfonamidas en la leche, se han publicado en los últimos años algunos trabajos que combinan la cromatografía líquida con detectores convencionales y espectroscopia de masas.

En los estudios que se presentan en el Cuadro 12 se observa la diversidad de métodos analíticos que existen para la determinación de sulfonamidas en la leche, destacando aquellos que emplean detección ultravioleta UV y PDA (Furusawa y Kishida, 2001; Pérez et al., 2002; Kishida y Furusawa, 2004; Yang et al., 2004; De Zayas-Blanco et al., 2004; When et al., 2005).

Estos métodos necesitan de una fase previa de preparación de la muestra para eliminar las interferencias de la matriz en el posterior análisis cromatográfico, empleando diferentes extracciones con reactivos, "cleanup" SPE o MSPD y ultrafiltración.

Por lo general, las características de funcionamiento de estos métodos presentaron buenos valores de detección (por debajo de los LMR de la UE) y elevados porcentajes de recuperación, excepto en el trabajo presentado por When et al. (2005), donde se indica una recuperación para uno de los analitos en estudio del 45\%.

Algunos autores utilizan la detección por fluorescencia para la detección de sulfonamidas (Viñas et al., 1996; Eder et al., 1997) empleando una derivatización pre o post-columna mediante la adición de reactivos (OPA, ME o fluorescamina) a la muestra purificada para formar moléculas fluorescentes y detectables con gran sensibilidad y selectividad. 


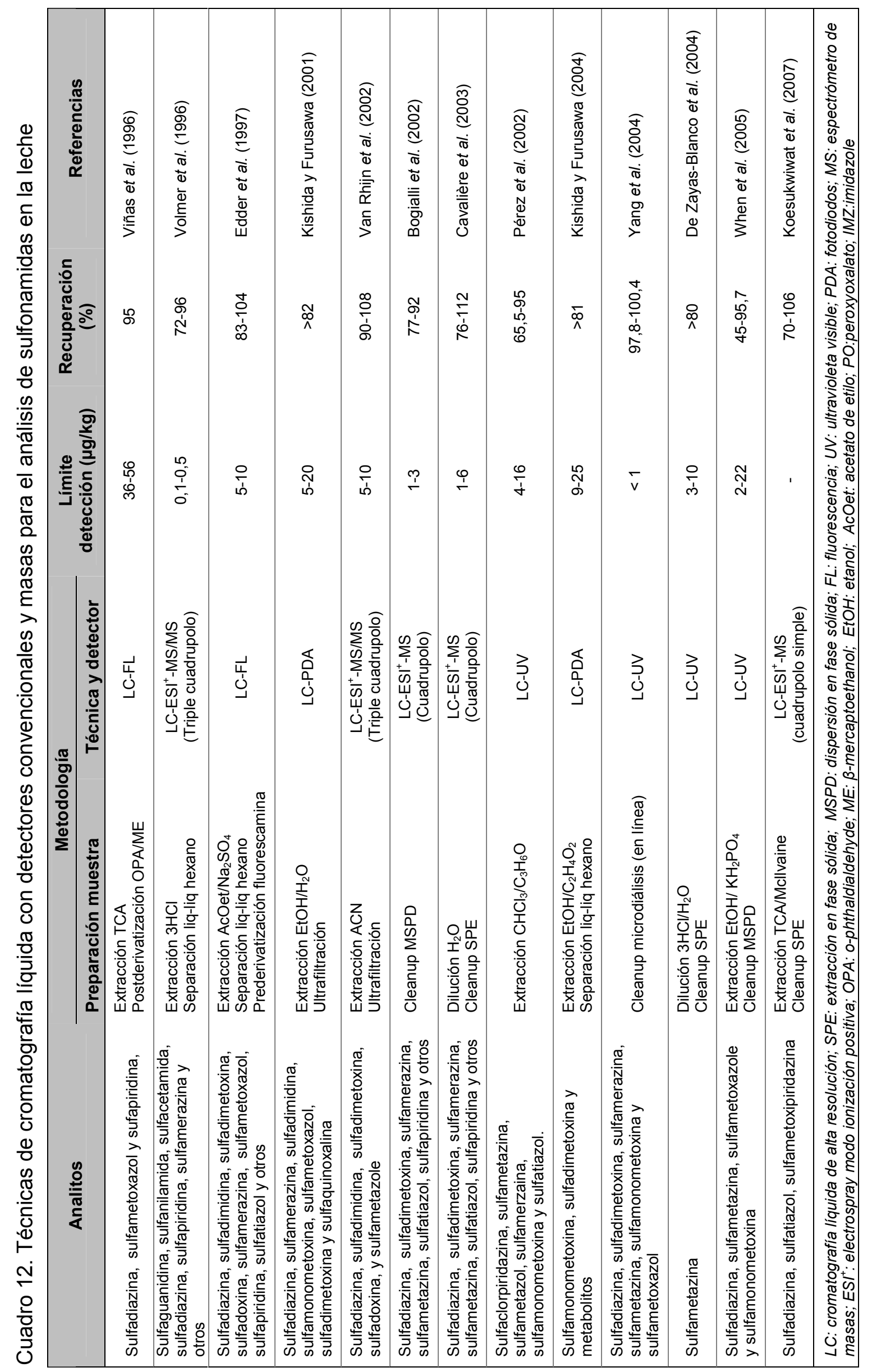


También se han empleado diferentes técnicas de detección espectrométrica de masas, con fuentes de ionización por electrospray positiva y analizador simple (Bogialli et al., 2002; Cavalière et al., 2003; Koesukwiwat et al., 2007) o triple cuadrupolo (Volmer et al., 1996; Van Rhijn et al., 2002).

Estos métodos presentan altas sensibilidades para la detección de sulfonamidas en la leche con límites de detección entre el 0,1 y $10 \mu \mathrm{g} / \mathrm{kg}$ y porcentajes de recuperación dentro del intervalo recomendado por la Decisión 657/2002/CEE.

\section{TERMOESTABILIDAD DE LAS SUSTANCIAS ANTIMICROBIANAS}

\subsection{GENERALIDADES}

\subsubsection{Estabilidad de los medicamentos en disolución}

La mayoría de los estudios realizados para determinar la estabilidad de los medicamentos están basados en la viabilidad de nuevas sustancias y productos farmacéuticos bajo condiciones de estrés térmico, $\mathrm{pH}$, almacenamiento, etc. Actualmente existen una serie de guías destinadas a las industrias farmacéuticas donde se recomiendan las pautas a seguir para la evaluación de la estabilidad de estos medicamentos (FDA, 2003 y 2004).

Respecto a los diferentes aspectos relativos a la estabilidad de los medicamentos en disolución, algunos son especialmente importantes en el ámbito de la tecnología farmacéutica como es el caso de los procesos de degradación química de principios activos que han sido objeto de numerosos estudios (Aulton, 2004).

Los trabajos que evalúan los procesos de degradación de fármacos en disolución, recurren con frecuencia al empleo de la cinética química (Grimm, 1995; Chow y Ki, 1997), ya que sus leyes y teorías proporcionan una base firme para la aplicación de modelos cinéticos a los problemas farmacéuticos relacionados con las reacciones químicas.

Las ecuaciones cinéticas aportan la información capaz de proporcionar una idea aproximada de los cambios producidos y permiten además predecir la magnitud con que se producirán, cuando haya transcurrido un período de tiempo determinado.

Resulta claro, sin embargo, que "estabilidad" no es sinónimo de "cinética química", a pesar de que en la mayoría de los procesos de degradación, la velocidad está limitada por diferentes factores, asociados a reacciones químicas o que pueden describirse por medio de una ecuación semejante a las empleadas en cinética. Por esta razón, Grimm (1995) afirma que "la aplicación de los conocimientos derivados de 
la cinética química permite una aproximación racional al problema de las reacciones de degradación de los fármacos".

Para caracterizar cuantitativamente el proceso degradativo de un fármaco, es conveniente conocer siempre el orden de reacción del proceso estudiado (Martin, 1993), debido a que se pueden encontrar diferentes situaciones donde la velocidad de degradación es constante e independiente a la concentración (reacción de "orden 0"), en otros casos es proporcional a la concentración (reacción de " $1^{\text {er }}$ orden") y por último, puede depender de la concentración de varios reactivos (reacción de " $2^{\circ}$ orden").

Con el fin de comparar la estabilidad de un mismo fármaco sometido a condiciones variables de $\mathrm{pH}$ y/o temperatura, evaluar el efecto de otros componentes de la formulación, o la estabilidad de varios principios activos que se encuentran en unas mismas condiciones, se emplea frecuentemente el concepto de "semivida" $\left(t_{1 / 2}\right) o$ tiempo de vida media (York, 1992; Chen et al., 1997), que se define como el tiempo requerido para que la concentración de analito se reduzca a la mitad de su valor original $\left(\mathrm{C}=\mathrm{C}_{0} / 2\right)$.

Las expresiones del tiempo de vida media en términos de constante de velocidad " $k$ ", difieren en función de la cinética a la que se ajuste la reacción. En el Cuadro 13 se resumen los parámetros para los procesos de orden cero, primer y segundo orden.

Cuadro 13. Parámetros relativos a los órdenes de reacción

\begin{tabular}{|cccc|}
\hline \multirow{2}{*}{ Parámetros } & \multicolumn{3}{c|}{ Orden } \\
\cline { 2 - 4 } & $\mathbf{0}$ & $\mathbf{1}^{\mathrm{er}}$ & $\mathbf{2}^{\mathbf{0}}$ \\
\hline Ecuación lineal & $\mathrm{C}=\mathrm{C}_{0}-\mathrm{kt}$ & $\mathrm{Ln} \mathrm{C}=\ln \mathrm{C}_{0}-\mathrm{kt}$ & $1 / \mathrm{C}=1 / \mathrm{C}_{0}+\mathrm{kt}$ \\
Intersección & $\mathrm{C}_{0}$ & $\mathrm{Ln} \mathrm{C}_{0}$ & $1 / \mathrm{C}_{0}$ \\
Pendiente & $-\mathrm{k}$ & $-\mathrm{k}$ & $\mathrm{k}$ \\
Semivida $\left(\mathrm{t}_{1 / 2}\right)$ & $\mathrm{C}_{0} / 2 \mathrm{k}$ & $\mathrm{Ln} 2 / \mathrm{k}$ & $1 / \mathrm{C}_{0} \mathrm{k}$ \\
\hline
\end{tabular}

Fuente: Aulton (1998)

\subsubsection{Factores que afectan a la estabilidad de los medicamentos en disolución}

La temperatura, es uno de los principales factores que puede afectar a la estabilidad de los medicamentos en disolución, además de la fuerza iónica y la naturaleza del disolvente, el $\mathrm{pH}$, la humedad, la luz, el oxígeno y la presencia de sales, entre otros (Connors et al., 1994; Carstensen y Rhodes, 2000). 
Las constantes de velocidad de reacción dependen, sustancialmente, de la temperatura y normalmente aumentan con ella. Una regla aproximada, válida para muchas reacciones en disolución, considera que cerca de la temperatura ambiente, el valor de la constante de velocidad " $\mathrm{k}$ " se duplica o triplica por cada $10^{\circ} \mathrm{C}$ que aumente la temperatura (Dukes, 1984; Chou y Shao, 2003).

A menudo, la aceleración de la reacción a causa de la temperatura sigue la teoría de Arrhenius (Ash y Ash, 1995), cuya ecuación relaciona la constante de velocidad con la temperatura de la siguiente forma:

$$
\mathrm{k}=\mathrm{A} \mathrm{e}^{-\mathrm{Ea} / \mathrm{RT}} \quad \mathrm{o} \ln \mathrm{k}=\ln \mathrm{A}-\mathrm{Ea} / \mathrm{RT}
$$

En esta expresión, "A" es una constante denominada "factor de frecuencia" o "frecuencia de choques", "Ea" es la energía de activación del proceso, "R" la constante de los gases perfectos $(8,3143 \mathrm{~J} / \mathrm{kmol})$ y "T" la temperatura absoluta ( ${ }^{\circ} \mathrm{K}$ ).

El cumplimiento de la ecuación de Arrhenius permite obtener una relación lineal cuando se representa el logaritmo de la velocidad de reacción en función de la inversa de la temperatura absoluta. En este caso, se puede asumir que el mecanismo de degradación del principio activo en disolución es constante en un intervalo de temperaturas y se puede calcular la energía de activación a partir de la pendiente.

A partir del modelo de Arrhenius se puede calcular la velocidad de reacción a cualquier temperatura y predecir por extrapolación el periodo de caducidad de los medicamentos a temperatura ambiente $u$ a otras temperaturas de almacenamiento $o$ procesado.

\subsection{EFECTO DE LA TEMPERATURA SOBRE LA ESTABILIDAD DE LAS SUSTANCIAS ANTIMICROBIANAS EN LA LECHE}

\subsubsection{Consideraciones previas}

Los alimentos de origen animal, en general, no son consumidos en estado original, sino que previamente son tratados térmicamente, mediante el cocinado doméstico o diferentes tratamientos industriales, sometidos a procesos de curado 0 fermentación, o bien conservados a bajas temperaturas hasta su utilización.

Los posibles residuos de agentes antimicrobianos presentes en los alimentos destinados al consumo pueden sufrir por lo tanto una degradación o pérdida de acción antimicrobiana por acción de las temperaturas durante los procesos de 
almacenamiento de las materias primas alimentarias o los tratamientos térmicos industriales empleados en el acondicionamiento de los alimentos para su consumo.

También en el caso de las muestras de alimentos necesarias para los diferentes controles oficiales y obligatorios, así como en los autocontroles, las temperaturas y el tiempo de almacenamiento de las muestras hasta su análisis pueden influir en las pérdidas de acción antimicrobiana. Igualmente pueden ocasionar pérdidas los tratamientos térmicos utilizados en los protocolos de análisis en los laboratorios.

Para el caso concreto de la leche, es importante resaltar que ésta se somete a diferentes temperaturas (bajas y altas) a lo largo de toda la cadena de producción, desde la granja hasta el consumidor o hasta el laboratorio de análisis.

Una vez se recoge la leche en la granja, ésta se mantiene refrigerada a una temperatura entre 4 y $6^{\circ} \mathrm{C}$, o hasta $8^{\circ} \mathrm{C}$ si la recogida es diaria y/o se usa conservante (RD 1728/2007), hasta su llegada a la industria donde se almacena en grandes silos refrigerados, hasta su posterior procesado.

También las muestras obtenidas en granjas y cisternas para comprobar la calidad higiénico-sanitaria de la leche, se envían a los laboratorios de análisis manteniendo la cadena de frío, donde pueden ser analizadas en el momento de su recepción o permanecer refrigeradas horas e incluso días antes de su análisis. En algunos casos las muestras de leche pueden ser congeladas hasta ser procesadas 0 empleadas en el caso de resultados dudosos, confirmación de resultados, etc.

Por otro lado, la leche se somete también a diferentes tratamientos térmicos a temperaturas elevadas, tanto en la industria láctea para asegurar la calidad y conservación de la leche, como en los laboratorios de control de calidad donde es calentada con el fin de facilitar el manejo de la muestra a analizar o evitar posibles interferencias en el análisis de algunos componentes.

Tanto las condiciones de refrigeración y congelación de las muestras durante el transporte y su conservación en el laboratorio, como los tratamientos térmicos a temperaturas elevadas, pueden producir una degradación, inactivación o pérdida de actividad antimicrobiana sobre algunas moléculas presentes en la leche.

Por ello, la Decisión 2002/657/CEE sobre el funcionamiento de métodos analíticos e interpretación de resultados, especifica que una de las características comunes de funcionamiento de un método para su validación, es la determinación de la estabilidad del analito tanto en las soluciones patrón como en la matriz empleada, en condiciones de refrigeración $\left(4^{\circ} \mathrm{C}\right)$, congelación $\left(-20^{\circ} \mathrm{C}\right)$ y temperatura ambiente $\left(20^{\circ} \mathrm{C}\right)$. 
Por otra parte, es importante resaltar que los componentes formados tras los procesos térmicos pueden producir respuestas alérgicas en las personas sensibilizadas, aunque la actividad antimicrobiana de dichos residuos se haya disminuido e inclusive destruido. Este hecho es conocido en el caso de las penicilinas donde se ha observado que muchos individuos alérgicos presentaron una respuesta tanto a los componentes originales como a los penicilinatos inactivos (Sullivan et al., 1981).

A lo largo del tiempo, son varios los autores que han estudiado la influencia de los tratamientos térmicos de calor y condiciones de almacenamiento en frío sobre la estabilidad y degradación de sustancias antimicrobianas presentes en diferentes matrices alimentarias.

Moats (1988), realizó una revisión bibliográfica sobre la inactivación de los antibióticos debida al calor, en diferentes alimentos (leche y carne), agua y soluciones tampón, que después actualizó años más tarde (Moats, 1999). En estas dos revisiones, este autor concluyó que los procedimientos más usuales para el tratamiento de los alimentos, no garantizan la inactivación completa de los residuos de antibióticos, incluso la de aquellos componentes más termosensibles. Sin embargo, temperaturas muy elevadas durante largos periodos de tiempo pueden inactivar algunos de los compuestos más sensibles, por lo que considera necesario realizar más estudios que analicen el efecto de distintos tratamientos térmicos sobre la degradación de antibióticos presentes en alimentos.

También, Haagsma (1993) efectuó una recopilación de trabajos sobre la estabilidad de los medicamentos veterinarios durante el almacenamiento, la preparación y el procesado de los alimentos de origen animal. El citado autor concluye que el contenido en residuos de la mayoría de los medicamentos veterinarios decrece como resultado de la preparación y procesado de los alimentos, y también durante su almacenamiento en refrigeración y congelación.

A su vez, Ghidini (1999) analiza la estabilidad de las moléculas de antibióticos y otros quimioterapeúticos en los alimentos durante su preparación a partir de los trabajos efectuados por otros autores. En esta revisión se indica que los tratamientos que sufren los alimentos antes de ser consumidos inducen modificaciones moleculares relacionadas con la pérdida de su actividad farmacológica, pero que a su vez, los metabolitos o degradados formados durante los procesos, pueden, o no, modificar también su peligrosidad toxicológica. 
También en la anterior revisión se indica el limitado número de trabajos que estudian la influencia de los tratamientos térmicos sobre la actividad y los productos de degradación de los residuos de antimicrobianos en los alimentos.

Por último, Botsoglou y Fletouris (2001) realizaron una recopilación bibliográfica sobre la estabilidad de los residuos de medicamentos veterinarios durante el procesamiento de los alimentos, señalando la necesidad de revisión, por parte de las autoridades responsables de los programas de control de residuos en alimentos, de los protocolos de muestreo, envío y condiciones de transporte de las muestras hasta el laboratorio.

Hay que señalar que la mayor parte de los trabajos comentados anteriormente en las respectivas revisiones, utilizan para la determinación de los antimicrobianos en estudio, métodos de detección basados en ensayos microbiológicos o algunas técnicas cromatográficas de separación que no son capaces de cuantificar con demasiada precisión los procesos de degradación estudiados.

La importancia que tiene para la Seguridad Alimentaria la posible inactivación térmica de los residuos de antimicrobianos en los alimentos, plantea la necesidad de llevar a cabo un estudio que evalúe el efecto que causan las temperaturas sobre esta inactivación.

En los apartados siguientes se profundiza en el estudio de la influencia que pueden tener las temperaturas empleadas en el almacenamiento o en los tratamientos térmicos empleados en los laboratorios e industrias lácteas, sobre los residuos de antimicrobianos pertenecientes a los grupos de betalactámicos, tetraciclinas y sulfonamidas, presentes en la leche, y en algunos casos en otras matrices alimentarias.

\subsubsection{Estabilidad de los antimicrobianos durante el almacenamiento}

\subsubsection{Antibióticos betalactámicos}

Las penicilinas, y en general, el resto de antibióticos betalactámicos, son relativamente inestables en solución acuosa, y altamente propensos al ataque de su núcleo peniciloico. Esta estabilidad depende del $\mathrm{pH}$ de la solución, y su degradación se cataliza tanto por ácidos como por bases (Hou y Poole, 1971). A pH 2,6 los betalactámicos ácido-lábiles como penicilina G, meticilina, y nafcilina, desaparecen casi totalmente, mientras que los compuestos ácido-resistentes como penicilina $\mathrm{V}$ y las isoxazolyl-penicilinas permanecen inalteradas (Pelz, 1992). 
Esta inestabilidad acuosa de los betalactámicos no sólo tiene consecuencias importantes para las condiciones de extracción, determinaciones cromatográficas y conservación de las soluciones de referencia (patrones) en determinados análisis, sino también para la estabilidad de los residuos (analitos) durante el almacenamiento de muestras biológicas hasta su análisis.

Así, Wiese y Martin (1989a) demostraron que las soluciones de penicilina G eran rápidamente degradadas bajo condiciones de $\mathrm{pH}$ bajo y alto, mientras que permanecían bastante estables a valores de $\mathrm{pH}$ comprendidos entre 5,0 y 9,0.

Okerman et al. (2007) investigaron la estabilidad de soluciones patrón de antibióticos betalactámicos y otros antimicrobianos bajo condiciones de congelación, analizando mensualmente alícuotas de cada solución durante un periodo de 6 meses. Los resultados obtenidos mostraron que la ampicilina fue la solución más estable mostrando pérdidas inferiores al $10 \%$ a los 6 meses, mientras que la amoxicilina y la penicilina perdieron aproximadamente el $50 \%$ y el ceftiofur más de la cuarta parte de su concentración inicial.

Por otra parte, es importante resaltar que la mayoría de los trabajos acerca del efecto del almacenamiento sobre los residuos de betalactámicos en alimentos, se han centrado en el análisis de la penicilina G, en matrices alimentarias de origen animal como el hígado, riñón o músculo, y en menor medida en la leche.

Wiese y Martin (1989c) investigaron, por ejemplo, la estabilidad de la penicilina $\mathrm{G}$ en muestras de plasma bovino que fueron mantenidas en armarios congeladores a temperaturas de $-20^{\circ} \mathrm{C}$. Los resultados mostraron un tiempo de "vida-media" para la penicilina $\mathrm{G}$ a esta temperatura de 75 días.

En contraposición con las muestras de plasma adicionadas artificialmente, los residuos en plasma bovino obtenidas tras el tratamiento de los animales con penicilina G, mostraron una tasa de degradación más lenta. En este caso, el período de "semi desintegración" fue calculado en 276 días para un almacenamiento a $-20{ }^{\circ} \mathrm{C}$ (Boison et al., 1992).

Este mismo autor mostró también que los residuos de penicilina incorporados en tejidos postratamiento y conservados a $-20^{\circ} \mathrm{C}$ disminuyeron más rápidamente que en plasma. Pérdidas de hasta un $20 \%$ fueron observadas en muestras de riñón e hígado cuando se conservaron a $-20^{\circ} \mathrm{C}$ después de tan sólo 10 días. Por otro lado, las muestras de músculo glúteo guardadas a la misma temperatura mostraron pérdidas de casi $50 \%$ del residuo presente inicialmente dentro de los 10 días de almacenamiento. 
A conclusiones análogas han llegado otros investigadores (Gee et al., 1996) que estudiaron la estabilidad de dos tipos de residuos de penicilina $\mathrm{G}$ (adicionados a las muestras y postratamiento) en hígado ovino, durante su almacenamiento a $-20{ }^{\circ} \mathrm{C}$ durante un tiempo de 3 meses. El período medio de semi-desintegración de penicilina G se calculó en 62 días para los tejidos adicionados y en 71 días para los tejidos obtenidos después del tratamiento.

Otros autores, Verdon et al. (2000), estudiaron la degradación de la ampicilina en muestras de músculo porcino almacenado a $-75^{\circ} \mathrm{C}$ a lo largo de 8 meses. Los resultados obtenidos no mostraron diferencias significativas en la concentración de analito presente en las muestras a lo largo del tiempo. Sin embargo, este mismo estudio mostró una degradación de la ampicilina en muestras conservadas a $-20^{\circ} \mathrm{C}$ a partir de los tres meses de almacenamiento.

En lo que se refiere a la estabilidad de penicilina $G$ y otros betalactámicos durante el almacenamiento de la leche cruda, los trabajos son muy limitados y son los que se comentan a continuación.

Haagsma (1993), demostró que aproximadamente el $60 \%$ de penicilina $G$ en leche se destruye dentro de las $48 \mathrm{~h}$ a $2{ }^{\circ} \mathrm{C}$, y que esta cifra de pérdida de actividad alcanza el $75 \%$ cuando la temperatura de conservación empleada es de $22{ }^{\circ} \mathrm{C}$. Además, la adición de la enzima beta-lactamasa a las muestras de leche incrementó aún más la pérdida de actividad de la penicilina, hecho que también queda reflejado en un trabajo anterior sobre la influencia de esta enzima en la presencia de penicilina $G$ (Guay et al., 1987).

Por el contrario, otros autores (Wiese y Martin, 1989b) obtuvieron un residuo constante de penicilina $G$ en muestras de leche fortificadas a 20 y $100 \mu \mathrm{g} / \mathrm{kg}$, cuando las muestras se refrigeraron durante más de 6 días a $4^{\circ} \mathrm{C}$. De un modo similar, muestras con $20 \mu \mathrm{g} / \mathrm{kg}$ de ampicilina y almacenadas a 4 y $-70{ }^{\circ} \mathrm{C}$, no presentaron pérdidas significativas del analito aún después de los 6 días de almacenamiento.

El efecto del almacenamiento a $4{ }^{\circ} \mathrm{C}$ y $-70{ }^{\circ} \mathrm{C}$, sobre la estabilidad de la ampicilina en leche mediante una técnica LC-FL, fue estudiado por Schenk et al. (2000). Estos autores no obtuvieron ninguna pérdida significativa en la concentración de ampicilina bajo ninguna de las dos condiciones de almacenamiento durante 6 días.

En un estudio más reciente, Riediker et al. (2004), estudiaron la estabilidad de 4 betalactámicos (amoxicilina, cloxacilina, oxacilina y penicilina $G$ ) en muestras y extractos de leche conservados a bajas temperaturas, mediante LC-ESI-MS/MS. Los resultados obtenidos para las muestras de leche indicaron una degradación para los 4 
analitos en refrigeración superior al $50 \%$ tras 7 días de conservación, y una degradación total a los 28 días. En cuanto a la congelación de las muestras de leche, también se observó una ligera degradación de la cloxacilina, oxacilina y penicilina G, en muestras almacenadas a $-20^{\circ} \mathrm{C}$ a partir de los tres días, sin embargo no se observó ninguna pérdida cuando las muestras se conservaron a $-76^{\circ} \mathrm{C}$.

Por el contrario, los resultados obtenidos en los extractos de leche, indicaron que los 5 analitos se mantuvieron estables durante el almacenamiento en un periodo superior a 14 días. Únicamente se observó una ligera pérdida de concentración de aproximadamente el $15 \%$ a los 28 días de refrigeración en todos los analitos, excepto en la amoxicilina. En cuanto a la congelación de los extractos, no se observó ninguna pérdida significativa tanto a - 20 como a $-76^{\circ} \mathrm{C}$.

A modo de ejemplo en la Figura 14 se presentan los resultados obtenidos por Riediker et al. (2004) para la penicilina G, en muestras y extractos de leche refrigerados a $4{ }^{\circ} \mathrm{C}$, expresados como la respuesta media del ratio (penicilina/azlocilina).

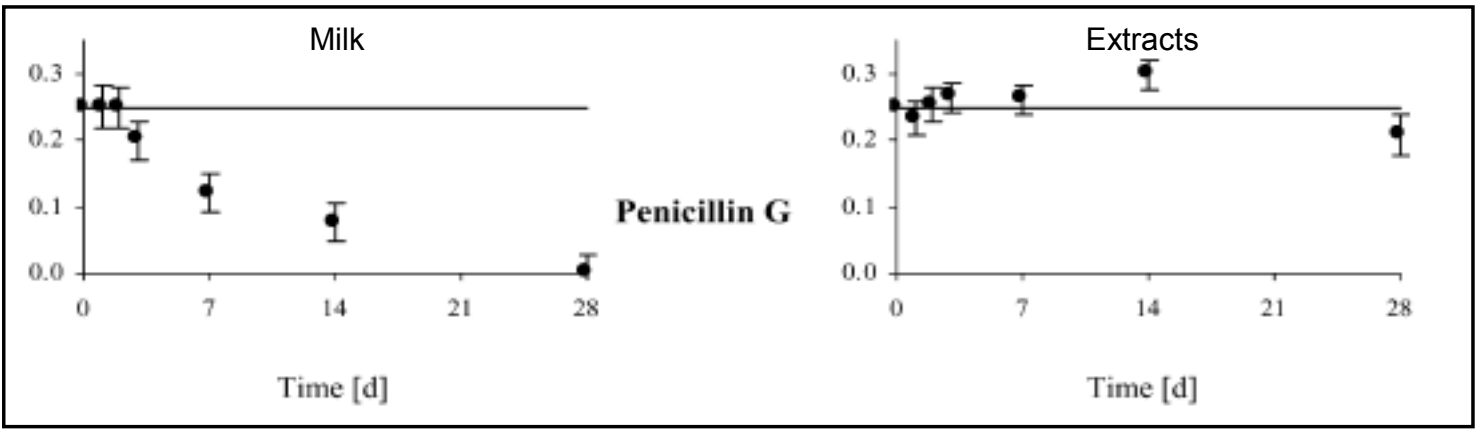

Figura 14. Variación de la concentración de penicilina $G$ en muestras y extractos de leche refriferados

Fuente: Riediker et al. (2004)

En este estudio los resultados se presentan como las señales de las áreas de los analitos normalizadas con el área del patrón interno azlocilina y como se observa en la Figura, la penicilina $G$ en muestras de leche se degrada totalmente a los 28 días de refrigeración mientras que el extracto correspondiente se mantiene prácticamente estable durante ese mismo periodo.

\subsubsection{Tetraciclinas}

El efecto de las temperaturas y condiciones de almacenamiento sobre la presencia de tetraciclinas en soluciones acuosas y otras matrices alimentarias como la leche, ha sido analizado por muy pocos autores. 
La oxitetraciclina presenta una limitada estabilidad en soluciones acuosas, donde se ha observado que su hidrólisis sigue un modelo cinético de "primer-orden". La estabilidad máxima de esta molécula se observa a $\mathrm{pH} 2$, mientras que la estabilidad óptima se sitúa entre un $\mathrm{pH}$ de 1 a 3 . Esto explica la conclusión de un estudio realizado por Kitts et al. (1992) al establecer que oxitetraciclina es más estable al calor a $\mathrm{pH} 3$ que a $\mathrm{pH} 6,9$.

Recientemente Okerman et al. (2007), estudiaron la estabilidad de patrones puros de clortetraciclina, doxicilina, oxitetraciclina y tetraciclina en congelación a una temperatura de $-20{ }^{\circ} \mathrm{C}$, analizando muestras mensualmente durante un total de 6 meses. Estos autores obtuvieron una pérdida de concentración menor del 10\% para la clortetraciclina y la doxicilina y del $25 \%$ en el caso de la oxitetraciclina y tetraciclina, después de los 6 meses de congelación.

En lo que se refiere a matrices alimentarias, O' Brien et al. (1981), obtuvieron mínimas pérdidas de actividad de la oxitetraciclina durante el almacenamiento de muestras de hígado, músculo y riñón a 4 y $-20{ }^{\circ} \mathrm{C}$ durante tres días consecutivos de almacenamiento.

Por otra parte, Doneva (1988), obtuvo pérdidas en la concentración de tetraciclina a los 12 días de refrigeración $\left(4^{\circ} \mathrm{C}\right)$ del $38-42 \%$ y $52 \%$ en muestras de músculo e hígado de pollo respectivamente.

En esta misma línea, otros autores (lonkova et al., 1994) estudiaron la influencia de la congelación a $-18^{\circ} \mathrm{C}$ durante 12 meses sobre la presencia de residuos de tetraciclinas en músculo e hígado de pato, mediante un método microbiológico. Los resultados de este estudio mostraron que los residuos de tetraciclinas en músculo e hígado desparecieron a los 9 y 12 meses de congelación respectivamente.

A su vez, autores como Podhorniak et al. (1999) evaluaron la estabilidad de las tetraciclinas bajo condiciones de almacenamiento de la leche. Para ello, fortificaron las muestras de leche con $50 \mu \mathrm{g} / \mathrm{kg}$ de tetraciclinas y las analizaron por HPLC después de ser mantenidas a 4 y $25^{\circ} \mathrm{C}$ durante 24,48 y 72 horas. No se observaron pérdidas de actividad de las tetraciclinas en las muestras conservadas a $4{ }^{\circ} \mathrm{C}$ durante 48 horas o a $25^{\circ} \mathrm{C}$ durante 24 horas. Sin embargo, las pérdidas se encontraron en los rangos del 4$13 \%$ y $0-18 \%$ después de 72 horas a $4{ }^{\circ} \mathrm{C}$ y 48 horas a $25^{\circ} \mathrm{C}$, respectivamente.

En otro estudio realizado por Samanidou et al. (2007) sobre la validación de un método de confirmación HPLC para la determinación de 7 tetraciclinas en leche de acuerdo a la Decisión 2002/657/CEE, se estudió la estabilidad de los antibióticos en 
los extractos obtenidos y refrigerados a $4{ }^{\circ} \mathrm{C}$ en la oscuridad, concluyendo que bajo estas condiciones, solo fueron estables durante una semana de almacenamiento.

Recientemente, Spisso et al. (2007), evaluaron también la estabilidad de la clortetraciclina, oxitetraciclina y tetraciclina en muestras de leche de oveja mediante un método LC-FL. Las muestras de leche se almacenaron a -20 y $-70{ }^{\circ} \mathrm{C}$ y se analizaron los días $0,6,12,24$ y 30 . Los resultados obtenidos no mostraron en ningún caso pérdidas en la concentración de los analitos estudiados.

Himanish et al., 2008, en un estudio reciente sobre la estabilidad de la oxitetraciclina en leche obtienen pérdidas del 6-18\% entre las 24 y 96 horas de refrigeración e inferiores al 5\% en congelación.

\subsubsection{Sulfonamidas}

La estabilidad de los residuos de sulfonamidas durante el almacenamiento en congelación de tejidos de origen animal ha sido investigada por diferentes autores, aunque la mayoría de estos estudios se han centrado en la sulfametazina y en matrices alimentarias diferentes a la leche como hígado, músculo o riñon (Mutha et al., 1977; O'Brien et al., 1981; Giera et al., 1982; Parks, 1984 y 1985; Haagsma et al., 1985; Rose et al., 1996, Alfredsson y Ohlsson, 1998; Croubels et al., 2003).

Los primeros estudios mostraron una disminución del 10\% en los niveles de sulfametazina en muestras de hígado de ternera congelado y almacenado durante 40 días (Mutha et al., 1977). También, O'Brien et al. (1981) hallaron una pérdida del $12,6 \%$ (hígado de cerdo) y $13,9 \%$ (tejido de músculo) en residuos de sulfametazina después de 15 días de almacenamiento a $-20^{\circ} \mathrm{C}$.

Los resultados de experimentos posteriores han confirmado estas conclusiones previas y han suministrado pruebas de que esta sulfamida se transforma durante el almacenamiento al derivado N4-glucopiranosil, que es un producto de la reacción de la sulfametazina con la glucosa (Giera et al., 1982; Parks, 1984). Un decrecimiento de aproximadamente un $50 \%$ en el contenido de sulfametazina incorporada o adicionada a muestras de músculo de cerdo pudo ser encontrado después de 15 meses de almacenamiento en condiciones de congelación (Alfredsson y Ohlsson, 1998).

Por el contrario, otros investigadores no señalan pérdida alguna en la cantidad de sulfametazina en músculo de cerdo después de su almacenamiento a $-20{ }^{\circ} \mathrm{C}$ durante 21 días (Haagsma et al., 1985) o 3 meses (Rose et al., 1996). 
A pesar de las discrepancias entre estos resultados, parece claro, que en la mayoría de los estudios se ha observado una tendencia hacia la reducción de los niveles de sulfametazina durante un almacenamiento muy prolongado a $-20^{\circ} \mathrm{C}$.

A parte de sulfametazina, la estabilidad de otras sulfamidas como sulfatiazol, sulfacloropiridazina, sulfaquinoxalina, y sulfadimetoxina, en hígado de cerdo adicionado y congelado a $-20{ }^{\circ} \mathrm{C}$ durante un período de 6 meses fue evaluada por Thomas et al. (1997). En este estudio los valores de estabilidad se expresaron como tiempos de vida media, encontrándose valores de 567 días para sulfadimetoxina, 457 días para sulfametazina, 312 días para sulfacloropiridazina, 291 días para sulfatiazol y 271 días para sulfaquinoxalina, lo que indica una gran persistencia de estas sustancias bajo condiciones de congelación.

Para conseguir más información acerca del efecto de otras condiciones alternativas de almacenamiento, Thomas et al. (1997) investigaron la estabilidad de la sulfamida y sulfaquinoxalina, bajo condiciones de degradación aceleradas. Cuando muestras de tejido de hígado de cerdo adicionado con sulfaquinoxalina fueron conservadas en refrigeración a $4{ }^{\circ} \mathrm{C}$, se pudo determinar un "tiempo de vida-media" de 11 días. Aunque estos resultados indican que la sulfaquinoxalina parece ser una sulfonamida muy inestable, otro estudio realizado en hígado de cerdo adicionado y congelado mostró que esta sustancia se degradaba con un periodo de semidesintegración algo mayor, del orden de los 14 días (Millar et al., 1995).

En otro estudio, Croubels et al. (2003) no encontraron diferencias significativas en la estabilidad de la sulfacloropiridazina en muestras de hígado, músculo y riñón de cerdo en congelación a $-15^{\circ} \mathrm{C}$ durante 4 meses.

En el caso de la leche, Pereira y Cass (2005) investigaron sobre la estabilidad en refrigeración y congelación del sulfametoxazol en patrones puros y muestras de leche fortificadas a distintas concentraciones, mediante LC-RAM-UV. Los resultados obtenidos en este estudio mostraron una buena estabilidad de esta sustancia en la leche durante 24 horas a temperatura ambiente y 120 horas a $4^{\circ} \mathrm{C}$. El sulfametoxazol también se mantuvo estable a $-20^{\circ} \mathrm{C}$, a las 24,72 y 120 horas de su conservación y hasta dos meses después. En cuanto a los patrones puros, estos se mantuvieron estables durante 2 meses en refrigeración a $4^{\circ} \mathrm{C}$.

Por otra parte, Foissy et al. (2005), evaluaron la reproducibilidad de los resultados en un método microbiológico (BR-Test) en muestras de leche fortificadas con sulfonamidas y almacenadas en refrigeración a $6{ }^{\circ} \mathrm{C}$ y $-18{ }^{\circ} \mathrm{C}$. Las muestras refrigeradas se analizaron diariamente y los resultados mostraron que al segundo día 
de refrigeración los resultados de 11 de las 15 muestras analizadas no eran reproducibles. En cuanto a las muestras conservadas en congelación, 8 de éstas presentaron resultados diferentes a los del inicio del experimento a la semana de conservación, y únicamente 4 de ellas mostraron los mismos resultados a las 4 semanas.

Esta información no coincide con los resultados indicados por Papapanagiotou et al. (2005) en un estudio sobre la estabilidad de la sulfametazina en muestras de leche, sometidas a diferentes tratamientos térmicos y a temperaturas bajas de conservación y analizadas mediante una técnica LC-UV. Estos autores indicaron que la sulfametazina se mantiene estable en las muestras congeladas a $-20{ }^{\circ} \mathrm{C}$ y $-75^{\circ} \mathrm{C}$ durante 3 y 5 meses respectivamente.

Por otra parte Gaugin et al. (2005), presentan los resultados obtenidos en una evaluación europea llevada a cabo entre laboratorios nacionales de referencia por la Agencia Francesa de Seguridad Alimentaria para la evaluación de residuos de sulfonamidas en músculo y leche, donde se evaluó la estabilidad de los residuos de 3 sulfonamidas (sulfadiazina, sulfadimetoxina y sulfadoxina) en muestras de leche almacenada a $-20^{\circ} \mathrm{C}$. Los resultados interlaboratorios verificaron la estabilidad de las tres sustancias en la leche durante un periodo de 95 días.

\subsubsection{Efecto del calentamiento sobre la estabilidad de los antimicrobianos}

\subsubsection{Antibióticos betalactámicos}

Diversos autores han investigado los efectos de los tratamientos térmicos industriales o utilizados durante el cocinado doméstico, sobre los residuos de betalactámicos presentes en soluciones acuosas y/o alimentos. Especialmente se ha estudiado la estabilidad de los residuos de penicilina $G$ en los procesos de cocinado, en los tratamientos industriales de pasteurización, evaporación y procesos de secado y curado, siendo muy limitados los trabajos sobre otros antibióticos betaláctamicos.

A modo de síntesis, en el Cuadro 14 se muestran los efectos que producen los tratamientos térmicos sobre la penicilina $G$ y otros antibióticos betalactámicos, presentes en soluciones acuosas y muestras de leche, obtenidos por diferentes autores.

Es importante señalar que todos los resultados presentados en este Cuadro están basados en estudios sobre pérdidas de actividad antimicrobiana mediante bioensayos microbiológicos. 


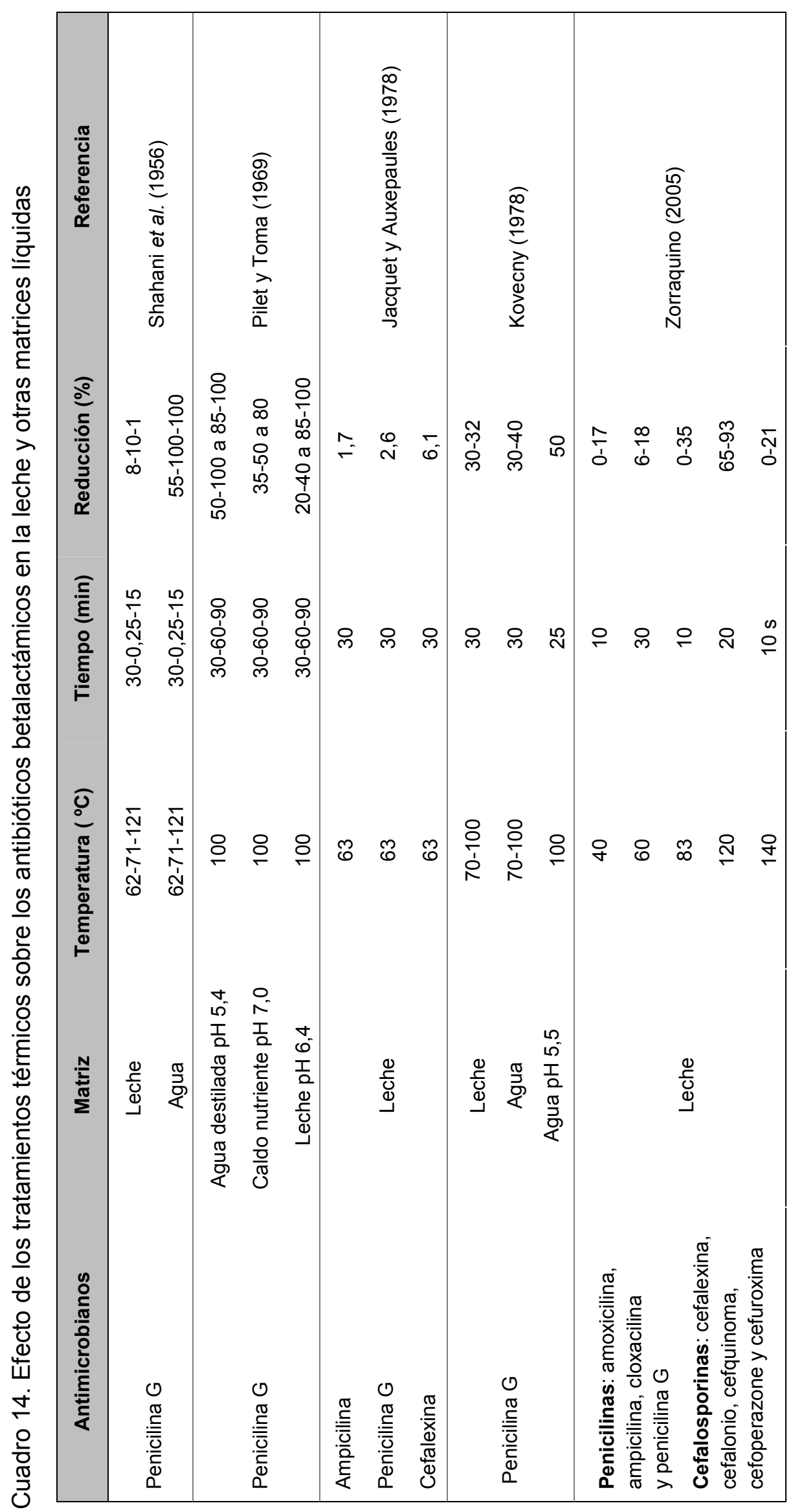


En el caso de la leche, agua y soluciones acuosas tampón, los primeros estudios sobre el efecto del calentamiento de los residuos de antibióticos fueron llevados a cabo, hace mucho años, por Shahani et al. (1956) y recogidos más tarde en la revisión bibiográfica de Moats (1999).

Los citados autores obtuvieron una leve inactivación térmica de la penicilina $G$ bajo diferentes tratamientos de pasteurización de la leche $\left(62{ }^{\circ} \mathrm{C}-30\right.$ minutos y $71^{\circ} \mathrm{C}$ 15 segundos) y esterilización $\left(121^{\circ} \mathrm{C}-20 \mathrm{~min}\right)$ y concluyeron que para inactivar totalmente la penicilina $\mathrm{G}$, había que calentar la leche a $71^{\circ} \mathrm{C}$, durante 1705 minutos y que la leche ejercía además un "efecto protector" notable sobre la penicilina $G$ en comparación con el calentamiento de este residuo en el agua.

En las revisiones de Moats $(1988,1999)$ también se cita a Pilet y Toma (1969) que estudiaron la termoestabilidad de la penicilina $G$ y otros antibióticos en la leche y otras matrices acuosas. En lo que se refiere a la leche, la penicilina presentó un porcentaje de degradación comprendido entre un 50 y un $65 \%$ para un tiempo de calentamiento de 60 minutos a $100{ }^{\circ} \mathrm{C}$, porcentaje que se incrementó al $85-100 \%$ para un calentamiento de 90 minutos, a la misma temperatura.

A su vez, Jacquet y Auxepaules (1978) investigaron el efecto de tres tipos de pasteurización: baja $\left(63^{\circ} \mathrm{C}-30\right.$ minutos), HTST $\left(75^{\circ} \mathrm{C}-15\right.$ segundos) y alta $\left(81^{\circ} \mathrm{C}-3\right.$ segundos), sobre la inactivación de 15 antibióticos en la leche.

A partir de los resultados del citado trabajo se observó que la inactivación se incrementaba conforme aumentaba la temperatura de pasteurización, independientemente de los tiempos de calentamiento aplicados. Así los porcentajes de inactivación que se calcularon estaban comprendidos en los rangos de 1,5-15\% para la pasteurización baja, 4-15\% para la pasteurización HTST y 5-20\% para la pasteurización alta. En lo que respecta a los antibióticos betalactámicos, dichos autores obtienen bajos porcentajes de inactivación para la ampicilina $(1,7 \%)$, penicilina G $(2,6 \%)$ y cefalexina $(6,1 \%)$ cuando las muestras de leche se someten a una pasteurización a $63^{\circ} \mathrm{C}$ durante 30 minutos.

Konecny (1978) presentó los resultados del calentamiento de diferentes antibióticos (penicilina G, estreptomicina, neomicina y cloranfenicol) en leche y agua. En dicho trabajo se observó una reducción en la actividad antimicrobiana comprendidas entre el $32 \%$ (penicilina) y el $41,7 \%$ (estreptomicina), después de calentar la leche durante 30 minutos a $100^{\circ} \mathrm{C}$. Cuando dicho calentamiento se realiza en agua, el rango de pérdida de la actividad antimicrobiana presentó valores comprendidos entre el $25 \%$ para neomicina y el $40 \%$ para la penicilina $\mathrm{G}$. 
Los resultados obtenidos por Zorraquino (2005), expuestos en el Cuadro 14, en un estudio realizado mediante un bioensayo microbiológico sobre la inactivación térmica de penicilinas y cefalosporinas causadas por los tratamientos de calentamiento empleados en el laboratorio (homogenización de las muestras de leche a $40{ }^{\circ} \mathrm{C}-10$ minutos e inactivación de inhibidores naturales a $83^{\circ} \mathrm{C}-10 \mathrm{~min}$ ), así como los tratamientos realizados en las industrias lácteas para garantizar la calidad y transformación de la leche (pasteurización baja: $60{ }^{\circ} \mathrm{C}-30 \mathrm{~min}$, esterilización convencional: $120^{\circ} \mathrm{C}-20$ min y tratamiento UHT: $140{ }^{\circ} \mathrm{C}-10 \mathrm{seg}$ ), señalan porcentajes de inactivación diferentes según el antibiótico y el tratamiento térmico empleado. Los resultados obtenidos en este estudio se presentan con mayor detalle en las Figura 15 y 16.

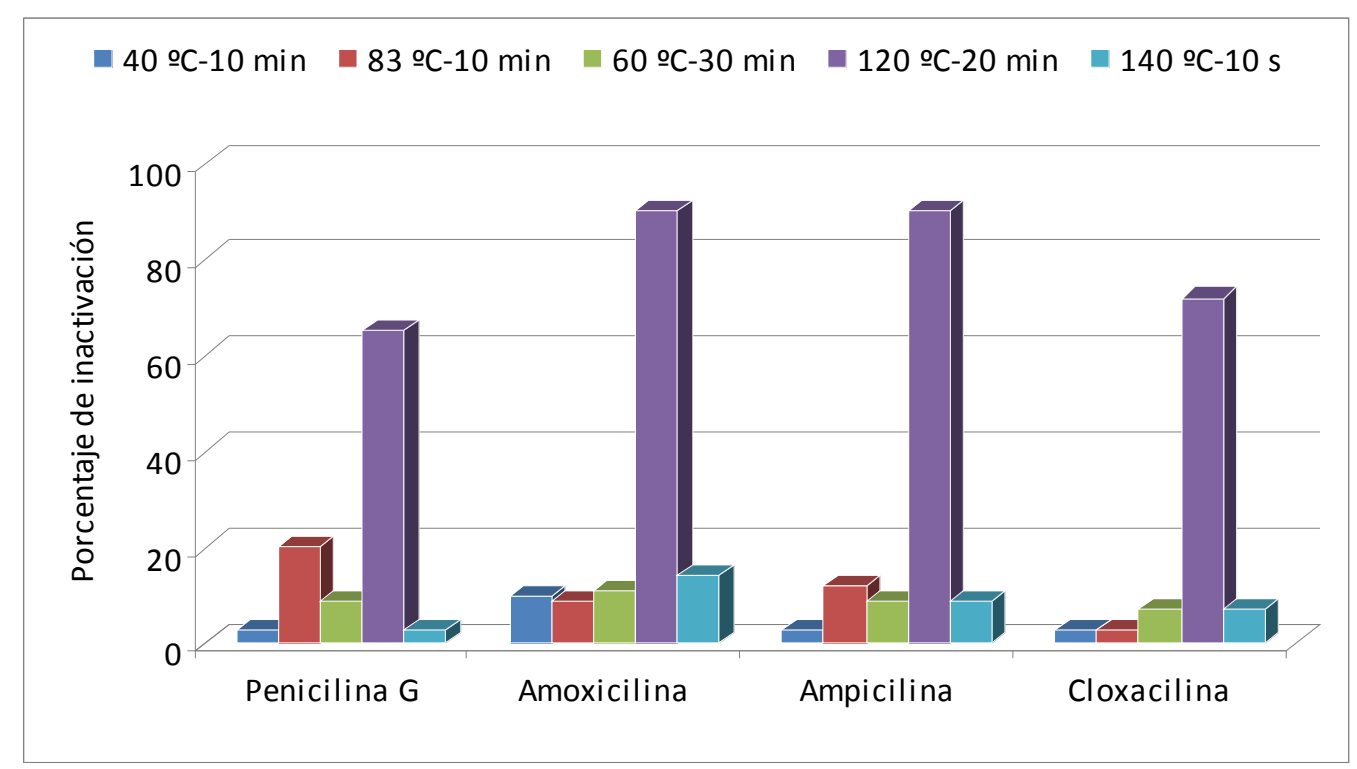

Figura 15. Porcentaje de inactivación de las penicilinas en la leche con diferentes tratamientos térmicos

Fuente: Zorraquino (2005)

Como se observa en la Figura 15, los residuos de penicilinas son bastante estables a calentamientos que impliquen bajas temperaturas tales como los utilizados en los laboratorios $\left(40^{\circ} \mathrm{C}-10 \mathrm{~min}\right.$ y $83^{\circ} \mathrm{C}-10 \mathrm{~min}$ ) o la pasteurización baja ( $60^{\circ} \mathrm{C}-30$ $\mathrm{min})$ e incluso a altas temperaturas pero con tiempos reducidos (140 $\mathrm{C}-10 \mathrm{~s})$ con valores de inactivación en todos los casos inferiores al 20\%. Sin embargo, estas sustancias experimentan una pérdida de actividad antimicrobiana apreciable cuando las muestras de leche se someten a temperaturas elevadas durante tiempos prolongados, como la esterilización convencional $\left(120^{\circ} \mathrm{C}-20 \mathrm{~min}\right)$. Dicho tratamiento presentó reducciones comprendidas entre el 65 y el $90 \%$ para las 4 penicilinas estudiadas. 


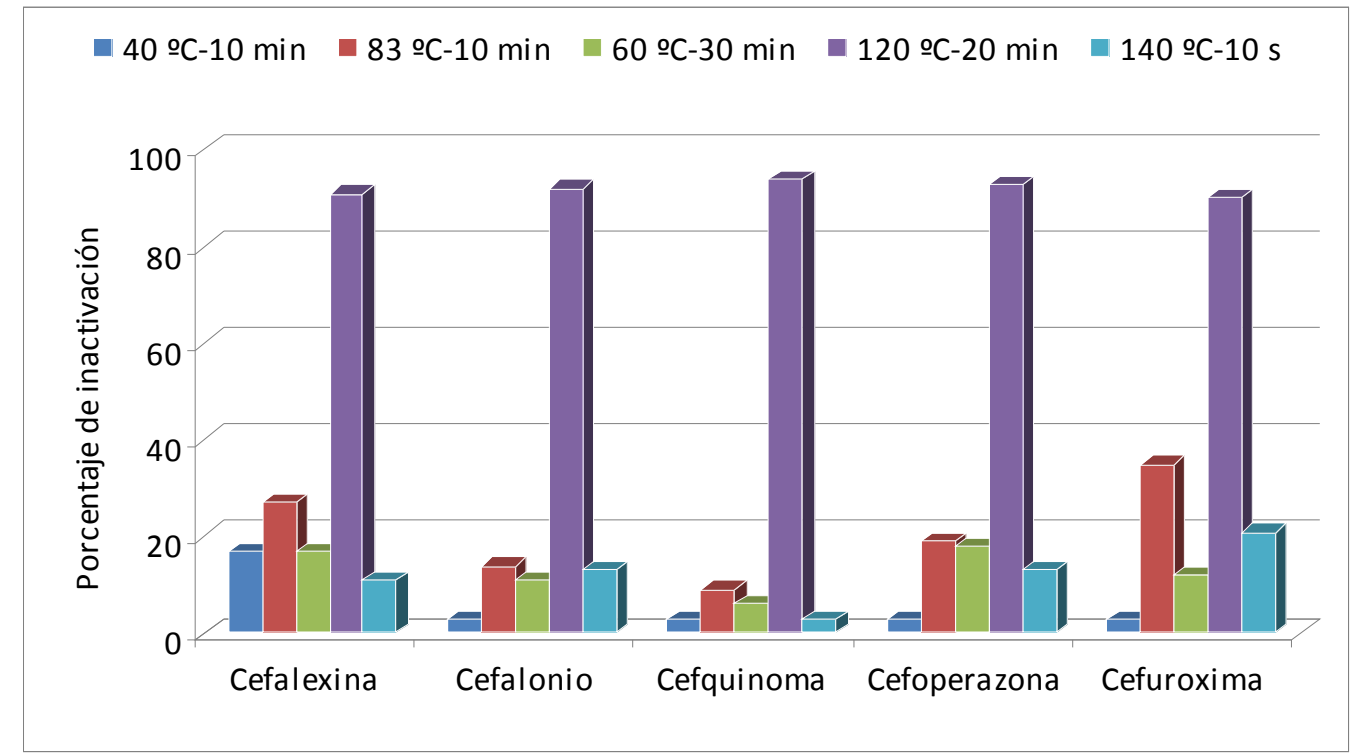

Figura 16. Porcentaje de inactivación de las cefalosporinas en la leche con diferentes tratamientos térmicos

Fuente: Zorraquino (2005)

Los resultados obtenidos en el estudio de las cefalosporinas por Zorraquino (2002) que se exponen en la Figura 16 muestran que estos antibióticos persisten peor a los tratamientos térmicos ensayados, aunque en la mayoría de los casos las inactivaciones son inferiores al $20 \%$, tal y como se observó en el estudio de las penicilinas. La esterilización convencional presentó pérdidas de actividad superiores al $90 \%$ en todas las cefalosporinas y en el caso concreto de la cefalexina y la cefuroxima éstas sustancias presentaron una inactivación entre el 20 y el 35\% respectivamente durante el tratamiento de $83^{\circ} \mathrm{C}-10 \mathrm{~min}$.

Por otra parte es importante resaltar que en todos los estudios realizados anteriormente se emplearon métodos microbiológicos o bioensayos y que, además, aquellos que se refieren al análisis de la degradación de antibióticos betalactámicos debido a tratamientos térmicos empleando técnicas de cromatografía líquida (HPLC) siguen siendo muy limitados.

A su vez, Zorraquino (1997), efectuó una evaluación de la estabilidad de 11 antibióticos betalactámicos en solución acuosa por HPLC, tras someter las muestras a un tratamiento térmico de $80^{\circ} \mathrm{C}$ durante tiempos comprendidos entre los 10 y 120 minutos. Los resultados de este estudio indicaron que los antibióticos betalactámicos se pueden clasificar en tres grupos diferentes en función de su estabilidad frente a la temperatura:

- Grupo I: formado por aquellos que poseen alta termoestabilidad (amoxicilina, cloxacilina, dicloxacilina). 
- Grupo II: constituido por las moléculas que presenta un valor de termoestabilidad media (ampicilina, penicilina $G$ y ceftiofur).

- Grupo III: representado por aquellos antimicrobianos que se ven afectados en mayor medida por la temperatura y poseen baja termoestabilidad (cefquinoma, cefoperazone, cefuroxima, cefalexina, cefalonio).

En este mismo estudio, se observó que para el calentamiento a $80^{\circ} \mathrm{C}$ durante 20 minutos, las cefalosporinas (cefalexina, cefalonio, cefquinoma, cefoperazone y cefuroxima) presentaron degradaciones mayores, entre el 16 y el $75 \%$, en comparación con las penicilinas (penicilina, amoxicilina, cloxacilina y dicloxacilina) que presentaron degradaciones entre el 0 y el $5 \%$.

\subsubsection{Tetraciclinas}

Dado que las tetraciclinas han sido, desde hace muchos años, uno de los grupos de antimicrobianos de mayor uso en medicina veterinaria, es elevado el número de trabajos experimentales que analizan el efecto de diferentes tratamientos térmicos de calor sobre la actividad de sus residuos en diversos alimentos de origen animal (O’Brien et al., 1981; Khüne et al., 2001). La mayoría de los estudios han sido desarrollados principalmente en carne y otros tejidos animales, siendo escasos aquellos realizados con muestras de leche y/o productos lácteos.

En el Cuadro 15, se recopila una síntesis de los estudios encontrados en la revisión bibliográfica sobre los efectos del calentamiento en muestras líquidas y en leche. Hay que tener en cuenta de nuevo, que los resultados presentados en dicho Cuadro proceden de estudios realizados mediante bioensayos microbiológicos, aunque también se expone el trabajo realizado por Hassani et al. (2008), donde se ha empleado la cromatografía líquida.

Los primeros estudios (Shahani, 1957, 1958) muestran que la leche con residuos de oxitetraciclina necesita 190 minutos a $71^{\circ} \mathrm{C}, 92 \mathrm{~min}$ a $79^{\circ} \mathrm{C}$ y $60 \mathrm{~min}$ a 85 ${ }^{\circ} \mathrm{C}$ para la inactivación total de esta sustancia. Sin embargo, en el caso de la clortetraciclina bastaron 15 minutos a $121^{\circ} \mathrm{C}$ para reducir al $100 \%$ su actividad.

La inestabilidad térmica de la oxitetraciclina también ha sido señalada por Pilet et al. (1969) en un estudio donde analizaron el efecto del calor en leche y disoluciones acuosas de varios antibióticos, alcanzando una pérdida de actividad completa de esta sustancia a los 30 minutos de calentamiento a $100^{\circ} \mathrm{C}$. 


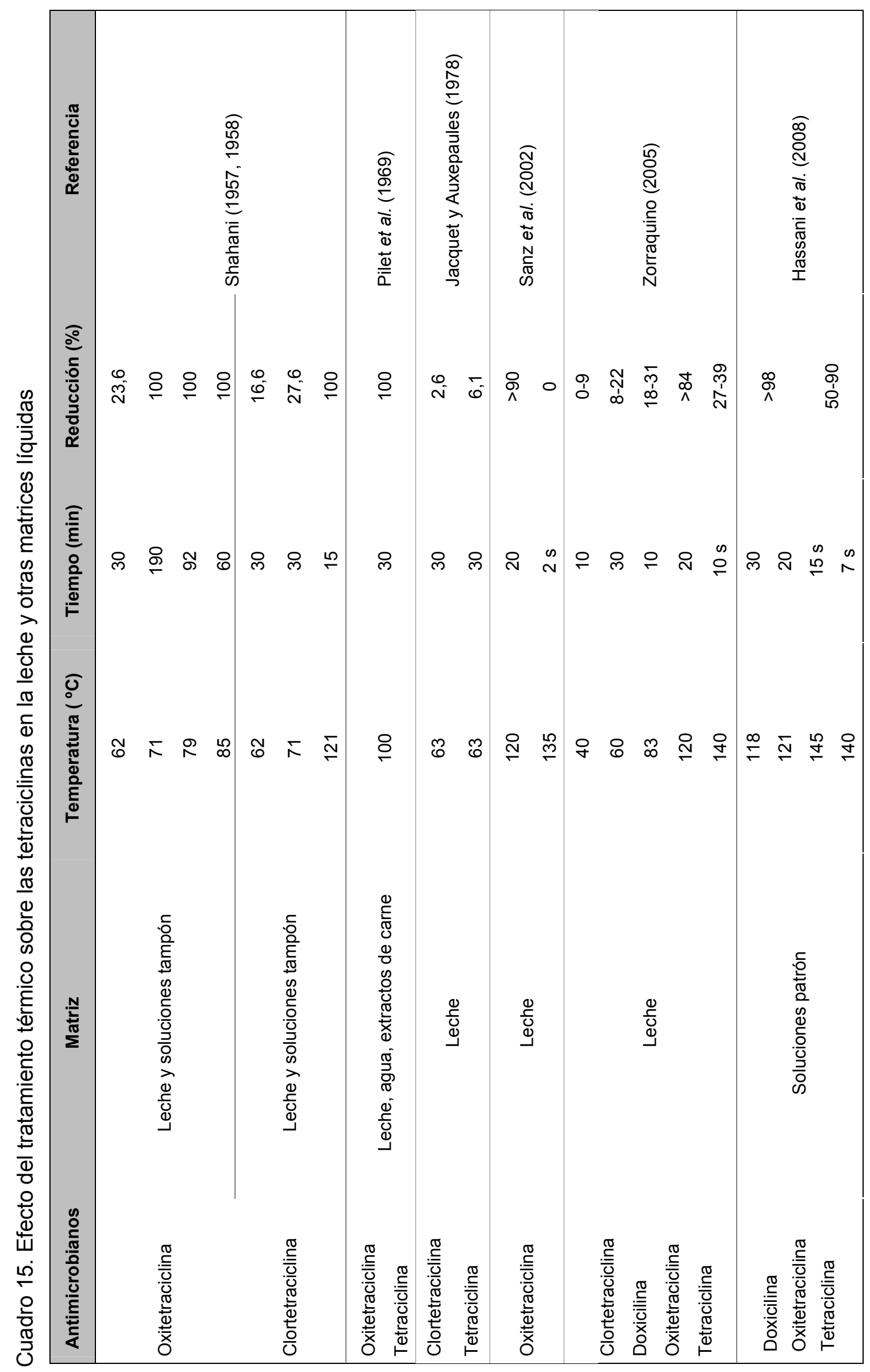


Jaquet y Auxepaules (1978) evaluaron la estabilidad térmica de la clortetraciclina y la tetraciclina presentes en muestras de leche después de ser sometidas a una pasteurización baja a $63^{\circ} \mathrm{C}$ durante 30 minutos, observando una elevada estabilidad con porcentajes de inactivación bajos del 2,6 y $6,1 \%$, respectivamente.

En otro estudio sobre la inactivación de antimicrobianos en leche a temperaturas de pasteurización y esterilización, Sanz et al. (2002), indicaron una degradación del $90 \%$ para la oxitetraciclina tras someter las muestras de leche a la esterilización de $120^{\circ} \mathrm{C}-20 \mathrm{~min}$. Sin embargo, esta inactivación no se presentó en los tratamientos térmicos de UHT $\left(135^{\circ} \mathrm{C}-2 \mathrm{~s}\right)$.

Por otra parte, Zorraquino (2005), realizó un estudio sobre la inactivación térmica de sustancias antimicrobianas en leche analizadas mediante un sistema microbiológico que ha sido comentado anteriormente en el caso de los betalactamicos. Los resultados de dicho estudio en lo que a pérdidas de actividad antimicrobiana se refiere, se presentan en la Figura 17. A partir de los resultados obtenidos, se concluye que los residuos de tetraciclinas son estables a tratamientos suaves como los utilizados en los laboratorios lactológicos, medianamente estables para la pasteurización baja y UHT, e inestables cuando se aplica una esterilización convencional con porcentajes de inactivación superiores al $84 \%$ en todos los casos.

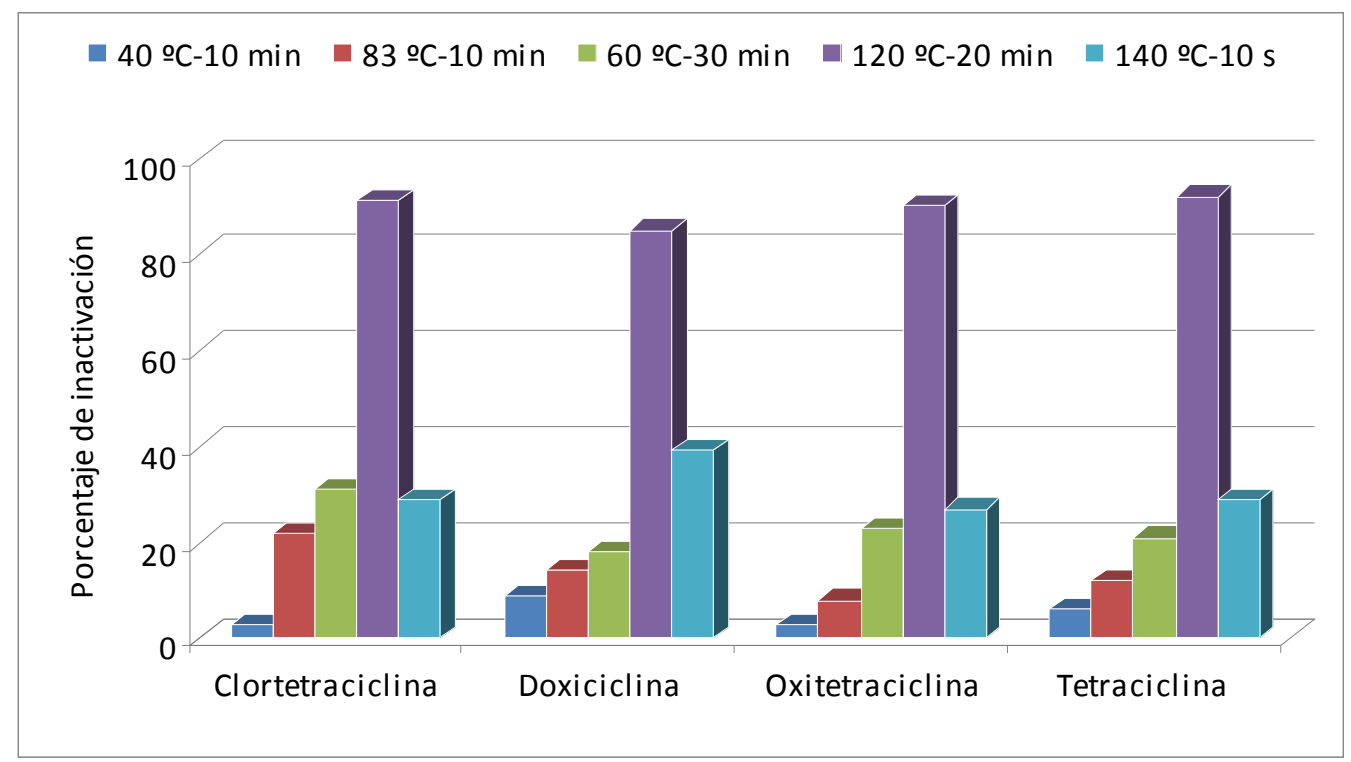

Figura 17. Porcentaje de inactivación de las tetraciclinas en la leche con diferentes tratamientos térmicos

Fuente: Zorraquino (2005) 
En cuanto a la cuantificación por HPLC de las pérdidas de tetraciclinas debidas al calentamiento de la leche, el Instituto Lactológico de Lekunberri (ILL, 2004), realizó un estudio sobre la descomposición estructural por calentamiento de 4 tetraciclinas. Los resultados de este estudio mostraron que el analito más estable era la doxicilina seguido de la tetraciclina y la oxitetraciclina y clortetraciclina con unos porcentajes de pérdidas de actividad a los 60 minutos de tratamiento a $80{ }^{\circ} \mathrm{C}$ del 40,55 y $100 \%$ respectivamente.

Muy recientemente, Hassani et al. (2008), han evaluado la estabilidad térmica de la doxicilina, oxitetraciclina y tetraciclina en soluciones patrón sometidas a los tratamientos térmicos de esterilización convencional $\left(118^{\circ} \mathrm{C}-30 \mathrm{~min} ; 121^{\circ} \mathrm{C}-20 \mathrm{~min}\right)$ y UHT ( $\left.145^{\circ} \mathrm{C}-15 \mathrm{~s} ; 140^{\circ} \mathrm{C}-7 \mathrm{~s}\right)$ utilizando una técnica LC-PDA. Estos autores observan una pérdida de estabilidad $>98 \%$ para los tres analitos bajo condiciones de esterilización convencional mientras que con los tratamientos UHT la reducción de la concentración inicial de cada solución patrón se encontraba entre el 50 y el 90\%.

\subsubsection{Sulfonamidas}

La estabilidad de los residuos de sulfamidas durante la preparación, cocinado, y procesamiento de los alimentos ha sido estudiada en diferentes matrices sólidas, como tejidos de diversas especies animales, y también, en matrices líquidas aunque en este caso los trabajos son muy limitados y se centran exclusivamente en la molécula de sulfametazina. En el Cuadro 16 se sintetizan las principales investigaciones sobre el efecto de diferentes tipos de calentamiento sobre la presencia de sulfonamidas en muestras líquidas, leche y leche en polvo.

Rose et al. (1996) encontraron una elevada estabilidad de la sulfametazina en muestras de agua en ebullición $\left(100^{\circ} \mathrm{C}\right)$, sin embargo en aceite de cocina calentado a $180^{\circ} \mathrm{C}$ y a $260{ }^{\circ} \mathrm{C}$ se observaron pérdidas de actividad correspondientes al $50 \%$ después de 2 horas y de 5 minutos, respectivamente.

En el caso de la leche, la sulfametazina no mostró ninguna pérdida de actividad después de un calentamiento a $100^{\circ} \mathrm{C}$ durante 15 minutos (Hasset et al., 1990).

Por otra parte, se demostró que las sulfonamidas son más estables que los antibióticos betalactámicos en el proceso de fabricación de leche en polvo tipo spray, conservando de forma íntegra su actividad en la leche deshidratada (Malik et al., 1994; Diserens, 1995). 


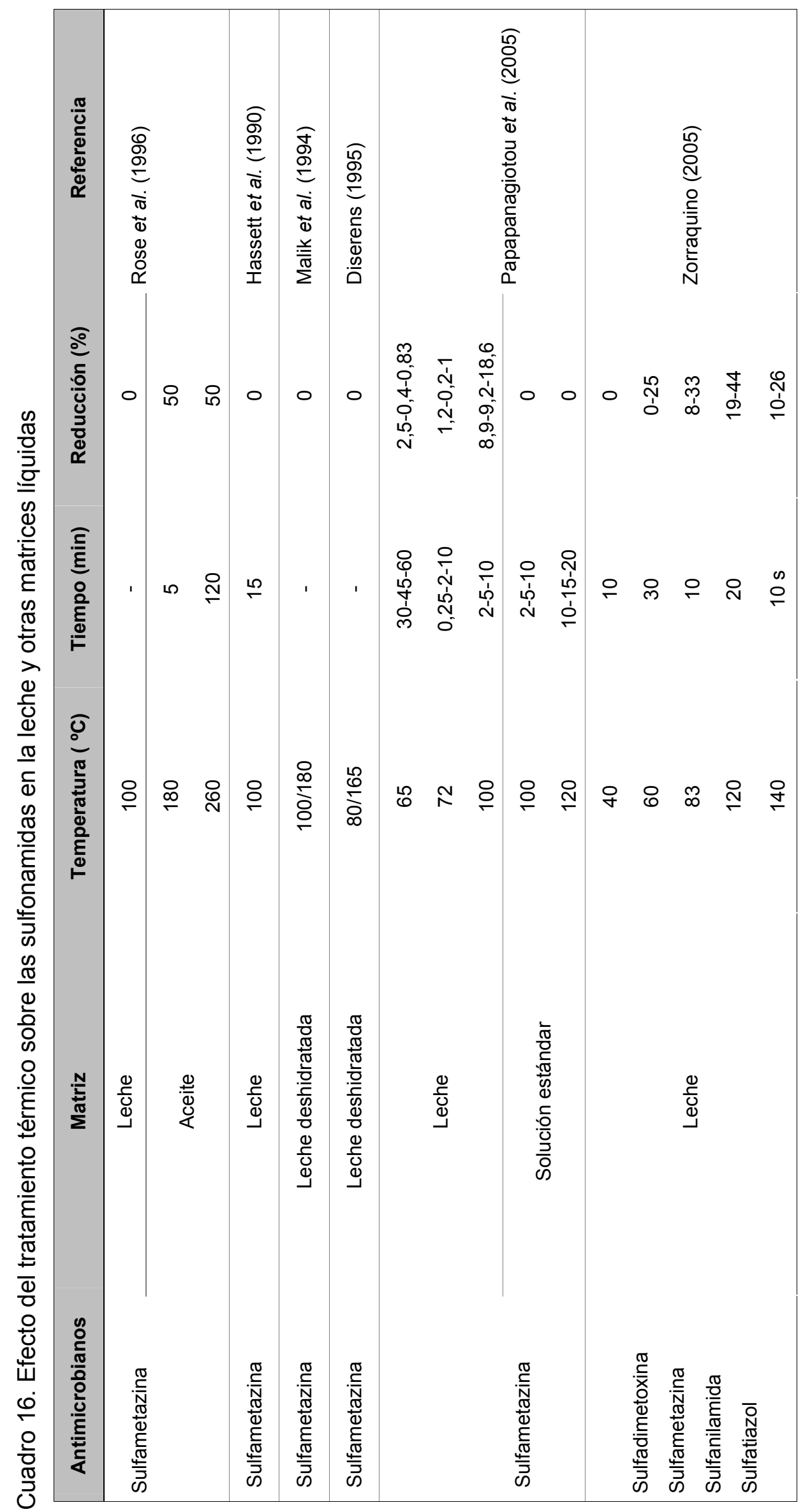


En el estudio realizado por Zorraquino (2005), citado anteriormente, también se investigó sobre el efecto de diferentes tratamientos térmicos sobre la estabilidad de sulfonamidas en leche, y los resultados obtenidos se muestran en la Figura 18.

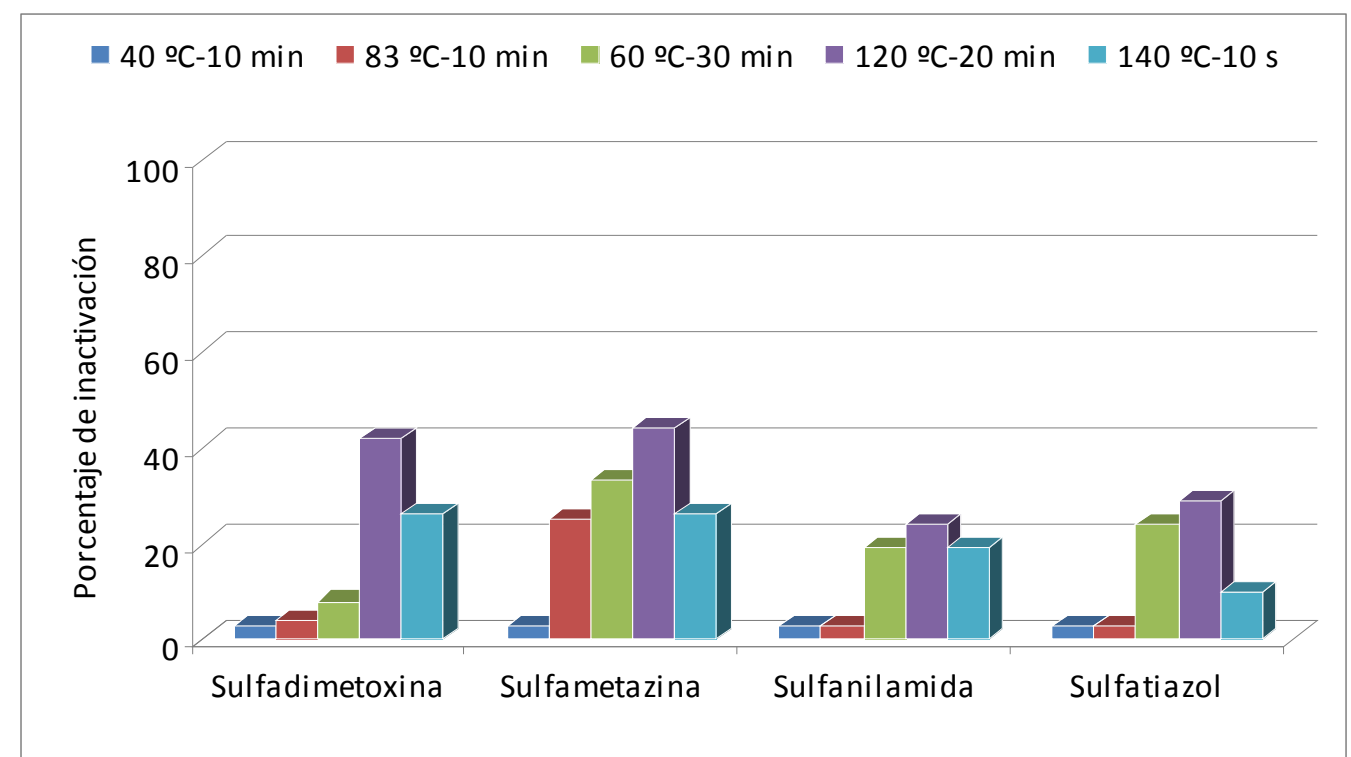

Figura 18. Porcentaje de inactivación de las sulfonamidas en la leche con diferentes tratamientos térmicos

Fuente: Zorraquino (2005)

A partir de ella se deduce que las sulfonamidas son moléculas muy estables a los tratamientos térmicos utilizados en los laboratorios lactológicos, presentando únicamente una reducción del $25 \%$ en el caso de la sulfametazina a $83^{\circ} \mathrm{C}$ durante 10 minutos, y medianamente inestables durante el tratamiento de $120{ }^{\circ} \mathrm{C}-20 \mathrm{~min}$, con porcentajes de inactivación entre el 25 y $44 \%$.

Empleando una técnica LC-UV, Papapanagiotou et al. (2005), estudiaron la estabilidad de la sulfametazina en muestras de leche y soluciones estándar sometidas a los tratamientos térmicos de pasteurización $\left(65^{\circ} \mathrm{C}-30,45\right.$ y $\left.60 \mathrm{~min}\right)$, hervido $\left(100{ }^{\circ} \mathrm{C}\right.$ 2, 5 y $10 \mathrm{~min}$ ) y autoclavado $\left(121^{\circ} \mathrm{C}-10,15\right.$ y $\left.20 \mathrm{~min}\right)$. Los resultados relativos a las soluciones estándar de sulfametazina mostraron una buena estabilidad en agua hirviendo a $100^{\circ} \mathrm{C}$ durante un tiempo superior a $1 \mathrm{~h} 30 \mathrm{~min}$, y 20 minutos en autoclave.

En cuanto a las muestras de leche, no se encontraron variaciones significativas en la concentración de esta sustancia después de la pasteurización, mientras que si se obtuvieron reducciones entre un 9 y $19 \%$ en el hervido y entre un 19 y $22 \%$ en el autoclavado, lo que indica una relativa estabilidad de la sulfametazina a los tratamientos de calor. 
OBJETIVOS 



\section{OBJETIVOS}

A lo largo de todas las etapas de almacenamiento, transporte y transformación de la leche en las explotaciones ganaderas, centros lácteos y laboratorios de control de calidad, la leche se somete a temperaturas de refrigeración y congelación, así como a diferentes tratamientos térmicos a temperaturas elevadas.

Tanto las condiciones de almacenamiento de las muestras como los tratamientos térmicos con calor, pueden producir una degradación o pérdida de estabilidad en algunas moléculas de antimicrobianos presentes en la leche $y$, a pesar de la importancia sanitaria e industrial que reviste la presencia de residuos de antimicrobianos en los alimentos, los estudios realizados sobre la influencia que pueden ejercer las temperaturas sobre la estabilidad de estas sustancias en la leche son muy limitados.

Por ello, el objetivo general de este trabajo ha sido estudiar, mediante técnicas cromatográficas de cuantificación, la estabilidad térmica de diferentes sustancias antimicrobianas pertenecientes a los grupos de antibióticos betalactámicos, tetraciclinas y sulfonamidas en la leche.

De modo más específico, los objetivos planteados en el estudio han sido:

- Evaluar la influencia de las condiciones de almacenamiento de la leche sobre la presencia de sustancias antimicrobianas mediante la aplicación de modelos cinéticos de primer orden y estimar los porcentajes de degradación de estas sustancias debidas a las prácticas habituales de almacenamiento en los laboratorios de análisis.

- Estudiar el efecto del calentamiento sobre la estabilidad de sustancias antimicrobianas en la leche por medio de la aplicación de modelos cinéticos de primer orden, el cálculo de las energías de activación mediante la aplicación de la ecuación de Arrhenius y la estimación de los porcentajes de degradación de estas sustancias debidos a los tratamientos térmicos empleados en los laboratorios de control de calidad y en la industria láctea. 

MATERIAL Y MÉTODOS 



\section{MATERIAL Y MÉTODOS}

Los análisis cromatográficos llevados a cabo en este trabajo han sido realizados en el Laboratorio de Salud Pública de la Generalitat Valenciana (Albal, Valencia) y en los laboratorios del Instituto Lactológico de Lekunberri (Lekunberri, Pamplona). La preparación de las muestras, revisiones bibliográficas, tratamiento estadístico de los datos y redacción final del documento han sido realizados en las dependencias de la del Departamento de Ciencia Animal de la Universidad Politécnica de Valencia.

Dado que el objetivo planteado es la evaluación de la termoestabilidad de algunas sustancias antimicrobianas en la leche, el plan de trabajo se planteó en base a la realización de los dos estudios siguientes:

- Primer estudio que evalúa la influencia de las condiciones de almacenamiento sobre la presencia de antimicrobianos en muestras de leche y sus correspondientes extractos

- Segundo estudio que analiza el efecto de diferentes tratamientos térmicos de calor sobre la estabilidad de los antimicrobianos en la leche

\section{PRIMER ESTUDIO: Influencia de las condiciones de almacenamiento sobre la estabilidad de antimicrobianos en la leche}

\subsection{DISEÑO EXPERIMENTAL}

Como se ha comentado anteriormente, este primer estudio pretende analizar la estabilidad de diferentes antimicrobianos presentes en las muestras de leche en diferentes condiciones de almacenamiento. También se consideró interesante desde el punto de vista operativo, estudiar la estabilidad de los analitos estudiados en los correspondientes extractos obtenidos a partir de las muestras de leche y expuestos a las mismas condiciones de conservación.

Para la realización de estos experimentos se emplearon muestras de leche en polvo enriquecidas con algunas de las principales sustancias antimicrobianas, empleadas en los tratamientos y profilaxis de enfermedades del ganado vacuno lechero, pertenecientes a los grupos de betalactámicos, tetraciclinas y sulfonamidas.

Las sustancias antimicrobianas empleadas en el estudio fueron las siguientes:

\section{- Betalactámicos:}

> Penicilinas: amoxicilina, ampicilina, cloxacilina y penicilina G

$>$ Cefalosporinas: cefalexina, cefapirina, cefoperazona y cefquinoma 
- Tetraciclinas: clortetraciclina, doxicilina, oxitetraciclina y tetraciclina

- Sulfonamidas: sulfacloropiradizina, sulfadiazina, sulfadimetoxina, sulfamerazina, sulfametazina, sulfapiridina, sulfaquinoxalina y sulfatiazol

Las disoluciones de leche adicionadas con antimicrobianos, a una concentración equivalente al LMR, se homogeneizaron y repartieron en alícuotas diferentes de $15 \mathrm{~mL}$, unas para realizar los análisis sobre la propia muestra de leche y las otras para obtener los respectivos extractos obtenidos a partir de las muestras de leche, previos al análisis cromatográfico.

Una vez preparadas las muestras y los extractos, éstos se dividieron a su vez en diferentes alícuotas para conservar parte de ellas refrigeradas en nevera a $4 \pm 2{ }^{\circ} \mathrm{C}$ y otras en congelación a $-20 \pm 2{ }^{\circ} \mathrm{C}$. Tanto las muestras como los extractos de leche se analizaron, por triplicado, el mismo día de su recogida (blanco: día 0 ) y a los 1, 2, 3, $7,10,15$ y 30 desde su almacenamiento.

Cada día de análisis, las muestras procesadas previamente, y los extractos conservados fueron analizados, mediante un equipo de cromatografía líquida de alta eficacia (HPLC-MS/MS), para llevar a cabo la cuantificación de la concentración de los antimicrobianos presentes y calcular la posible pérdida de concentración en relación al tiempo transcurrido.

En la Figura 19 se presenta un esquema del diseño experimental llevado a cabo en este primer estudio.

\subsection{PATRONES Y MUESTRAS FORTIFICADAS}

El estudio se realizó sobre muestras de leche en polvo de calidad microbiológica (Ref: 115363, Merck), reconstituida al 10\% con agua ultra pura, a las que se les adicionaron una concentración de antimicrobianos equivalente al Límite Máximo de Residuos (LMR) de cada una de las sustancias estudiadas pertenecientes a los grupos de betalactámicos, tetraciclinas y sulfonamidas.

Para cada antimicrobiano, se preparó una disolución "madre" o "stock" con una concentración de $1000 \mu \mathrm{g} / \mathrm{g}$, teniendo en cuenta la pureza indicada por el fabricante y el disolvente más adecuado para cada uno de ellos.

A partir de cada solución "madre" se prepararon disoluciones diluidas de 10 $\mu \mathrm{g} / \mathrm{g}$, enrasando $100 \pm 4 \mu \mathrm{L}$ en $10 \mathrm{~g}$ de agua ultra pura. Estas disoluciones se homogeneizaron en el baño de ultrasonidos 5 minutos y se emplearon en la preparación de leches fortificadas y controles positivos. 


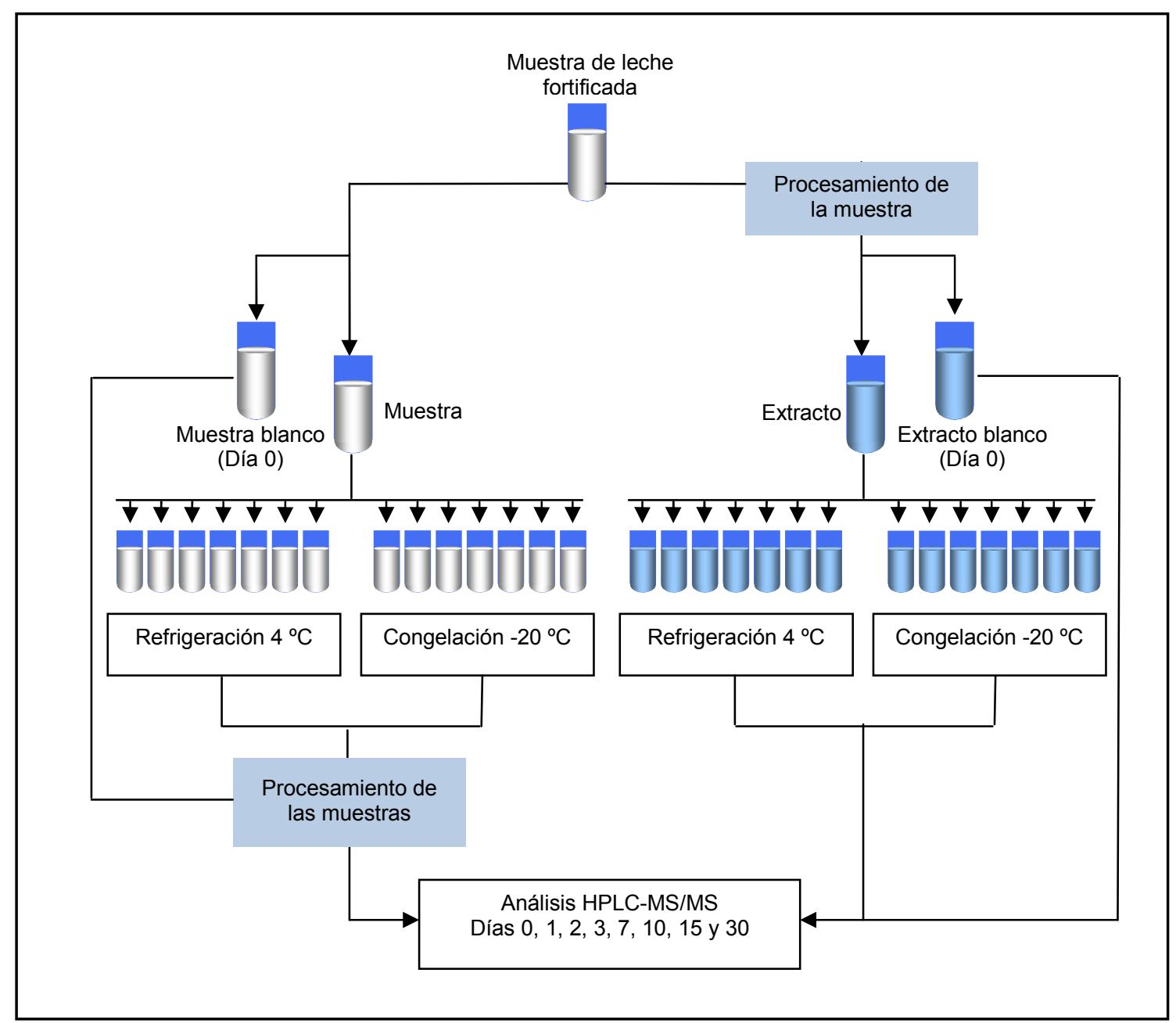

Figura 19. Diseño experimental empleado en el estudio de la influencia de las condiciones de almacenamiento sobre la estabilidad de antimicrobianos en la leche

Para la preparación de las muestras de leche fortificadas se siguieron las recomendaciones de la Federación Internacional de Lechería (FIL, 1997), teniendo la precaución que el volumen de disolución acuosa de un fármaco no superase al $1 \%$ del volumen de disolución final en la leche.

Las diferentes sustancias antimicrobianas estudiadas, así como la concentración empleada (LMR), procedencia comercial y disolvente más adecuado para cada caso, se presentan en el Cuadro 17.

\subsection{EQUIPOS Y MATERIAL}

\subsubsection{Equipo cromatográfico LC-MS/MS}

Para la realización de este estudio se utilizó un equipo de cromatografía líquida de alta resolución acoplado a un espectrómetro de masas (Waters, EEUU), con las características que se describen a continuación. 
Cuadro 17. Antimicrobianos, concentraciones y disolventes utilizados

\begin{tabular}{|c|c|c|c|c|}
\hline Antim & icrobianos & $\begin{array}{c}\text { Concentración } \\
\text { (LMR) }\end{array}$ & Disolvente & Ref. comercial \\
\hline & Amoxicilina & 4 & $\mathrm{H}_{2} \mathrm{O}$ & Sigma A-8523 \\
\hline & Ampicilina & 4 & $\mathrm{H}_{2} \mathrm{O}$ & Sigma A-9518 \\
\hline & Cloxacilina & 30 & $\mathrm{H}_{2} \mathrm{O}$ & Sigma C-9393 \\
\hline Betalactámicos & Penicilina G & 4 & $\mathrm{H}_{2} \mathrm{O}$ & Sigma PEN-Na \\
\hline & Cefalexina & 100 & $\mathrm{H}_{2} \mathrm{O}$ & Sigma C-4895 \\
\hline & Cefapirina & 60 & $\mathrm{H}_{2} \mathrm{O}$ & Sigma C-8270 \\
\hline & Cefoperazona & 50 & $\mathrm{H}_{2} \mathrm{O}$ & Sigma C-4292 \\
\hline & Cefquinoma & 20 & $\mathrm{HCl} 0,1 \mathrm{~N}$ & Intervet $^{1}$ \\
\hline & Clortetraciclina & 100 & $\mathrm{HCl} 0,1 \mathrm{~N}$ & Sigma C-4881 \\
\hline Tetraciclinas & Doxiciclina & 100 & $\mathrm{HCl} 0,1 \mathrm{~N}$ & Sigma D-9891 \\
\hline & Oxitetraciclina & 100 & $\mathrm{HCl} 0,1 \mathrm{~N}$ & Sigma O-5750 \\
\hline & Tetraciclina & 100 & $\mathrm{HCl} 0,1 \mathrm{~N}$ & Sigma T-3258 \\
\hline & Sulfacloropiradazina & 100 & Metanol & Sigma S-9882 \\
\hline & Sulfadiazina & 100 & Metanol & Sigma S-8626 \\
\hline & Sulfadimetoxina & 100 & Metanol & Sigma S-7007 \\
\hline Sulfonamidas & Sulfaquinoxalina & 100 & Metanol & Sigma S-7382 \\
\hline & Sulfamerazina & 100 & Metanol & Sigma S-8876 \\
\hline & Sulfametazina & 100 & Metanol & Sigma S-6256 \\
\hline & Sulfapiridina & 100 & Metanol & Sigma S-6252 \\
\hline & Sulfatiazol & 100 & Metanol & Sigma S-9876 \\
\hline
\end{tabular}

${ }^{1}$ Intervet International GmbH, Feldstraße 1a , D-85716 Unterschelßheim, Alemania

- Módulo de separación cromatográfica Waters Alliance ${ }^{\circledR} 2695$ con desgasificador, bomba y autoinyector integrados (Waters, EEUU)

- Columna cromatográfica $\mathrm{XBridge}^{\mathrm{TM}} \mathrm{C}_{18}$ (Waters) con las siguientes características:

$>$ Diámetro interno y longitud : $2,1 \times 100 \mathrm{~mm}$

$>$ Tamaño partícula: $3,5 \mu \mathrm{m}$

$>$ Tamaño de poro: $135 \AA$

- Detector de espectrometría de masas MS/MS Waters Micromass Quattro Micro ${ }^{\mathrm{TM}} \mathrm{API}$ (Ionización a Presión Atmosferica) con:

- Fuente de ionización por electrospray (ESI)

$>$ Fuente de ionización APCl (Ionización Química a Presión Atmosferica) 
$>$ Analizador tipo triple cuadrupolo con rango de masas de 2 a 4000 uma, con una resolución de 1 uma

$>$ Generador de nitrogeno N2LCMS (Teknokroma ${ }^{\circledR}$ )

$>$ Bala de argon comprimido 99,999\% (Praxair España S.L.)

- Software MassLynx 4.0 (Waters) para el tratamiento de datos

En la Figura 20 se muestra el equipo completo empleado en este estudio y con más detalle el espectrómetro de masas.
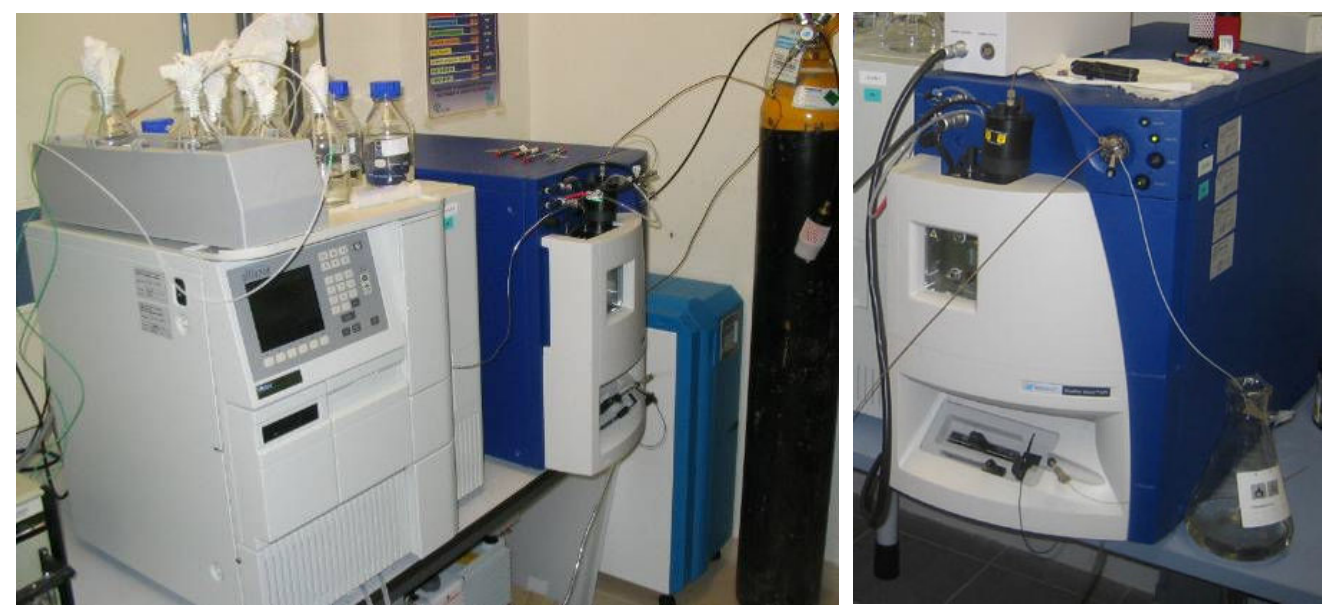

Figura 20. Equipo cromatográfico y detector de espectrometría de masas

\subsubsection{Otros equipos}

Además del sistema cromatográfico descrito en el apartado anterior también se utilizaron los siguientes equipos para las fases de preparación y almacenamiento de las muestras, patrones y reactivos:

- Balanza analítica con una precisión $\pm 0,001 \mathrm{~g}$ (Mettler Toledo AB104S)

- $\quad$ Centrífuga con rotor angular 8 x 50mL y 5.500-10.000 r.p.m. (Hermlez 323)

- $\quad$ Sistema de filtración de reactivos (Millipore)

- $\quad$ PH-metro con una precisión de $\pm 0,01 \mathrm{~g}$ (Crison GLP21)

- Baño de ultrasonidos (Fungilab S.A.)

- $\quad$ Sistema de evaporación (TurboVap ${ }^{\circledR} 500$, Caliper Life Sciences)

- Sistema de extracción en fase sólida conectado a bomba de vacío

- $\quad$ Agitador vibrador tipo vortex ( Heidolph Reax Top)

- $\quad$ Agitador magnético (Variomag)

- Nevera con una temperatura de $4 \pm 2{ }^{\circ} \mathrm{C}$ (Bosch)

- Congelador con una temperatura de $-20 \pm 2{ }^{\circ} \mathrm{C}$ (Radiver S.A) 


\subsubsection{Materiales}

Los materiales empleados fueron los siguientes:

- Tubos de centrífuga de polipropileno de $40 \mathrm{~mL}$

- Lana de vidrio

- Bureta de vidrio de $50 \pm 0,5 \mathrm{~mL}$ graduada

- Jeringuillas de plástico de $5 \mathrm{~mL}$ desechables

- Micropipetas automáticas $(100,500,1000$ y $5000 \mu \mathrm{L})$

- Filtros de polifluoruro de vinilideno (PVDF) de 2,5 mm de diámetro y 0,2 $\mu \mathrm{m}$ de tamaño de poro (Waters)

- Cartuchos SPE (extracción en fase sólida) Oasis ${ }^{\circledR}$ HLB 3 cc 60 mg (Waters)

- Viales de cromatografía de $2 \mathrm{~mL}$ con sus respectivos tapones y septums

- Microinsertos o microviales de $300 \mu \mathrm{L}$

Además se empleó el material habitual del laboratorio (guantes de látex, pesa sustancias, probetas, matraces aforados, erlenmeyers, espátulas, etc.).

\subsection{REACTIVOS}

1.4.1. Fase móvil del sistema de análisis cromatográfico

Para el análisis cromatográfico de las sustancias antimicrobianas pertenecientes a los tres grupos estudiados, se utilizó la misma fase móvil en el módulo de separación, compuesta por dos reactivos en dos bombas diferentes:

Bomba A: ácido fórmico $0,1 \%$

Bomba B: acetonitrilo grado gradiente

Los reactivos necesarios para la preparación de la fase móvil correspondiente fueron los siguientes:

- Acetonitrilo grado gradiente para cromatografía liquida

- Ácido fórmico $\mathrm{H}-\mathrm{COOH}\left(\mathrm{CH}_{2} \mathrm{O}_{2}\right)$

- Agua ultra pura grado reactivo

Para preparar la fase móvil, se pesaron $10 \pm 0,1 \mathrm{~g}$ de ácido fórmico en un vaso de precipitados y se disolvieron en $1 \mathrm{~L}$ de agua ultra pura. La disolución se filtró y se mantuvo 10 minutos en el baño de ultrasonidos para evitar posibles interferencias o "ruidos" en el análisis cromatográfico. 


\subsubsection{Otros reactivos}

Para el análisis de las tetraciclinas fue necesario preparar también los siguientes reactivos:

Tampón Mcllvaine: Se pesaron 10,93 $\pm 0,1 \mathrm{~g}$ de $\mathrm{Na}_{2} \mathrm{HPO}_{4}$ y se disolvieron en $385 \mathrm{~mL}$ de agua ultra pura. Por otro lado, se pesaron 12,9 $\pm 0,1 \mathrm{~g}$ de ácido cítrico y se disolvieron en $615 \mathrm{~mL}$ de agua ultra pura. Se mezclaron las dos disoluciones y se comprobó que el pH presentaba un valor de $4 \pm 0,3$.

Tampón Mcllvaine/EDTA: Se añadieron 3,72 $\pm 0,1 \mathrm{~g}$ de etil diamina tetra acetato disódico (EDTA) a $1 \mathrm{~L}$ de tampón Mcllvaine, mezclando bien la disolución.

\subsection{DETERMINACIÓN CROMATOGRÁFICA DE LOS ANTIMICROBIANOS}

Las técnicas analíticas, descritas a continuación, se han desarrollado siguiendo los protocolos puestos a punto y validados por el equipo de I+D del Instituto Lactológico de Lekunberri (Lekunberri, Pamplona), bajo la Norma Internacional de Calidad ISO:17025 (ISO, 2005).

\subsubsection{Análisis cromatográfico de los antibióticos betalactámicos}

Una vez transcurrido el tiempo de almacenamiento en refrigeración y congelación para las diferentes alícuotas, las muestras se atemperaron 0 descongelaron en baño de agua a $25^{\circ} \mathrm{C}$ y se homogeneizaron correctamente. A continuación se procedió a la preparación específica de las muestras correspondientes a los procedimientos analíticos aplicados.

En los apartados posteriores se describe el procedimiento llevado a cabo para realizar la extracción y purificación de los analitos, las condiciones cromatográficas empleadas en el módulo de separación y las características del detector de masas específicas para cada una de las penicilinas y cefalosporinas estudiadas.

\subsubsection{Extracción y purificación de las muestras}

En un tubo de centrífuga de polipropileno de $40 \mathrm{~mL}$ se añadieron $10 \pm 0,01 \mathrm{~g}$ de la muestra de leche fortificada previamente homogeneizada y se centrifugó durante 15 minutos a 10.000 r.p.m. A continuación se filtró el extracto sobrenadante a través de lana de vidrio y se recuperó el filtrado para purificarlo mediante el sistema de extracción (SPE). 
Antes de proceder a la purificación del extracto, se acondicionó el cartucho SPE debidamente colocado en la unidad de filtración a vacío, pasando $1 \mathrm{~mL}$ de metanol seguido de $1 \mathrm{~mL}$ de agua ultra pura.

Inmediatamente y sin dejar secar la columna, se pasaron $2 \mathrm{~mL}$ de la muestra filtrada por gravedad, y en el caso de resultar necesario se conectó la bomba de vacío para regular la presión, sin que la velocidad de elución superase los $3 \mathrm{~mL} / \mathrm{min}$.

Una vez pasada toda la muestra se procedió al lavado de la columna con 2,5 $\mathrm{mL}$ de agua ultra pura y después se secó mediante vacío durante 10 segundos y bombeando aire con una jeringa de plástico conectada en la boca superior de la columna para eliminar el agua.

Seguidamente se colocó un tubo de vidrio previamente rotulado bajo la columna SPE y se eluyó el extracto con $2 \mathrm{~mL}$ de metanol. El eluato recuperado se evaporó hasta casi sequedad en el sistema de evaporación con corriente de nitrógeno (Turbo-VAP).

Finalmente se reconstituyó el eluato con $0,5 \mathrm{~mL}$ de fase móvil (ácido fórmico $0,1 \%)$ agitando durante 30 segundos. Después se mantuvo el tubo 5 minutos en ultrasonidos y con ayuda de una jeringa se filtró el colectado a través de un filtro de PVDF de $25 \mathrm{~mm}$ y 0,2 $\mu \mathrm{m}$, en un microvial de $300 \mu \mathrm{L}$ debidamente insertado en un vial cromatográfico de $2 \mathrm{~mL}$ para su análisis inmediato o refrigeración y congelación.

\subsubsection{Separación y detección cromatográfica}

El procedimiento empleado cada día de análisis para el estudio de las muestras de leche y sus correspondientes extractos, es el que se describe a continuación.

Tras la puesta en marcha, purgación manual y automática del equipo y estabilización total del sistema cromatográfico completo (sistema de separación y detector de masas), se insertó la tanda de muestras en el siguiente orden:

- Vial 1: Fase móvil

- Vial 2: Control negativo de la muestra

- Vial 3: Control positivo de penicilinas: muestra fortificada con las penicilinas estudiadas a las concentraciones equivalentes a sus LMR

- Vial 4: Control positivo de cefalosporinas: muestra fortificada con las cefalosporinas a las concentraciones equivalentes a sus LMR

- Vial 5: Patrón 1 de penicilinas (5 $\mu \mathrm{g} / \mathrm{kg})$ : disolución de penicilinas en fase móvil con una concentración equivalente a $5 \mu \mathrm{g} / \mathrm{kg}$ 
- Vial 6: Patrón 2 de penicilinas $(10 \mu \mathrm{g} / \mathrm{kg})$

- Vial 7: Patrón 3 de penicilinas $(25 \mu \mathrm{g} / \mathrm{kg})$

- Vial 8: Patrón 4 de penicilinas $(50 \mu \mathrm{g} / \mathrm{kg})$

- Vial 9: Patrón 1 de cefalosporinas $(30 \mu \mathrm{g} / \mathrm{kg})$ : disolución de cefalosporinas en fase móvil con una concentración equivalente a $30 \mu \mathrm{g} / \mathrm{kg}$

- Vial 10: Patrón 2 de cefalosporinas $(50 \mu \mathrm{g} / \mathrm{kg})$

- Vial 11: Patrón 3 de cefalosporinas $(80 \mu \mathrm{g} / \mathrm{kg})$

- Vial 12: Patrón 4 de cefalosporinas $(100 \mu \mathrm{g} / \mathrm{kg})$

- Vial 13 y sucesivos: Muestras y extractos problema

El análisis del conjunto de muestras se programó y realizó mediante el Software MassLynx 4.0 (Waters) con las siguientes condiciones cromatográficas:

- Fase móvil en modo gradiente con las siguientes condiciones:

\begin{tabular}{ccc}
\hline $\begin{array}{c}\text { Tiempo } \\
(\mathrm{min})\end{array}$ & $\begin{array}{c}\text { Bomba } \mathrm{A} \\
(\% \text { ácido fórmico })\end{array}$ & $\begin{array}{c}\text { Bomba B } \\
(\%)\end{array}$ \\
\hline $0-10$ & 100 & 0 \\
$10-12$ & 0 & 100 \\
$12-16$ & 100 & 0 \\
\hline
\end{tabular}

- Flujo de 0,6 $\mathrm{mL} / \mathrm{min}$

- Volumen de inyección de muestra de $20 \mu \mathrm{L}$

En cuanto al funcionamiento del espectrómetro de masas se utilizó la fuente de ionización por electrospray en modo positivo $\left(\mathrm{ESI}^{+}\right)$, así como las condiciones de detección establecidas en el proceso de puesta a punto de la técnica para la identificación y cuantificación de los antibióticos betalactámicos.

En el Cuadro 18 se presentan las características de voltaje de cono y de colisión para la selección de los iones precursores y el fraccionamiento específico en los iones primarios y secundarios de las penicilinas y cefalosporinas estudiadas.

\subsubsection{Interpretación de los cromatogramas}

Para la identificación inequívoca de un antimicrobiano por espectroscopía de masas, la UE en la decisión 2002/657 establece unos criterios básicos que establecen la necesidad de establecer al menos 4 puntos de identificación. Teniendo en cuenta que la generación del ión precursor equivale a un punto de identificación y que cada 
ión hijo equivale a 1,5 puntos, únicamente es necesario obtener dos iones hijo para poder identificar el analito estudiado.

Cuadro 18. Condiciones del espectrómetro de masas para la identificación y cuantificación de antibióticos betalactámicos

\begin{tabular}{|lccccccc|}
\hline Antimicrobianos & $\begin{array}{c}\mathbf{R T} \\
(\mathbf{m i n})\end{array}$ & $\begin{array}{c}\text { Ion } \\
\text { precursor } \\
(\mathbf{m} / \mathbf{z})\end{array}$ & $\begin{array}{c}\text { Voltaje } \\
\mathbf{c o n o} \\
\mathbf{( V )}\end{array}$ & $\begin{array}{c}\text { Ion } \\
\text { primario } \\
(\mathbf{m} / \mathbf{z})\end{array}$ & $\begin{array}{c}\text { Energía } \\
\text { colisión } \\
\mathbf{( 1 / V )}\end{array}$ & $\begin{array}{c}\text { Ion } \\
\text { secundario } \\
\text { (m/z) }\end{array}$ & $\begin{array}{c}\text { Energía } \\
\text { colisión } \\
(\mathbf{2} / \mathbf{V})\end{array}$ \\
\hline Ampicilina & 7,30 & 350,3 & 20 & 105,9 & 15 & 160,1 & 15 \\
Amoxicilina & 3,34 & 366,3 & 18 & 114,0 & 20 & 208,0 & 13 \\
Cloxacilina & 11,29 & 436,3 & 22 & 160,2 & 10 & 277,3 & 10 \\
Penicilina G & 7,77 & 335,4 & 40 & 91,0 & 25 & 128,1 & 40 \\
Cefalexina & 7,30 & 348,2 & 15 & 106,2 & 30 & 157,9 & 20 \\
Cefapirina & 5,88 & 424,0 & 32 & 292,2 & 16 & 152,0 & 24 \\
Cefquinoma & 6,90 & 265,2 & 18 & 134,2 & 15 & 199,2 & 25 \\
Cefoperazona & 8,71 & 645,9 & 22 & 530,0 & 12 & 143,0 & 35 \\
\hline
\end{tabular}

${ }^{1}$ ión primario= ión hijo mayoritario $=$ ión de cuantificación; ${ }^{2}$ ión secundario= ión hijo secundario= ión de confirmación

Una vez verificados todos los parámetros de identificación (tiempo de retención, pesos moleculares de los iones precursores e hijos y energías de cono y colisión) así como la recuperación, linealidad y ajuste de la recta de calibrado, se procedió a la cuantificación de los analitos en estudio, a partir de los iones hijos mayoritarios formados.

Esta cuantificación se realizó integrando el área de los picos de los iones hijo mayoritarios en las rectas de calibrado de cada antibiótico betalactámico, obtenidas con anterioridad en la puesta a punto del método, y cuyos valores se exponen en el Cuadro 19.

Cuadro 19. Ecuaciones de las rectas de calibrado de los antibióticos betalactámicos

\begin{tabular}{|llccc|}
\hline Antimicrobianos & \multicolumn{2}{c}{ Ecuaciones } & $\mathbf{R}^{2}$ & $\mathbf{C V}(\%)$ \\
\hline Amoxicilina & $\mathrm{y}=109,30 \cdot \mathrm{x}-11,70$ & 0,9027 & 5,20 \\
Ampicilina & $\mathrm{y}=22,01 \cdot \mathrm{x}+44,60$ & 0,9504 & 2,37 \\
Cloxacilina & $\mathrm{y}=71,67 \cdot \mathrm{x}-15,49$ & 0,9024 & 6,55 \\
Penicilina G & $\mathrm{y}=133,52 \cdot \mathrm{x}+38,46$ & 0,9628 & 5,87 \\
Cefalexina & $\mathrm{y}=779,36 \cdot \mathrm{x}-18,77$ & 0,9852 & 4,66 \\
Cefapirina & $\mathrm{y}=3145,61 \cdot \mathrm{x}-104,44$ & 0,9993 & 5,01 \\
Cefoperazona & $\mathrm{y}=1283,31 \cdot \mathrm{x}-230,11$ & 0,9952 & 4,00 \\
Cefquinoma & $\mathrm{y}=1103,20 \cdot \mathrm{x}-24.05$ & 0,9655 & 5,12 \\
\hline
\end{tabular}


A modo de ejemplo, en la Figura 21 se presenta el espectro del ión precursor de la cloxacilina obtenido a partir de una muestra de leche el primer día de refrigeración y en la Figura 22 los cromatogramas de los iones primarios y secundarios correspondientes obtenidos ese mismo día de análisis.

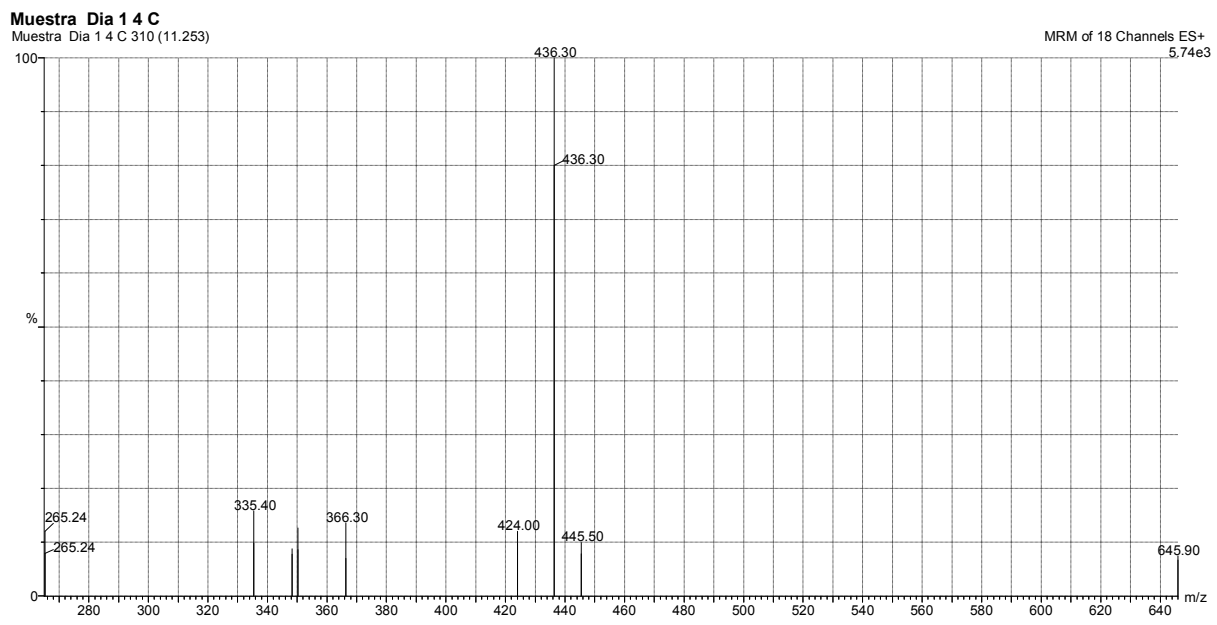

Figura 21. Espectro correspondiente al ión precursor de la cloxacilina en leche el primer día de refrigeración

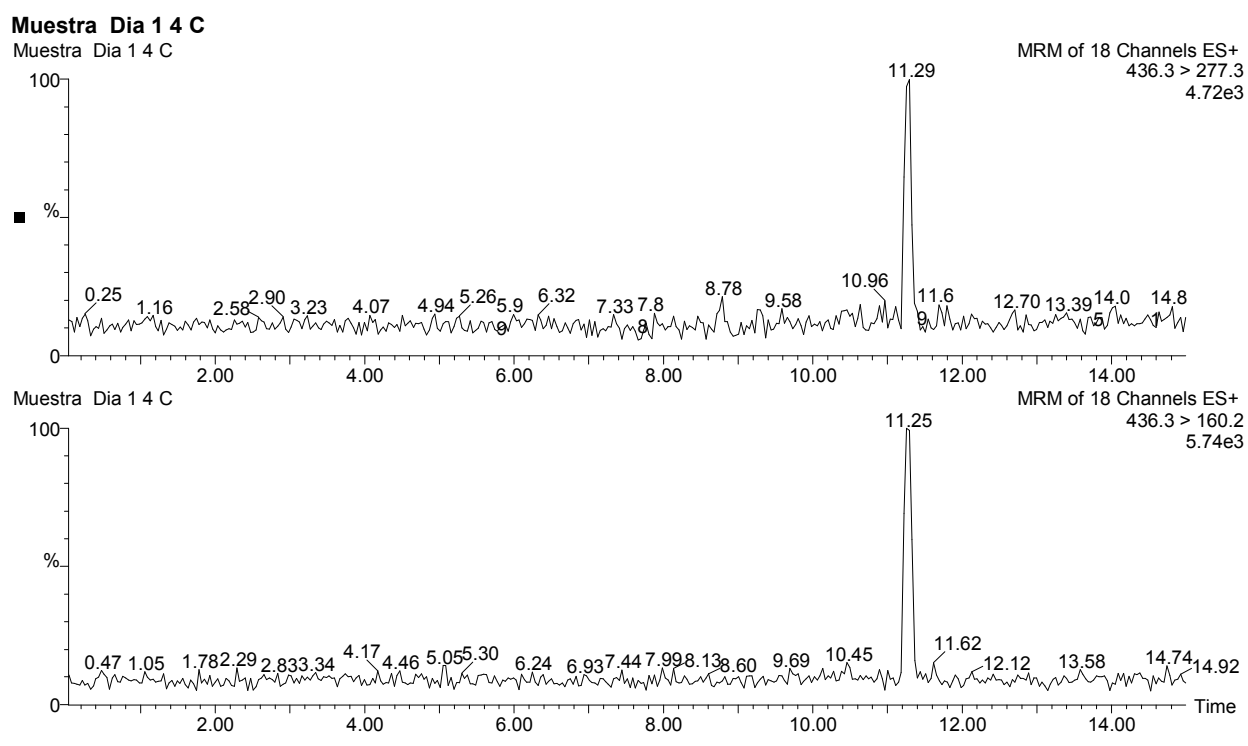

Figura 22. Cromatogramas correspondientes a los iones primario y secundario de la cloxacilina en leche el primer día de refrigeración

\subsubsection{Análisis cromatográfico de las tetraciclinas}

En los apartados siguientes se describen las diferentes etapas empleadas en el análisis cromatográfico de las tetraciclinas. 


\subsubsection{Extracción y purificación de las muestras}

Al igual que se procedió con los antibióticos betalactámicos, las muestras y los extractos de leche se acondicionaron y homogeneizaron correctamente para proceder a la extracción de los analitos.

En este caso es importante resaltar que durante todo el proceso de extracción de las tetracicilinas, se trabajó preservando las muestras de la luz directa.

En un tubo topacio de centrífuga de polipropileno de $50 \mathrm{~mL}$ se añadieron $10 \pm$ $0,01 \mathrm{~g}$ de la muestra de leche fortificada previamente homogeneizada y $20 \mathrm{~mL}$ de tampón Mcllvaine/EDTA. La mezcla se agitó en el agitador magnético durante 10 minutos antes de centrifugarla durante 15 minutos a 5.500 r.p.m.

A continuación se filtró el extracto sobrenadante a través de lana de vidrio a un matraz aforado topacio de $100 \mathrm{~mL}$.

El precipitado que queda en el tubo de centrífuga se resuspendió con $20 \mathrm{~mL}$ más de tampón Mcllvaine, se agitó 10 minutos y se centrifugó de nuevo durante 15 minutos a 5.500 r.p.m.

El extracto sobrenadante se recuperó en el matraz utilizado anteriormente para proceder a su posterior purificación mediante el sistema de extracción SPE.

A partir de este momento el procedimiento empleado corresponde con el llevado a cabo para los antibióticos betalactámicos.

Después de purificar el extracto este se reconstituyó con 0,5 $\mathrm{mL}$ de fase móvil (ácido fórmico $0,1 \%$ ) y se filtró con ayuda de una jeringa a través de un filtro PVDF de $25 \mathrm{~mm}$ y $0,2 \mu \mathrm{m}$, en un microvial de $300 \mu \mathrm{L}$ insertado en un vial cromatográfico de 2 $\mathrm{mL}$.

\subsubsection{Separación y detección cromatográfica}

A continuación se describe el procedimiento realizado para la separación cromatográfica de las tetraciclinas en las muestras y extractos almacenados, cada día de análisis.

Tras la purgación manual y automática y la estabilización total del sistema cromatográfico de análisis y detección se insertó la tanda de muestras en el orden siguiente:

- Vial 1: Fase móvil

- Vial 2: Control negativo de la muestra 
- Vial 3: Control positivo de tetraciclinas: muestra fortificada con las tetraciclinas a una concentración de $100 \mu \mathrm{g} / \mathrm{kg}$, equivalente al LMR de cada una de ellas

- Vial 4: Patrón 1 de tetraciclinas $(25 \mu \mathrm{g} / \mathrm{kg})$ : disolución de tetraciclinas en fase móvil con una concentración equivalente a $25 \mu \mathrm{g} / \mathrm{kg}$

- Vial 5: Patrón 2 de tetraciclinas $(50 \mu \mathrm{g} / \mathrm{kg})$

- Vial 6: Patrón 3 de tetraciclinas $(100 \mu \mathrm{g} / \mathrm{kg})$

- Vial 7: Patrón 4 de tetraciclinas $(200 \mu \mathrm{g} / \mathrm{kg})$

- Vial 8 y sucesivos: Muestras y extractos problema

El análisis del conjunto de muestras se programó y realizó mediante el software MassLynx 4.0 (Waters) con las siguientes condiciones cromatográficas:

- Fase móvil en modo gradiente con las siguientes condiciones:

\begin{tabular}{ccc}
\hline $\begin{array}{c}\text { Tiempo } \\
\text { (min) }\end{array}$ & $\begin{array}{c}\text { Bomba A } \\
\text { (\% ácido fórmico) }\end{array}$ & $\begin{array}{c}\text { Bomba B } \\
\text { (\% Acetonitrilo) }\end{array}$ \\
\hline $0-6$ & 85 & 15 \\
$6-8$ & 82 & 18 \\
$8-15$ & 50 & 50 \\
$15-20$ & 85 & 15 \\
\hline
\end{tabular}

- Flujo de 0,2 $\mathrm{mL} / \mathrm{min}$

- Volumen de inyección de muestra de $20 \mu \mathrm{L}$

En el Cuadro 20 se presentan las condiciones de detección del espectrómetro de masas para las tetraciclinas estudiadas, especificando el tiempo de retención de cada sustancia, la relación $\mathrm{m} / \mathrm{z}$ de los iones precursores seleccionados así como las de los iones primario y secundarios fragmentados y los respectivos voltajes de cono y colisión empleados.

\subsubsection{Interpretación de los cromatogramas}

Una vez comprobados el tiempo de retención, las recuperaciones y los parámetros de identificación de cada analito (peso molecular del ión precursor, voltaje de cono, peso molecular de los iones primario y secundario y energías de colisión) se procedió a la cuantificación de las pérdidas de concentración de las tetraciclinas debidas a las condiciones de almacenamiento, utilizando las ecuaciones de las rectas de calibrado obtenidas en la puesta a punto del método presentadas en el Cuadro 21. 
Cuadro 20. Condiciones del espectrómetro de masas para la identificación y cuantificación de las tetraciclinas

\begin{tabular}{|c|c|c|c|c|c|c|c|}
\hline Antimicrobianos & $\underset{(\min )}{\mathrm{RT}}$ & $\begin{array}{l}\text { lon } \\
\text { precursor } \\
(\mathrm{m} / \mathrm{z})\end{array}$ & $\begin{array}{l}\text { Voltaje } \\
\text { cono } \\
\text { (V) }\end{array}$ & $\begin{array}{c}\text { lón } \\
\text { primario }{ }^{1} \\
(\mathbf{m} / \mathbf{z})\end{array}$ & $\begin{array}{c}\text { Energía } \\
\text { colisión } \\
(1 / V)\end{array}$ & $\begin{array}{c}\text { lón } \\
\text { secundario } \\
(\mathrm{m} / \mathrm{z})\end{array}$ & $\begin{array}{c}\text { Energía } \\
\text { colisión } \\
(2 / V)\end{array}$ \\
\hline Doxicilina & 11,54 & 445,16 & 20 & 428,22 & 22 & 321,08 & 35 \\
\hline Clortetraciclina & 8,76 & 479,12 & 21 & 444,11 & 20 & 462,12 & 15 \\
\hline Oxitetraciclina & 3,00 & 461,10 & 18 & 426,26 & 16 & 443,23 & 11 \\
\hline Tetraciclina & 3,74 & 445,17 & 20 & 410,21 & 18 & 153,94 & 25 \\
\hline
\end{tabular}

${ }^{1}$ ión primario= ión hijo mayoritario $=$ ión de cuantificación; ${ }^{2}$ ión secundario= ión hijo secundario= ión de confirmación

Cuadro 21. Ecuaciones de las rectas de calibrado de las tetraciclinas

\begin{tabular}{|lccc|}
\hline Antimicrobianos & \multicolumn{1}{c}{ Ecuaciones } & $\mathbf{R}^{\mathbf{2}}$ & $\mathbf{C V}(\%)$ \\
\hline Clortetraciclina & $\mathrm{y}=76,75 \cdot \mathrm{x}-21,31$ & 0,990 & 6,54 \\
Doxicilina & $\mathrm{y}=129,75 \cdot \mathrm{x}-168,32$ & 0,979 & 6,99 \\
Oxitetraciclina & $\mathrm{y}=117,99 \cdot \mathrm{x}-446,11$ & 0,987 & 6,67 \\
Tetraciclina & $\mathrm{y}=131,56 \cdot \mathrm{x}-388,23$ & 0,981 & 6,15 \\
\hline
\end{tabular}

En las Figuras 23 y 24 se muestran a modo de ejemplo, el espectro del ión precursor de la oxitetraciclina y por otro lado los cromatogramas de los iones fragmentados obtenidos a partir de este, el primer día de refrigeración, en muestras de leche.

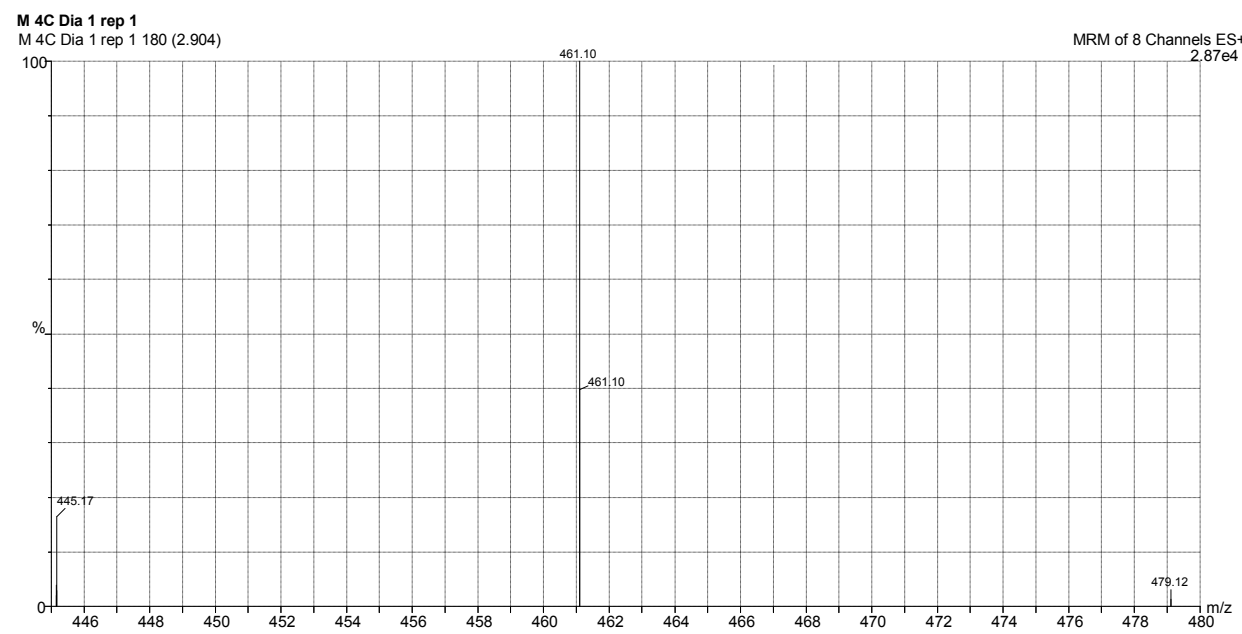

Figura 23. Espectro correspondiente al ión precursor de la oxitetraciclina en leche el primer día de refrigeración 


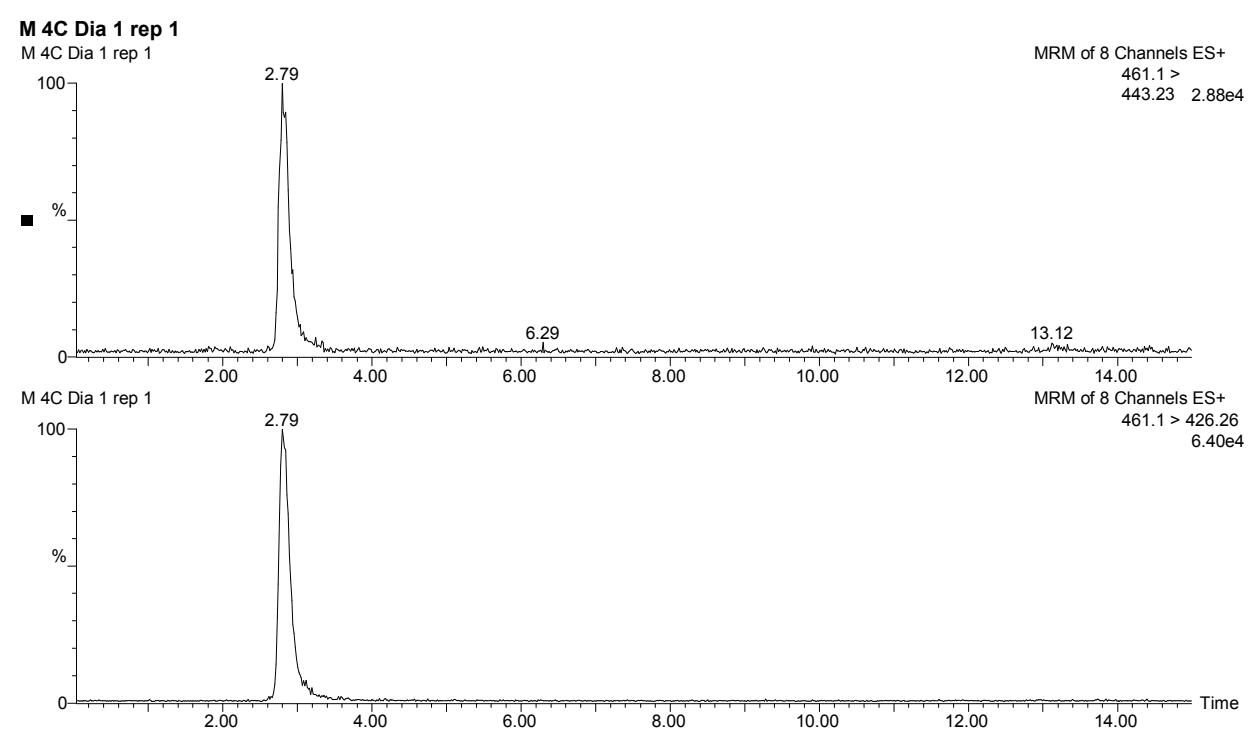

Figura 24. Cromatogramas correspondientes a los iones primarios y secundarios de la oxitetraciclina en leche el primer día de refrigeración

\subsubsection{Análisis cromatográfico de las sulfonamidas}

El análisis de las sulfonamidas se realizó siguiendo las fases descritas en los apartados siguientes. Hay que tener en cuenta que debido al amplio número de sulfonamidas estudiadas, éstas se separaron en dos grupos diferentes para facilitar su manejo y posterior análisis. Los dos grupos formados fueron:

> Grupo A : sulfacloropiradizina, sulfadiazina, sulfadimetoxina y sulfamerazina

$>$ Grupo B: sulfametazina, sulfapiridina, sulfaquinoxalina y sulfatiazol

\subsubsection{Extracción y purificación de las muestras}

El proceso de extracción y purificación de las sulfonamidas en la leche fue el mismo empleado para el caso de los betalactámicos, descrito previamente en el apartado 1.5.1.1 de Material y Métodos.

Así, a partir de $10 \mathrm{~g}$ de muestra fortificada se obtuvo y purificó el extracto con las diferentes sulfonamidas siguiendo las indicaciones correspondientes y se preparó para insertarlo en el sistema cromatográfico de análisis.

\subsubsection{Separación y detección cromatográfica}

Cada día de análisis se estabilizó el sistema cromatográfico de forma manual y automática y se insertó la tanda de muestras preparadas en el siguiente orden: 
- Vial 1: Fase móvil

- Vial 2: Control negativo de la muestra

- Vial 3: Control positivo de sulfonamidas grupo A: muestra de leche fortificada con una concentración de sulfonamidas A equivalente al LMR de cada una de ellas $(100 \mu \mathrm{g} / \mathrm{kg})$

- Vial 4: Control positivo de sulfonamidas grupo B: muestra de leche fortificada con una concentración de sulfonamidas B equivalente al LMR de cada una de ellas $(100 \mu \mathrm{g} / \mathrm{kg})$

- Vial 5: Patrón 1 de sulfonamidas A: disolución de sulfonamidas en fase móvil con una concentración equivalente a $25 \mu \mathrm{g} / \mathrm{kg}$

- Vial 6: Patrón 2 de sulfonamidas A (50 $\mu \mathrm{g} / \mathrm{kg})$

- Vial 7: Patrón 3 de sulfonamidas A (100 $\mu \mathrm{g} / \mathrm{kg})$

- Vial 8: Patrón 4 de sulfonamidas A (200 $\mu \mathrm{g} / \mathrm{kg})$

- Vial 9: Patrón 1 de sulfonamidas B $(25 \mu \mathrm{g} / \mathrm{kg})$

- Vial 10: Patrón 2 de sulfonamidas B $(50 \mu \mathrm{g} / \mathrm{kg})$

- Vial 11: Patrón 3 de sulfonamidas B $(100 \mu \mathrm{g} / \mathrm{kg})$

- Vial 12: Patrón 4 de sulfonamidas B $(200 \mu \mathrm{g} / \mathrm{kg})$

- Vial 13 y sucesivos: Muestras y extractos problema

El análisis del conjunto de muestras se programó y realizó mediante el software MassLynx 4.0 (Waters) con las siguientes condiciones cromatográficas:

- Fase móvil en modo gradiente con las siguientes condiciones:

\begin{tabular}{ccc}
\hline $\begin{array}{c}\text { Tiempo } \\
(\mathrm{min})\end{array}$ & $\begin{array}{c}\text { Bomba A } \\
\text { (\% ácido fórmico) }\end{array}$ & $\begin{array}{c}\text { Bomba B } \\
\text { (\% Acetonitrilo) }\end{array}$ \\
\hline $0-8$ & 95 & 5 \\
$8-14$ & 25 & 75 \\
$14-15$ & 5 & 95 \\
\hline
\end{tabular}

- Flujo de 0,2 mL/min

- Volumen de inyección de muestra de $20 \mu \mathrm{L}$

Por otro lado, la fuente de ionización empleada en este estudio fue la de electrospray en modo positivo $\left(\mathrm{ESI}^{+}\right)$y las condiciones de detección del espectrómetro de masas para la identificación de las sulfonamidas las que se presentan en el Cuadro 22. 
Cuadro 22. Condiciones del espectrómetro de masas para la identificación y cuantificación de sulfonamidas

\begin{tabular}{|lccccccc|}
\hline \multicolumn{1}{|c}{ Antimicrobianos } & $\begin{array}{c}\mathbf{R T} \\
(\mathbf{m i n})\end{array}$ & $\begin{array}{c}\text { Ion } \\
\text { precursor } \\
(\mathbf{m} / \mathbf{z})\end{array}$ & $\begin{array}{c}\text { Voltaje } \\
\text { cono } \\
\mathbf{( V )}\end{array}$ & $\begin{array}{c}\text { Ion } \\
\text { primario } \\
(\mathbf{m} / \mathbf{z})\end{array}$ & $\begin{array}{c}\text { Energía } \\
\text { colisión } \\
(\mathbf{1 / N})\end{array}$ & $\begin{array}{c}\text { Ion } \\
\text { secundario } \\
(\mathbf{m} / \mathbf{z})\end{array}$ & $\begin{array}{c}\text { Energía } \\
\text { colisión } \\
(\mathbf{2 / V})\end{array}$ \\
\hline Sulfacloropiradazina & 8,64 & 285 & 28 & 156 & 28 & 92 & 15 \\
Sulfadiazina & 5,34 & 251 & 30 & 156 & 26 & 92 & 16 \\
Sulfadimetoxina & 9,69 & 311 & 40 & 156 & 32 & 92 & 20 \\
Sulfamerazina & 7,01 & 265 & 32 & 156 & 28 & 92 & 18 \\
Sulfametazina & 7,70 & 279 & 30 & 186 & 30 & 92 & 17 \\
Sulfapiridina & 6,75 & 250 & 30 & 156 & 27 & 92 & 16 \\
Sulfaquinoxalina & 9,69 & 301 & 35 & 156 & 30 & 92 & 18 \\
Sulfatiazol & 6,68 & 256 & 28 & 156 & 28 & 92 & 15 \\
\hline
\end{tabular}

${ }^{1}$ ión primario= ión hijo mayoritario $=$ ión de cuantificación; ${ }^{2}$ ión secundario= ión hijo secundario= ión de confirmación

\subsubsection{Interpretación de los cromatogramas}

El procedimiento empleado para la interpretación de los resultados en el análisis de las sulfonamidas fue el mismo que en el caso de los betalactámicos y las tetraciclinas. Una vez verificados los parámetros de identificación en las tablas de datos y cromatogramas obtenidos y comprobado que el sistema era lineal y apto para la cuantificación de los antimicrobianos en el rango de trabajo establecido, se procedió a la integración de las áreas de los picos de los iones mayoritarios seleccionados en las curvas de calibrado que se presentan en el Cuadro 23.

Cuadro 23. Ecuaciones de las rectas de calibrado de las sulfonamidas

\begin{tabular}{|c|c|c|c|}
\hline Antimicrobianos & Ecuaciones & $\mathbf{R}^{2}$ & CV (\%) \\
\hline Sulfacloropiradazina & $y=316,49 \cdot x+3756,04$ & 0,9356 & 6,72 \\
\hline Sulfadiazina & $y=574,95 \cdot x-14453,20$ & 0,9408 & 6,73 \\
\hline Sulfadimetoxina & $y=1154,68 \cdot x+45860,80$ & 0,9725 & 5,87 \\
\hline Sulfamerazina & $y=764,15 \cdot x-2441,00$ & 0,9895 & 6,61 \\
\hline Sulfametazina & $y=553,34 \cdot x-2801,62$ & 0,9913 & 6,84 \\
\hline Sulfapiridina & $y=762,20 \cdot x+12771,50$ & 0,9623 & 4,00 \\
\hline Sulfaquinoxalina & $y=212,94 \cdot x+4266,41$ & 0,9766 & 6,80 \\
\hline Sulfatiazol & $y=2583,86 \cdot x+18924,8$ & 0,9767 & 6,79 \\
\hline
\end{tabular}

Como ejemplo de los resultados obtenidos se presenta en la Figura 25 el espectro de masas del ión precursor del sulfatiazol obtenido a partir de la muestra de leche refrigerada durante 24 horas (1 día). 


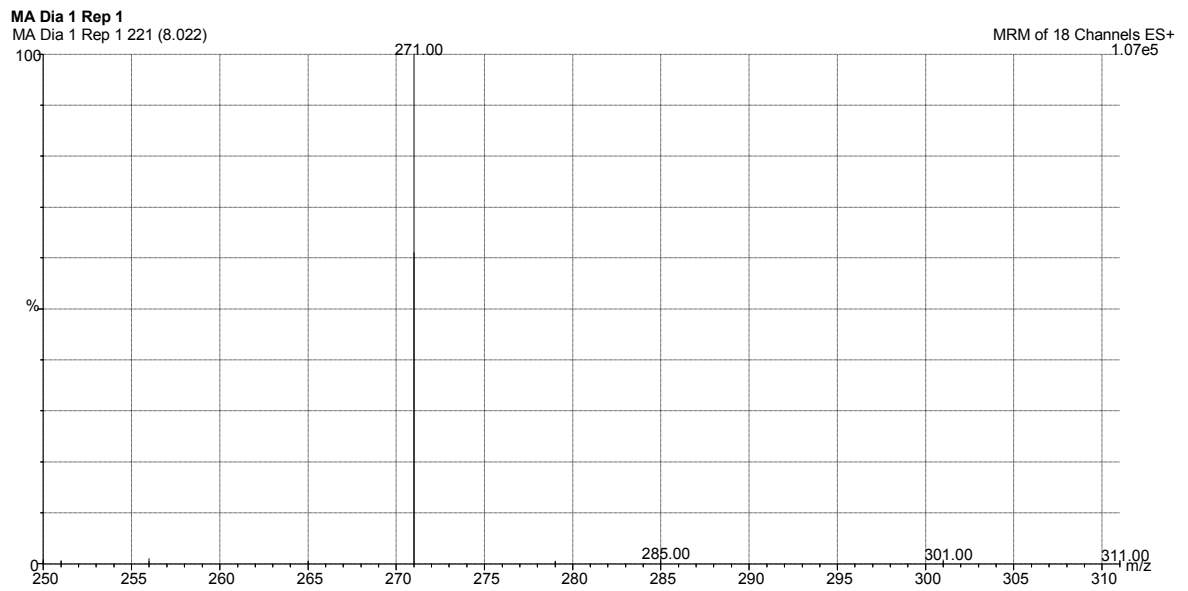

Figura 25. Espectro correspondiente al ion precursor del sulfatiazol en leche el primer día de refrigeración

También se muestra en la Figura 26 un ejemplo de los cromatogramas de los iones hijos extraídos del análisis del sulfametizol en muestras de leche después de un día de refrigeración.

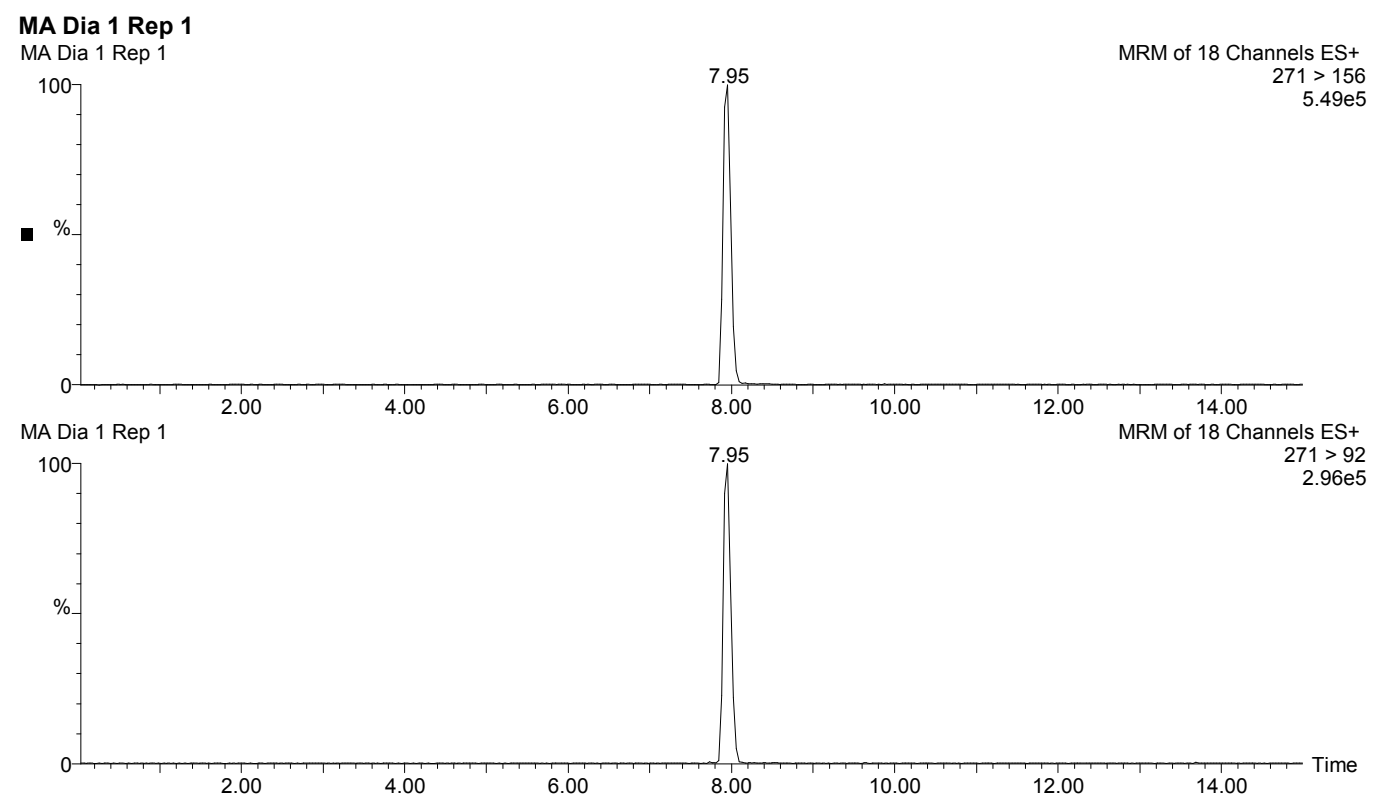

Figura 26. Cromatogramas correspondientes a los iones primario y secundario del sulfatiazol en leche el primer día de refrigeración 


\subsection{ANÁLSIS ESTADÍSTICO}

\subsubsection{Estudio de la degradación de antimicrobianos mediante modelos de primer orden}

Con el propósito de evaluar el efecto del tiempo de refrigeración o de congelación de las muestras y extractos de leche sobre la concentración de antimicrobianos presentes se aplicó el modelo cinético de primer orden, cuya expresión matemática, escrita en forma diferencial, es la siguiente:

$$
\frac{\partial[C]}{\partial t}=-k_{1} \cdot[C]
$$

Donde $\partial[C]$ : derivada de la concentración del antimicrobiano en la muestra de leche, $\partial t$ : derivada del tiempo $(t), \mathrm{k}_{1}$ : constante específica de reacción de primer orden, [C] : concentración del antimicrobiano presente en la muestra de leche. Distribuyendo los términos se obtiene:

$$
\frac{\partial[C]}{[C]}=-k_{1} \cdot \partial t
$$

Al integrar los miembros de la ecuación (2) se obtienen:

$$
\begin{gathered}
\int_{C o}^{C} \frac{\partial[C]}{[C]}=\int-k_{1} \cdot \partial t \\
\operatorname{Ln}[C]=\operatorname{Ln}\left[C_{\mathrm{o}}\right]-k_{1} \cdot t \\
\operatorname{Ln}[C]-\operatorname{Ln}\left[C_{\mathrm{o}}\right]=-k_{1} \cdot t
\end{gathered}
$$

Esta ecuación se puede linealizar mediante la representación de las transformaciones logarítmicas de las concentraciones de antibióticos en función del tiempo.

En caso de evaluar el efecto del tipo de matriz ("leche fortificada con antibióticos" o "extractos de muestras de leche previamente fortificados con antibióticos") sobre la concentración de antibiótico en el tiempo, es posible escribir una ecuación más general de la ecuación (5) que contemple además el efecto de la matriz láctea y su interacción con el tiempo del modo siguiente:

$$
\operatorname{Ln}[C]-\operatorname{Ln}\left[C_{\circ}\right]=-k_{1} \cdot t-k_{2} \cdot M-k_{1,2} \cdot t \cdot M
$$

Donde $\mathrm{k}_{2}$ : representa el cambio en la ordenada al origen de la ecuación linealizada debido al empleo de diferentes matrices lácteas y se interpreta como rectas 
paralelas de igual pendiente con una misma velocidad en la pérdida de actividad antimicrobiana, M: representa el tipo de matriz láctea en términos de variable dummy $(\mathrm{M}=+1$ : para muestras de leche refrigeradas o congeladas a las cuales se les extrae los antibióticos antes de efectuar su análisis por HPLC y $M=-1$ : para los extractos de leche obtenidos en el momento de preparación de las muestras de leche fortificadas y refrigerados o congelados a diferentes tiempos), $k_{1,2}$ : representa la interacción entre el tiempo de refrigeración (o congelación) y la matriz láctea utilizada.

Los resultados de las concentraciones de antibióticos para diferentes tiempos de refrigeración y congelación fueron introducidos en una hoja de cálculo Excel ${ }^{\circledR}$, al igual que sus transformaciones logarítmicas. Posteriormente se aplicó la opción STEPWISE del modelo de regresión lineal múltiple a la ecuación (6) utilizando el procedimiento PROC REG del paquete estadístico SAS ${ }^{\circledR}$ (SAS, 2001).

Para cada sustancia y valor de temperatura se determinaron los tiempos de vida media $\left(\mathrm{t}_{1 / 2}\right)$ como el tiempo necesario para que la concentración de antimicrobiano se reduzca al $50 \%$ respecto a su concentración inicial

De este modo, al reemplazar "[C]" por “ $1 / 2\left[\mathrm{C}_{\mathrm{o}}\right]$ " en la ecuación (6) se obtiene:

$$
\operatorname{Ln}\left[\frac{1}{2} C\right]-\operatorname{Ln}\left[C_{\circ}\right]=-k_{1} \cdot t-k_{2} \cdot M-k_{1,2} \cdot t \cdot M
$$

Reagrupando los términos y simplificando se llega a:

$$
t_{1 / 2}=\frac{\operatorname{Ln} 2}{\left(k_{1}+\left(k_{2}+k_{1,2}\right) \cdot M\right)}
$$

Así, los tiempos de vida media se han calculado como el cociente entre el logaritmo natural de "2" y las constantes específicas estimadas mediante la ecuación del modelo de primer orden y el valor de la variable Dummy "M" correspondiente.

\subsubsection{Estimación de los porcentajes de degradación de los antimicrobianos}

Haciendo uso de la ecuación (6) determinada mediante el modelo de regresión lineal múltiple, se calcularon los porcentajes de degradación térmica para cada antimicrobiano mediante la siguiente expresión:

$$
\% \text { Degradación }=\frac{C_{0}-C}{C_{0}} \cdot 100=\left(1-e^{\left(-k_{1} \cdot t-k_{2} \cdot M-k_{1,2} \cdot \cdot \cdot M\right)}\right) \cdot 100
$$

La ecuación anterior permite calcular las pérdidas en las concentraciones de antimicrobianos como una función del tiempo (“ $t$ ”) de conservación y del tipo de matriz utilizada (“M"). 


\section{SEGUNDO ESTUDIO. Efecto de diferentes tratamientos térmicos de calor sobre la estabilidad de los antimicrobianos en la leche}

\subsection{DISEÑO EXPERIMENTAL}

Con el fin de estudiar la influencia de diferentes tratamientos térmicos de calor sobre la presencia de antimicrobianos en la leche, se planteó el diseño experimental utilizando algunas de las principales sustancias empleadas en los tratamientos y profilaxis de enfermedades del ganado vacuno lechero.

Este estudio se realizó sobre muestras de leche en polvo adicionadas con una concentración establecida de antimicrobianos pertenecientes a los grupos de betalactámicos, tetraciclinas y sulfonamidas.

Las sustancias estudiadas fueron las siguientes:

- Betalactámicos:

Penicilinas: amoxicilina, ampicilina, cloxacilina y penicilina $\mathrm{G}$

$>$ Cefalosporinas: cefalexina, cefalonio, cefapirina, cefoperazona, cefquinoma y cefuroxima

- Tetraciclinas: clortetraciclina, doxicilina, oxitetraciclina y tetraciclina

- Sulfonamidas: sulfacloropiradazina, sulfadiazina, sulfadimetoxina, sulfamerazina, sulfametazina, sulfapiridina, sulfaquinoxalina y sulfatiazol

Las disoluciones de leche fortificadas, se sometieron a los tratamientos térmicos correspondientes a las temperaturas y tiempos que se presentan en el Cuadro 24.

A continuación, las disoluciones tratadas térmicamente, así como las que no fueron sometidas a ningún tratamiento (muestras blanco) se analizaron por triplicado, previo procesamiento de la muestra, mediante un equipo de cromatografía líquida de alta eficacia (HPLC), para llevar a cabo la cuantificación de pérdidas de concentración de los diferentes antimicrobianos estudiados en función de los distintos tratamientos.

\section{2. PATRONES Y MUESTRAS FORTIFICADAS}

De cada uno de los antibióticos estudiados, se preparó una disolución madre o "stock" con una concentración de $1000 \mu \mathrm{g} / \mathrm{g}$, teniendo en cuenta la pureza indicada por el fabricante y el disolvente más adecuado para cada sustancia. 
Cuadro 24. Temperaturas y tiempos empleados en el esudio del efecto de diferentes tratamientos térmicos de calor sobre la estabilidad de los antimicrobianos en la leche

\begin{tabular}{|c|c|c|c|}
\hline \multirow{2}{*}{\multicolumn{2}{|c|}{ Antimicrobianos }} & \multicolumn{2}{|r|}{ Tratamientos térmicos } \\
\hline & & $\mathrm{T}^{\mathrm{a}} \pm 2\left({ }^{\circ} \mathrm{C}\right)$ & Intervalos de tiempo (min) \\
\hline \multirow{10}{*}{ Betalactámicos } & \multirow{5}{*}{ Penicilinas } & 60 & $0,60,120,180,240,300,360$ \\
\hline & & 70 & $0,60,120,180,240,300,360$ \\
\hline & & 80 & $0,60,120,180,240,300,360$ \\
\hline & & 90 & $0,30,60,90,120,150,180$ \\
\hline & & 100 & $0,30,60,90,120,150,180$ \\
\hline & \multirow{5}{*}{ Cefalosporinas } & 60 & $0,10,20,30,40,50,60$ \\
\hline & & 70 & $0,10,20,30,40,50,60$ \\
\hline & & 80 & $0,10,20,30,40,50,60$ \\
\hline & & 90 & $0,5,10,15,20,25,30$ \\
\hline & & 100 & $0,5,10,15,20,25,30$ \\
\hline \multirow{5}{*}{\multicolumn{2}{|c|}{ Tetraciclinas }} & 60 & $0,60,120,180,240,300,360$ \\
\hline & & 70 & $0,60,120,180,240,300,360$ \\
\hline & & 80 & $0,60,120,180,240,300,360$ \\
\hline & & 90 & $0,15,30,45,60,75,90$ \\
\hline & & 100 & $0,15,30,45,60,75,90$ \\
\hline \multirow{5}{*}{ Sulfonamidas } & & 60 & $0,30,60,90,120,150,180$ \\
\hline & & 70 & $0,30,60,90,120,150,180$ \\
\hline & & 80 & $0,30,60,90,120,150,180$ \\
\hline & & 90 & $0,15,30,45,60,75,90$ \\
\hline & & 100 & $0,15,30,45,60,75,90$ \\
\hline
\end{tabular}

A partir de estas disoluciones se prepararon otras diluidas de $10 \mu \mathrm{g} / \mathrm{g}$ de concentración tomando $100 \pm 4 \mu \mathrm{L}$ de la solución "madre" de cada antibiótico y enrasando en un matraz con $10 \mathrm{~g}$ de agua ultra pura. Estas disoluciones se homogeneizaron en el baño de ultrasonidos durante 5 minutos y se utilizaron para la preparación de muestras de leche fortificadas y los controles positivos.

Las diferentes sustancias antimicrobianas ensayadas, su procedencia comercial y el disolvente más adecuado empleado en cada caso se presentan en el Cuadro 25. 
Cuadro 25. Antimicrobianos y disolventes utilizados

\begin{tabular}{|c|c|c|c|}
\hline \multicolumn{2}{|c|}{ Antimicrobianos } & Disolvente & Ref. comercial \\
\hline \multirow{10}{*}{$\begin{array}{l}\text { Betalactámicos } \\
\quad(5 \mu \mathrm{g} / \mathrm{g})\end{array}$} & Penicilina G & $\mathrm{H}_{2} \mathrm{O}$ & Sigma PEN-Na \\
\hline & Amoxicilina & $\mathrm{H}_{2} \mathrm{O}$ & Sigma A-8523 \\
\hline & Ampicilina & $\mathrm{H}_{2} \mathrm{O}$ & Sigma A-9518 \\
\hline & Cloxacilina & $\mathrm{H}_{2} \mathrm{O}$ & Sigma C-9393 \\
\hline & Cefalexina & $\mathrm{H}_{2} \mathrm{O}$ & Sigma C-4895 \\
\hline & Cefalonio & $\mathrm{AcN} / \mathrm{H}_{2} \mathrm{O}$ & Shering-Plough ${ }^{1}$ \\
\hline & Cefapirina & $\mathrm{H}_{2} \mathrm{O}$ & Sigma C-8270 \\
\hline & Cefoperazona & $\mathrm{H}_{2} \mathrm{O}$ & Sigma C-4292 \\
\hline & Cefquinoma & $\mathrm{HCl} 0,1 \mathrm{~N}$ & Intervet $^{2}$ \\
\hline & Cefuroxime & $\mathrm{H}_{2} \mathrm{O}$ & Sigma C-4417 \\
\hline \multirow{4}{*}{$\begin{array}{l}\text { Tetraciclinas } \\
\qquad(5 \mu \mathrm{g} / \mathrm{g})\end{array}$} & Clortetraciclina & $\mathrm{HCl} 0,1 \mathrm{~N}$ & Sigma C-4881 \\
\hline & Doxiciclina & $\mathrm{HCl} 0,1 \mathrm{~N}$ & Sigma D-9891 \\
\hline & Oxitetraciclina & $\mathrm{HCl} 0,1 \mathrm{~N}$ & Sigma O-5750 \\
\hline & Tetraciclina & $\mathrm{HCl} 0,1 \mathrm{~N}$ & Sigma T-3258 \\
\hline \multirow{8}{*}{$\begin{array}{l}\text { Sulfonamidas } \\
(0,2 \mu \mathrm{g} / \mathrm{g})\end{array}$} & Sulfacloropiradazina & Metanol & Sigma S-9882 \\
\hline & Sulfadiazina & Metanol & Sigma S-8626 \\
\hline & Sulfadimetoxina & Metanol & Sigma S-7007 \\
\hline & Sulfametazina & Metanol & Sigma S-6256 \\
\hline & Sulfamerazina & Metanol & Sigma S-8876 \\
\hline & Sulfapiridina & Metanol & Sigma S-6252 \\
\hline & Sulfaquinoxalina & Metanol & Sigma S-7382 \\
\hline & Sulfatiazol & Metanol & Sigma S-9876 \\
\hline
\end{tabular}

1 Shering-Plough (Bray), Boghall Road, Bray, Co. Wicklow, Irlanda; ${ }^{2}$ Intervet International GmbH, Feldstraße $1^{\mathrm{a}}, \mathrm{D}-85716$ Unterschelßheim, Alemania.

Para los antimicrobianos pertenecientes a los grupos de betalactámicos y tetraciclinas se prepararon muestras de leche fortificadas que contenían $5 \mu \mathrm{g} / \mathrm{g}$ de cada una de las sustancias en estudio. Para ello, se añadieron $5000 \pm 0,7 \mu \mathrm{L}$ de solución madre de cada una de ellas a $1000 \mathrm{~g}$ de leche en polvo de calidad microbiológica (Ref: 115363, Merck) reconstituida al 10\% con anterioridad con agua ultra pura.

Dado que el análisis de las sulfonamidas se realizó mediante espectrometría de masas, que presenta una mayor sensibilidad en la detección de sustancias, se prepararon muestras de leche fortificadas con $0,2 \mu \mathrm{g} / \mathrm{g}$ de cada antimicrobiano perteneciente a este grupo, añadiendo $200 \pm 0,7 \mu \mathrm{L}$ de cada solución madre a $1000 \mathrm{~g}$ de leche. Para la preparación de estas muestras fortificadas se siguieron las recomendaciones de la Federación Internacional de Lechería (FIL, 1997), teniendo la precaución que el volumen de disolución acuosa de un fármaco no superase al $1 \%$ del volumen de disolución final en leche. 
Como ya se ha comentado anteriormente, las muestras de leche fortificadas y homogeneizadas, se repartieron en diferentes alícuotas de $15 \mathrm{~mL}$ en tubos de vidrio provistos de tapón rosca, que en el caso de las tetraciclinas fueron de color topacio, para someterlas a los correspondientes tratamientos térmicos en baño termoestático de agua o de aceite para el calentamiento de $100^{\circ} \mathrm{C}$.

\subsection{EQUIPOS Y MATERIALES}

\subsubsection{Equipos cromatográficos}

Para el análisis de antibióticos betalactámicos y tetraciclinas se emplearon los dos equipos cromatográficos (Waters, EEUU) que se describen a continuación. Las analíticas se han desarrollado siguiendo los protocolos puestos a punto y validados por el equipo de I+D del Instituto Lactológico de Lekunberri (Lekunberri, Pamplona), bajo la Norma Internacional de Calidad ISO:17025 (ISO, 2005).

- Sistema de limpieza o "cleanup" empleado en la separación cromatográfica de penicilinas y cefalosporinas y la cuantificación de cefalosporinas, con las siguientes características:

Desgasificador en línea Waters

Bomba controladora de flujo Waters 600

Inyector automático Waters 717 plus

Detector UV-Visible Waters 486

Colector automático de fracciones Waters

Columna Novapack ${ }^{\circledR} \mathrm{C}_{18}$ de Waters con las siguientes características:

- Diámetro interno y longitud : 3,9 x $150 \mathrm{~mm}$

- Tamaño partícula: $4 \mu \mathrm{m}$

- Tamaño de poro: $40 \AA$

- Sistema integrado de análisis cromatográfico con detector UV utilizado en la cuantificación de penicilinas y separación y cuantificación de tetraciclinas, compuesto por:

> Módulo de separación Waters Alliance ${ }^{\circledR}$ 2695, con desgasificador, bomba y autoinyector integrados en un solo equipo

D Detector de fotodiodos Waters 996 PDA (200 nm y $400 \mathrm{~nm}$ )

$>$ Columna Novapack ${ }^{\circledR} \mathrm{C}_{18}$ (la misma que en el sistema cleanup) 
En las Figuras 27 y 28, se muestran el colector automático de fracciones, el inyector y el detector UV empleados en la separación cromatográfica de este equipo.

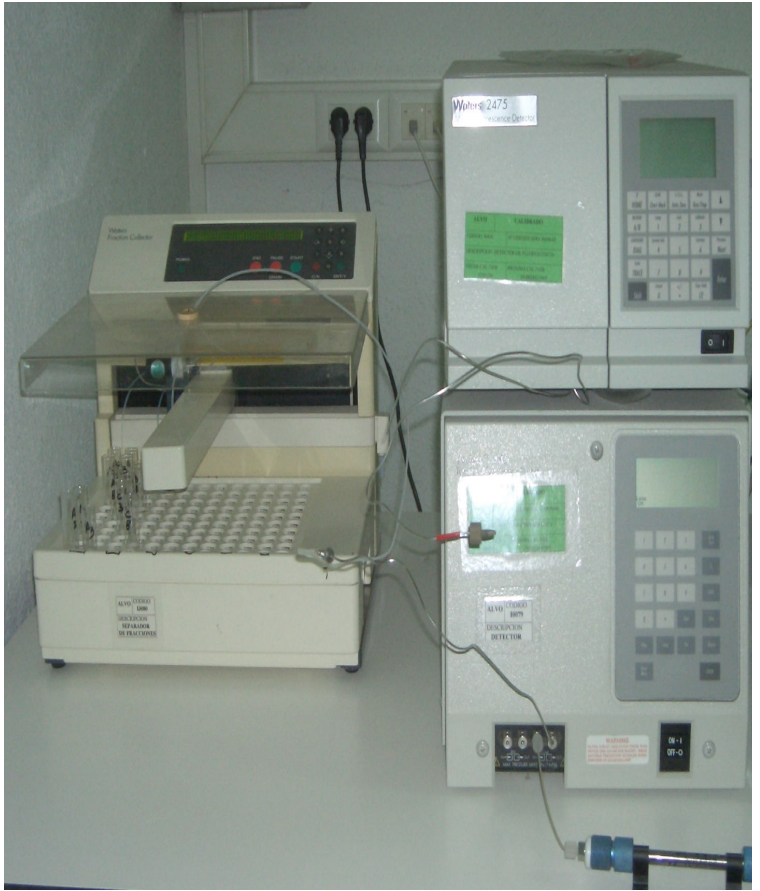

Figura 27. Colector automático de fracciones

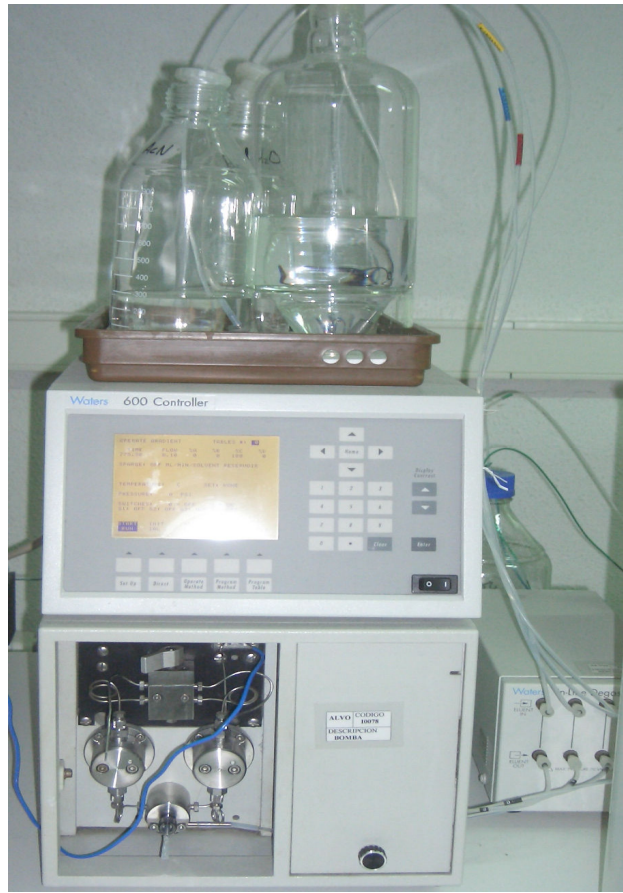

Figura 28. Inyector y detector UV

A su vez, en las Figuras 29 y 30 , se muestra el sistema integrado de análisis cromatográfico con detector UV y un detalle de la columna $\mathrm{C}_{18}$ empleada en la cuantificación de penicilinas y tetraciclinas.

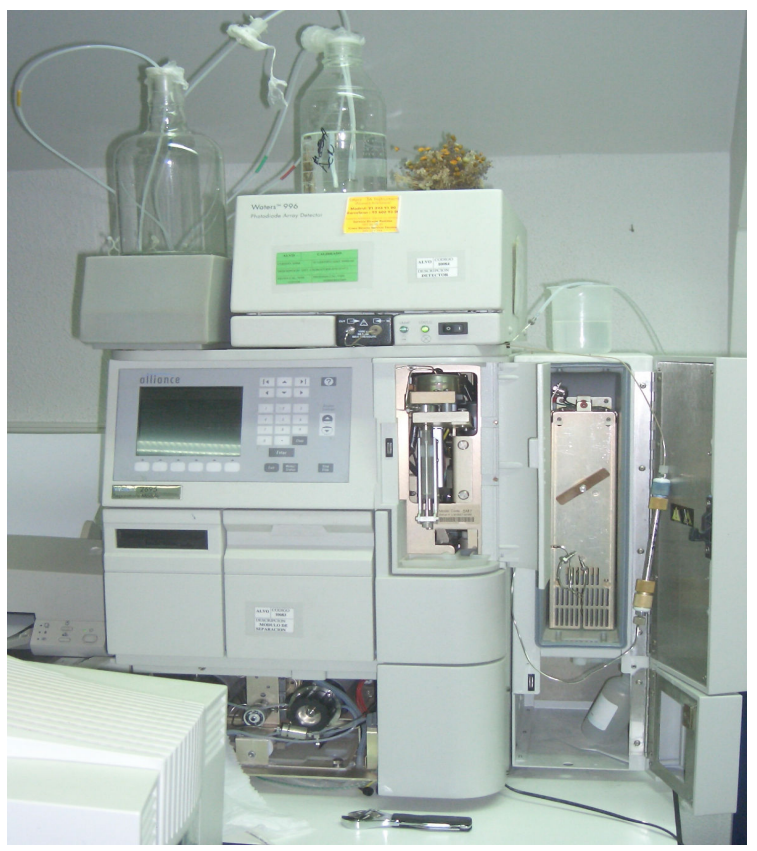

Figura 29. Sistema integrado de análisis

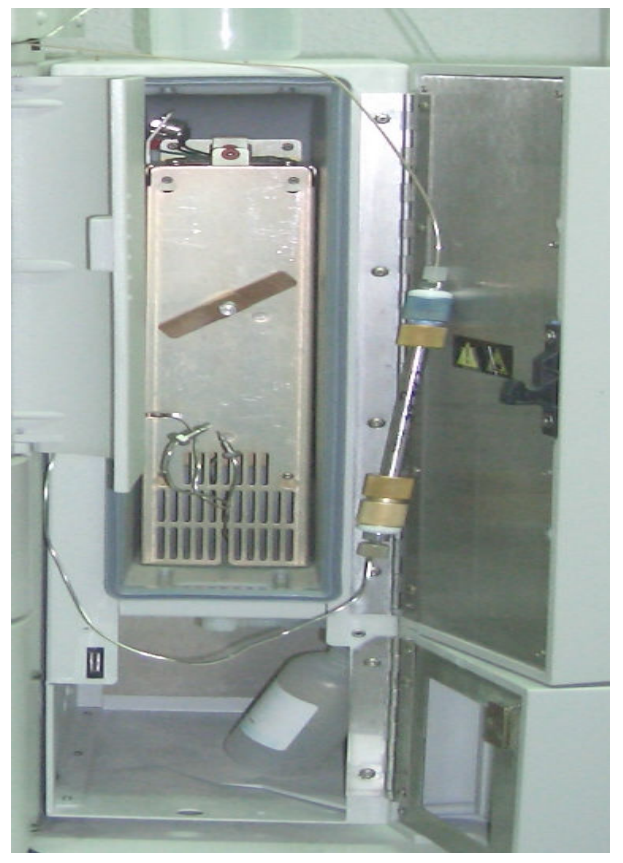

Figura 30. Detalle de la columna $\mathrm{C}_{18}$ 
En el caso de la identificación y cuantificación de las sulfonamidas se empleó el mismo sistema de análisis cromatográfio acoplado a detector de masas utilizado en el primer estudio y descrito previamente en el apartado 1.3.1, de Materiales y Métodos.

\subsubsection{Otros equipos}

Además de los equipos cromatográficos descritos en el apartado anterior, también se utilizaron los siguientes para la fase de preparación de las muestras, patrones y tratamientos térmicos:

- Balanza analítica con una precisión $\pm 0,001 \mathrm{~g}$ (Mettler Toledo AB104S)

- Centrífuga con rotor angular de 8 x 50mL y 5.500 r.p.m. (Hermlez 323)

- Sistema de filtración de reactivos (Millipore)

- $\quad$ PH-metro con una precisión de \pm 0,01g (Crison GLP21)

- Baño termoestático de aceite con temperatura regulable (Selecta)

- Baño de ultrasonidos (Fungilab S.A.)

- Baño termostático de agua con temperatura regulable (Selecta)

- Concentrador evaporador con termostato (UVS 400ª Savant)

- Sistema de vacío con flujo constante

- Sistema de extracción en fase sólida

- $\quad$ Agitador vibrador tipo vortex (Heidolph Reax Top)

- Agitador magnético (Variomag)

\subsubsection{Materiales}

Los materiales empleados para la realización de este estudio fueron los siguientes:

- Matraces cilindrocónicos de vidrio de $125 \mathrm{~mL}$

- Matraces kitasatos de vidrio de $250 \mathrm{~mL}$ con tapones de goma

- Tubos graduados Pyrex de vidrio de $10 \mathrm{~mL}$

- Tubos de centrífuga Pirex de $10 \mathrm{~mL}$ y de polipropileno copolímero (PPCO) de $50 \mathrm{~mL}$

- Bureta de vidrio de $50 \pm 0,5 \mathrm{~mL}$ graduada

- Jeringuillas de plástico de $5 \mathrm{~mL}$ desechables

- Micropipetas automáticas

- Filtros polifluoruro de vinilideno (PVDF) de $2,5 \mathrm{~mm}$ de diámetro y $0,45 \mu \mathrm{m}$ de tamaño de poro

- Cartuchos Sep-Pac Vac RC (500 mg) C ${ }_{18}$ (Waters) 
- Viales de vidrio de 2 y $4 \mathrm{~mL}$ con sus respectivos tapones y septums

- Microinsertos o microviales de $300 \mu \mathrm{L}$

Además se empleó el material habitual del laboratorio (guantes de látex, pesa sustancias, probetas, matraces aforados, erlenmeyers, espátulas, pipetas de vidrio, etc.).

\subsection{REACTIVOS}

\subsubsection{Fase móvil del sistema cromatográfico "cleanup"}

Para el sistema cromatográfico "cleanup" se preparó una fase móvil compuesta por dos reactivos, repartidos en dos bombas diferentes de la siguiente manera:

- Bomba A: Acetonitrilo grado gradiente

- Bomba B: Fosfato potásico monobásico $\left(\mathrm{KH}_{2} \mathrm{PO}_{4}\right)$ 0,01M

Los reactivos necesarios para la preparación de esta fase móvil fueron:

- Acetonitrilo grado gradiente para cromatografía líquida.

- Fosfato potásico monobásico $\left(\mathrm{KH}_{2} \mathrm{PO}_{4}\right)$

- Agua ultra pura grado reactivo

La preparación de $\mathrm{KH}_{2} \mathrm{PO}_{4}$ se llevó a cabo en un vaso de precipitados de 250 $\mathrm{mL}$ donde se pesaron 2,7 $\pm 0,1 \mathrm{~g}$ de $\mathrm{KH}_{2} \mathrm{PO}_{4}$ y se disolvieron con agua ultra pura hasta 2 L. La disolución obtenida se filtró y se desgasificó posteriormente en el baño de ultrasonidos durante quince minutos.

\subsubsection{Fase móvil del sistema cromatográfico de análisis con detector UV}

Este sistema de separación cromatográfica se utilizó, como se ha mencionado anteriormente, para la cuantificación de las penicilinas así como para la separación cuantitativa de las tetraciclinas.

Para el análisis de las penicilinas, se utilizó una fase móvil compuesta por una mezcla de reactivos en una única bomba (Bomba A). Estos reactivos necesarios para la preparación de la fase móvil fueron los siguientes:

- Acetonitrilo grado isocrático

- Dodecil sulfato sódico SDS 0,0075 M

- Acido fosfórico $\left(\mathrm{H}_{3} \mathrm{PO}_{4}\right)$ 0,015 M

- Agua ultra pura grado reactivo 
Por un lado, se introdujeron $700 \mathrm{~mL}$ de acetonitrilo grado gradiente en una botella de $2 \mathrm{~L}$.

Por otra parte, se pesaron $2,8 \pm 0,1 \mathrm{~g}$ de SDS y se disolvieron con $1,3 \mathrm{~L}$ de agua ultra pura. La disolución se introdujo en la botella dónde estaba el acetonitrilo.

A continuación se añadieron $1,326 \mu \mathrm{L}$ de $\mathrm{H}_{3} \mathrm{PO}_{4} \quad 0,015 \mathrm{M}$ a la disolución anterior y la mezcla se homogeneizó, se filtró y posteriormente se desgasificó en el baño de ultrasonidos durante quince minutos.

En el caso de las tetraciclinas, se empleó una fase móvil compuesta por varios reactivos repartidos en dos bombas diferentes de la siguiente forma:

- Bomba A: Acido oxálico 0,05 M

- Bomba B: Acetonitrilo grado gradiente

Los reactivos necesarios para la preparación de la fase móvil correspondiente fueron los siguientes:

- Acetonitrilo grado gradiente para cromatografía liquida

- Ácido oxálico dihidratado ACS-ISO $(\mathrm{COOH})_{2} 2 \mathrm{H}_{2} \mathrm{O}$

- Agua ultra pura grado reactivo

En un vaso de precipitados de $250 \mathrm{~mL}$ se pesaron $6,3 \pm 0,1 \mathrm{~g}$ de ácido oxálico y se disolvieron en $1 \mathrm{~L}$ de agua ultra pura.

A continuación se mezclaron $850 \mathrm{~mL}$ de esta disolución con $150 \mathrm{~mL}$ de acetonitrilo. La disolución se filtró, se desgasificó posteriormente en el ultrasonidos durante 10 minutos y se ajustó el $\mathrm{pH}$ hasta un valor de 2,1 $\pm 0,5$.

\subsubsection{Fase móvil del sistema cromatográfico de análisis con detector MS/MS}

El sistema LC-MS/MS se utilizó para la determinación de las sulfonamidas. En este caso la fase móvil se empleó en modo gradiente como se ha descrito en el apartado 1.4.1. de este trabajo.

\subsubsection{Otros reactivos}

En el caso de las tetraciclinas, para la fase de preparación de las muestras, también fue necesario preparar los reactivos que se citan a continuación:

Ácido oxálico en metanol 0,05 M: Se disolvieron 6,3 $\pm 0,1 \mathrm{~g}$ de ácido oxálico en $1 \mathrm{~L}$ de metanol (pureza > 99,9) 
Ácido clorhídrico $0,1 \mathrm{~N}$ : Se diluyeron $100 \mathrm{~mL}$ de ácido clorhídrico $1 \mathrm{~N}$ en $1 \mathrm{~L}$ de agua ultra pura.

Buffer Fosfato $\mathrm{pH}$ 6,7: Se pesaron 2,5 $\pm 0,1 \mathrm{~g}$ de $\mathrm{KH}_{2} \mathrm{PO}_{4}$ y 2,5 $\pm 0,1 \mathrm{~g}$ de $\mathrm{K}_{2} \mathrm{HPO}_{4} \cdot 3 \mathrm{H}_{2} \mathrm{O}$ y se disolvieron en $1 \mathrm{~L}$ de agua ultra pura. A continuación se filtró la disolución y se ajustó el pH hasta un valor de 6,7 $\pm 0,2$.

Tampón Mcllvaine: Se pesaron 10,93 $\pm 0,1 \mathrm{~g}$ de $\mathrm{Na}_{2} \mathrm{HPO}_{4}$ y se disolvieron en $385 \mathrm{~mL}$ de agua ultra pura. Por otro lado, se pesaron 12,9 $\pm 0,1 \mathrm{~g}$ de ácido cítrico y se disolvieron en $615 \mathrm{~mL}$ de agua ultra pura. Se mezclaron las dos disoluciones y se comprobó que el pH resultante debía presentar un valor de $4 \pm 0,3$.

Tampón Mcllvaine/EDTA: Se añadieron 3,72 $\pm 0,1 \mathrm{~g}$ de etil diamina tetra acetato disódico (EDTA) a $1 \mathrm{~L}$ de tampón Mcllvaine, mezclando bien la disolución.

\subsection{ANÁLISIS CROMATOGRÁFICO DE LOS ANTIMICROBIANOS}

La puesta a punto de las distintas metodologías y protocolos de trabajo que se describen en los apartados siguientes se han realizado en el Laboratorio de Salud Pública de la Generalitat Valenciana (Albal, Valencia) y en el laboratorio del Instituto Lactológico de Lekunberri (Lekunberri, Pamplona), de acuerdo a la Norma Internacional de Calidad ISO:17025 (ISO, 2005).

\subsubsection{Determinación cromatográfica de los antibióticos betalactámicos}

Una vez transcurrido el tiempo de tratamiento a una determinada temperatura para cada alícuota, las muestras se llevaron, en recipiente con agua, a temperatura ambiente y se procedió a la preparación específica de la muestra correspondiente a los procedimientos analíticos aplicados.

El protocolo de trabajo para penicilinas y cefalosporinas fue prácticamente el mismo. En el caso de las penicilinas el método consistió en un "cleanup" y un análisis cromatográfico de las fracciones separadas, mientras que en el caso de las cefalosporinas el método consistió únicamente en un único análisis cromatográfico que permitió cuantificar directamente los antibióticos sin la necesidad de un análisis posterior.

Las condiciones cromatográficas de lectura en el detector fueron distintas para cada grupo de betalactámicos, por lo que, una vez procesadas y analizadas las muestras de penicilinas, se modificaron las condiciones de trabajo del cromatógrafo y se analizaron, a continuación las muestras fortificadas con las cefalosporinas. 


\subsubsection{Preparación y extracción de la muestra}

En un matraz de $125 \mathrm{~mL}$ se añadieron $10 \pm 0,01 \mathrm{~g}$ de la muestra de leche adicionada y $2 \mathrm{~mL}$ de cloruro de tetraetilamonio $0,2 \mathrm{M}$. Se colocó el matraz en un agitador magnético y se añadió a continuación $38 \pm 0,4 \mathrm{~mL}$ de acetonitrilo desde una bureta mientras la muestra estaba en agitación, para poder realizar así la desproteinización de la leche.

A continuación se dejó reposar la muestra durante cinco minutos, para conseguir una separación de fases y se filtró el sobrenadante a través de lana de vidrio a un kitasatos y se añadió $1 \mathrm{~mL}$ de agua destilada para asegurar la eliminación del acetonitrilo durante la evaporación.

El matraz kitasatos se colocó en un baño termostático a $65 \pm 2^{\circ} \mathrm{C}$ y se conectó a vacío con el fin de evaporar el colectado bajo presión reducida hasta prácticamente sequedad.

El residuo se redisolvió con pequeñas porciones de agua destilada de $1 \mathrm{~mL}$ hasta un volumen de $3 \mathrm{~mL}$, que se recolectó en un tubo graduado de $10 \mathrm{~mL}$. Después de homogeneizar en el vortex 30 segundos y mantener 5 minutos en ultrasonidos, con ayuda de una jeringa se filtró el colectado a un vial de $4 \mathrm{~mL}$ a través de un filtro de PVDF de $25 \mathrm{~mm}$ y $0,45 \mu \mathrm{m}$.

Este vial se insertó en el sistema cromatográfico de "cleanup" para separar las diferentes fracciones en las que eluirían los antibióticos betalactámicos.

\subsubsection{Separación de fracciones por "cleanup"}

Tras la puesta en marcha y estabilización del sistema cromatográfico de "cleanup" se insertó en el carro la del equipo cromatográfico la siguiente serie analítica:

- Vial 1: Agua ultra pura

- Vial 2: Control negativo de la muestra de leche

- Vial 3: Control positivo de identificación. Se añadieron $100 \pm 5 \mu \mathrm{L}$ de las disoluciones madre $(1000 \mu \mathrm{g} / \mathrm{g})$ de los distintos antibióticos a $10 \mathrm{~g}$ de la leche, obteniendo muestras con una concentración de $10 \mu \mathrm{g} / \mathrm{g}$

- Vial 4: Control positivo de cuantificación. A una muestra de leche de $10 \mathrm{~g}$ se le añadieron los volúmenes necesarios de cada solución diluida $(10 \mu \mathrm{g} / \mathrm{g})$ para obtener una muestra de leche con una concentración final de antibióticos igual al límite de cuantificación de cada uno de ellos 
- Vial 5: Control positivo de detección. A una muestra de leche de $10 \mathrm{~g}$ se le añadieron los volúmenes necesarios de cada solución diluida $(10 \mu \mathrm{g} / \mathrm{g})$ para obtener una muestra de leche con una concentración final de antibióticos igual al límite de detección de cada uno de ellos

- Vial 6: Agua ultra pura

- Vial 7 y sucesivos: Extractos de las muestras de leche fortificadas y tratadas térmicamente

A continuación, se programó el análisis del conjunto de muestras mediante el software Empower Pro. (Waters) con las siguientes condiciones cromatográficas:

- Fase móvil en modo gradiente con las siguientes condiciones:

\begin{tabular}{ccc}
\hline $\begin{array}{c}\text { Tiempo } \\
(\mathrm{min})\end{array}$ & $\begin{array}{c}\text { Bomba A } \\
(\% \mathrm{AcN})\end{array}$ & $\begin{array}{c}\text { Bomba B } \\
\left(\% \mathrm{KH}_{2} \mathrm{PO}_{4}\right)\end{array}$ \\
\hline $0-3$ & 100 & 0 \\
$3-40$ & 60 & 40 \\
$40-50$ & 100 & 0 \\
\hline
\end{tabular}

- Flujo de $1 \mathrm{~mL} /$ minuto

- Tiempo de análisis por muestra de 50 minutos

- Tiempo entre inyecciones de 10 minutos

- Volumen de inyección de $1000 \mu \mathrm{L}$

- Lectura mediante detector UV a $210 \mathrm{~nm}$ para las penicilinas y $265 \mathrm{~nm}$ para las cefalosporinas

Se programó también un colector a la salida del detector para recoger las fracciones en las que eluirían los analitos. Estas se colectaron en intervalos de tiempo de 5 minutos en el transcurro del ensayo cromatográfico.

Debido al volumen de inyección tan elevado, era posible que ocurrieran pequeñas variaciones en el tiempo de retención, y de esta forma se aseguró que el antibiótico se encontraba realmente en una de las fracciones recogidas.

Se observó el tiempo de retención de cada antibiótico correspondiente al control de $10 \mu \mathrm{g} / \mathrm{g}$ y se tomó esa fracción para la determinación cromatográfica, tanto en muestras de leche fortificadas, controles positivos y control negativo, en tubos graduados convenientemente rotulados. Puesto que el flujo de la fase móvil era de 1 $\mathrm{mL} / \mathrm{min}$ las fracciones obtenidas resultaron de $5 \mathrm{~mL}$. 
Como condición indispensable para continuar con el ensayo, se observó un pico claramente diferenciado entre el control negativo y la muestra control de identificación.

En el caso de las cefalosporinas, todos los analitos se recogieron en las fracciones 4 y 5 y además las condiciones de este análisis cromatográfico ofrecieron una resolución elevada, por lo que no resultó necesario emplear otro sistema cromatográfico para proceder a la cuantificación de las posibles pérdidas de concentración de los antibióticos estudiados.

\subsubsection{Análisis cromatográfico}

Una vez obtenidos los resultados correspondientes al "cleanup" cromatográfico para las penicilinas, se identificaron las fracciones que contenían a cada uno de los analitos a determinar (Cuadro 26) y se concentraron empleando un evaporador a temperatura ambiente hasta alcanzar el volumen constante de $1 \mathrm{~mL}$.

Cuadro 26. Fracciones relativas a las penicilinas

\begin{tabular}{|ccc|}
\hline Fracción & Tiempo retención & Antimicrobiano \\
\hline F1 & $4-9 \mathrm{~min}$ & Amoxicilina \\
F4 & $19-24 \mathrm{~min}$ & Ampicilina \\
F6 & $28-33 \mathrm{~min}$ & Penicilina \\
F7 & $33-38 \mathrm{~min}$ & Cloxacilina \\
\hline
\end{tabular}

A continuación se trasvasó parte del volumen del extracto resultante de la evaporación, a microviales de $300 \mu \mathrm{L}$ para su posterior determinación cuantitativa, empleando una segunda cromatografía con las siguientes características:

- Bomba, desgasificador e inyector en continuo

- Fase móvil: (Bomba A: $\mathrm{H}_{3} \mathrm{PO} 0,015 \mathrm{M}$; SDS 0,075M / Bomba B: AcN) en modo isocrático con un proporción 65:35

- Volumen inyección de $200 \mu \mathrm{L}$

- Tiempo de análisis por muestra de 20 minutos para betalactámicos y 50 minutos para cefalosporinas

- Detector PDA con rango de trabajo entre 200 y $300 \mathrm{~nm}$

- Lectura a $210 \mathrm{~nm}$ para las penicilinas, excepto la amoxicilina que emplea una longitud de onda de $230 \mathrm{~nm}$ 
Tras la puesta en marcha y estabilización del sistema inyector automático se insertó las muestras en el siguiente orden:

- Vial 1: Agua ultra pura

- Vial 2: Control positivo de amoxicilina y ampicilina $(1000 \mu \mathrm{g} / \mathrm{kg})$

- Vial 3: Control positivo de penicilina G y cloxacilina $(1000 \mu \mathrm{g} / \mathrm{kg})$

- Vial 4: Control positivo de amoxicilina y ampicilina $(2500 \mu \mathrm{g} / \mathrm{kg})$

- Vial 5: Control positivo de penicilina G y cloxacilina $(2500 \mu \mathrm{g} / \mathrm{kg})$

- Vial 6: Control positivo de amoxicilina y ampicilina $(5000 \mu \mathrm{g} / \mathrm{kg})$

- Vial 7: Control positivo de penicilina G y cloxacilina $(5000 \mu \mathrm{g} / \mathrm{kg})$

- Viales 8, 9, 10 y 11: Controles negativos de las fracciones recogidas a los tiempos de retención de los diferentes analitos

- Viales 12, 13, 14 y 15: Controles positivos de identificación de las fracciones recogidas a los tiempos de retención de los diferentes analitos en las muestras de leche

- Viales 16, 17, 18 y 19: Controles positivos de cuantificación de las fracciones recogidas a los tiempos de retención de los diferentes analitos, en las muestras de leche

- Viales 20, 21, 22 y 23: Controles positivos de detección de las fracciones recogidas a los tiempos de retención de los diferentes analitos en las muestras de leche

- Vial 24: Agua ultra pura

- Vial 25 y sucesivos: Extractos de las muestras de leche fortificadas y tratadas térmicamente

\subsubsection{Interpretación de los cromatogramas}

Los picos de los cromatogramas obtenidos para cada uno de los antibióticos betalactámicos ensayados, se analizaron en un primer momento, con la verificación del tiempo de retención, seguido de la comparación espectral, todo ello con respecto a muestras ensayadas con anterioridad en los procesos de validación y con las librerías, así como con los controles analizados en cada secuencia de ensayo o "set" de muestras.

Se verificó que cada pico y el ensayo en general cumplían con los criterios de aceptación y rechazo específicos establecidos en los procedimientos de trabajo. 
Para realizar los cálculos de las concentraciones de las muestras fortificadas con los diferentes analitos, se insertaron las áreas obtenidas en la curva de calibrado correspondiente $(y=b x+a$, donde $y=$ respuesta; $x=$ concentración en $\mu \mathrm{g} / \mathrm{kg}$ ) realizada con anterioridad, en la puesta a punto del método.

En la Figura 31 se muestra un ejemplo de un cromatograma de la Fracción 5 de las cefalosporinas, obtenido en el análisis cromatográfico de antibióticos betalactámicos en la leche.

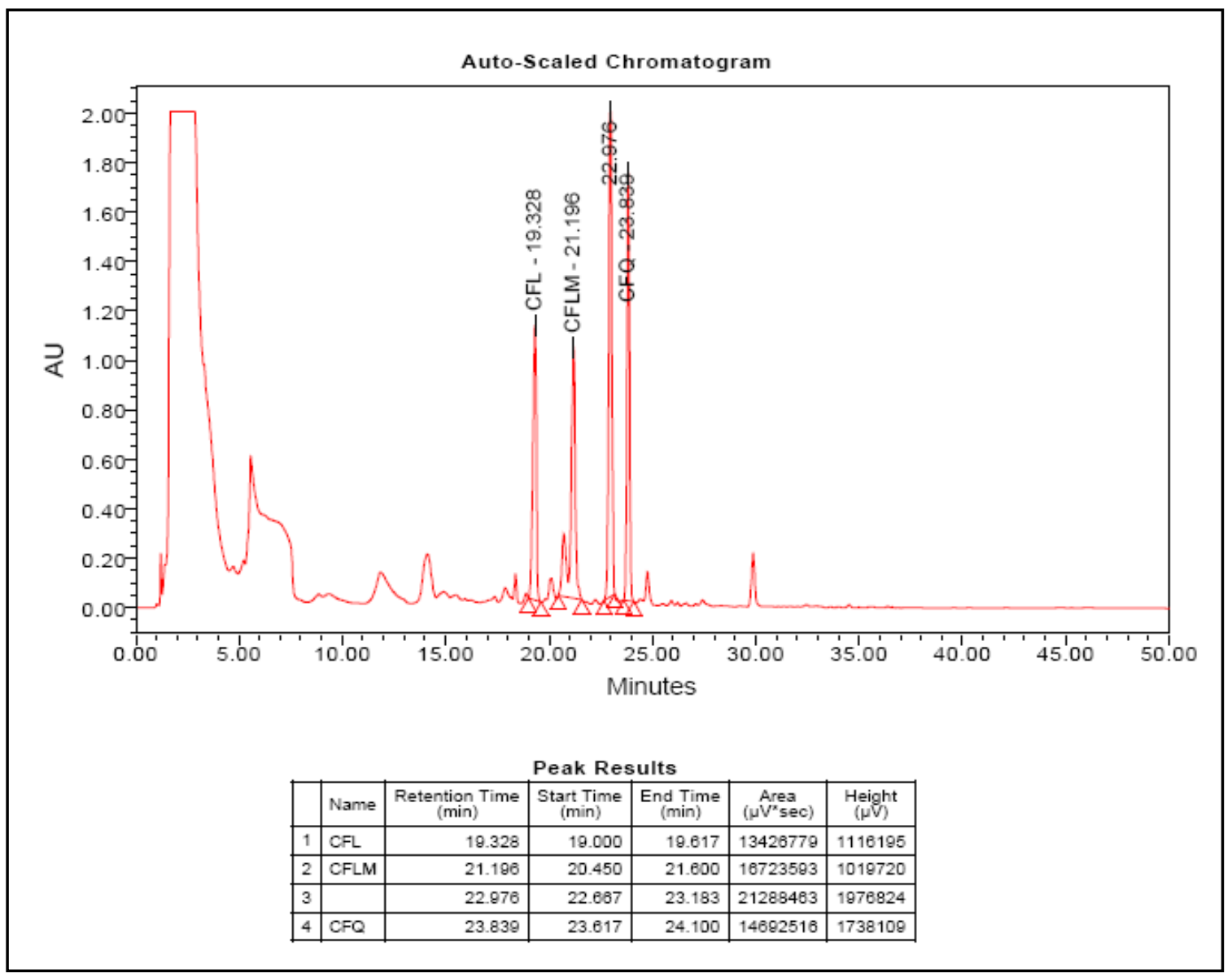

Figura 31. Cromatograma y tabla de resultados de las cefalosporinas recogidas en la fracción 5 (F5) del sistema cromatográfico de "cleanup"

En el Cuadro 27, se muestran las diferentes ecuaciones de las rectas de calibrado utilizadas para cada uno de los betalactámicos ensayados junto a los correspondientes coeficientes de regresión.

Las rectas de calibrado se calcularon cada vez que se cambiaba de columna cromatográfica o se hacía una verificación con patrones nuevos, y se realizó inyectando en el sistema cromatográfico más de 8 concentraciones de patrones puros a partir de una solución de $1 \mathrm{mg} / \mathrm{g}$ de cada sustancia. 
Cuadro 27. Ecuaciones correspondientes a las rectas de calibrado de los antibióticos betalactámicos

\begin{tabular}{|llcc|}
\hline Antimicrobianos & \multicolumn{1}{c}{ Ecuaciones } & $\mathbf{R}^{2}$ & $\mathbf{C V}(\%)$ \\
\hline Amoxicilina & $\mathrm{y}=316,06 \cdot x-4197,50$ & 0,9989 & 6,2 \\
Ampicilina & $\mathrm{y}=347,42 \cdot \mathrm{x}-189,04$ & 0,9995 & 3,6 \\
Cloxacilina & $\mathrm{y}=641,15 \cdot x-4681,60$ & 0,9998 & 5,8 \\
Penicilina G & $\mathrm{y}=283,96 \cdot x+2837,60$ & 0,9994 & 3,9 \\
Cefalexina & $\mathrm{y}=2395,30 \cdot x+620521$ & 0,9944 & 4,6 \\
Cefalonio & $\mathrm{y}=2089,00 \cdot x+914746$ & 0,9935 & 4,9 \\
Cefapirina & $\mathrm{y}=2381,90 \cdot x-614725$ & 0,9969 & 3,8 \\
Cefoperazona & $\mathrm{y}=1461,60 \cdot x-115070$ & 0,9951 & 5,2 \\
Cefquinoma & $\mathrm{y}=3227,10 \cdot x-207170$ & 0,9995 & 4,7 \\
Cefuroxime & $\mathrm{y}=3091,10 \cdot x+543700$ & 0,9995 & 3,9 \\
\hline
\end{tabular}

Para el caso de los betalactámicos se constató que el sistema era lineal y apto para la cuantificación de los antibióticos a estudiar en un rango de trabajo comprendido entre 5 y $5000 \mu \mathrm{g} / \mathrm{kg}$.

A todos los resultados obtenidos se les aplicó un factor de dilución, ya que en este caso se empleaban $10 \mathrm{~g}$ de muestra inicial y el extracto final inyectado consistía en un volumen de $3 \mathrm{~mL}$.

Así mismo, fue necesario aplicar también un factor de recuperación ( $R \%)$ a todos los resultados de esa misma secuencia, ya que este factor se debe a la preparación y análisis de la muestra y no al propio tratamiento térmico.

Los factores de recuperación aplicados en el estudio de los antibióticos betalactámicos fueron los obtenidos en las rectas de calibrado de la puesta a punto de las técnicas con valores comprendidos entre el 81 y $99,7 \%$ Estos valores se consideran correctos puesto que se encuentran dentro del rango de recuperaciones de 80 - $110 \%$ descrito en los criterios de aceptación y rechazo específicos establecidos en los procedimientos de trabajo de acuerdo con lo establecido en la Decisión 2002/657/CEE para concentraciones $>10 \mu \mathrm{g} / \mathrm{kg}$.

La fórmula utilizada para calcular la concentración final de las muestras problema fue la siguiente:

$$
\begin{aligned}
& \text { Volumen extracto (3 } \mathrm{mL})
\end{aligned}
$$

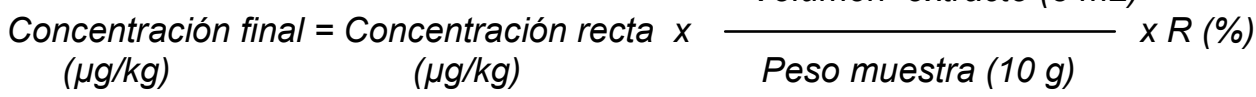




\subsubsection{Determinación cromatográfica de las tetraciclinas}

En el caso de las tetraciclinas, como ya se ha comentado anteriormente, es necesario realizar todo el proceso preservando las muestras de la luz directa.

Una vez transcurrido el tiempo de tratamiento, las muestras se llevaron, al igual que en el caso de los betalactámicos, a temperatura ambiente para proceder a su preparación.

\subsubsection{Preparación y extracción de las muestras}

Para realizar la extracción de los analitos, se pesaron $10 \pm 0,1 \mathrm{~g}$ de cada muestra homogeneizada en un tubo de centrífuga topacio de PPCO de $50 \mathrm{~mL}$ y se añadieron $20 \mathrm{~mL}$ de tampón Mcllvaine/EDTA agitando durante 10 minutos. Se centrifugó durante 15 minutos a 5500 r.p.m. aproximadamente y se filtró el sobrenadante a un matraz aforado topacio de $100 \mathrm{~mL}$.

El filtrado se resuspendió con $20 \mathrm{~mL}$ de tampón Mcllvaine/EDTA y se agitó durante 10 minutos antes de volver a centrifugar otros 15 minutos.

A continuación se filtró de nuevo el sobrenadante al matraz topacio utilizado con anterioridad, se mezcló bien el extracto y se centrifugó durante 20 minutos más. Finalmente, se recuperó el sobrenadante, filtrándolo al mismo matraz.

Para la purificación del extracto recogido, en primer lugar se acondicionaron los cartuchos Sep-Pac $C_{18}$ en el sistema de extracción en fase sólida, pasando $5 \pm 0,07$ $\mathrm{mL}$ de acetonitrilo y $5 \pm 0,07 \mathrm{~mL}$ de agua ultra pura en este orden y teniendo la precaución de no dejar que se desequen.

A continuación se pasó el extracto recuperado por los cartuchos, y después se secaron en concentrador-evaporador a temperatura ambiente y en oscuridad durante 5 minutos.

Las tetraciclinas se eluyeron con $6 \pm 0,1 \mathrm{~mL}$ de ácido oxálico $0,05 \mathrm{M}$, y el eluato se evaporó hasta prácticamente sequedad en el evaporador-concentrador, a temperatura ambiente y en oscuridad.

El extracto se resuspendió en $1 \pm 0,02 \mathrm{~mL}$ de Buffer fosfato $\mathrm{pH} 6,7$, y se homogeneizó antes de filtrarla por filtros de PVDF, de $25 \mathrm{~mm}$ y $0,45 \mu \mathrm{m}$ a viales de 2 $\mathrm{mL}$ provistos de un microinsertos de $300 \mu \mathrm{L}$. 


\subsubsection{Análisis cromatográfico}

Tras la puesta en marcha y estabilización del sistema cromatográfico de análisis se insertaron las muestras en el siguiente orden:

- Vial 1: Agua ultra pura

- Vial 2: Control negativo de una muestra de leche exenta de residuos

- Vial 3: Control positivo de tetraciclinas $(1000 \mu \mathrm{g} / \mathrm{L})$

- Vial 4: Control positivo de tetraciclinas $(2500 \mu \mathrm{g} / \mathrm{L})$

- Vial 5: Control positivo de tetraciclinas $(5000 \mu \mathrm{g} / \mathrm{L})$

- Vial 6: Agua ultra pura

- Vial 7 y sucesivos: Extractos de las muestras de leche fortificadas y tratadas térmicamente

A continuación, se programó el análisis del conjunto de muestras mediante el software Millenium ${ }^{32}$ (Waters) con las siguientes condiciones cromatográficas:

- Fase móvil isocrática (Bomba A: Acido oxálico 0,05 M / Bomba B: Acetonitrilo) en una proporción 85:15

- Flujo de 1,2 $\mathrm{mL} / \mathrm{min}$

- Volumen de inyección de muestra de $100 \mu \mathrm{L}$

- Lectura mediante detector UV a $365 \mathrm{~nm}$

\subsubsection{Interpretación de los cromatogramas}

Los cromatogramas y resultados obtenidos para las tetraciclinas ensayadas, se analizaron de la misma forma que los betalactámicos, verificando en primer lugar el tiempo de retención, y realizando la comparación espectral con muestras ensayadas con anterioridad en los procesos de validación y en las librerías disponibles.

En La Figura 32 se muestra un ejemplo de cromatograma obtenido en el análisis de las tetraciclinas.

Para cada resultado obtenido, se verificó que cada pico de cromatograma y el ensayo en general cumplían con los criterios de aceptación y rechazo específicos establecidos en los procedimientos de trabajo.

Además, también se constató que el sistema era lineal y apto para la cuantificación de los antibióticos a estudiar en un rango de trabajo comprendido entre 5 y $5000 \mu \mathrm{g} / \mathrm{kg}$, para las tetraciclinas. 


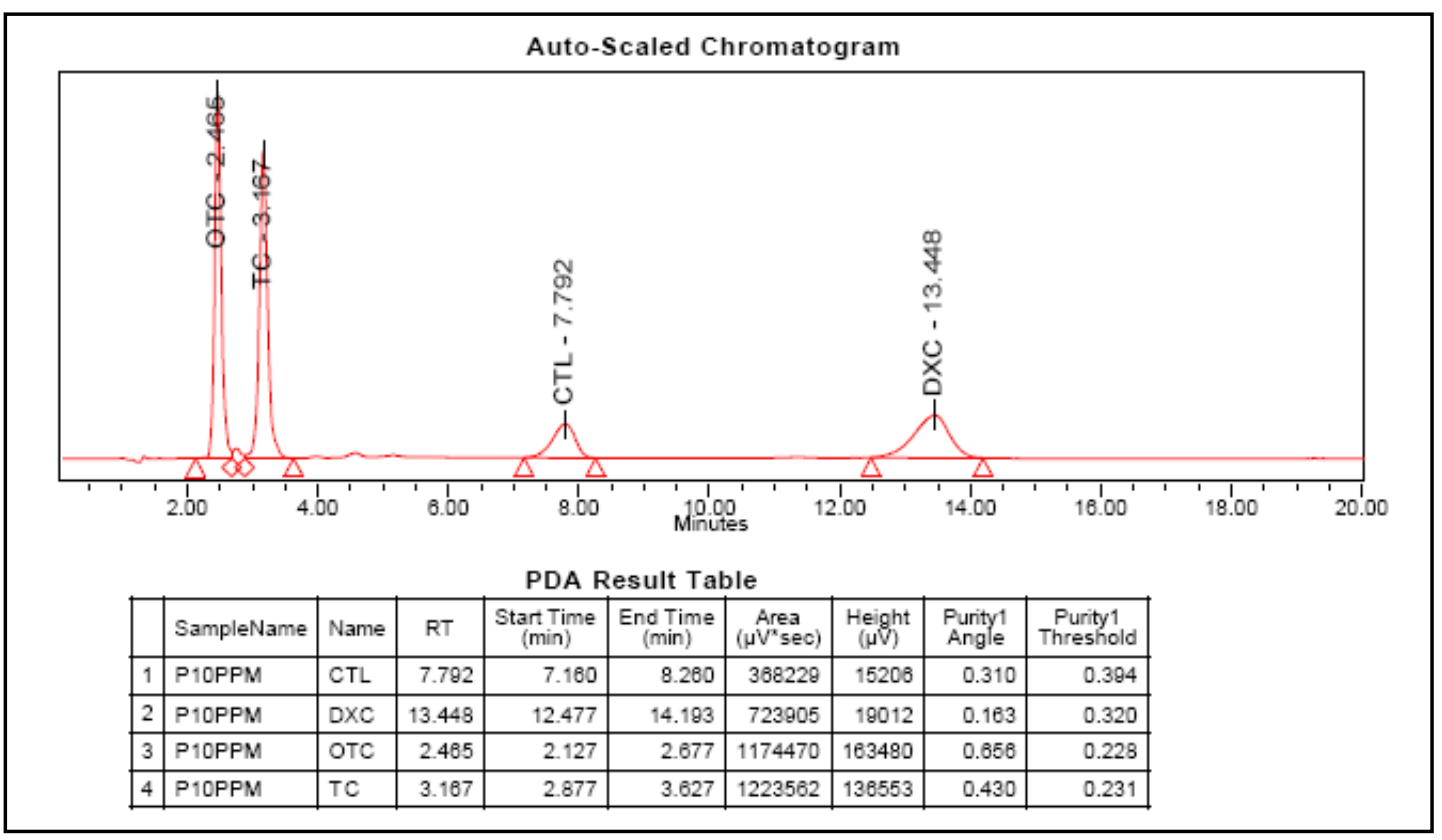

Figura 32. Ejemplo de cromatograma y tabla de resultados obtenidos en el análisis cromatográfico de las tetraciclinas.

De la misma forma que se procedió con los betalactámicos, para realizar los cálculos de las concentraciones de las muestras fortificadas con los diferentes analitos, se insertaron las áreas obtenidas en la curva de calibrado correspondiente. Además a todos los resultados obtenidos se les tuvo que aplicar también el factor de dilución y de recuperación calculados en este caso, cuyos valores, obtenidos en la validación del método, oscilaron entre 80 y 99,5\%.

En el Cuadro 28, se presentan las diferentes ecuaciones de las rectas de calibrado utilizadas para cada una de las tetraciclinas ensayadas.

Cuadro 28. Ecuaciones correspondientes a las rectas de calibrado de las tetraciclinas

\begin{tabular}{|c|c|c|c|}
\hline Antimicrobianos & Ecuaciones & $\mathbf{R}^{2}$ & CV (\%) \\
\hline Clortetraciclina & $y=52,09 \cdot x+21,61$ & 0,9985 & 5,03 \\
\hline Doxicilina & $y=62,53 \cdot x+837,10$ & 0,9986 & 4,11 \\
\hline Oxitetraciclina & $y=118,39 \cdot x-9930,70$ & 0,9997 & 7,00 \\
\hline Tetraciclina & $y=169,60 \cdot x+7330,50$ & 0,9983 & 4,60 \\
\hline
\end{tabular}

\subsubsection{Determinación cromatográfica de las sulfonamidas}

Con las sulfonamidas se procedió de la misma forma que con los otros grupos de antimicrobianos. De esta forma, una vez transcurrido el tiempo de los distintos 
tratamientos, las muestras se llevaron a temperatura ambiente para proceder a su preparación y posterior análisis.

\subsubsection{Preparación y extracción de las muestras}

El procedimiento empleado para la extracción y purificación de las sulfonamidas en las muestras de leche después de los distintos tratamientos térmicos fue el mismo que se empleó en el primer estudio y que se describe en el apartado 1.5.3.1. de Material y Métodos.

\subsubsection{Separación y detección cromatográfica}

El análisis de las sulfonamidas en el sistema de separación cromatográfico, así como las condiciones de funcionamiento del espectrómetro de masas fueron los descritos anteriormente en el apartado 1.5.3.2.

\subsubsection{Interpretación de los cromatogramas}

A diferencia de los resultados obtenidos con los equipos cromatográficos acoplados a detectores convencionales, con el espectrómetro de masas la interpretación de los resultados se realizó de forma diferente, y corresponde con la descrita en el apartado 1.5.3.3. del primer estudio.

A modo de ejemplo en las Figuras 33 y 34 se muestran algunos de los resultados obtenidos en este estudio, el espectro de masas del ión precursor de la sulfadiazina y los cromatogramas de los iones primario y secundario relativos a los 30 minutos del tratamiento de $70^{\circ} \mathrm{C}$.

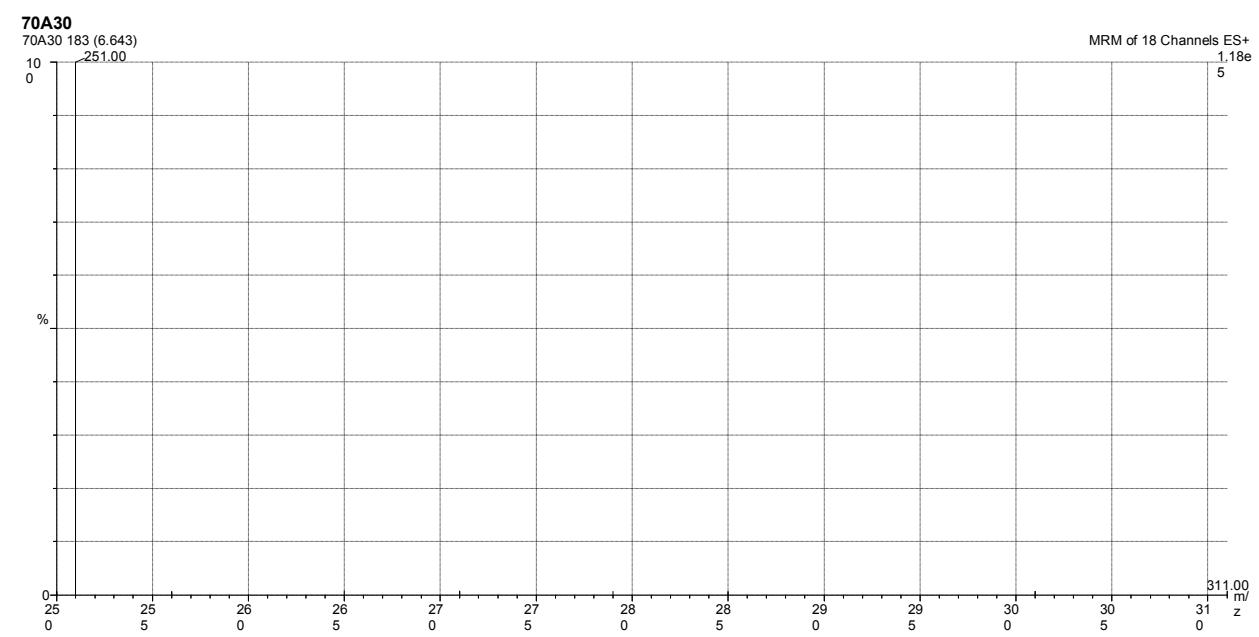

Figura 33. Espectro de masas del ión precursor relativo a la sulfadiazina a los 30 minutos de tratamiento a $70^{\circ} \mathrm{C}$ 


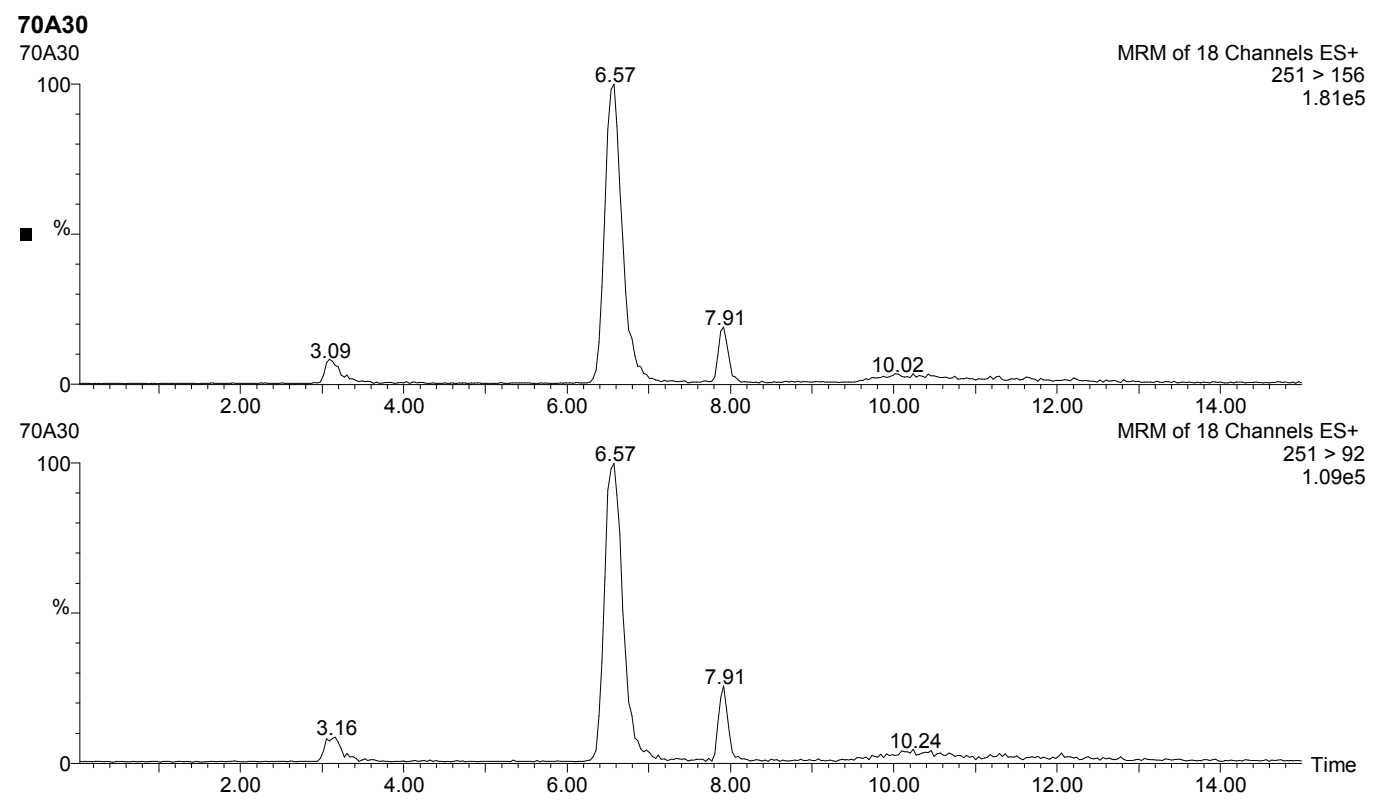

Figura 34. Cromatogramas de los iones primario y secundario de la sulfadiazina a los 30 minutos de tratamiento a $70^{\circ} \mathrm{C}$

\subsection{ANÁLISIS ESTADÍSTICO}

\subsubsection{Estudio de la degradación térmica de antimicrobianos mediante modelos de primer orden}

Debido a los antecedentes bibliográficos disponibles acerca de la aplicación de modelos de primer orden en los estudios de degradación de preparados farmacéuticos, se aplicó un modelo de primer orden para el estudio de cada antibiótico.

En dicho modelo se plantea que la velocidad de degradación de un antibiótico depende de su concentración en la muestra. Así la relación en modelos de primer orden es la siguiente:

$$
\frac{\partial[C]}{\partial t}=-k_{1} \cdot[C]
$$

Donde $\partial[C]$ : derivada de la concentración del antimicrobiano en la muestra de leche, $\partial t$ : derivada del tiempo $(t), \mathrm{k}$ : constante específica de reacción de primer orden, [C] : concentración del antimicrobiano presente en la muestra de leche. Distribuyendo los términos se obtiene:

$$
\frac{\partial[C]}{[C]}=-k_{1} \cdot \partial t
$$


Al integrar y distribuir los miembros de la ecuación (2) se obtienen las expresiones (3) y (4).

$$
\begin{aligned}
& \int_{C_{0}}^{C} \frac{\partial[C]}{[C]}=\int-k_{1} \cdot \partial t \\
& \operatorname{Ln}[C]=\operatorname{Ln}\left[C_{0}\right]-k_{1} \cdot t
\end{aligned}
$$

En caso de cumplirse el modelo de primer orden, al representar gráficamente el Ln [C] en función del tiempo se obtiene una recta cuya ordenada al origen está definida por $\operatorname{Ln}\left[\mathrm{C}_{\mathrm{o}}\right.$ ] siendo $\mathrm{C}_{0}$ la concentración inicial antes del tratamiento y la pendiente corresponde al valor de la constante específica de la degradación de primer orden " $\mathrm{k}_{1}$ ".

Con el propósito de modelizar las variaciones de las concentraciones de antimicrobianos en el tiempo se aplicó el modelo de Regresión Lineal Simple a las transformaciones logarítmicas de las concentraciones en función del tiempo mediante el procedimiento PROC REG del paquete estadístico SAS ${ }^{\circledR}$ (SAS, 1998). Como parámetro indicador del grado de ajuste alcanzado mediante este modelo, se calculó el coeficiente de regresión cuadrático.

Para cada valor de temperatura se determinaron los tiempos de vida media $\left(t_{1 / 2}\right)$ como el tiempo necesario para que la concentración de antimicrobiano se reduzca al $50 \%$ respecto a su concentración inicial

De este modo, al reemplazar "[C]" por “ $1 / 2\left[\mathrm{C}_{0}\right]$ " en la ecuación (4) se obtiene:

$$
\operatorname{Ln}\left[\frac{1}{2} C_{0}\right]=\operatorname{Ln}\left[C_{0}\right]-k \cdot t
$$

Reagrupando los términos y simplificando se llega a:

$$
\begin{aligned}
& \operatorname{Ln} \frac{\left[\frac{1}{2} C_{0}\right]}{\left[C_{0}\right]}=-k \cdot t_{1 / 2} \\
& t_{1 / 2}=\frac{\operatorname{Ln} 2}{k}
\end{aligned}
$$

Así, los tiempos de vida media para cada valor de temperatura se han calculado como el cociente entre el logaritmo natural de "2" y la constante específica estimada mediante la ecuación del modelo de primer orden. 


\subsubsection{Cálculo de la energía de activación}

La variación de la constante específica de reacción " $k_{1}$ " en función de la temperatura sigue la teoría postulada por Arrhenius, siendo la expresión matemática que vincula ambos parámetros la siguiente:

$$
k=A \cdot e^{-\frac{E a}{R \cdot T}}
$$

Donde: A: factor preexponencial o frecuencia de choques, e: base de los logaritmos naturales (e = 2,718281), Ea: Energía de activación de la ecuación de Arrhenius, $\mathrm{R}$ : constante general de los gases $\left(\mathrm{R}=8,315 \mathrm{~J}\right.$ Joule $\left./ \mathrm{mol} \cdot{ }^{\circ} \mathrm{K}\right)$ y $\mathrm{T}$ : Temperatura absoluta en grados Kelvin $\left({ }^{\circ} \mathrm{K}\right)$.

Aplicando logaritmos naturales a ambos términos de la ecuación se obtiene:

$$
\operatorname{Lnk}=\operatorname{LnA}-\frac{E a}{R \cdot T}
$$

La representación gráfica de los logaritmos naturales de las constantes específicas de las degradaciones en función de las inversas de la temperaturas absolutas se ajusta a la ecuación de una recta, donde la ordenada al origen corresponde al Ln A y la pendiente a - Ea/R.

Al igual que en el caso anterior, en el análisis estadístico de los resultados se empleó el modelo de Regresión Lineal Simple a las transformaciones logarítmicas de las constantes específicas de degradación en función de las inversas de las temperaturas absolutas. Para ello se aplicó el procedimiento PROC REG del paquete estadístico SAS ${ }^{\circledR}$ (SAS, 2001). También se calculó el coeficiente de regresión como parámetro estimador del ajuste logrado.

\subsubsection{Estimación de los porcentajes de degradación de los antimicrobianos para diferentes tratamientos térmicos}

Para la estimación de los porcentajes de degradación de cada uno de los antibióticos en función de diferentes tratamientos térmicos aplicados a las muestras de leche en los laboratorios de control de calidad, así como en las industrias lácteas, se calcularon las degradaciones como una función de la Temperatura $(T)$ y el tiempo (t) a partir de la ecuación (10). 


$$
\% \text { Degradación }=\frac{C_{0}-C}{C_{0}} \cdot 100=\left(1-\cdot e^{\left[A \cdot e^{\left(-\frac{E a}{R \cdot T}\right)}\right] \cdot t}\right) \cdot 100
$$

En donde, como se ha comentado anteriormente, [C] : concentración del antimicrobiano presente en la leche, $\left[\mathrm{C}_{0}\right]$ : concentración inicial del antimicrobiano en la leche antes del tratamiento térmico, A: factor preexponencial o frecuencia de choques, e: base de los logaritmos naturales (e = 2,718281), Ea: Energía de activación de la ecuación de Arrhenius, $\mathrm{R}$ : constante general de los gases ( $\left.\mathrm{R}=8,315 \mathrm{Joule} / \mathrm{mol}{ }^{\circ} \mathrm{K}\right), \mathrm{T}$ : Temperatura absoluta en grados Kelvin $\left({ }^{\circ} \mathrm{K}\right)$ y t: tiempo (minutos). 

RESULTADOS Y DISCUSIÓN 



\section{RESULTADOS}

1. PRIMER ESTUDIO. Influencia de las condiciones de almacenamiento sobre la presencia de antimicrobianos en la leche

\subsection{ANTIBIÓTICOS BETALACTÁMICOS: PENICILINAS}

\subsubsection{Influencia de la refrigeración de las muestras y extractos de leche}

En la Figura 35 se muestra la variación porcentual de la concentración, respecto a la inicial, de las penicilinas estudiadas en muestras de leche y sus correspondientes extractos con el tiempo de refrigeración a $4 \pm 2{ }^{\circ} \mathrm{C}$.
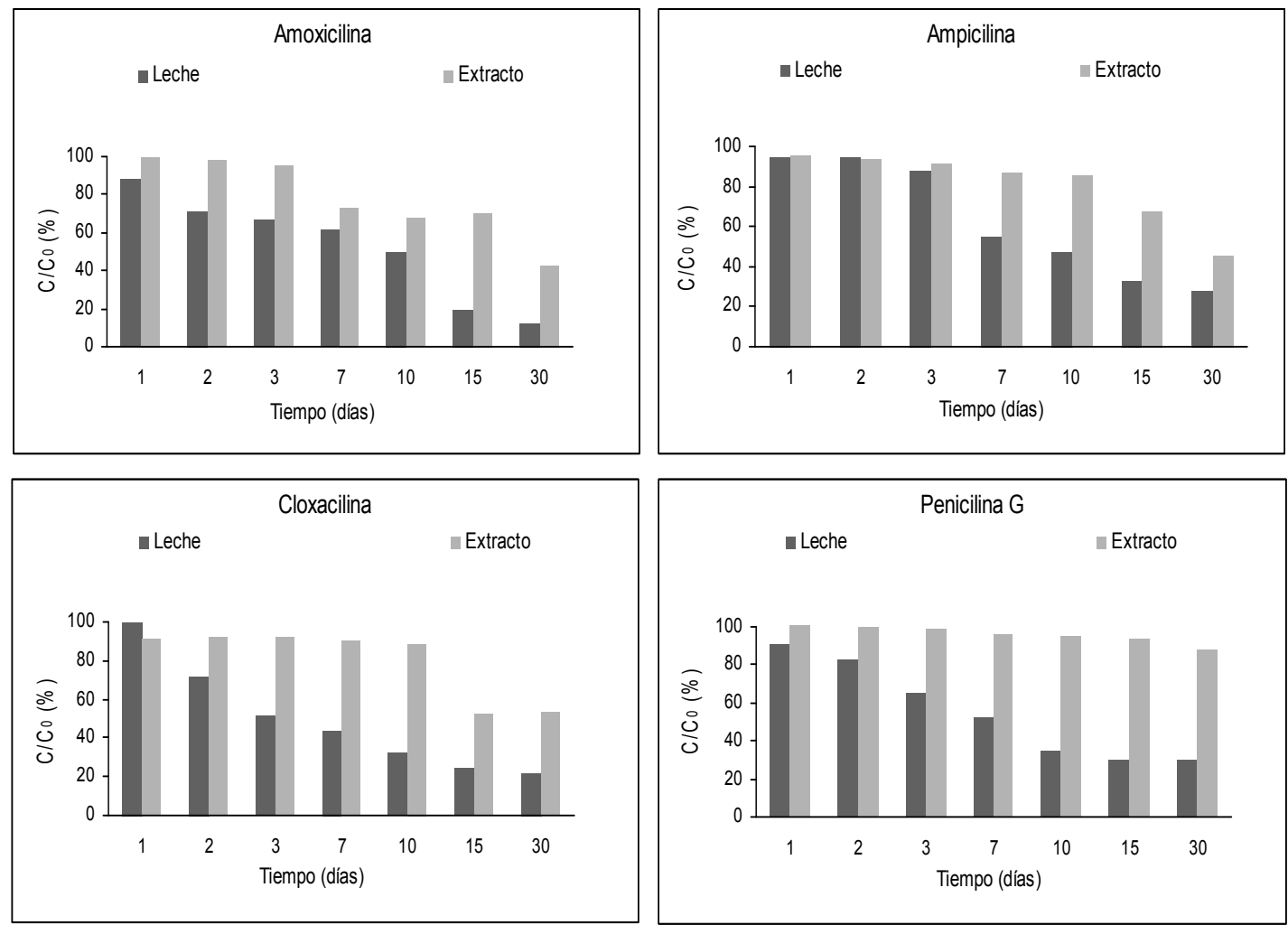

Figura 35. Porcentajes de variación de la concentración de penicilinas en los extractos y muestras de leche con el tiempo de refrigeración

Como se observa en la Figura, en todos los casos, las concentraciones de las cuatro penicilinas disminuyen durante el tiempo de conservación. Al comparar los porcentajes presentes en los extractos con los obtenidos para las muestras de leche se observa que la disminución en la concentración es mayor en la propia leche que en sus respectivos extractos y éstas diferencias parecen más acentuadas en el caso de la cloxacilina y la penicilina $\mathrm{G}$.

Con el propósito de evaluar los efectos del tiempo de refrigeración y el tipo de matriz (leche y extracto) utilizada en las determinaciones cromatográficas, se empleó 
el modelo cinético de primer orden y para ello se aplicó la regresión lineal múltiple a los valores medios de las concentraciones de penicilinas, obtenidas por triplicado, y transformadas en logaritmos naturales. Los resultados obtenidos de este análisis estadístico se muestran en el Cuadro 29.

Cuadro 29. Efecto del tiempo de refrigeración y de la matriz sobre la concentración de penicilinas en las muestras de leche

\begin{tabular}{|lcccccc|}
\hline \multirow{2}{*}{ Penicilinas } & \multicolumn{2}{c}{ Tiempo } & \multicolumn{2}{c|}{ Matriz } & \multicolumn{2}{c|}{ Tiempo-Matriz } \\
\cline { 2 - 7 } & Valor $\mathbf{F}$ & Valor $\mathbf{p}$ & Valor $\mathbf{F}$ & Valor $\mathbf{p}$ & Valor $\mathbf{F}$ & Valor $\mathbf{p}$ \\
\hline Amoxicilina & 128,04 & 0,0001 & 0,99 & 0,3406 & 23,38 & 0,0004 \\
Ampicilina & 86,21 & 0,0001 & 0,24 & 0,6345 & 7,72 & 0,0167 \\
Cloxacilina & 30,87 & 0,0001 & 2,35 & 0,1509 & 4,80 & 0,0489 \\
Penicilina G & 19,55 & 0,0008 & 3,27 & 0,0956 & 12,58 & 0,0040 \\
\hline
\end{tabular}

Se observa que el tiempo de conservación afecta de forma significativa ( $p<$ $0,001)$ a los logaritmos de las concentraciones de las cuatro penicilinas, mientras que el efecto de la matriz no resulta significativo $(p \geq 0,05)$ para ninguna de ellas.

Este hecho significa que la variable dummy "matriz" no muestra un cambio en la ordenada al origen en el momento de iniciar los experimentos, es decir, se cumple la equivalencia inicial de las concentraciones de las muestras de leche y los extractos. Por el contrario, un efecto significativo para esta variable categórica pondría de manifiesto diferencias en la concentración de penicilinas a tiempo cero, es decir, las concentraciones de las muestras no serían equiparables al comienzo del experimento.

También en el Cuadro 29 se observa que la interacción entre el tiempo y el tipo de matriz afecta de forma significativa $(p<0,05)$ a las concentraciones de las penicilinas, poniendo de manifiesto que, la velocidad de degradación de las concentraciones de estas sustancias se ve afectada por el tipo de matriz. Por ello, los resultados analíticos no serán iguales si se trabaja con leche o con extractos de las muestras de leche obtenidos previamente y mantenidos en refrigeración.

Los parámetros de las ecuaciones estimadas por el modelo de regresión lineal múltiple para las penicilinas se recogen en el Cuadro 30. Hay que señalar que los ajustes alcanzados mediante la aplicación de este modelo, resultan adecuados, con coeficientes de regresión elevados entre $R^{2}=0,8125$ (cloxacilina) y $R^{2}=0,9387$ (amoxicilina). 
Cuadro 30. Ecuaciones de regresión lineal múltiple de los efectos del tiempo de refrigeración y de la matriz sobre la concentración de penicilinas

\begin{tabular}{|llc|}
\hline Penicilinas & \multicolumn{1}{c}{ Ln [Penicilinas] $=\mathbf{a}+\mathbf{k}_{\mathbf{1}} \cdot \mathbf{t}+\mathbf{k}_{\mathbf{2}} \cdot \mathbf{M}+\mathbf{k}_{\mathbf{1 , 2}} \cdot \mathbf{t} \cdot \mathbf{M}$} & $\mathbf{R}^{\mathbf{2}}$ \\
\hline Amoxicilina & Ln [Amoxicilina] $=1,32826-0,00209 \cdot \mathrm{t}-0,00089 \cdot(\mathrm{t} \cdot \mathbf{M})$ & 0,9387 \\
Ampicilina & Ln [Ampicilina] $=1,37071-0,00151 \cdot \mathrm{t}-0,00045 \cdot(\mathrm{t} \cdot \mathrm{M})$ & 0,8965 \\
Cloxacilina & Ln [Cloxacilina] $=3,24461-0,00155 \cdot \mathrm{t}-0,00061 \cdot(\mathrm{t} \cdot \mathrm{M})$ & 0,8125 \\
Penicilina G & Ln [Penicilina G] $=1,27314-0,00098 \cdot \mathrm{t}-0,00079 \cdot(\mathrm{t} \cdot \mathrm{M})$ & 0,8419 \\
\hline
\end{tabular}

M: matriz (Leche: $\mathrm{M}=+1$; Extracto: $\mathrm{M}=-1$ ); $\mathrm{t}$ : tiempo (horas)

Como se aprecia en dicho Cuadro, las transformaciones logarítmicas de las concentraciones de las cuatro penicilinas disminuyen conforme transcurre el tiempo de refrigeración (pendientes negativas de los valores de las constantes "k ${ }_{1}$ ", siendo la la amoxicilina la sustancia que se deteriora más rápido y la penicilina $G$ la más estable.

También se observa que las interacciones entre el tiempo de conservación de las muestras y el tipo de matriz (leche o extracto) disminuyen en la medida que transcurre el tiempo de refrigeración (valores negativos de las constantes " $\mathrm{k}_{1,2}$ "). Esta disminución en las pendientes de las concentraciones de las penicilinas en las muestras de leche $(M=+1)$ en comparación con el aumento en la concentración que experimentan los extractos $(M=-1)$ a medida que transcurre el tiempo, señala un deterioro más rápido de las moléculas de estos antibióticos cuando se refrigeran muestras de leche en comparación con los extractos.

Por otra parte, con el fin de visualizar el efecto del tiempo conservación y el tipo de matriz sobre las concentraciones de penicilinas se han elaborado las Figuras 36 y 37 a partir de las ecuaciones del Cuadro 31.

En dichas Figuras se evidencia el deterioro en los niveles de penicilinas con el tiempo de refrigeración, resaltando la mayor inestabilidad de las penicilinas en las muestras de leche (Figura 36) comparado con los extractos (Figura 37).

Teniendo en cuenta que un tiempo habitual de trabajo en los laboratorios de control de calidad podría ser aproximadamente de una semana (7 días), haciendo uso de las ecuaciones de regresión (Cuadro 30) se han estimado los porcentajes de pérdidas de concentración de penicilinas durante este periodo de tiempo, tanto en muestras como en extractos de leche, cuyos resultados se presentan en los Cuadros 31 y 32 , para cada una de las matrices respectivamente. 

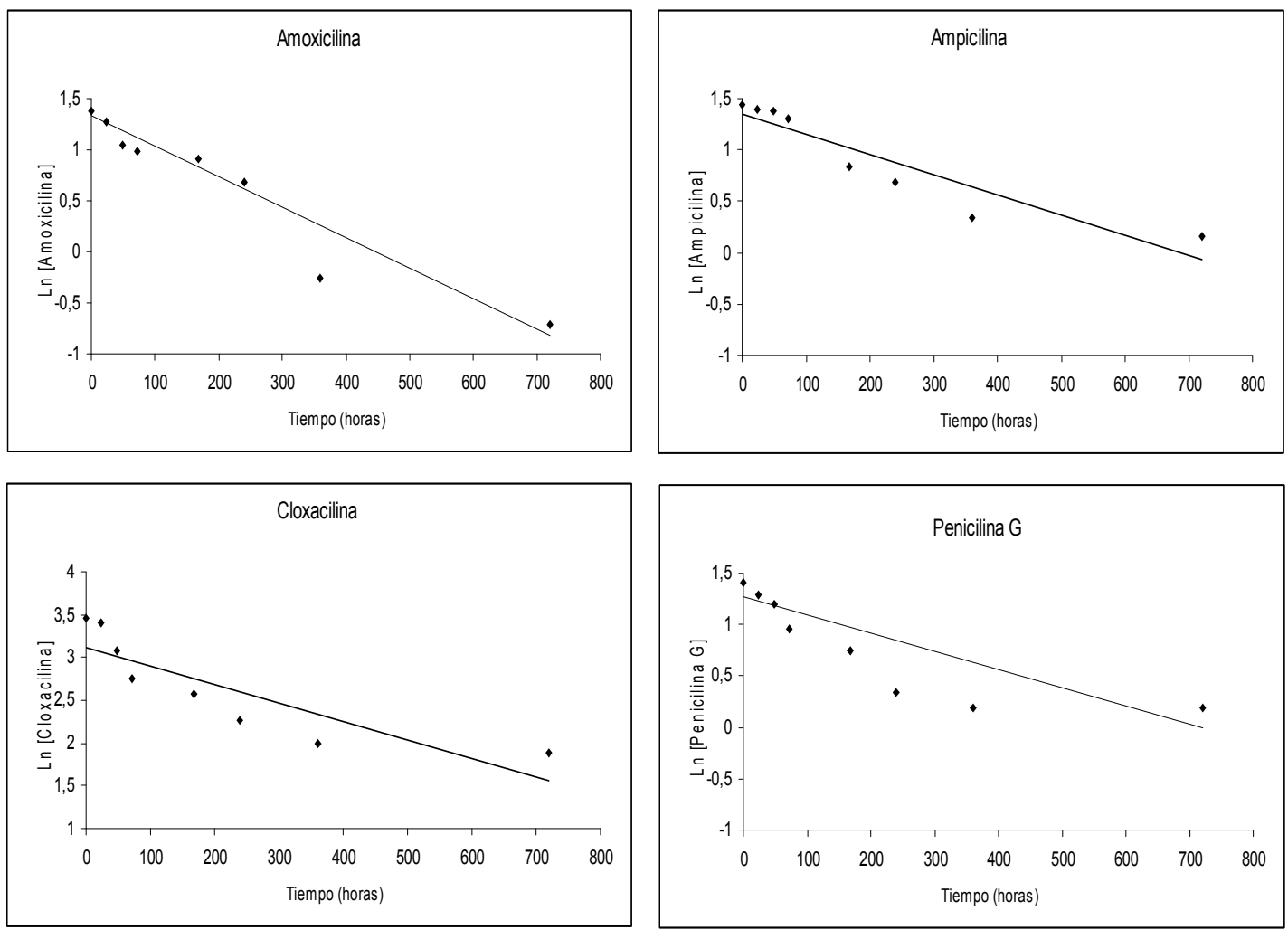

Figura 36. Efecto del tiempo de refrigeración sobre la concentración de penicilinas en muestras de leche
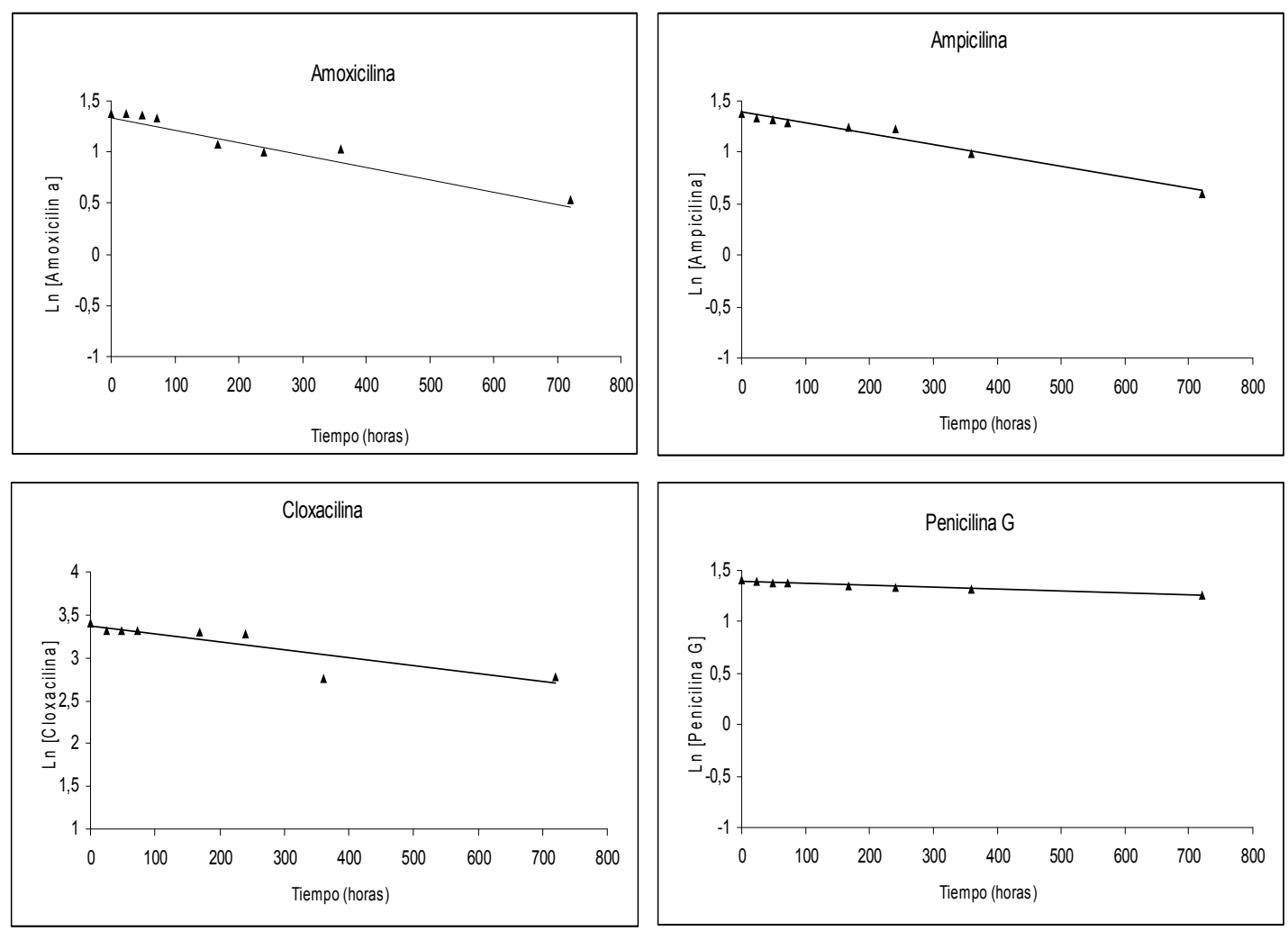

Figura 37. Efecto del tiempo de refrigeración sobre la concentración de penicilinas en extractos de leche 
Cuadro 31. Porcentajes de degradación de penicilinas en muestras de leche refrigeradas

\begin{tabular}{|lccccccc|}
\hline \multirow{2}{*}{ Penicilinas } & \multicolumn{7}{c|}{ Tiempo de refrigeración (días) } \\
\cline { 2 - 8 } & $\mathbf{1}$ & $\mathbf{2}$ & $\mathbf{3}$ & $\mathbf{4}$ & $\mathbf{5}$ & $\mathbf{6}$ & $\mathbf{7}$ \\
\hline Amoxicilina & 12,2 & 18,2 & 23,9 & 29,1 & 34,0 & 38,6 & 42,8 \\
Ampicilina & 6,1 & 10,4 & 14,5 & 18,4 & 22,2 & 25,8 & 29,2 \\
Cloxacilina & 18,7 & 22,8 & 26,7 & 30,4 & 33,9 & 37,2 & 40,4 \\
Penicilina G & 14,4 & 18,0 & 21,4 & 24,6 & 27,8 & 30,8 & 33,7 \\
\hline
\end{tabular}

Cuadro 32. Porcentajes de degradación de penicilinas en extractos de leche refrigerados

\begin{tabular}{|lccccccc|}
\hline \multirow{2}{*}{ Penicilinas } & \multicolumn{7}{c|}{ Tiempo de refrigeración (días) } \\
\cline { 2 - 8 } & $\mathbf{1}$ & $\mathbf{2}$ & $\mathbf{3}$ & $\mathbf{4}$ & $\mathbf{5}$ & $\mathbf{6}$ & $\mathbf{7}$ \\
\hline Amoxicilina & 8,3 & 10,9 & 13,4 & 15,9 & 18,3 & 20,6 & 22,9 \\
Ampicilina & 4,0 & 6,4 & 8,8 & 11,1 & 13,3 & 15,5 & 17,6 \\
Cloxacilina & 16,3 & 18,1 & 19,9 & 21,7 & 23,5 & 25,2 & 26,9 \\
Penicilina G & 11,1 & 11,5 & 11,9 & 12,3 & 12,8 & 13,2 & 13,6 \\
\hline
\end{tabular}

Como se aprecia en el Cuadro 31, la ampicilina es la molécula más resistente a la refrigeración de la leche con porcentajes de degradación, a lo largo de los 7 días de refrigeración, menores que en el resto de penicilinas.

La cloxacilina por su parte, presenta mayores pérdidas el primer día de refrigeración, sin embargo como se aprecia en la Figura 35 , la pendiente de degradación es más suave que la de la amoxicilina, por lo que a los 7 días de refrigeración el porcentaje de disminución obtenido es ligeramente inferior al de esta sustancia.

En el caso de los extractos (Cuadro 32), tal y como se indicó anteriormente, las pérdidas de concentración son inferiores a las de las muestras de leche, siendo en este caso la penicilina $G$ la molécula que más lentamente se deteriora con el tiempo de conservación con un rango comprendido entre 11,1 y $13,6 \%$ de degradación después de 7 días de refrigeración.

Por otra parte, la cloxacilina parece ser la sustancia más inestable, presentando además la mayor pendiente de degradación y, por lo tanto, el porcentaje de degradación más elevado $(26,9 \%)$ al final de la semana de refrigeración.

A efectos prácticos y con el fin de poder comparar los resultados de este estudio con los presentados por otros autores, se han calculado a partir del modelo 
de regresión los tiempos de vida media $\left(t_{1 / 2}\right)$ para cada una de las penicilinas en las muestras de leche y sus correspondientes extractos refrigerados, cuyos resultados se exponen en el Cuadro 33.

Cuadro 33. Tiempos de vida media $\left(t_{1 / 2}\right)$ de las penicilinas en muestras de leche y extractos refrigerados

\begin{tabular}{|ccccc|}
\hline \multirow{2}{*}{ Matriz } & \multicolumn{4}{c|}{$\mathbf{t}_{\mathbf{1} / \mathbf{2}}$ (días) } \\
\cline { 2 - 5 } & Amoxicilina & Ampicilina & Cloxacilina & Penicilina G \\
\hline Leche & 9 & 14 & 10 & 14 \\
Extractos & 12 & 27 & 24 & 125 \\
\hline
\end{tabular}

A partir de los tiempos de vida media estimados para cada una de las penicilinas en los extractos y las muestras de leche, se observa claramente la diferencia entre los resultados obtenidos para las dos matrices, sobre todo en el caso de la penicilina $G$ que pasa de un tiempo de vida media en refrigeración de 14 días en el caso de las muestras de leche a 125 días en los extractos.

Por ello es importante resaltar que en caso que los laboratorios lactológicos necesiten analizar un elevado número de muestras por técnicas cromatográficas y deban recurrir a su refrigeración, sería conveniente extraer las penicilinas previamente y refrigerar los extractos, ya que las pérdidas de concentración de estos antibióticos son menores a las alcanzadas para muestras de leche.

En cuanto a estudios realizados por otros autores sobre la estabilidad de penicilinas en la leche, Haagsma (1993) obtiene pérdidas de concentración de la penicilina $G$ superiores al $60 \%$ en muestras refrigeradas 48 horas a $2{ }^{\circ} \mathrm{C}$, valor superior al obtenido en este estudio (18\%). Estas diferencias entre los resultados, pueden explicarse si se tiene en cuenta que las metodologías y las temperaturas empleadas son diferentes, así como el tipo de matriz empleado, ya que dicho autor trabaja con leche cruda con una posible carga de actividad enzimática debida al crecimiento bacteriano y a la presencia de células somáticas, etc., que pueden influir notoriamente en la degradación de las sustancias antimicrobianas.

Por el contrario, Wiese y Martin (1989) y Boison et al. (1994) evaluaron la estabilidad de la penicilina $G$ en muestras de leche refrigeradas sin obtener pérdidas significativas durante los 6 primeros días de almacenamiento. De la misma manera Shenck (2000) en otro estudio realizado en leche tampoco determinó pérdida alguna en la ampicilina al cabo de los 6 días de refrigeración. 
Los resultados presentados por estos autores no coinciden con las degradaciones obtenidas en este trabajo, lo que podría explicarse como se ha comentado anteriormente por la utilización de las diferentes metodologías empleadas en cada uno de ellos.

Más recientemente, Riediker et al. (2004) estudiaron la degradación de la amoxicilina, ampicilina, cloxacilina, oxacilina y penicilina $G$ en muestras y extractos de leche en refrigeración a $4{ }^{\circ} \mathrm{C}$ mediante HPLC. Estos autores indican que los analitos en la leche se mantienen estables durante los tres primeros días de refrigeración y presentan pérdidas en torno al $50 \%$ en casi todas las sustancias entre los 7 y 14 días alcanzando el $100 \%$ entre los 21 y 28 días, resultados similares a los obtenidos en este trabajo.

Por otro lado, Riedicker et al. (2004) señalan que los extractos de leche permanecen estables (pérdidas inferiores al 10\%) durante 14 días, mostrando pequeñas pérdidas significativas alrededor de un $15 \%$ a las 4 semanas de conservación, excepto en el caso de la amoxicilina que se mantiene más estable. Estos porcentajes resultan inferiores a los obtenidos en este trabajo, lo que podría estar causado por los diferentes métodos empleados en la extracción de los analitos en cada uno de los estudios.

\subsubsection{Influencia de la congelación de las muestras y extractos de leche}

Otra posibilidad, en el caso de que los laboratorios deban recurrir a un sistema de conservación de las muestras para su posterior análisis, es la congelación a $-20^{\circ} \mathrm{C}$, bien de las muestras de leche o de los extractos obtenidos a partir de ellas, por lo que se planteó el estudio de la congelación de muestras y extractos de leche a esta temperatura y su análisis en diferentes momentos del almacenamiento.

En la Figura 38 se exponen las variaciones porcentuales de las concentraciones de penicilinas presentes en los extractos y las muestras de leche para diferentes tiempos de congelación.

De forma similar a lo observado en el caso de la refrigeración, las concentraciones de las penicilinas disminuyen mientras se prolonga el tiempo de conservación, tanto para las muestras de leche como para sus extractos. También se aprecia que las diferencias existentes en las concentraciones de penicilinas entre ambas matrices son diferentes dependiendo de la sustancia empleada. 

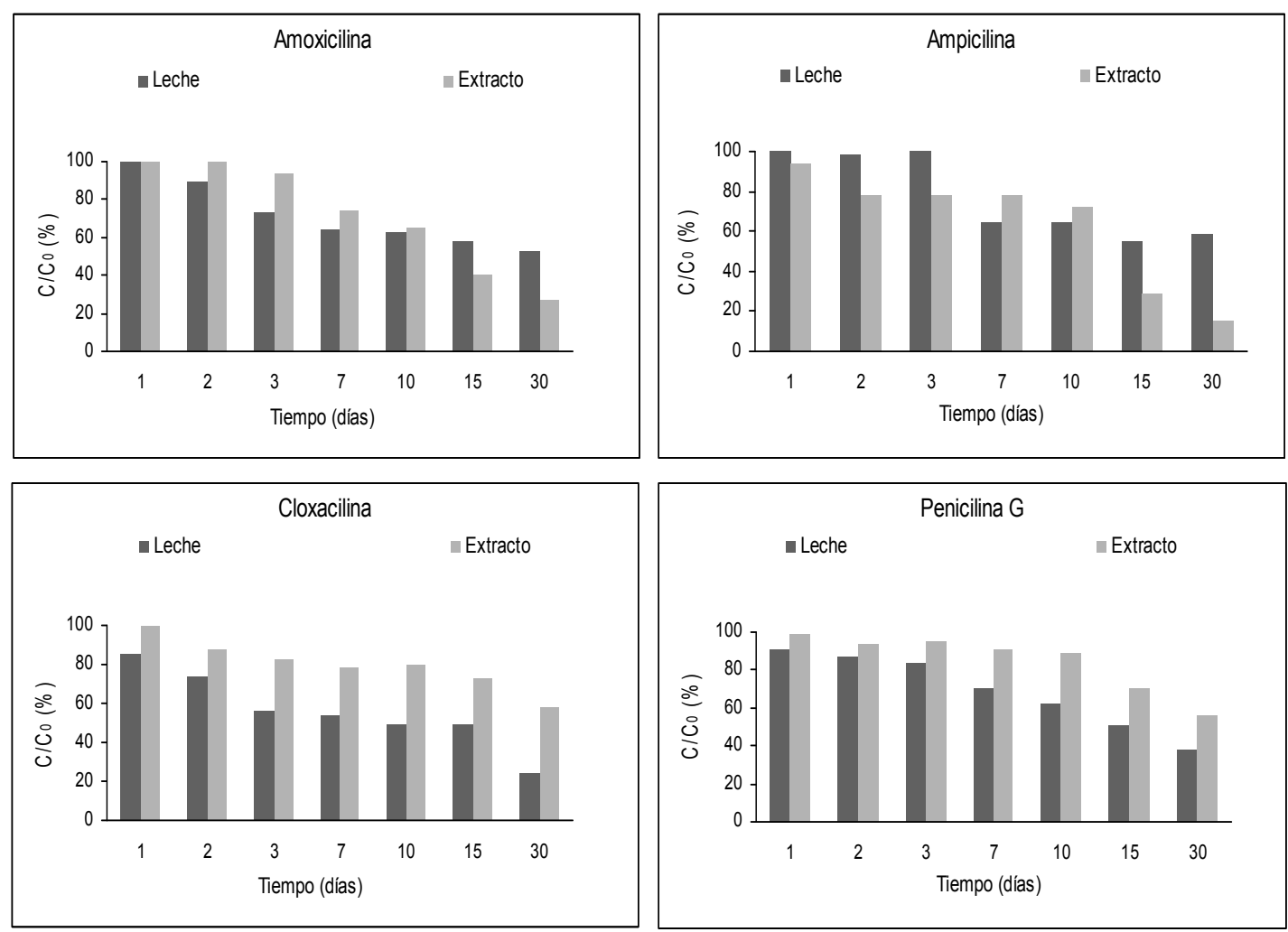

Figura 38. Porcentajes de variación de la concentración de penicilinas en los extractos y muestras de leche con el tiempo de congelación

En la Figura 38 se aprecia que en el caso de la cloxacilina y la penicilina G las concentraciones de los analitos en las muestras de leche son más inestables que en los extractos, mientras que estas diferencias no son tan notorias en la amoxicilina y la ampicilina, mostrando esta última, una mayor estabilidad en los extractos congelados los días 7 y 10 de almacenamiento.

Para evaluar el efecto del tiempo de congelación y la matriz utilizada, en el Cuadro 34 se exponen los resultados obtenidos al aplicar el modelo de regresión lineal múltiple a los logaritmos naturales de las concentraciones de penicilinas en muestras de leche y sus extractos congelados a $-20^{\circ} \mathrm{C}$.

Cuadro 34. Efecto del tiempo de congelación y de la matriz sobre la concentración de penicilinas

\begin{tabular}{|lcccccc|}
\hline \multirow{2}{*}{ Penicilina } & \multicolumn{2}{c}{ Tiempo } & \multicolumn{2}{c|}{ Matriz } & \multicolumn{2}{c|}{ Tiempo-Matriz } \\
\cline { 2 - 7 } & Valor $\mathbf{F}$ & Valor $\mathbf{p}$ & Valor $\mathbf{F}$ & Valor $\mathbf{p}$ & Valor $\mathbf{F}$ & Valor $\mathbf{p}$ \\
\hline Amoxicilina & 87,63 & 0,0001 & 3,12 & 0,1027 & 11,64 & 0,0052 \\
Ampicilina & 71,47 & 0,0001 & 0,21 & 0,6569 & 16,46 & 0,0016 \\
Cloxacilina & 80,57 & 0,0001 & 3,87 & 0,0726 & 12,91 & 0,0037 \\
Penicilina G & 245,79 & 0,0001 & 4,98 & 0,0525 & 13,60 & 0,0031 \\
\hline
\end{tabular}


En todos los casos, el tiempo de congelación afecta significativamente $(p<$ $0,001)$ a las concentraciones de estos antibióticos, mientras que la matriz no resulta significativa y la interacción sí presenta niveles de significación $(p<0,01)$ para todas las sustancias.

Los modelos matemáticos que expresan los cambios en la concentración de penicilinas en función del tiempo de congelación $\left(-20^{\circ} \mathrm{C}\right)$ y el tipo de matriz se muestran en el Cuadro 35, donde se observa que los ajustes alcanzados con la aplicación del modelo de regresión lineal son adecuados con valores de los coeficientes de regresión entre $R^{2}=0,8901$ (ampicilina) y $R^{2}=0,9615$ (cloxacilina).

Cuadro 35. Ecuaciones de regresión lineal múltiple de los efectos del tiempo de congelación y de la matriz sobre la concentración de penicilinas

\begin{tabular}{|llc|}
\hline Penicilinas & \multicolumn{1}{c|}{ Ln [Penicilinas] $=\mathbf{a}+\mathbf{k}_{\mathbf{1}} \cdot \mathbf{t}+\mathbf{k}_{\mathbf{2}} \cdot \mathbf{M}+\mathbf{k}_{\mathbf{1}, \mathbf{2}} \cdot \mathbf{t} \cdot \mathbf{M}$} & $\mathbf{R}^{\mathbf{2}}$ \\
\hline Amoxicilina & Ln $[$ Amoxicilina] $=1,34056-0,00147 \cdot \mathbf{t}+0,00054 \cdot(\mathrm{t} \cdot \mathrm{M})$ & 0,8926 \\
Ampicilina & Ln $[$ Ampicilina $]=1,36210-0,00179 \cdot \mathrm{t}+0,00086 \cdot(\mathrm{t} \cdot \mathrm{M})$ & 0,8901 \\
Cloxacilina & Ln [Cloxacilina] $=3,26939-0,00119 \cdot \mathrm{t}-0,00048 \cdot(\mathrm{t} \cdot \mathrm{M})$ & 0,9144 \\
Penicilina & Ln [Penicilina G] $=1,23498-0,00108 \cdot \mathrm{t}-0,00025 \cdot(\mathrm{t} \cdot \mathrm{M})$ & 0,9615 \\
\hline
\end{tabular}

M: matriz (Leche: $M=+1$; Extracto: $M=-1$ ); t: tiempo (horas)

En cuanto a las constantes de velocidad de reacción se aprecia que las cuatro penicilinas disminuyen su concentración (valores de " $\mathrm{k}_{1}$ " negativos) en la medida que se prolonga el tiempo de congelación, siendo ligeramente superior el deterioro de las moléculas de la amoxicilina y la ampicilina.

Por otra parte, cuando se comparan las pérdidas de las concentraciones de las penicilinas en las muestras de leche con sus respectivos extractos, resulta evidente que las moléculas de amoxicilina y ampicilina se deterioran más rápido cuando se congelan los extractos que las muestras de leche, puesto que presentan un valor positivo de " $k_{1,2}$ ". Por el contrario en el caso de la cloxacilina y penicilina $G$ las constantes de las interacciones son negativas por lo que la degradación en este caso es mayor en las muestras que en los extractos congelados.

Las Figura 39 y 40 muestran las transformaciones logarítmicas de las concentraciones de penicilinas en función del tiempo de congelación y el tipo de matriz utilizada. 

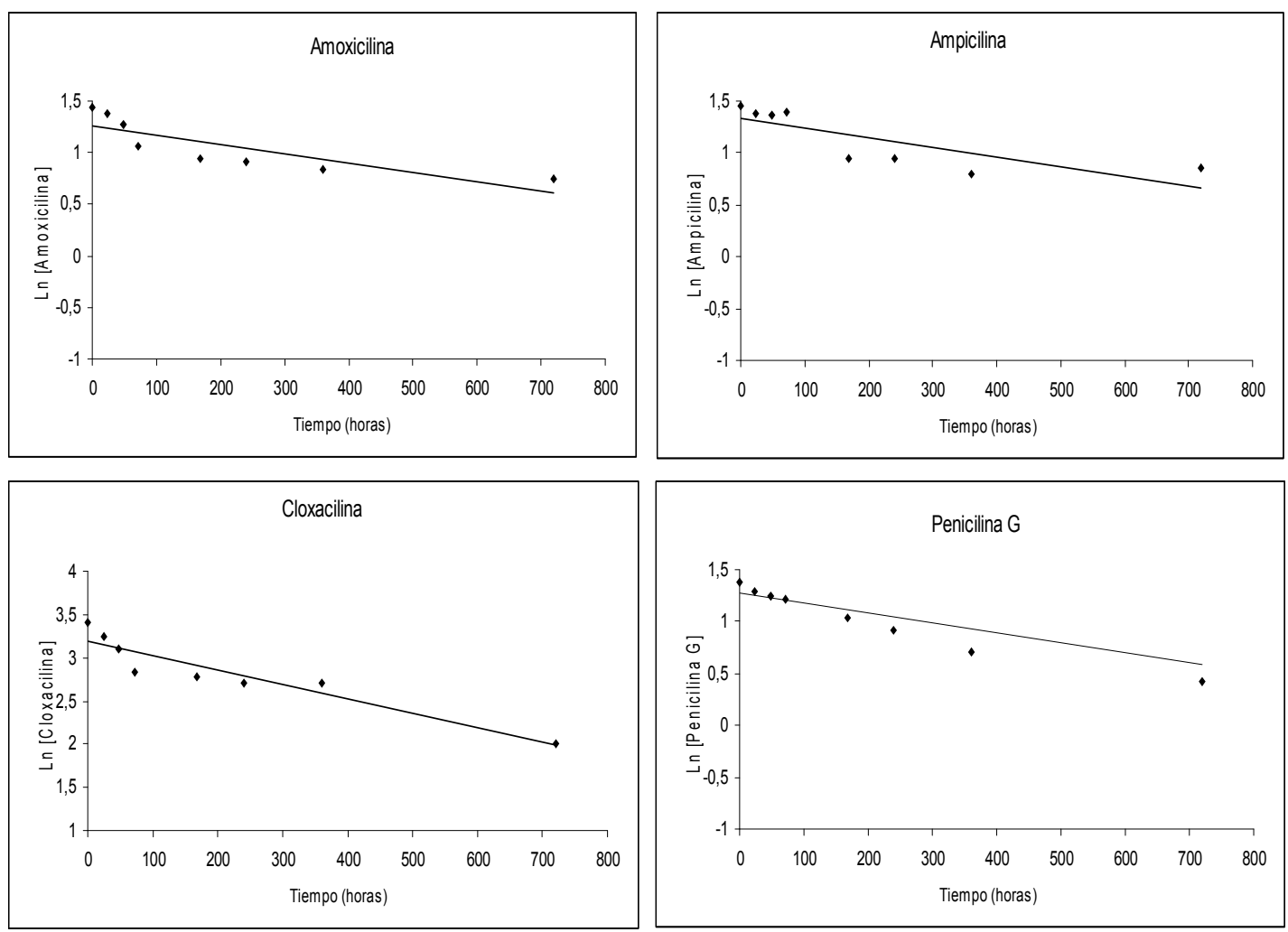

Figura 39. Efecto del tiempo de congelación sobre la concentración de penicilinas en muestras de leche
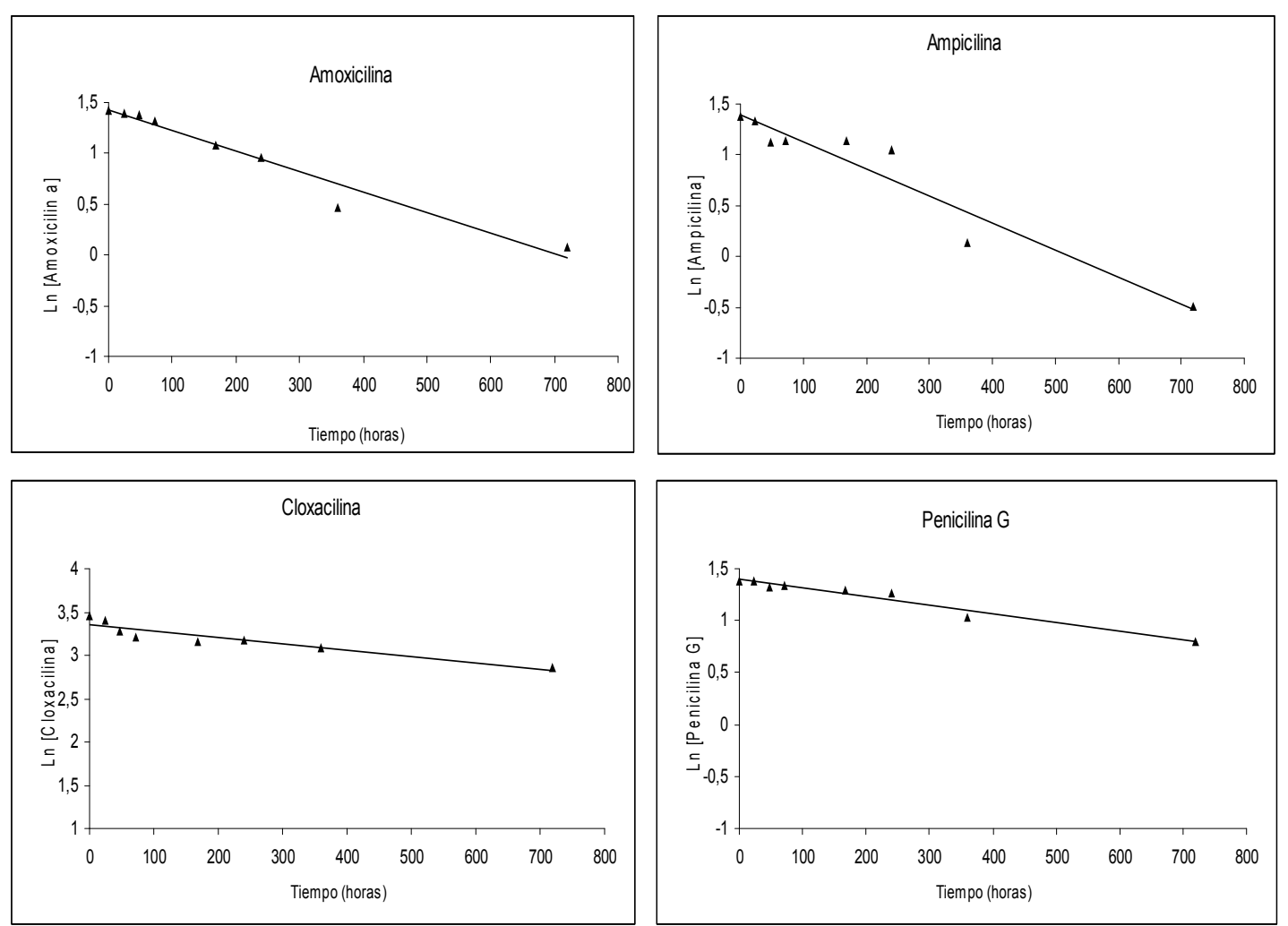

Figura 40. Efecto del tiempo de congelación sobre la concentración de penicilinas en extractos de leche 
En estas Figuras también se aprecia la mayor inestabilidad de la amoxicilina y la ampicilina en los extractos comparado con las muestras de leche.

En los Cuadros 36 y 37 se resumen los porcentajes de las pérdidas de concentración de las penicilinas en la leche y sus extractos, estimadas a partir de las ecuaciones del Cuadro 35, para los días 1, 3, 7, 15, 30, 45 y 60 de conservación a $20^{\circ} \mathrm{C}$, tiempos que podrían resultar interesantes desde un punto de vista práctico en la rutina de un laboratorio de análisis.

Cuadro 36. Porcentajes de degradación de penicilinas en muestras de leche congeladas

\begin{tabular}{|lccccccc|}
\hline \multirow{2}{*}{ Penicilinas } & \multicolumn{7}{c|}{ Tiempo de congelación (días) } \\
\cline { 2 - 8 } & $\mathbf{1}$ & $\mathbf{3}$ & $\mathbf{7}$ & $\mathbf{1 5}$ & $\mathbf{3 0}$ & $\mathbf{4 5}$ & $\mathbf{6 0}$ \\
\hline Amoxicilina & 6,6 & 10,7 & 18,3 & 31,7 & 51,1 & 65,0 & 75,0 \\
Ampicilina & 4,5 & 8,7 & 16,5 & 30,2 & 50,0 & 64,2 & 74,4 \\
Cloxacilina & 15,8 & 22,3 & 33,8 & 52,0 & 73,7 & 85,6 & 92,1 \\
Penicilina G & 16,7 & 21,9 & 37,5 & 46,7 & 67,0 & 79,6 & 87,3 \\
\hline
\end{tabular}

Cuadro 37. Porcentajes de degradación de penicilinas en extractos de leche congelados

\begin{tabular}{|lccccccc|}
\hline \multirow{2}{*}{ Penicilinas } & \multicolumn{7}{c|}{ Tiempo de congelación (días) } \\
\cline { 2 - 8 } & $\mathbf{1}$ & $\mathbf{3}$ & $\mathbf{7}$ & $\mathbf{1 5}$ & $\mathbf{3 0}$ & $\mathbf{4 5}$ & $\mathbf{6 0}$ \\
\hline Amoxicilina & 9,0 & 17,3 & 31,8 & 53,7 & 77,5 & 89,1 & 94,7 \\
Ampicilina & 8,4 & 19,3 & 37,5 & 62,4 & 85,5 & 94,4 & 97,9 \\
Cloxacilina & 13,8 & 16,7 & 22,2 & 32,1 & 47,4 & 59,3 & 68,5 \\
Penicilina G & 15,7 & 19,0 & 29,6 & 36,2 & 52,7 & 64,9 & 74,0 \\
\hline
\end{tabular}

A partir de estos resultados se puede deducir que las penicilinas son moléculas poco estables en congelación, puesto que muestran degradaciones considerables (superiores al 20\%) a los 7 días, tanto en muestras como en extractos, excepto en el caso de la amoxicilina y ampicilina con porcentajes ligeramente menores en las muestras de leche.

Cuando aumenta el tiempo de conservación de las muestras y los extractos hasta un mes de congelación (30 días), todas las sustancias presentan porcentajes de degradación muy elevados con valores entre el 50 y el $86 \%$.

Si se comparan estos resultados con los obtenidos en el estudio de refrigeración (cuadros 31 y 32) se deduce que la congelación mejora en todos los 
casos la estabilidad de las sustancias en la leche, excepto en el de la penicilina G, mientras que en los extractos la estabilidad es ligeramente menor en congelación a los 7 días, salvo para la cloxacilina.

Estas diferencias entre la refrigeración y la congelación de extractos podrían deberse a un posible efecto del proceso de "congelación-descongelación" que afectaría e mayor medida a la matriz acuosa empleada en estos casos.

De la misma manera que se procedió en el apartado anterior, con un objetivo práctico, se han calculado los tiempos de vida media $\left(t_{1 / 2}\right)$ de cada una de las penicilinas tanto en los extractos como en las muestras de leche congelados, cuyos valores se presentan en el Cuadro 38.

Cuadro 38. Tiempos de vida media $\left(t_{1 / 2}\right)$ de las penicilinas en muestras de leche y extractos congelados

\begin{tabular}{|ccccc|}
\hline \multirow{2}{*}{ Matriz } & \multicolumn{4}{c|}{$\mathbf{t}_{\mathbf{1 / 2}}$ (días) } \\
\cline { 2 - 5 } & Amoxicilina & Ampicilina & Cloxacilina & Penicilina G \\
\hline Leche & 29 & 30 & 14 & 21 \\
Extractos & 13 & 11 & 33 & 27 \\
\hline
\end{tabular}

A partir de estos tiempos de vida media se aprecia que la cloxacilina es más inestable en las muestras de leche congeladas que el resto de penicilinas, y que la amoxicilina y ampicilina resultan más estables. No obstante, en los extractos congelados, la amoxicilina y la ampicilina muestran mayor inestabilidad que la cloxacilina o la penicilina $\mathrm{G}$.

Estos cambios de estabilidad de los analitos entre las muestras y extractos dependen seguramente también del efecto de "congelación-descongelación" que exprimentan, de forma diferente, los dos tipos de matrices estudiados. Se podría decir incluso en este caso que la matriz de leche ejerce en algunos casos un efecto protector sobre las moléculas estudiadas que se corresponde con aquellas sustancias que presentan menor degradación en leche que en matriz acuosa.

También se observa que los tiempos de vida media obtenidos en el caso de las leches congeladas son superiores (14-30 días) a los calculados anteriormente en refrigeración (9-14 días). Este hecho indica que en el caso de trabajar con un gran número de muestras en el laboratorio que no se pudieran procesar hasta antes de 4 a 7 días desde su llegada al laboratorio y fuera necesario conservar las muestras durante ese periodo de tiempo sería más recomendable congelar las muestras de leche en vez de refrigerar, siempre y cuando se tenga en cuenta que el proceso de 
congelación puede influir en la calidad de la leche si no se trabaja de manera adecuada.

Por el contrario en el caso de emplear extractos de leche, sería más aconsejable refrigerar antes que congelar, puesto que parece que el efecto de la congelación produce un mayor deterioro en las penicilinas con unas pérdidas de concentración más elevadas.

Respecto a los trabajos sobre la estabilidad de penicilinas realizados en leche por otros autores, son pocos los estudios encontrados. Por un lado Shenck (2000) no determinó degradación en la ampicilina presente en muestras de leche congeladas a $-76{ }^{\circ} \mathrm{C}$ al cabo de 6 días de almacenamiento lo que se debe seguramente a la elevada temperatura de congelación empleada.

Por otra parte Riediker et al. (2004) obtienen una degradación entre el 10 y el $20 \%$ en muestras de leche congeladas a $-20{ }^{\circ} \mathrm{C}$ que contienen penicilina $\mathrm{G}$ y cloxacilina después de tan solo 3 días de conservación, coincidiendo con el 22,3 y $12,4 \%$ calculadas en este trabajo para las mismas sustancias y condiciones de almacenamiento. En cuanto a la estabilidad de la amoxicilina y ampicilina en muestras de leche, los citados autores no determinan pérdidas significativas a lo largo de 28 días de almacenamiento, lo que contrasta con el 31,7 y $30,2 \%$ obtenidos en este estudio a los 30 días de congelación.

Estos mismos autores, respecto a los extractos de leche congelados a $-20^{\circ} \mathrm{C}$, únicamente señalan una pérdida de concentración en el caso de la cloxacilina, aunque no indican el porcentaje de degradación obtenido.

Otros autores también han estudiado la influencia de la congelación sobre la estabilidad de algunos antibióticos betalactámicos en matrices alimentarias diferentes de la leche.

Así, Boison et al. (1992) en un estudio sobre la termoestabilidad de la penicilina $G$ en muestras de hígado de vaca congeladas a $-20{ }^{\circ} \mathrm{C}$ determinó un tiempo de vida media para esta sustancia de 114 días. De forma similar, Gee et al. (1996) estudiaron la estabilidad en congelación a $-20^{\circ} \mathrm{C}$ de la penicilina $\mathrm{G}$ en hígado de oveja utilizando el modelo cinético de primer orden y obtuvieron un tiempo de vida media de 62 días en muestras fortificadas.

Más recientemente Vahdat (2007), estudió la estabilidad de la amoxicilina en solución acuosa a $-20^{\circ} \mathrm{C}$ observando una relación lineal al graficar el logaritmo decimal de la concentración con el tiempo de almacenamiento. 
Los resultados de estos autores aunque no pueden compararse con los del presente trabajo al tratarse de matrices y análisis diferentes, muestran cierta similitud, ya que establecen un efecto degradativo de la penicilina $\mathrm{G}$ en congelación.

\subsection{ANTIBIÓTICOS BETALACTÁMICOS: CEFALOSPORINAS}

\subsubsection{Influencia de la refrigeración de las muestras y extractos de leche}

El efecto del tiempo de refrigeración sobre la variación porcentual de la concentración de las cefalosporinas en las muestras de leche y los respectivos extractos se presentan en forma de diagrama de barras en la Figura 41.
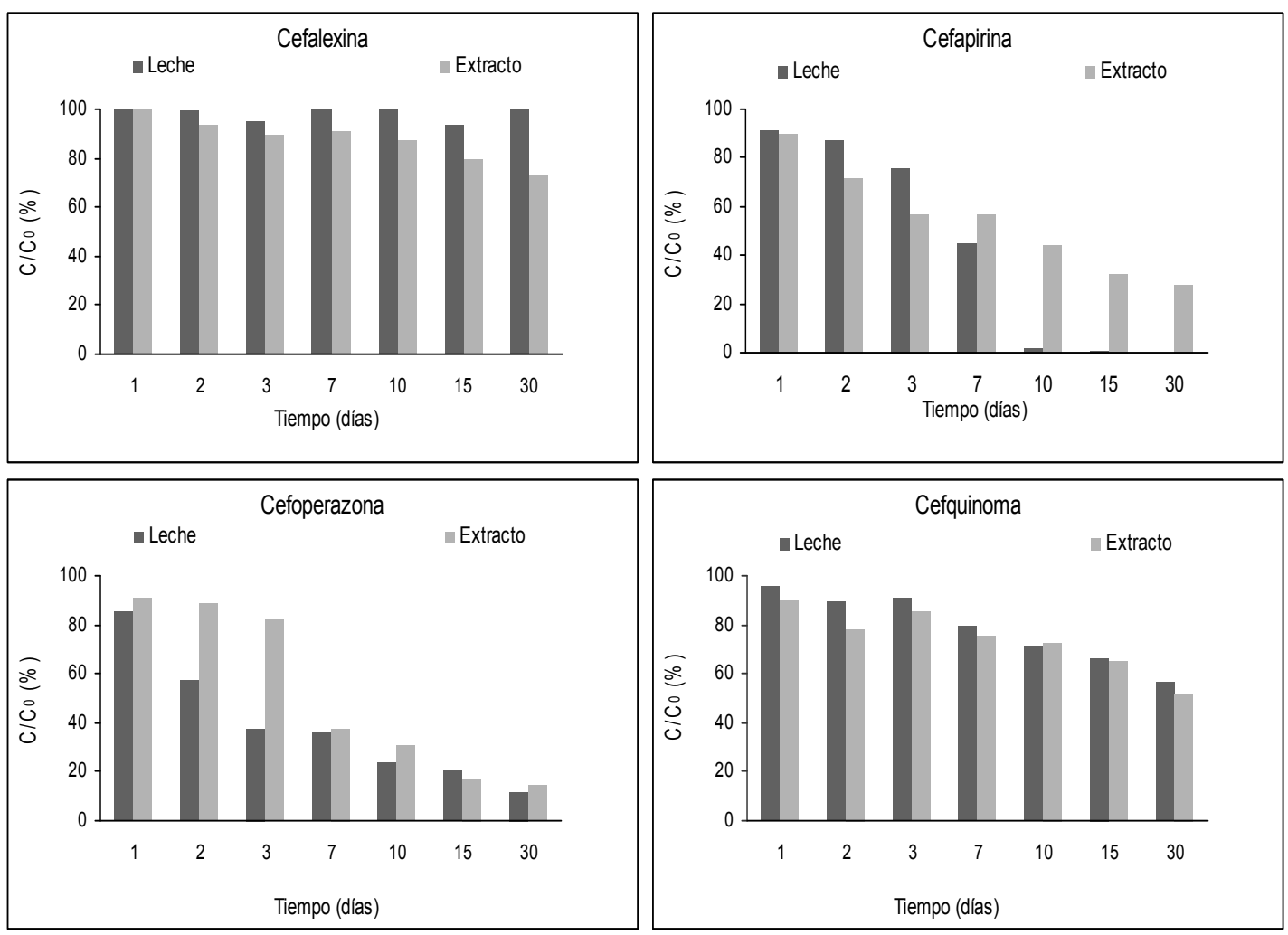

Figura 41. Porcentajes de variación de la concentración de cefalosporinas en los extractos y muestras de leche con el tiempo de refrigeración

Se observa que las cefalosporinas ensayadas disminuyen su concentración con el tiempo transcurrido en refrigeración, excepto en el caso de la cefalexina que en las muestras de leche no presenta apenas variación con respecto a la concentración inicial durante todo el periodo experimental.

La cefapirina y la cefoperazona son las dos moléculas que manifiestan un mayor deterioro en la medida que se incrementa el tiempo de refrigeración, más elevado aún en la leche que en los extractos, poniendo de manifiesto la marcada inestabilidad de estas dos sustancias en el almacenamiento a $4^{\circ} \mathrm{C}$. 
La cefquinoma, por su parte, presenta una degradación más moderada y progresiva con el tiempo con una concentración a los 15 días de refrigeración en torno al $70 \%$ respecto a la concentración inicial, sin apenas variaciones entre las muestras de leche y los extractos.

Los valores medios de las pérdidas de concentración de los analitos obtenidas a lo largo del tiempo de refrigeración, se analizaron mediante el modelo cinético de primer orden aplicando la regresión lineal múltiple a las transformaciones logarítmicas de las concentraciones de cefalosporinas en función del tiempo y la matriz empleada. Los parámetros estadísticos obtenidos en este análisis se muestran en el Cuadro 39.

Cuadro 39. Efecto del tiempo de refrigeración y de la matriz sobre la concentración de cefalosporinas

\begin{tabular}{|lcccccc|}
\hline \multirow{2}{*}{ Cefalosporinas } & \multicolumn{2}{c}{ Tiempo } & \multicolumn{2}{c}{ Matriz } & \multicolumn{2}{c|}{ Tiempo·Matriz } \\
\cline { 2 - 7 } & Valor F & Valor $\mathbf{p}$ & Valor $\mathbf{F}$ & Valor $\mathbf{p}$ & Valor F & Valor $\mathbf{p}$ \\
\hline Cefalexina & 11,99 & 0,0047 & 2,03 & 0,1798 & 8,51 & 0,0129 \\
Cefapirina & 36,47 & 0,0001 & 3,07 & 0,1101 & 22,70 & 0,0008 \\
Cefoperazona & 58,42 & 0,0001 & 1,20 & 0,2947 & 0,11 & 0,7492 \\
Cefquinoma & 105,61 & 0,0001 & 2,23 & 0,1612 & 0,01 & 0,9958 \\
\hline
\end{tabular}

Como se observa en este Cuadro, el tiempo de refrigeración afecta de forma significativa a las concentraciones de las cuatro cefalosporinas $(p<0,01)$, mientras que la matriz no resulta significativa $(p>0,05)$ en ningún caso, señalando la equivalencia en las concentraciones de las cefalosporinas al momento de iniciar el experimento. Por el contrario, la interacción entre la matriz empleada y el tiempo de refrigeración afecta de forma significativa a las transformaciones logarítmicas de las concentraciones de cefapirina y cefalexina $(p<0,05)$.

Las ecuaciones matemáticas que expresan los cambios en las transformaciones logarítmicas de las concentraciones de cefalosporinas en función del tiempo, para las dos matrices analizadas, se muestran en el Cuadro 40.

Respecto a los coeficientes de regresión obtenidos en el análisis de regresión, se observa que la cefalexina y la cefapirina obtiene valores más bajos $\left(R^{2}=0,7744\right.$ y $\mathrm{R}^{2}=0,7891$ respectivamente) que se deben por un lado a la escasa variación de la concentración de cefalexina en las muestras de leche con el tiempo de refrigeración $y$, por otro, a la diferencia existente entre la variación de concentración de la cefapirina en la leche respecto a los extractos a lo largo del periodo de refrigeración. 
Cuadro 40. Ecuaciones de regresión lineal múltiple de los efectos del tiempo de refrigeración y de la matriz sobre la concentración de cefalosporinas

\begin{tabular}{|llc|}
\hline Cefalosporinas & Ln [Cefalosporina] $\left.=\mathbf{a}+\mathbf{k}_{\mathbf{1}} \cdot \mathbf{t}+\mathbf{k}_{\mathbf{2}} \cdot \mathbf{M}+\mathbf{k}_{\mathbf{1 , 2}} \cdot \mathbf{( t \cdot} \cdot \mathbf{M}\right)$ & $\mathbf{R}^{\mathbf{2}}$ \\
\hline Cefalexina & Ln [Cefalexina] $=4,54301-0,00026 \cdot \mathrm{t}+0,00022 \cdot(\mathrm{t} \cdot \mathrm{M})$ & 0,7744 \\
Cefapirina & Ln [Cefapirina] $=4,19614-0,00799 \cdot \mathrm{t}-0,00631 \cdot(\mathrm{t} \cdot \mathrm{M})$ & 0,7891 \\
Cefoperazona & Ln [Cefoperazona] $=3,61389-0,002831 \cdot \mathbf{t}$ & 0,8331 \\
Cefquinoma & Ln [Cefquinoma] $=2,89714-0,00078 \cdot \mathbf{t}$ & 0,9013 \\
\hline
\end{tabular}

M: matriz (Leche: $\mathrm{M}=+1$; Extracto: $\mathrm{M}=-1$ ); $\mathrm{t}$ : tiempo (horas)

La cefapirina y la cefoperazona presentan mayores valores de sus constantes " $k_{1}$ ", señalando una disminución más rápida en sus respectivas concentraciones conforme transcurre el tiempo de refrigeración.

También se puede observar en este cuadro que la cefalexina $\left(k_{1,2}=+\right.$ $0,00022)$ es más estable en la leche y la cefapirina $\left(k_{1,2}=-0,00631\right)$ en los extractos, debido a que las constantes de velocidad " $k_{1,2}$ " varían al pasar de muestras de leche $(M=+1)$ a extractos $(M=-1)$.

Las representaciones gráficas correspondientes a las rectas estimadas por el modelo de regresión lineal múltiple se muestran en la Figura 41 para las muestras de leche y en la Figura 42 para los extractos correspondientes.

Las pendientes de las rectas de regresión representadas en estas Figuras revelan claramente la menor estabilidad de la cefapirina en la leche (Figura 42) en comparación con los extractos (Figura 43).

Con el fin de establecer desde un punto de vista práctico los protocolos de trabajo en el laboratorio de control de calidad de leche, se han estimado los porcentajes de pérdidas de concentración de las cefalosporinas en muestras y extractos de leche a lo largo de una semana (7 días), haciendo uso de las ecuaciones de regresión obtenidas anteriormente (Cuadro 40) cuyos resultados se presentan en los Cuadros 41 y 42.

A partir de los resultados de dichos Cuadros se observa que lógicamente la cefalexina en las muestras de leche no presenta prácticamente variación con el tiempo de refrigeración con un porcentaje de degradación el séptimo día del $6,7 \%$, al igual que la cefquinoma que también se muestra estable en las muestras de leche refrigeradas aunque con pérdidas ligeramente superiores (11-20,5\%). 

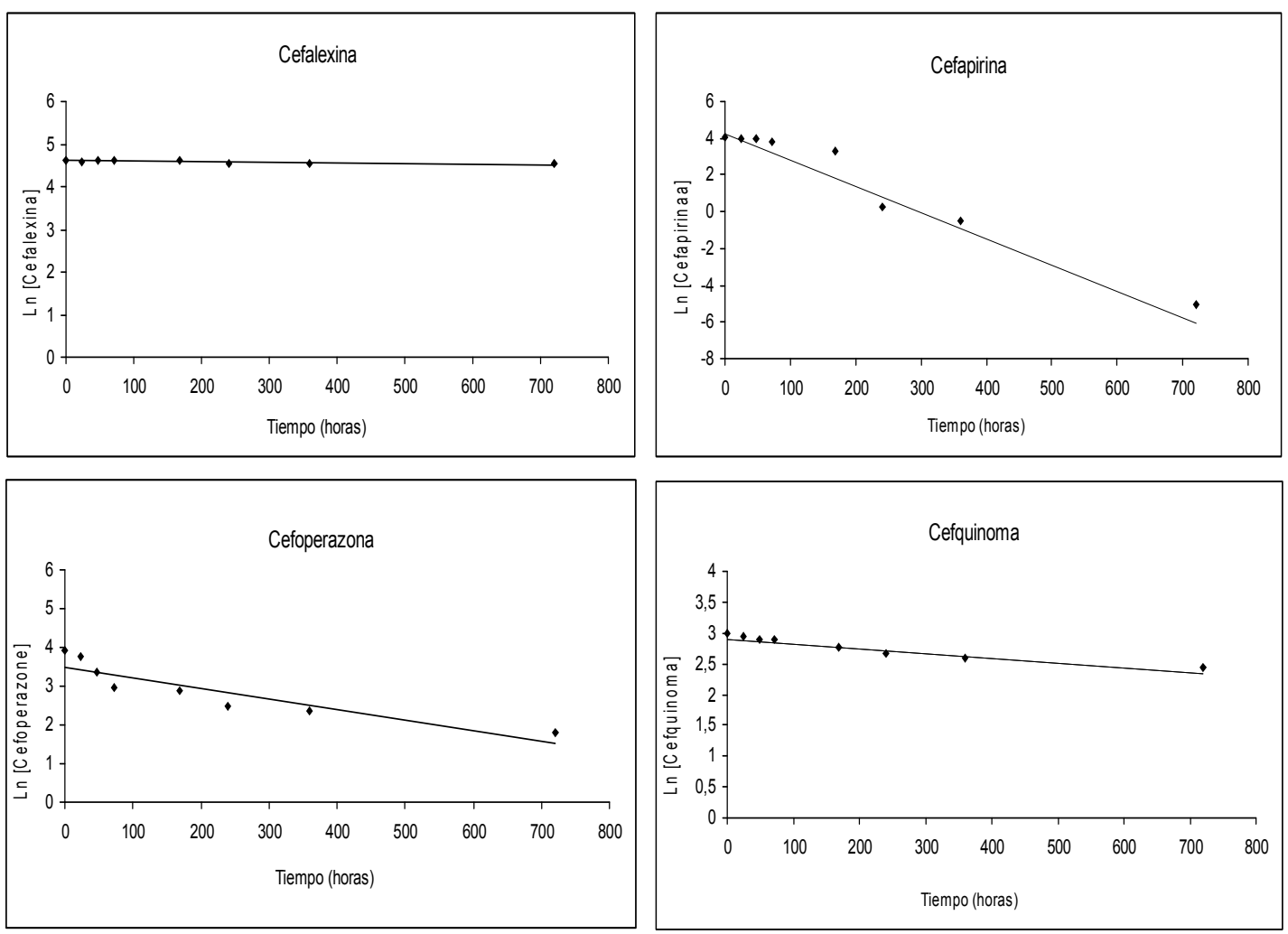

Figura 42. Efecto del tiempo de refrigeración sobre la concentración de cefalosporinas en muestras de leche
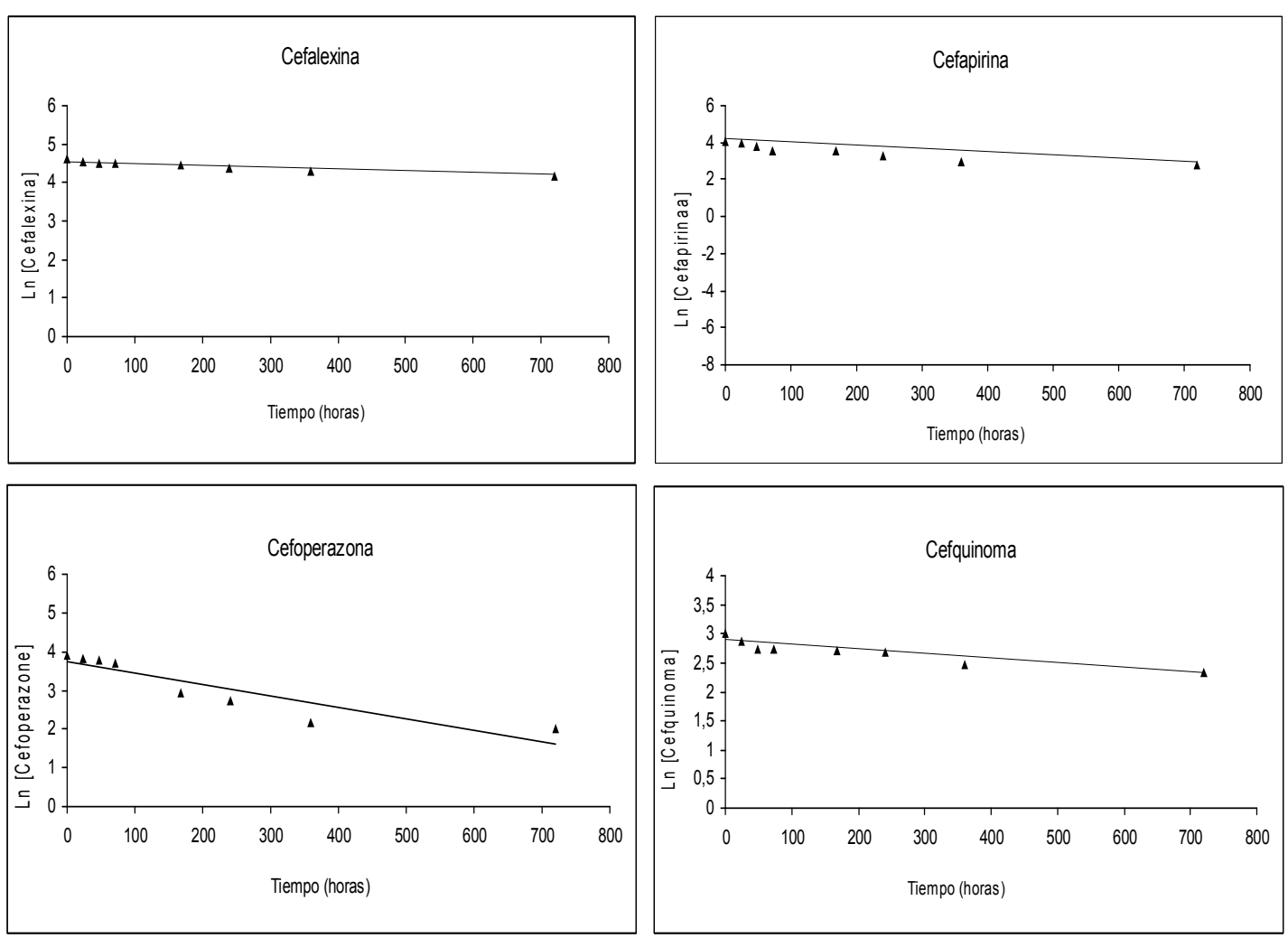

Figura 43. Efecto del tiempo de refrigeración sobre la concentración de cefalosporinas en extractos de leche 
Cuadro 41. Porcentajes de degradación de cefalosporinas en muestras de leche refrigeradas

\begin{tabular}{|lccccccc|}
\hline \multirow{2}{*}{ Cefalosporinas } & \multicolumn{7}{c|}{ Tiempo de refrigeración (días) } \\
\cline { 2 - 9 } & $\mathbf{1}$ & $\mathbf{2}$ & $\mathbf{3}$ & $\mathbf{4}$ & $\mathbf{5}$ & $\mathbf{6}$ & $\mathbf{7}$ \\
\hline Cefalexina & 6,1 & 6,2 & 6,3 & 6,4 & 6,5 & 6,6 & 6,7 \\
Cefapirina & 21,4 & 44,3 & 60,5 & 71,9 & 80,1 & 85,9 & 90,0 \\
Cefoperazona & 30,7 & 35,2 & 39,5 & 43,4 & 47,2 & 50,6 & 53,9 \\
Cefquinoma & 11,1 & 12,7 & 14,3 & 15,9 & 17,5 & 19,0 & 20,5 \\
\hline
\end{tabular}

Cuadro 42. Porcentajes de degradación de cefalosporinas en extractos de leche refrigerados

\begin{tabular}{|lccccccc|}
\hline \multirow{2}{*}{ Cefalosporinas } & \multicolumn{7}{c|}{ Tiempo de refrigeración (días) } \\
\cline { 2 - 8 } & $\mathbf{1}$ & $\mathbf{2}$ & $\mathbf{3}$ & $\mathbf{4}$ & $\mathbf{5}$ & $\mathbf{6}$ & $\mathbf{7}$ \\
\hline Cefalexina & 7,1 & 8,2 & 9,2 & 10,3 & 11,3 & 12,3 & 13,3 \\
Cefapirina & 0,0 & 0,0 & 1,9 & 5,8 & 9,5 & 13,1 & 16,5 \\
Cefoperazona & 30,7 & 35,2 & 39,5 & 43,4 & 47,2 & 50,6 & 53,9 \\
Cefquinoma & 11,1 & 12,7 & 14,3 & 15,9 & 17,5 & 19,0 & 20,5 \\
\hline
\end{tabular}

Por el contrario, la cefapirina y la cefoperazona en leche muestran mayor inestabilidad, especialmente la cefapirina, con pérdidas de concentración superiores al $21,4 \%$ el primer día de refrigeración y en torno al $90 \%$ a los 7 días.

Si se comparan estos resultados con los obtenidos en el estudio de la refrigeración de penicilinas en muestras de leche, se observa que la cefapirina y la cefoperazona son más inestables que las penicilinas, mientras que la cefquinoma presenta un comportamiento similar y la cefalexina se muestra mucho más estable.

En cuanto a los extractos de leche refrigerados (Cuadro 42), hay que destacar el aumento de la degradación de la cefalexina comparado con las muestras de leche, aunque los porcentajes obtenidos a lo largo de los 7 días siguen siendo muy bajos con valores que oscilan entre el 7,1 y el $13,3 \%$.

La cefapirina por el contrario, mejora mucho su estabilidad cuando se refrigera en extractos de leche disminuyendo desde el $60,5 \%$ hasta el 1,9\% el tercer día de refrigeración y obteniendo como máximo, unas pérdidas inferiores al $20 \%$ a los 7 días.

Estos resultados son semejantes a los obtenidos en el caso de las penicilinas excepto en el caso de la cefoperazona que presenta porcentajes de degradación superiores, resaltando de nuevo la inestabilidad térmica de esta sustancia. 
En resumen, se puede establecer que, cuando en un laboratorio de análisis haya que refrigerar las muestras para su posterior análisis por cromatografía HPLC, resultaría conveniente realizar las extracciones y refrigerar los extractos antes que refrigerar las muestras de leche, aunque moléculas como cefoperazona pueden llegar a desnaturalizarse hasta un $50 \%$ después de permanecer conservadas 6 días en refrigeración.

A partir de las ecuaciones de regresión del Cuadro 40 también se han calculado los tiempos de vida media $\left(t_{1 / 2}\right)$ necesarios para reducir a la mitad la concentración inicial de cada una de las cefaloporinas en muestras y extractos de leche, cuyos resultados se presentan en el Cuadro 43.

Cuadro 43. Tiempos de vida media $\left(t_{1 / 2}\right)$ de las cefalosporinas en muestras de leche y extractos refrigerados

\begin{tabular}{|ccccc|}
\hline \multirow{2}{*}{ Matriz } & \multicolumn{4}{c|}{$\mathbf{t}_{1 / 2}$ (días) } \\
\cline { 2 - 5 } & Cefalexina & Cefapirina & Cefoperazona & Cefquinoma \\
\hline Leche & 644 & 2 & 6 & 32 \\
Extractos & 54 & 20 & 6 & 32 \\
\hline
\end{tabular}

Del Cuadro 43 se deduce que la cefalexina es una molécula muy estable en las muestras de leche refrigeradas con un tiempo de vida media muy largo. Esta molécula también presenta una relativa estabilidad en los extractos si se compara con el resto de cefalosporinas, no obstante no es comparable con la obtenida en las muestras de leche. Esta diferencia entre los dos tipos de matriz podría deberse a un posible efecto protector de la materia grasa de la leche sobre esta molécula.

Por otra parte es importante resaltar la gran inestabilidad que muestran la cefapirina y la cefoperazona, con unos tiempos de vida media muy bajos entre 2 y 6 días en las muestras de leche y entre 6 y 20 días en los extractos.

Respecto a los estudios realizados por otros autores, dado que las cefalosporinas son moléculas que se han empezado a utilizar en medicina veterinaria recientemente y que su uso aún no se encuentra muy difundido en ganado lechero, no se ha encontrado ningún trabajo que evalúe la estabilidad en refrigeración de estas sustancias en la leche a partir de los cuales se puedan comparar los resultados obtenidos en este estudio.

En otras matrices alimentarias, Nouws (1976), estableció mediante un método microbiológico, una disminución rápida de la concentración de cefalexina en 
muestras de riñón después de 7 días de refrigeración a $4^{\circ} \mathrm{C}$ y una estabilidad mayor cuando se trabajó con muestras de hígado.

Los resultados de dicho autor y los establecidos en el presente trabajo, aunque no son comparables, muestran una tendencia similar en la degradación de la cefapirina presente en matrices alimentarias.

\subsubsection{Influencia de la congelación de las muestras y extractos de leche}

En la Figura 44 se representan las variaciones porcentuales de las concentraciones de cefalosporinas presentes en extractos y muestras de leche almacenados a $-20 \pm 2^{\circ} \mathrm{C}$.
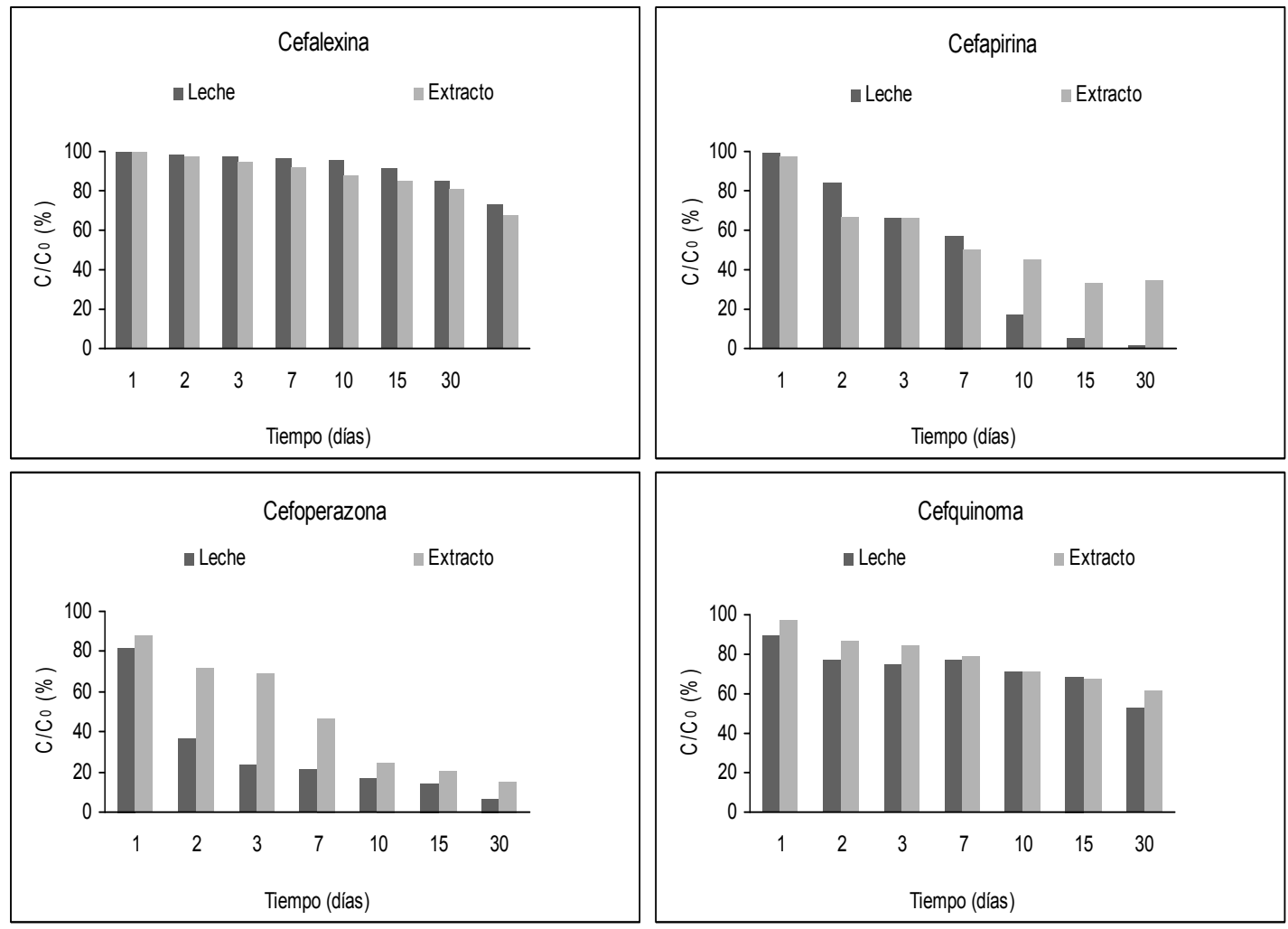

Figura 44. Porcentajes de variación de la concentración de cefalosporinas en los extractos y muestras de leche con el tiempo de congelación

Los histogramas de la Figura 43 muestran que las cefalosporinas disminuyen su concentración inicial a medida que avanza el tiempo de congelación, siendo la cefalexina y la cefquinoma las que muestran menor degradación. Esta disminución es, en casi todos los casos más acentuada en las muestras de leche que en los extractos, excepto en el caso de la cefalexina donde las muestras se mantuvieron ligeramente más estables. 
Los parámetros estadísticos obtenidos mediante la aplicación del modelo de regresión lineal múltiple a las transformaciones logarítmicas de las concentraciones de cefalosporinas en función del tiempo y el tipo de matriz se resumen en el Cuadro 44.

Cuadro 44. Efecto del tiempo de congelación y de la matriz sobre la concentración de cefalosporinas

\begin{tabular}{|lllllcc|}
\hline \multirow{2}{*}{ Cefalosporinas } & \multicolumn{2}{c}{ Tiempo } & \multicolumn{2}{c|}{ Matriz } & \multicolumn{2}{c|}{ Tiempo-Matriz } \\
\cline { 2 - 7 } & Valor $\mathbf{F}$ & Valor $\mathbf{p}$ & Valor $\mathbf{F}$ & Valor $\mathbf{p}$ & Valor $\mathbf{F}$ & Valor $\mathbf{p}$ \\
\hline Cefalexina & 81,52 & 0,0001 & 3,52 & 0,0852 & 5,95 & 0,0312 \\
Cefapirina & 95,59 & 0,0001 & 1,30 & 0,2757 & 35,28 & 0,0001 \\
Cefoperazona & 30,79 & 0,0001 & 2,34 & 0,1488 & 0,14 & 0,7129 \\
Cefquinoma & 57,76 & 0,0001 & 0,78 & 0,3942 & 0,11 & 0,7506 \\
\hline
\end{tabular}

Al igual que en los estudios anteriores, el tiempo de congelación resulta significativo $(p<0,001)$ en todos los casos, mientras que el tipo de matriz no afecta a la concentración de las cefalosporinas. Por otro lado, la interacción entre la matriz y el tiempo de congelación únicamente afecta de forma significativa a la cefalexina $(p<$ $0,05)$ y en mayor medida a la cefapirina $(p<0,001)$.

En el Cuadro 45 se presentan las ecuaciones de regresión lineal múltiple que relacionan las concentraciones de cefalosporinas con el tiempo de congelación y el tipo de matriz empleada.

Cuadro 45. Ecuaciones de regresión lineal múltiple de los efectos del tiempo de congelación y de la matriz sobre la concentración de cefalosporinas

\begin{tabular}{|lll|}
\hline Cefalosporinas & Ln [Cefalosporina] $\left.=\mathbf{a}+\mathbf{k}_{\mathbf{1}} \cdot \mathbf{t}+\mathbf{k}_{\mathbf{2}} \cdot \mathbf{M}+\mathbf{k}_{\mathbf{1 , 2}} \cdot \mathbf{( t \cdot} \cdot \mathbf{M}\right)$ & $\mathbf{R}^{\mathbf{2}}$ \\
\hline Cefalexina & Ln [Cefalexina] $=4,59238-0,00047 \cdot \mathrm{t}+0,00004 \cdot(\mathrm{t} \cdot \mathbf{M})$ & 0,9861 \\
Cefapirina & Ln [Cefapirina] $=3,96596-0,00379 \cdot \mathrm{t}-0,00230 \cdot(\mathrm{t} \cdot \mathrm{M})$ & 0,9238 \\
Cefoperazona & Ln [Cefoperazona] $=3,48568-0,00288 \cdot \mathrm{t}$ & 0,7540 \\
Cefquinoma & Ln [Cefquinoma] $=2,88157-0,00067 \cdot \mathbf{t}$ & 0,8335 \\
\hline
\end{tabular}

M: matriz (Leche: $M=+1$; Extracto: $M=-1$ ); $\mathrm{t}$ : tiempo (horas)

Los ajustes obtenidos mediante la aplicación de este modelo fueron, aunque en el caso de la cefoperazona un poco más bajo $\left(R^{2}=0,7540\right)$, adecuados lo que indica que el modelo cinético de primer orden se ajusta correctamente al estudio de la estabilidad térmica de estas moléculas en congelación. 
En cuanto a las pendientes de estas ecuaciones se observa que la cefapirina es la que muestra mayor valor de la constante de reacción " $\mathrm{k}_{1}$ ", lo que indica que se degrada más rápido con el tiempo de congelación si se compara con el resto de sustancias.

Por otra parte la cefalexina presenta un bajo valor positivo de " $\mathrm{k}_{1,2}$ ", lo que señala que las muestras $(M=+1)$ se deterioran menos que los extractos $(M=-1)$, aunque las diferencias entre las degradaciones son muy escasas. A su vez, la cefapirina muestra un valor elevado y negativo de la constante de la interacción, indicando la mayor degradación de las muestras de leche respecto a sus correspondientes extractos.

Las Figuras 45 y 46 muestran las rectas de regresión correspondientes a las concentraciones de cefalosporinas en función del tiempo de congelación y el tipo de matriz utilizada, donde se aprecian sobre todo las diferencias entre las pendientes obtenidas en el caso de la cefapirina en los dos tipos de matrices ensayadas.
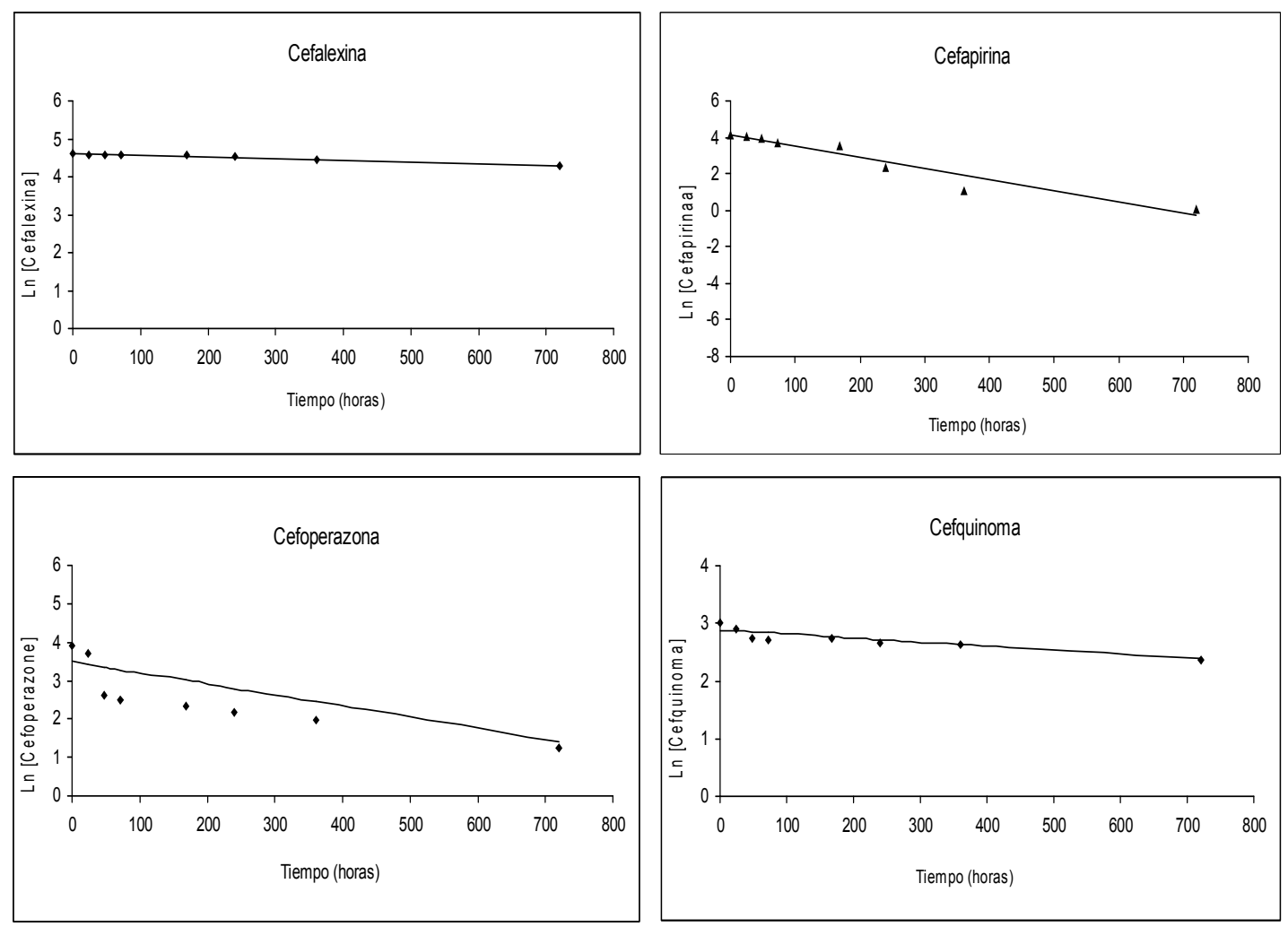

Figura 45. Efecto del tiempo de congelación sobre la concentración de cefalosporinas en muestras de leche 

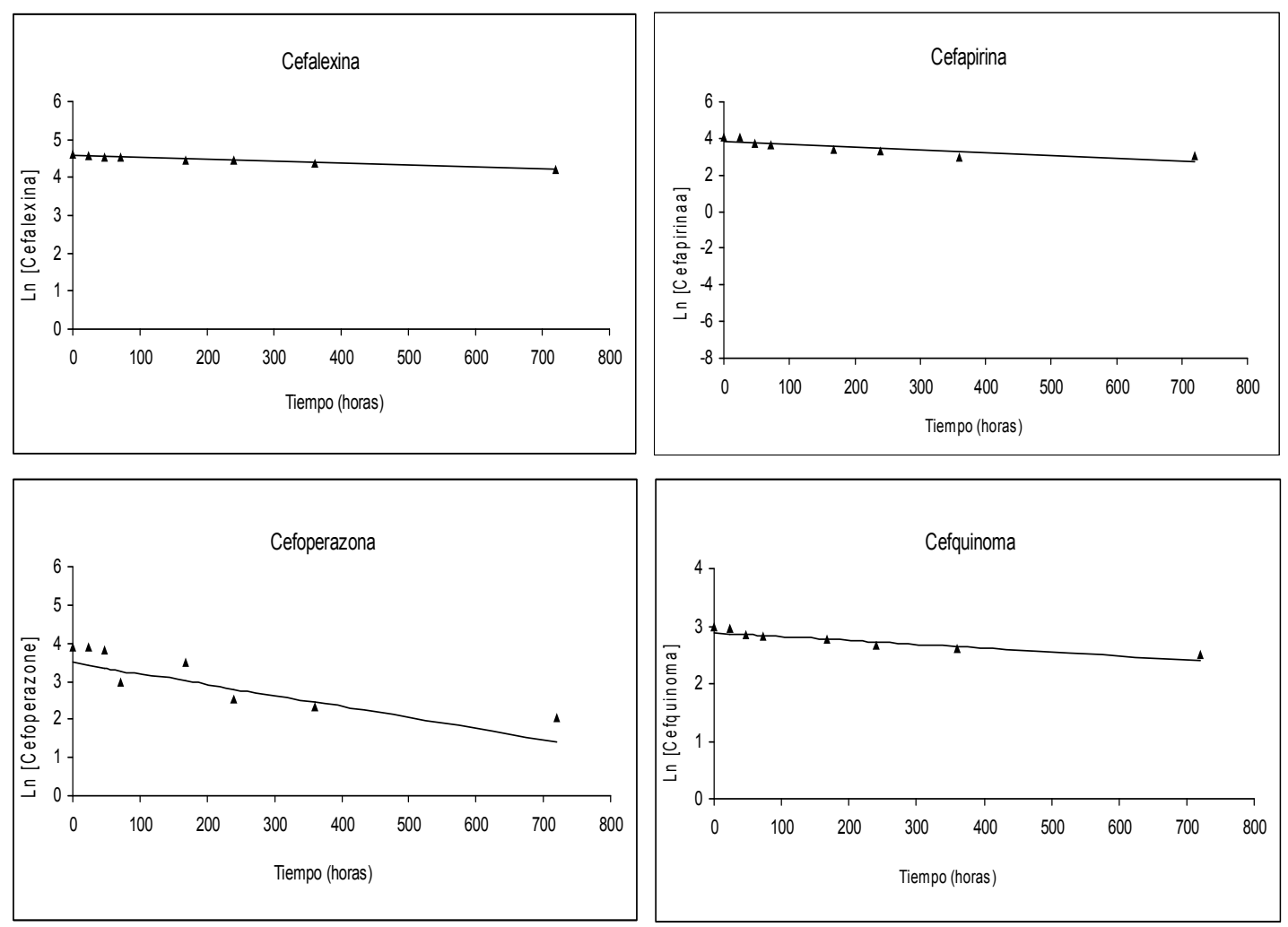

Figura 46. Efecto del tiempo de congelación sobre la concentración de cefalosporinas en extractos de leche

Desde un punto de vista práctico se han estimado las pérdidas de concentración, en porcentaje, que pueden experimentar las cefalosporinas en muestras y extractos a lo largo del almacenamiento de la leche en congelación durante los periodos de tiempo que se consideran viables en los protocolos de análisis, cuyos resultados se presentan en los Cuadros 46 y 47.

Cuadro 46. Porcentajes de degradación de las cefalosporinas en muestras de leche congeladas

\begin{tabular}{|lccccccc|}
\hline \multirow{2}{*}{ Cefalosporinas } & \multicolumn{7}{c|}{ Tiempo de congelación (días) } \\
\cline { 2 - 8 } & $\mathbf{1}$ & $\mathbf{3}$ & $\mathbf{7}$ & $\mathbf{1 5}$ & $\mathbf{3 0}$ & $\mathbf{4 5}$ & $\mathbf{6 0}$ \\
\hline Cefalexina & 2,3 & 4,3 & 8,2 & 15,4 & 27,6 & 37,9 & 46,8 \\
Cefapirina & 24,0 & 43,3 & 68,4 & 90,2 & 98,9 & 99,9 & 100,0 \\
Cefoperazona & 42,3 & 49,7 & 61,9 & 78,1 & 92,2 & 97,2 & 99,0 \\
Cefquinoma & 12,2 & 15,0 & 20,3 & 29,9 & 44,9 & 56,7 & 66,0 \\
\hline
\end{tabular}

A partir de los resultados de dichos Cuadros se advierte que la cefalexina y la cefquinoma son las moléculas más estables en congelación mientras que la cefapirina y en mayor medida la cefoperazona son muy termosensibles con unos porcentajes de degradación muy elevados. 
Cuadro 47. Porcentajes de degradación de las cefalosporinas en extractos de leche congelados

\begin{tabular}{|lccccccc|}
\hline \multirow{2}{*}{ Cefalosporinas } & \multicolumn{7}{c|}{ Tiempo de congelación (días) } \\
\cline { 2 - 8 } & $\mathbf{1}$ & $\mathbf{3}$ & $\mathbf{7}$ & $\mathbf{1 5}$ & $\mathbf{3 0}$ & $\mathbf{4 5}$ & $\mathbf{6 0}$ \\
\hline Cefalexina & 2,5 & 4,8 & 9,4 & 17,8 & 31,6 & 43,1 & 52,6 \\
Cefapirina & 15,1 & 21,0 & 31,5 & 48,6 & 69,9 & 82,4 & 89,7 \\
Cefoperazona & 42,3 & 49,7 & 61,9 & 78,1 & 92,2 & 97,2 & 99,0 \\
Cefquinoma & 12,2 & 15,0 & 20,3 & 29,9 & 44,9 & 56,7 & 66,0 \\
\hline
\end{tabular}

También se observa que la diferencia en la concentración de la cefalexina con el tiempo de congelación en muestras y extractos de leche es muy pequeña, con unos porcentajes de degradación similares en ambas matrices aunque ligeramente superiores en los extractos.

Por otro lado, la cefapirina muestra una estabilidad notablemente mayor cuando está presente en los extractos de leche, especialmente durante los primeros 15 días de almacenamiento.

La cefquinoma, a su vez, muestra una degradación más moderada aunque alcanza unos porcentajes elevados $(66 \%)$ a los dos meses de congelación.

También en este caso se han calculado los tiempos de vida media de las cefalosporinas, a partir del modelo de regresión lineal múltiple. Estos tiempos se presentan en el Cuadro 48 y a partir de ellos se deduce de nuevo que la cefapirina y la cefoperazona son las moléculas más sensibles a la congelación de las muestras de leche y los extractos con tiempos muy bajos de vida media entre 3 y 16 días, lo que pone de manifiesto la gran inestabilidad de estas moléculas.

Cuadro 48. Tiempos de vida media $\left(t_{1 / 2}\right)$ de las cefalosporinas en muestras de leche y extractos congelados

\begin{tabular}{|ccccc|}
\hline \multirow{2}{*}{ Matriz } & \multicolumn{4}{c|}{$\mathbf{t}_{\mathbf{1 / 2}}$ (días) } \\
\cline { 2 - 5 } & Cefalexina & Cefapirina & Cefoperazona & Cefquinoma \\
\hline Leche & 66 & 4 & 3 & 36 \\
Extractos & 56 & 16 & 3 & 36 \\
\hline
\end{tabular}

La inestabilidad de estas dos cefalosporinas también se expuso anteriormente en el estudio de refrigeración, lo que indica que se trata de sustancias susceptibles a la degradación por acción de la temperatura que puede deberse seguramente a la estructura química que presenta cada una de ellas. 
Deshpande et al. (2004) en una revisión bibliográfica sobre los mecanismos de degradación de antibióticos betalactámicos indica que la naturaleza de los radicales situados en la posición C-3 y C-7 del anillo betalactámico desarrollan un papel decisivo en la facilidad con que los enlaces betalactámicos se hidrolizan o rompen por acción química o enzimática, lo que podría estar relacionado con la diferente estabilidad que presentan las cefalosporinas, ya que en cada una de ellas se encuentran radicales de naturaleza química muy diferentes.

Por otra parte, hay que destacar que no se ha encontrado ninguna referencia bibliográfica en donde se analice la estabilidad en congelación de las cefalosporinas presentes en matrices alimentarias, debido quizás como se ha comentado anteriormente a la relativamente reciente introducción de estos medicamentos en medicina veterinaria comparado con otros productos.

Por otro lado, Okerman et al., (2007) en un estudio realizado sobre la estabilidad de patrones puros de sustancias antimicrobianas bajo condiciones de congelación $\left(-20{ }^{\circ} \mathrm{C}\right)$ mediante un método microbiológico con Bacillus subilis, obtienen pérdidas de actividad para la cefapirina y el ceftiofur en torno al $25 \%$ al cabo de los 3 meses de congelación, resultados que no pueden compararse con los presentados en este trabajo debido a las diferentes matrices y métodos de detección empleados en cada caso.

\subsection{TETRACICLINAS}

\subsubsection{Influencia de la refrigeración de las muestras y extractos de leche}

Los resultados obtenidos en el estudio de la refrigeración de las muestras de leche y los extractos fortificados con tetraciclinas se representan gráficamente en la Figura 47 donde se expresan como la variación porcentual respecto a la concentración inicial en función del tiempo de refrigeración.

Como se observa en esta Figura, las concentraciones de las tetraciclinas disminuyen en la medida que se incrementa el tiempo de almacenamiento en refrigeración. También se aprecia que, en todos los casos, los extractos se conservan mejor que las muestras, con porcentajes de degradación menores.

Como en experimentos anteriores y empleando el modelo cinético de primer orden se aplicó la regresión lineal múltiple a los logaritmos de las concentraciones de las tetraciclinas, en función del tiempo y la matriz empleada, obteniendo los parámetros estadísticos que se recogen en el Cuadro 49. 

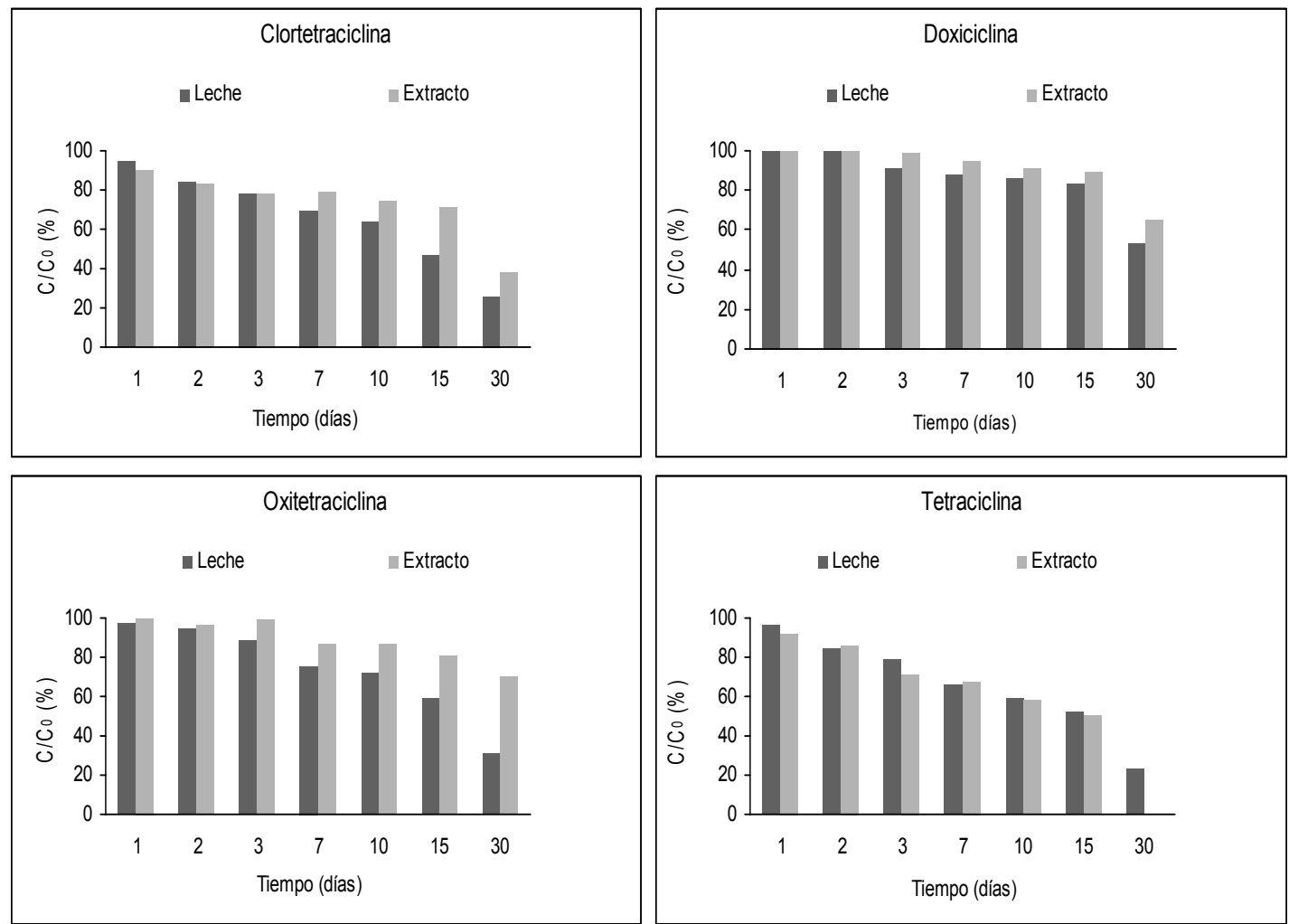

Figura 47. Porcentajes de variación de la concentración de tetraciclinas en los extractos y muestras de leche con el tiempo de refrigeración

Cuadro 49. Efecto del tiempo de refrigeración y de la matriz sobre la concentración de tetraciclinas

\begin{tabular}{|lcccccc|}
\hline \multirow{2}{*}{ Tetraciclinas } & \multicolumn{2}{c}{ Tiempo } & \multicolumn{2}{c|}{ Matriz } & \multicolumn{2}{c|}{ Tiempo-Matriz } \\
\cline { 2 - 7 } & Valor F & Valor $\mathbf{p}$ & Valor F & Valor $\mathbf{p}$ & Valor F & Valor $\mathbf{p}$ \\
\hline Clortetraciclina & 347,42 & 0,0001 & 0,06 & 0,8061 & 17,68 & 0,0001 \\
Doxiciclina & 181,96 & 0,0001 & 0,01 & 0,9382 & 33,33 & 0,0001 \\
Oxitetraciclina & 623,61 & 0,0001 & 0,01 & 0,9836 & 151,48 & 0,0001 \\
Tetraciclina & 258,38 & 0,0001 & 0,16 & 0,6972 & 27,63 & 0,0002 \\
\hline
\end{tabular}

En este caso también resulta altamente significativo el tiempo de refrigeración $(p<0,001)$, así como la interacción de la matriz con el tiempo de conservación para todas las sustancias ensayadas $(p<0,001)$.

A continuación, en el Cuadro 50, se presentan las ecuaciones correspondientes a la aplicación del modelo de regresión lineal múltiple a las concentraciones de las tetraciclinas con el tiempo de refrigeración, donde se alcanzan unos ajustes adecuados con coeficientes de regresión elevados superiores a 0,95 en todos los casos. 
Cuadro 50. Ecuaciones de regresión lineal múltiple de los efectos del tiempo de refrigeración y de la matriz sobre las concentraciones de tetraciclinas

\begin{tabular}{|lll|}
\hline Tetraciclinas & Ln [Tetraciclina] $\left.=\mathbf{a}+\mathbf{k}_{\mathbf{1}} \cdot \mathbf{t}+\mathbf{k}_{\mathbf{2}} \cdot \mathbf{M}+\mathbf{k}_{\mathbf{1 , 2}} \cdot \mathbf{( t \cdot} \cdot \mathbf{M}\right)$ & $\mathbf{R}^{\mathbf{2}}$ \\
\hline Clortetraciclina & Ln [Clortetraciclina] $=4,5555-0,00148 \cdot \mathrm{t}-0,00033 \cdot(\mathrm{t} \cdot \mathrm{M})$ & 0,9691 \\
Doxiciclina & Ln [Doxiciclina] $=4,6436-0,00101 \cdot \mathrm{t}-0,00043 \cdot(\mathrm{t} \cdot \mathrm{M})$ & 0,9526 \\
Oxitetraciclina & Ln [Oxitetraciclina] $=4,6088-0,00105 \cdot \mathrm{t}-0.00052 \cdot(\mathrm{t} \cdot \mathrm{M})$ & 0,9868 \\
Tetraciclina & Ln [Tetraciclina] $=4,53988-0,00144 \cdot \mathrm{t}-0.00047 \cdot(\mathrm{t} \cdot \mathrm{M})$ & 0,9620 \\
\hline
\end{tabular}

M: matriz (Leche: $M=+1$; Extracto: $M=-1$ ); $t$ : tiempo (horas)

En cuanto a las pendientes de estas ecuaciones se observa que todas las tetraciclinas presentan valores de las constantes de velocidad " $\mathrm{k}_{1}$ " similares entre ellas, lo que indica que se degradan prácticamente con la misma rapidez, siendo la interacción entre la matriz y el tiempo de refrigeración quien marca el comportamiento de degradación final de cada una de ellas.

En todos los casos los valores de las constantes de la interacción " $\mathrm{k}_{1,2}$ " fueron negativos indicando una mayor degradación de las muestras de leche $(M=+1)$ comparado con sus respectivos extractos $(M=-1)$ cuanto más tiempo permanezcan las muestras en refrigeración.

En las Figuras 48 y 49 se representan las ecuaciones recogidas en el Cuadro 46 para las muestras y extractos respectivamente.

A partir de estas Figuras se puede señalar que ninguna tetraciclina muestra una pendiente demasiado acusada, evidenciando la relativa estabilidad de estas sustancias en refrigeración de muestras y extractos de leche. También se observa que no existen grandes diferencias entre las degradaciones de estas tetraciclinas en los dos tipos de matrices empleados (matriz y extracto) con pendientes similares en ambos casos.

De la misma manera que se procedió en el estudio de los antibióticos betalactámicos, se han estimado los porcentajes de pérdida de concentración de las tetraciclinas en muestras y extractos de leche a lo largo de los siete primeros días de refrigeración a $4 \pm 2{ }^{\circ} \mathrm{C}$ cuyos resultados se exponen respectivamente en los Cuadros 51 y 52. 

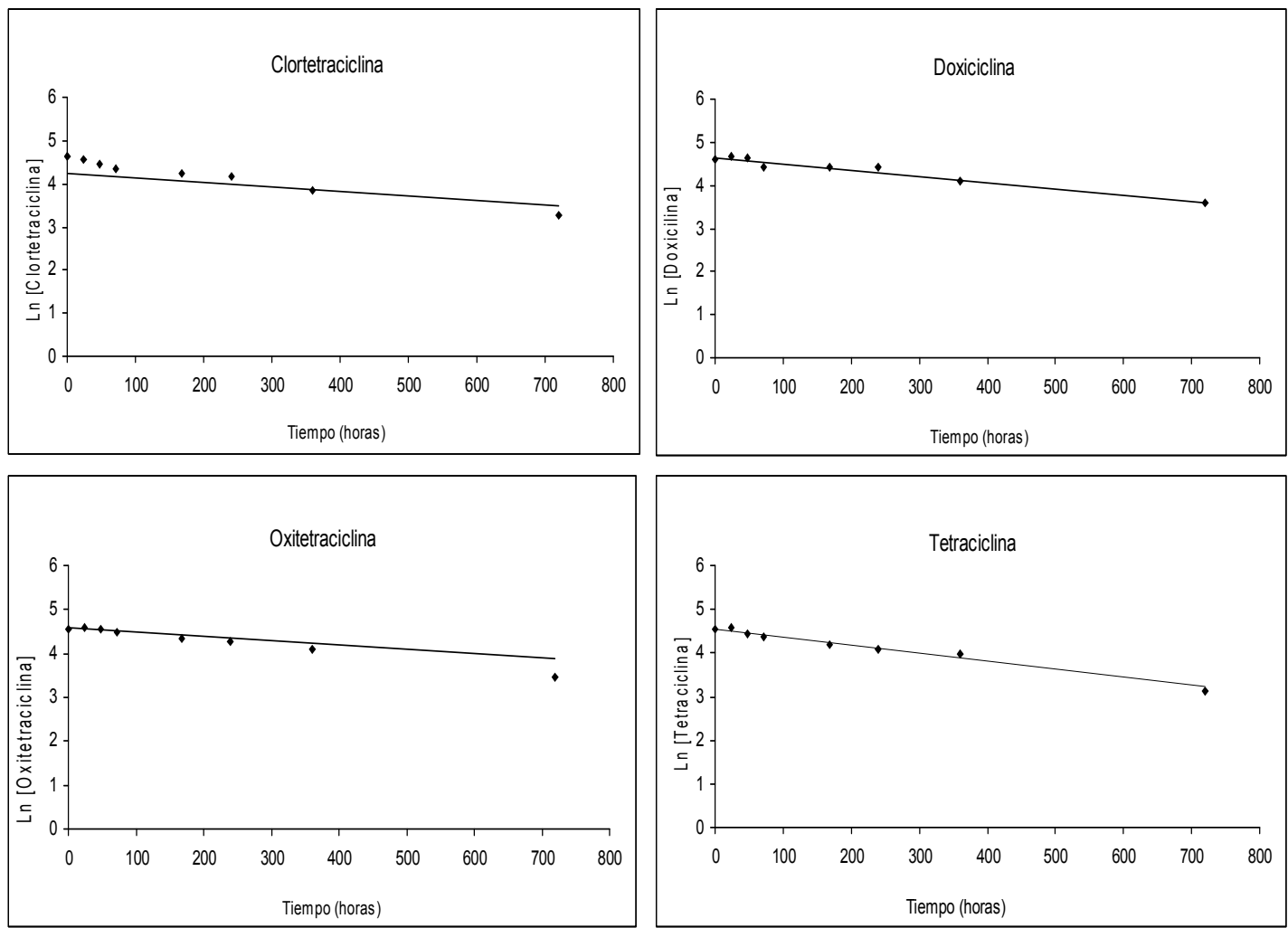

Figura 48. Efecto del tiempo de refrigeración sobre la concentración de tetraciclinas en muestras de leche
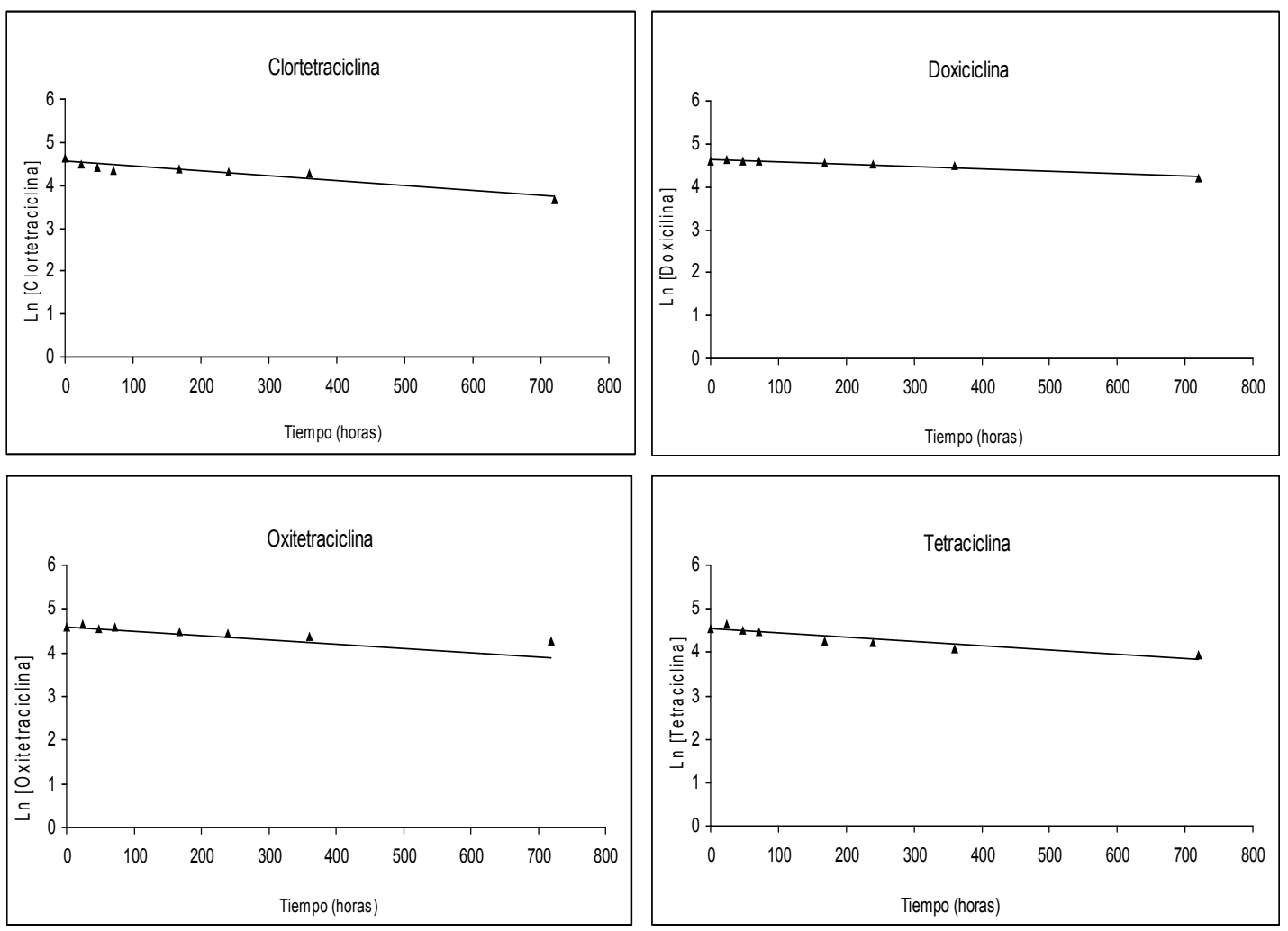

Figura 49. Efecto del tiempo de refrigeración sobre la concentración de tetraciclinas en extractos de leche 
Cuadro 51. Porcentajes de degradación de tetraciclinas en muestras de leche refrigeradas

\begin{tabular}{|lccccccc|}
\hline \multirow{2}{*}{ Tetraciclinas } & \multicolumn{7}{c|}{ Tiempo de refrigeración (días) } \\
\cline { 2 - 8 } & $\mathbf{1}$ & $\mathbf{2}$ & $\mathbf{3}$ & $\mathbf{4}$ & $\mathbf{5}$ & $\mathbf{6}$ & $\mathbf{7}$ \\
\hline Clortetraciclina & 8,9 & 12,8 & 16,5 & 20,1 & 23,5 & 26,7 & 29,8 \\
Doxiciclina & 0,0 & 3,0 & 6,3 & 9,5 & 12,6 & 15,5 & 18,4 \\
Oxitetraciclina & 3,3 & 6,9 & 10,4 & 13,7 & 16,9 & 19,9 & 22,9 \\
Tetraciclina & 10,5 & 14,5 & 18,4 & 22,0 & 25,5 & 28,8 & 32,0 \\
\hline
\end{tabular}

Cuadro 52. Porcentajes de degradación de tetraciclinas en extractos de leche refrigerados

\begin{tabular}{|lccccccc|}
\hline \multirow{2}{*}{ Tetraciclinas } & \multicolumn{7}{c|}{ Tiempo de refrigeración (días) } \\
\cline { 2 - 8 } & $\mathbf{1}$ & $\mathbf{2}$ & $\mathbf{3}$ & $\mathbf{4}$ & $\mathbf{5}$ & $\mathbf{6}$ & $\mathbf{7}$ \\
\hline Clortetraciclina & 7,5 & 10,0 & 12,5 & 14,8 & 17,2 & 19,4 & 21,6 \\
Doxiciclina & 0,0 & 0,0 & 0,3 & 1,7 & 3,1 & 4,4 & 5,7 \\
Oxitetraciclina & 0,9 & 2,2 & 3,4 & 4,6 & 5,8 & 7,0 & 8,2 \\
Tetraciclina & 8,5 & 10,6 & 12,6 & 14,7 & 16,6 & 18,5 & 20,4 \\
\hline
\end{tabular}

En el caso de la refrigeración de las muestras de leche, la clortetraciclina y la tetraciclina presentan los porcentajes de degradación más elevados, con valores que oscilan entre el 9 y el $32 \%$ durante los 7 días de conservación, mientras que la doxiciclina y la oxitetraciclina se muestran más estables con porcentajes menores entre el 0 y el $23 \%$ durante el mismo periodo de tiempo.

En cuanto a los extractos refrigerados, la estabilidad de las tetraciclinas es aún mayor, en especial para la doxiciclina y la oxitetraciclina con unas pérdidas máximas a los 7 días inferiores al $10 \%$. A efectos prácticos sería por lo tanto conveniente refrigerar los extractos, empleando el material adecuado para preservarlos de la luz directa, en el caso de tener la necesidad de conservar las muestras de leche durante un breve periodo de tiempo antes de analizarlas por HPLC.

Para poder comparar estos resultados con los expuestos anteriormente para los antibióticos betalactámicos, así como con los obtenidos por otros autores, se han calculado a partir de las ecuaciones del modelo de regresión lineal (Cuadro 49), la vida media $\left(t_{1 / 2}\right)$ de cada una de las tetraciclinas en condiciones de refrigeración de muestras y extractos de leche, que se muestran en el Cuadro 53. 
Cuadro 53. Tiempos de vida media $\left(t_{1 / 2}\right)$ de las tetraciclinas en muestras de leche y extractos refrigerados

\begin{tabular}{|ccccc|}
\hline \multirow{2}{*}{ Matriz } & \multicolumn{4}{c|}{$\mathbf{t}_{\mathbf{1} / \mathbf{2}}$ (días) } \\
\cline { 2 - 5 } & Clortetraciclina & Doxiciclina & Oxitetraciclina & Tetraciclina \\
\hline Leche & 15 & 21 & 18 & 14 \\
Extractos & 23 & 53 & 55 & 27 \\
\hline
\end{tabular}

Al comparar estos tiempos de vida media con los obtenidos anteriormente para los antibióticos betalactámicos, se aprecia que por lo general éstos son menores en los dos tipos de matrices, excepto en el caso de la cefalexina y cefquinoma (muestras y extractos) y la penicilina $G$ (extractos), lo que indica una mayor estabilidad de estos antimicrobianos en estas condiciones de almacenamiento respecto a otras sustancias antimicrobianas.

En cuanto a los estudios realizados sobre la estabilidad en refrigeración de tetraciclinas en alimentos, la mayor parte de los trabajos han sido realizados en matrices cárnicas y son muy limitados los que evalúan el caso de la leche, destacando únicamente los que se citan a continuación.

Así, Podhorniak et al. (1999), en un estudio sobre la evaluación de la estabilidad en leche refrigerada a $4{ }^{\circ} \mathrm{C}$ de seis tetraciclinas, incluidas la clortetraciclina y la tetraciclina, indican unas pérdidas entre el 4 y 13\% después de 72 horas de refrigeración, resultados similares al rango 6,3-18,4\% establecido en este trabajo.

De la misma manera, Da Silva et al. (2006) evaluaron mediante HPLC, la estabilidad de tetraciclinas en yogur refrigerado obteniendo unas degradaciones a los 30 días de conservación del 52, 61 y $67 \%$ para la oxitetraciclina, doxiciclina y tetraciclina respectivamente, resultados similares a los obtenidos en las muestras de leche refrigeradas en el presente estudio (Figura 46).

En otro estudio realizado por Samanidou et al. (2007) sobre la validación de un método HPLC para la determinación de tetraciclinas en la leche, se indica que los extractos obtenidos y refrigerados a $4^{\circ} \mathrm{C}$ se mantuvieron estables únicamente una semana de acuerdo al criterio de aceptación indicado por este autor para la medición de la estabilidad de las sustancias antimicrobianas establecido en un $-5 \%$ respecto a la concentración inicial. Estos resultados coinciden con los de este trabajo puesto que a los 7 días de refrigeración se obtienen, en los extractos refrigerados, pérdidas entre el 5,7 y $21,6 \%$, correspondiendo con la pérdida de estabilidad establecida por dicho autor. 
También en un estudio publicado muy recientemente (Himanish et al., 2008), establecen, mediante HPLC-UV, pérdidas significativas entre un 6 y un 18\%, en la concentración de oxitetraciclina en muestras de leche entre las 24 y 96 horas de conservación en frío a $6{ }^{\circ} \mathrm{C}$, resultados muy similares a los establecidos en este trabajo para esta sustancia con un rango de porcentaje de degradación entre 3,3 y $13,6 \%$ para ese mismo periodo de tiempo.

\subsubsection{Influencia de la congelación de las muestras y extractos de leche}

Los resultados obtenidos en el estudio del efecto de la congelación sobre la variación de las concentraciones de las tetraciclinas ensayadas se presentan gráficamente en la Figura 50.
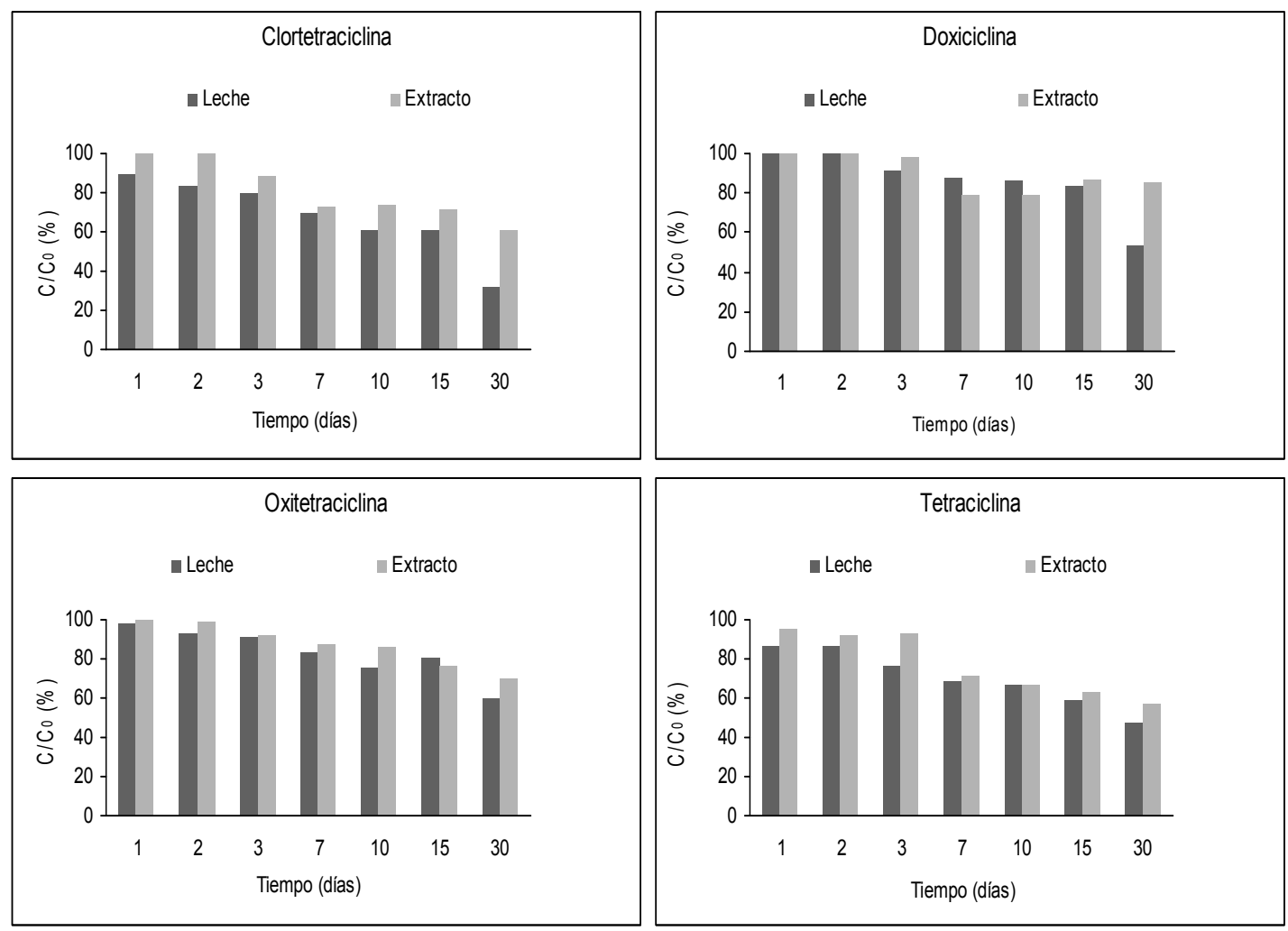

Figura 50. Porcentajes de variación de la concentración de tetraciclinas en los extractos y muestras de leche con el tiempo de congelación

De forma general se observa que la clortetraciclina y la tetraciclina son más inestables a la congelación de las muestras y los extractos, mientras que la oxitetraciclina y la doxiciclina muestran una degradación más moderada con el tiempo de conservación.

En todos los casos los extractos se mantienen ligeramente más estables que las muestras de leche, salvo en algunos momentos puntuales, como es el caso de la 
doxiciclina los días 7 y 10, aunque con diferencias prácticamente insignificantes entre ambas matrices.

En el Cuadro 54 se resumen los parámetros estadísticos obtenidos de la aplicación del modelo cinético de primer orden a la degradación térmica de las tetraciclinas en muestras y extractos de leche, mediante un modelo de regresión lineal múltiple.

Cuadro 54. Efecto del tiempo de congelación y de la matriz sobre la concentración de tetraciclinas

\begin{tabular}{|lcccccc|}
\hline \multirow{2}{*}{ Tetraciclinas } & \multicolumn{2}{c}{ Tiempo } & \multicolumn{2}{c|}{ Matriz } & \multicolumn{2}{c|}{ Tiempo·Matriz } \\
\cline { 2 - 7 } & Valor $\mathbf{F}$ & Valor $\mathbf{p}$ & Valor $\mathbf{F}$ & Valor $\mathbf{p}$ & Valor $\mathbf{F}$ & Valor $\mathbf{p}$ \\
\hline Clortetraciclina & 132,28 & 0,0001 & 0,53 & 0,4791 & 12,94 & 0,0037 \\
Doxiciclina & 36,64 & 0,0001 & 1,65 & 0,2227 & 9,74 & 0,0088 \\
Oxitetraciclina & 110,13 & 0,0001 & 0,72 & 0,4116 & 1,02 & 0,333 \\
Tetraciclina & 83,37 & 0,0001 & 0,76 & 0,3990 & 0,65 & 0,4354 \\
\hline
\end{tabular}

Como era de esperar el tiempo de congelación resulta altamente significativo ( $p<0,001)$ en todos los casos, así como la interacción entre el tiempo y la matriz para la clortetracilina y la doxiciclina aunque con niveles de significación menores ( $p$ $<0,01)$.

En el Cuadro 55 y en las Figuras 51 y 52 se presentan las ecuaciones de regresión lineal múltiple y sus correspondientes representaciones gráficas, de las cuatro tetraciclinas ensayadas, donde se observa que el ajuste alcanzado mediante la aplicación de este modelo es adecuado con unos coeficientes de regresión elevados para la clortetraciclina $\left(R^{2}=0,9315\right)$, oxitetraciclina $\left(R^{2}=0,9058\right)$ y tetraciclina $\left(R^{2}=0,8796\right)$ y algo más bajo en el caso de la doxiciclina $\left(R^{2}=0,7985\right)$.

Cuadro 55. Ecuaciones de regresión lineal múltiple de los efectos del tiempo de congelación y de la matriz sobre las concentraciones de tetraciclinas

\begin{tabular}{|lll|}
\hline Tetraciclinas & Ln [Tetraciclina] $\left.=\mathbf{a}+\mathbf{k}_{\mathbf{1}} \cdot \mathbf{t}+\mathbf{k}_{\mathbf{2}} \cdot \mathbf{M}+\mathbf{k}_{\mathbf{1 , 2}} \cdot \mathbf{( t \cdot} \cdot \mathbf{M}\right)$ & $\mathbf{R}^{\mathbf{2}}$ \\
\hline Clortetraciclina & Ln [Clortetraciclina] $=4,5519-0,00111 \cdot \mathrm{t}-0,00034 \cdot(\mathrm{t} \cdot \mathrm{M})$ & 0,9315 \\
Doxiciclina & Ln [Doxiciclina] $=4,6084-0,00058 \cdot \mathrm{t}-0,00030 \cdot(\mathrm{t} \cdot \mathrm{M})$ & 0,7985 \\
Oxitetraciclina & Ln [Oxitetraciclina] $=4,5767-0,00059 \cdot \mathrm{t}$ & 0,9058 \\
Tetraciclina & Ln [Tetraciclina] $=4,4860-0,00084 \cdot \mathrm{t}$ & 0,8796 \\
\hline
\end{tabular}

M: matriz (Leche: $M=+1$; Extracto: $M=-1$ ); t: tiempo (horas) 

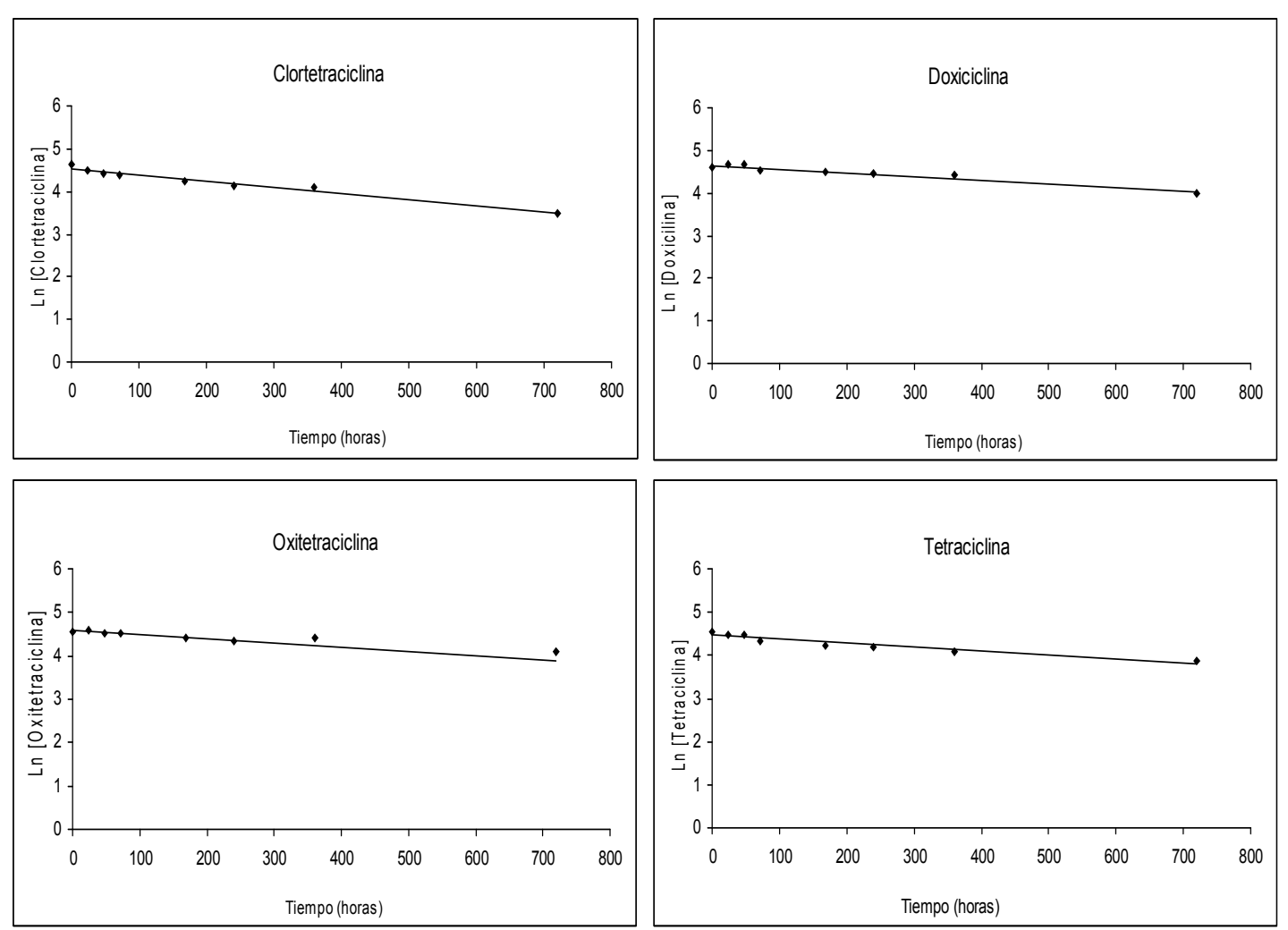

Figura 51. Efecto del tiempo de congelación sobre la concentración de tetraciclinas en muestras de leche
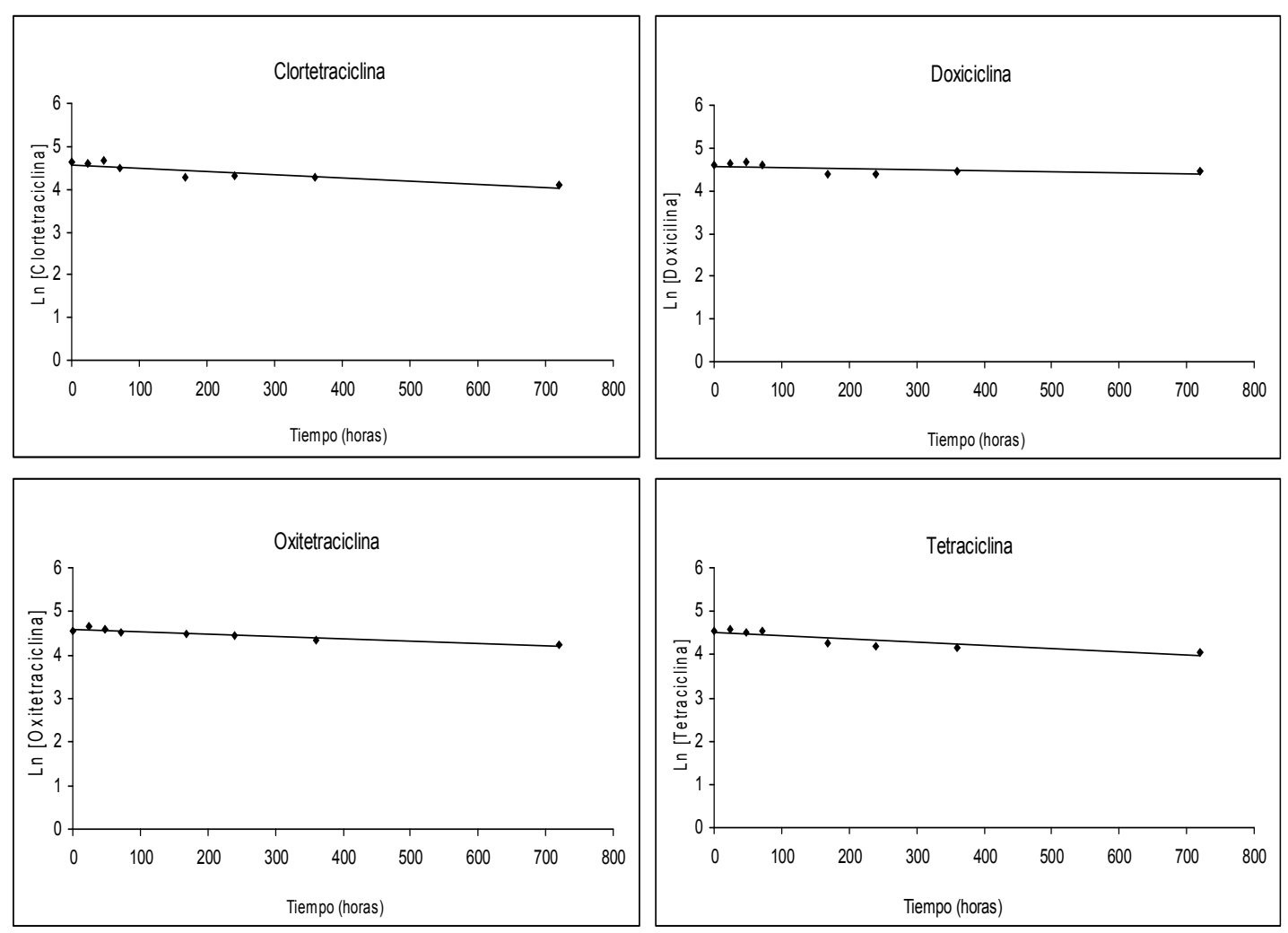

Figura 52. Efecto del tiempo de congelación sobre la concentración de tetraciclinas en extractos de leche 
Se observa que la clortetraciclina presenta la mayor constante de velocidad de degradación " $k_{1}$ " señalando el rápido deterioro de esta molécula con el tiempo de congelación comparado con las otras tetraciclinas.

En cuanto a las interacciones del tiempo con la matriz, las constantes " $\mathrm{k}_{1,2}$ " de la clortetracilina y la doxiciclina son muy parecidas entre ellas lo que indica un comportamiento similar en la degradación de estas moléculas cuanto más largo es el tiempo de congelación, siendo en ambos casos mayor en la leche $(M=+1)$ que en los extractos $(M=-1)$.

Como se ha señalado anteriormente solo existen diferencias significativas entre los resultados obtenidos en muestras y en extractos de leche con el tiempo de congelación en el caso de la clortetraciclina y la doxiciclina, por lo que las rectas de ajuste estimadas a partir del modelo son diferentes en las Figuras 50 y 51, mientras que las correspondientes a la oxitetraciclina y la tetraciclina son idénticas en ambos casos.

La degradación que pueden sufrir las tetraciclinas en un laboratorio de análisis a lo largo de diferentes tiempos de conservación a $-20^{\circ} \mathrm{C}$, en muestras de leche y extractos, se ha estimado a partir de las ecuaciones correspondientes del modelo, (Cuadro 55) y estos porcentajes se muestran en los Cuadros 56 y 57.

Cuadro 56. Porcentajes de degradación de tetraciclinas en muestras de leche congeladas

\begin{tabular}{|lccccccc|}
\hline \multirow{2}{*}{ Tetraciclinas } & \multicolumn{7}{c|}{ Tiempo de congelación (días) } \\
\cline { 2 - 8 } & $\mathbf{1}$ & $\mathbf{3}$ & $\mathbf{7}$ & $\mathbf{1 5}$ & $\mathbf{3 0}$ & $\mathbf{4 5}$ & $\mathbf{6 0}$ \\
\hline Clortetraciclina & 8,4 & 14,6 & 25,7 & 43,7 & 66,6 & 80,2 & 88,2 \\
Doxiciclina & 1,8 & 5,8 & 13,5 & 26,9 & 46,8 & 61,2 & 71,7 \\
Oxitetraciclina & 4,2 & 6,8 & 12,0 & 21,4 & 36,4 & 48,6 & 58,4 \\
Tetraciclina & 13,0 & 16,4 & 22,9 & 34,4 & 51,5 & 64,2 & 73,5 \\
\hline
\end{tabular}

Cuadro 57. Porcentajes de degradación de tetraciclinas en extractos de leche congelados

\begin{tabular}{|lccccccc|}
\hline \multirow{2}{*}{ Tetraciclinas } & \multicolumn{7}{c|}{ Tiempo de congelación (días) } \\
\cline { 2 - 8 } & $\mathbf{1}$ & $\mathbf{3}$ & $\mathbf{7}$ & $\mathbf{1 5}$ & $\mathbf{3 0}$ & $\mathbf{4 5}$ & $\mathbf{6 0}$ \\
\hline Clortetraciclina & 6,9 & 8,6 & 10,3 & 16,7 & 28,1 & 45,5 & 68,7 \\
Doxiciclina & 0,3 & 1,0 & 1,7 & 4,3 & 9,3 & 18,0 & 33,0 \\
Oxitetraciclina & 4,2 & 6,8 & 12,0 & 21,4 & 36,4 & 48,6 & 58,4 \\
Tetraciclina & 13,0 & 16,4 & 22,9 & 34,4 & 51,5 & 64,2 & 73,5 \\
\hline
\end{tabular}


En dichos Cuadros se aprecia como la doxiciclina en las muestras de leche refrigeradas experimenta una aceleración de la degradación a partir del séptimo día de congelación, pasando de tener los porcentajes más bajos el primer y tercer día (1,8 y 5,8\%) a porcentajes muy elevados a los 45 y 60 días de conservación (61,2 y $71,7 \%$ ), valores cercanos a los obtenidos para la clortetraciclina y tetraciclina en ese mismo periodo.

Este hecho puede explicarse por la constante negativa de la interaccón " $\mathrm{k}_{1,2}$ " de la matriz con el tiempo de conservación y al valor positivo de la variable Dummy $(M=+1)$ correspondiente a la muestra de leche, que hace que la descomposición de esta sustancia en esta matriz sea cada vez mayor cuanto más aumenta el tiempo de congelación.

Lo mismo ocurre para la clortetraciclina, solo que en este caso, esta sustancia presenta mayor inestabilidad al frío que la doxiciclina por lo que las diferencias entre los porcentajes de degradación obtenidos no son tan apreciables a medida que aumenta el tiempo de conservación.

En cuanto a los extractos congelados (Cuadro 57), las pérdidas estimadas para la clortetraciclina y la doxiciclina son menores que en las muestras de leche, y en este caso, la doxiciclina presenta una degradación mucho más lenta a medida que transcurre el tiempo de congelación, alcanzando un valor máximo del $33 \%$ después de dos meses.

También en el Cuadro 58 se exponen los tiempos de vida media calculados para las tetraciclinas en muestras y extractos de leche.

Cuadro 58. Tiempos de vida media $\left(t_{1 / 2}\right)$ de las tetraciclinas en muestras de leche y extractos congelados

\begin{tabular}{|ccccc|}
\hline \multirow{2}{*}{ Matriz } & \multicolumn{4}{c|}{$\mathbf{t}_{\mathbf{1 / 2}}$ (días) } \\
\cline { 2 - 5 } & Clortetraciclina & Doxiciclina & Oxitetraciclina & Tetraciclina \\
\hline Leche & 18 & 33 & 47 & 28 \\
Extractos & 35 & 104 & 47 & 28 \\
\hline
\end{tabular}

Con estos resultados se vuelve a poner de manifiesto la menor estabilidad de la clortetraciclina y la tetraciclina, además del gran aumento en la estabilidad que experimenta la doxiciclina cuando se conserva en los extractos de leche alcanzando una vida media de 104 días. Este hecho indica que si se trabaja con este analito y es necesario congelar muestras hasta su análisis sería más conveniente preparar y congelar los extractos antes que las muestras originales. 
Comparando los tiempos de vida media con los obtenidos en la refrigeración (Cuadro 53) se aprecia que en todos los casos estos tiempos son mayores, excepto para la oxitetraciclina que mostró un tiempo más largo en los extractos refrigerados (55 días) que en los congelados (47 días).

Respecto a los resultados obtenidos en la congelación de antibióticos betalactámicos, también se observa que los tiempos de vida media establecidos para las tetraciclinas son generalmente mayores, excepto en el caso de la amoxicilina en la leche y la cefalexina y la cefquinoma en leche y extractos, demostrando la mayor estabilidad de estas sustancias en las condiciones de conservación a bajas temperaturas.

Otros estudios realizados sobre la estabilidad de las tetraciclinas en la leche a temperaturas de congelación, muestran resultados diferentes a los indicados en este trabajo. Así, Spisso et al. (2007), no determinan ninguna pérdida de concentración en la clortetraciclina, oxitetraciclina y tetraciclina en muestras de leche congeladas y analizadas mediante HPLC-FL, los días 0, 6, 12,24 y 30 desde su almacenamiento a dos temperaturas $\left(-20\right.$ y $\left.-76{ }^{\circ} \mathrm{C}\right)$. Hay que señalar que este autor analiza los resultados mediante ratios respuesta normalizados con un patrón interno y establece que existe degradación cuando la variación de las áreas relativas (respecto a la concentración inicial) y normalizadas con el patrón interno son superiores al $10 \%$.

Por otro lado, Himanish et al. (2008) indican un efecto significativo del tiempo de conservación con respecto a los porcentajes de pérdidas de concentración de la oxitetraciclina en muestras de leche analizadas mediante HPLC-UV, aunque los valores que obtiene son inferiores al $5 \%$ a los 4 días de almacenamiento. Estos resultados se alejan de los obtenidos en este trabajo, ya que las pérdidas estimadas para la oxitetraciclina durante ese mismo periodo de tiempo a $-20^{\circ} \mathrm{C}$ oscilan entre el 4,2 y el $12 \%$.

En otro estudio que emplea un método microbiológico para analizar soluciones patrón de tetraciclinas congeladas a - $20{ }^{\circ} \mathrm{C}$ (Okerman et al., 2007) obtienen pérdidas de actividad inferiores al $10 \%$ para la clortetraciclina y doxiciclina y del $25 \%$ en el caso de la oxitetraciclina y tetraciclina después de 6 meses en congelación. Estos valores resultan muy superiores a los del presente trabajo, aunque hay que tener en cuenta las diferentes metodologías y disolventes empleados en ambos estudios. 


\subsection{SULFONAMIDAS}

\subsubsection{Influencia de la refrigeración de las muestras y extractos de leche}

En la Figura 53 se muestra el porcentaje de variación de la concentración de las sulfonamidas, respecto a la inicial, en las muestras de leche y sus correspondientes extractos con el tiempo de refrigeración a $4 \pm 2{ }^{\circ} \mathrm{C}$.

Como se observa en dicha Figura, las sulfonamidas no parecen presentar variaciones apreciables de la concentración en función del tiempo de conservación en los dos tipos de matrices, indicando una elevada estabilidad de estas sustancias a bajas temperaturas.

También se puede apreciar que no existen diferencias entre las muestras y los extractos refrigerados a medida que aumenta el tiempo de conservación, lo que señala que el tipo de matriz no afecta a la concentración de las sulfonamidas aunque los tiempos en refrigeración sean largos.

Para describir el comportamiento de estabilidad de estas sustancias antimicrobianas en las muestras y los extractos de leche con el tiempo de refrigeración, se utilizó el modelo cinético de primer orden aplicando la regresión lineal múltiple que relaciona el logaritmo de la concentración con ambas variables. Los parámetros estadísticos resultantes se presentan en el Cuadro 59, y como se observa, el tiempo de refrigeración, tipo de matriz y su interacción con el tiempo, no presentan un efecto significativo sobre la variación de la concentración de las ocho sulfonamidas ensayadas, tanto en las muestras de leche, como en sus extractos.

Cuadro 59. Efecto del tiempo de refrigeración y de la matriz sobre la concentración de sulfonamidas

\begin{tabular}{|lcccccc|}
\hline \multirow{2}{*}{ Sulfamida } & \multicolumn{2}{c}{ Tiempo } & \multicolumn{2}{c}{ Matriz } & \multicolumn{2}{c|}{ Tiempo*Matriz } \\
\cline { 2 - 7 } & Valor $\mathbf{F}$ & Valor $\mathbf{p}$ & Valor $\mathbf{F}$ & Valor $\mathbf{p}$ & Valor F & Valor $\mathbf{p}$ \\
\hline Sulfacloropiridazina & 0,79 & 0,3925 & 4,01 & 0,0685 & 0,32 & 0,5832 \\
Sulfadiazina & 0,01 & 0,9523 & 1,14 & 0,3071 & 0,05 & 0,8242 \\
Sulfadimetoxina & 0,76 & 0,4001 & 0,69 & 0,4212 & 0,06 & 0,8085 \\
Sulfamerazina & 0,01 & 0,9094 & 2,14 & 0,1691 & 0,29 & 0,6023 \\
Sulfametazina & 0,02 & 0,8930 & 0,35 & 0,5729 & 1,15 & 0,3041 \\
Sulfapiridina & 0,87 & 0,3681 & 0,16 & 0,6937 & 0,01 & 0,9926 \\
Sulfaquinoxalina & 0,39 & 0,5441 & 0,35 & 0,5671 & 0,01 & 0,9649 \\
Sulfatiazol & 0,14 & 0,7142 & 2,32 & 0,1406 & 0,88 & 0,3667 \\
\hline
\end{tabular}



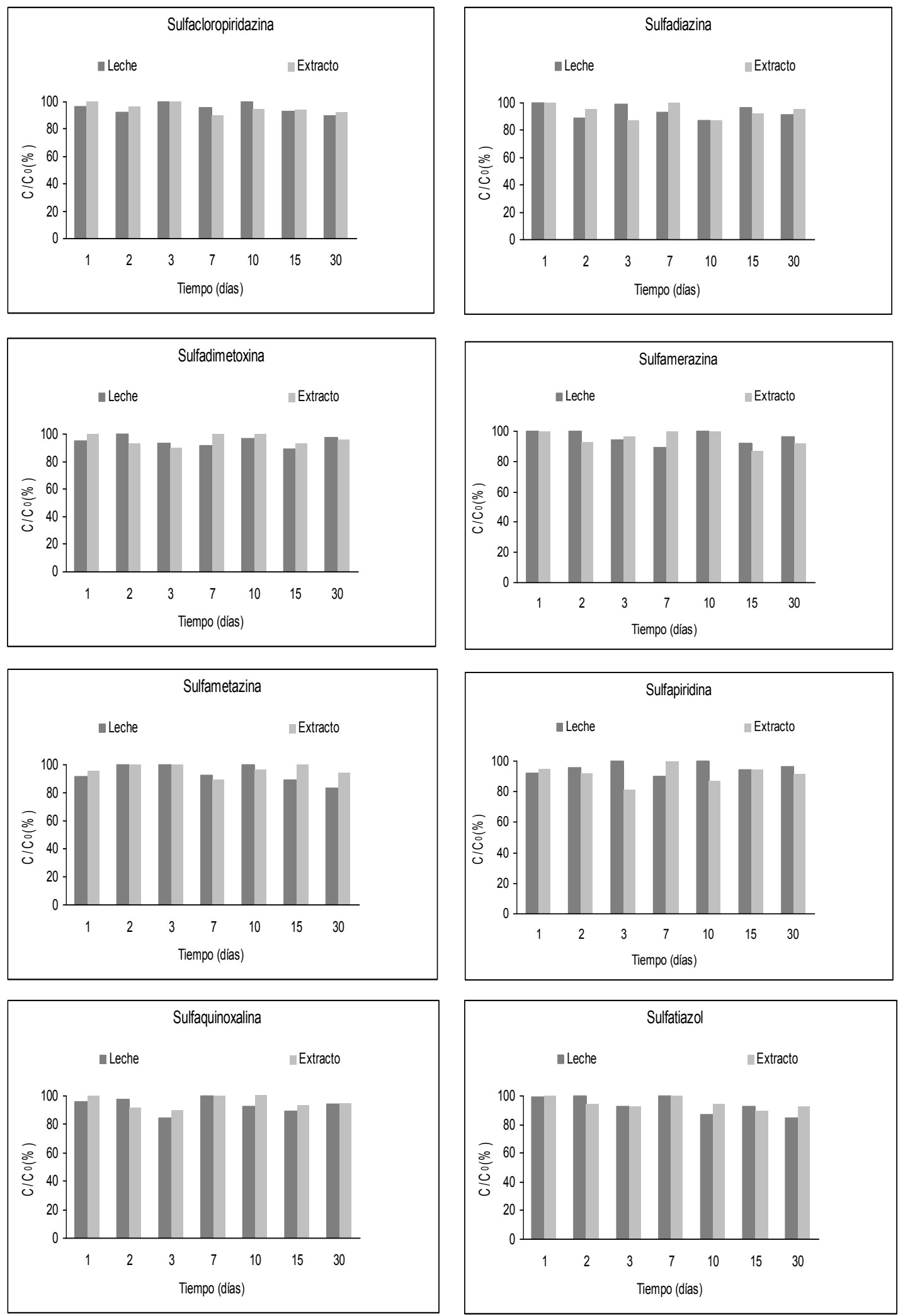

Figura 53. Porcentajes de variación de la concentración de sulfonamidas en los extractos y muestras de leche con el tiempo de refrigeración 
Los resultados obtenidos demuestran la gran estabilidad de las sulfonamidas frente a las temperaturas de refrigeración tanto en las muestras de leche como en los extractos refrigerados durante un largo periodo de 30 días.

Aunque el tiempo de refrigeración de la leche no presenta un efecto significativo sobre la concentración de las sulfonamidas, si que se aprecian (Figura 53) ligeras variaciones en las concentraciones de cada una de las sustancias ensayadas, con unos valores máximos entre el $0-13 \%$ en las muestras de leche y 0 $16 \%$ en los extractos.

En cuanto a los trabajos realizados por otros autores, se han encontrado muy pocos que evalúen la estabilidad de las sulfonamidas en la leche refrigerada.

Así, Pereira y Cass (2005), obtienen mediante la utilización de un método HPLC que el sulfametoxazole se mantiene estable en muestras de leche refrigeradas a $4{ }^{\circ} \mathrm{C}$ durante al menos 120 horas de conservación y dos meses en soluciones patrón.

Por el contrario, Foissy et al. (2005) en un estudio sobre la reproducibilidad de los resultados obtenidos por un método microbiológico (BRT) sobre muestras de leche refrigeradas a $6{ }^{\circ} \mathrm{C}$ a lo largo del tiempo, obtienen resultados no reproducibles a partir del segundo día de conservación, aunque hay que tener en cuenta que el método BRT no presenta buena sensibilidad para la detección de sulfonamidas en la leche (Molina et al., 2003).

Por otro lado, en otro estudio realizado en soluciones patrón de sulfametazina, Gaudin et al. (2005), empleando un método inmunológico (Biacore) obtienen pérdidas de estabilidad de esta sustancia en torno a un $36 \%$ al cabo de las 8 semanas de refrigeración a $4{ }^{\circ} \mathrm{C}$, lo que indica una relativa estabilidad de la sulfametazina durante largos periodos de conservación.

Estos resultados no aportan demasiada información acerca de la estabilidad de estas sustancias en la leche conservada a $4{ }^{\circ} \mathrm{C}$, no obstante parecen indicar una tendencia a la estabilidad de las sulfonamidas cuando las matrices se refrigeran largos periodos de tiempo, tal y como se observa en los resultados de este trabajo. Sin embargo hay que destacar que en cada caso se han empleado técnicas y tiempos de refrigeración diferentes, lo que supone un problema a la hora de de la comparación de los distintos resultados obtenidos. 


\subsubsection{Influencia de la congelación de las muestras y extractos de leche}

Los resultados de las variaciones porcentuales de concentración obtenidos en el estudio de la congelación de muestras y extractos de leche congelados en las ocho sulfonamidas ensayadas, se describen en la Figura 54.

Al igual que en el caso de la refrigeración, no se observan diferencias importantes entre las concentraciones de las sulfonamidas con el incremento del tiempo de congelación con porcentajes de pérdidas de concentración comprendidas en el rango de $0-15 \%$ en el caso de las muestras de leche y $0-17 \%$ en los extractos, así como tampoco existen diferencias apreciables entre los resultados obtenidos entre ambas matrices.

En el Cuadro 60 se presentan los parámetros estadísticos obtenidos al aplicar el modelo de regresión lineal múltiple a los resultados descritos anteriormente, donde se observa que efectivamente ninguna de las variables estudiadas, matriz y tiempo de congelación presentan un efecto significativo $(p>0,5)$, lo que indica que estas pequeñas variaciones en las concentraciones de la sulfonamidas no están relacionadas ni con el tiempo de congelación ni con el tipo de matriz empleado (leche y extracto).

Cuadro 60. Efecto del tiempo de congelación y de la matriz sobre las concentraciones de sulfonamidas

\begin{tabular}{|lcccccc|}
\hline \multirow{2}{*}{ Sulfamida } & \multicolumn{2}{c}{ Tiempo } & \multicolumn{2}{c}{ Matriz } & \multicolumn{2}{c|}{ Tiempo*Matriz } \\
\cline { 2 - 7 } & Valor $\mathbf{F}$ & Valor $\mathbf{p}$ & Valor $\mathbf{F}$ & Valor $\mathbf{p}$ & Valor $\mathbf{F}$ & Valor $\mathbf{p}$ \\
\hline Sulfacloropiridazina & 0,01 & 0,9198 & 3,06 & 0,1058 & 0,03 & 0,8684 \\
Sulfadiazina & 0,65 & 0,4369 & 3,17 & 0,1005 & 0,10 & 0,7575 \\
Sulfadimetoxina & 0,01 & 0,9693 & 1,21 & 0,2921 & 0,12 & 0,7299 \\
Sulfamerazina & 0,58 & 0,4619 & 0,03 & 0,8684 & 0,02 & 0,9013 \\
Sulfametazina & 0,79 & 0,3920 & 0,35 & 0,5670 & 0,73 & 0,4104 \\
Sulfapiridina & 0,04 & 0,8540 & 0,36 & 0,5577 & 0,01 & 0,9304 \\
Sulfaquinoxalina & 0,18 & 0,6828 & 3,33 & 0,0929 & 0,42 & 0,5274 \\
Sulfatiazol & 0,01 & 0,9404 & 0,80 & 0,3893 & 0,01 & 0,9479 \\
\hline
\end{tabular}

Esta elevada estabilidad térmica de las sulfonamidas en la leche conservada a bajas temperaturas $\left(-20^{\circ} \mathrm{C}\right)$ durante largos periodos de tiempo ha sido también demostrada por otros autores, aunque el número de estudios sobre el efecto de la congelación en leche es muy limitado. 

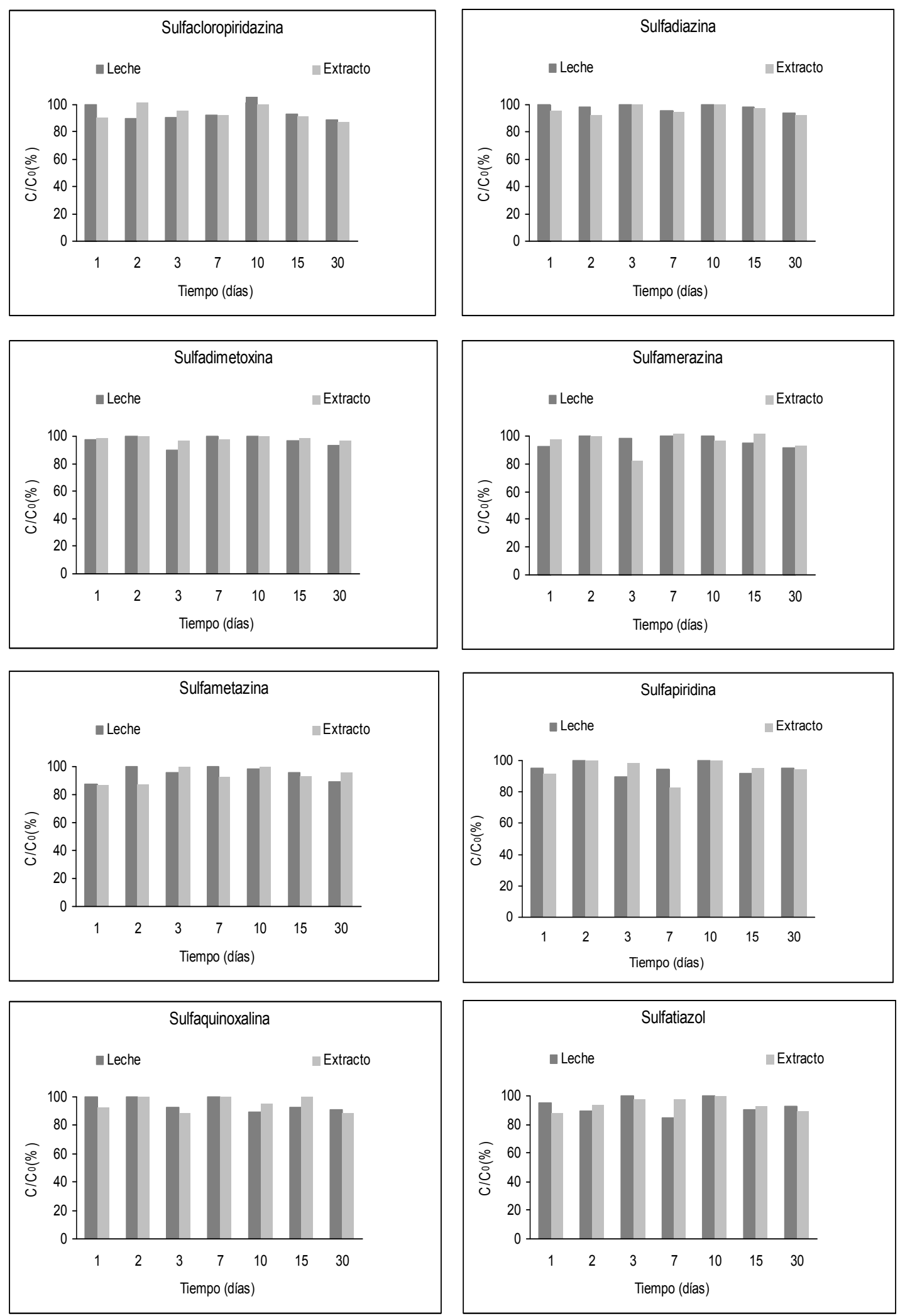

Figura 54. Porcentajes de variación de la concentración de sulfonamidas en los extractos y muestras de leche con el tiempo de congelación 
Papapanagiotou et al. (2005), no obtienen pérdidas de sulfametazina en la leche congelada a -20 y $-75^{\circ} \mathrm{C}$ al cabo de los tres y cinco meses respectivamente, al igual que Gaugin et al., (2005) que comprueban que la sulfadiazina, sulfadimetoxina y sulfadoxine se mantienen estables 95 días en la leche congelada a $-20^{\circ} \mathrm{C}$.

También Pereira y Cass (2005) obtienen que el sulfametoxazole se mantiene estable en la leche congelada a $-20^{\circ} \mathrm{C}$ durante al menos dos meses.

Por el contrario, Foissy et al. (2005) obtienen que 8 de las 15 muestras de leche congeladas a $-18 \%$ no presentan resultados reproducibles al test microbiológico BRT y únicamente 4 de ellas muestran los mismos resultados a las 4 semanas, pero como se ha comentado anteriormente hay que resaltar que este método microbiológico no presenta buena sensibilidad para las sulfonamidas en la leche (Molina et al., 2003) y no se considera adecuado para evaluar las posibles pérdidas de concentración de las sulfonamidas debidas al efecto de la congelación de la leche.

Lo mismo ocurre con el método inmunológico Biacore empleado por Gaudin et al. (2007), ya que estos autores obtienen en muestras de leche fortificadas con sulfametazina y congeladas a $-20{ }^{\circ} \mathrm{C}$ un incremento de la concentración de esta sustancia a lo largo de 20 semanas de conservación, sin encontrar ninguna explicación científica a este fenómeno y atribuyéndolo a un hecho fortuito debido a la gran variabilidad de los resultados cuantitativos obtenidos con este método analítico.

Debido al escaso número de trabajos encontrados sobre termoestabilidad de las sulfonamidas en la leche, se ha considerado interesante comparar la estabilidad de las sulfonamidas obtenida en este trabajo con los resultados de otros autores en algunas matrices diferentes de la leche.

Algunos estudios muestran una disminución del $10 \%$ en las concentraciones de sulfametazina en muestras de hígado de ternera congelado y almacenado durante 40 días (Mutha et al., 1977). También, O'Brien et al. (1981) hallaron una pérdida del $12,6 \%$ (hígado de cerdo) y $13,9 \%$ (tejido de músculo) en residuos de sulfametazina después de 15 días de almacenamiento a $-20^{\circ} \mathrm{C}$.

Otros investigadores no señalan ninguna degradación en la sulfametazina presente en músculo de cerdo al cabo de 21 días a $-20^{\circ} \mathrm{C}$ (Haagsma et al., 1985) o 3 meses (Rose et al., 1996).

Un decrecimiento del $50 \%$ en el contenido de sulfametazina en muestras de músculo de cerdo no se obtiene hasta después de un largo periodo de 15 meses de almacenamiento en condiciones de congelación (Alfredsson y Ohlsson, 1998). Estos 
resultados coinciden con los obtenidos por Thomas et al. (1997), donde indican unos tiempos de vida media para algunas sulfonamidas en hígado de cerdo adicionado y congelado a $-20^{\circ} \mathrm{C}$, de 567 días para sulfadimetoxina, 457 días para sulfametazina, 312 días para sulfacloropiridazina, 291 días para sulfatiazol y 271 días para sulfaquinoxalina, lo que indica una gran persistencia de estas sustancias bajo condiciones de congelación.

A su vez Croubels et al. (2003) no encuentran diferencias significativas en la estabilidad de la sulfacloropiridazina en muestras de hígado, músculo y riñón de cerdo en congelación a $-15{ }^{\circ} \mathrm{C}$ durante cuatro meses.

A pesar de algunas de las discrepancias encontradas entre algunos de los trabajos citados anteriormente, en la mayoría de estos estudios se aprecia una tendencia a la etabilidad de las sulfonamidas durante un almacenamiento muy prolongado a $-20^{\circ} \mathrm{C}$, con variaciones leves en los niveles de concentración, lo que concide con los resultados expuestos en este trabajo. No obstante es importante resaltar de nuevo las diferentes metodologías, matrices y ensayos realizados en cada uno de los trabajos descritos anteriormente.

\section{SEGUNDO ESTUDIO. Efecto de diferentes tratamientos térmicos de calor sobre la estabilidad de los antimicrobianos en la leche}

\subsection{ANTIBIÓTICOS BETALACTÁMICOS: PENICILINAS}

\subsubsection{Estudio de la degradación térmica de las penicilinas mediante modelos de primer orden}

Para la determinación de la estabilidad térmica de preparados farmacológicos en condiciones de altas temperaturas o variaciones de $\mathrm{pH}$, se suele emplear el modelo cinético de primer orden para calcular de una forma sencilla los parámetros cinéticos de la descomposición de estas sustancias (Carstensen y Morris, 1993; Yamana y Tsuji, 1976; Nassar et al., 1992; Martens et al., 1993; Wolfe et al., 1994; Slater et al., 1997, Chapman \& Hall, 2007).

Por ello, en este estudio sobre la degradación térmica de las penicilinas a las diferentes temperaturas de $60,70,80,90$ y $100{ }^{\circ} \mathrm{C}$, se emplearon los modelos cinéticos de primer orden, aplicando la regresión lineal simple a las transformaciones logarítmicas de las concentraciones de penicilinas en la leche en función de los distintos tiempos de calentamiento. Los valores de las ecuaciones de regresión $(y=a$ $+\mathrm{k}_{1} \cdot \mathrm{t}$ ) calculados a partir de la aplicación este modelo se presentan en los Cuadros $61,62,63$ y 64 para las diferentes penicilinas ensayadas. 
Cuadro 61. Parámetros resultantes de la aplicación del modelo cinético de primer orden a la degradación de la amoxicilina en la leche a diferentes temperaturas

\begin{tabular}{|c|c|c|c|c|c|c|}
\hline \multirow{2}{*}{$\mathrm{T}^{\mathrm{a}}\left({ }^{\circ} \mathrm{C}\right)$} & \multirow{2}{*}{$\begin{array}{c}\text { Ordenada } \\
\text { (a) }\end{array}$} & \multirow{2}{*}{$\begin{array}{c}\text { Pendiente } \\
\left(\mathbf{k}_{\mathbf{1}}\right)\end{array}$} & \multicolumn{2}{|c|}{ Error estándar } & \multirow{2}{*}{$\mathbf{p}$} & \multirow{2}{*}{$\mathbf{R}^{2}$} \\
\hline & & & a & $k_{1}$ & & \\
\hline 60 & 8,519 & $-0,00093$ & 0,01583 & 0,00007 & 0,0001 & 0,9601 \\
\hline 70 & 8,495 & $-0,00154$ & 0,02942 & 0,00013 & 0,0003 & 0,9414 \\
\hline 80 & 8,654 & $-0,00702$ & 0,18494 & 0,00085 & 0,0003 & 0,9387 \\
\hline 90 & 8,399 & $-0,00745$ & 0,09058 & 0,00084 & 0,0003 & 0,9406 \\
\hline 100 & 8,561 & $-0,02627$ & 0,06973 & 0,00065 & 0,0001 & 0,9970 \\
\hline
\end{tabular}

Cuadro 62. Parámetros resultantes de la aplicación del modelo cinético de primer orden a la degradación de la ampicilina en la leche a diferentes temperaturas

\begin{tabular}{|c|c|c|c|c|c|c|}
\hline \multirow{2}{*}{$\mathrm{T}^{\mathrm{a}}\left({ }^{\circ} \mathrm{C}\right)$} & \multirow{2}{*}{$\begin{array}{c}\text { Ordenada } \\
\text { (a) }\end{array}$} & \multirow{2}{*}{$\begin{array}{c}\text { Pendiente } \\
\left(\mathbf{k}_{1}\right)\end{array}$} & \multicolumn{2}{|c|}{ Error estándar } & \multirow{2}{*}{$\mathbf{p}$} & \multirow{2}{*}{$\mathbf{R}^{2}$} \\
\hline & & & a & $k_{1}$ & & \\
\hline 60 & 8,437 & $-0,00181$ & 0,04080 & 0,00019 & 0,0002 & 0,9487 \\
\hline 70 & 8,450 & $-0,00395$ & 0,08052 & 0,00037 & 0,0001 & 0,9575 \\
\hline 80 & 8,506 & $-0,00558$ & 0,09322 & 0,00043 & 0,0001 & 0,9711 \\
\hline 90 & 8,387 & $-0,01058$ & 0,09322 & 0,00086 & 0,0001 & 0,9679 \\
\hline 100 & 8,477 & $-0,01506$ & 0,16003 & 0,00148 & 0,0002 & 0,9540 \\
\hline
\end{tabular}

Cuadro 63. Parámetros resultantes de la aplicación del modelo cinético de primer orden a la degradación de la cloxacilina en la leche a diferentes

\begin{tabular}{|c|c|c|c|c|c|c|}
\hline \multirow{2}{*}{$\mathrm{T}^{\mathrm{a}}\left({ }^{\circ} \mathrm{C}\right)$} & \multirow{2}{*}{$\begin{array}{l}\text { Ordenada } \\
\text { (a) }\end{array}$} & \multirow{2}{*}{$\begin{array}{c}\text { Pendiente } \\
\left(\mathbf{k}_{\mathbf{1}}\right)\end{array}$} & \multicolumn{2}{|c|}{ Error estándar } & \multirow{2}{*}{$\mathbf{p}$} & \multirow{2}{*}{$\mathbf{R}^{2}$} \\
\hline & & & $\mathbf{a}$ & $k_{1}$ & & \\
\hline 60 & 8,496 & $-0,00187$ & 0,03681 & 0,00017 & 0,0001 & 0,9601 \\
\hline 70 & 8,448 & $-0,00311$ & 0,07500 & 0,00035 & 0,0003 & 0,9414 \\
\hline 80 & 8,352 & $-0,00539$ & 0,13326 & 0,00062 & 0,0003 & 0,9385 \\
\hline 90 & 8,378 & $-0,00859$ & 0,11436 & 0,00100 & 0,0010 & 0,9484 \\
\hline 100 & 8,308 & $-0,01386$ & 0,16587 & 0,00153 & 0,0003 & 0,9423 \\
\hline
\end{tabular}

A partir de los valores expuestos en estos Cuadros, se observa que los ajustes obtenidos con la aplicación del modelo cinético de primer orden a la degradación de las penicilinas con las diferentes temperaturas de calentamiento son adecuados para todos los casos con valores de los coeficientes de regresión elevados entre $R^{2}=0,9385$ para la amoxicilina a $80{ }^{\circ} \mathrm{C}$ (Cuadro 61) y $R^{2}=0,9970$ (Cuadro 62) para la ampicilina a $100^{\circ} \mathrm{C}$. 
Cuadro 64. Parámetros resultantes de la aplicación del modelo cinético de primer orden a la degradación de la penicilina $\mathrm{G}$ en la leche a diferentes temperaturas

\begin{tabular}{|c|c|c|c|c|c|c|}
\hline \multirow{2}{*}{$\mathrm{T}^{\mathrm{a}}\left({ }^{\circ} \mathrm{C}\right)$} & \multirow{2}{*}{$\begin{array}{l}\text { Ordenada } \\
\text { (a) }\end{array}$} & \multirow{2}{*}{$\begin{array}{c}\text { Pendiente } \\
\left(\mathbf{k}_{1}\right)\end{array}$} & \multicolumn{2}{|c|}{ Error estándar } & \multirow{2}{*}{$\mathbf{p}$} & \multirow{2}{*}{$\mathbf{R}^{2}$} \\
\hline & & & $a$ & $k_{1}$ & & \\
\hline 60 & 8,437 & $-0,00181$ & 0,04080 & 0,00019 & 0,0002 & 0,9487 \\
\hline 70 & 8,419 & $-0,00325$ & 0,07266 & 0,00033 & 0,0002 & 0,9492 \\
\hline 80 & 8,539 & $-0,00503$ & 0,06469 & 0,00030 & 0,0001 & 0,9826 \\
\hline 90 & 8,444 & $-0,01343$ & 0,12414 & 0,00115 & 0,0001 & 0,9648 \\
\hline 100 & 8,453 & $-0,01595$ & 0,11383 & 0,00105 & 0,0001 & 0,9787 \\
\hline
\end{tabular}

También se aprecia en dichos Cuadros que el efecto del tiempo calentamiento sobre la degradación térmica de las penicilinas resulta altamente significativo en todos los casos $(p<0,001)$, por lo que se deduce que el modelo cinético de primer orden resulta adecuado para describir los cambios de concentración que experimentan las penicilinas con las diferentes temperaturas ensayadas.

En cuanto a las pendientes de las ecuaciones recogidas en dichos Cuadros, se observa como, para cada penicilina, las constantes de velocidad de reacción " $k_{1}$ " aumentan conforme se incrementa el calentamiento, reflejando una mayor degradación de estas sustancias antimicrobianas a medida que aumentan las temperaturas.

Si se comparan los valores de las constantes de velocidad de reacción " $k_{1}$ " de las cuatro penicilinas estudiadas a cada temperatura, se observa que la amoxicilina, cloxacilina y penicilina G muestran valores similares en los calentamientos de 60, 70 y $80^{\circ} \mathrm{C}$, sin embargo, la ampicilina presenta valores de estas constantes inferiores. Por el contrario, en el calentamiento de $90^{\circ} \mathrm{C}$ la amoxicilina y la ampicilina presentan valores " $\mathrm{k}_{1}$ " inferiores a los obtenidos para la cloxacilina y la penicilina $\mathrm{G}$, y a $100{ }^{\circ} \mathrm{C}$ la ampicilina es la molécula con la mayor constante de velocidad de reacción.

Se deduce por lo tanto que la variación de la degradación con las temperaturas es diferente dependiendo de la sustancia estudiada. Por ello, para visualizar de forma detallada el comportamiento de degradación de cada una de las penicilinas se han elaborado las Figuras 55, 56, 57 y 58 donde se muestran las representaciones gráficas correspondientes a las ecuaciones recogidas en los Cuadros $61,62,63$ y 64 . 


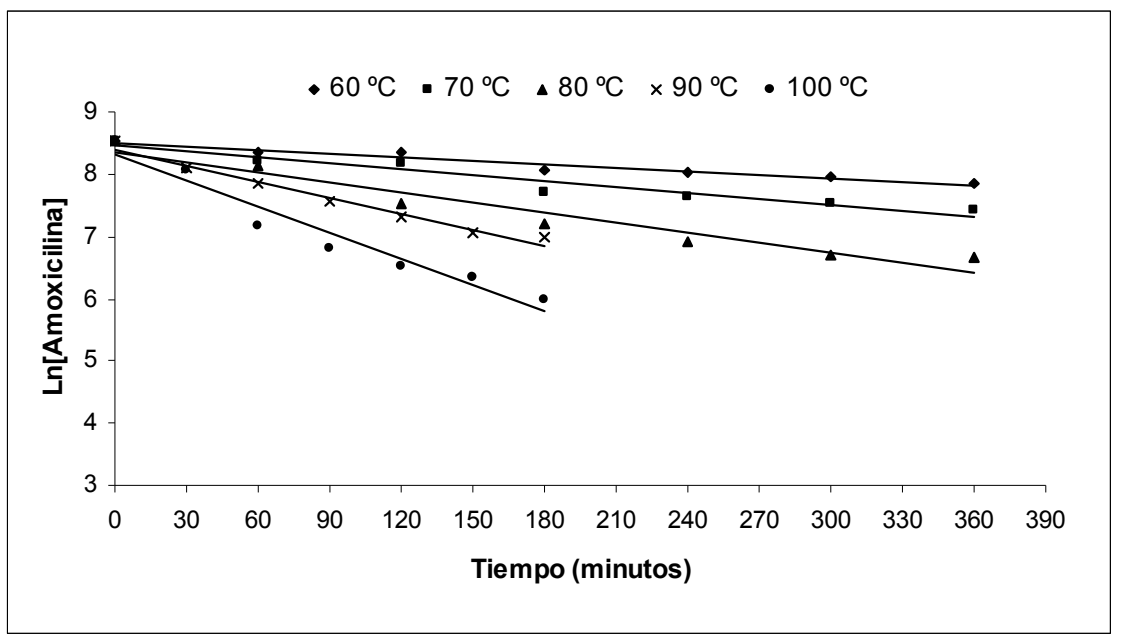

Figura 55. Relación entre la concentración de amoxicilina en la leche y el tiempo de calentamiento a diferentes temperaturas

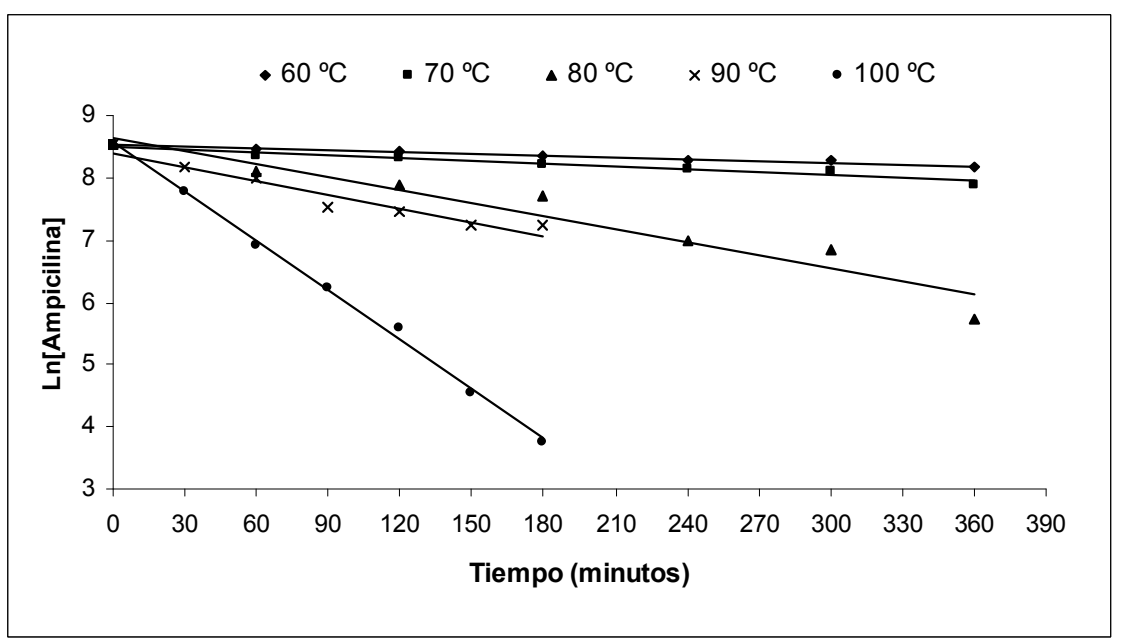

Figura 56. Relación entre la concentración de ampicilina en la leche y el tiempo de calentamiento a diferentes temperaturas

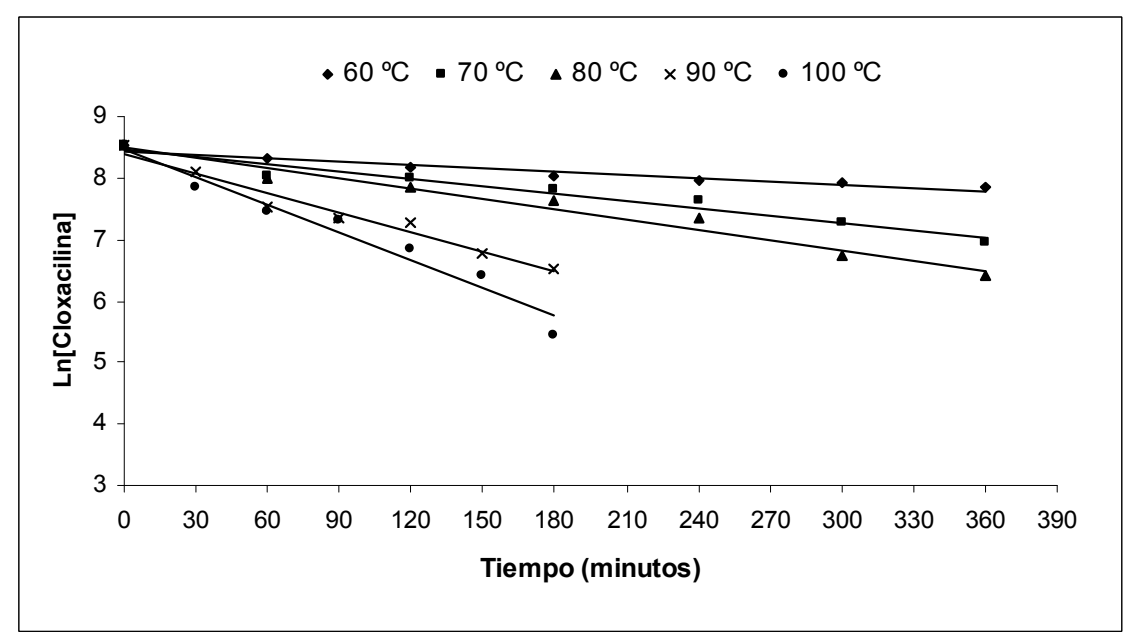

Figura 57. Relación entre la concentración de cloxacilina en la leche y el tiempo de calentamiento a diferentes temperaturas 


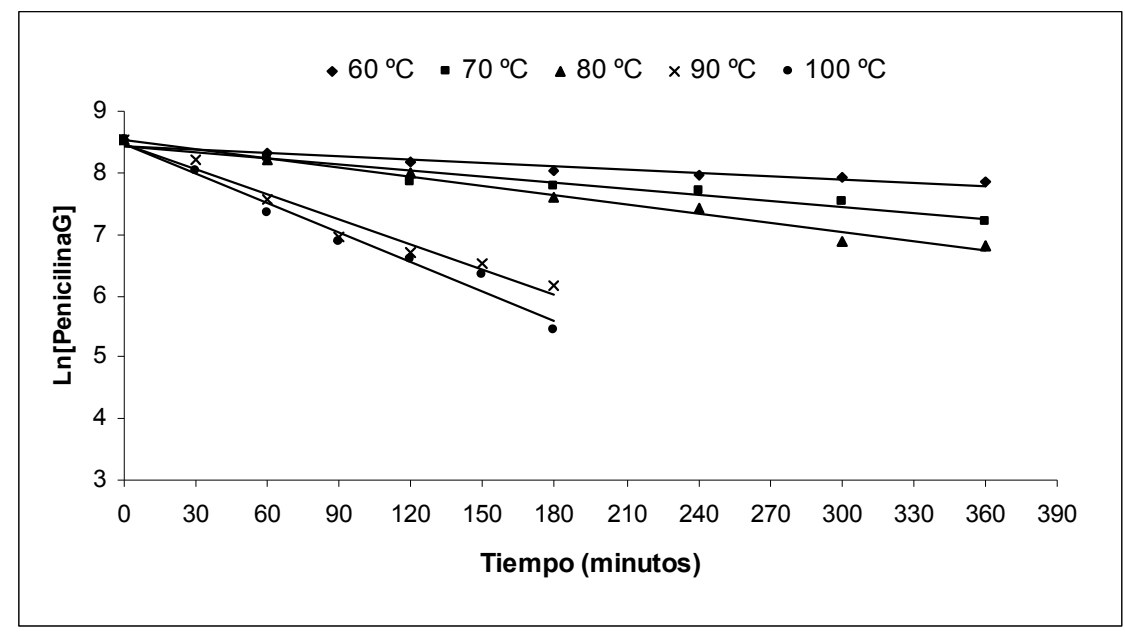

Figura 58. Relación entre la concentración de penicilina $\mathrm{G}$ en la leche y el tiempo de calentamiento a diferentes temperaturas

Es importante resaltar que en el caso de la amoxicilina (Figura 55) el incremento de las pendientes se realiza de forma constante y uniforme, ya que aumentan de forma gradual, sin cambios bruscos entre las temperaturas.

Por el contrario, la ampicilina (Figura 56) se muestra estable a temperaturas suaves e intermedias con leves pendientes, mientras que a temperaturas elevadas alrededor de los $100^{\circ} \mathrm{C}$, la reacción de degradación se acelera y la molécula se vuelve muy inestable presentando una pendiente de degradación muy pronunciada, mayor que las del resto de penicilinas.

La cloxacilina (Figura 57) y la penicilina G (Figura 58), por su parte, muestran pendientes muy similares entre ellas, indicando un comportamiento semejante a lo largo de las diferentes temperaturas de calentamiento, siendo relativamente estables a 60,70 y $80^{\circ} \mathrm{C}$ y muy inestables a 90 y $100^{\circ} \mathrm{C}$.

Para obtener mayor información sobre la estabilidad térmica de las penicilinas en la leche durante los tratamientos térmicos de calor, se han estimado a partir de las ecuaciones del modelo cinético de primer orden, los tiempos de vida media $\left(t_{1 / 2}\right)$ de las penicilinas en la leche para las cinco temperaturas ensayadas, cuyos valores se muestran en el Cuadro 65.

Como se observa en este Cuadro, la ampicilina es una molécula muy estable en el calentamiento de 60 y $70{ }^{\circ} \mathrm{C}$ con tiempos de vida media elevados entre 741 y 450 minutos, medianamente estables entre los 80 y $90{ }^{\circ} \mathrm{C}$ con tiempos más cortos entre 93 y 99 minutos, y muy inestable en torno a los $100^{\circ} \mathrm{C}$ presentando el menor valor de vida media (26 minutos). 
Cuadro 65. Tiempos de vida media $\left(t_{1 / 2}\right)$ estimados para las penicilinas en la leche a diferentes temperaturas de calentamiento

\begin{tabular}{|lccccc|}
\hline \multirow{2}{*}{ Penicilinas } & \multicolumn{5}{c|}{$\mathbf{t}_{\mathbf{1 / 2}}$ (minutos)= Ln2/k } \\
\cline { 2 - 6 } & $\mathbf{6 0} \mathbf{~}^{\circ} \mathbf{C}$ & $\mathbf{7 0}^{\circ} \mathbf{C}$ & $\mathbf{8 0}^{\circ} \mathbf{C}$ & $\mathbf{9 0}^{\circ} \mathbf{C}$ & $\mathbf{1 0 0}^{\circ} \mathbf{C}$ \\
\hline Amoxicilina & 372 & 223 & 129 & 81 & 50 \\
Ampicilina & 741 & 450 & 99 & 93 & 26 \\
Cloxacilina & 367 & 176 & 124 & 66 & 46 \\
Penicilina G & 382 & 213 & 138 & 52 & 43 \\
\hline
\end{tabular}

Por otra parte, la amoxicilina, cloxacilina y penicilina $G$ muestran un comportamiento más inestable a temperaturas suaves, ya que a 60 y $70{ }^{\circ} \mathrm{C}$ los tiempos de vida media estimados son muy inferiores a los de la ampicilina. Sin embargo, a pesar de ser más inestables a bajas temperaturas (mayor degradación), el comportamiento que muestran estas moléculas a lo largo de los tratamientos térmicos es diferente dependiendo de la temperatura ensayada.

Así, por un lado, la amoxicilina presenta los tiempos de vida media en la leche más bajos en los tratamientos de 60,70 y $80^{\circ} \mathrm{C}$ y la penicilina $\mathrm{G}$ los más elevados pero a 90 y $100{ }^{\circ} \mathrm{C}$, la penicilina $\mathrm{G}$ presenta los tiempos más bajos y la amoxicilina los más elevados.

Estas diferencias en la termoestabilidad de cada una de las penicilinas puede explicarse mediante las energías de activación y los choques eficaces que se producen entre las moléculas activadas de las sustancias, y que se calculan en el apartado siguiente al aplicar la ecuación de Arrhenius a las constantes de velocidad de reacción de cada una de las penicilinas en estudio.

Como se ha comentado anteriormente, los trabajos realizados para la determinación de la estabilidad térmica de medicamentos suelen emplear el modelo cinético de primer orden para determinar los parámetros cinéticos de la descomposición de estas sustancias. No obstante, los trabajos encontrados al respecto, se centran por lo general en distintos tipos de medicamentos veterinarios en disolución o en compuestos sólidos, siendo muy escasos los estudios realizados sobre la estabilidad térmica de fármacos, especialmente de antimicrobianos, en los alimentos.

Rodante et al. (2002), en un estudio cinético sobre la descomposición en múltiples etapas de antibióticos en solución acuosa, emplea el modelo cinético de 
primer orden para evaluar la degradación de la cloxacilina, dicloxacilina y oxacilina bajo diferentes condiciones de temperatura.

De la misma manera, Miller et al. (2004), emplean el modelo cinético de primer orden para realizar un estudio sobre la estimación rápida de los parámetros cinéticos de la descomposición térmica de la penicilina $\mathrm{G}$ por medio de análisis termogravimétrico.

Respecto al empleo del modelo cinético de primer orden sobre la estabilidad de antimicrobianos en la leche, no se ha encontrado ninguna referencia bibliográfica para poder comparar con los resultados obtenidos en el presente estudio.

\subsubsection{Cálculo de la energía de activación}

Para el cálculo de la energía de activación (Ea) de cada penicilina se ha empleado el modelo de regresión lineal propuesto por Arrhenius que relaciona las transformadas logarítmicas de las constantes específicas de degradación " $k_{1}$ ", obtenidas en el apartado anterior, con la inversa de la temperatura absoluta de la siguiente manera: "Ln k = Ln A - Ea/RT". Los parámetros resultantes de la aplicación de esta ecuación para el caso de las penicilinas en la leche se resumen en el Cuadro 66.

Cuadro 66. Ecuación de Arrhenius aplicada a la degradación térmica de las penicilinas en la leche

\begin{tabular}{|c|c|c|c|c|c|c|c|}
\hline \multirow{2}{*}{ Penicilinas } & \multirow{2}{*}{$\begin{array}{l}\text { Ordenada } \\
\text { (Ln A) }\end{array}$} & \multirow{2}{*}{$\begin{array}{l}\text { Pendiente } \\
\text { (-Ea/R) }\end{array}$} & \multicolumn{2}{|c|}{ Error estándar } & \multirow{2}{*}{$\mathbf{p}$} & \multirow{2}{*}{$\mathbf{R}^{2}$} & \multirow{2}{*}{ Ea } \\
\hline & & & $\operatorname{Ln} A$ & $-E a / R$ & & & \\
\hline Amoxicilina & 12,456 & 6244,91 & 0,20205 & 71,1528 & 0,0001 & 0,9996 & 51,92 \\
\hline Ampicilina & 23,647 & 10233,50 & 4,01719 & 1414,65 & 0,0054 & 0,9458 & 85,09 \\
\hline Cloxacilina & 13,004 & 6397,53 & 1,10100 & 387,715 & 0,0005 & 0,9891 & 53,19 \\
\hline Penicilina G & 15,185 & 7169,19 & 2,08645 & 734,751 & 0,0023 & 0,9695 & 59,61 \\
\hline
\end{tabular}

Ea= Energía de activación $(\mathrm{kJ} / \mathrm{mol}) ; \mathrm{R}=$ constante especifica de los gases ideales $\left(8,314472 \mathrm{~J} / \mathrm{mol} \cdot{ }^{\circ} \mathrm{K}\right) ; \mathrm{A}=$ frecuencia de choque

En este Cuadro, se aprecia que los ajustes alcanzados mediante la aplicación del modelo de regresión lineal son adecuados, con coeficientes de regresión elevados en todos los casos $\left(R^{2}=0,9458\right.$ : ampicilina y $R^{2}=0,9996$ : amoxicilina).

También se observa que el efecto de la temperatura resulta altamente significativo $(p<0,001)$ para la amoxicilina y cloxacilina y en menor medida $(p<0,01)$ en el caso de la ampicilina y penicilina $G$. 
Estos resultados demuestran que la ecuación de Arrhenius es adecuada para describir la relación existente entre las constantes de velocidad de degradación de las sustancias con la temperatura.

Las ordenadas en el origen de las ecuaciones anteriores (factor preexponencial), corresponden a las transformaciones logarítmicas de las frecuencias de choques " $A$ " que pueden darse entre las moléculas activadas de una sustancia a diferentes temperaturas. Se observa que el mayor valor corresponde a la ampicilina $(23,647)$ en comparación con el resto de antibióticos ensayados, lo que indica la mayor frecuencia de choques efectivos que pueden ocasionarse entre las moléculas de ampicilina una vez alcanzada la suficiente energía para que se lleve a cabo la reacción de descomposición de esta molécula.

Con respecto a las pendientes de dichas ecuaciones, se observa que la ampicilina presenta de nuevo el mayor coeficiente $(-E a / R)$, poniendo de manifiesto la elevada energía de activación que necesita alcanzar esta molécula para poder reaccionar y degradarse.

Con el fin de analizar más detalladamente los cambios de las constantes específicas de velocidad de degradación térmica de las penicilinas "Ln k" para diferentes temperaturas, en la Figura 59 se representan las ecuaciones linealizadas del Cuadro 66.

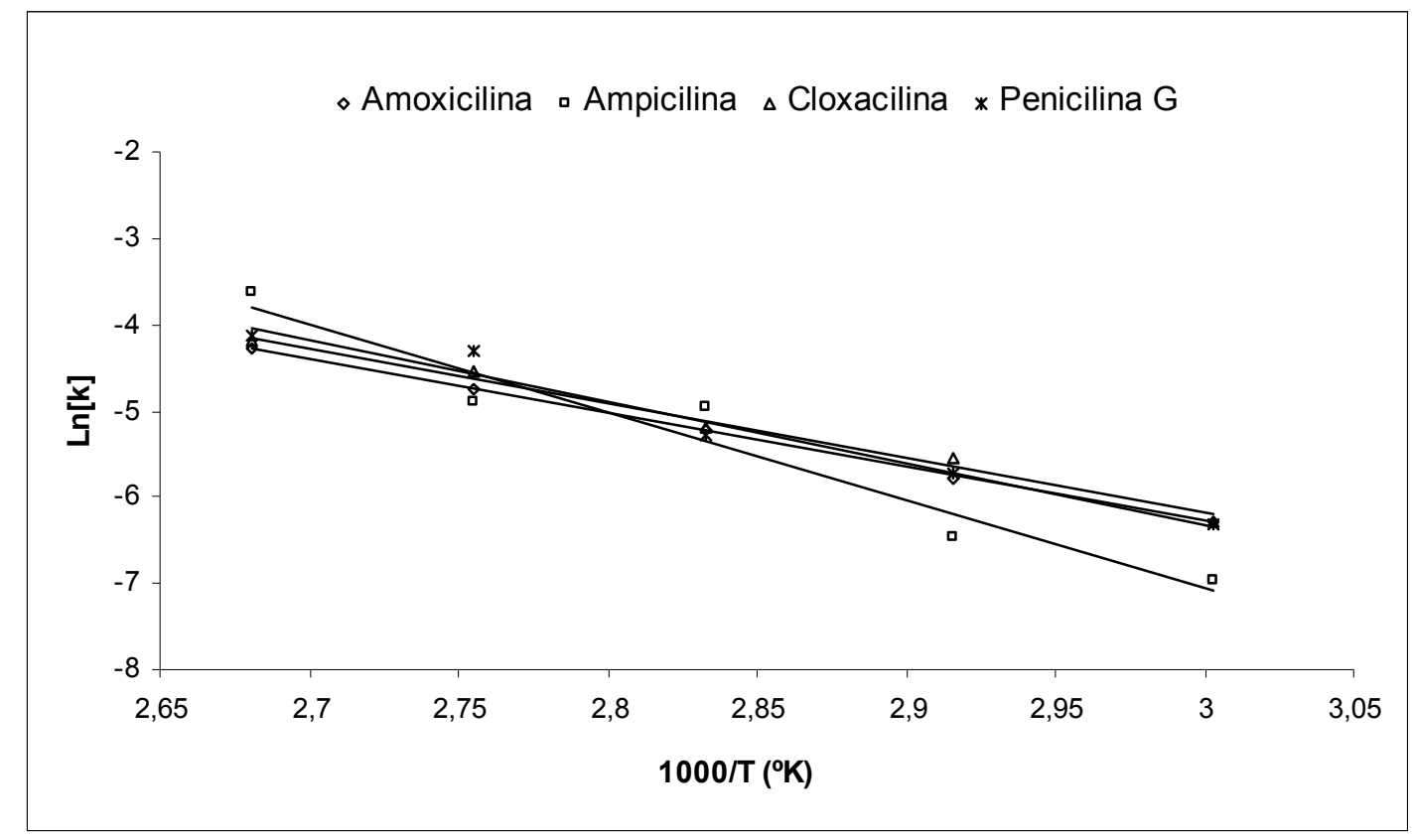

Figura 59. Representación gráfica de la ecuación de Arrhenius para las penicilinas 
Como se aprecia en dicha Figura, la ampicilina presenta una pendiente superior a la del resto de penicilinas, acentuándose más la degradación de la molécula en la medida que se incrementa la temperatura y pasando de tener el menor valor de " $k_{1}$ " a $60^{\circ} \mathrm{C}$ a obtener el mayor valor a $100{ }^{\circ} \mathrm{C}$. Por otro lado, la amoxicilina, cloxacilina y penicilina $G$ manifiestan un comportamiento similar entre ellas con pendientes de degradación menores.

A partir de las ecuaciones de Arrhenius (Cuadro 66) se han calculado las energías de activación (Ea) correspondientes a cada penicilina cuyos valores se presentan también en el Cuadro 66.

De las penicilinas ensayadas, la ampicilina presenta mayor valor de la energía de activación $(85,09 \mathrm{~kJ} / \mathrm{mol})$ mientras que la amoxicilina, cloxacilina y penicilina $\mathrm{G}$ manifiestan energías de activación similares entre ellas $(51,92,53,19$ y 59,61 kJ/mol respectivamente).

Estos valores de las energías de activación junto a las frecuencias de choque ( $\operatorname{Ln} A)$, las constantes de velocidad de reacción $\left(k_{1}\right)$ y los tiempos de vida media $\left(t_{1 / 2}\right)$ de cada una de las sustancias antimicrobianas, son parámetros cinéticos que proporcionan la información necesaria para determinar la estabilidad de estas sustancias en función del tiempo y la temperatura de calentamiento de la leche.

La ampicilina es, por ejemplo, una molécula estable en la leche calentada a temperaturas de 60,70 y $80^{\circ} \mathrm{C}$, presentando poca degradación (menores pendientes y tiempos de vida media más largos), lo que no es extraño si se toma en cuenta que esta molécula presenta una energía de activación elevada de $85,09 \mathrm{~kJ} / \mathrm{mol}$ que indica que a estas temperaturas solamente una pequeña cantidad de moles de ampicilina en la leche alcanzan la energía de activación necesaria para que ocurra la reacción de descomposición.

Por el contrario, el calentamiento a 90 y $100^{\circ} \mathrm{C}$ aporta la energía suficiente para que una gran cantidad de moléculas de ampicilina alcancen el estado de transición y la reacción de descomposición de esta sustancia se acelere rápidamente. Además el elevado valor de la frecuencia de choques estimado para la ampicilina indica una mayor probabilidad de choques eficaces entre las partículas de esta sustancia que se traduce en una reacción rápida y unos tiempos de vida media cortos, sobre todo en el calentamiento de $100^{\circ} \mathrm{C}$.

Por otro lado, la amoxicilina, cloxacilina y penicilina G son moléculas menos estables a temperaturas de 60 y $70^{\circ} \mathrm{C}$ puesto que presentan mayores pendientes de degradación y tiempos de vida media más cortos. Este hecho se debe a los valores 
más bajos de las energías de activación $(<60 \mathrm{~kJ} / \mathrm{mol}$ ) que presentan estas moléculas, más fáciles de alcanzar a temperaturas suaves $\left(t_{1 / 2}\right.$ más cortos a $60{ }^{\circ} \mathrm{C}$ comparado con la ampicilina).

No obstante, la estabilidad térmica de cada una de estas penicilinas varía a lo largo de los cinco tratamientos empleados, debido a las diferentes energías de activación y frecuencias de choque eficaces que presentan cada una de ellas.

De esta manera, la amoxicilina con menor energía de activación (51,92 $\mathrm{kJ} / \mathrm{mol}$ ) y frecuencia de choques ( $\mathrm{Ln} A=12,456$ ) alcanza rápido la energía suficiente para degradarse, pero la cantidad de choques eficaces es bastante limitada por lo que la degradación es lenta y progresiva en el tiempo, tal y como se ha indicado en los apartados anteriores. Por el contrario la penicilina $G$ con una energía de activación ligeramente superior $(59,61 \mathrm{~kJ} / \mathrm{mol})$ y una frecuencia de choques más elevada $(15,185)$ se degrada un poco más rápido que la amoxicilina a partir de los 80 ${ }^{\circ} \mathrm{C}$.

Estos hechos también explican por qué en el calentamiento de la leche a 100 ${ }^{\circ} \mathrm{C}$, la reacción de degradación de la amoxicilina, cloxacilina y penicilina $\mathrm{G}$ es menor que la de la ampicilina, y es porque con el aporte de energía que se realiza en este calentamiento se alcanzan las energías de activación de las cuatro sustancias pero la ampicilina tiene mayor probabilidad de degradarse debido a la elevada frecuencia de choques que presenta comparado con las otras penicilinas.

Dado que la revisión bibliográfica no aporta información sobre la energía de activación de penicilinas en matrices alimentarias y en concreto en la leche, no se han podido comparar los resultados de este trabajo con los realizados por otros autores en las mismas condiciones.

Únicamente se han encontrado algunos estudios que calculan energías de activación de penicilinas en compuestos sólidos, como el realizado por Pawelczyk et al. (1980) para la ampicilina y penicilina G con unas energías de activación de 143,9 y $84,5 \mathrm{~kJ} / \mathrm{mol}$ respectivamente, valores superiores a los obtenidos en este trabajo.

Otros autores (Rodante et al., 2002) obtienen una energía de activación para la cloxacilina de $98 \pm 2 \mathrm{~kJ} / \mathrm{mol}$ cuando se calientan compuestos sólidos de este antibiótico a temperaturas superiores a los $300^{\circ} \mathrm{C}$.

También Miller et al. (2004), publican valores para la ampicilina y penicilina G en compuestos sólidos de 149,7 y 92,4 kJ/mol respectivamente cuando se utiliza un rango de temperaturas entre los 60 y los $140^{\circ} \mathrm{C}$. 
La diferencia encontrada entre los resultados de estos autores con los del presente estudio se pueden deber a las diferentes metodologías empleadas así como a las distintas estructuras de las matrices donde se encuentran las moléculas en estudio, rango de temperaturas utilizado, y también en algunos casos a los parámetros cinéticos diferentes $(\log \mathrm{k}$ y $\log \mathrm{z})$ calculados en los estudios citados.

\subsubsection{Estimación de la degradación de penicilinas para diferentes tratamientos térmicos}

Desde un punto de vista práctico, a partir de la ecuación de Arrhenius y la aplicación de los modelos cinéticos expuestos en los apartados anteriores, se han estimado los porcentajes de degradación térmica de las penicilinas en la leche debida a diferentes tratamientos térmicos que se realizan en los laboratorios de control de calidad de leche y en las industrias lácteas.

Las temperaturas y tiempos seleccionados corresponden al calentamiento que se realiza para la homogeneización de las muestras $\left(40^{\circ} \mathrm{C}-\mathrm{min}\right)$ y el empleado en la inactivación de inhibidores naturales en el análisis de residuos $\left(83^{\circ} \mathrm{C}-\mathrm{min}\right)$, en lo que se refiere a los laboratorios de control de calidad. A su vez, los tratamientos industriales corresponden a las pasteurizaciones bajas de $63^{\circ} \mathrm{C}-30$ min y $72{ }^{\circ} \mathrm{C}-15 \mathrm{~s}$, a la esterilización convencional $\left(120^{\circ} \mathrm{C}-20 \mathrm{~min}\right)$ y a la esterilización UHT $\left(140^{\circ} \mathrm{C}-4 \mathrm{~s}\right)$.

Los porcentajes de degradación térmica estimados para las penicilinas en la leche se presentan en el Cuadro 67.

Cuadro 67. Porcentajes de degradación de las penicilinas en la leche para diferentes tratamientos térmicos

\begin{tabular}{|c|c|c|c|c|c|c|}
\hline \multirow{2}{*}{ Penicilinas } & \multicolumn{2}{|c|}{$\begin{array}{l}\text { Tratamientos } \\
\text { laboratorio }\end{array}$} & \multicolumn{2}{|c|}{ Pasteurización } & \multicolumn{2}{|c|}{ Esterilización } \\
\hline & $\begin{array}{l}40^{\circ} \mathrm{C} \\
10 \mathrm{~min}\end{array}$ & $\begin{array}{l}83^{\circ} \mathrm{C} \\
10 \mathrm{~min}\end{array}$ & $\begin{array}{c}63^{\circ} \mathrm{C} \\
30 \mathrm{~min}\end{array}$ & $\begin{array}{l}72^{\circ} \mathrm{C} \\
15 \mathrm{~s} \\
\end{array}$ & $\begin{array}{l}120^{\circ} \mathrm{C} \\
20 \mathrm{~min}\end{array}$ & $\begin{array}{c}140^{\circ} \mathrm{C} \\
4 \mathrm{~s} \\
\end{array}$ \\
\hline Amoxicilina & 0,6 & 6,0 & 6,3 & 0,1 & 47,6 & 0,5 \\
\hline Ampicilina & 0,1 & 5,9 & 3,3 & 0,1 & 84,0 & 2,1 \\
\hline Cloxacilina & 0,6 & 6,7 & 6,9 & 0,1 & 53,1 & 0,6 \\
\hline Penicilina G & 0,4 & 6,8 & 6,2 & 0,1 & 61,0 & 0,8 \\
\hline
\end{tabular}

Se observa que tanto en los tratamientos térmicos realizados normalmente en los laboratorios como en la pasteurización y la esterilización UHT, se produce una leve degradación de las penicilinas ya que la máxima pérdida estimada alcanza un $6,9 \%$ en el caso de la cloxacilina durante el tratamiento de $63^{\circ} \mathrm{C}-30 \mathrm{~min}$. 
Por el contrario en el tratamiento térmico de $120^{\circ} \mathrm{C}-20 \mathrm{~min}$, los porcentajes de degradación estimados son elevados, alcanzando valores comprendidos entre el $47,6 \%$ para la amoxicilina y el $84 \%$ para la ampicilina.

Estos resultados de los porcentajes de degradación estimados para distintos tratamientos térmicos de calor, coinciden con los obtenidos por otros autores, aunque es importante recordar, como se ha comentado en la Introducción, que en general son estudios realizados sobre la penicilina $G$ y mediante la utilización de métodos microbiológicos y no cromatográficos, como los empleados en este estudio.

Así, Shahani et al. (1956) al efectuar un calentamiento a $62{ }^{\circ} \mathrm{C}$ durante 30 minutos en muestras de leche fortificadas con penicilina $G$ obtienen un $8 \%$ de inactivación, porcentaje que se incrementa a un 10\% cuando el calentamiento se efectúa a $71^{\circ} \mathrm{C}$ durante 15 minutos. Estos valores resultan ligeramente superiores al 5,8 y $5,1 \%$ estimados respectivamente para esos mismos tratamientos a partir de la ecuación de Arrhenius obtenida en este estudio para el caso de la penicilina G (Cuadro 66).

También, Konecny (1978) observa un bajo porcentaje de inactivación térmica $(10 \%)$ en muestras de leche fortificadas con penicilina $\mathrm{G}$ y calentadas a $83^{\circ} \mathrm{C}-10$ min, valor similar al $6,8 \%$ obtenido en este estudio para las mismas condiciones.

Por otro lado, al efectuar una pasteurización baja a $63^{\circ} \mathrm{C}$ durante 30 minutos, Jacquet y Auxepaules (1978) señalan bajos porcentajes de inactivación para ampicilina $(1,7 \%)$ y penicilina "G" $(2,6 \%)$, valores también cercanos a los estimados en este trabajo para ese mismo tratamiento.

Las revisiones bibliográficas efectuadas por Moats $(1988,1999)$ presentan los estudios de Shahani et al. (1956) donde se indican pérdidas del $59,7 \%$ en la actividad de la penicilina $\mathrm{G}$ cuando las muestras de leche se tratan a $121{ }^{\circ} \mathrm{C}$ durante 15 minutos, porcentaje próximo al calculado en este trabajo (Cuadro 67) para la esterilización convencional (61\%).

Por otro lado, Pilet et al. (1969) al emplear una temperatura de $100^{\circ} \mathrm{C}$ durante 30 minutos, indican porcentajes de inactivación comprendidos entre el 20 y $40 \%$ para la penicilina $G$ en la leche, al igual que Konecny (1978) que al calentar las muestras de leche fortificadas con penicilina $\mathrm{G}$ a $100^{\circ} \mathrm{C}-30 \mathrm{~min}$, determina un porcentaje de inactivación similar (32\%). Estos resultados coinciden con los obtenidos en este estudio, ya que al estimar la degradación de la penicilina $\mathrm{G}$ que resultaría al calentar la leche a $100{ }^{\circ} \mathrm{C}$ durante 30 minutos se obtiene un porcentaje de degradación del $41,2 \%$, valor similar a los establecidos por dichos autores. 
Zorraquino (1997) al estudiar mediante una técnica HPLC el efecto del calentamiento a $80{ }^{\circ} \mathrm{C}$ durante un tiempo de 20 minutos en soluciones acuosas tamponadas y fortificadas con antibióticos betalactámicos, determina bajos porcentajes de inactivación para la penicilina $(0 \%)$, amoxicilina $(1 \%)$ y cloxacilina $(5 \%)$, resultados similares aunque ligeramente inferiores a los presentados en el Cuadro 67.

Este mismo autor en otro trabajo (Zorraquino, 2005), estudia la inactivación térmica de los antimicrobianos en la leche mediante un bioensayo microbiológico multiplaca. Al comparar los resultados obtenidos en dicho estudio, expuestos en el Cuadro 15 y Figura 16 de la Introducción, con los porcentajes de degradación estimados en este trabajo, se puede observar que los resultados son muy similares en casi todos los casos.

Así, Zorraquino (2005), al emplear los tratamientos de laboratorio $\left(40{ }^{\circ} \mathrm{C}-10\right.$ min y $83{ }^{\circ} \mathrm{C}-10 \mathrm{~min}$ ) obtiene bajos porcentajes de inactivación, con valores comprendidos entre un $9 \%$ (amoxicilina) y $20 \%$ (penicilina G), que resultan levemente superiores a los determinados en este trabajo.

En cuanto a la esterilización a $120{ }^{\circ} \mathrm{C}-20 \mathrm{~min}$, según se ha comentado anteriormente, los porcentajes de degradación estimados en este trabajo aunque elevados son inferiores a los estimados por dicho autor que presenta inactivaciones de: $65 \%$ (penicilina G), 72\% (cloxacilina) y superiores al 88\% (amoxicilina).

Las diferencias encontradas entre ambos trabajos pueden explicarse por un lado, a que los métodos analíticos utilizados son diferentes, ya que Zorraquino (2005) utiliza un método de inhibición microbiológico multiplaca empleando el Geobacillus stearothermophilus, y por el otro lado, a que dicho autor mide pérdida de actividad antimicrobiana debido a las moléculas madres y sus posibles metabolitos, pudiendo resultar menos específica la cuantificación realizada por esta metodología, que la realizada por HPLC.

\subsection{ANTIBIÓTICOS BETALACTÁMICOS: CEFALOSPORINAS}

\subsubsection{Estudio de la degradación térmica de las cefalosporinas mediante modelos de primer orden}

Los parámetros de las ecuaciones de regresión lineal simple resultantes de la aplicación del modelo cinético de primer orden a la degradación térmica de las cefalosporinas en la leche se exponen en los Cuadros 68, 69, 70, 71, 72 y 73. 
Cuadro 68. Parámetros resultantes de la aplicación del modelo cinético de primer orden a la degradación de la cefalexina en la leche a diferentes temperaturas

\begin{tabular}{|c|c|c|c|c|c|c|}
\hline \multirow{2}{*}{$\mathrm{T}^{\mathrm{a}}\left({ }^{\circ} \mathrm{C}\right)$} & \multirow{2}{*}{$\begin{array}{c}\text { Ordenada } \\
\text { (a) }\end{array}$} & \multirow{2}{*}{$\begin{array}{c}\text { Pendiente } \\
\left(\mathbf{k}_{1}\right)\end{array}$} & \multicolumn{2}{|c|}{ Error estándar } & \multirow{2}{*}{$\mathbf{p}$} & \multirow{2}{*}{$\mathbf{R}^{2}$} \\
\hline & & & a & $k_{1}$ & & \\
\hline 60 & 8,492 & $-0,00601$ & 0,02559 & 0,00071 & 0,0004 & 0,9349 \\
\hline 70 & 8,505 & $-0,00792$ & 0,03202 & 0,00089 & 0,0003 & 0,9408 \\
\hline 80 & 8,416 & $-0,02165$ & 0,05682 & 0,00157 & 0,0001 & 0,9741 \\
\hline 90 & 8,447 & $-0,05123$ & 0,08889 & 0,00493 & 0,0001 & 0,9557 \\
\hline 100 & 8,483 & $-0,06130$ & 0,05988 & 0,00332 & 0,0001 & 0,9855 \\
\hline
\end{tabular}

Cuadro 69. Parámetros resultantes de la aplicación del modelo cinético de primer orden a la degradación del cefalonio en la leche a diferentes temperaturas

\begin{tabular}{|c|c|c|c|c|c|c|}
\hline \multirow{2}{*}{$\mathrm{T}^{\mathrm{a}}\left({ }^{\circ} \mathrm{C}\right)$} & \multirow{2}{*}{$\begin{array}{l}\text { Ordenada } \\
\text { (a) }\end{array}$} & \multirow{2}{*}{$\begin{array}{c}\text { Pendiente } \\
\left(\mathbf{k}_{\mathbf{1}}\right)\end{array}$} & \multicolumn{2}{|c|}{ Error estándar } & \multirow{2}{*}{$\mathbf{p}$} & \multirow{2}{*}{$\mathbf{R}^{2}$} \\
\hline & & & $a$ & $k_{1}$ & & \\
\hline 60 & 8,545 & $-0,00545$ & 0,02093 & 0,00058 & 0,0002 & 0,9468 \\
\hline 70 & 8,462 & $-0,01063$ & 0,03147 & 0,00087 & 0,0001 & 0,9674 \\
\hline 80 & 8,462 & $-0,01441$ & 0,03683 & 0,00102 & 0,0001 & 0,9755 \\
\hline 90 & 8,462 & $-0,02934$ & 0,03862 & 0,00214 & 0,0001 & 0,9740 \\
\hline 100 & 8,512 & $-0,05142$ & 0,03076 & 0,00171 & 0,0001 & 0,9945 \\
\hline
\end{tabular}

Cuadro 70. Parámetros resultantes de la aplicación del modelo cinético de primer orden a la degradación de la cefapirina en la leche a diferentes temperaturas

\begin{tabular}{|c|c|c|c|c|c|c|}
\hline \multirow{2}{*}{$\mathrm{T}^{\mathrm{a}}\left({ }^{\circ} \mathrm{C}\right)$} & \multirow{2}{*}{$\begin{array}{c}\text { Ordenada } \\
\text { (a) }\end{array}$} & \multirow{2}{*}{$\begin{array}{c}\text { Pendiente } \\
\left(\mathbf{k}_{1}\right)\end{array}$} & \multicolumn{2}{|c|}{ Error estándar } & \multirow{2}{*}{$\mathbf{p}$} & \multirow{2}{*}{$\mathbf{R}^{2}$} \\
\hline & & & a & $k_{1}$ & & \\
\hline 60 & 8,445 & $-0,01734$ & 0,06489 & 0,00180 & 0,0002 & 0,9489 \\
\hline 70 & 8,345 & $-0,02189$ & 0,08313 & 0,00231 & 0,0002 & 0,9474 \\
\hline 80 & 8,308 & $-0,03865$ & 0,15677 & 0,00435 & 0,0003 & 0,9405 \\
\hline 90 & 8,282 & $-0,14753$ & 0,14753 & 0,00818 & 0,0002 & 0,9529 \\
\hline 100 & 8,262 & $-0,11303$ & 0,18419 & 0,01022 & 0,0001 & 0,9607 \\
\hline
\end{tabular}

Como se observa en estos Cuadros, los ajustes obtenidos al aplicar el modelo cinético de primer orden son adecuados, ya que la relación entre las transformaciones logarítimicas de la concentración de las cefalosporinas y el tiempo de calentamiento es lineal en todos los casos con coeficientes de regresión elevados entre $R^{2}=0,9349$ (cefalexina, $60^{\circ} \mathrm{C}$ ) y $R^{2}=0,9855$ (cefapirina, $100^{\circ} \mathrm{C}$ ) y niveles de "p" significativos $(p<0,001)$. 
Cuadro 71. Parámetros resultantes de la aplicación del modelo cinético de primer orden a la degradación de la cefoperazona en la leche a diferentes temperaturas

\begin{tabular}{|c|c|c|c|c|c|c|}
\hline \multirow{2}{*}{$\mathrm{T}^{\mathrm{a}}\left({ }^{\circ} \mathrm{C}\right)$} & \multirow{2}{*}{$\begin{array}{l}\text { Ordenada } \\
\text { (a) }\end{array}$} & \multirow{2}{*}{$\begin{array}{c}\text { Pendiente } \\
\left(\mathbf{k}_{1}\right)\end{array}$} & \multicolumn{2}{|c|}{ Error estándar } & \multirow{2}{*}{$\mathbf{p}$} & \multirow{2}{*}{$\mathbf{R}^{2}$} \\
\hline & & & a & $k_{1}$ & & \\
\hline 60 & 8,536 & $-0,00733$ & 0,02821 & 0,00078 & 0,0002 & 0,9461 \\
\hline 70 & 8,520 & $-0,01261$ & 0,04132 & 0,00115 & 0,0001 & 0,9604 \\
\hline 80 & 8,373 & $-0,01729$ & 0,06738 & 0,00187 & 0,0002 & 0,9448 \\
\hline 90 & 8,219 & $-0,12542$ & 0,13166 & 0,00730 & 0,0001 & 0,9833 \\
\hline 100 & 8,266 & $-0,17518$ & 0,15660 & 0,00869 & 0,0001 & 0,9878 \\
\hline
\end{tabular}

Cuadro 72. Parámetros resultantes de la aplicación del modelo cinético de primer orden a la degradación de la cefquinoma en la leche a diferentes temperaturas

\begin{tabular}{|c|c|c|c|c|c|c|}
\hline \multirow{2}{*}{$\mathrm{T}^{\mathrm{a}}\left({ }^{\circ} \mathrm{C}\right)$} & \multirow{2}{*}{$\begin{array}{c}\text { Ordenada } \\
\text { (a) }\end{array}$} & \multirow{2}{*}{$\begin{array}{c}\text { Pendiente } \\
\left(\mathbf{k}_{\mathbf{1}}\right)\end{array}$} & \multicolumn{2}{|c|}{ Error estándar } & \multirow{2}{*}{$\mathbf{p}$} & \multirow{2}{*}{$\mathbf{R}^{2}$} \\
\hline & & & a & $k_{1}$ & & \\
\hline 60 & 8,523 & $-0,00688$ & 0,01799 & 0,00050 & 0,0001 & 0,9744 \\
\hline 70 & 8,492 & $-0,00772$ & 0,03037 & 0,00084 & 0,0003 & 0,9439 \\
\hline 80 & 8,464 & $-0,00813$ & 0,03268 & 0,00090 & 0,0003 & 0,9414 \\
\hline 90 & 8,415 & $-0,02329$ & 0,04901 & 0,00272 & 0,0004 & 0,9362 \\
\hline 100 & 8,504 & $-0,04677$ & 0,04032 & 0,00224 & 0,0001 & 0,9887 \\
\hline
\end{tabular}

Cuadro 73. Parámetros resultantes de la aplicación del modelo cinético de primer orden a la degradación de la cefuroxima en la leche a diferentes temperaturas

\begin{tabular}{|c|c|c|c|c|c|c|}
\hline \multirow{2}{*}{$\mathrm{T}^{\mathrm{a}}\left({ }^{\circ} \mathrm{C}\right)$} & \multirow{2}{*}{$\begin{array}{l}\text { Ordenada } \\
\text { (a) }\end{array}$} & \multirow{2}{*}{$\begin{array}{c}\text { Pendiente } \\
\left(\mathbf{k}_{1}\right)\end{array}$} & \multicolumn{2}{|c|}{ Error estándar } & \multirow{2}{*}{$\mathbf{p}$} & \multirow{2}{*}{$\mathbf{R}^{2}$} \\
\hline & & & $\mathbf{a}$ & $k_{1}$ & & \\
\hline 60 & 8,557 & $-0,00786$ & 0,03232 & 0,00090 & 0,0003 & 0,9388 \\
\hline 70 & 8,528 & $-0,01276$ & 0,04518 & 0,00125 & 0,0002 & 0,9540 \\
\hline 80 & 8,474 & $-0,02423$ & 0,04855 & 0,00135 & 0,0001 & 0,9848 \\
\hline 90 & 8,306 & $-0,06775$ & 0,13935 & 0,00773 & 0,0003 & 0,9389 \\
\hline 100 & 8,301 & $-0,13860$ & 0,20215 & 0,01121 & 0,0001 & 0,9683 \\
\hline
\end{tabular}

Respecto a los valores de las constantes de velocidad de reacción " $k_{1}$ " obtenidas para cada cefalosporina, se observa que éstas aumentan a medida que se incrementa la temperatura, y este incremento varía en función de cada sustancia.

De forma general se aprecia que la cefapirina y la cefuroxima muestran las constantes de velocidad más elevadas, mostrando una mayor inestabilidad térmica en la leche calentada a diferentes temperaturas frente al resto de cefalosporinas. De igual modo ocurre en el caso de la cefoperazona, aunque en este caso, el aumento 
de la degradación se realiza más bruscamente al pasar de las temperaturas de 60 , 70 y $80^{\circ} \mathrm{C}$ a las de 90 y $100^{\circ} \mathrm{C}$.

Al comparar los valores de las constantes específicas de estas sustancias con las correspondientes a las penicilinas, se observa que las cefalosporinas presentan, en casi todos los casos, valores más elevados, revelando la mayor inestabilidad térmica de estas moléculas en comparación con las penicilinas, a excepción de la cefquinoma que presenta una estabilidad similar.

En las Figuras 60, 61, 62, 63, 64 y 65 se representan, para cada cefalosporina ensayada, las ecuaciones de regresión lineal del modelo cinético de primer orden obtenidas anteriormente, a partir de las cuales se interpreta más claramente el comportamiento degradativo que muestra cada una de estas sustancias con el tiempo de calentamiento a las diferentes temperaturas.

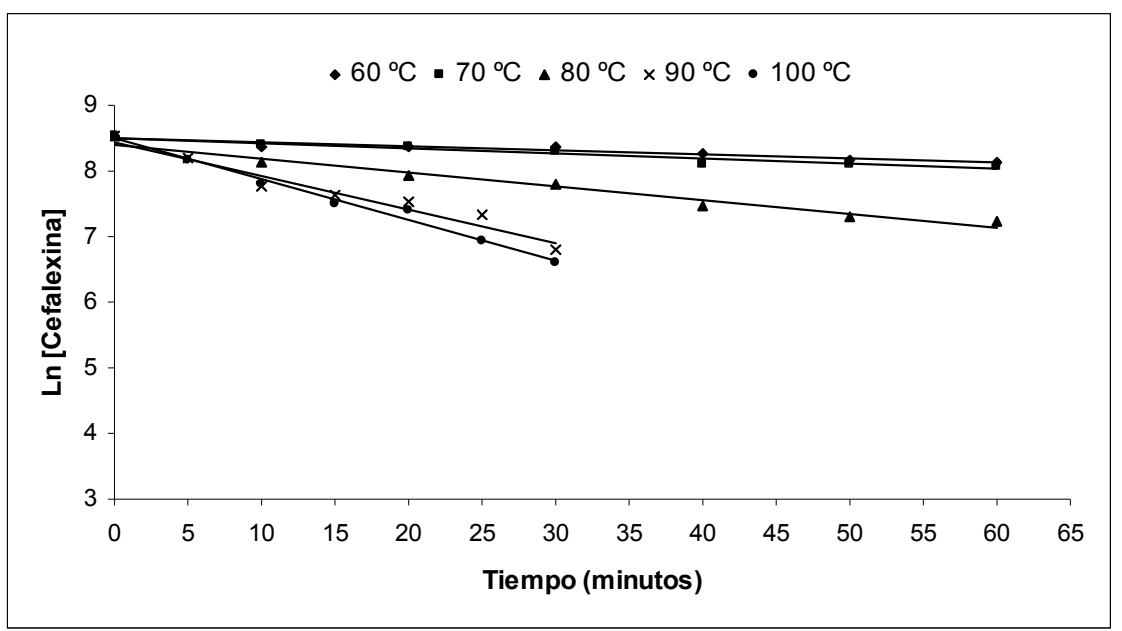

Figura 60. Relación entre la concentración de cefalexina en la leche y el tiempo de calentamiento a diferentes temperaturas

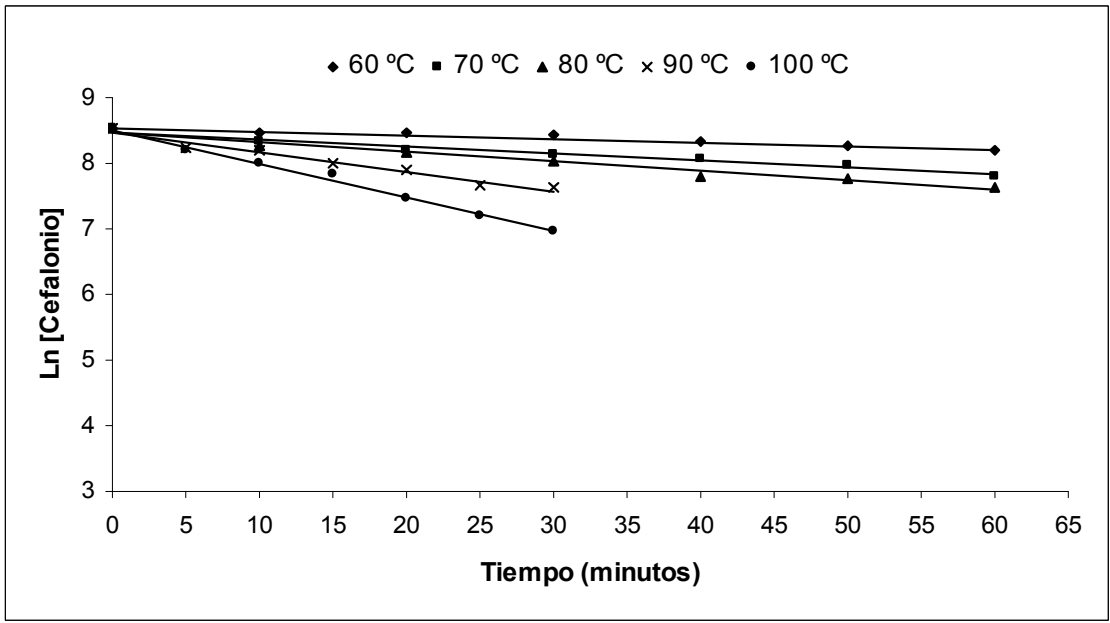

Figura 61. Relación entre la concentración de cefalonio en la leche y el tiempo de calentamiento a diferentes temperaturas 


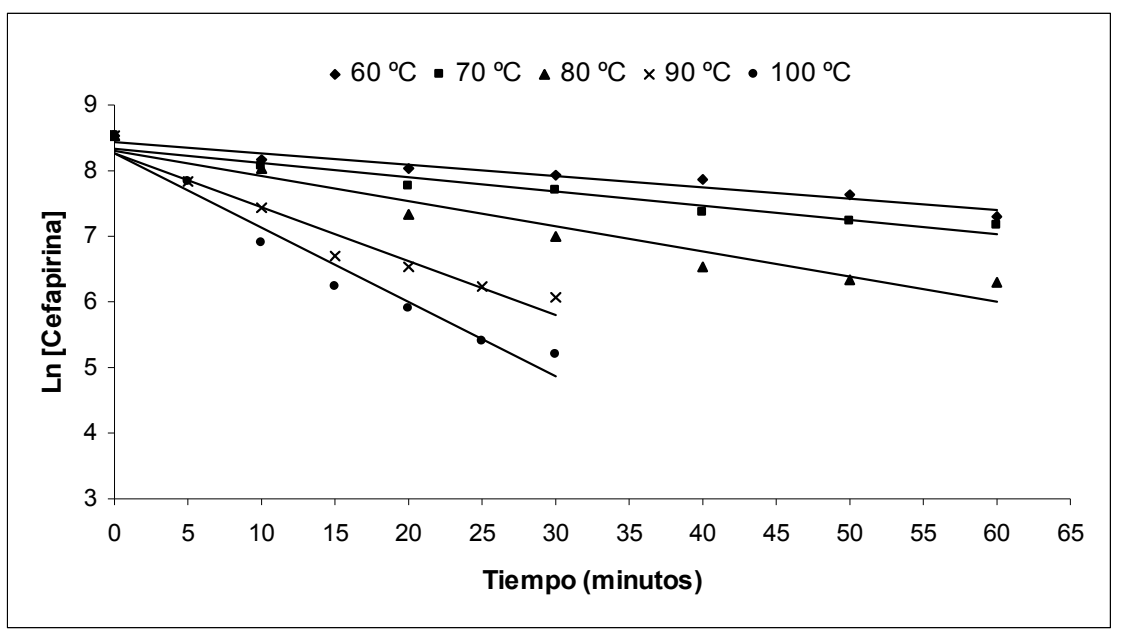

Figura 62. Relación entre la concentración de cefapirina en la leche y el tiempo de calentamiento a diferentes temperaturas

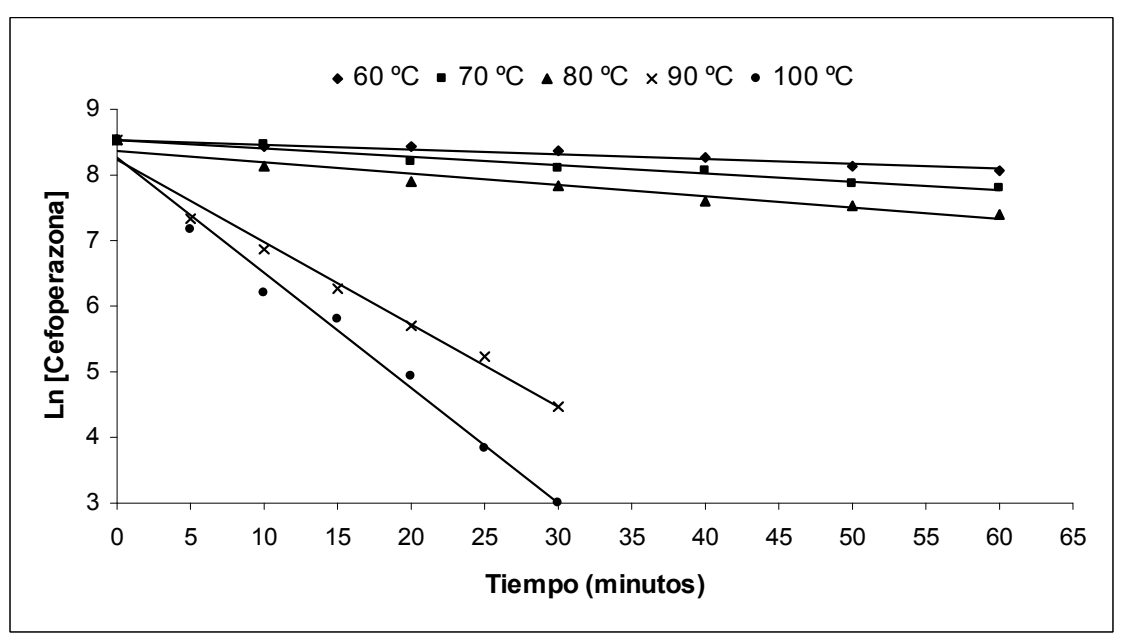

Figura 63. Relación entre la concentración de cefoperazona en la leche y el tiempo de calentamiento a diferentes temperaturas

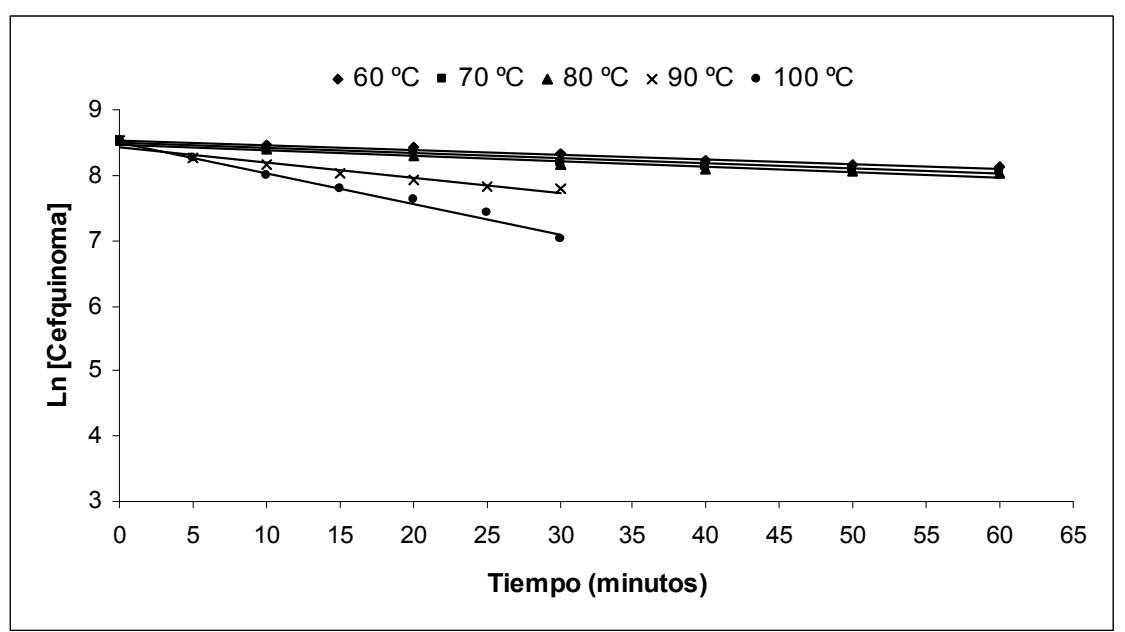

Figura 64. Relación entre la concentración de cefquinoma en la leche y el tiempo de calentamiento a diferentes temperaturas 


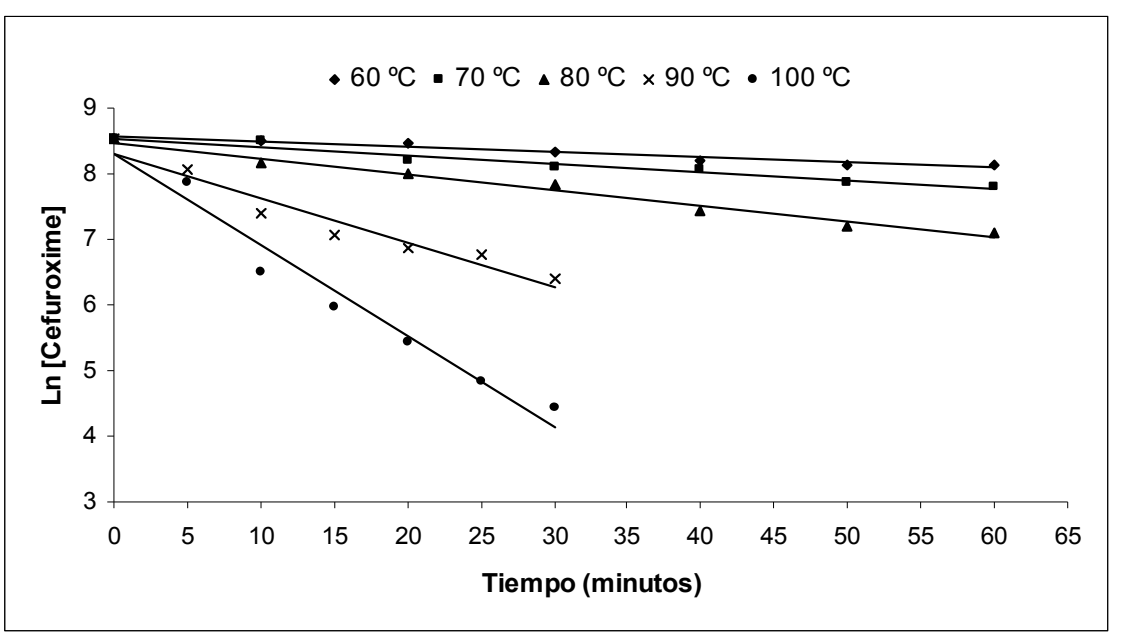

Figura 65. Relación entre la concentración de cefuroxima en la leche y el tiempo de calentamiento a diferentes temperaturas

Si se comparan las pendientes de las diferentes cefalosporinas para el mismo tratamiento térmico se puede apreciar en general que, la cefalexina, cefalonio y cefquinoma presentan menor valor de la pendiente, es decir mayor estabilidad cuando se someten a la acción del calor durante tiempos prolongados, mientras que la cefapirina, cefoperazona y en algunos casos la cefuroxima, presentan por lo general, mayores pendientes, indicando una mayor inestabilidad térmica de estas moléculas.

Es importante resaltar el caso concreto de la cefoperazona, ya que esta molécula presenta las mayores pendientes de degradación en los tratamientos térmicos de 80,90 y $100{ }^{\circ} \mathrm{C}$, siendo en este rango de temperaturas donde la reacción de degradación es más rápida.

Por otra parte, la cefapirina presenta la mayor pendiente a 60 y $70{ }^{\circ} \mathrm{C}$ por lo que es la molécula que más rápido se degrada a temperaturas suaves, indicando la inestabilidad térmica de esta sustancia incluso a temperaturas bajas.

Para analizar más detalladamente el comportamiento de degradación de las cefalosporinas con los tratamientos térmicos de calor se han estimado los valores de los tiempos de vida media $\left(\mathrm{t}_{1 / 2}\right)$ para cada sustancia y temperatura ensayada a partir de las ecuaciones de primer orden descritas anteriormente, cuyos valores resultantes se resumen en el Cuadro 74.

A partir de los resultados de este Cuadro se observa que la cefapirina, cefoperazona y cefuroxima son las moléculas más inestables térmicamente ya que presentan tiempos de vida media más cortos incluso a bajas temperaturas. 
Cuadro 74. Tiempos de vida media $\left(t_{1 / 2}\right)$ estimados para las penicilinas en la leche a diferentes temperaturas de calentamiento

\begin{tabular}{|lccccc|}
\hline \multirow{2}{*}{ Cefalosporinas } & \multicolumn{5}{c|}{$\mathbf{t}_{\mathbf{1 / 2}}$ (minutos) $=\mathbf{~ L n 2 / k}$} \\
\cline { 2 - 6 } & $\mathbf{6 0} \mathbf{~}^{\mathbf{C}} \mathbf{C}$ & $\mathbf{7 0}^{\circ} \mathbf{C}$ & $\mathbf{8 0}^{\circ} \mathbf{C}$ & $\mathbf{9 0}^{\circ} \mathbf{C}$ & $\mathbf{1 0 0}^{\circ} \mathbf{C}$ \\
\hline Cefalexina & 115 & 88 & 32 & 14 & 11 \\
Cefalonio & 127 & 65 & 48 & 24 & 13 \\
Cefapirina & 40 & 32 & 18 & 8 & 6 \\
Cefoperazona & 95 & 55 & 40 & 6 & 4 \\
Cefquinoma & 101 & 90 & 85 & 30 & 15 \\
Cefuroxima & 88 & 54 & 29 & 10 & 5 \\
\hline
\end{tabular}

Sin embargo entre estas tres cefalosporinas, hay diferencias en el comportamiento de degradación dependiendo de la temperatura empleada. Por ejemplo la cefoperazona es inestable a 60,70 y $80^{\circ} \mathrm{C}$ aunque con tiempos de vida media superiores a la cefapirina y cefuroxima, pero a 90 y $100{ }^{\circ} \mathrm{C}$ la reacción de descomposición se acelera y los tiempos de vida media para esta molécula son más bajos.

Esta diferencia de comportamiento puede explicarse en parte, por las diferentes energías de activación y las frecuencias de choque que presentan cada una de estas sustancias, cuyo cálculo se realiza en el apartado siguiente al aplicar la ecuación de Arrhenius.

Por otro lado, la cefalexina, cefalonio y cefquinoma son moléculas más termoestables ya que presentan tiempos de vida media ligeramente superiores. Como en el caso anterior, la rapidez de degradación de estas moléculas en cada temperatura depende entre otros factores de la cantidad de moléculas activadas que hayan alcanzado la energía de activación, cuyo valor, para cada una de estas cefalosporinas se calcula también en el apartado siguiente.

Cuando se compara el comportamiento de degradación de las cefalosporinas con los obtenidos por otros autores que aplican el modelo cinético de primer orden para analizar la estabilidad de estos fármacos, únicamente se han encontrado trabajos realizados sobre soluciones acuosas. Así, Yamana y Tsuji (1976), señalan un comportamiento lineal de degradación de la cefalexina y cefradine con el tiempo de calentamiento y diferentes valores de $\mathrm{pH}$.

También Fabre et al. (1983) evalúan la degradación del cefotaxine mediante cinética de primer orden obteniendo rectas a diferentes valores de $\mathrm{pH}$. 
Por otra parte, los trabajos realizados por Fubara y Notari (1998a) destinados a evaluar la hidrólisis de ceftazidime demuestran un comportamiento lineal de esta cefalosporina al representar las transformaciones logarítmicas de las concentraciones en función del tiempo, poniendo de manifiesto un comportamiento cinético de primer orden.

Ninguno de los resultados obtenidos por estos autores pueden compararse con los resultados del presente trabajo, puesto que se trata de estudios de estabilidad de sustancias y factores diferentes, aunque aplican la cinética de primer orden para describir la estabilidad de las sustancias antimicrobianas.

\subsubsection{Cálculo de la energía de activación}

En el Cuadro 75 se recogen las ecuaciones obtenidas al aplicar la ecuación de Arrhenius a las constantes específicas de degradación obtenidas en el apartado anterior, donde se observa que la relación existente entre estas dos variables es lineal con coeficientes de regresión elevados entre $R^{2}=0,8286$ para la cefquinoma y $R^{2}=0,9863$ para el cefalonio.

Cuadro 75. Ecuación de Arrhenius aplicada a la degradación térmica de las cefalosporinas en la leche

\begin{tabular}{|c|c|c|c|c|c|c|c|}
\hline \multirow{2}{*}{ Cefalosporinas } & \multirow{2}{*}{$\begin{array}{c}\text { Orden } \\
\text { ada } \\
\text { (Ln A) }\end{array}$} & \multirow{2}{*}{$\begin{array}{l}\text { Pendiente } \\
\text { (-Ea/R) }\end{array}$} & \multicolumn{2}{|c|}{ Error estándar } & \multirow{2}{*}{$\mathbf{p}$} & \multirow{2}{*}{$\mathbf{R}^{2}$} & \multirow{2}{*}{ Ea } \\
\hline & & & $\operatorname{Ln} A$ & $-E a / R$ & & & \\
\hline Cefalexina & 19,046 & 8090,43 & 2,90258 & 1022,14 & 0,0042 & 0,9543 & 67,27 \\
\hline Cefalonio & 15,235 & 6812,55 & 1,31614 & 463,48 & 0,0007 & 0,9863 & 56,64 \\
\hline Cefapirina & 14,674 & 6285,83 & 1,89054 & 665,754 & 0,0025 & 0,9674 & 52,26 \\
\hline Cefoperazona & 26,887 & 10685,50 & 5,65634 & 1991,88 & 0,0127 & 0,9056 & 88,84 \\
\hline Cefquinoma & 12,869 & 6049,44 & 4,51156 & 1588,74 & 0,0318 & 0,8286 & 50,30 \\
\hline Cefuroxima & 22,493 & 9167,59 & 2,30389 & 811,313 & 0,0015 & 0,9770 & 76,22 \\
\hline
\end{tabular}

Ea= Energía de activación $(\mathrm{kJ} / \mathrm{mol}) ; \mathrm{R}=$ constante específica de los gases ideales $\left(8,314472 \mathrm{~J} / \mathrm{mol} \cdot{ }^{\circ} \mathrm{K}\right)$; $A=$ frecuencia de choque

El menor valor del coeficiente de regresión que presenta la cefquinoma $\left(R^{2}=\right.$ $0,8286)$ comparado con las otras cefalosporinas, se debe a la menor variabilidad que existe en la degradación de esta molécula entre los tratamientos térmicos de 60, 70 y $80^{\circ} \mathrm{C}$, comparado con la rapidez de la reacción a 90 y $100^{\circ} \mathrm{C}$.

A pesar de presentar un coeficiente de regresión menor, el ajuste del modelo es adecuado para describir la velocidad de degradación de la cefquinoma y el resto de cefalosporinas en función de la temperatura empleada con valores de $p<0,05$ en todos los casos. 
Respecto a las pendientes (-Ea/R) y las frecuencias de choques (Ln A), se observa que la cefoperazona muestra los mayores valores y la cefquinoma los menores, indicando el diferente comportamiento de estabilidad de ambas sustancias a lo largo de los mismos tratamientos térmicos, lo que seguramente está relacionado con las estructuras moleculares de cada una de ellas.

Para analizar los cambios de las constantes específicas de degradación térmica de cada cefalosporina para las diferentes temperaturas ensayadas, en la Figura 66 se han representado las ecuaciones linealizadas del Cuadro 75.

Tal y como se indicó anteriormente, la cefapirina, cefoperazona y cefuroxima son las cefalosporinas que presentan mayor inestabilidad térmica puesto que se degradan más rápido a temperaturas bajas de 60 y $70{ }^{\circ} \mathrm{C}$ (necesitan menos de 100 minutos para reducir al 50\% su concentración inicial) y tienen los logaritmos de las constantes de velocidad más elevados. No obstante también se observa que el comportamiento de estas sustancias es diferente dependiendo de la temperatura, hecho que se aprecia detalladamente en la Figura 66, donde la cefoperazona y la cefuroxima presentan una pendiente más pronunciada que la cefapirina.

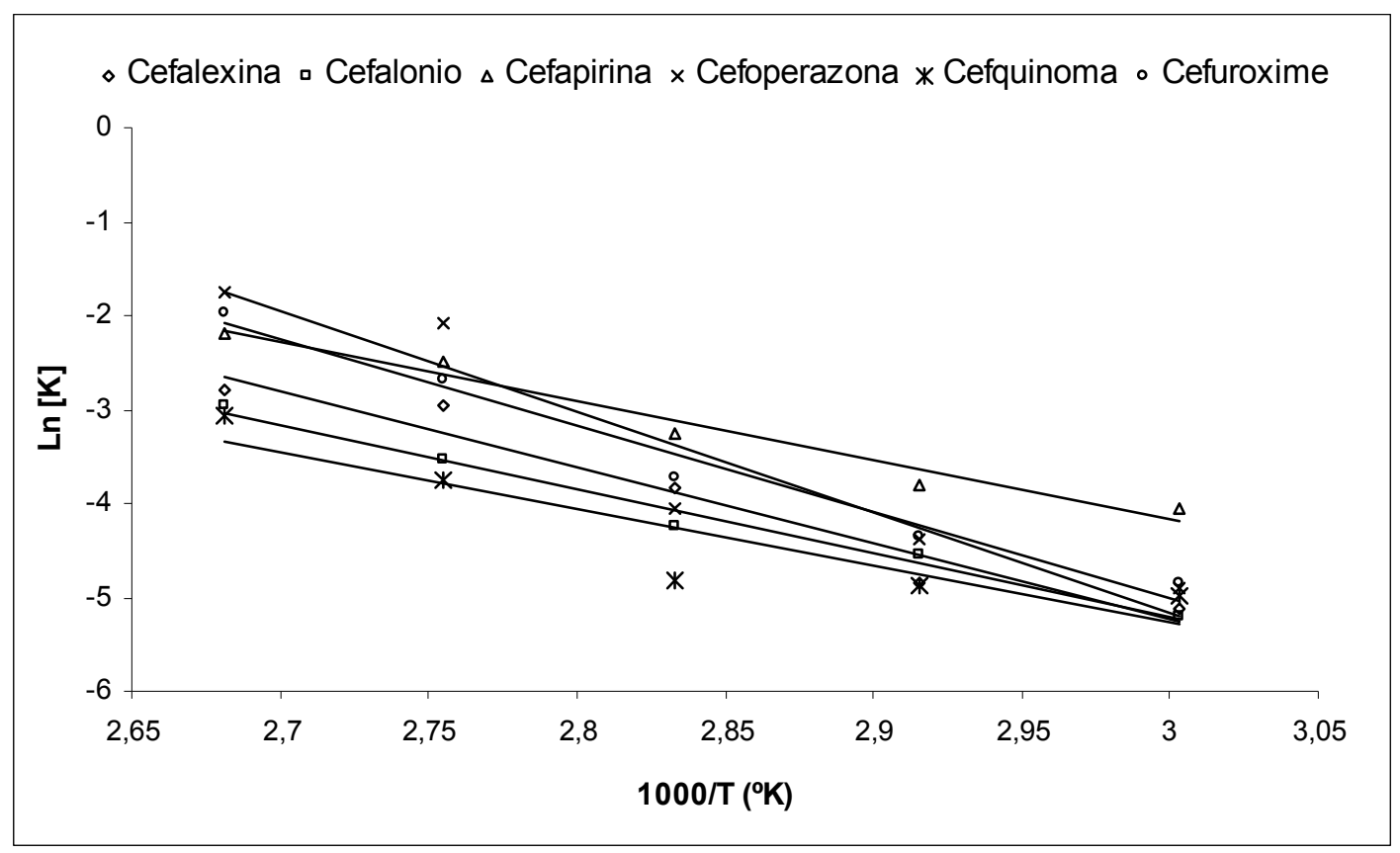

Figura 66. Representación gráfica de la ecuación de Arrhenius para las cefalosporinas

En cuanto a las energías de activación calculadas a partir de las ecuaciones del Cuadro 75, se observa que la cefoperazona es la molécula que muestra mayor valor $(84,88 \mathrm{~kJ} / \mathrm{mol})$ y la que presenta pendientes de degradación más pronunciadas 
en los calentamientos de la leche a 80,90 y $100^{\circ} \mathrm{C}$, lo que indica que es a partir de estas temperaturas donde la cefoperazona alcanza la energía de activación suficiente para activarse y que ocurra la reacción.

Además, la frecuencia de choques calculada para esta molécula es la más elevada $(26,887)$, lo que justifica la aceleración de la reacción de degradación una vez que la temperatura empleada aporta la suficiente energía para que un gran número de moles de cefoperazona entren en estado activado o de transición.

Por otro lado, la cefapirina es de las tres cefalosporinas más inestables, la que presenta menor energía de activación $(52,26 \mathrm{~kJ} / \mathrm{mol})$ y la pendiente más suave, lo que era de esperar ya que como se ha constatado anteriormente, esta sustancia sigue un modelo de degradación progresivo y uniforme con los cambios de temperatura, debido seguramente al bajo valor de la energía de activación que alcanza fácilmente a temperaturas suaves, y a la baja frecuencia de choques que presenta ( $\operatorname{Ln} A=14,674)$.

En cuanto a las cefalosporinas más estables, (cefalexina, cefalonio y cefquinoma), muestran energías de activación no muy elevadas con valores en el rango comprendido entre $50,30 \mathrm{~kJ} / \mathrm{mol}$ (cefquinoma) y $67,27 \mathrm{~kJ} / \mathrm{mol}$ (cefalexina).

Estas energías de activación junto a las frecuencias de choque que presentan estas sustancias $(19,046,15,235$ y 12,869 respectivamente) hacen que se reduzcan las probabilidades de choques eficaces entre moléculas y por lo tanto que las reacciones sean más lentas, sobre todo en el caso de la cefquinoma.

Respecto a los resultados obtenidos por otros autores, se han encontrado algunos estudios que evalúan la estabilidad térmica de las cefalosporinas, calculando los parámetros cinéticos de energía de activación y tiempos de vida media aunque la mayoría se refieren a sustancias diferentes a las empleadas en este estudio, en compuestos o preparados farmacéuticos sólidos y soluciones acuosas. Estos resultados no son por lo tanto comparables a los obtenidos en este estudio, ya que se han realizado sobre diferentes condiciones de temperatura, $\mathrm{pH}$, matrices y métodos analíticos.

Los estudios cinéticos de primer orden aplicados a la degradación térmica de cefalosporinas a diversos valores de $\mathrm{pH}$ realizados por Fabre et al. (1984) señalan valores de energías de activación comprendidos entre $91,03 \mathrm{~kJ} / \mathrm{mol}(\mathrm{pH}=7,0)$ y 12,02 $\mathrm{kJ} / \mathrm{mol}(\mathrm{pH}=10,0)$.

La estabilidad de soluciones acuosas de cefuroxima y el efecto del pH sobre la hidrólisis alcalina fue estudiada por Wang y Notari (1993), observando energías de 
activación dentro de un rango entre 65,21 y $110,42 \mathrm{~kJ} / \mathrm{mol}$, que contiene al valor obtenido en el presente estudio $(74,91 \mathrm{~kJ} / \mathrm{mol})$.

Por otro lado, Zhou y Notari (1995) analizaron los efectos de $\mathrm{pH}$ y temperatura sobre la cinética de degradación de ceftazidime, donde la aplicación del modelo de Arrhenius permitió determinar valores de la energía de activación a diferentes valores de $\mathrm{pH}$, comprendidos entre $62,60 \mathrm{~kJ} / \mathrm{mol}$ (en metóxido de sodio) y $157,93 \mathrm{~kJ} / \mathrm{mol}$ (en ácido acético).

Los estudios cinéticos de primer orden de la hidrólisis de ceftazidime realizados por Fubara y Notari (1997) revelan un comportamiento lineal entre los logaritmos naturales de la concentración de este betalactámico y el tiempo, para diferentes concentraciones iniciales y temperaturas, no llegando a determinar los valores de la energía de activación.

De forma similar Fubara y Notari (1998a) evaluaron el efecto del $\mathrm{pH}$ y la temperatura sobre la estabilidad de soluciones acuosas de cefepime, obteniendo una respuesta lineal al representar el logaritmo natural de la constante específica de reacción de primer orden en función de la inversa de la temperatura absoluta en ácido bórico $(76,35 \mathrm{~kJ} / \mathrm{mol})$, acético $(71,32 \mathrm{~kJ} / \mathrm{mol})$ y fosfórico $(84,73 \mathrm{~kJ} / \mathrm{mol})$.

\subsubsection{Estimación de la degradación de las cefalosporinas para diferentes tratamientos térmicos}

Los porcentajes de degradación térmica de las cefalosporinas para aquellos tratamientos más frecuentes, tanto en la industria láctea, como en los laboratorios lactológicos de control de calidad, se han calculado a partir de las ecuaciones expuestas en el apartado 2.2.2., y los valores obtenidos se resumen en el Cuadro 76.

Cuadro 76. Porcentajes de degradación de las cefalosporinas en la leche para diferentes tratamientos térmicos.

\begin{tabular}{|c|c|c|c|c|c|c|}
\hline \multirow{2}{*}{ Cefalosporinas } & \multicolumn{2}{|c|}{$\begin{array}{l}\text { Tratamientos } \\
\text { laboratorio }\end{array}$} & \multicolumn{2}{|c|}{ Pasteurización } & \multicolumn{2}{|c|}{ Esterilización } \\
\hline & $\begin{array}{l}40^{\circ} \mathrm{C} \\
10 \mathrm{~min}\end{array}$ & $\begin{array}{c}83^{\circ} \mathrm{C} \\
10 \mathrm{~min}\end{array}$ & $\begin{array}{c}63^{\circ} \mathrm{C} \\
30 \mathrm{~min}\end{array}$ & $\begin{array}{l}72^{\circ} \mathrm{C} \\
15 \mathrm{~s}\end{array}$ & $\begin{array}{l}120^{\circ} \mathrm{C} \\
20 \mathrm{~min}\end{array}$ & $\begin{array}{c}140^{\circ} \mathrm{C} \\
4 \mathrm{~s}\end{array}$ \\
\hline Cefalexina & 1,1 & 22,3 & 17,8 & 0,3 & 98,6 & 3,8 \\
\hline Cefalonio & 1,4 & 18,3 & 17,6 & 0,3 & 91,3 & 1,9 \\
\hline Cefapirina & 4,4 & 39,8 & 41,2 & 0,7 & 99,5 & 3,8 \\
\hline Cefoperazona & 0,7 & 35,5 & 19,8 & 0,4 & 100,0 & 16,8 \\
\hline Cefquinoma & 1,6 & 15,0 & 16,2 & 0,2 & 79,9 & 1,1 \\
\hline Cefuroxima & 1,1 & 31,9 & 22,1 & 0,4 & 100,0 & 8,6 \\
\hline
\end{tabular}


Los porcentajes de degradación térmica, indican que el tratamiento de $40^{\circ} \mathrm{C}$ $10 \mathrm{~min}$, no produce pérdidas apreciables en los niveles de cefalosporinas, mientras que el tratamiento utilizado para la desnaturalización de inhibidores naturales $\left(83^{\circ} \mathrm{C}\right.$ $10 \mathrm{~min}$ ) ocasiona pérdidas apreciables en las concentraciones de estos antimicrobianos, comprendidas entre el $15 \%$ (cefquinoma) y $39,8 \%$ (cefapirina). Por ello, en este caso no resultaría aconsejable llevar a cabo este tratamiento antes de aplicar los métodos de cribado o screening para la detección de inhibidores, ya que podría llegar a ser la causa de resultados "falsos negativos".

Respecto a la pasteurización, se observa que aquella de tiempo corto $\left(72{ }^{\circ} \mathrm{C}\right.$ 15 s) no produce apenas disminución apreciable en los niveles de cefalosporinas. Por el contrario, la pasteurización baja $\left(63^{\circ} \mathrm{C}-30 \mathrm{~min}\right)$ sí es causa de pérdidas importantes de estos antimicrobianos, alcanzando un $42,1 \%$ en el caso de la cefapirina. Otros autores, Jacquet y Auxpaules (1978), obtuvieron para este mismo tratamiento una leve degradación del $6,3 \%$ en el caso de la cefalexina, valor inferior al $17,8 \%$ estimado en este trabajo. Estas diferencias pueden explicarse debido a las distintas metodologías analíticas empleadas en ambos estudios.

En cuanto a la esterilización, se observa que el tratamiento a $120^{\circ} \mathrm{C}-20 \mathrm{~min}$ influye de forma notable en la degradación de las cefalosporinas obteniéndose porcentajes de degradación muy elevados, con valores superiores en todos los casos al $90 \%$ salvo para la cefquinoma $(79,9 \%)$, y llegando a degradaciones del $100 \%$ para la cefoperazona y cefuroxima.

Por otro lado, la esterilización UHT produce degradaciones menos importantes siendo los valores más elevados los presentados en el caso de la cefoperazona $(16,8 \%)$ y la cefuroxima $(8,6 \%)$.

Cuando se comparan los resultados de este trabajo con los presentados por Zorraquino (2005) para el tratamiento de $40{ }^{\circ} \mathrm{C}-10 \mathrm{~min}$, se constata que en ambos estudios las pérdidas son muy pequeñas, inferiores al $5 \%$ en los dos casos.

En lo que se refiere al tratamiento de laboratorio de $83{ }^{\circ} \mathrm{C}-10 \mathrm{~min}$, las degradaciones estimadas mediante el modelo de primer orden expuesto en el Cuadro 76 (22,3\%: cefalexina, 15\%: cefquinoma y $31,9 \%$ : cefuroxima) resultan levemente inferiores a los porcentajes determinados por Zorraquino (1997) cuando evalúa la termoestabilidad de residuos de cefalosporinas en soluciones acuosas tamponadas mediante técnicas HPLC, al detectar disminuciones del $27-29 \%$ en la cefalexina, $16-$ $18 \%$ en la cefquinoma y $38-40 \%$ en la cefuroxima. Este hecho podría atribuirse al posible efecto protector de la materia grasa en las muestras de leche fortificadas con 
cefalosporinas, y a la diferencia de temperatura empleada en este tratamiento, ocasionando degradaciones inferiores a las observadas en soluciones acuosas tamponadas.

Este mismo autor en un estudio realizado mediante métodos microbiológicos (Zorraquino, 2005) determina porcentajes de inactivación térmica levemente superiores a los estimados en el Cuadro 76, alcanzando en el citado estudio, el $27 \%$ para la cefalexina y el $35 \%$ para la cefuroxima durante el calentamiento a $83{ }^{\circ} \mathrm{C}-10$ min. Estos resultados, aunque ligeramente superiores, coinciden con los expuestos en este trabajo. Al igual que para los tratamientos industriales de $60^{\circ} \mathrm{C}-30$ min y 140 ${ }^{\circ} \mathrm{C}-4 \mathrm{~s}$ realizados por este mismo autor con pérdidas de actividad moderadas entre el $6-21 \%$ y $0-21 \%$ ligeramente inferiores a las pérdidas de concentración del $14-36,2 \%$ y 2,8-36,8\% que se obtienen a partir de los resultados de este estudio para esos mismos tratamientos.

Por otro lado, las elevadas degradaciones obtenidas en el calentamiento a $120^{\circ} \mathrm{C}-20$ min son similares a las inactivaciones térmicas determinadas también por dicho autor, al resultar superiores al 89\% para todas las cefalosporinas estudiadas.

\subsection{TETRACICLINAS}

\subsubsection{Estudio de la degradación térmica de las tetraciclinas mediante modelos de primer orden}

En el estudio de la termoestabilidad de las tetraciclinas a diferentes temperaturas se procedió de la misma manera que para los antibióticos betalactámicos (penicilinas y cefalosporinas), aplicando el modelo cinético de primer orden a la degradación de las tetraciclinas en la leche en función del tiempo de calentamiento. Los parámetros de las ecuaciones de regresión resultantes de la aplicación de este modelo se resumen en los Cuadros 77 a 80.

Cuadro 77. Parámetros resultantes de la aplicación del modelo cinético de primer orden a la degradación de la clortetraciclina en la leche a diferentes temperaturas

\begin{tabular}{|c|c|c|c|c|c|c|}
\hline \multirow{2}{*}{$\mathrm{T}^{\mathrm{a}}\left({ }^{\circ} \mathrm{C}\right)$} & \multirow{2}{*}{$\begin{array}{l}\text { Ordenada } \\
\text { (a) }\end{array}$} & \multirow{2}{*}{$\begin{array}{c}\text { Pendiente } \\
\left(\mathbf{k}_{\mathbf{1}}\right)\end{array}$} & \multicolumn{2}{|c|}{ Error estándar } & \multirow{2}{*}{$\mathbf{p}$} & \multirow{2}{*}{$\mathbf{R}^{2}$} \\
\hline & & & a & $k_{1}$ & & \\
\hline 60 & 8,521 & $-0,002564$ & 0,02496 & 0,00011 & 0,0001 & 0,9900 \\
\hline 70 & 8,574 & $-0,003506$ & 0,07149 & 0,07149 & 0,0001 & 0,9575 \\
\hline 80 & 8,519 & $-0,005171$ & 0,07881 & 0,00036 & 0,0001 & 0,9758 \\
\hline 90 & 8,602 & $-0,020709$ & 0,14878 & 0,00206 & 0,0002 & 0,9527 \\
\hline 100 & 8,282 & $-0,045778$ & 0,18137 & 0,00339 & 0,0001 & 0,9732 \\
\hline
\end{tabular}


Cuadro 78. Parámetros resultantes de la aplicación del modelo cinético de primer orden a la degradación de la doxiciclina en la leche a diferentes temperaturas

\begin{tabular}{|c|c|c|c|c|c|c|}
\hline \multirow{2}{*}{$\mathrm{T}^{\mathrm{a}}\left({ }^{\circ} \mathrm{C}\right)$} & \multirow{2}{*}{$\begin{array}{l}\text { Ordenada } \\
\text { (a) }\end{array}$} & \multirow{2}{*}{$\begin{array}{c}\text { Pendiente } \\
\left(\mathbf{k}_{1}\right)\end{array}$} & \multicolumn{2}{|c|}{ Error estándar } & \multirow{2}{*}{$\mathbf{p}$} & \multirow{2}{*}{$\mathbf{R}^{2}$} \\
\hline & & & a & $k_{1}$ & & \\
\hline 60 & 8,527 & $-0,000539$ & 0,00437 & 0,00002 & 0,0001 & 0,9930 \\
\hline 70 & 8,516 & $-0,000627$ & 0,01098 & 0,00005 & 0,0001 & 0,9682 \\
\hline 80 & 8,535 & $-0,001063$ & 0,02046 & 0,00009 & 0,0001 & 0,9619 \\
\hline 90 & 8,564 & $-0,002502$ & 0,02558 & 0,00035 & 0,0009 & 0,9087 \\
\hline 100 & 8,560 & $-0,011352$ & 0,04324 & 0,00081 & 0,0001 & 0,9752 \\
\hline
\end{tabular}

Cuadro 79. Parámetros resultantes de la aplicación del modelo cinético de primer orden a la degradación de la oxitetraciclina en la leche a diferentes temperaturas

\begin{tabular}{|c|c|c|c|c|c|c|}
\hline \multirow{2}{*}{$\mathrm{T}^{\mathrm{a}}\left({ }^{\circ} \mathrm{C}\right)$} & \multirow{2}{*}{$\begin{array}{c}\text { Ordenada } \\
\text { (a) }\end{array}$} & \multirow{2}{*}{$\begin{array}{c}\text { Pendiente } \\
\left(\mathbf{k}_{1}\right)\end{array}$} & \multicolumn{2}{|c|}{ Error estándar } & \multirow{2}{*}{ p } & \multirow{2}{*}{$\mathbf{R}^{2}$} \\
\hline & & & $\mathbf{a}$ & $k_{1}$ & & \\
\hline 60 & 8,535 & $-0,001211$ & 0,02413 & 0,00011 & 0,0001 & 0,9593 \\
\hline 70 & 8,506 & $-0,001416$ & 0,01616 & 0,00007 & 0,0001 & 0,9863 \\
\hline 80 & 8,519 & $-0,002025$ & 0,04147 & 0,00019 & 0,0001 & 0,9571 \\
\hline 90 & 8,453 & $-0,006037$ & 0,04498 & 0,00062 & 0,0002 & 0,9493 \\
\hline 100 & 8,489 & $-0,013961$ & 0,06339 & 0,00119 & 0,0001 & 0,9651 \\
\hline
\end{tabular}

Cuadro 80. Parámetros resultantes de la aplicación del modelo cinético de primer orden a la degradación de la tetraciclina en la leche a diferentes temperaturas

\begin{tabular}{|c|c|c|c|c|c|c|}
\hline \multirow{2}{*}{$\mathrm{T}^{\mathrm{a}}\left({ }^{\circ} \mathrm{C}\right)$} & \multirow{2}{*}{$\begin{array}{c}\text { Ordenada } \\
\text { (a) }\end{array}$} & \multirow{2}{*}{$\begin{array}{c}\text { Pendiente } \\
\left(\mathbf{k}_{1}\right)\end{array}$} & \multicolumn{2}{|c|}{ Error estándar } & \multirow{2}{*}{$\mathbf{p}$} & \multirow{2}{*}{$\mathbf{R}^{2}$} \\
\hline & & & a & $k_{1}$ & & \\
\hline 60 & 8,543 & $-0,000690$ & 0,01834 & 0,00008 & 0,0006 & 0,9234 \\
\hline 70 & 8,541 & $-0,000741$ & 0,01397 & 0,00006 & 0,0001 & 0,9634 \\
\hline 80 & 8,525 & $-0,001006$ & 0,00522 & 0,00002 & 0,0001 & 0,9971 \\
\hline 90 & 8,519 & $-0,007242$ & 0,02863 & 0,00039 & 0,0001 & 0,9852 \\
\hline 100 & 8,594 & $-0,015229$ & 0,03927 & 0,00073 & 0,0001 & 0,9885 \\
\hline
\end{tabular}

A partir de estos Cuadros se observa que los ajustes alcanzados mediante la aplicación del modelo cinético de regresión lineal resultan adecuados en todos los casos con coeficientes de regresión comprendidos entre $R^{2}=0,9087$ y $R^{2}=0,9971$ obtenidos en el estudio de la doxiciclina y la tetraciclina en el calentamiento de $90{ }^{\circ} \mathrm{C}$ y a $60^{\circ} \mathrm{C}$ respectivamente. También se aprecia que los valores estadísticos muestran una relación significativa entre los logaritmos de las concentraciones y el tiempo de 
tratamiento con valores de $p<0,001$ para todas las tetraciclinas y temperaturas empleadas.

Por otra parte, como era de esperar, las constantes de velocidad de reacción de las tetraciclinas aumentan conforme se incrementa la temperatura ensayada, y como ya se ha indicado en el estudio de los antibióticos betalactámicos, este aumento se realiza de forma diferente según la sustancia empleada.

La clortetraciclina por ejemplo, presenta las constantes de velocidad de reacción " $k_{1}$ " más elevadas comparado con el resto de tetraciclinas, revelando la mayor inestabilidad térmica de esta sustancia frente a las temperaturas. También se aprecia que en casi todas las tetraciclinas, a partir del tratamiento de $90{ }^{\circ} \mathrm{C}$, los valores de estas constantes aumentan bruscamente, lo que indica que es en torno a esta temperatura cuando la reacción de descomposición de las tetraciclinas se acelera, lo que es debido seguramente al elevado aporte energético que supone este calentamiento.

Si se comparan los valores de las constantes de velocidad de reacción con las calculadas para las antibióticos betalactámicos se aprecia que los valores de las tetraciclinas son mucho menores que los de las penicilinas y cefalosporinas lo que indica que estos antibióticos son más estables en la leche y se degradan más lentamente con el calor.

En las Figuras $67,68,69$ y 70 se representan gráficamente las ecuaciones de regresión correspondientes a cada una de las tetraciclinas presentadas en los Cuadros anteriores.

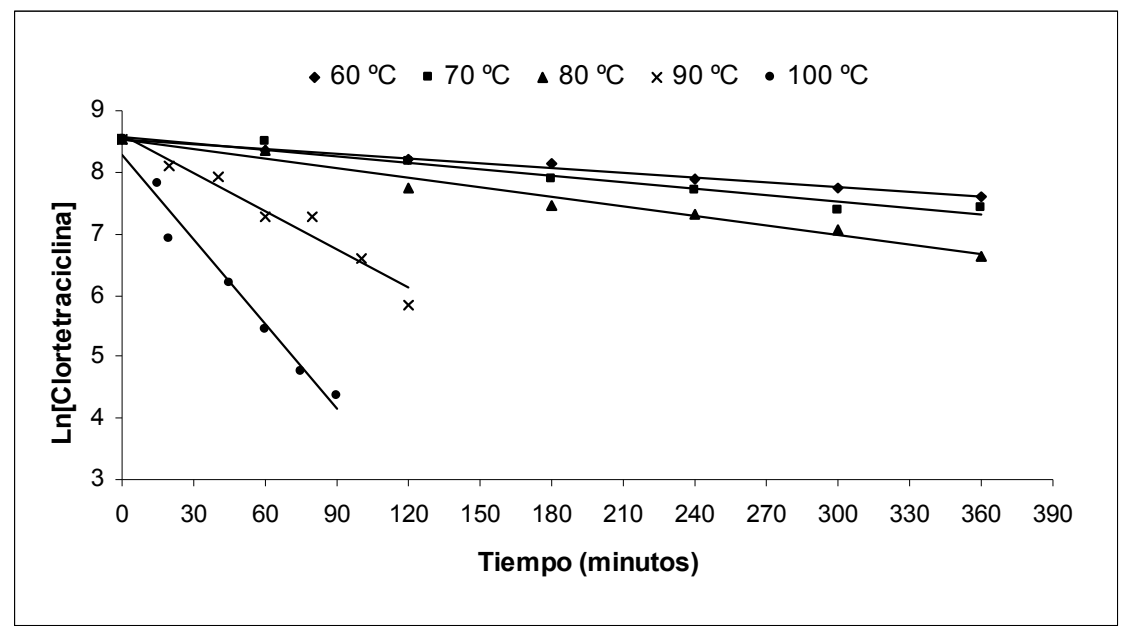

Figura 67. Relación entre la concentración de clortetraciclina en la leche y el tiempo de calentamiento a diferentes temperaturas 


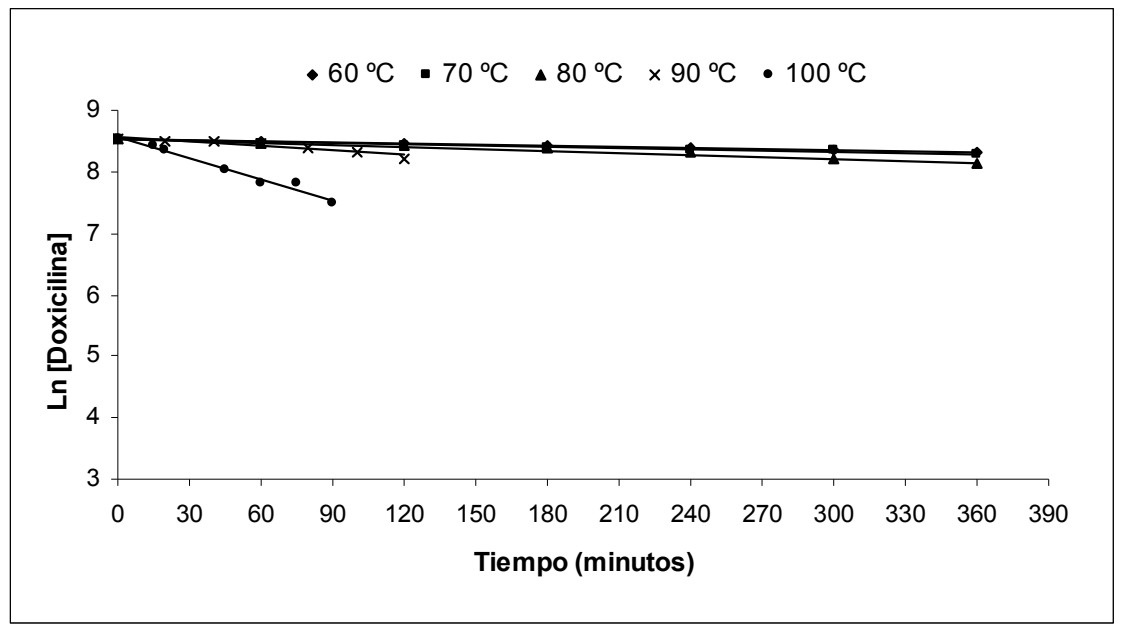

Figura 68. Relación entre la concentración de doxiciclina en la leche y el tiempo de calentamiento a diferentes temperaturas

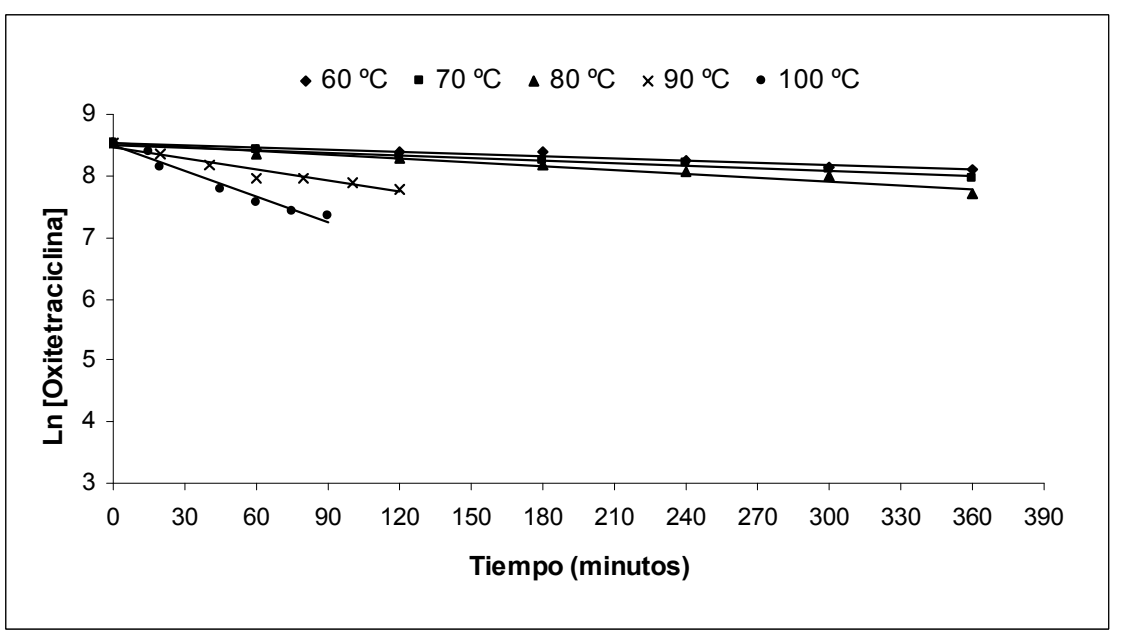

Figura 69. Relación entre la concentración de oxitetraciclina en la leche y el tiempo de calentamiento a diferentes temperaturas

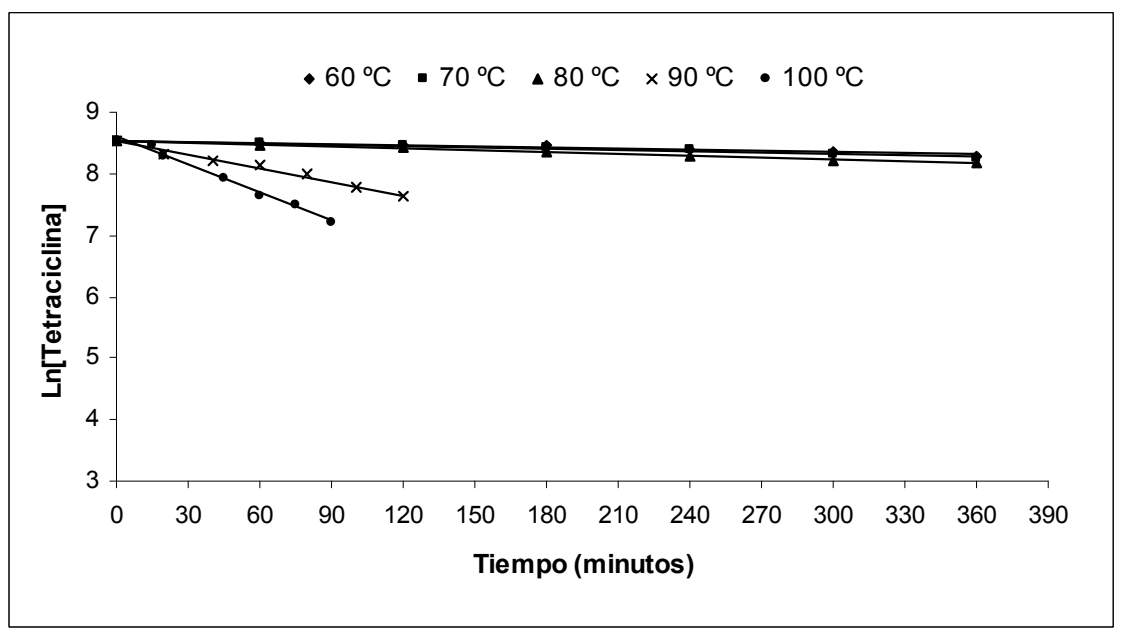

Figura 70. Relación entre la concentración de tetraciclina en la leche y el tiempo de calentamiento a diferentes temperaturas 
A partir de las Figuras anteriores se aprecia claramente como la clortetraciclina es la sustancia con mayor carácter termolábil, mostrando las pendientes de degradación más acusadas en todos los tratamientos, aunque es importante resaltar que el incremento de pendientes se realiza de forma progresiva a medida que aumenta la temperatura. La doxiciclina, por el contrario, muestra unas pendientes de degradación muy suaves, con apenas diferencias entre los tratamientos térmicos de $60,70,80$ y $90{ }^{\circ} \mathrm{C}$, acelerando la degradación en el calentamiento de $100^{\circ} \mathrm{C}$.

A efectos prácticos y para poder comparar los resultados de este estudio con otros autores y resultados anteriores, a partir de las ecuaciones de regresión lineal descritas anteriormente se han calculado los valores de tiempo de vida media $\left(t_{1 / 2}\right)$ para cada tetraciclina y temperatura ensayada cuyos valores se muestran en el Cuadro 81.

Cuadro 81. Tiempos de vida media $\left(t_{1 / 2}\right)$ estimados para las tetraciclinas en la leche a diferentes temperaturas de calentamiento

\begin{tabular}{|lccccc|}
\hline \multirow{2}{*}{ Tetraciclinas } & \multicolumn{5}{c|}{$\mathbf{t}_{\mathbf{1 / 2}}$ (minutos)= Ln2/k } \\
\cline { 2 - 6 } & $\mathbf{6 0} \mathbf{~}^{\circ} \mathbf{C}$ & $\mathbf{7 0}^{\circ} \mathbf{C}$ & $\mathbf{8 0}^{\circ} \mathbf{C}$ & $\mathbf{9 0}^{\circ} \mathbf{C}$ & $\mathbf{1 0 0}^{\circ} \mathbf{C}$ \\
\hline Clortetraciclina & 270 & 198 & 134 & 33 & 15 \\
Doxiciclina & 1285 & 1106 & 652 & 277 & 61 \\
Oxitetraciclina & 573 & 490 & 342 & 115 & 50 \\
Tetraciclina & 1053 & 936 & 689 & 96 & 46 \\
\hline
\end{tabular}

Tal y como se ha comentado anteriormente, la clortetraciclina se degrada con mayor rapidez y presenta los tiempos de vida media más cortos. Se trata por lo tanto de una molécula poco estable al calentamiento si se compara con las otras tetraciclinas estudiadas, pero medianamente estable al comparar con los antibióticos betalactámicos estudiados en apartados anteriores.

Por otro lado, la doxiciclina y la tetraciclina presentan gran estabilidad a la temperatura de $60^{\circ} \mathrm{C}$ con unos tiempos de vida media muy largos (1285 y 1053 minutos respectivamente) que se mantienen elevados hasta el calentamiento de 80 ${ }^{\circ} \mathrm{C}$ en el caso de la tetraciclina y $90^{\circ} \mathrm{C}$ en el de la doxiciclina.

La oxitetraciclina, por su parte muestra una estabilidad más moderada y progresiva con el aumento de temperaturas, con tiempos de vida media elevados aunque inferiores a los presentados en el caso de la doxiciclina y la tetraciclina. 
Esta diferencia en el comportamiento de estabilidad de estas sustancias antimicrobianas puede explicarse por los parámetros cinéticos (Ea y LnA) que presentan cada una de ellas en los tratamientos de calor utilizados en el presente trabajo cuyo cálculo se expone en el apartado siguiente.

En cuanto al estudio de la estabilidad térmica de las tetraciclinas mediante modelos cinéticos de primer orden se han encontrado muy pocos trabajos, realizados además en matrices diferentes de la leche. Así, Sah (2000) empleó este modelo cinético para estudiar la degradación de tetraciclinas en micelas y agua.

También Gratacós et al. (2007) estudiaron la degradación de tetraciclinas y la formación de sus productos derivados en carne de pollo y cerdo en distintas condiciones de cocinado mediante el modelo cinético de primer orden.

Más recientemente, Wang y Yates (2008), emplearon el modelo cinético de primer orden para realizar un estudio sobre la degradación de la oxitetraciclina en estiércol y suelo, al igual que Hassani et al. (2008) en un estudio sobre la termoestabilidad de la doxiciclina, oxitetraciclina y tetracilina en solución acuosa sometidas a temperaturas de entre 110 y $140^{\circ} \mathrm{C}$.

\subsubsection{Cálculo de la energía de activación}

Al aplicar la ecuación de Arrhenius para el cálculo de las expresiones matemáticas que vinculan las transformaciones logarítmicas de las constantes específicas de degradación con las inversas de las temperaturas absolutas se obtienen los parámetros que se presentan en el Cuadro 82.

Cuadro 82. Ecuación de Arrhenius aplicada a la degradación térmica de las tetraciclinas en la leche

\begin{tabular}{|c|c|c|c|c|c|c|c|}
\hline \multirow{2}{*}{ Tetraciclinas } & \multirow{2}{*}{$\begin{array}{l}\text { Ordenada } \\
\text { (Ln A) }\end{array}$} & \multirow{2}{*}{$\begin{array}{c}\text { Pendiente } \\
\text { (-Ea/R) }\end{array}$} & \multicolumn{2}{|c|}{ Error estándar } & \multirow{2}{*}{ p } & \multirow{2}{*}{$\mathbf{R}^{2}$} & \multirow{2}{*}{ Ea } \\
\hline & & & $\operatorname{Ln} A$ & $-E a / R$ & & & \\
\hline Clortetraciclina & 21,523 & 9266,82 & 4,53544 & 1597,15 & 0,0102 & 0,9182 & 77,05 \\
\hline Doxiciclina & 19,588 & 9174,21 & 5,79498 & 2040,70 & 0,0205 & 0,8707 & 76,28 \\
\hline Oxitetraciclina & 16,348 & 7795,79 & 4,31152 & 1518,30 & 0,0143 & 0,8978 & 64,82 \\
\hline Tetraciclina & 23,754 & 10524,9 & 7,15592 & 2519,95 & 0,0250 & 0,8533 & 87,51 \\
\hline
\end{tabular}

Ea= Energía de activación $(\mathrm{kJ} / \mathrm{mol}) ; \mathrm{R}=$ constante específica de los gases ideales $\left(8,314472 \mathrm{~J} / \mathrm{mol} \cdot{ }^{\circ} \mathrm{K}\right) ; \mathrm{A}=$ frecuencia de choque

A partir de los parámetros de las ecuaciones de regresión expresados en el Cuadro 82, se observa que la bondad del ajuste alcanzado no es tan elevada como en el caso de los antibióticos betalactámicos puesto que los coeficientes de regresión calculados para las tetraciclinas son inferiores con valores entre $R^{2}=0,8533$ 
(tetraciclina) y $\mathrm{R}^{2}=0,9182$ (clortetraciclina). Este hecho se debe a la baja variabilidad que presentan algunas tetraciclinas entre los calentamientos realizados a 60,70 y 80 ${ }^{\circ} \mathrm{C}$.

No obstante, a pesar de mostrar coeficientes de regresión menores, éstos son elevados, y en todos los casos significativos $(p<0,05)$ lo que indica que son adecuados para justificar la relación lineal entre los parámetros estudiados.

Respecto a las pendientes obtenidas para cada una de las tetraciclinas todas muestran coeficientes elevados, siendo el mayor valor el que corresponde a la tetraciclina $(-E a / R=10524,9)$ y el menor a la oxitetraciclina $(-E a / R=7795,79)$. Para analizar claramente las diferencias encontradas entre estas pendientes se ha elaborado la Figura 71 donde se representan gráficamente las ecuaciones de Arrhenius (Cuadro 82).

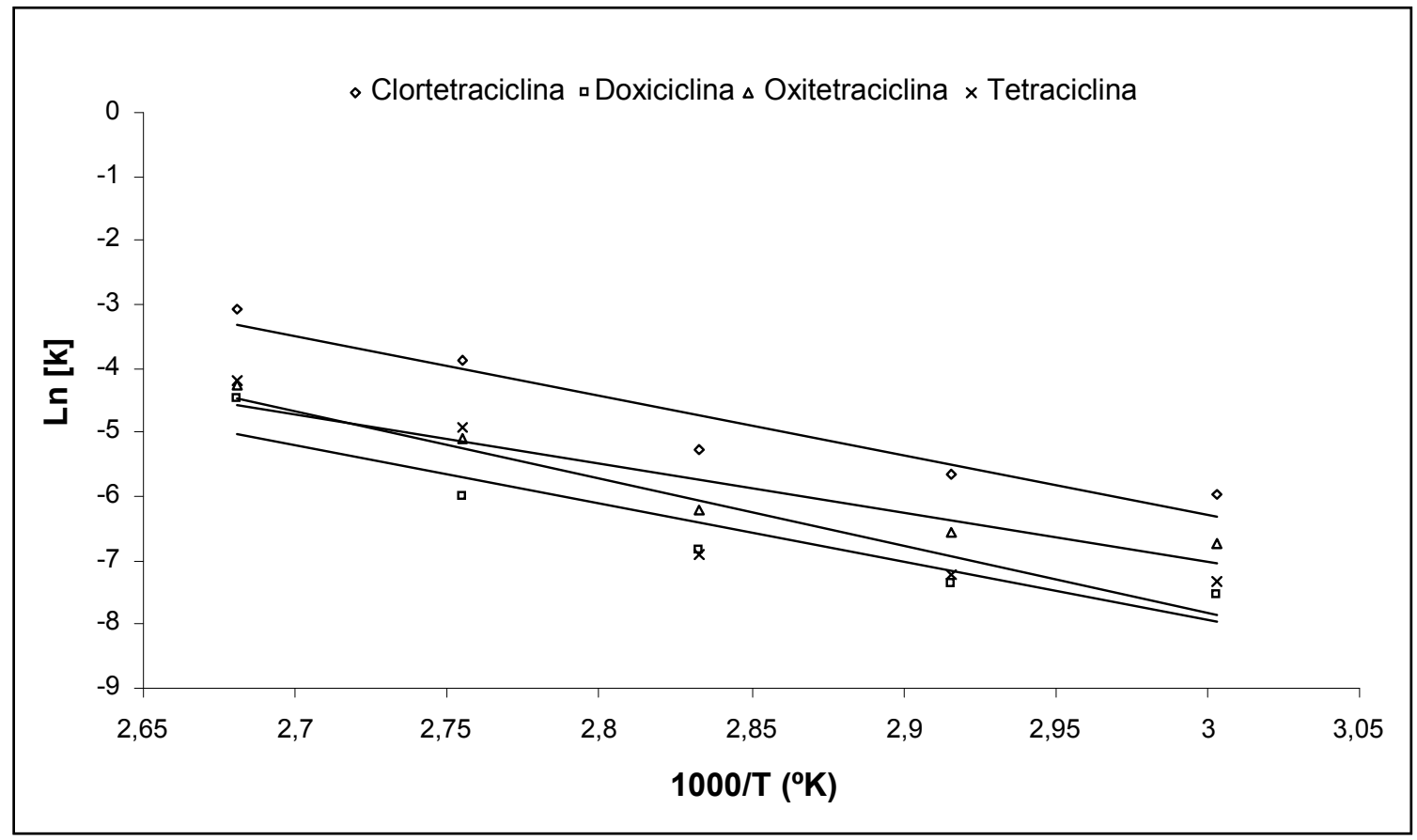

Figura 71. Representación gráfica de la ecuación de Arrhenius para las tetraciclinas

Como se observa en esta Figura, la oxitetraciclina presenta una pendiente menos pronunciada que el resto de tetraciclinas, que presentan entre ellas unas pendientes bastante similares pero con diferentes valores de "Ln k". Este hecho indica que esta sustancia se deteriora más lentamente y de forma progresiva con el incremento de la temperatura, mientras que las otras tetracilinas muestran un comportamiento menos gradual, sobre todo en el caso de la tetraciclina. 
En cuanto a las energías de activación y las frecuencias de choque estimadas para cada una de las tetraciclinas (Cuadro 81), es importante resaltar el caso de la clortetraciclina y la oxitetraciclina.

Como se indicó anteriormente, estas sustancias son las que presentan mayores degradaciones en casi todas las temperaturas ensayadas, en mayor medida en el caso de la clortetraciclina que en la oxitetraciclina. Si relacionamos este comportamiento con las energías de activación y las frecuencias de choque de estas dos sustancias se observa que la clortetraciclina muestra valores mayores en ambos casos $(E a=77,05 \mathrm{~kJ} / \mathrm{mol}$ y $\operatorname{Ln} A=21,523)$ lo que significa que necesita un mayor aporte de energía pero con una probabilidad de choques eficaces muy elevada que hace que la reacción sea rápida.

La oxitetraciclina por su parte, necesita una energía de activación menor (Ea $=64,82 \mathrm{~kJ} / \mathrm{mol}$ ) por lo que debería ser más inestable que la clortetraciclina, pero como la frecuencia de choques es mucho menor ( $\operatorname{Ln} A=16,348)$, se produce menos reacción y por lo tanto la descomposición es más lenta que en el caso de la clortetraciclina.

De la misma manera se explica el comportamiento de termoestabilidad obtenido en el estudio de la doxiciclina y la tetraciclina. En el caso de la doxiciclina a pesar de presentar una energía de activación similar a la de la clortetraciclina $(76,28$ $\mathrm{kJ} / \mathrm{mol}$ ), la frecuencia de choques es menor, por lo que la reacción es más lenta.

Por el contrario en el caso de la tetraciclina, la degradación más lenta sucede porque la energía de activación que presenta es la más elevada $(87,51 \mathrm{~kJ} / \mathrm{mol})$ y necesita mayores temperaturas para poder alcanzarla. Sin embargo, una vez superada esta energía, la probabilidad de choques válidos que den lugar a la descomposición de la sustancia es mayor (valor de "Ln A" muy elevado), lo que explica los tiempos de vida media tan cortos que presenta esta sustancia en el tratamiento de $100{ }^{\circ} \mathrm{C}$ (Cuadro 81).

\subsubsection{Estimación de la degradación de las tetraciclinas para diferentes tratamientos térmicos}

Con el propósito de evaluar la influencia de los tratamientos térmicos realizados normalmente en los laboratorios de control de calidad y en las industrias lácteas sobre la estabilidad de las tetraciclinas presentes en la leche, se han estimado los porcentajes de degradación térmica que pueden presentar estas sustancias en estos tratamientos, utilizando las ecuaciones del Cuadro 82 y los 
modelos cinéticos de primer orden expuestos en el apartado 2.3.1. Estos porcentajes de degradación se resumen en el Cuadro 83.

Cuadro 83. Porcentajes de degradación de las tetraciclinas en la leche para diferentes tratamientos térmicos.

\begin{tabular}{|c|c|c|c|c|c|c|}
\hline \multirow{2}{*}{ Tetraciclinas } & \multicolumn{2}{|c|}{$\begin{array}{c}\text { Tratamientos } \\
\text { laboratorio }\end{array}$} & \multicolumn{2}{|c|}{ Pasteurización } & \multicolumn{2}{|c|}{ Esterilización } \\
\hline & $\begin{array}{l}40^{\circ} \mathrm{C} \\
10 \mathrm{~min}\end{array}$ & $\begin{array}{l}83^{\circ} \mathrm{C} \\
10 \mathrm{~min}\end{array}$ & $\begin{array}{l}63^{\circ} \mathrm{C} \\
30 \mathrm{~min}\end{array}$ & $\begin{array}{c}72^{\circ} \mathrm{C} \\
15 \mathrm{~s} \\
\end{array}$ & $\begin{array}{l}120^{\circ} \mathrm{C} \\
20 \mathrm{~min}\end{array}$ & $\begin{array}{c}140^{\circ} \mathrm{C} \\
4 \mathrm{~s} \\
\end{array}$ \\
\hline Clortetraciclina & 0,3 & 10,5 & 6,8 & 0,1 & 92,3 & 2,6 \\
\hline Doxiciclina & 0,1 & 2,0 & 1,3 & 0,0 & 37,4 & 0,5 \\
\hline Oxitetraciclina & 0,2 & 3,8 & 3,1 & 0,0 & 45,7 & 0,5 \\
\hline Tetraciclina & 0,1 & 3,0 & 1,5 & 0,0 & 62,1 & 1,2 \\
\hline
\end{tabular}

Respecto a los resultados de dicho Cuadro hay que comentar que los tratamientos térmicos del laboratorio no dan lugar a degradaciones apreciables, con porcentajes inferiores al $5 \%$ en todos los casos, excepto para la clortetraciclina que presenta una degradación ligeramente superior (10,5\%).

Lo mismo sucede en los tratamientos de pasterización y esterilización UHT realizados en las industrias lácteas, ya que la mayor descomposición se da en el caso de la clortetraciclina con un porcentaje del $5,3 \%$ en el tratamiento de $83^{\circ} \mathrm{C}-30$ $\min$.

Solamente la esterilización convencional $\left(120{ }^{\circ} \mathrm{C}-20 \mathrm{~min}\right)$, produce una degradación apreciable de los antimicrobianos estudiados presentando porcentajes del $37,4 \%$ (doxiciclina), $45,7 \%$ (oxitetraciclina), $62,1 \%$ (tetraciclina) y $92,3 \%$ (clortetraciclina).

Con respecto a los estudios realizados por otros autores, Shahani et al., (1956 y 1958) al calentar muestras de leche fortificadas con tetraciclinas a $62^{\circ} \mathrm{C}$ durante 30 minutos, obtienen disminuciones de la actividad antimicrobiana mayores con valores del $16 \%$ para el caso de la clortetraciclina y del $23,6 \%$ para la oxitetraciclina, frente al $6,3 \%$ y $2,9 \%$ que se obtendrían en este trabajo para ese mismo tratamiento.

Por el contrario, Jacquet y Auxepaules (1978) después de someter muestras de leche fortificadas con clortetraciclina y tetraciclina a una pasteurización baja (63 ${ }^{\circ} \mathrm{C}$-30 min) obtienen porcentajes de inactivación similares a los señalados en el Cuadro 83.

Otros autores también señalan elevados porcentajes de inactivación de tetraciclinas presentes en muestras de leche al ser tratadas con diferentes 
temperaturas. Así, Pilet et al. (1969) al calentar muestras de leche a $100{ }^{\circ} \mathrm{C}-30 \mathrm{~min}$ observan porcentajes de inactivación comprendidos entre el 75 y 100\% para residuos de oxitetraciclina y tetraciclina. Estas inactivaciones son muy superiores a las estimadas a partir de las ecuaciones de este trabajo (Cuadro 82) con pérdidas de concentración del 27,1 y $29,3 \%$ para la oxitetraciclia y tetraciclina respectivamente.

También Sanz et al. (2002) concluyen que más de un 90\% de la oxitetraciclina se inactiva tras someter muestras de leche a la esterilización convencional $\left(120^{\circ} \mathrm{C}\right.$ $20 \mathrm{~min})$.

Como ya se ha comentado en el estudio de otros grupos, las diferencias encontradas entre los resultados de los autores citados anteriormente y los de este trabajo pueden deberse principalmente a las diferentes técnicas analíticas empleadas en cada caso. Las técnicas cromatográficas permiten cuantificar de forma precisa las pérdidas de concentración de las sustancias con los tiempos de calentamiento, mientras que los métodos microbiológicos son técnicas cualitativas y en algunos casos semicuantiativas cuyos resultados se traducen en pérdidas de actividad antimicrobiana, por lo que las diferencias entre las distintas metodologías son esperables.

Por otro lado, al comparar lo resultados del presente trabajo con los obtenidos por Zorraquino (2005) mediante el empleo de un bioensayo microbiológico multiplaca, se observa, al igual que en el caso de los betalactámicos, que para las tetraciclinas empleadas los valores de los porcentajes de degradación estimados en este estudio resultaron inferiores a los calculados por dicho autor.

En cuanto a la esterilización de $120{ }^{\circ} \mathrm{C}-20 \mathrm{~min}$, el citado autor obtiene porcentajes de inactivación superiores en todos los casos al $84 \%$, valor cercano al $94 \%$ estimado en este trabajo para la clortetraciclina (Cuadro 83 ) pero superiores a los obtenidos en el caso de la doxiciclina $(37,4 \%)$, oxitetraciclina $(45,7 \%)$ y tetraciclina $(62,1 \%)$. Este hecho se puede atribuir como ya se ha comentado al empleo de un método microbiológico basado en la inhibición del crecimiento del Bacillus cereus y al cálculo de las pérdidas de actividad antimicrobiana.

En otro trabajo realizado recientemente, Himanish et al. (2008) cuantifican por HPLC-UV pérdidas en muestras de leche fortificadas con oxitetraciclina y calentadas a $97 \pm 0,5^{\circ} \mathrm{C}$ durante 10 minutos del $54,38 \%$ y del $57,66 \%$ cuando el calentamiento se realiza en baño de agua y microondas respectivamente, valores muy superiores al $8,5 \%$ estimado por el modelo obtenido en este estudio para esas mismas condiciones. 


\subsection{SULFONAMIDAS}

\subsubsection{Estudio de la degradación térmica de las sulfonamidas mediante modelos de primer orden}

Al igual que en los otros grupos de antimicrobianos se ha aplicado el modelo cinético de primer orden a la degradación térmica de las sulfonamidas en la leche y los parámetros obtenidos se resumen en los Cuadros 84 a 91 para cada una de las moléculas estudiadas respectivamente.

Cuadro 84. Ecuaciones resultantes de la aplicación del modelo cinético de primer orden a la degradación térmica de la sulfacloropiridazina con el tiempo

\begin{tabular}{|c|c|c|c|c|c|c|}
\hline \multirow{2}{*}{$\mathrm{T}^{\mathrm{a}}\left({ }^{\circ} \mathrm{C}\right)$} & \multirow{2}{*}{$\begin{array}{l}\text { Ordenada } \\
\text { (a) }\end{array}$} & \multirow{2}{*}{$\begin{array}{c}\text { Pendiente } \\
\left(\mathbf{k}_{1}\right)\end{array}$} & \multicolumn{2}{|c|}{ Error estándar } & \multirow[b]{2}{*}{ p } & \multirow{2}{*}{$\mathbf{R}^{2}$} \\
\hline & & & a & $k_{1}$ & & \\
\hline 60 & 5,1515 & $-0,00119$ & 0,0627 & 0,00058 & 0,0415 & 0,6782 \\
\hline 70 & 5,1780 & $-0,00453$ & 0,0713 & 0,00066 & 0,0102 & 0,9510 \\
\hline 80 & 5,2782 & $-0,00619$ & 0,0137 & 0,00105 & 0,0201 & 0,9348 \\
\hline 90 & 5,0419 & $-0,00781$ & 0,1097 & 0,00203 & 0,0126 & 0,8648 \\
\hline 100 & 5,3633 & $-0,01098$ & 0,1061 & 0,00378 & 0,0324 & 0,8991 \\
\hline
\end{tabular}

Cuadro 85. Ecuaciones resultantes de la aplicación del modelo cinético de primer orden a la degradación térmica de la sulfadiazina con el tiempo

\begin{tabular}{|cccccccc|}
\hline \multirow{2}{*}{$\mathbf{T}^{\mathbf{a}}\left({ }^{\circ} \mathbf{C}\right)$} & $\begin{array}{c}\text { Ordenada } \\
\text { (a) }\end{array}$ & $\begin{array}{c}\text { Pendiente } \\
\left(\mathbf{k}_{\mathbf{1}}\right)\end{array}$ & \multicolumn{2}{c}{ Error estándar } & $\mathbf{0}$ & \multirow{2}{*}{$\mathbf{R}^{\mathbf{2}}$} \\
\hline 60 & 5,2136 & $-0,00049$ & 0,0389 & 0,00036 & 0,0251 & 0,5196 \\
70 & 5,0752 & $-0,00111$ & 0,0929 & 0,00086 & 0,0204 & 0,5025 \\
80 & 5,3523 & $-0,00267$ & 0,0485 & 0,00045 & 0,0019 & 0,9362 \\
90 & 5,2083 & $-0,00563$ & 0,0431 & 0,00079 & 0,0009 & 0,9533 \\
100 & 5,2331 & $-0,00813$ & 0,0714 & 0,00254 & 0,0002 & 0,9144 \\
\hline
\end{tabular}

Como se observa en estos Cuadros, los ajustes alcanzados mediante la aplicación del modelo de regresión lineal simple varían dependiendo de la sulfonamida estudiada y son, en general, adecuados con valores de los coeficientes de regresión superiores a 0,8 excepto en algunos casos concretos obtenidos en los calentamientos de $60^{\circ} \mathrm{C}$ y $70^{\circ} \mathrm{C}$, donde las sustancias muestran coeficientes bajos con valores comprendidos entre $R^{2}=0,5054$ (sulfamerazina $60^{\circ} \mathrm{C}$ ) y $R^{2}=0,7703$ (sulfametazina $70^{\circ} \mathrm{C}$ ). 
Cuadro 86. Ecuaciones resultantes de la aplicación del modelo cinético de primer orden a la degradación térmica de la sulfadimetoxina con el tiempo

\begin{tabular}{|c|c|c|c|c|c|c|}
\hline \multirow{2}{*}{$\mathrm{T}^{\mathrm{a}}\left({ }^{\circ} \mathrm{C}\right)$} & \multirow{2}{*}{$\begin{array}{l}\text { Ordenada } \\
\text { (a) }\end{array}$} & \multirow{2}{*}{$\begin{array}{c}\text { Pendiente } \\
\left(\mathbf{k}_{1}\right)\end{array}$} & \multicolumn{2}{|c|}{ Error estándar } & \multirow{2}{*}{$\mathbf{p}$} & \multirow{2}{*}{$\mathbf{R}^{2}$} \\
\hline & & & a & $k_{1}$ & & \\
\hline 60 & 5,2137 & $-0,00112$ & 0,0384 & 0,00035 & 0,0246 & 0,8180 \\
\hline 70 & 5,2709 & $-0,00125$ & 0,0147 & 0,00013 & 0,0003 & 0,9717 \\
\hline 80 & 5,2414 & $-0,00153$ & 0,0247 & 0,00023 & 0,0011 & 0,9483 \\
\hline 90 & 5,2595 & $-0,00212$ & 0,0178 & 0,00033 & 0,0014 & 0,9445 \\
\hline 100 & 5,2917 & $-0,00239$ & 0,0095 & 0,00033 & 0,0192 & 0,9808 \\
\hline
\end{tabular}

Cuadro 87. Ecuaciones resultantes de la aplicación del modelo cinético de primer orden a la degradación térmica de la sulfamerazina con el tiempo

\begin{tabular}{|c|c|c|c|c|c|c|}
\hline \multirow{2}{*}{$\mathrm{T}^{\mathrm{a}}\left({ }^{\circ} \mathrm{C}\right)$} & \multirow{2}{*}{$\begin{array}{l}\text { Ordenada } \\
\text { (a) }\end{array}$} & \multirow{2}{*}{$\begin{array}{c}\text { Pendiente } \\
\left(\mathbf{k}_{1}\right)\end{array}$} & \multicolumn{2}{|c|}{ Error estándar } & \multirow{2}{*}{$\mathbf{p}$} & \multirow{2}{*}{$\mathbf{R}^{2}$} \\
\hline & & & a & $k_{1}$ & & \\
\hline 60 & 5,1360 & $-0,00063$ & 0,0684 & 0,00083 & 0,0366 & 0,5054 \\
\hline 70 & 5,1716 & $-0,00166$ & 0,0648 & 0,00060 & 0,0105 & 0,8720 \\
\hline 80 & 5,1796 & $-0,00239$ & 0,0705 & 0,00065 & 0,0123 & 0,7505 \\
\hline 90 & 5,1413 & $-0,00774$ & 0,0702 & 0,00129 & 0,0019 & 0,9364 \\
\hline 100 & 5,2869 & $-0,02457$ & 0,0122 & 0,00043 & 0,0003 & 0,9997 \\
\hline
\end{tabular}

Cuadro 88. Ecuaciones resultantes de la aplicación del modelo cinético de primer orden a la degradación térmica de la sulfametazina con el tiempo

\begin{tabular}{|c|c|c|c|c|c|c|}
\hline \multirow{2}{*}{$\mathrm{T}^{\mathrm{a}}\left({ }^{\circ} \mathrm{C}\right)$} & \multirow{2}{*}{$\begin{array}{l}\text { Ordenada } \\
\text { (a) }\end{array}$} & \multirow{2}{*}{$\begin{array}{c}\text { Pendiente } \\
\left(\mathbf{k}_{1}\right)\end{array}$} & \multicolumn{2}{|c|}{ Error estándar } & \multirow[b]{2}{*}{$\mathbf{p}$} & \multirow{2}{*}{$\mathbf{R}^{2}$} \\
\hline & & & a & $k_{1}$ & & \\
\hline 60 & 5,0982 & $-0,00105$ & 0,0840 & 0,00078 & 0,0494 & 0,5179 \\
\hline 70 & 5,1395 & $-0,00203$ & 0,1088 & 0,00100 & 0,0233 & 0,7703 \\
\hline 80 & 5,1980 & $-0,00256$ & 0,0168 & 0,00043 & 0,0020 & 0,9352 \\
\hline 90 & 5,0758 & $-0,01092$ & 0,0944 & 0,00175 & 0,0015 & 0,9416 \\
\hline 100 & 5,2522 & $-0,03092$ & 0,0996 & 0,00355 & 0,0129 & 0,9871 \\
\hline
\end{tabular}

Estos coeficientes de regresión bajos se deben a que las sulfamidas son moléculas muy estables y los calentamientos a temperaturas moderadas $\left(60^{\circ} \mathrm{C}, 70^{\circ} \mathrm{C}\right.$ y $80^{\circ} \mathrm{C}$ ), resultan demasiado débiles para llegar a ocasionar grandes cambios en sus concentraciones. 
Cuadro 89. Ecuaciones resultantes de la aplicación del modelo cinético de primer orden a la degradación térmica de la sulfapiridina con el tiempo

\begin{tabular}{|c|c|c|c|c|c|c|}
\hline \multirow{2}{*}{$\mathrm{T}^{\mathrm{a}}\left({ }^{\circ} \mathrm{C}\right)$} & \multirow{2}{*}{$\begin{array}{l}\text { Ordenada } \\
\text { (a) }\end{array}$} & \multirow{2}{*}{$\begin{array}{c}\text { Pendiente } \\
\left(\mathbf{k}_{1}\right)\end{array}$} & \multicolumn{2}{|c|}{ Error estándar } & \multirow{2}{*}{$p$} & \multirow{2}{*}{$\mathbf{R}^{2}$} \\
\hline & & & a & $k_{1}$ & & \\
\hline 60 & 5,1941 & $-0,00134$ & 0,0441 & 0,00041 & 0,0221 & 0,8257 \\
\hline 70 & 5,1441 & $-0,00204$ & 0,0548 & 0,00051 & 0,0101 & 0,8739 \\
\hline 80 & 5,2663 & $-0,00313$ & 0,0289 & 0,00027 & 0,0001 & 0,9823 \\
\hline 90 & 5,1353 & $-0,00527$ & 0,0444 & 0,00082 & 0,0014 & 0,9442 \\
\hline 100 & 5,3517 & $-0,00882$ & 0,0862 & 0,00307 & 0,0129 & 0,8971 \\
\hline
\end{tabular}

Cuadro 90. Ecuaciones resultantes de la aplicación del modelo cinético de primer orden a la degradación térmica de la sulfaquinoxalina con el tiempo

\begin{tabular}{|c|c|c|c|c|c|c|}
\hline \multirow{2}{*}{$\mathrm{T}^{\mathrm{a}}\left({ }^{\circ} \mathrm{C}\right)$} & \multirow{2}{*}{$\begin{array}{c}\text { Ordenada } \\
\text { (a) }\end{array}$} & \multirow{2}{*}{$\begin{array}{c}\text { Pendiente } \\
\left(\mathbf{k}_{1}\right)\end{array}$} & \multicolumn{2}{|c|}{ Error estándar } & \multirow{2}{*}{ p } & \multirow{2}{*}{$\mathbf{R}^{2}$} \\
\hline & & & $\mathbf{a}$ & $k_{1}$ & & \\
\hline 60 & 5,1600 & $-0,00235$ & 0,0594 & 0,00055 & 0,0079 & 0,8860 \\
\hline 70 & 5,1213 & $-0,00238$ & 0,1198 & 0,00111 & 0,0344 & 0,6929 \\
\hline 80 & 5,1802 & $-0,00290$ & 0,0564 & 0,00052 & 0,0026 & 0,9280 \\
\hline 90 & 5,1298 & $-0,01115$ & 0,0735 & 0,00136 & 0,0004 & 0,9648 \\
\hline 100 & 5,1807 & $-0,01725$ & 0,1268 & 0,00452 & 0,0223 & 0,9378 \\
\hline
\end{tabular}

Cuadro 91. Ecuaciones resultantes de la aplicación del modelo cinético de primer orden a la degradación térmica del sulfatiazol con el tiempo

\begin{tabular}{|cccccccc|}
\hline \multirow{2}{*}{$\mathbf{T}^{\mathbf{a}}\left({ }^{\circ} \mathbf{C}\right)$} & $\begin{array}{c}\text { Ordenada } \\
\text { (a) }\end{array}$ & $\begin{array}{c}\text { Pendiente } \\
\left(\mathbf{k}_{\mathbf{1}}\right)\end{array}$ & \multicolumn{2}{c}{ Error estándar } & $\mathbf{a}$ & $\mathbf{0}$ & $\mathbf{R}^{\mathbf{2}}$ \\
\hline 60 & 5,2761 & $-0,00055$ & 0,0116 & 0,00010 & 0,0037 & 0,9167 \\
70 & 5,2263 & $-0,00076$ & 0,0300 & 0,00028 & 0,0408 & 0,7748 \\
80 & 5,2439 & $-0,00084$ & 0,0229 & 0,00021 & 0,0106 & 0,8716 \\
90 & 5,2425 & $-0,00204$ & 0,0242 & 0,00046 & 0,0068 & 0,8928 \\
100 & 5,2951 & $-0,00272$ & 0,0039 & 0,00014 & 0,0027 & 0,9973 \\
\hline
\end{tabular}

A pesar de que para algunas sustancias en determinados tratamientos se hayan encontrado bajos coeficientes de regresión, se observa que la aplicación del modelo cinético de primer orden es adecuada para evaluar la estabilidad de las sulfonamidas en la leche, ya que los valores estadísticos de " $p$ " fueron significativos en todos los casos $(p<0,05)$.

Las constantes de velocidad de degradación de las sulfonamidas aumentan conforme se incrementa la temperatura de calentamiento. Este aumento de la 
velocidad de degradación parece seguir un patrón diferente según la sustancia, siendo la sulfadimetoxina y el sulfatiazol los que presentan la menor variación con el incremento de temperaturas.

Las otras sulfonamidas muestran un comportamiento variable entre ellas, aunque se observa, por ejemplo, que la sulfadiazina y la sulfapiridina aumentan de forma similar las constantes de degradación alcanzando unos valores en el calentamiento a $100^{\circ} \mathrm{C}$ de " $\mathrm{k}_{1}$ " $=-0,00813$ y " $\mathrm{k}_{1}$ “ $=-0,00862$ respectivamente.

Si se comparan los valores de las constantes de velocidad con los obtenidos a lo largo de este trabajo para otros grupos de antimicrobianos se advierte que en muchos casos estos valores son similares o ligeramente superiores a los de las tetraciclinas, por lo que se puede considerar que son grupos de antimicrobianos con una termoestabilidad similar y superior a la de los antibióticos betalactámicos.

En las Figuras $72,73,74,75,76,77,78$ y 79 , se exponen las representaciones gráficas correspondientes a las ecuaciones presentadas anteriormente.

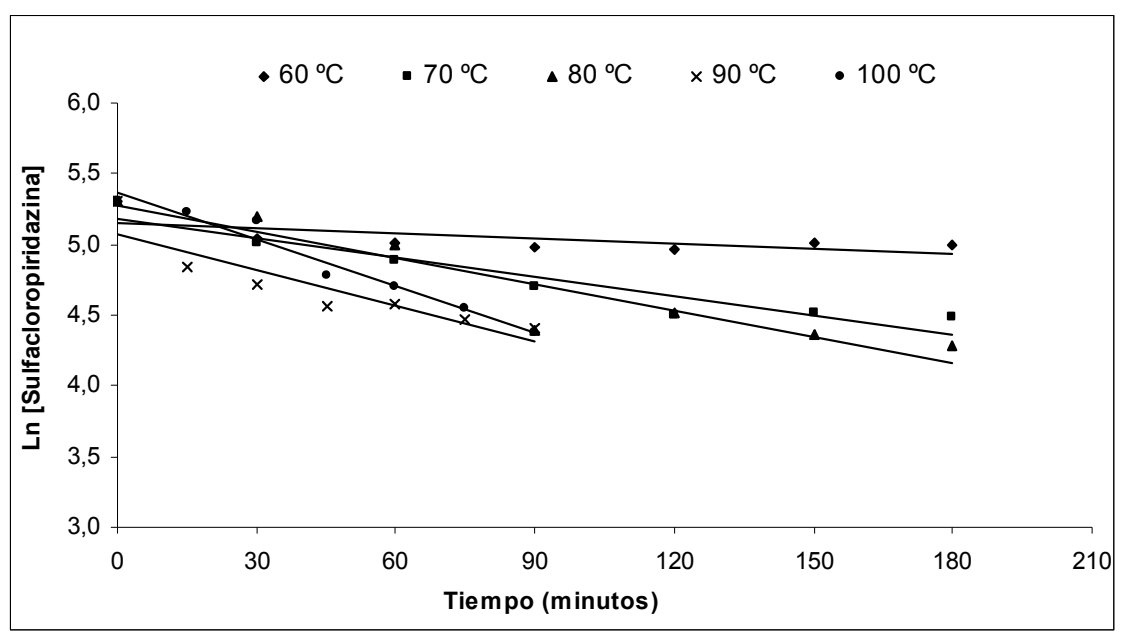

Figura 72. Relación entre la concentración de sulfacloropiradizina en la leche y el tiempo de calentamiento a distintas temperaturas

Se observa que la sulfadimetoxina (Figura 74) y el sulfatiazol (Figura 79) presentan una leve pendiente a $60^{\circ} \mathrm{C}$ que aumenta muy poco con las temperaturas lo que sugiere que se trata de moléculas estables térmicamente que se degradan lentamente. 


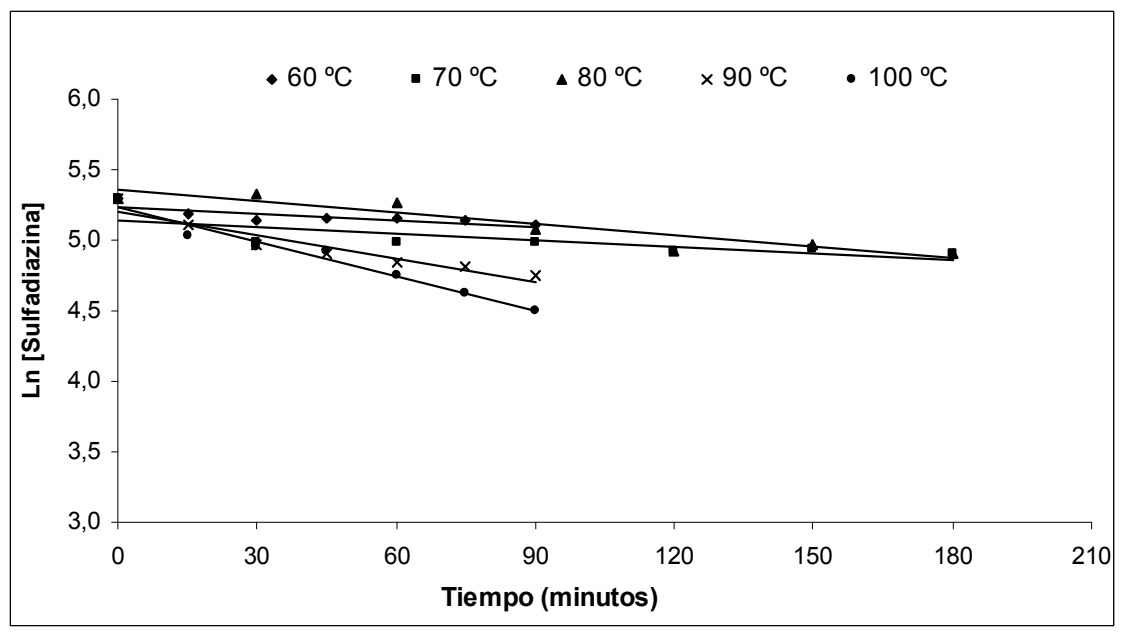

Figura 73. Relación entre la concentración de sulfadiazina en la leche y el tiempo de calentamiento a diferentes temperaturas

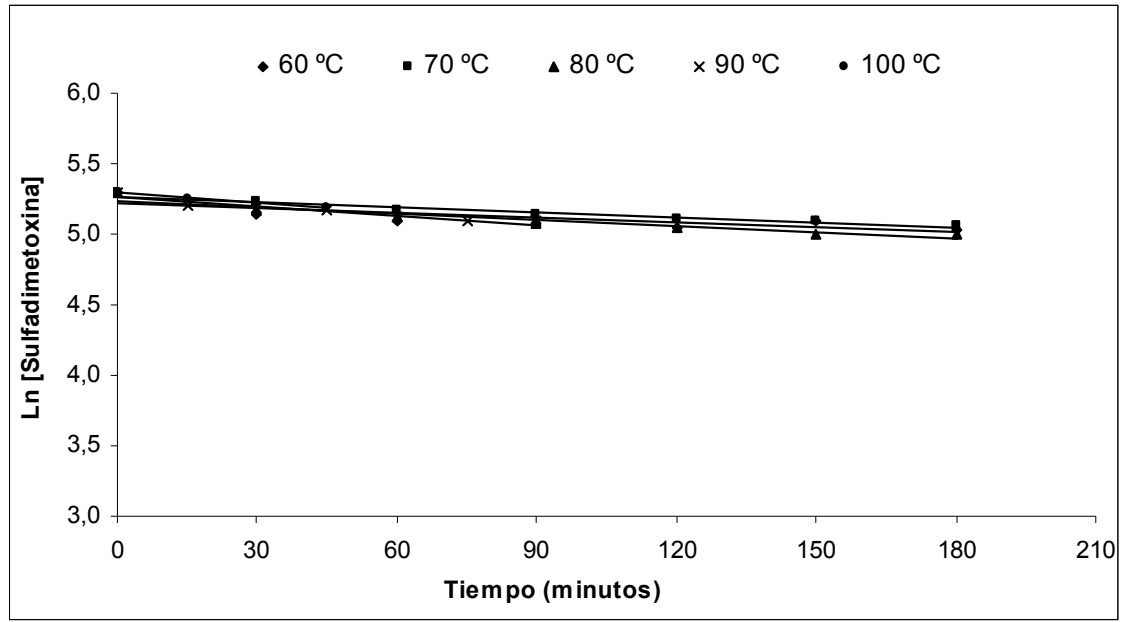

Figura 74. Relación entre la concentración de sulfadimetoxina en la leche y el tiempo de calentamiento a diferentes temperaturas

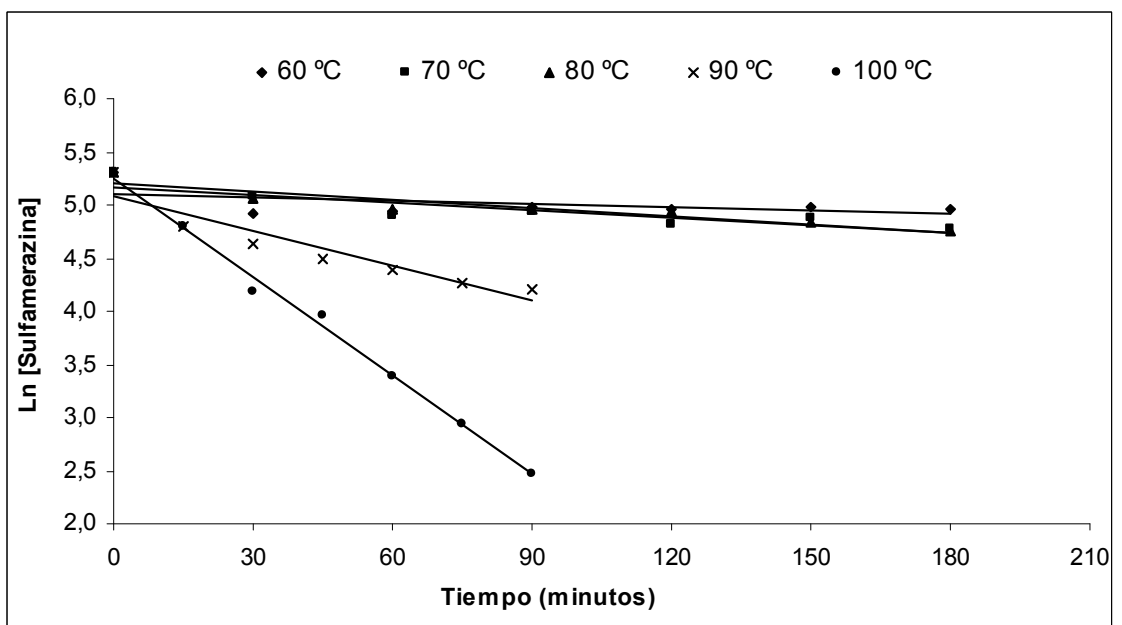

Figura 75. Relación entre la concentración de sulfamerazina en la leche y el tiempo de calentamiento a diferentes temperaturas 


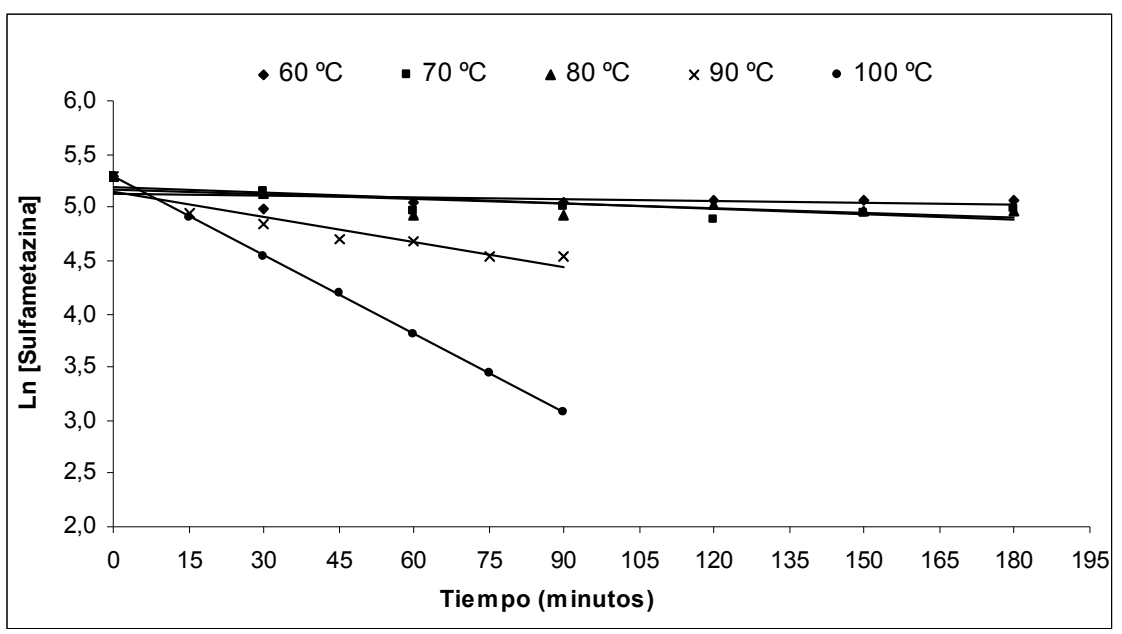

Figura 76. Relación entre la concentración de sulfametazina en la leche y el tiempo de calentamiento a diferentes temperaturas

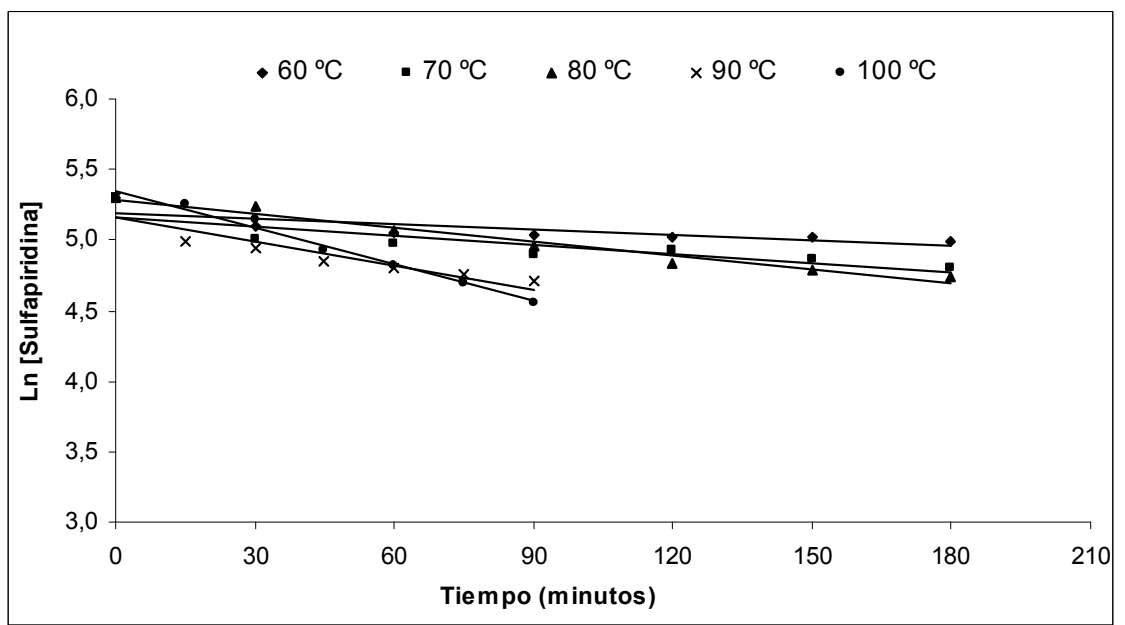

Figura 77. Relación entre la concentración de sulfapiridina en la leche y el tiempo de calentamiento a diferentes temperaturas

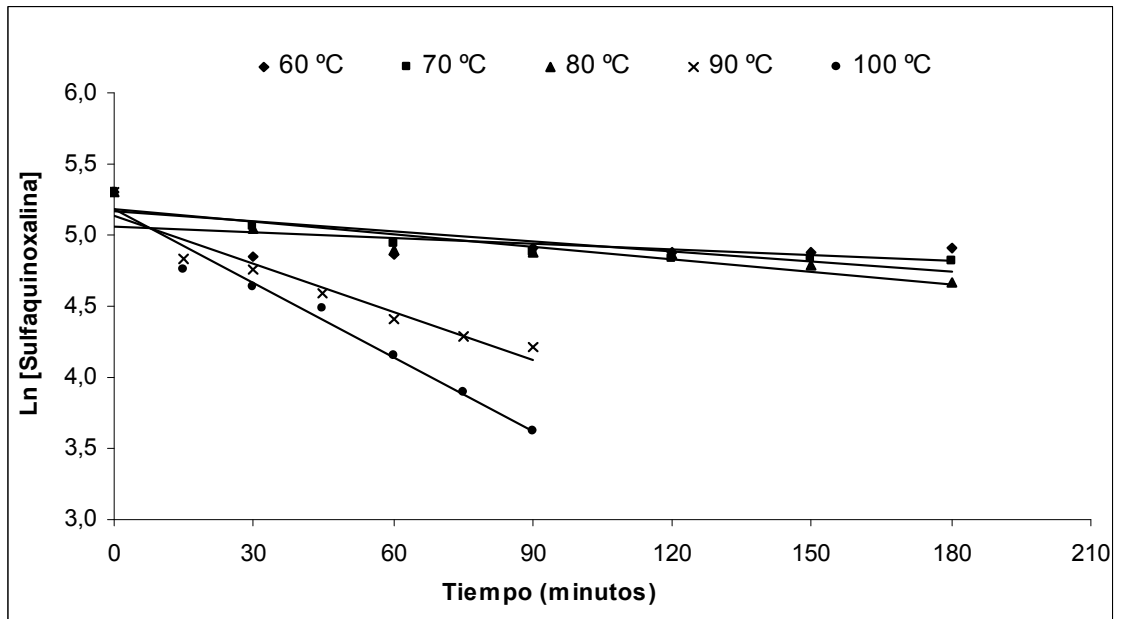

Figura 78. Relación entre la concentración de sulfaquinoxalina en la leche y el tiempo de calentamiento a diferentes temperaturas 


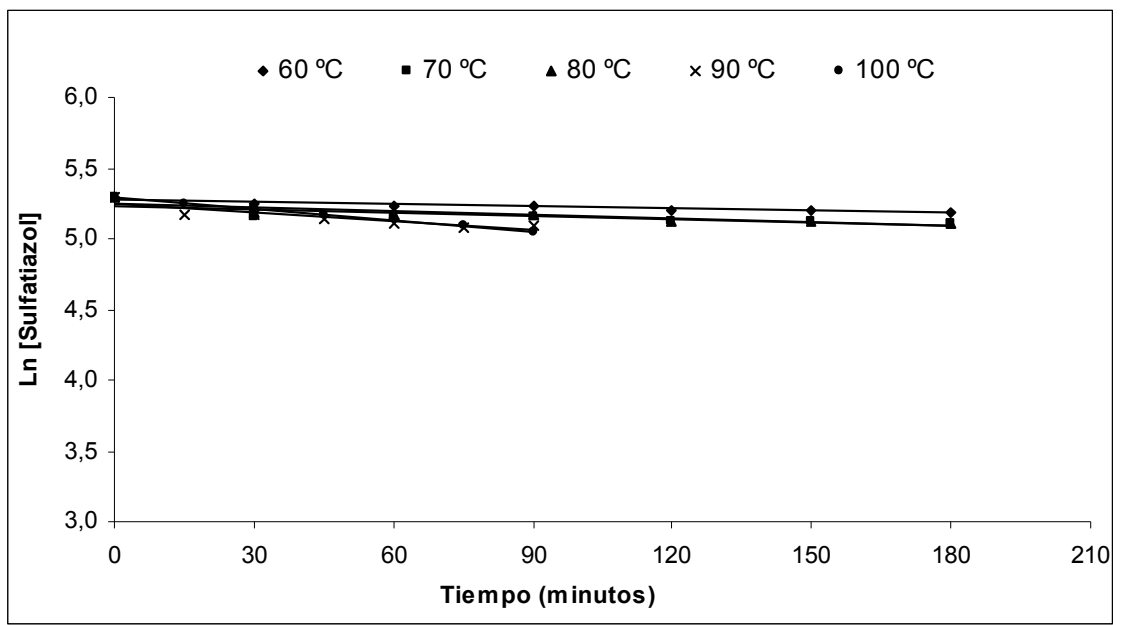

Figura 79. Relación entre la concentración de sulfatiazol en la leche y el tiempo de calentamiento a diferentes temperaturas

La sulfacloropiradizina (Figura 72), sulfadiazina (Figura 73) y sulfapiridina (Figura 77), muestran un comportamiento similar entre ellas con pendientes de degradación intermedias que aumentan ligeramente a medida que aumenta la temperatura, siendo la sulfacloropiradizina la que muestra mayor variación entre las pendientes de las 5 temperaturas ensayadas.

Por otro lado la sulfamerazina (Figura 75), sulfametazina (Figura 76) y sulfaquinoxalina (Figura 78) se comportan de manera diferente, puesto que se deterioran lentamente a 60,70 y $80^{\circ} \mathrm{C}$, pero a temperaturas superiores $\left(90\right.$ y $100{ }^{\circ} \mathrm{C}$ ) aumentan rápidamente sus pendientes. Este hecho está seguramente relacionado con unas elevadas energías de activación de estas sustancias, así como altas probabilidades de choques eficaces entre los moles de estas moléculas en fase de transición.

A partir de las ecuaciones del modelo cinético de primer orden obtenidas anteriormente se han estimado los valores de los tiempos de vida media $\left(t_{1 / 2}\right)$, para cada sulfonamida y temperatura ensayada, cuyos valores resultantes se exponen en el Cuadro 92.

A partir de los tiempos de vida media presentados en el Cuadro anterior, se aprecia que las sulfonamidas son moléculas resistentes a los tratamientos térmicos de calor con tiempos de vida media muy largos a $60^{\circ} \mathrm{C}$ con valores entre 295 y 1415 minutos) que se mantienen elevados a lo largo del resto de temperaturas alcanzando unos tiempos de vida media entre 40 y 290 minutos incluso en el calentamiento de la leche a $100{ }^{\circ} \mathrm{C}$. Solamente la sulfametazina y sulfamerazina presentan unos tiempos de vida media menores aunque cercanos a los 30 minutos. 
Cuadro 92. Tiempos de vida media $\left(t_{1 / 2}\right)$ estimados para las sulfonamidas en la leche a diferentes temperaturas de calentamiento

\begin{tabular}{|c|c|c|c|c|c|}
\hline \multirow{2}{*}{ Sulfamidas } & \multicolumn{5}{|c|}{$t_{1 / 2}$ (minutos) $=\operatorname{Ln} 2 / k$} \\
\hline & $60^{\circ} \mathrm{C}$ & $70^{\circ} \mathrm{C}$ & $80^{\circ} \mathrm{C}$ & $90^{\circ} \mathrm{C}$ & $100^{\circ} \mathrm{C}$ \\
\hline Sulfacloropiradizina & 582 & 153 & 112 & 89 & 63 \\
\hline Sulfadiazina & 1415 & 624 & 260 & 123 & 85 \\
\hline Sulfadimetoxina & 619 & 555 & 453 & 327 & 290 \\
\hline Sulfamerazina & 620 & 341 & 271 & 63 & 22 \\
\hline Sulfametazina & 835 & 418 & 290 & 90 & 28 \\
\hline Sulfaquinoxalina & 295 & 291 & 239 & 62 & 40 \\
\hline Sulfapiridina & 517 & 340 & 221 & 132 & 79 \\
\hline Sulfatiazol & 1260 & 912 & 825 & 340 & 255 \\
\hline
\end{tabular}

Los tiempos de vida media obtenidos para cada sulfonamida y temperatura, son muy diferentes dependiendo de la sustancia ensayada aunque se puede describir el comportamiento de degradación de cada una de las sulfonamidas agrupándolas en tres grupos diferenciados según la variación existente entre los $t_{1 / 2}$ con las temperaturas.

De esta manera la sulfadimetoxina y el sulfatiazol, aunque en el tratamiento de $60{ }^{\circ} \mathrm{C}$ difieren bastante en sus tiempos de vida media (619 y 1260 respectivamente) debido a las diferentes constantes de velocidad que presentan a estas temperaturas, son las moléculas que se degradan más lentamente a lo largo de los distintos calentamientos con los tiempos más elevados (290 y $255 \mathrm{~min}$ ) en el tratamiento de $100{ }^{\circ} \mathrm{C}$. Hay que destacar también que el sulfatiazol presenta los mayores tiempos de vida media en todas las temperaturas ensayadas, lo que indica que esta molécula es la más termorresistente con un comportamiento de degradación lento y uniforme.

Por otra parte, la sulfamerazina, sulfametazina y sulfaquinoxalina formarían parte de un segundo grupo de sustancias, con valores de tiempos de vida media que disminuyen de forma progresiva hasta aproximadamente el calentamiento de $90^{\circ} \mathrm{C}$, donde aceleran el proceso de degradación disminuyendo bruscamente estos tiempos, sobre todo en el caso de la sulfamerazina y sulfametazina (22 y $28 \mathrm{~min}$ ). En este caso las diferencias entre los tiempos de vida media de las tres sulfonamidas a $60{ }^{\circ} \mathrm{C}$ pueden explicarse por las diferentes energías de activación y frecuencias de choques de cada una de ellas que se calcularán en el apartado siguiente. 
Por último, las sustancias de sulfacloropiradizina, sulfadiazina y sulfapiridina muestran una degradación más moderada desde el calentamiento de $60^{\circ} \mathrm{C}$ hasta el de $100{ }^{\circ} \mathrm{C}$. En este caso las diferencias en la magnitud de los tiempos estimados se deben también seguramente a los diferentes parámetros cinéticos (energías de activación y probabilidad de choques) de cada una de ellas.

\subsubsection{Cálculo de la energía de activación}

Para el cálculo de la energía de activación de las sulfonamidas se aplicó, como en los estudios anteriores, el modelo propuesto por Arrhenius y los parámetros correspondientes a las ecuaciones obtenidas se presentan en el Cuadro 93.

Cuadro 93. Ecuación de Arrhenius aplicada a la degradación térmica de las sulfonamidas en la leche

\begin{tabular}{|c|c|c|c|c|c|c|c|}
\hline \multirow{2}{*}{ Sulfonamidas } & \multirow{2}{*}{$\begin{array}{c}\text { Ordenada } \\
\text { (Ln A) }\end{array}$} & \multirow{2}{*}{$\begin{array}{c}\text { Pendiente } \\
\text { (-Ea/R) }\end{array}$} & \multicolumn{2}{|c|}{ Error estándar } & \multirow{2}{*}{$\mathbf{p}$} & \multirow{2}{*}{$\mathbf{R}^{2}$} & \multirow{2}{*}{ Ea } \\
\hline & & & $\operatorname{Ln} A$ & $-E a / R$ & & & \\
\hline Sulfacloropiradizina & 12,466 & 6266,9 & 4,000 & 1408,7 & 0,0211 & 0,9319 & 52,10 \\
\hline Sulfadiazina & 19,539 & 9024,7 & 1,570 & 552,9 & 0,0005 & 0,9944 & 75,03 \\
\hline Sulfadimetoxina & 0,754 & 2532,0 & 0,776 & 273,3 & 0,0027 & 0,9830 & 21,05 \\
\hline Sulfamerazina & 24,152 & 10416,5 & 4,715 & 1660,4 & 0,0082 & 0,9639 & 86,60 \\
\hline Sulfametazina & 24,121 & 10500,9 & 6,174 & 2174,4 & 0,0169 & 0,9413 & 87,30 \\
\hline Sulfaquinoxalina & 13,979 & 6794,2 & 4,996 & 1759,5 & 0,0307 & 0,9124 & 56,49 \\
\hline Sulfapiridina & 10,878 & 5846,2 & 0,821 & 289,1 & 0,0003 & 0,9964 & 48,61 \\
\hline Sulfatiazol & 7,890 & 5168,4 & 2,511 & 884,2 & 0,0100 & 0,9588 & 42,97 \\
\hline
\end{tabular}

Ea= Energía de activación $(\mathrm{kJ} / \mathrm{mol}) ; \mathrm{R}=$ constante especifica de los gases ideales $\left(8,314472 \mathrm{~J} / \mathrm{mol} \cdot{ }^{\circ} \mathrm{K}\right) ; \mathrm{A}=$ frecuencia de choque

En dicho Cuadro se observa que los ajustes alcanzados por medio de la aplicación del modelo de Arrhenius son muy elevados para el estudio de la estabilidad térmica de las sulfonamidas en la leche, con coeficientes de regresión entre $R^{2}=0,9124$ (sulfaquinoxalina) y $R^{2}=0,9944$ (sulfadiazina), así como valores de p significativos $(p<0,05)$.

En cuanto a las ordenadas en el origen ( $\operatorname{Ln} A)$, se aprecia que los valores obtenidos son muy diferentes entre las sustancias, siendo los más elevados los que corresponden a la sulfamerazina y sulfametazina $(24,152$ y 24,121). Estas frecuencias de choque van acompañadas de los valores más elevados de las pendientes de degradación $(E a / R)$ de donde se calculan las mayores energías de activación $(86,60$ y $87,30 \mathrm{~kJ} / \mathrm{mol})$. 
Si se relacionan estos valores de energía de activación y frecuencia de choques con los resultados del modelo cinético de primer orden presentados en el apartado anterior, se deduce que estas dos sustancias requieren un aporte elevado de energía (calor) para que un gran número de moles se activen y entren en fase de transición donde la elevada probabilidad de choques que presentan hace que las moléculas reaccionen y se degraden rápidamente. Este hecho explica por qué hasta el calentamiento de la leche a $80^{\circ} \mathrm{C}$ la degradación de estas moléculas es más lenta mientras que una vez alcanzadas temperaturas más elevadas (90 y $100{ }^{\circ} \mathrm{C}$ ) la reacción se acelera bruscamente y los valores de vida media disminuyen.

En el caso de la sulfadiazina, la energía de activación calculada también es elevada $(75,03 \mathrm{~kJ} / \mathrm{mol})$, por lo que esta sustancia también necesita un gran aporte de energía para alcanzar la energía de activación y acelerar el proceso de degradación, aunque la frecuencia de choques para esta sustancia ( $\operatorname{Ln} A=19,539)$ es menor que en el caso de la sulfamerazina y sulfametazina por lo que hace que la degradación sea menor para esta sustancia.

Por otra parte, respecto a las sulfonamidas que presentan energías de activación intermedias, entre 42,97 y $49 \mathrm{~kJ} / \mathrm{mol}$, cabe destacar el sulfatiazol con una frecuencia de choques muy baja ( $\operatorname{Ln} A=7,890$ ) que explica la poca reacción de degradación de esta molécula que además, muestra los tiempos de vida media más elevados.

Lo mismo sucede en el caso de la sulfadimetoxina con una energía de activación y una frecuencia de choques muy bajos $(E a=21,05 \mathrm{~kJ} / \mathrm{mol}, \operatorname{Ln} A=0,754)$ que hacen que la molécula presente muy poca inestabilidad a bajas temperaturas y que la degradación con el incremento de temperaturas sea muy lenta.

Los diferentes comportamientos descritos anteriormente para cada una de las sulfonamidas se pueden apreciar en las Figuras 80 y 81 donde se han representado las ecuaciones de Arrhenius para cuatro sulfonamidas en cada una de ellas con la finalidad de distinguir mejor las pendientes de cada una de las rectas representadas.

Como se ha indicado anteriormente, en estas Figuras se aprecia como la sulfadimetoxina presenta la pendiente más suave mostrando un comportamiento de degradación lento y progresivo a lo largo de las temperaturas, contrarrestando con las pendientes acusadas de sulfamerazina, sulfametazina y sulfadiazina que parten de los valores más bajos de "Ln k" a $60^{\circ} \mathrm{C}$ hasta los más elevados a $100^{\circ} \mathrm{C}$.

También se observa como la sulfacloropiradizina, sulfapiridina, sulfaquinoxalina y sulfatiazol muestran pendientes similares entre ellas (rectas 
paralelas) aunque con diferentes valores de "Ln k", siendo el sulfatiazol quien presenta los valores más bajos y por lo tanto la menor degradación.

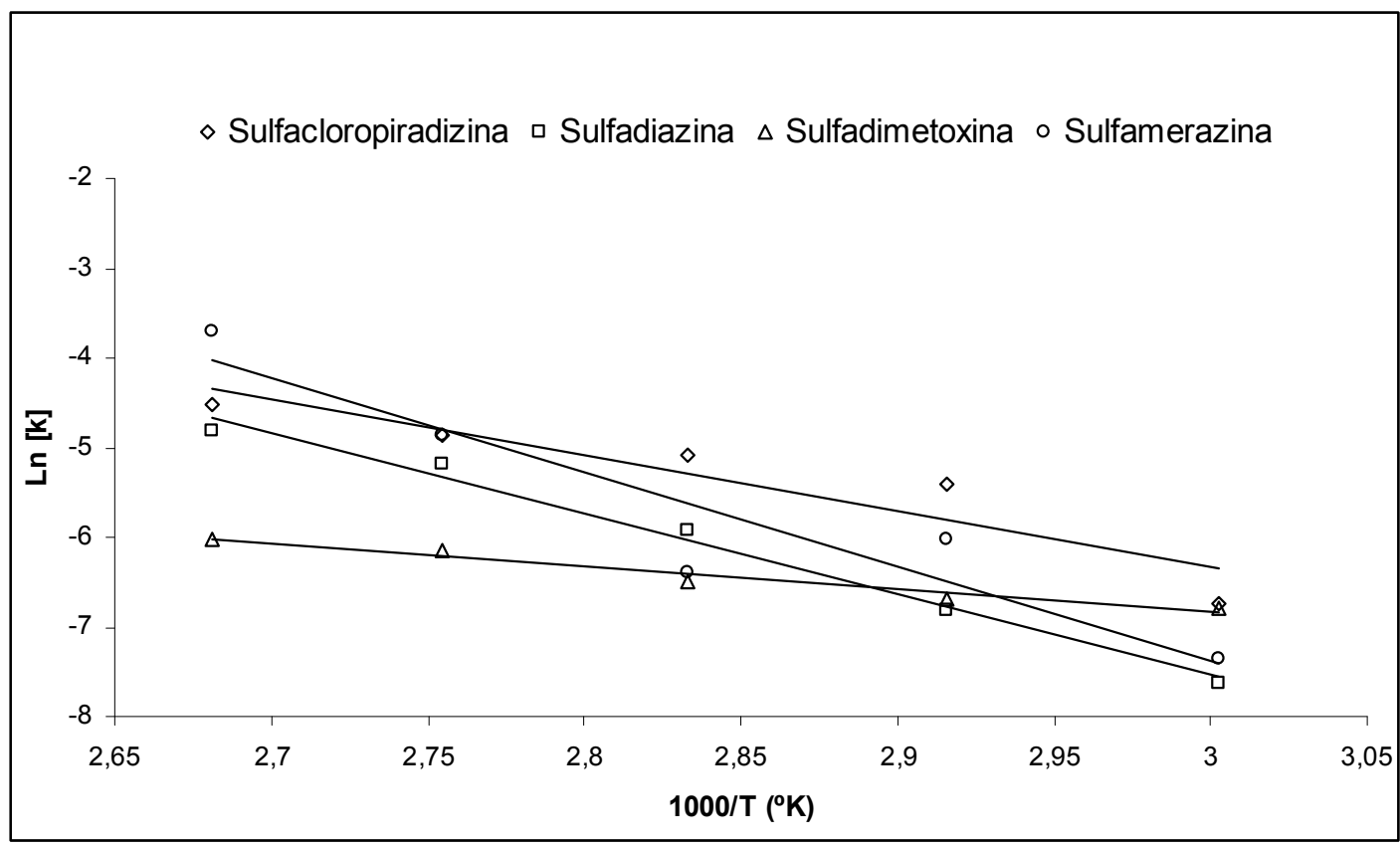

Figura 80. Representación gráfica de la ecuación de Arrhenius para la sulfacloropiradizina, sulfadiazina, sulfadimetoxina y sulfamerazina

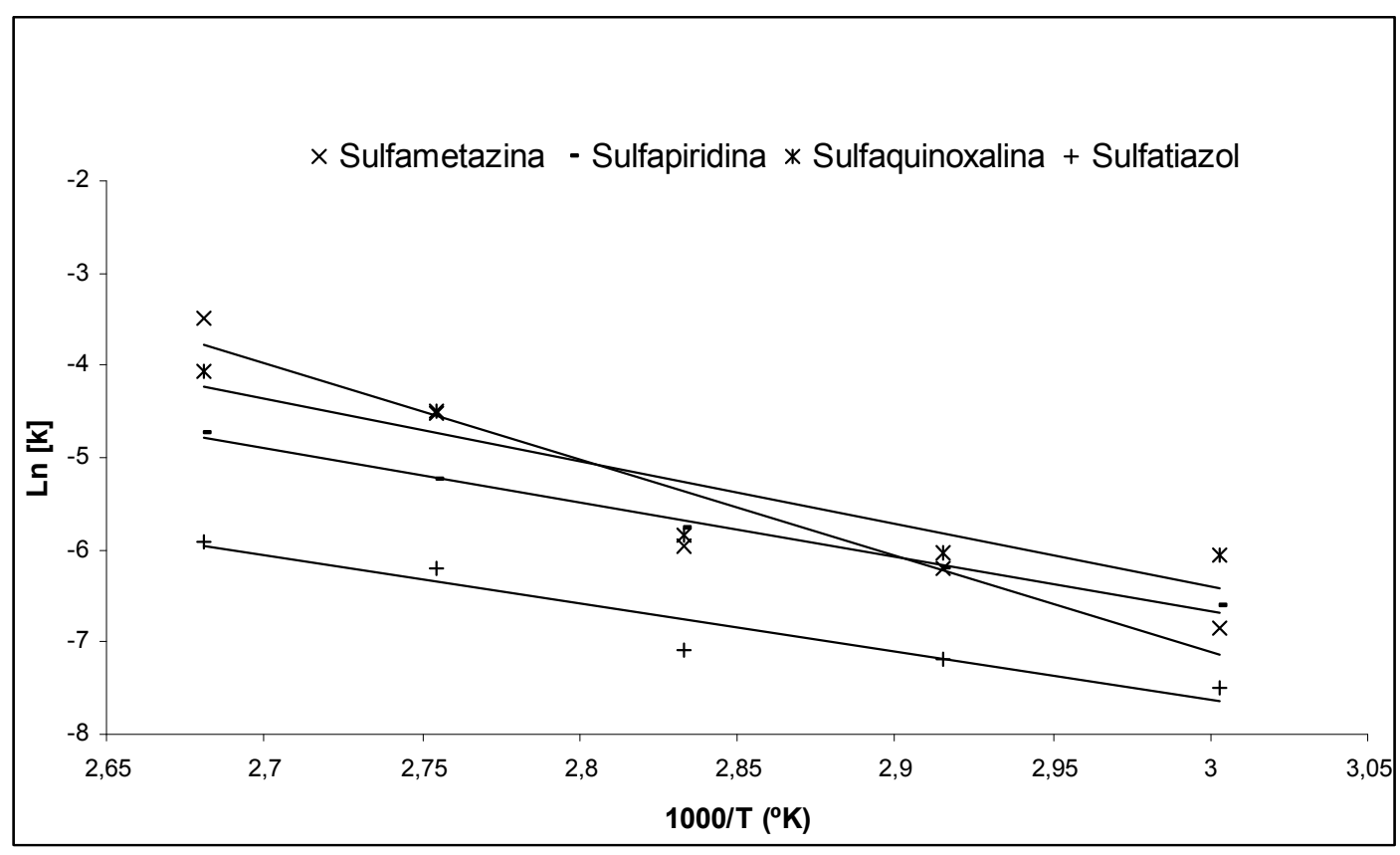

Figura 81. Representación gráfica de la ecuación de Arrhenius para la sulfametazina, sulfapiridina, sulfaquinoxalina y sulfatiazol 


\subsubsection{Estimación de la degradación de las sulfonamidas para diferentes tratamientos térmicos}

Los porcentajes de degradación térmica de las sulfonamidas en la leche estimados a partir de los modelos matemáticos (Cuadro 93) para los diferentes tratamientos de calor realizados en los laboratorios de control de calidad y en las industrias lácteas se presentan en el Cuadro 94.

Cuadro 94. Porcentajes de degradación de las sulfonamidas en la leche para diferentes tratamientos térmicos

\begin{tabular}{|c|c|c|c|c|c|c|}
\hline \multirow{2}{*}{ Sulfonamidas } & \multicolumn{2}{|c|}{$\begin{array}{l}\text { Tratamientos } \\
\text { laboratorio }\end{array}$} & \multicolumn{2}{|c|}{ Pasteurización } & \multicolumn{2}{|c|}{ Esterilización } \\
\hline & $\begin{array}{c}40^{\circ} \mathrm{C} \\
10 \mathrm{~min} \\
\end{array}$ & $\begin{array}{c}83^{\circ} \mathrm{C} \\
10 \mathrm{~min} \\
\end{array}$ & $\begin{array}{c}63^{\circ} \mathrm{C} \\
30 \mathrm{~min} \\
\end{array}$ & $\begin{array}{l}72^{\circ} \mathrm{C} \\
15 \mathrm{~s} \\
\end{array}$ & $\begin{array}{l}120^{\circ} \mathrm{C} \\
20 \mathrm{~min} \\
\end{array}$ & $\begin{array}{c}140^{\circ} \mathrm{C} \\
4 \mathrm{~s} \\
\end{array}$ \\
\hline Sulfacloropiradizina & 0,5 & 5,7 & 6,0 & 0,1 & 46,0 & 0,4 \\
\hline Sulfadiazina & 0,1 & 3,0 & 2,0 & 0,0 & 47,9 & 1,7 \\
\hline Sulfadimetoxina & 0,7 & 1,7 & 3,3 & 0,0 & 6,5 & 0,0 \\
\hline Sulfamerazina & 0,1 & 4,5 & 2,4 & 0,0 & 77,4 & 1,8 \\
\hline Sulfametazina & 0,1 & 5,9 & 3,1 & 0,1 & 85,1 & 2,3 \\
\hline Sufapiridina & 0,4 & 3,8 & 4,3 & 0,1 & 30,7 & 0,3 \\
\hline Sulfaquinoxalina & 0,4 & 5,9 & 5,7 & 0,1 & 51,9 & 0,6 \\
\hline Sulfatiazol & 0,2 & 1,3 & 1,7 & 0,0 & 9,9 & 0,1 \\
\hline
\end{tabular}

Los tratamientos térmicos de laboratorio $\left(40{ }^{\circ} \mathrm{C}-10 \min\right.$ y $83^{\circ} \mathrm{C}-10 \mathrm{~min}$ ) no muestran pérdidas de concentración apreciables en ninguna de las sustancias, con porcentajes de degradación inferiores al $6 \%$ en todas las sulfonamidas. Lo mismo ocurre en las distintas pasteurizaciones y en la esterilización a $140^{\circ} \mathrm{C}-4 \mathrm{~s}$, donde en este último tratamiento, el mayor porcentaje de degradación equivale al 2,3\% obtenido en el caso de la sulfametazina.

Por el contrario, la esterilización convencional $\left(120^{\circ} \mathrm{C}-20 \mathrm{~min}\right)$, produce una degradación apreciable en algunos de los antimicrobianos estudiados con porcentajes de degradación muy elevados del 85,1 y $77,4 \%$ en el caso de la sulfametazina y sulfamerazina y más moderados entre el 30,7 y $51,9 \%$ para la sulfacloropiradizina, sulfadiazina, sulfapiridina y sulfaquinoxalina. Las moléculas de sulfadimetoxina y sulfatiazol se mostraron muy resistentes al calor con porcentajes de degradación inferiores al 10\% incluso en este tratamiento.

Es importante destacar que, como se ha comentado en la Introducción, existen muy pocos estudios realizados sobre la estabilidad térmica de las 
sulfonamidas en la leche, y los trabajos encontrados se centran fundamentalmente en el estudio de la sulfametazina.

Así, Rose et al. (1996) y Hassett et al. (1990), en dos estudios acerca de la estabilidad térmica de la sulfametazina en leche calentada a $100{ }^{\circ} \mathrm{C}$, mediante métodos microbiológicos no obtienen ninguna reducción en la concentración de este antimicrobiano durante 15 minutos de calentamiento. Al estimar el porcentaje de pérdidas que resultaría para la sulfametazina el aplicar este tratamiento de $100{ }^{\circ} \mathrm{C}-15$ min, mediante la ecuación de Arrhenius y la cinética de primer orden obtenidos en este trabajo, se obtiene un porcentaje del $20,5 \%$, lo que supone unas pérdidas superiores a las establecidas por los autores citados anteriormente, atribuyendo estas diferencias a las diferentes metodologías empleadas en cada caso.

Por otro lado, Zorraquino (2005) en el estudio sobre la termoestabilidad de los antimicrobianos en la leche mediante un ensayo microbiológico empleando el Bacillus subtilis BGA como microorganismo de prueba, determina la inactivación térmica de la sulfadimetoxina, sulfametazina, sulfanilamida y sulfatiazol. Los resultados obtenidos por dicho autor difieren de los porcentajes de degradación estimados en este estudio (Cuadro 94), ya que obtiene valores superiores tanto en la pasteurización a $60^{\circ} \mathrm{C}-30$ min (sulfadimetoxina: $8 \%$, sulfametazina: $33 \%$ y sulfatiazol: $24 \%$ ), como en la esterilización UHT (sulfadimetoxina y sulfametazina: $26 \%$ y sulfatiazol: $10 \%$ ) y en la esterilización a $120^{\circ} \mathrm{C}$ (sulfadimetoxina: $26 \%$ y sulfatiazol: $29 \%$ ). Únicamente en el caso de la sulfametazina en el tratamiento de $120^{\circ} \mathrm{C}$ durante 20 minutos el porcentaje obtenido por este autor es inferior (44\%) al presentando en el presente trabajo.

Estas diferencias entre resultados se pueden atribuir a las causas ya comentadas anteriormente, en cuanto a las diferentes metodologías analíticas empleadas. No obstante, a pesar de las diferencias encontradas en los resultados, en ambos trabajos se describe a la sulfametazina como la molécula más termosensible de entre las sulfonamidas estudiadas.

En otro trabajo reciente realizado por Papapanagiotou et al. (2005) se cuantificaron mediante una técnica HPLC-UV las pérdidas de sulfametazina en muestras de leche calentadas a $100{ }^{\circ} \mathrm{C}$, obteniendo pérdidas del $18,6 \%$ a los 10 minutos de calentamiento, resultado similar al $20,5 \%$ estimado en este estudio a partir de la ecuación de Arrhenius establecida para esta sustancia (Cuadro 93), el en el caso de calentar la leche a $100^{\circ} \mathrm{C}$ durante 10 minutos. 

CONCLUSIONES 



\section{CONCLUSIONES}

De los resultados de este trabajo se deducen una serie de conclusiones que se exponen a continuación, teniendo en cuenta los distintos estudios realizados.

\section{Primer estudio: Influencia de las condiciones de almacenamiento sobre la estabilidad de antimicrobianos en la leche}

Respecto al estudio de la influencia de las condiciones de almacenamiento sobre la estabilidad de los antibióticos betalactámicos, tetraciclinas y sulfonamidas en la leche, las conclusiones obtenidas se pueden resumir según sea el estudio de refrigeración o congelación en las siguientes:

Efecto de la refrigeración de la leche sobre las sustancias antimicrobianas:

- Para los antibióticos betalactámicos y las tetraciclinas, en todos los casos los logaritmos de las concentraciones de los antimicrobianos disminuyen conforme aumenta el tiempo de refrigeración a $4^{\circ} \mathrm{C}$, mostrando un efecto significativo del tiempo de almacenamiento sobre la estabilidad de estas sustancias en la leche. Por el contrario en el caso de las sulfonamidas no se detecta ninguna variación significativa de su concentración con el tiempo de almacenamiento a $4{ }^{\circ} \mathrm{C}$.

- La interacción entre el tipo de matriz (leche y extracto) y el tiempo de refrigeración resulta significativa en algunas sustancias antimicrobianas, lo que indica que la degradación de estas sustancias puede verse afectada por la matriz empleada cuando se prolonga el tiempo de refrigeración. Las pérdidas de concentración obtenidas en estos casos resultan en general inferiores en los extractos que en las propias muestras de leche.

- Las penicilinas y las cefalosporinas, excepto la cefalexina, son las moléculas que presentan los porcentajes de degradación más elevados y los tiempos de vida media más cortos, en condiciones de refrigeración, tanto en muestras como en extractos, mientras que las tetraciclinas, a excepción de la tetraciclina muestran pérdidas menores $y$, por el contrario, las sulfonamidas se mantienen estables en todos los casos a $4^{\circ} \mathrm{C}$.

Efecto de la congelación de la leche sobre las sustancias antimicrobianas:

- El tiempo de congelación afecta de forma significativa a las pérdidas de concentración de los antibióticos betalactámicos y tetraciclinas en la leche aumentando las mismas a lo largo del período de conservación a $-20^{\circ} \mathrm{C}$. Sin embargo, en el caso de las sulfonamidas la congelación de las muestras y los 
extractos no presenta variaciones significativas en la concentración de estas sustancias durante el todo el periodo de almacenamiento.

- El tiempo de congelación y su interacción con el tipo de matriz también resulta significativa para algunas sustancias antimicrobianas, mostrando diferencias en las pérdidas de concentración con el tiempo de congelación, más pronunciadas en las muestras de leche que en los extractos, excepto para el caso concreto de la ampicilina.

- Las penicilinas y las cefalosporinas, a excepción de la cefalexina y cefquinoma, presentan tanto en las muestras de leche como en los extractos congelados, los mayores porcentajes de degradación, así como los tiempos de vida media menores, mientras que las tetraciclinas, excepto la clortetraciclina presentan degradaciones más moderadas y las sulfonamidas resultan estables a $-20^{\circ} \mathrm{C}$.

- Si se comparan los resultados obtenidos en el estudio de refrigeración y congelación se deduce que generalmente las pérdidas de concentración obtenidas en la congelación son inferiores a las de la refrigeración

De todo ello, se puede resumir que las condiciones de almacenamiento, en refrigeración y congelación, de las muestras de leche pueden afectar a la estabilidad de las moléculas de algunos grupos de antimicrobianos (betalactámicos y tetraciclinas) por lo que se recomienda conservar las muestras de leche el mínimo tiempo posible antes de su análisis, tanto a $4{ }^{\circ} \mathrm{C}$ como a $-20^{\circ} \mathrm{C}$. También podría resultar conveniente la obtención previa al almacenamiento, de extractos en aquellos casos en los que las moléculas presentan mayor estabilidad respecto a las muestras de leche. Con todo ello se pretende reducir las posibles diferencias entre resultados analíticos, realizados sobre una misma muestra de leche, después de un tiempo de almacenamiento que podría ser la causa de resultados contradictorios en las diferentes etapas de control.

\section{Segundo estudio: Efecto de diferentes tratamientos térmicos de calor sobre la estabilidad de las sustancias antimicrobianas en la leche}

En cuanto al estudio del efecto de los tratamientos térmicos de calor sobre la estabilidad de los antibióticos betalactámicos, tetraciclinas y sulfonamidas en la leche mediante los modelos cinéticos de primer orden se pueden extraer las siguientes conclusiones:

- En todos los casos la transformación logarítmica de las concentraciones de antimicrobianos en la leche sigue un comportamiento lineal, con coeficientes de regresión elevados en casi todos los casos, lo que indica que la aplicación del 
modelo cinético de primer orden al estudio de la degradación térmica de los antibióticos betalactámicos, tetraciclinas y sulfonamidas en la leche resulta adecuada.

- Las pendientes de degradación de cada sustancia antimicrobiana (constantes específicas de reacción) se incrementan a medida que aumenta la temperatura, siendo las cefalosporinas las moléculas que presentan las constantes de velocidad de degradación más elevadas, seguidas de las penicilinas, y en último lugar las tetraciclinas y sulfonamidas con pendientes similares.

- Los tiempos de vida media obtenidos para cada sustancia antimicrobiana varían con las diferentes temperaturas, siendo por lo general las tetraciclinas y las sulfonamidas las que presentan los valores más elevados en comparación con las penicilinas y las cefalosporinas.

En lo que se refiere a la aplicación del modelo de Arrhenius a las constantes específicas de degradación de cada antimicrobiano para el cálculo de las energías de activación y frecuencias de choque se deduce que:

- Los coeficientes de regresión obtenidos en todos los casos resultan elevados poniendo de manifiesto la buena linealidad existente entre las variables relacionadas.

- En lo que respecta a las energías de activación, los valores calculados para todos los grupos varían desde 21,05 hasta $87,50 \mathrm{KJ} / \mathrm{mol}$, con frecuencias de choques diferentes para cada una de las sustancias.

El conjunto de los parámetros cinéticos obtenidos a lo largo de este estudio determinan la estabilidad de cada sustancia antimicrobiana, siendo el comportamiento de cada una de estas sustancias diferente dependiendo de la temperatura empleada, aunque, por lo general, se observa que las cefalosporinas son las moléculas más inestables sobre todo a las temperaturas más bajas entre 60 y $80^{\circ} \mathrm{C}$.

Finalmente respecto a los porcentajes de degradación estimados para los diferentes tratamientos térmicos se puede señalar que:

- Los tratamientos térmicos aplicados frecuentemente en los laboratorios lactológicos de control de calidad ocasionan leves pérdidas en los antimicrobianos, exceptuando el calentamiento de $83{ }^{\circ} \mathrm{C}-10$ minutos que produce sobre algunas cefalosporinas (cefoperazona y cefapirina) unos porcentajes de degradación más importantes $(53,2$ y $39 \%$ respectivamente). 
- Los porcentajes de degradación estimados para los dos tratamientos de pasteurización muestran pérdidas destacables únicamente en el tratamiento a $63{ }^{\circ} \mathrm{C}-30$ minutos para el caso de las cefalosporinas con porcentajes de degradación comprendidos entre el 16\% para la cefquinoma y el $42 \%$ de la cefapirina.

- La esterilización a $120^{\circ} \mathrm{C}-20$ minutos es el único tratamiento que ocasiona mayores porcentajes de degradación en penicilinas (40,3 y $91 \%)$, cefalosporinas ( 80,1 y $100 \%)$, tetraciclinas $(40,3$ y $91,6 \%$ ) y sulfonamidas $(30,7$ y $85,1 \%)$, excepto en el caso de la sulfadimetoxina y sulfatiazol con porcentajes del 6,5 y 9,9\% respectivamente. Por el contrario la esterilización UHT ocasiona pérdidas inferiores al $10 \%$ en todos los casos excepto para la cefoperazona $(16,8 \%)$.

Se puede concluir que los tratamientos térmicos de calor realizados en los laboratorios no producen apenas efectos de degradación sobre los antimicrobianos pertenecientes a los grupos de antibióticos betalactámicos, tetraciclinas y sulfonamidas, por lo que estos tratamientos no interfieren en los resultados de algunas de las pruebas empleadas en el control de la leche.

Por otra parte, los tratamientos realizados en las industrias lácteas tampoco ocasionan pérdidas importantes en la concentración de estos antimicrobianos, salvo en el caso la esterilización de la leche en su envase, lo que significa que la mayor parte de los tratamientos térmicos no actúan como barrera para impedir la llegada de sustancias antimicrobianas al consumidor. Resulta necesario, por lo tanto, aplicar correctamente las medidas preventivas y de control a lo largo de toda la cadena de producción de la leche para evitar el riesgo potencial de la presencia de residuos de sustancias antimicrobianas.

Por último hay que señalar, que independientemente de las conclusiones comentadas, los resultados de este trabajo establecen un punto de partida hacia futuros estudios sobre la estabilidad de sustancias antimicrobianas en la leche. Sería por lo tanto interesante, evaluar la estabilidad de otros grupos de antimicrobianos de uso emergente en ganado lechero como quinolonas y macrólidos. También se considera de gran interés estudiar los cambios moleculares que se pueden producir en los antimicrobianos debido a los tratamientos térmicos y los posibles efectos toxicológicos y/o tecnológicos de sus metabolitos sobre la salud pública. Todo ello para colaborar con uno de los principios básicos de la seguridad alimentaria que es la protección del consumidor. 
BIBLIOGRAFÍA 



\section{BIBLIOGRAFÍA}

ADAMS H. R. 2003. Quimioterapia en las enfermedades microbianas. 835-981. In Farmacología y terapéutica veterinaria. Ed. Acribia. Zaragoza.

ALFREDSSON G., OHLSSON A. 1998. Stability of sulphonamide drugs in meat during storage. Food Add. Contam., 15: 302-306

ANTHONY F., ACAR J., FRANKLIN A., GUPTA R., NICHOLLS T., YAMURA S., THOMPSON S., THRELFALL E.J., VOSE D., Van VUUREN M., WHITE D.G. 2001. Antimicrobial resistance: responsible and prudent use of antimicrobial agents in veterinary medicine. Rev. Sci. Tech. Off. Int. Epiz., 20: 829-839.

ANDERSEN W. C., ROYBAL J. E., GONZALES S. A., TURNIPSEED S. B., PFENNING A. P., KUCK L. R. 2005. Determination of tetracycline residues in shrimp and whole milk using liquid chromatography with ultraviolet detection and residue confirmation by mass spectrometry. Anal. Chim. Acta, 529: 145-150.

ASH I., ASH M. 1995. Handbook of pharmaceutical additives. Ed. Gower technicalHampshire. UK

AULTON M. E. 2004. Farmacia: la ciencia del diseño de las formas farmacéuticas. Ed. Elsevier España S.A. Madrid.

BECKER M., ZITTLAU E., PETZ M. 2004. Residue analysis of 15 penicillins and cephalosporins in bovine muscle, kidney and milk by liquid chromatography tandem mass spectrometry. Anal. Chim. Acta, 520: 19-32.

BEVILL R. F. 1989. Sulfonamide residues in domestic animals. J. Vet. Phar. Ther., 12: 241-246.

BERRUGA M. I., MOLINA M. P., NOVES B., ROMAN M., MOLINA A. 2007a. In vitro study about the effect of several penicillins during the fermentation of yogurt made from ewe's milk. Milchwissenschaft, 62: 303-305.

BERRUGA M. I., BATTACONE G., MOLINA M. P., ROMAN M., MOLINA A. 2007b. Influence of Beta-lactams on Manchego Cheese manufacture. 148. $5^{\text {th }}$ International Symposium on The challenge to sheep and goats milk sectors. Alghero (Italia). International Dairy Federation. Bruselas, Bélgica.

BISHOP J. R., WHITE C. H. 1984. Antibiotic residue detection in milk. A review. J. Food Prot., 47: 647-652.

BOGIALLI S., CURINI R., DI CORCIA A., NAZZARIN M., POLCI M. L. 2003. Rapid confirmatory assay for determining 12 sulfonamides antimicrobials in milk an eggs by matrix solid phase dispersión and liquid chromatography-mass sepectrometry. J. Agric. Food Chem., 51: 4225-4232.

BOISON J. O., KORSRUD G. 0, PAPICH M. G., MACNEIL J. D., YATES W. D. 1992. Effect of cold-temperature storage on stability of benzylpenicillin residues in plasma and tissues of food-producing animals. J. Assoc. Off. Anal. Chem., 75: 974-978.

BOTSOGLOU N. A., FLEUTORIS J. D. 1996. Analysis of Residual Antibacterians in Food of Animal Origin In Handbook of Food Analysis, volume 2, Ed. Marcel Dekker, Inc. New York.

BOTSOGLOU N. A., FLETOURIS, J. D. 2001. Drugs residues in foods: Pharmacology, food safety, and analysis. Serie Food Science and thecnology. Ed. Marcel Dekker, Inc. New York.

BRADY M. S., KATZ S. E. 1987. Simplified Plate Diffusion System for Microbial Assays of Antibiotics. J. Assoc. Off. Anal. Chem., 70: 641-646. 
BRANDSTETEROVÁ E., KUBALEC P., BOVANOVA L., SIMKO P., BEDNARIKOVA A., MACHACKOVA L. 1997. SPE and MSPD as pre-separation techniques for HPLC of tetracyclines in meat, milk and cheese. Z. Lebensm. -Unters. Forsch., 205: 311-315.

BUSANI L., GRAZIANI C., FRANCO A., DI EGIDIO A., BINKIN N., BATTISTI A. 2004. Survey of the knowledge, attitudes and practice of Italian beef and dairy cattle veterinarians concerning the use of antibiotics. Vet. Rec., 155: 733-738.

BUSANI L., GRAZIANI C., FRANCO A., DI EGIDIO A., GRIFONI G., FORMATO G., SALA M., BINKIN N., BATTISTI A. 2003. Antibiotic use in cattle farms: Results of a survey among veterinarians. Bolletino Epidemiologico Nazionale (BEN), 16 n 7-8.

BYWATER R. J. 2004. Veterinary use of antimicrobials and emergence of resistance in zoonotic and sentinel bacteria in the EU. J. Vet. Med., 51: 361-363.

CARSON M. C., BRESLYN W. 1996. Simultaneous determination of multiple tetracycline residues in milk by metal chelate affinity chromatography: collaborative study. J. Assoc. Off. Anal. Chem., 79: 29-42.

CARSTENSEN, J. T., MORRIS T., 1993. Chemical stability of indomethacin in the amorphous and molten states. J. Pharm. Sci., 82: 657-659.

CARSTENSEN, J. T., RHODES C. 2000. Drug stability: principles and practices. Ed. Marcel Dekker, Inc. New York and Basel.

CAVALIERE C., CURINI R., DI CORCIA A., NAZZARI M., SAMPERI R. 2003. A simple and sensitive liquid chromatography-mass spectrometry confirmatory method for analysing sulphonamide antibacterials in milk and egg. J. Agric. Food Chem., 51: 558566.

CHAPMAN \& HALL. 2007. Statiscal design and analysis of stability studies. Ed. Taylor and Francis group, Boca Raton, Florida.

CHEN J. J., AHN H., TSONG Y. 1997. Shelf-life estimation for multifactor stability studies. Drug Inf. J., 31: 573-587.

CHOW S. C., KI, F. Y. C. 1997. Statistical comparison between dissolution profiles of drug products. J. Biopharm.Statis., 7: 241-258.

CHOW S. C., SHAO J. 2003. Stability analysis with discrete responses. J. Biopharm. Statis., 13: 451-462.

CHAUVIN C., MADEC F., GUILLEMOT D., SANDERS P. 2001. The crucial question of standardization when measuring drug consumption. Vet. Res., 32: 533-543.

CINQUINA A. L., LONGO F., ANASTASI G., GIANNETTI L., COZZANI R. 2003. Validation of high-performance liquid chromatography method for the determination of oxytetracycline, tetracycline, chlortetracycline and doxycyline in bovine milk and muscle. J. Chromatogr., 987: 227-233.

CODEX ALIMENTARIUS, 1996. Residuos de medicamentos veterinarios en los alimentos". Codex Alimentarius, 3. Programa conjunto FAO/OMS sobre Normas Alimentarias, FAO. Roma.

CODEX ALIMENTARIUS, 2007. Examen de la labor realizada por la FAO, OMS y OIE sobre la resistencia a los antimicrobianos. Codex Alimentarius, 3. Programa conjunto FAO/OMS sobre Normas Alimentarias. FAO. Roma.

CONNORS K. A., STELLA V. J., AMIDON G. L. 1994. Chemical stability of pharmaceuticals. Ed. John Wiley \& Sons. New York.

CROUBELS S., PETEGHEM C., BAEYENS W. 1994. Sensitive spectrofluorimetric determination of tetracycline residues in bovine milk. Analyst., 119: 2713-2716. 
CROUBELS S., BAEYENS W., VAN PETEGHEM C. 2003. Post-column zirconium chelation and fluorescence detection for the liquid chromatographic determination of tetracyclines. Anal. Chim. Acta, 303: 11-16.

DAESELEIRE E., DE RUYCK H., VAN RENTERGHEM R. 2000. Confirmatory assay for the simultaneous detection of penicillins and cephalosporins in milk using liquid chromatography tandem mass spectrometry. Rapid Commun. Mass Spectrom., 14: 1404-1409.

DA SILVA L. S., RATH S., REYES F. G. R. 2006. Effect of processing on the degradation of tetracyclines in milk and milk products. Toxicol. Lett. 274.

DEBACKERE M. 1995. Comparison of disk assay, Intest and Delvotest $P$ sensitivity for antibiotic residues in milk. 41-53. In Residues of Antimicrobial Drugs and Other inhibitors in Milk. IDF S. I. No 9505. International Dairy Federation. Bruselas, Bélgica.

DECISION 2002/657/CEE del Consejo del 12 de Agosto de 2002 por la que se aplica la Directiva 96/23/CE del consejo en cuanto al funcionamiento de los métodos analíticos y la interpretación de los resultados. Diario Oficial $n^{\circ} L$ 73: 30-31.

DEMOLY P., ROMANO A. 2005. Update on Beta-lactam allergy diagnosis. Curr. Allergy Asthma Rep., 1: 9-14.

DE RUYCK H., DE RIDDER H. 2007. Determination of tetracycline antibiotics in cow's milk by liquid chromatography tandem mass spectrometry. Rapid Commun. Mass Spectrom., 21: 1511-1520.

DE ZAYAS-BLANCO F., GARCÍA-FALCÓN M. S., SIMAL-GÁNDARA J. 2004. Determination of sulfamethazine in milk by solid phase extraction and liquid chromatographic separation with ultraviolet detection. Food Control, 15: 375-378.

DESHPANDE A. D., BAHETI K. G., CHATTERJEE N. R. 2004. Degradation of $\beta$ lactam antibiotics. Curr. Sci. 87: 684-1695.

DIRECTIVA 96/23/CEE del Consejo, de 29 de abril de 1996, relativa a las medidas de control aplicables respecto de determinadas sustancias y sus residuos en los animales vivos y sus productos y por la que se derogan las Directivas 85/358/CEE y 86/469/CEE y las Decisiones 89/187/CEE y 91/664/CEE. Diario Oficial $n^{\circ} \mathrm{L} 125: 10-32$.

DIRECTIVA 70/524/CEE del Parlamento Europeo y del Consejo de 16 de febrero de 1998, relativa a la comercialización de biocidas. Diario Oficial nº L123: 1-63.

DIRECTIVA 2001/82/CEE del Parlamento Europeo y del Consejo de 6 de noviembre de 2001 por la que se establece un código comunitario sobre medicamentos veterinarios. Diario Oficial $n^{\circ}$ L 311: 1-66.

DIRECTIVA 2004/28/CEE del Parlamento Europeo y del Consejo de 31 de marzo de 2004 que modifica la Directiva 2001/82/CE por la que se establece un código comunitario sobre medicamentos veterinarios. Diario Oficial $n^{\circ} \mathrm{L} 136$ : $58-84$.

DISERENS J. M. 2005. Review of available screening tests for the detection/determination of veterinary drug residues in milk. IDF JAT on Veterinary Residues meeting, Item 5. Parma, Italia.

DOMINGUEZ L., MORENO M. A. 2001. Utilización de antimicrobianos en producción animal y otras alternativas. Conferencia Real Academia de Ciencias Veterinarias. Madrid.

DONEVA M. 1988. Effect of low temperature storage of broiler carcasses on the stability of residual tetracyclines and oleandomycin in the meat. Vet. Sb., 86: 54-55.

DUKES G. R. 1984. Stability programs for formulation studies. Drug Dev. Ind. Pharm., 10: $1413-1424$. 
ERSKINE R. J., WAGNER S., DEGRAVES F. J. 2003. Mastitis therapy and pharmacology. Vet. Clin. Food Anim., 19: 109-138.

EDDER P., COMINOLI A., CORVI C. 1997. Analysis of residues of sulfonamides in foods animal origin (liver, kidney, meat, fish, eggs, milk) by liquid chromatography with prederivatization and fluorometric detection. Mitt. Geb. Lebensm. unters Hyg., 88: 554569.

FABRE H., USAN EDDINE N., BERGE, G. 1983. Degradation kinetics in aqueous solution of Cefotaxime sodium, a third-generation cephalosporin. J. Pharm. Sci., 73: 611-618

FABRE J. M., MORETAIN J. P., ASCHER F., BROUILLET O., BERTHELOT X. 1995. Main causes of inhibitors in milk a survey in one thousand french dairy farms. 27-31. In Residues of Antimicrobial Drugs and Other inhibitors in Milk. IDF S. I. N $N^{0} 9505$. International Dairy Federation. Bruselas, Bélgica.

FDA. 2003. Guidance for industry: Analytical testing of drugs substances and drug products (revision 2). The United States Food and Drug administration, Rockville, MD.

FDA. 2004. Guidance for industry: Evaluation of stability data. The United States Food and Drug administration, Rockville, MD.

FOISSY H., LINDNER G., FUGGER F., WAGNER M. 2005. Investigations on the reproducibility of microbial inhibitor test results in raw milk after sample storage. Wien. Tierärztl. Mon.schr., 92: 126-130.

FRITZ J. W., ZUO Y. 2007. Simultaneous determination of tetracycline and 4epitetracycline in milk by high-performance liquid chromatography. Food Chem., 105: 1297-1301.

FUBARA J. O., NOTARI R. E., 1998a. "A kinetic oxymoron: concentration-dependent first-order rate constans for hydrolysis of ceftazidime". J. Pharm. Sci., 87: 53-58.

FUBARA J. O., NOTARI R. E., 1998b. Influence of pH, temperature and buffers on cefepime degradation kinetics and stability predictions in aqueous solutions. J. Pharm. Sci., 87: 1572-1576.

FURUSAWA N. 2003. Isolation of tetracyclines in milk using a solid-phase extracting column and water eluant. Talanta, 59: 155-159.

FURUSAWA N., KISHIDA K. 2001. High-performance liquid chromatographic procedure for routine residue monitoring of seven sulphonamides in milk. J. Anal. Chem., 371: 1031-1033.

GAUDIN V., HÉDOU C., SANDERS P. 2007. Validation of a biacore method for screening eight sulfonamides in milk and porcine muscle tissues according to European Decision 2002/657/EC. J. Assoc. Off. Anal. Chem., 90: 1706-1715.

GEE H. E., HO K. B., TOOTHHILL, J. 1996. Liquid chromatographic determination of benzylpenicillin and cloxacillin in animal tissues and its application to a study of the stability at $-20^{\circ} \mathrm{C}$ of spiked and incurred residues of benzylpenicillin in ovine liver. $\mathrm{J}$. Assoc. Off. Anal. Chem., 79: 640-644.

GHIDINI S. 1999. Residui di farmaci ad attività antimicrobica negli alimenti di origene animale. Annali della Facoltà di Medicina Veterinaria Vol. XIX. Università degli Studi di Parma.

GHIDINI S., ZANARDII E., VARISCO G., CHIZZOLINI R. 2003. Residues of beta lactam antibiotics in bovine milk: confirmatory analysis by liquid chromatography tandem mass spectrometry after microbial assay screening. Food Addit. Contam., 20: 528-534. 
GIERA, D. D., ABDULLA R. F., OCCOLOWITZ J. L., DORMAN D. E., MERTZ J. L., SIECK R. F. 1982. Isolation and identification of a polar sulfamethazine 'metabolite' from swine tissue. J. Agric. Food Chem., 30: 260-263.

GOURSAND L. 1991.Composición y propiedades fisico-químicas. 1-92. In Leche y productos lácteos: vaca-oveja-cabra. Ed. Acribia, Zaragoza.

GUAY R., CARDINAL P., BOURASSA C., BRASSARD N. 1987. Decrease of penicillin $G$ residue incidence in milk: a fact or an artefact?. Int. J. Food Microb., 4: 187-196.

GRATACOS M., FERNANDEZ A., PICOUET P., VALERO A., GARCÍA J. A., CASTELLARI M. 2007. Formation of tetracycline degradation products in chicken and pig meat under different thermal processing conditions. J. Agric. Food Chem., 55: 6104616.

GRIMM W. 1995. International Harmonization of Stability Tests for Pharmaceuticals. The ICH Triplicate Guideline for Stability Testing of New Drug Substances and Products. Eu. J. Pharm. Biopharm., 41: 194-196.

GRUET P., MAINCENT P., BERTHELOT X., KALTSATOS V. 2001. Bovine mastitis and intramammary drug delivery: review and perspectives. Adv. Drug Delivery Rev., 50: 245-259.

GRUNWALD L., PETZ M. 2003. Food processing effects on residues: penicillins in milk and yogurt. Anal. Chim. Acta, 483: 73-79.

HAAGSMA N., NOOTEBOOM R. J., GORTEMAKER B.Q.M., MAAS M. J. 1985. Rapid Sample preparation method for the determination of suphamethazine (sulphamidine) in swine tissues by high-performance liquid chromatography. Z. Lebensm. Unters. Forsch. 181: 194-197.

HAAGSMA N. 1993. "Stability of veterinary drug residues during storage, preparation and processing". 41-49. In Proceedings of EuroResidue II Conference on Residues of Veterinary Drugs in Food. Ed. Haagsma, N.; Ruiter, A.; Czedik-Eysenberg, P. B., Veldhoven, The Netherlands.

HASSANI M., LÁZARO R., PÉREZ C., CONDÓN S, PAGÁN R. 2008. Thermostability of oxytetracycline at ultrahigh temperatures. J. Agric. Food Chem., 56: 2676-2680.

HASHIMOTO N., TASAKI T., TANAKA H. 1984. Degradation and epimerization kinetics of moxalactam in aqueous solution. J. Pharm. Sci., 73: 369-73.

HASSET T., PATEY A. L., SHEARER G. 1990. The effect of cooking on drug residues in meat and offal. 21-23. In Proceedings of EuroResidue I Conference on Residues of Veterinary Drugs in Food. Ed. Haagsma, Ruiter and Czedik-Eysenberg. Veldhoven, The Netherlands.

HEESCHEN W. H., SUHREN G. 1995. IDF integrated detection system for antimicrobials: Introductory statement and practical experiences in Germany. 310-318. In Residues of Antimicrobial Drugs and Other inhibitors in Milk. IDF S. I. No 9505. International Dairy Federation. Bruselas, Bélgica.

HIMANISH D., MAHADEVA N., JAYARAMAN S., BAWA A. S. 2008. Effect of processing, preservation and storage on oxytetracycline in spiked milk. J. Food Sci. Technol., 45: 50-55.

HOLSTEGE D.M., PUSCHNER B., WHITEHEAD G., GALEY F.D. 2002. Screening and mass spectral confirmation of beta-lactam antibiotic residues in milk using LCMS/MS. J. Agric. Food Chem, 50: 406-411.

HONKANEN-BUZALSKI T., REYBROECK W. 1997. Antimicrobials. 26-34. In Residues and contaminants in milk and milk products. IDF S.I. $n^{\circ}$ 9701. International Dairy Federation. Bruselas, Bélgica. 
HOLSTEGE D. M., PUSCHNER B., WHITEHEAD G., GALEY F. D. 2007. Screening and mass spectral confirmation of $\beta$-lactam antibiotic residues in milk using Liquid chromatography-MS/MS. J. Agric. Food Chem., 50: 406-411.

HOU J. P., POOLE J. W. 1971. $\beta$-Lactamic antibiotics: Their physicochemical properties and biological activities in relation to structure. J. Pharm. Sci., 60: 503-532.

IFAH (International Federation for Animal Health). 1997. Antibiotics and animals. IFAH. Brussels, Belgium.

IFAH (International Federation for Animal Health). 1999. Antibióticos para animales. IFAH. Brussels, Belgium.

IFAH (International Federation for Animal Health). 2001. Antibiotic use in farm animals does not threaten human health. IFAH. Brussels, Belgium.

IFAH (International Federation for Animal Health). 2006. Annual Report. IFAH. Brussels, Belgium.

INSTITUTO LACTOLÓGICO DE LEKUNBERRI. 2004. Estudio de descomposición estructural por calentamiento de cuatro tetraciclinas mediante cromatografía líquida. Datos sin publicar.

IONKOVA G., KIROVA M., NIKEVA S. 1994. Residual quantities of tetracycline antibiotics in duk meat and liver. Khranitelna Promishlenost, 43:5.

JACQUET J., AUXEPAULES M. 1978. Le problème de la pollution du lait par les antibiotiques. État actuel de la question. Bull. Acad. Vét. de France, 51: 73-79.

KAALE E., CHAMBUSCO M., KITWALA J. 2007. Analysis of residual oxytetracycline in fresh milk using polymer reversed-phase column. Food Chem., 107: 1289-12932.

KITTS D. D., YU C. W. Y., AOYAMA R. G., BURT H. M., MCERLANE K. M. 1992. Oxytetracycline degradation in thermally processed farmed salmon. J. Agric. Food Chem., 40: 1977-1981.

KISHIDA K., FURUSAWA N. 2004. Application of shielded column liquid chromatography for determination of sulfamonomethoxine, sulfadimetoxine, and their N4-acetyl metabolites in milk. J. Chromatogr., 1028: 175-177.

KOESUKWIWAT U., JAYANTAS S., LEEPIPATPIBOON N. 2007. Solid-phase extraction for multiresidue determination of sulfonamides, tetracyclines and pyrimethamine in bovine's milk. J. Chromatogr., 1149: 102-111.

KONECNY S. 1978. Effect of temperature and time on biological activity reduction of some kinds of antibiotics in milk. Vetemarstvi, 28: 409-410.

KÜHNE M., HAMSCHER G., KÖRNER U., SCHEDL D., WENZEL S. 2001. Formation of anhydrotetracycline during a high-temperature treatment of animal-derived feed contaminated with tetracycline. Food Chem., 75: 423-429.

LERNER D. A., BONNEFORD G., FABRE H., MANDROU B., DEBUOCHBERG M. S. 1988. Photodegradation paths of cefotaxime. Pharm. Sci., 77: 699-703.

LEY 29/2006 de 26 de julio, de garantías y uso racional de los medicamentos y productos sanitarios. BOE, 27 de Julio 2006, n 178: 28122-28165.

LOSCHER W. 1994. Animal experiments in the development and evaluation of veterinary drugs. Tierarztliche-Umschau, 49: 67-68.

LUO W., HANSEN JUNIOR E. B., ANG C. Y. W., DECK J., FREEMAN J. P., THOMPSON JUNIOR H. C. 1997. Simultaneous determination of amoxicillin and ampicillin in bovine milk by HPLC with fluorescence detection. J. Agric. Food Chem., 45: $1264-1268$. 
MACHO. M.L. 2003. Enzimoinmunoanálisis en el análisis de residuos de antibióticos. $15^{\mathrm{a}}$ Jornada sobre Residuos en alimentos. CNA-AESA.

MAKESWARA S., PATTERSON I., POINTS J. 2005. An analytical method to determine conjugated residues of ceftiofur in milk using liquid chromatography with tandem mass spectrometry. Anal. Chim. Acta, 529: 151-157.

MALIK S., DUNCAN S. E., TAYLOR L. T., BISHOP J. R. 1994. Extraction and detection of sulphamethazine in spray-dried milk. J. Dairy Sci., 77: 418-425.

MARCO J. C., GARCÍA I., ZIGORRAGA C., MOLINERO M. E., AZPIRI M. 2001. Evolución del uso de antimicrobianos en el tratamiento de enfermedades del ganado vacuno lechero y presencia de residuos inhibidores en leche de vaca cruda y tratada térmicamente. 1-8. Jornada Técnica sobre el uso de antimicrobianos en medicina veterinaria y sus posibles repercusiones en la salud pública. Bilbao.

MARCHETTI M., SCHWAIGER I., SCHMID E. R. 2001. Determination of benzylpenicillin, oxacillin, cloxacillin, and dicloxacillin in cow's milk by ion-pair highperformance liquid chromatography after precolumn derivatization. J. Anal. Chem., 371: 64-67.

MARTENS T., LANGEVIN BERMOND D., FLEURY M. B., 1993. "Ditiocarb: Decomposition in aqueous solution and effect of the volatile product on its pharmacological use". J. Pharm. Sci., 82: 379-383.

MARTINS JUNIOR H. A., KUSSUMI T. A., WANG A. Y., LEBRE T. 2007. A rapid method to determine antibiotic residues in milk using liquid chromatography coupled to electrospray tandem mass spectrometry. J. Braz. Chem. Soc., 18: 397-405.

MATEOS P. F. 2002. Agentes antimicrobianos y microorganismos. Curso de microbiología. Ingeniería de Alimentos. http://geocities.com/College Park/Lab/2960/Mic20.htm

MÄYRÄ-MÄKINEN A. 1995. Technological significance of residues for the dairy industry. 136-143. In Residues of Antimicrobial Drugs and Other Inhibitors in Milk. IDF S.I. N ${ }^{\circ}$ 9505. International Dairy Federation. Bruselas, Belgica.

MENDEZ A., FERNÁNDEZ G., DÍAZ A., MARCO J. C. 1999. Tratamiento de las mamitis bovinas. Bovis, 86: 49-75.

MERCK \& COL. 2003. El manual Merck de Veterinaria. $5^{\text {a }}$ ed. Ed. Océano. Barcelona.

MILLAR R. G., ARMISHAW P., WILSON M. G., MAJEWSKI J. M. 1995. Recent developments in Australia-reference materials and proficiency testing. J. Anal. Chem., 352: 28-32.

MILLER J. M., KALE U. J., LAU S. K., GREENE L., WANG H. Y. 2004. Rapid estimation of kinetic parameters for thermal decomposition of penicillins by modulated thermogravimetric analysis. J. Pharma. Biomed. Anal., 35:65-73.

MITCHELL J. M., GRIFITHS M. W., MC EWEN S. A., MC NAB W. B., YEE A. J. 1998. Antimicrobial drug residues in milk and meat: causes, concerns, prevalence, regulations, test, and test performance. J. Food. Prot., 61: 742-756.

MOATS W. A., HARIK-KHAN R. 1995. Identification and measurement of beta-lactam antibiotic residues in milk: integration of screening kits with liquid chromatography. J. Assoc. Off. Anal. Chem., 78: 978-986.

MOATS W. A. 1988. Inactivation of antibiotics by heating in foods and other substratesA review. J. Food Prot., 51: 491-497. 
MOATS W. A. 1999. The effect of processing on veterinary residues in foods. 233-241. In Impact of processing on Food Safety. ed. by Jackson et al., Ed. Kluwer Academic, Plenum Publishers, New York.

MOLINA M.P., ALTHAUS R.L., BALASCH S., TORRES A., PERIS C., FERNANDEZ N., 2003. "Evaluation of screening test for detection of antimicrobial residues in ewe milk". J. Dairy Sci., 86: 1947-1952.

MORÉTAIN J. P. 1996. Elimination des medicaments veterinaires dans le lait. XIII Reunión de Técnicos especialistas en control de mamitis y calidad de leche (GTemcal). Pamplona.

MOUROT D., LOUSSOUARN S. 1981. Sensibilité des ferments lactiques aux antibiotiques utilisés en médecine vétérinaire. Rec. Med. Vét.,157: 175-177.

MUTHA S. C., BROWN T. L, CHAMBERLAIN B., LEE C. E. 1977. Sulfamethazine residue in calf tissues. J. Agric. Food Chem., 25: 556-558.

NASSAR M., HOUSE C., AGHARKAR S. 1992. Stability of batanopride hydrochloride in aqueous solutions. J. Pharm. Sci., 81: 1088-1091.

NAZINA T. N., TOUROVA T. P., POLTARAUS A. B., NOVIKOVA E. V., GRIGORYAN A. A., IVANOVA A. E., LYSENKO A. M., PETRUNYAKA W., OSIPOV G. A., BELYAEV S. S., IVANOV M. V. 2001. Taxonomic study of aerobic thermophilic bacilli: descriptions of Geobacillus subterraneus gen. nov., sp nov and Geobacillus uzenensis sp nov from petroleum reservoirs and transfer of Bacillus stearothermophilus, Bacillus thermocatenulatus, Bacillus thermoleovorans, Bacillus kaustophilus, Bacillus thermoglucosidasius and Bacillus thermodenitrificans to Geobacillus as the new combinations G-stearothermophilus, G-thermocatenulatus, G-thermoleovorans, Gkaustophilus, G-thermoglucosidasius and G-thermodenitrificans. Int. J. Syst. Evol. Microbiol., 51: 433-446.

O'BRIEN J. J., CAMPBELL N., CONAGHAN T. 1981. The effect of cooking and cold storage on biologically active antibiotic residues in meat. J. Hyg. 87: 511-523.

ODA T., HIWAKI H. 1996. Heat stability of 24 antibiotics in food extracts. J. Food. Hyg. Soc. Japan, 37: 97-103.

OIE (ORGANIZACIÓN MUNDIAL DE LA SANIDAD ANIMAL), 2007. Resistencia a los antimicrobianos Título 3.9 In Código sanitario para los animales Terrestres. Paris.

OLIVEIRA R. V., CASS Q. B. 2006. Evaluation of liquid chromatographic behaviour of cephalosporin antibiotics using access medium columns for on-line sample cleanup of bovine milk. J. Agric. Food Chem., 54: 1180-1187.

OLIVEIRA R. V., DE PIETRO A. C., CASS Q. B. 2007. Quantification of cephalexin as residue levels in bovine milk by high-performance liquid chromatography with on-line sample cleanup. Talanta, 71: 1233-1238.

OKERMAN L., VAN HENDE J., DE ZUTTER L. 2007. Stability of frozen stock solutions of beta-lactam antibiotics, cephalosporins, tetracyclines and quinolones used in antibiotic residue screening and antibiotic susceptibility testing. Anal. Chim. Acta, 586: 284-288.

PACKHAM W., BROOME M. C., LIMSOWTIN G. K. Y. ROGINSKI H. 2001. Limitations of standard antibiotic screening assays when applied to milk for cheesemaking. Australian J. Dairy Tech., 56: 15-18.

PAPAPANAGIOTOU E. P., FLETOURIS D. J., PSOMAS E. I. 2005. Effect of various heat treatments and cold storage on sulphamethazine residues stability in incurred piglet muscle and cow milk samples. Anal. Chim. Acta, 529: 305-309. 
PARKS O. W. 1985. Screening tests for sulfonamides drugs and/or dinitrobenzamide coccidiostats and their monoaminometabolites in chiken livers. J. Assoc. Off. Anal. Chem., 68: 1232-1234.

PARKS O. W. 1994. Stability of sulfaquinoxaline, sulfadimethoxine, and their N4-acetyl derivatives in chicken tissues during frozen storage. J. Assoc. Off. Anal. Chem., 77: 486-488.

PAWELCZYK E., PLOTKOWIAK Z., KNITTER K., KOZAKIEWICZWEGNER B., 1980. Kinetic of drug descomposition. Kinetics of penicillin $G$ potassium salt (PGP) thermal degradation in solid phase. Pol. J. Pharmacol. Pharm., 32:55-62.

PELZ M. 1992. Comparison of chromatographic procedures for determining residues of penicillins, 147-163. In Analysis of Antibiotic Drug Residues in Food Products of Animal Origin. Ed. Agarwal V. P. Plenum Press, New York.

PEREIRA A. V., CASS Q. B. 2005. High-performance liquid chromatography method for the simultaneous determination of sulfamethoxazole and trimethoprim in bovine milk using an on-line cleanup column. J. Chromatogr., 826: 139-146.

PEREZ-TRALLERO E., IGLESIAS L. 2003. Tetracyclines, sulfonamides and metronidazole. Enferm. Infecc. Microbiol. Clín., 21: 520-529

PILET C., TOMA B. 1969. Study on thermostability of some antibiotics. Rec. Méd. Vet., 145: 897-909.

PODHORNIAK L. V., LEAKE S., SCHENCK F. J. 1999. Stability of tetracycline antibiotics in raw milk under laboratory storage conditions. J. Food Prot., 62: 547-548.

RANG H. P., DALE M. M., RITTER J. M. 2000. Quimioterapia de enfermedades infecciosas y malignas. 742-748, In Farmacología, $4^{a}$ ed. Ed Harcort. Madrid.

RECOMENDACIÓN 2002/77/CEE del Consejo, de 15 de noviembre de 2001, sobre la utilización prudente de los agentes antimicrobianos en la medicina humana. Diario Oficial $L n^{\circ} 34: 13-16$.

REAL DECRETO 1749/98 de 31 de julio de 1998, por el que se establecen las medidas de control aplicables a determinadas sustancias y sus residuos en los animales vivos y sus productos. BOE, 7 de agosto de 1998, n 188: 26910-26927.

REAL DECRETO 217/2004 de 6 de febrero, por el que se regulan la identificación y registro de los agentes, establecimientos y contenedores que intervienen en el sector lácteo, y el registro de los movimientos de la leche. BOE, 19 de febrero de 2004, $n^{\circ} 43$ : 7802-7806.

REAL DECRETO 1728/2007 de 21 de diciembre, por el que se establece la normativa básica de control que deben cumplir los operadores del sector lácteo y se modifica el Real Decreto 217/2004, de 6 de febrero, por el que se regulan la identificación y registro de los agentes, establecimientos y contenedores que intervienen en el sector lácteo, y el registro de los movimientos de la leche. BOE, 17 de enero de $2008, n^{\circ} 15$ : 3508-3519.

REGLAMENTO 2377/90/CEE del Consejo, de 26 de junio de 1990, por el que se establece un procedimiento comunitario de fijación de los límites máximos de residuos de medicamentos veterinarios en los alimentos de origen animal. Diario Oficial $n^{\circ} \mathrm{L}$ 224: 1-8.

REGLAMENTO 178/2002/CEE del Parlamento Europeo y del Consejo, de 28 de enero de 2002, por el que se establecen los principios y los requisitos generales de la legislación alimentaria, se crea la Autoridad Europea de Seguridad Alimentaria y se fijan procedimientos relativos a la seguridad alimentaria. Diario Oficial $n^{\circ} L$ 31: 1-24. 
REGLAMENTO 1831/2003/CEE del Parlamento Europeo y del Consejo, de 22 de septiembre de 2003, sobre los aditivos en la alimentación animal. Diario Oficial $n^{\circ} \mathrm{L}$ 268: 29-43.

REGLAMENTO 852/2004/CEE del Parlamento Europeo y del Consejo, de 29 de abril de 2004, relativo a la higiene de los productos alimenticios. Diario Oficial $n^{\circ} L$ 139: 1 54.

REGLAMENTO 853/2004/CEE del Parlamento Europeo y del Consejo, de 29 de abril de 2004, por el que se establecen normas específicas de higiene de los alimentos de origen animal. Diario Oficial $n^{\circ}$ L 139: 55-205.

REGLAMENTO 854/2004/CEE del Parlamento Europeo y del Consejo, de 29 de abril de 2004, por el que se establecen normas específicas para la organización de controles oficiales de los productos de origen animal destinados al consumo humano. Diario Oficial $n^{\circ} \mathrm{L}$ 139: 206-319.

REGLAMENTO 882/2004/CEE del Parlamento Europeo y del Consejo, de 29 de abril de 2004, sobre los controles oficiales efectuados para garantizar la verificación del cumplimiento de la legislación en materia de piensos y alimentos y la normativa sobre salud animal y bienestar de los animales. Diario Oficial $n^{\circ} L$ 165: 1-141.

RIEDIKER S., STADLER R.H. 2001. Simultaneous determination of five beta-lactam antibiotics in bovine milk using liquid chromatography coupled with electrospray ionization tandem mass spectrometry. Anal. Chem. Acta, 73: 1614-1621.

RIEDIKER S., RYTZ A., STADLER R. H. 2004. Cold-temperature stability of five $\beta$ lactam antibiotics in bovine milk and milk extracts prepared for liquid chromatographyelectrospray ionization tandem mass spectrometry analysis. J. Chromatogr., 1054: 359-363.

RODANTE F., VECCHIO S., TOMASSETTI M. 2002. Multi-step decomposition processes for some antibiotics. A kinetic study. Thermochim. Acta, 394:7-18.

ROSE M. D., FARRINGTON W. H. H., SHEARER G. 1996. The Effect of Cooking on Veterinary Drug Residues in Food. 3. Sulfamethazine. Food Addit. Contam., 12: 739750.

RUELA I. C. A., LIMA J. A., SOUZA S. V. C. 2005. Optimization and validation of a method for determination of oxytetracycline and chlortetracycline residues in milk by high performance liquid chromatography. Cienc. Tecnol. Aliment., 25: 139-146.

SAMANIDOU V. F., NIKOLAIDOU K.I., PAPADOYAMIS I. N. 2007. Development and validation of an HPLC confirmatory method for the determination of tetracycline antibiotics residues in bovine muscle according to the European Union Regulation 2002/657/CEE. J. Sep. Sci., 30: 2430-2439.

SANZ D., VIRTO R., CONDÓN S., PAGÁN R. 2002. Modificaciones en la actividad de antimicrobianos. Inactivación de antibióticos y sulfamidas a temperaturas de pasteurización y esterilización. Comunicación oral presentada en la XIX Reunión de especialistas en control de mamitis y calidad de leche (G-Temcal). Palencia.

SÁNCHEZ A., HERNÁNDEZ M., LUNA J., MOYANO G. M., VILLANUEVA M. J., MUÑÓZ E. 2001. Riesgos de residuos en leche debidos a tratamientos indebidos. XVIII Reunión de especialistas en control de mamitis y calidad de leche (G-Temcal). Lisboa.

SAS Institute Inc., 2001. SAS users guide: Statistics version 9.1. SAS Institute Cary, NC. 
SARMAH A. K., MEYER M. T., BOXALL A. B. A. 2006. A global perspective on the use, sales, exposure pathways, occurrence, fate and effects of veterinary antibiotics (VAs) in the environment. Chemosphere, 65: 725-759.

SAWANT A. A., SORDILLO L. M., JAYARAO B. M. 2005. A survey on antibiotic usage in dairy herds in Pennsylvania. J. Dairy Sci., 88: 2991-2999.

SHAHANI K. M., GOULD I. A., WEISER H. H., SLATTER W. L. 1956. Stability of small concentrations of penicillin in milk as affected by heat treatment and storage. J. Dairy Sci., 39: 971-977.

SHAHANI K. M., 1957. The effect of heat and storage on the stability of aureomycin in milk, buffer, and water. J. Dairy Sci., 40: 289-296.

SHAHANI K. M., 1958. Factors affecting terramycin activity in milk, broth, buffer, and water. J. Dairy Sci., 41: 382-391.

SHENCK F. J., FRIEDMAN S. L. 2000. The effect of storage at $4{ }^{\circ} \mathrm{C}$ on the stability of ampicillin residues in raw Milk. Food Add. Contam., 17: 675-677.

SLATER J., STONE H., PALREMO B., DUVALL R. 1979. Reliability of arrhenius equation in predicting vitamin A stability in multivitamin tablets. J. Pharm. Sci., 68: 4952.

SPISSO B. F., DE OLIVEIRA E JESUS A. L., GONÇALVES DE ARAUJO M. A., MONTEIRO M. A. 2007. Validation of a high-performance liquid chromatographic method with fluorescence detection for the simultaneous determination of tetracycline residues in bovine milk. Anal. Chim. Acta, 581: 108-117.

SORENSEN L. K., RASMUSSEN B. M., BOISON J. O., KENG L.1997. Simultaneous determination of six penicillins in cows' raw milk by a multiresidue high-performance liquid chromatographic method. J. Chromatogr., 694: 383-391.

SORENSEN L. K., SNOR L. K. 2000. Determination of cephalosporins in raw milk by high-performance liquid chromatography. J. Chromatogr., 882: 145-151.

SUHREN G. 1995. Possibilities and limitations of microbiological inhibitor test. 159171. In Residues of Antimicrobial Drugs and Other Inhibitors in Milk. IDF S.I. N 9505. International Dairy Federation. Bruselas, Bélgica.

SULLIVAN T. J., WEDNER J., SHATZ G. S., YECIES L. D., PARKER C. W. 1981. Skin testing to penicillin allergy. J. Allergy. Clin. Immunol., 68: 171-180.

SUMANO H. S., OCAMPO L. 1997. Quimioterapia de las enfermedades microbianas. 118-137. In Farmacología Veterinaria, $2^{\mathrm{a}}$ ed. Ed. McGraw-Hill Interamericana. Madrid.

SUNKARA G., NAVARRE C. B., KOMPELLA U. B. 1999. Influence of pH and temperature on kinetics of ceftiofur degradation in aqueous solutions. J. Pharm. Pharmacol., 51: 249-255.

SCHWARTZ H. J., SHER T. H. 1984. Anaphylaxis to penicillin in a frozen dinner. Ann. Allergy, 52: 342-343.

TAGUCHI S., YOSHIDA S., TANAKA Y., HORI S. 1999. Simple and rapid analysis of penicillins in milk by HPLC using multidimensional on-line clean-up and post-column photolysis with UV detection. J. Food. Hyg. Soc. Japan, 40: 375-381.

TARBIN J. A., FARRINGTON H. H., SHEARER G. 1995. Determination of penicillins in animal tissues at trace residue concentrations. Part I. Determination of benzylpenicillin in milk by reversed-phase liquid chromatography with solid phase extraction and liquid chromatographic fractionation clean-up. Anal. Chim. Acta, 318: 95-101. 
THOMAS G. K., MILLAR R. G., ANSTIS P. W. 1997. Stability of sulphonamide antibiotics in spiked pig liver tissue during frozen storage. J. Assoc. Off. Anal. Chem., 80: 988-995.

TOLLEFSON L., KARP B. E. 2004. Human health impact from antimicrobial use in food animals. Médecine et Maladies Infectieuses, 34: 514-521.

VAHDAT L., SUNDERLAN V. B. 2007. Kinetics of amoxicillin and clavulanate degradation alone and in combination in aqueous solution under frozen conditions. Int. J. Pharma., 342: 95-104.

VAN RHIJN J. A., LASAROMS J. J. P., BERENDSEN B. J. A., BRINKMAN U. A. TH. 2002. Liquid chromatographic-tandem mass spectrometry determination of selected sulphonamides in milk. J. Chromatogr., 960: 121-133.

VETERINDUSTRIA. 2006. Guía de productos zoosanitarios 2005-2006. 9a ed. Ed. Veterindustria, Madrid.

VERDON E., COUEDOR P. 1998. Determination of isoxazolylpenicillins residues in milk by ion-pair reversed phase high performance liquid chromatography after precolumn derivatization. J. Chromatogr., 705: 71-78.

VERDON E., FUSELIER R., HURTAUD-PESSEL, D., COUEDOR P., CADIEU N., LAURENTIE M. 2000. Stability of penicillin antibiotic residues in meat during storage. Ampicillin. J. Chromatogr., 882: 135-143.

VILANOVA B., MUÑÓZ F., DONOSO J., FRAU J., GARCÍA BLANCO F. 1994. Alkaline hydrolysis of cefotaxime. A HPLC and ${ }^{1}$ H NMR study. J. Pharm. Sci., 83: 322-327.

VIÑAS P., LÓPEZ ERROZ C., CAMPILLO N., HERNÁNDEZ-CÓRDOBA M. 1996. Determination of sulphonamides in foods by liquid chromatography with postcolumn fluorescence derivatization. J. Chromatogr., 726: 125-131.

VOLMER D. A. 1996. Multiresidue determination of sulphonamide antibiotics in milk by short-column liquid chromatography coupled with electrospray ionization tandem mass spectrometry. Rapid Commun. Mass Spectrom., 10: 1615-1620.

WANG D., NOTARI, R. E. 1994. Cefuroxime Hydrolysis Kinetics and Stability Preditions in Aqueous Solution. J. Pharm. Sci., 83: 577-581.

WANG Q., YATES S. 2008. Laboratory Study of Oxytetracycline DegradationKinetics in Animal Manure and Soil. J. Agric. Food Chem., 56: 1683-1688.

WEN Y., ZHANG M., ZHAO Q., FENG Y. Q. 2005. Monitoring of five sulphonamide antibacterial residues in milk by in-tube solid-phase microextration coupled to highperformance liquid chromatography. J. Agric. Food Chem., 53: 8468-8473.

WIESE B., MARTIN K. 1989a. Basic extraction studies of benzylpenicillin and its determination by liquid chromatography with pre-column derivatisation. J. Pharm. Biomed. Anal., 7: 67-78

WIESE B., MARTIN K. 1989b. Determination of benzylpenicillin in milk at the $\mathrm{pg} \mathrm{ml}^{-1}$ level by reversed-phase liquid chromatography in combination with digital subtraction chromatography technique. J. Pharm. Biomed. Anal., 7: 95-106.

WIESE B., MARTIN K. 1989c. Determination of benzylpenicillin in plasma and lymph at the $\mathrm{ng} \mathrm{ml}^{-1}$ level by reversed-phase liquid chromatography in combination with digital subtraction chromatography technique. J. Pharm. Biomed. Anal., 7: 107-118.

WOLFE J., LEE G., POTTI G., GALLELLI J. 1994. Degradation of antiflammin 2 in aqueous solution. J. Pharm. Sci., 83: 1762-1764.

YAMANA T., TSUJI A. 1976. Comparative stability of Cephalosporins in aqueous solution: kinetics and mechanisms of degradation. J. Pharm. Sci., 65: 1563-1574. 
YANG T. C. C., YANG I. L., LIAO L. J. 2004. Determination of sulphonamide residues in milk by on-line microdialysis and HPLC. J. Liq. Chromatogr. Relat. Technol., 27: 501510.

YORK J. L. 1992. Enzymes: classification, kinetics and control. 157-162. In Textbook of biochemistry, $3^{\text {rd }}$ ed. Ed. Devlin T.M. Wiley, New York.

ZANG C. P., LIU Y. H., MEN L. Q., WANG S. H. 2005. Identification of residual tetracyclines in milk by electrospray high performance liquid chromatography tandem mass spectrometry. Chinese J. Vet. Sci., 25: 649-654.

ZHAO F., ZHANG X., GAN Y. 2004 Determination of tetracyclines in ovine milk by high-performance liquid chromatography with a coulometric electrode array system. J. Chromatogr., 1055: 109-114.

ZHOU M., NOTARI R. E. 1995. Influence of $\mathrm{pH}$, temperature and buffers on the kinetics of ceftazidime degradation in aqueous solutions. J. Pharm. Sci., 84: 534-538.

ZORRAQUINO M. A. 1996. Aplicación de un sistema de análisis de riesgos y puntos críticos para asegurar una leche libre de residuos de medicamentos veterinarios. XIII Reunión de Técnicos especialistas en control de mamitis y calidad de leche (GTemcal), Pamplona.

ZORRAQUINO M. 1997. Niveles de residuos de medicamentos veterinarios en leche por debajo de los límites máximos de residuos de la UE. XIV Reunión de técnicos especialistas en control de mamitis y calidad de la leche (G-Temcal), Mallorca.

ZORRAQUINO M. A., BERRUGA M. I., SOLAZ T. 2003. Análisis de las técnicas de detección de residuos de medicamentos veterinarios en la leche cruda y sistema de control. Informe Técnico. Federación Industrias Lácteas Españolas (INLAC). Madrid

ZORRAQUINO M. A. 2005. Inactivación térmica de sustancias antimicrobianas en leche. Tesis Doctoral. Universidad Pública de Navarra.

ZORRAQUINO M. A., BERRUGA M. I., MOLINA M. P. 2007. Investigación de campo de los antibióticos (principio activo-formulación) utilizados en vacuno de leche en España y patología tratada". Ministerio de Agricultura, Pesca y Alimentación, Madrid.

ZORRAQUINO M. A., ROCA M., CASTILLO M., ALTHAUS R. L., MOLINA M. P. 2008a. Effect of thermal treatments on the activity of quinolones in milk. Milchwissenschaft. 63:192-195.

ZORRAQUINO M. A., ROCA M., FERNANDEZ N., MOLINA M. P., ALTHAUS R. L. 2008b. Heat inactivation of beta-lactam antibiotics in milk. J. Food Prot. En prensa.

ZWALD A. G., RUEGG P. L., KANEENE J. B., WARNICK L. D., WELLS S. J., FOSSLER C., HALBERT L. B. 2004. Management practices and reported antimicrobial usage on conventional and organic dairy farms. J. Dairy Sci., 87: 191-201. 